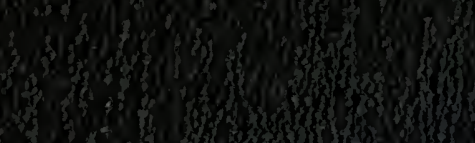

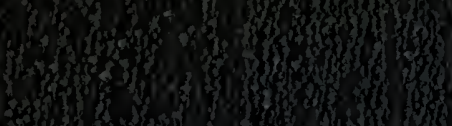

\title{
19.
} 3 3.6.

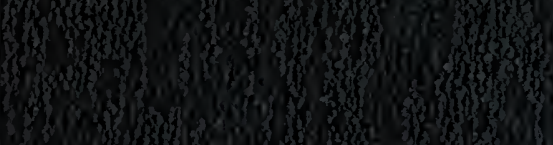

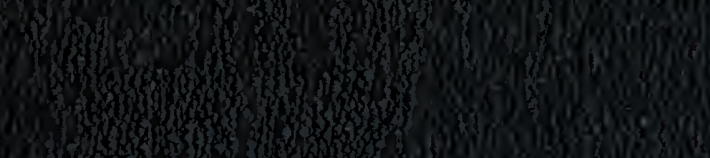

mon 3 on 3.0. 3. 3)

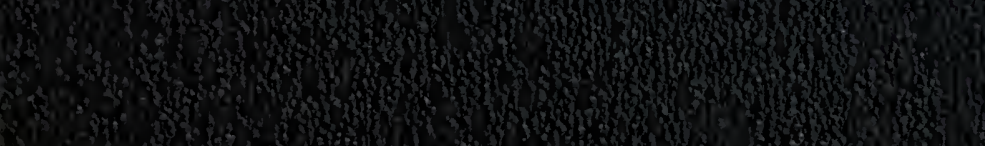




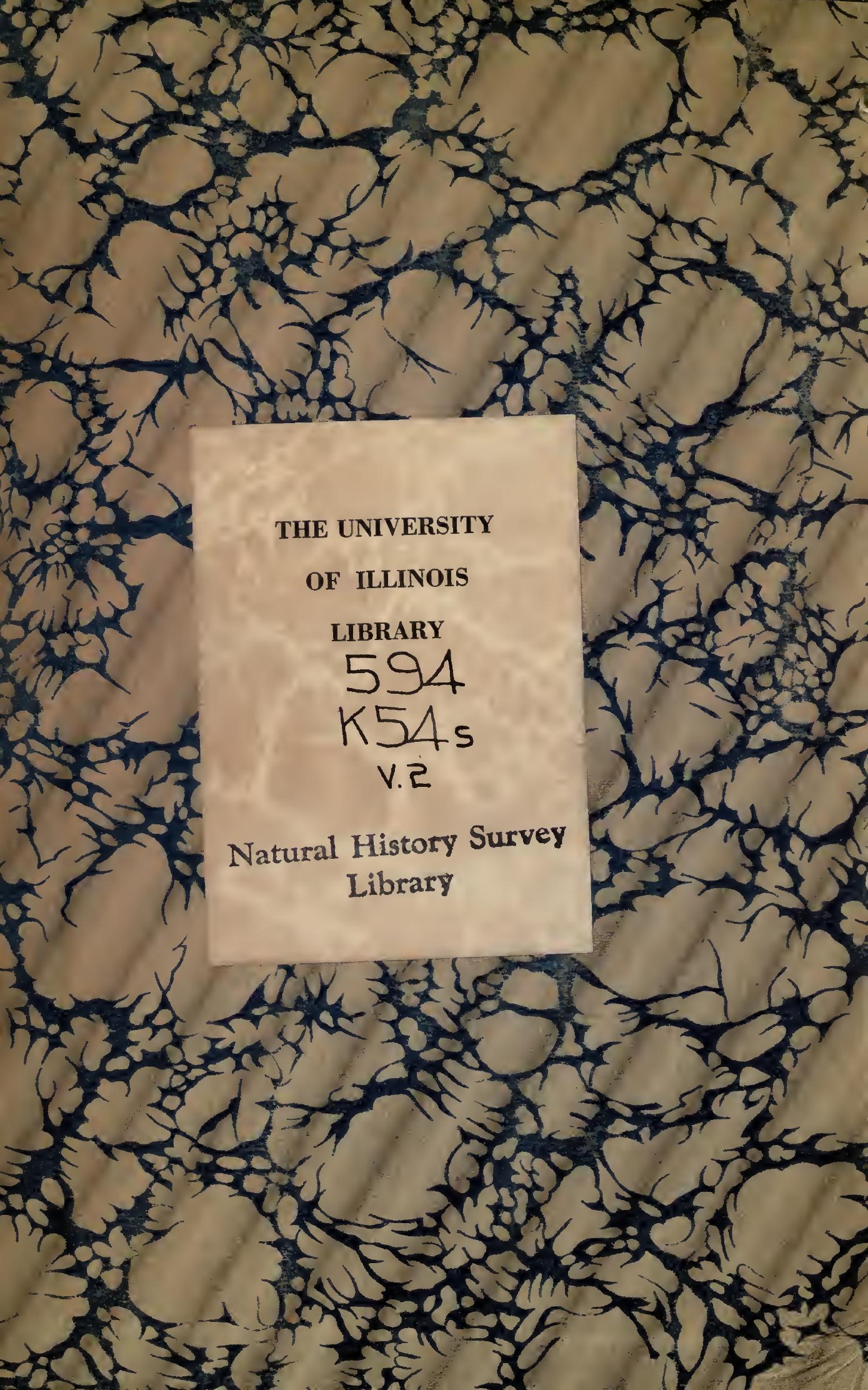




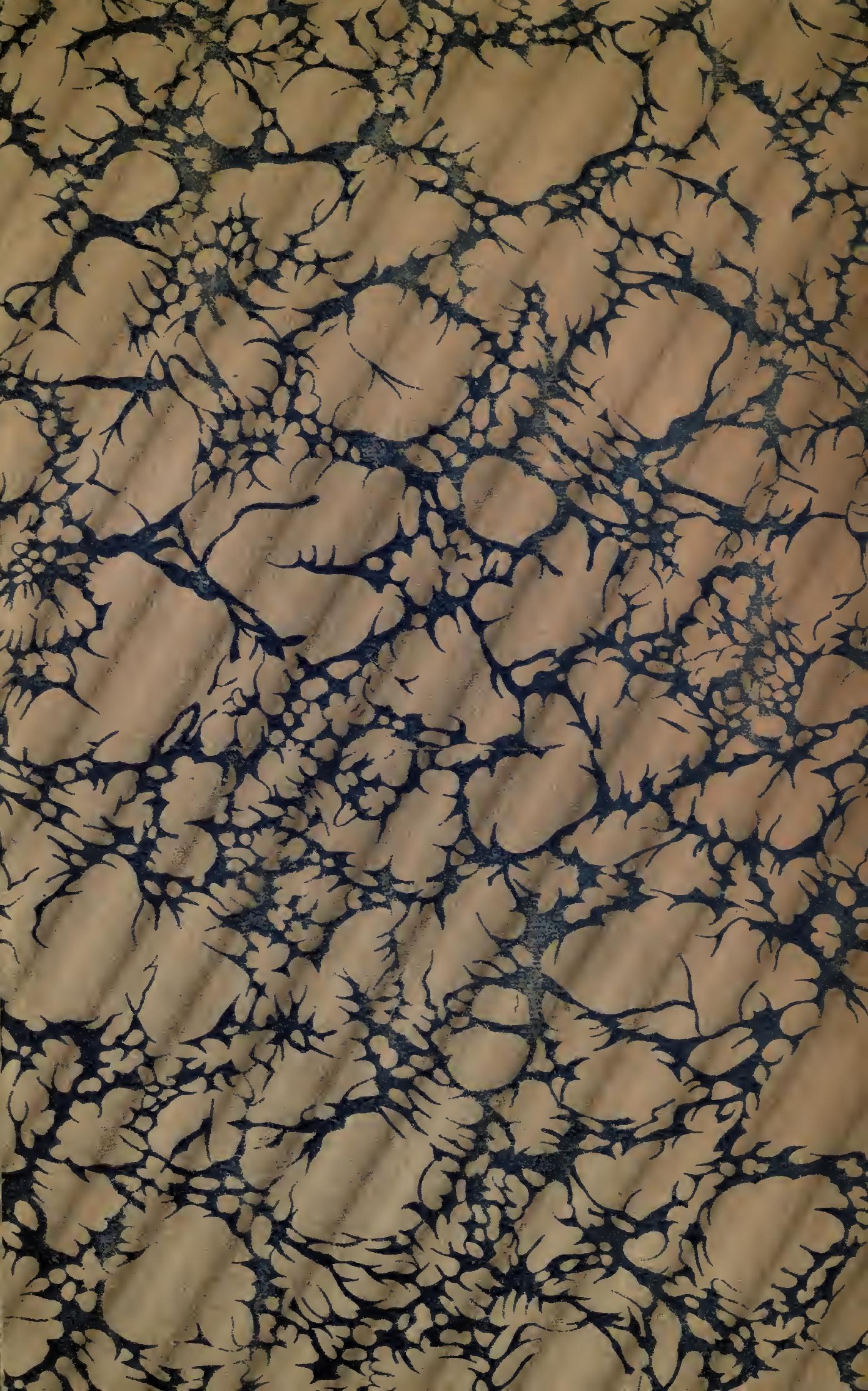


?

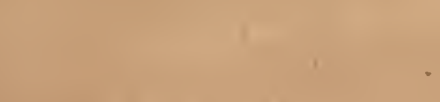

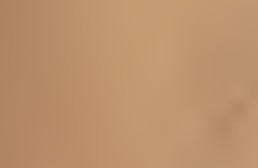

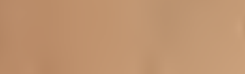

,

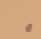


,

$\sqrt{2}$

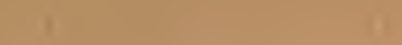

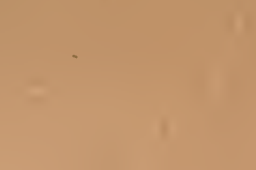

1

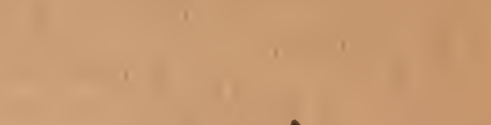

$-1+2+20$

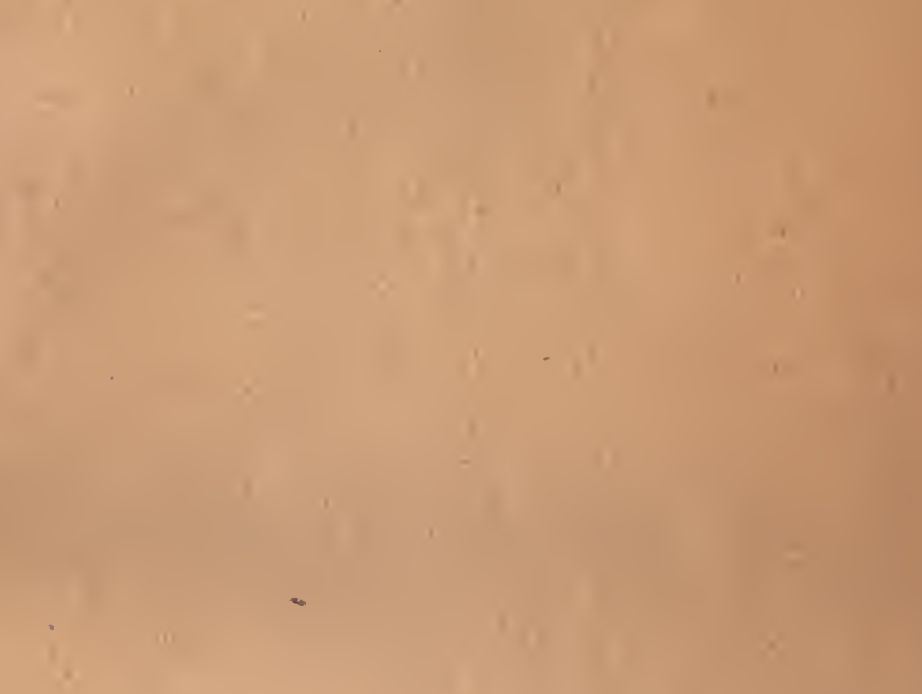

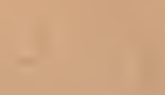

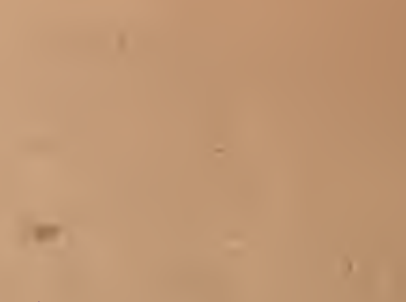


SPÉCIES GÉNÉRAL ET ICONOGRAPHIE DES

\section{COQUILLES VIVANTES}

FAIMILLE DES ENROULEES 


\section{LIBRAIRIE J.-B. BAILLIERE ET FILS}

Le Spécies et Iconographie des Coquilles, de KIENER, continué par M. P. Fischer, continue à paraitre par livraisons. 140 livraisons sont en vente.

Prix de ta livraison grand in- $8^{\circ}$ raisin, figures coloriées. . $6 \mathrm{fr}$.

La livraison in- $4^{\circ}$ vèlin, figures coloriées. . . . . . $12 \mathrm{fr}$.

Les livraisons 139 et 140 contienrent le texte complet du genre Turbo, rédıgé par M. Fischer, 128 pages et 6 planches nouvelles.

Voici la liste des monographies parues, avec le nombre de pages et de planches dont elles se composent, et le prix auquel chaque famille, chaque genre, se vendent séparément format grand in $-8^{\circ}$ :

\begin{tabular}{|c|c|c|c|c|c|c|}
\hline \multicolumn{3}{|l|}{ FAMILLE DES ENROULÉES } & \multicolumn{4}{|l|}{ FAMILLE DES PURPERIFÈlES } \\
\hline $2 \mathrm{rol}$. & $8 \mathrm{Pl}$. & Pris & $2 \mathrm{rol}$. & Pages & PI. & Pris \\
\hline Porcelaine (Cypræa, Lix.). . 166 & 57 & $57 \mathrm{fr}$ & G. Cassidaire (Cassidaria, LAs.) 1 & 10 & 2 & \\
\hline (Ovula, Brug.). . . 26 & 6 & 6 & - Casque (Cassis, Las.). . . & 40 & 16 & 16 \\
\hline re(Terebellum, LaM.). . & 1 & 1 & - Tonne (Dolium, Lam.). . . . & 16 & 5 & 5 \\
\hline ire (Ancillaria, LAs.). 29 & 6 & 6 & - Harpe (Harpa, LaM.). & 12 & 6 & 6 \\
\hline Conus, Lis.) . . . 379 & 111 & 111 & - lourpre (Purpura, ADAss). 1 & 151 & 46 & $40^{\circ}$ \\
\hline & & 181 & - Colombelle (Columbella, Las.) & 63 & 16 & 16 \\
\hline $\begin{array}{l}\text { FAMILLE DES COLUMELLAIRES } \\
\text { / rol. }\end{array}$ & & & urna, $\mathrm{L}$ & 8 & 3 & \\
\hline . . . 120 & 34 & 34 & iolaire (Slrulhiolaria). & 6 & 2 & \\
\hline Volula, Laм.). . . 69 & 52 & 52 & erebra, LAs.). & 42 & 14 & 14 \\
\hline Marginelle (Marginella, Lам.) 44 & 15 & 13 & & & & 1 \\
\hline & & 99 & FAMILLE DES TURBINACÉES & & & \\
\hline $\begin{array}{l}\text { FAMILLE DES AILÉES } \\
1 \mathrm{rol.}\end{array}$ & & & Turrilell & & 14 & \\
\hline a, LAY.) 14 & 4 & 4 & laria, LAм.). . & 22 & 7 & 7 \\
\hline (Plerocera, LAM.) 15 & 10 & 10 & (Solarium, Lay.). & 12 & 4 & 4 \\
\hline (Strombus, Lis.). · 68 & 34 & 34 & ette (Rolella, Laм.). & 10 & $\mathbf{3}$ & 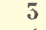 \\
\hline & & 48 & $\begin{array}{l}\text { phinule (Delphinula, Lam) } \\
\text { sianelle (Phasianella). }\end{array}$ & $\begin{array}{l}12 \\
11\end{array}$ & $\frac{4}{3}$ & $\begin{array}{l}4 \\
5\end{array}$ \\
\hline 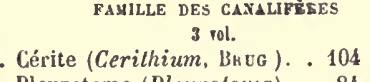 & 52 & 52 & $\begin{array}{c}\text { - Turbo (Turbo, Moctr.). IV-1 } \\
\text { - Troque (Trochus, Lis.). (En } \\
\text { cours de publication, sera }\end{array}$ & & 43 & 5 \\
\hline Pleurotoma). . 84 & 27 & 27 & terminé par M. Fischer). . & - & 56 & \\
\hline La, LAM.). . . 54 & $\begin{array}{ll}01 \\
13\end{array}$ & 15 & & & & \\
\hline laire (Fasciolaria,LaM.) 18 & 13 & 15 & Pamille das plicacées & & & \\
\hline (Turbinella, LAм.) 50 & 21 & 21 & G. To & 6 & 1 & 1 \\
\hline Cancellaria) . 44 & 9 & 9 & idelle (Pyra & 8 & 2 & \\
\hline (urex, LAs.). . . 150 & 47 & 47 & & & & \\
\hline LAM.). . . 48 & 18 & 18 & & & & \\
\hline tanelle (Ranella, LaM.). • 40 & 15 & 15 & FAMILLE DES MYAIRES & & & \\
\hline & & & Iracie (Thracia, LeAcil) . & 7 & 2 & \\
\hline
\end{tabular}

Prix des 140 livraisons parues in-0 tavo, $840 \mathrm{fr}$.

Prix d'une reliure de luxe, dos en maroquin, les planches montées sur onglet, tranche supérieure dorée, $6 \mathrm{fr}$. le volume in-octavo.

On peut acquérir chaqne famille, chaque genre, format in-4. au double du prix indiqué ci-dessus pour l'édition in- $\mathrm{S}^{\circ}$.

paris - IMP. SimoN raģoN et CoMp., rue D'erfuhtil, 1. 


\section{SPÉGIES GÉNÉRAL ET' ICONOGRAPIIL}

DES

\section{COQUILLES VIVANTES}

Comprenant la Collection du Muséum d'Histoire naturelle de Parss

IA COLLECTSON LAMARCK

CELle do priyce masséva (APpartenant Maintesant a M. B. velesseat)

ET LES DÉCOUVERTES RÉCENTES DES VOYAGEURS

Par L.-G. KIENER

Conservateur des collections du Muséum d'Histoire naturelle,

CONTINUE

Par le docteur P. FISCHER

Aide-naturaliste au Muséum d'Iistoire naturelle

FAMILLE DES ENROULÉES

\section{PARIS}

J. -B. BAILLIÈRE ET FILS

19, RUE IIAUTEFEUILLE, PRÈS DU BOULEVARD, SAINT-GERMAIN 



\section{4 K5 $54 \mathrm{~s}$ \\ V. 2}

\section{GENRE CONE.}

(CONUS, Lin.)

Coquille turbinée, ou en cône renversé, roulée sur elle-même. Ouverture longitudinale, étroite, à bords parallèles, à columelle simple, versante à la base. Opercule corné, allongé, fort petit et onguiculé.

Testa turbinata seu inversè conica, convoluta. Apertura longitudinalis, angusta, edentula, basi effusa ; columella simplex. Opercula cornea, elongata, parvula, unguiculata.

Animal ayant une tête d'un médiocre volume, se prolongeant en un petit mufle proboscidiforme, à la base duquel s'élève, de chaque côté, un tentacule assez grêle et cylindrique; vers le milieu de ce tentacule, du côté externe, est placé le point oculaire ; à l'extrémité de cette espèce de trompe se trouve l'ouverture buccale, armée en dedans de nombreux crochets cornés. Le pied est allongé, fort étroit, tronqué en avant, portant, à l'extrémité postérieure, un très-petit opercule rudimentaire. Le manteau se prolonge en avant pour former le siphon, en un canal charnu, cylindracé, évasé à son extrémité. Les branchies, au nombre de 


\section{deux, sont inégales; la plus grande est fortement arquée:}

Le genre Cône est, comme|l'a dit Lamarck, le plus beau, le plus étendu et l'un des plus considérables de la classe des Univalves. C'est celui qui renferme les coquilles les plus précieuses et en même temps les plus remarquables, soit par la régularité de leur forme, soit par l'éclat et l'admirable variété de plusieurs d'entre elles. Aussi sont-elles très-recherchées des amateurs.

Ce genre, considéré sous le rapport des espèces qu'il contient, est un des exemples les plus frappants de la difficulté de déterminer ce que l'on est convenu de désigner ainsi parmi les coquilles; la même espèce peut offrir des différences notables, non-seulement sous le rapport des couleurs, qui sont en général assez inconstantes, mais encore sous celui de l'aplatissement plus ou moins considérable de la spire et des tubercules qui couronnent les tours, et enfin de l'état lisse ou granuleux du corps de la coquille. Le caractère le plus remarquable des Cônes est une forme véritablement turbinée, s'atténuant vers la base et s'élargissant jusqu'à la spire ; celle-ci est généralement courte, tantôt trèsaplatie, tantôt un peu convexe, et tantôt légèrement conoïde.

G'est linné qui caractérisa définitivement, dans son Systema naturae, le genre Cône. Plusieurs des coquilles de ce genre avaient déjà été mentionnées par la plus grande partie ldes savants qui ont précédé ce grand naturaliste. Depuis cette époque, des travaux remarquables ont été entrepris sur lẹs Cônes: Bruguières, en 1792, a publié, dans le premier volume de l'Encyclopédie méthodique, une monographie très-bien faite de ce genre; son travail est surtout remarquable par les descriptions et les déterminations spécifiques, qui sont d'une grande exactitude. Il a été fait sur la collection d'un riche amateur hollandais, M. Hwass. Adanson, dans son Voyage au Sénégal, a donné le premier la description de l'animal de quelques espèces de Cònes; Bruguières, dans le voyage qu'il fit à Madagascar, eut l'occasion d'en observer vivantes quelques autres espèces; mais c'est surtout dans ces dernières années que MM. Quoy et Gaymara' (Voyage de l'Astrolabe) ont publié des descriptions et de bonnes figures de plusieurs espèces avec leur anatomie détaillée.

Lamarck, conduit par certaines considérations, comprit les Cônes dans la fanille des Enroulées; Cuvier adopta les idées de ce savant; Férussac, dans ses Tableaux systématiques des Mollusques, propose de rapprocher les Cônes des Strombes, tout en établissant pour eux une pe- 
tite famille. Bruguières, dans son travail, avait déjà admis cette opinion, parce que, dans tous les genres de la famille des Enroulées (Olive, Porcelaine, etc.), l'animal est pourvu d'un très-large manteau, le renverse sur la coquille, et lui donne ce poli naturel qui les caractérise; dans les Cônes, au contraire, l'animal a le manteau très-court, et la coquille est toujours revêtue d'un épiderme. Conséquemment, ces différences lui paraissaient suffisantes pour éloigner ces coquilles des 0lives et des Porcelaines.

M. de Blainville (Traité de Malacologie) place les Cônes dans sa famille des Angyostomes, à la suite des Strombes, ayant remarqué une très-grande affinité entre ces genres, pour la forme de la coquille dans le jeune âge. On a quelquefois de la peine à distinguer un Strombe d'un Cône. M. Quoy, d'après les observations qu'il a pu faire sur les animaux de ces deux genres, ne doute pas de leur analogie; car on pourrait même dire de l'animal des Cioncs que c'est un Strombe dont certaines parties sont raccourcies, comme la trompe, les tentacules et le pied.

M. Deshayes, dans son ar ticle Côse, du Diclionnaire universel d'his. toire naturelle, indique presque le rapprochement du genre Cône avec les Mitres et les Colombelles; la seule différence notable que ce savant indique entre ces coquilles consiste en ce que dans celles-ci il existe une trompe quelquefois très-allongée, tandis qne dans les Cônes cette trompe paraît manquer et est remplacée par une langue hérissée de crochets. Nous voyons ensuite ce savant revenir (dans la deuxième édition des Animaux sans vertèbres de Lamarck) à l'opinion de M. Férussac, mais en la modifiant et rapprochant les Cônes des Buccins, pour les rattacher aux Pleurotomes, parce qu'un certain nombre d'espèces de ce dernier genre ont quelque analogie avec les Cônes par la forme générale de la coquille et les caractères du bord droit.

Les Cônes sont des mollusques de toutes les mers, où ils vivent en très-grande abondance; on n'en connaît qu'un petit nombre dans la Méditcrranée. Ils sont communs dans les pays chauds; certaines espèces vivent à des profondeurs plus ou moins grandes, et presque toujours dans le sable ou dans la vase. En général, ce sont des coquilles d'un médiocre volume; quelques espèces acquièrent une taille assez considérable, et alors elles deviennent lourdes et solides. Dans cet état, la pesanteur de leur coquille, jointe au peu de grandeur de leur pied, nuit beaucoup à leur accroissement. Toutes sont couvertes d'un épiderme grossier, membraneux, s'enlevant par couches longitudiriales par la dessiccation, et souvent si épais, qu'il cache entièrement les couleurs de la coquille. Ce n'est que lorsqu'elles en sont débarrassées qu'elles paraissent dans l'état brillant où nous les trouvons dans les collections. 
GENRE CÔNE.

Lamarck a divisé le genre Cône en deux sections, en coquille couronnée, et en coquille non couronnée. La première renferme les coquilles dont la spire est couronnée, sans avoir égard à la forme; la seconde prend sa place, au contraire, de la forme de la coquille, et la spire n'y est jamais couronnée. Quoique ces deux sections ne nous paraissent pas bien tranchées par la variabilité de leur caractère, nous les conserverons cependant jusqu'à ce que nous soyons assez heureux pour trouver à grouper définitivement les espèces des Cônes.

\section{Coquille couronnée.}

1. CONE DAMIER. Conus marmoreus, LiN.

(Collect. Lam.) Lister, Conch. t. 787, fig. 39.

Pl. II, fig. 1.

C. testâ oblongo-turbinatâ, nigrâ ; maculis albis, subtrigonis; spirâ tuberculis coronatâ, obtusâ ; anfractibus concavo-canaliculatis.

Coquille très-épaisse, pesante, turbinée, à peu près régulière, offrant un léger rétrécissement vers son milieu. La spire est fort large, subconique, peu élevée, formée de dix ou douze tours environ; elle est canaliculée, lisse, couronnée par de petits tubercules noduleux et légèrement comprimés ; la surface du dernier tour est traversée par un grand nombre de stries généralement fines, mais cependant plus prononcées vers la base qui est aussi munie de stries longitudinales plus ou moins marquées et espacées entre elles, indiquant les accroissements successifs de la coquille. La colora- 
tion consiste en un fond d'un brun noirâtre, sur lequel se détachent de larges taches blanches, trigones, assez régulièrement disposées par séries obliques. L'ouverture est allongée, un peu dilatée à sa base; le bord droit est mince et tranchant; il offre à son sommet une échancrure assez profonde. L'intérieur de l'ouverture est blanc ou légèrement teinté de rose.

\section{Long. 9 cent.}

Habite les mers de l'Océanie, l'île de Vanikoro.

Cette espèce n'est pas rare; elle est bien caractérisée par ses taches blanches trigones se détachant sur un fond noir, disposition qui la fait désigner vulgairement sous le nom de Damier. Elle offre plusieurs variétés remarquables par la disposition que présentent ses taches; quelquefois elles sont séparés par deux larges ceintures formées par le fond de la coloration; d'autres fois elles ont une forme allongée et onduleuse. La surface des jeunes individus est garnie de stries transverses et de petites granulations.

2. CONE MARQUIS. Conus marchionatus, HiNDs.

(Collection Verreaux.) Reeve, Conch. iconica, pl. 15. fig. 65 .

Pl. XXXVII, fig. 1.

C. testâ abbreviato-turbinatâ, lævi, basim versùs sulcatâ, albâ, fusco latè reti culatã ; spirâ depressâ, læviter caniculatâ, spiraliter striatâ ; apice mucronato.

Coquille turbinée, conique, très-raccourcie, élargie à sa partie supérieure, étroite à sa base. La spire est un peu élevée, subdéprimée, mucronée, pointue au sommet; on y compte environ huit ou dix tours lé- 
gèrement canaliculés, striés et couronnés de très-petits tubercules; le dernier tour est lisse; sa base seulement est ornée de quelques sillons transverses. La coloration consiste en de larges alvéoles blanchâtres, quadrangulaires, disposées en quinconces et limitées par des lignes d'un brun marron qui forment un véritable réseau. La spire est veinée de brun.

Long. 40 millim.

Habite les iles Marquises.

Espèce voisine du Conus marmoreus; elle en a généralement le facies; mais elle s'en distingue par la forme de sa spire, qui est trèslégèrement couronnée, et la coloration de son dernier tour formant un réseau brun à trame fine et à mailles extrêmement larges.

3. CONE DE BANDA. Conus Bandanus, Brug.

(Collect. Lam.) Seba, Mus. 3, t. 55, fig. 2-3.

Pl. IV, fig. 1.

C. testâ turbinatâ, nigricante; maculis parvis albis, trigono-cordatis, roseo cæruleoque tinctis ; spirâ depressâ, tuberculis coronatâ.

Coquille allongée, turbinée, formant un cône médiocre à sa base, double environ de celui du sommet; les plans latéraux, légèrement renflés vers les extrémités, sont resserrés et concaves au milieu. La spire est conique, peu élevée, assez acuminée; elle est formée d'une dizaine de tours un peu canaliculés en dessus; leur angle externe est surmonté d'une série de petits tubercules coniques et déprimés; toute la superficie 
du dernier tour est lisse; cependant quelques sillons transverses paraissent à sa partie inférieure, ainsi que des stries longitudinales plus ou moins marquées. La coloration consiste en un grand nombre de taches blanchâtres ou légèrement rosées, plus ou moins larges, irrégulièrement trigones ou cordiformes, affectant une disposition de séries obliques qui deviennent d'un brun très-foncé sur la partie supérieure et à la base de la coquille. L'ouverture, assez large à son sommet, est un peu teintée de rose; le bord droit est mince, tranchant, échancré près de la spire.

\section{Long. 9 cent.}

Habite les mers des Moluques.

Cettte espèce est très-voisine du Conus marmoreus; elle en a la forme générale et présente le même système de coloration ; les taches cependant sont plus petites, en plus grand nombre, d'une teinte rosée, et par leur arrangement produisent des fascies qui suffisent pour la rendre distincte de celle à laquelle nous la comparons. On désigne vulgairement ce cône sous le nom de Damier rose.

4. CONE NOCTURN E. Conus nocturnus, Brog.

(Collect. Lam.) Seba, Mus. 3, t. 46, fig. 5-6.

Pl. IJ, fig. 2, $2^{\text {a }}$ var.

C. testâ turbinatâ, nigrâ; maculis albis, cordiformibus, connatis, fasciatìn digestis ; spirâ obtusâ, coronatâ.

Coquille turbinée, allongée, un peu effilée, formant un cône à base étroite, et dont les plans latéraux sont 
convexes. La spire est assez élevée, conique, mucronée au sommet; on y compte environ une douzaine de tours striés circulairement en dessus et un peu concaves ; leur angle externe est surmonté d'une série de tubercules élevés, coniques, pointus et espacés entre eux ; la surface du dernier tour est lisse et luisante, excepté vers sa base, qui est pourvue de douze ou quinze stries assez saillantes, colorées en noir et un peu granuleuses. Le fond de la coquille est noirâtre, avec de nombreuses lignes transverses rapprochées entre elles, tantôt plus foncées, tantôt plus claires que le fond lui-même, sur lequel se détachent aussi des maculations blanches, irrégulièrement anguleuses; elle sont disposées en séries transverses et forment trois sortes de fascies irrégulières. Sur quelques individus on voit encore, dans l'intervalle des fascies, des maculations isolées qui semblent, pour ainsi dire, détachées des fascies elles-mêmes. La spire est presque blanche, offrant seulement quelques légères veines brunes.

Long. 65 millim.

Habite les mers de l'Inde et des Moluques.

Cette espèce est remarquable par ses séries de taches blanches; elle se distingue du Conus bandanus, dont elle est d'ailleurs très-voisine, par cette singulière disposition, ainsi que par sa forme plus élancée et sa spire plus élevée. Ce cône est quelquefois granuleux à sa base. Vulgairement le Damier à bandes (Voy. notre fig. $2^{\mathbf{a}}$ ). 
5. CONE DE NICOBAR. Conus Nicobaricus, Breg.

(Collect. Lam.) Chems. Conch. 10, t. 159, fig. 1292.

Pl. VIII, fig. 1 et 2 var.

C. test $\hat{\imath}$ turbinatâ, nigricante, maculis albis numerosis furvo inclusis reticulatâ ; subbifasciatâ; spirâ depressâ, nucronatâ, coronatâ ; anfractibus concavo-canaliculatis ; fauce luteâ.

Coquille assez régulièrement conique, large à son sommet, rétrécie à sa base. La spire est peu élevée, mucronée; les tours sont étroits, lisses, canaliculés; leur angle externe est pourvu d'une rangée de tuber.cules très-élevés, comprimés, assez espacés entre eux ; le dernier tour est presque complétement lisse, excepté vers sa base, où l'on aperçoit quelques stries fort légères; il est couvert de nombreuses taches plus ou moins larges et d'un blanc rosé, de forme anguleuse, trigone ou carrée, séparées entre elles apar des lignes brunes ou noires; ces lignes constituent le fond lui-même et forment une sorte de réseau; deux fascies transverses et brunes garnissent encore le dernier tour; elles sont dues à des taches plus petites, plus rapprochées entre elles et plus foncées. La spire est comme réticulée ou veinée par les lignes brunes qui séparent les taches. L'ouverture, presque régulièrement linéaire, est cependant plus large à sa base; le bord droit est tranchant et un peu flexueux.

Long. 50 millim.

Habite les mers des Indes, l'Islande et Nicobar. 
Cette espèce est remarquable par sa forme régulièrement conique, par l'élévation des tubercules de la spire et par la disposition de sa coloration. Vulgairement le Damier à réseau. La variété, fig. $\mathbf{2}$, est surtout remarquable parce que le réseau de sa surface est plus fin, et les deux fascies de son dernier tour plus marquées.

6. CONE ISPLANDIAN. Conus araneosus, Brug.

(Collect. Lam.) D'Argenvilie, Conch. append. pl. 1, fig. T.

Pl. VI, fig. 1.

G. testâ turbinatâ, albidâ, furvo-fasciatâ, filis fuscis araneosis reticulatâ; spirâ convexo-obtusâ, mucronatâ, tuberculis coronatâ.

Coquille turbinée, assez régulièrement conique, à plans légèrement convexes, très-large à sa partie supérieure, étroite à sa base. La spire est plus ou moins élevée; son sommet est mucroné; elle est formée d'une douzaine de tours lisses, peu convexes et ornés d'une série de tubercules peu élevés et assez comprimés. La surface de la coquille est presque entièrement lisse; seulement sa base est garnie de quelques sillons transverses. La coloration consiste en un double réseau, l'un formé par des taches trigones, assez grandes et blanches, l'autre remplissant l'intervalle de ces taches,- et composé de taches beaucoup plus petites, souvent arrondies et d'un blanc rose ; les linéoles qui constituent principalement ce réseau sont d'un brun roussâtre; quelquefois elles se confondent entre elles, et produisent sur le dernier tour deux ou trois fascies transverses dont l'inférieure est la plus large et la plus 
marquée. Les intervalles des tubercules de la spire offrent des lignes brunes qui les joignent entre eux. L'ouverture est blanche et un peu dilatée à sa base.

\section{Long. 76 millim.}

Habite les mers des grandes Indes et des Moluques.

Cette espèce est assez voisine du Conus Nicobaricus; elle en est distincte par ses plans latéraux qui sont płus convexes, et par les tubercules de la spire qui sont moins saillants. Ses taches surtout sont différentes; elles sont généralement moins régulières et comme contenues dans un second réseau à mailles beaucoup plus petites, que l'on a comparé à une toile d'araignée. Enfin son dernier tour offre le plus souvent trois fascies transverses, tandis qu'il ne s'en trouve que deux sur l'espèce à laquelle nous la comparons. Avant la publication de Bruguières, cette espèce avait déjà été indiquée par Gmélin, sous le nom de Conus arachnoideus.

7. CONE IMPÉRIAI. Conus imperialis, Las.

(Collect. LaM.) Lister, Conch. t. 766, f. 15.

Pl. V, fig. 1, 1a, $1^{\mathrm{b}}$, et Pl. VII, fig. 1.

C. testâ oblongo-turbinatâ, albidâ ; fasciis olivaceo-flavis; lineis transversis albo fuscoque articulatis ; spirâ obtusâ, depressâ, tubèrculis majusculis coronatâ.

Coquille oblongue, turbinée, épaisse, très-élargie vers son sommet. La spire est fort peu élevée, quelquefois plane; chacun de ses tours est garni d'une série de gros tubercules coniques, saillants et comprimés; la surface est finement striée en travers; les stries sont plus fortes vers la base et un peu granuleuses. La co- 
GENRE CÔNE.

loration consiste en un fond blanchâtre et nuageux, traversé par un grand nombre de lignes noires plus ou moins larges, souvent interrompues et comme articulées par de petites tachesblanches quadrangulaires ; deux larges fascies brunes ou jaunâtres garnissent le dernier tour, l'une son sommet, l'autre sa partie inférieure; ces fascies, quelquefois unies, sont le plus souvent variées de grandes taches longitudinales, irrégulières et blanchâtres. L'ouverture est étroite, linéaire, légèrement rétrécie vers son milieu et d'une teinte blanche; le bord droit est mince et tranchant; il est coupé vers sa base d'une manière un peu oblique pour former l'échancrure qui est colorée en brun.

\section{Long. 8 centim.}

Habite l’Océan des grandes Indes et des Moluques.

Cette cspèce, rare autrefois et cncore reclıcrchée aujourd'lıui des amateurs, présente des caractères fort remarquables par la disposition articuléc de ses lignes transverses ct cclle de ses deux fascies; elle offre, sous le rapport de la coloration, des variétés asscz notables qui ont donné lieu à l'établissement d'espèces que nous considérons au moins comme très-douteuses; tel est, entre autres, lc Conus viridulus de Lamarck (Voy. notre pl. 7, fig. 1) qui n'est qu'un Conus imperialis, dont le fond de coloration est un jaune verdâtre offrant des lignes transverses brunes, articulées de points blancs. Ses taches blanches sont ponctuées et disposées en flammules ou masses longitudinales. Les fig. $1^{\mathrm{a}}$, $1_{\text {b }}$ de la pl. 5 sont aussi différentes du type par la forme et la disposition des taches. 
8. CONE MAURE. Conus fuscatus, Brog.

(Collect. LaM.) Encyclop. pl. 319, f. 7.

Pl. VII, fig. 2.

C. testâ oblongo-turbinatâ, coronatâ, fusco-virescente, albo-maculatâ ; filis transversis nigris; spirâ planissimâ, truncatâ; aperturâ busi fuscâ.

Coquille turbinée, formant un cône peu élevé, à sommet élargi et à plans latéraux légèrement convexes. La spire est aplatie et même concave; sa partie centrale est un peu saillante. Les tours sont très-étroits, munis d'une rangée de tubercules assez saillants et comprimés. La coloration consiste en flammules longitudinales noires, très-irréłulières, anguleuses, peu distantes entre elles, alternant avec d'autres flammules blanchàtres qui constituent le fond de la coquille; deux fascies transverses brunes garnissent le dernier tour ; toute la surface est, en outre, traversée par des lignes - noires, étroites, souvent interrompues et comme articulées par des taches d'un blanc mat, quadrangulaires, donnant à la coquille un aspect tigré

Long. 60 millim.

Habite l'océan Méridional.

Il cst encore assez difficile dc décidèr si cette espèce cst réellement distincte du Conus imperialis, ou si elle n'cn est qu'une variété. On trouve, il est vrai, quelques différcnces dans sa forme et sa coloration ; 
ainsi elle est un peu plus raccourcie, sa spire est plus aplatie, concave même; les flammules dont elle est ornée sont beaucoup plus petites, plus rapprochées entre elles; enfin les petites taches qui la couvrent la rendent comme tigrée. Mais ces différences s'effacent, pour ainsi dire, peu à peu, par la gradation qu'on observe dans un grand nombre d'individus des deux espèces. Celui que nous avons fait représenter, pl. 5, fig. $1^{\mathrm{a}}$, est un de ceux qui montre le mieux cette analogie.

9. CONE ZONAI. Conus zonatus, BRtg.

(Collect. Lasr.) Chenv. Conch. 10, t. 139. f. 1286-1288.

Pl. III, fig. 5 .

C. testâ turbinatâ, coronatâ, violaceo-cæsiâ, tessulis albis alternatim zonatâ ; filis transversis croceis parallelis; spirâ plano-obtusâ, truncatà.

Coquille turbinée, très-régulièrement conique, élargie à sa partie supérieure. La spire est médiocrement élevée, conique; on y compte une dizaine de tours étroits, surmontés d'une série de tubercules arrondis, obtus et peu saillants. Le dernier tour est lisse ou marqué de stries longitudinales qui indiquent les accroissements; on voit aussi vers la base quelques stries transverses peu saillantes. La coloration consiste en un fond blanc partagé en quatre fascies transverses, d'un brun violacé, formées de taches très-irrégulières, plus ou moins confondues entre elles, généralement anguleuses ou linéaires; en outre, toute la superficie est traversée par des lignes d'un jaune safran, légèrement onduleuses, assez régulièrement distantes, et sur lesquelles viennent se placer les taches brunes qui forment les fascies ou celles qui se trouvent dans leurs intervalles. La spire est marquée de taches ou de flam- 
mules brunes. L'ouverture est blanche à l'intérieur; elle est un peu dilatée vers sa base.

$$
\text { Long. } 6 \text { centim. }
$$

Habite l'océan Indien.

Ciette belle et rare espèce est extrêmement remarquable entre toutes celles du même genre, par les fascies d'un brun violet qui la traversent, ainsi que par les lignes orangées ou noirâtres sur lesquelles les taches sont disposées comme des espèces de notes de musique.

10. CON2 ROY AI. Conus regius, Chems.

(Collect. Lay et Mus.) Favanne, Conch. pl. 17, fig. B. Pl. III, fig. 2, et Pl. XI, fig. 4 .

C. testâ oblongo-turbinatâ, coronatâ, roseâ; lineis purpureo-fuscis longitudinalibus subramosis ; spirâ convexâ.

Coquille régulièrement conique, très-large à sa partie supérieure, atténuée à sa base, c'est-à-dire, vers l'échancrure. I a spire est très-surbaissée, mucronée au sommet, composée de sept ou huit tours aplatis ou légèrement concaves, un peu marginés près de la suture; leur angle externe est muni d'une série de tubercules assez gros, arrondis et obtus. Le dernier tour paraît presque complétement lisse ou marqué de quelques stries transverses vers sa base; cependant sa surface est couverte de stries transverses extrêmement fines qu'on n'aperçoit bien qu'à l'aide de la loupe. La coquille est rougeâtre, avec des flammules longitudi- 
nales étroites, onduleuses et d'un beau noir. La spire est tachetée de noir. L'ouverture est assez grande, à peine élargie à sa base, et d'un rouge orangé à l'intérieur.

\section{Long. 7 centim.}

Habite l'océan Pacifique, les còtes du Mexique, la baie de Panama.

Belle espèce cncore rare dans les collections. Les flammules, plus ou moins nombreuses, sont quelquefois réduites à de simples linéaments à peine onduleux, très-rapprochés entre eux. Le fond est d'un jaune orangé ; telle est la variété très-remarquable que nous avons fait représenter sur notre pl. 11, fig. 4. Il arrive aussi que ccrtains individus sont d'une coloration uniforme d'un jaune orangé, n'ayant aucune flaminule longitudinale apparente. Le nom de Conus princeps avait été donné par Linné au Conus regius des auteurs modernes.

11. CONE PAPIER-MARBRÉ. Conus nebulosus, Solaxd.

(Collect. Lam.) Sess, Mus. 3, t. 44, fig. 17.

Pl. XXIV, fig. 2-2a .

C. testâ turbinatâ, coronatâ, crassâ, interdùm granulatâ, luleo-fuscâ, maculis albis marmoratâ; lineis transversis fuscis; spirâ acutâ.

Coquille épaisse, turbinée, formant un cône trèsraccourci, large à sa base, c'est-à-dire, vers l'angle spiral, atténuée à son sommet et à plans légèrement convexes. La spire est assez élevée, concave et acuminée; on y compte une dizaine de tours striés concentriquement, et dont l'angle externe est orné d'une rangée de tubercules arrondis et obtus; toute la su- 
perficie du dernier tour est traversée par des stries extrêmement fines, devenant cependant plus fortes et plus espacées vers la base, où elles sont granuleuses. La coloration consiste en un fond brun, quelquefois jannâtre, traversé par des lignes plus foncées, nombreuses et comme articulées; des taches blanches, irrégulières, nuageuses, se dessinent sur le fond et $\mathrm{y}$ forment le plus souvent des fascies transverses dont l'une, assez nette, est placée à peu près vers le milieu du dernier tour ; les autres, moins constantes, occupent les extrémités et ne forment souvent que de grandes flammules allongées, parsemées de séries de points d'un blanc laiteux. Quelquefois la coloration brine est pen abondante et semble alors former les fascies, tandis que le reste de la coquille est blanc. La spire est flammulée et veinée de brun et de blanc. L'ouverture est presque égale dans toute son étendue.

\section{Long. 60 millim.}

Habite l'océan Américain et celui des grandes Indes.

Ce Cône, très-commun et très-répandu dans les collections, est voisin du Conus cedonulli, et la distinction de ces deux espèces présente quelquefois de véritables difficultés par leurs nombreuses variétés ; cependant on peut dire que le Conus nebulosus diffère du Conus cedonulli par - a forme plus raccourcie, sa spire plus large, plus acuminée el pourvue de plus gros tubercules. La coloration, moins élégante, n'offre pas les lignes ponctıées et articulées de la même manière. Les jeunes individus sont remarquables par leurs stries transverses qui sont munies de granulations. (Voir notre pl.24, fig. 2.) M. Reewe, dans son Conchological iconica, a fait représenter, pl.18, fig. 96, une variété d'un très-jeune individu du Conus nebulosus, sous le nom de Conus sphacelatus, Sow. 
12. CONE CE DONULLI. Conus cedonulli, lis.

(Collect. Las. el de M. Delessert.) D’Argenv. Conch. append. pl. 1, fig. H.

PI. XVI, firg. 1, $1^{n}$ à $1^{e}$ var.

C. testâ turbinatâ. coronatâ, maculis albis disjunctis aut confluentibus; lineis transversis fusco niveoque articulatis ; spirâ concavo-acutâ.

Coquille turbinée, conique, formée de plans à peu près rectilignes. La spire est élevée, légèrement concave et pointue ; on y compte huit ou dix tours subcanaliculés et pourvus sur leur angle externe d'une série de petits tubercules arrondis, obtus et peu saillants. La coloration consiste en taches plus ou moins étendues, les unes blanches ou d'un gris perle, lesautres jaunâtres, orangées ou brunes, constituant le fond luimêne ; ces taches forment, le plus souvent, des fascies plus ou moins larges et nombreuses, suivant les variétés; toute la superficie est ornée d'un grand nombre de lignnes ou coldons transverses rapprochés entre eux, composés de trois petits points alternativement bruns et blancs; ceux-ci sont quelquefois renflés et arrondis, de manière à simuler de petites perles. La base du dernier tour est.garnie de quelques stries transverses. La spire est flammulée et veinée de blanc et de fauve. L'ouverture est assez étroite et un peu dilatée à sa partie inférieure.

Long. 46 millim.

Habite les mers de l'Amérique méridionale et des Antilles. 
Cette jolie espèce, toujours rare et recherchée des anateurs, présente un grand nombre de variétés que l'on a cherché à distinguer et auxquelles on a mème donné des noms particuliers. Nous avons fait ligurer les principales sur notre même planche 16 ; celle que nous venons de décrire est celle que Lamarck a désignée sous le nom de $C_{\ell-}$ donulli verus seu principalis, et Bruguières sous celui de Cedonulli amiralis.

13. CONE ÍCORCE-D'ORANGE. COnus uurantius, BHEG

(Collect. Lon. el de M. Delesserit.) Lister, Conch. t. 775 , fig. 21 .

Pl. XV, lig. 2, 2n

C. testà oblongo-turbinatâ, coronatâ, granulatâ, aurantiâ vel citrinà aut fulvorufescente, albo-maculatâ ; lineis transversis punctatis ; spirâ acutà.

Coquille turbinée, épaisse, oblongue, allongée. La spire est élevée, conique, composée d'une dizaine de tours lisses en dessous et dont l'angle est pourvu d'une rangée de tubercules mousses et un peu obliques; le dernier tour, un peu convexe, est couvert de granulations disposées en séries transverses; cependant ces granulations manquent quelquefois sur le tiers supérieur, mais sont toujours nettement marquées sur le reste de la coquille. Cette espèce est d'un bel orangé plus ou moins vif avec de larges taches blanches irrégulières, formant ordinairement une fascie découpée et sinueuse qui occupe le milieu du tour; les taches qui garnissent l'angle spiral sont arrondies ou en forme de flammules, comme celles de la base.

Long. 54 millim.

Habite l'océan Asiatique. 
Cette belle espèce est encore très-voisine du Conus cedonulli, et quelques auteurs l'ont mêne confondue avec celle-ci; elle en est distincte par sa forme plus allongée, la différence de ses granulations, sa couleur d'un bel orangé; pruriant quelques variétés ne conservent pas cette teint's et deviennent d'un brun noiràtre (Voir même planche, fig. :2ّa.)

14. CONE CEAGRIN. Conus varius, LiN.

(Collect. Lay. el Mus.) D'Argenv. Conch. pl. 12, fig. R.

PI. VII, fig. 3 et $3^{\text {n }}$ var., et PI. XIII, tig. 4

C. testâ oblongo-turbinatâ, coronatâ, granoso-muriculatà, albâ, castaneo-naculatà : spirâ acutâ.

Coquille oblongue, turbinée, à spire élevée, conique, pointue, formée de huit ou dix tours étroits, marqués de stries décurrentes et couronnés d'une série de tubercules arrondis et obtus. Le dernier tour est assez régulier; les plans sont cependant légèrement convexes. Sa surface est couverte de granulations arrondies et nombreuses, placées sur des stries et disposées en séries transverses; ces granulations ne sont bien marquées que vers la base du tour. L'ouverture est allongée, étroite, si ce n'est à sa base; le bord droit est tranchant. Le fond de la coquille est blanchâtre ou couleur de chair, traversé par des séries de petits points noirs ou bruns correspondant aux granulation. ou placés dans leurs intervalles. Deux rangées de grandes maculations brunes ou de couleur marron se voient au sommet et un peu au-dessus de l'échan- 
crure; elles produisent deux fascies de largeur inégale.

$$
\text { Long. } 42 \text { millim. }
$$

Habite les mers des îles Philippines.

Espèce remarquable par ses deux fascies brunes et par les granulations qui couvrent sa surface. Vulgairement la Peau-de-chagrin. La variété que nous avons fait représenter, $\mathrm{pl} .15$, fig. 4, est celle que Lamarck a indiquée, qui u'est granuleuse que vers la base du dernier tour, et a une coloration uniforme d'un blanc grisâtre. C'est avec cette variété que H. Sowerby a établi son Conus pulchellus, espèce qui doit être supprimée des catalogues.

15. CONE PONCTUÉ. Conus punctatus, Brug.

(Collect. Lam.) Chemv. Conch. 10, t. 139, fig. 1294.

$$
\text { Pl. IX, fig. } 1 .
$$

C. testâ turbinatâ, obsoletè coronatà, helvaceâ, albo-zonatâ, strïs transversis elevatis fusco-punctatis ; spirâ obtusâ, albo fuscoque maculatâ.

Coquille turbinée, formant un cône assez régulier, à base médiocrement élargie. La spire est peu élevée, acuminée au sommet; on y compte sept ou huit tours légèrement étagés, marqués de stries concentriques et à suture faiblement marginée; ils portent sur leur angle externe une série de tubercules mousses et peu saillants; ces tubercules tendent à disparaître sur le dernier tour; celui-ci est finement -strié en travers: les stries, un peu onduleuses, deviennent plus saillantes vers la base et $\mathrm{y}$ sont finement granuleuses. Les stries longitudinales d'accroissement sont assez visibles. Le fond de la coquille est gris-cendré 
mêlé d'une teinte rosée ou légèrement violacée; elle est traversée par une fascie blanchâtre, étroite et ornée de lignes ou de flammules brunes plus ou moins larges, composées elles-mêmes de séries de petits points bruns. La spire est tachetée ou veinée de brun noiratre dans l'intervalle des tubercules. L'ouverture est grande, à peine élargie à sa partie inférieure; elle est blanchâtre en dedans avec une teinte violette. Le bord droit, mince et tranchant, est liséré de brun.

Long. 60 millim.

Habite l'océan Africain.

Cette espèce, assez rare et d'une coloration peu brillante, est cepe'ndant facile à distinguer par la disposition de ses points bruns réunis en flammules.

16. CONI ROSÉ. Conus roseus, LAy.

(Collect. Lam. et Mus.) Martini, Conch. 2, t. 65, fig. 707. PI. IX, fig. 5.

C. testâ turbinatà, coronatâ, transversim sulcatâ, roseù, fuscis sparsim punctis ; fasciâ albidâ ; apice obtusâ.

Coquille turbinée, épaisse, large et convexe à sa partie supérieure, étroite et resserrée à sa base. La spire est obtuse, peu élevée, formée de sept ou huit tours légèrement concaves, ornès de stries décurrentes et surmontés d'une rangée de tubercules obtus; le derıier tour est traversé par des sillons assez forts, 
surlout vers la base. La coloration consiste en une teinte générale rosée. La coquille est traversée d'une fascie blanchâtre; une même fascie couronne l'angle de la spire; la surface est en outre parsemée de petits points noirs ou bruns; dans l'intervalle des tubercules. la spire est tachetée de brun; la base de la columelle est colorée de brun pourpre.

\section{Long. 40 millim.}

Habite les mers des Antilles.

Cette espèce, très-voisine du Conus mus, en est distincte par sa formo moins renflée, sa spire moins élevée, et enfin parce que les sillons qui la traversent ne sont point chargés de granulations. En outre, sa coloration rose piquetée de brun et la teinte foncée de la base de la colu nıelle établissent également des différences entre les deux coquilles. M. Reeve, dans sun Conchol. icon., a fait représenter un Conus lividus var., pour le Conus roseus de Lamarck.

17. CONE soURIs. Conus mus, Breg.

(Collect. Lam.) Gualt. Test. t. 20, fig. R.

Pl. XXIV, fig. 3.

C. testà ovato-turbinatâ, coronatâ, cinereâ, albo-fasciatà : maculis fulvis longıtudinalibus; strïs transversis elevatis ; spirâ variegatâ, acutà.

Coquille ovale, turbinée, formant un cône large à sa base, atténuée à son sommet et à plans latéraux très-convexes. La spire est assez élevée et pointue ; elle est formée de dix tours un peu étagés, concaves, pourvus de stries décurrentes et ornés sur leur angle externe d'une rangée de tubercules allongés, transverses, assez saillants et obtus. Le dernier tour est 
traversé par des stries saillantes et rapprochées les unes des antres : elles sont séparées par d'autres stries parallèles plus petites. L'ouverture est assez large, surtout vers la base qui est simple et non échancrée; le bord droit, assezépais, est faiblement entaillé à son sommet. La coloration de cette coquille consiste en un fond cendré bleuàtre sur lequel se détachent des flammules longitudinales, fauves ou brunes; une fascie blanche colore l's tubercules dont les interstices sont munis d'une tache blanche; une autre fascie blanche garnit le dernier tour. L'ouverture est blanchâtre, nuancée de violet.

Long. 44 millim.

Habite l'océan des Antilles, sur les côtes de la Guadeloupe.

Cette espèce, remarquable par sa forme renflée et très-atténuée à sa base, l'est aussi par les fortes stries de sa surface. Ses points bruns ou noiràtres, qui occupent les interstices des tubercules de la spire, fournissent un caractère très-facile à apprécier.

18. CONE BRUN. Conus brunneus, Wood.

(Collect. de M. Delessertr.) Wood. Ind. test. supp. pl.5, fig. 1 .

Pl. XV, fig. 1-19.

G. testâ turbinatâ, fuscâ, maculis albis, longitudinaliter sinuatis, fasciatim dispositis, cinctâ ; spirâ subprominulà, albo fuscoque macnlatâ, spiraliter sulcatâ, coronatâ; basi lineatâ, lineis elevatis subgranosis.

Coquille turbinée, à spire large, médiocrement 
élevée, conique et pointue. On y compte huit ou dix tours striés concentriquement, concaves en dessus et couronnés par une rangée de tubercules assez forts ; le dernier tour, lisse à sa partie supérieure, est traversé, vers les deux tiers inférieurs, par des stries également distantes entre elles et granuleuses. La coquille est presque entièrement brunâtre; son dernier tour est parsemé de lignes formées de petits points blancs et vers le sommet de quelques taches irrégulières plus larges. La spire est tachetée de blanc et de brun. L'ouverture est assez grande; sa base est simple, sans échancrure; elle est blanchâtre à l'intérieur avec une légère teinte bleue vers le tranchant du bord droit qui est faiblement entaillé ì son sommet.

\section{Long. 48 millim.}

Habite les côtes de Panama et celles des îles Gallapagos.

Espèce bien distincte par sa forme élargie et rentrue à son sommet, ainsi que par les saillies de ses tuhercules. La variété représentée (fig. 1) est remarquable par sa coloration tnute brune ct sa sirure d'un blauc jaunâtıe.

19. CON E GLAdATzUT. Conus gladiator, Bitur).

(Collect. du Mus.) Sowerby, Conch. illustr. fig. 34.

Pl. XV, fig. 4 .

C. testâ conicì, brunneâ, albo obscurè longitudinaliter strigatâ, balteo subcentrali subobsoleto, albente ; spirâ subcoronatâ, granuloso-striatâ, brunneâ, alhomaculatâ.

Coquille épaisse, turbinée, assez régulièrement 
conique, légèrement renflée au milieu; la spire est conique, pein élevée; on y compte six ou sept tours étroits, marqués de fines stries décurrentes ou munis sur leur angle externe d'une série de tubercules coniques et saillants; toúte la surface est finement striée en travers; les stries sont plus saillantes vers la base. A des intervalles plus ou moins rapprochés, on remarque des stries longitudinales d'accroissement assez profondes. L'ouverture est assez large et légèrement dilatée à sa base qui est simple et sans échancrure. La coloration consiste en un fond rougeâtre, traversé de lignes noires qui correspondent aux stries; une fascie, composée de taches blanches, irrégulières, anguleuses et allongées, orne le dernier tour; vers l'angle de la spire existe une autre série de taches blanches qui naissent de chaque tubercule et se prolongent quelquefois assez pour former une rangée longitudinale de petits points. La spire est presque entièrement blanche : on y voit cependant quelques taches brunes dans l'intervalle des tubercules. L'ouverture est blanchàtre.

\section{Long. 38 millim.}

Habite la mer du Sud, les côtes de Panama.

felte espèce est extrèmement voisine du Conus brunneus; on trouve cependant, soit dans sa forne moins renflée, soit dans sa coloration, des différences qui permettent assez bien de la distinguer. 
GENRE CÔNE.

20. CONE BAUDRIER. Conus balteatus, Sow.

(Collect. de M. Cuming.) Sowerby, Conch. illustr.pl. 8, fig. 58.

PI. XV, fig. 5.

C. lestầ abbreviato-conicâ, basinı versùs sulcatâ, pallidè cæeruleo-flavesceute, olivaceo-fusco medianè et infernè balteatâ, basi subpurpureâ ; spirâ depressoconvexâ, coronatâ, spiraliter striatâ, apice roseâ.

Coquille conique, turbinée, renflée au milieu et atténuée vers la base. La spire est convexe, peu élevée, composée de six ou sept tours pourvus de stries décurrentes et dont l'angle externe est orné d'une rangée de tubercules coniques et peu élevés; la surface du dernier tour est striée transversalement; les stries sont fines vers le sommet et assez marquées à la base pour former de véritables sillons. La coloration consiste en un fond cendré ou léşèrement jaunàtre traversé de deux fascies d'un brun olive. La spire est blanchâtre ou cendrée; son sommet est teinté de rose.

Long. 30 millim.

Habite la mer de Chine, les îles Philippines.

Cette petite espèce, que nous ne connaissons encore qu'imparfaitement, paraît assez voisine du Conus lividus. Il serait peut-être bon de l’y réunir, et $\mathrm{M}$. Sowerbỵ, qui l'a décrite, était porté à le croire. 
GENRE CO̊NE.

21 CONE MeNNONITE. Conus distans, Brec

(Collect. Lasr.) Chems. Conch. 10, t. 138, f. 1281.

PI. HI, fig. 1.

C. testâ turbinatâ, coronatà, flavescente, basi subviolaceâ; lineis transversis impressis distantibus; spirà convexâ, albo fuscoque maculatâ.

Coquille assez épaisse, pesante, régulièrement conique, à plans latéraux droits, à peine convexes vers la partie supérieure et faiblement resserrés au milieu. La spire est surbaissée; on y compte dix ou douze tours marginés près de la suture; les derniers sont un peu concaves, creusés en forme de gouttière et assez étagés; leur angle externe est garni d'une rangée de tubercules obtus qui vont en diminuant sur les derniers tours et qui finissent par ne plus former que de simples ondulations; le dernier tour est finement strié transversalement; quelques-unes des stries. plus prononcées que les autres, sont parallèles. A la base il existe quelques sillons très-larges, mais pen profonds. L'ouverture est un peu dilatée à sa partie inférieure qui est simple et non échancrée; le bord droit est profondément entaillé à son sommet La coquille a une teinte jaunâtre à peu près uniforme qui ‘lisparaît sur les individus un peu frustes; elle est traversée par une fascie blanche; sa base est teinte ou maculée de brun rougeâtre ; la spire est parsemée de tachies jaunes ou rousses situées dans les interstices des tubercules. 
L'ouverture est blanche; sa base est un peu teintée de violet.

$$
\text { Long. } 70 \text { millim. }
$$

Habite l'océan Pacifique, les còtes de la Nouvelle-Zélande.

Cette grande espèce n'a rien de bien remarquable dans ses différ('nts caractères; cependant son aspect général et sa teinte jaunâtre uniforme. les maculations rousses de sa spire, les stries de sil surface la rendent facilement distincte; à la première vue, elle a un peu l'apparence du Conus virgo.

22. CONE ITVIDE. Conus lividus, Brug.

('ollect. Lam.) Knork, Vergn. 4, t. 13, fig. 3.

Pl. IX, tig. 2, 2n var.

C. testâ turbinatà, coronatà, infernè granoso-muriculatâ, livido-virescente, basi subcæruleâ ; zonâ albidâ; spirâ albâ, obtusâ.

Coquille épaisse, pesante, turbinée, formant un cône assez régulier, un peu resserré vers le milieu. La spire est conique, tantôt surbaissée et arrondie, tantôt mucronée au sommet; elle est formée de dix tours aplatis ou légèrement concaves, quelquefois un peu étagés et pourvus de fines stries décurrentes; leur angle externe est surmonté d'une rangée de tubercules généralement obtus et peu saillants; le dernier tour paraît presque lisse; cependant il est couvert de stries transverses extrêmement fines, mais qui, vers sa base, deviennent plus saillantes et plus ou moins granuleuses. L'ouverture est étroite, resserrée au milieu, 
dilatée à la base qui est simple, sans échancrure. Le bord droit, mince et tranchant, est légèrement entaillé au sommet. Cette coquille est d'une teinte olivâtre plus ou moins foncée; l'angle de la spire est entouré d'une fascie étroite, blanchâtre; une autre fascie, également blanche ou jaune, est située vers la base du dernier tour. La spire, rosée au sommet, est quelquefois toute blanche et le plus souvent maculée de jaune ou de rougeâtre dans les interstices des tubercules; ceux-ci sont blancs. L'ouverture est violette; sa base est d'une teinte plus foncée.

Long. 54 millim.

\section{Habite l'océan des grandes Indes.}

Lspèce extrêmement commune, très-distincte par sa teinte livide et les deux fascies de son dernier tour. Elle offre des variations assez grandes, dans l'intensité de sa coloration qui du jaune passe au verdàtre pour arriver au brun noir assez foncé. Chez les jeunes individus, la coquille est le plus souvent garnie sur toute sa surface de rangées transverses de granulations très-apparentes; quelquefois ces mêmes granulations n'existent que sur la moitié inférieure du dernier tour. (Voir notre pl. 9, fig. 2a.)

23. CONE AIIONGE. Conus elongatus, ReEvr.

(Collect.de M. Delessert.) Reeve, Conch. icon.pl.27, fig. 157.

$$
\text { Pl. XXXIII, fig. } 1 .
$$

G. testâ elongato-turbinatâ, læri, luteo-olivaceâ, supernè cærulco-aibâ, fascià interruptâ subindistinctâ deorsùm cingulatâ ; spirâ convexâ, cæruleo-albâ, subtilissimè coronatâ, apice rosaceo ; basi et aperturâ fauce vividè violaceis.

Coquille allongée, turbinée, peu épaisse, très-atténuée à sa base; les côtés, assez convexes à leur som- 
met, offrent vers leur milieu un léger rétrécissement. La spire est peu élevée, convexe; on y compte huit tours étroits, finement striés circulairement ou surmontés d'une rangée de petits tubercules nombreux, mousses et obtus. Le dernier tour est presque lisse; seulement, à sa partie inférieure, il est muni de quelques stries fines. L'ouverture est très-étroite, linéaire, s'élargissant un peu à sa base. Le canal est simple, non échancré, le bord droit peu entaillé. La coquille est d'un jaune olivâtre, un peu veiné longitudinalement; sa partie inférieure est brunàtre. L'angle de la spire est ceint d'une fascie blanche; les interstices des tubercules sont marqués d'une petite tache roussâtre, et une autre fascie blanchâtre peu prononcée orne le milieu du dernier tour. L'ouverture est violacée à l'intérieur.

\section{Long. 40 millim.}

Habite la mer des Indes.

Cette espèce est voisine du Conus lividus; on y remarque à peu près le même ensemble de caractères; mais elle s'en distingue par sa forme beaucoup plus allongée et par ses tubercules plus petits et plus nombreux.

24. conz costż. Conus costatus, Chems.

(Collect. du Mus.) Chems. Conch. 11, t.181, fig.174̄̄ et 1747.

Pl. VI, fig. 2.

C. testà turbinatà, coronatà, transversim sulcatâ, albido-luteà ; sulcis elevatis scabris ; spirâ convexo-acutâ; labro denticulato.

Coquille turbinée, assez régulièrement conique, 
très-large à sa partie supérieure, atténuée à sa base, c'est-à-dire, vers le canal. La spire est peu élevée, excepté à son sompmet qui est acuminé et pointu ; elle est composée de dix tours concaves, creusés en une sorte de gouttière et marqués de sillons décurrents; leur angle externe est relevé en une carène qui est comme festonnée par de petits tubercules; le dernier tour est traversé par des sillons ou cannelures transverses assez profondes, produisant des espèces de côtes un peu granuleuses ; les stries d'accroissement, assez bien marquées, forment, au fond des sillons, des séries de crénelures extrêmement fines. Le canal est un peu relevé vers le dos. L'ouverture est grande, assez dilatée à sa base. La coquille a une teinte générale fauve; les côtes sont un peu plus vivement colorées; la spire est blanchậtre, son sommet un peu jaune.

\section{Long. 60 millim,}

Habite les mers des Indes orientales.

Cette espèce est bien remarquable, entre toutes celles du même genre, par les sillons et les cannelures qui la traversent et sa coloration fauve à peu près uniforme. Bruguières l'a fail connaître sous le nom de Conus sulcalus, et plus tard Lamarck en distingua, sous le nom de Conus asper, un individu qui n'en est évidemmient qu'une variété ; c'est pourquoi nous pensons qu'il vaut mieux lui conserver le nom que Chemnitz lui a imposé. 
25. CONE D'OKBIGNY. Conus Orbignyi, AdDour.

(Collect. du Mus.) Magasin de roologie, 1831, pl. 20.

Pl. XIII, fig. 3.

C. testâ tenui, subfusiformi, gracillimè turbinatâ, versùs basim valdè attenuatâ, transversim costatâ, costis lævibus, planissimis; albâ, maculis spadiceis sparsis plùs minùsve irregulariter pictâ; spirâ elevato-acutâ, minutissimè moniliferùm coronatâ.

Coquille allongée, subfusiforme, à spire élevée et pointue, régulièrement conique, composée de treize ou quatorze tours traversés par des stries qui treillissent leurs intervalles. Ces tours sont légèrement canaliculés en dessus et bordés d'une carène élégamment couronnée de tubercules ou de crénelures; le dernier est entièrement garni de stries transverses fort prononcées, régulières, très-rapprochées entre elles, plus distantes vers le sommet. L'ouverture est étroite, un peu dilatée dans le milieu; le bord droit est mince et se détache de la spire par une échancrure assez pro. fonde. Le fond de la coloration est blanc et il s'y dessine des lignes transverses de taches quadrangulaires et de flammules oblongues, d'un roux brunâtre, qui ont quelquefois la forme de chevrons.

$$
\text { Long. } 56 \text { millim. }
$$

Habite les mers de la Chine.

Cette belle espèce, toujours rare, a été décrite et figurée, pour la première fois, par Audouin, en 1831. M. Sowerby, dans son Conchological illust., fig. 15, a fait représenter ce Cône sous le nom de Conus planicoslalus. 
GENRE CÔNE.

26. CONI CALÉDONIEN, Conus caledonius, Breg.

(Collect. de M. Delessert.) Encyclop. pl. 321, fig. 10. Pl. LXXIX, fig. 3.

C. testâ turbinatâ, coronatâ, aurantiâ, filis rufis tenuissimis parallelis contiguis cinctâ; spirâ acutâ.

Coquille conique, oblonq̧ue, à spire élevée, composée de dix tours; les deux derniers sont légèrement canaliculés, un peu aplatis, tandis que les antres, garnis de tubercules semblables à des rides, s'élèvent en angle aigu. Le dernier tour est garni d'un bout à l'autre de lignes circulaires parallèles, semblables à des fils et formant une légère saillie sur sa superficie; celles de la moitié inférieure du tour sont légèrement granuleuses; on y distingue aussi quelques sillons longitudinaux, inégalement distants entre eux et qui indiquent les accroissements successifs. L'ouverture est simple, droite et terminée à son extrémité supérieure par une échancrure profonde; elle est uniformément blanche à l'intérieur ; au dehors, elle est d'un jaune orangé assez vif, coupée par des lignes circulaires d'un roux foncé et disposées parallèlement. La spire offre partout une teinte orangée sans aucun mélange dautre couleur.

\section{Long. 58 millim.}

Habite la mer Pacifique, vers les côtes de la NouvelleCalédonie.

Ciette coquille, extrêmement rare, est bien distincte des autres Cônes, et a une coloration tout à fait différente. Nous nous sommes servi, pour notre figure, du dessin original que Bruguières a fait copier pou' l'Encyclopédie. 
GENRE CÔNE.

27. CONE PONTIFICAx. Conus pontificalis, Las.

(Collect. Lam.) Delessert, Recueil de Coq. pl. 40, fig. 15 a b.

PI. XIII, fig. 5.

C. testâ ovato-turbinatâ, coronatâ, transversim subtilissimè sulcatâ, albâ; epidermide luteo-virescente; spirâ elevatâ, conicâ.

Coquille turbinée, à spire allongée, conique, formant plus du tiers de la longueur totale; elle est composée de neuf tours peu concaves, bordés d'un rang de tubercules arrondis, situés près de la suture et joints par une rampe spirale striée transversalement. Le dernier tour est chargé de stries transverses assez fines dont les plus profondes sont celles de la base. Toutes ces stries sont marquées de petits points enfoncés. La coquille est blanche, mais recouverte d'un épiderme d'un vert jaunàtre, qui se détache aisément.

Long. 43 millim.

Habite les parages de la terre de Diémen.

Espèce que l'on rencontre rarement, mais que l'on distingue sans peine, parce que sa forme rappelle une tiare pontificale. 
28. CONE DE SOI ANDER. Conus coccineus, GMEL.

(Collect. de M. Borvin) KNorr, Vergn. t. 5, pl. 24, fig. 2.

Pl. LXXVII, fig. 3-5n.

C. testâ cyllindraceo-turbinatâ, subcoronatâ, transversè striatâ, striis frequentibus, aut infernè, aut ubiquè granulosis ; pallidè aurantiâ, interdùm aurantiococcineâ, interdùm spadiceo-laccâ, fasciâ albâ in medio, castaneo-maculatâ et punctatâ; spirâ mediocri, rudi, læviter striatâ.

Coquille cylindracée, conique, à spire convexe, pointue au sommet, composée de onze ou douze tours, traversés par des stries découpées en réseau et couronnés d'une rangée de tubercules assez gros et souvent irréguliers; toute la surface du dernier tour est chargée de petits sillons transverses plus ou moins granuleux : ceux de la base sont plus gros et plus écartés entre eux que ceux du sommet. L'ouverture est blanche et étroite ; toute la coquille est d'un beau brun rougeâtre peu foncé; le milieu du dernier tour est orné d'une zone blanche assez large sur laquelle se dessinent des flammules longitudinales, irrégulières, assez foncées, et des rangées de ponctuations alternant avec le fond blanc; les tours de spire ont une zone d'un brun noiràtre qui se découpe en taches irrégulières, alternant avec le fond rosé et qui finit par disparaître au sommet.

Long. 45 millim.

Habite les mers des îles Philippines.

M. Deshayes, dans la $2^{\mathrm{e}}$ édition de Lamarck, a rendu à cette belle 


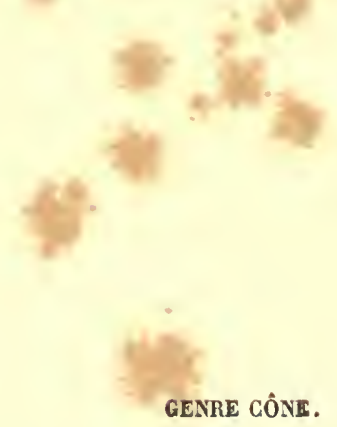

espèce son premier nom, celui de Conus coccineus, que Gmelin lui avait donné; mais les conchyliologistes anglais l'ont décrite sous celui de Conus Solanderi. La coloration de cette coquille est assez variable; nous en avons fait représenter sur notre même planche 77, fig. 3, un individu dont le fond est d'un jaune citron, nais qui conserve tous les caractères du type.

29. CoN E CARDINAL. Conus cardinalis, Brvg.

(Collect. LaM.) Knorr, Vergn. 5, t. 17, fig. 5. Pl. XIV, fig. 3 .

C. testâ turbinatâ, coronatâ, granulosâ, coccineâ; fasciâ albâ, fúsco-maculatâ ; spirâ depressâ.

Coquille conique, turbinée, à spire composée de huit ou neuf tours dont la superficie est aplatie, légèrement tuberculeuse vers les bords et élevée en angle obtus; le dernier, quoique luisant, offre des stries circulaires écartées, souvent granuleuses, plus prononcées vers la base et même dès la moitié inférieure. L'ouverture est faiblement échancrée vers son sommet, simple à sa base. blanche ou nuancée de rose très-clair à l'intérieur. La coloration de la coquille est incarnate ou d'un rouge corail, à l'exception d'une zone blanche tachetée de brun, située un peu au-dessous du milieu du dernier tour; la spire est blanche, nuancée de rose et parsemée irrégulièrement de quelques taches orangées.

\section{Long. 27 millim.}

Habite l'océan Indien.

Ce joli petit Cône est peu commun; il offre quelquefois une variété ayant deux zones blanches tachetées de brun, au lieu d'une seule. 
30. CONE PIQURE-DE-MOUCHE. Conus arenatus, LAM.

(Collect. Lam.) Lister, Conch. t. 761, fig. 10.

Pl. $X$, fig. 1, 1a, $1^{\mathrm{b}}$ var.

G. testâ turbinatâ, coronatâ, albâ, punctis nigris aut rubris acervatim conspersâ ; spirâ convexo-planulatâ, mucronatâ.

Coquille épaisse, formant un cône à base étroite, à plans latéraux convexes, excepté au milieu où il existe un léger étranglement. La spire est peu élevée, mucronée au sommet; on y compte douze ou quinze tours dont l'angle externe est orné d'une série de tubercules coniques, comprimés et subtranchants. Le dernier tour paraît lisse dans toute son étendue, il présente cependant à sa base quelques stries transverses ; sa surface est également couverte de stries longitudinales extrêmement fines : ce sont les stries d'accroissement. La coloration consiste en un fond blanchàtre ou rosé sur lequel sont parsemés un trèsgrand nombre de petits points bruns ou noirâtres, irrégulièrement disposés mais tendant à former des flammules longitudinales, plus confuses et plus rapprochées entre elles vers la base.

Long. 52 millim.

Habite les mers des Philippines et de la NouvelleGuinèe.

Espèce extrêmement commune et facilement distincte. Les variétés $1^{a}, 1^{b}$, montrent les dispositions diverses qu'affectent les points. 
31. CONE MORSURE-DE-PUCE. Conus pulicarius, Brvg.

(Collect. Lam.) Lister, Conch. t. 774, fig. 20.

Pl. X, fig. 2.

C. testâ turbinatâ, coronatâ, albâ, punctis majusculis fuscis ; zonâ duplici aurantiâ ; spirâ subdepressâ, mucronatâ.

Coquille épaisse, raccourcie, un peu resserrée vers sa partie moyenne, formant un cône à base étroite et à plans convexes. La spire est courte, légèrement conique, mucronée au sommet; elle est couronnée par des tubercules occupant l'angle externe des tours qui sont munis de stries décurrentes; la surface du dernier paraît lisse ; elle est cependant couverte de stries transverses et longitudinales d'une finesse extrême; il existe aussi à la base, au-dessus de l'échancrure, quelques sillons transverses. Cette coquille offre, sur un fond blanc très-luisant, une série de taches noires quadrangulaires, carrées ou allongées, plus rapprochées entre elles à la base du dernier tour. L'ouverture est blanchàtre ou légèrement rosée; elle est profondément échancrée à sa base.

Long. 56 millim.

Habite l'océan Pacifique, les côtes de la Nouvelle-Guinée.

Cette espece, voisine du Conus arenatus, en est distincte par la forme 
de ses points quadrangulaires, beaucoup plus gros et moins nombreux que dans celui-ci; elle présente sous ce rapport beaucoup de variétés.

32. CONE FUSTrGí. Conus fustigatus, Brug.

(Collect. Lam.) Rumph. Mus. 1. 33, fig. 2.

PI. XI, fig. 5.

C. testâ turbinatâ, coronatâ, albâ ; guttis nigris aut fusco-cinnamomeis difformibus; spirâ subdepressâ, mucronatâ.

Coquille un peu raccourcie, renflée, très-solide et pesante. La spire est courte, obtuse; on y compte environ huit ou dix tours à suture marginée; ils sont munis de sillons décurrents et couronnés d'une série de tubercules comprimés et subtranchants; le dernier tour, presque lisse, très-finement strié, offre is sa base quelques sillons transverses. La coloration consiste en un fond blanc ou légèrement rosé, parsemé de taches, la plupart allongées transversalement, noiràtres, irrégulièrement disposées; l'ouverture, dilatée à sa base, est blanchâtre à l'intérieur.

$$
\text { Long. } 40 \text { millim. }
$$

Habite les mers de l'Inde et des Moluques.

Il est assez difficile de distinguer cette espèce du Conus pulicarius; on remarque seulement que ses taches quadrangulaires sont plus larges, plus nombreuses et qu'elles couvrent à peu près également toute 
la surface, se dessinant vaguement en deux fascies. Mais ces caractères sont de peu d'importance, car le Conus pulicarius varie extrêmement sous ce rapport: nous ne sommes donc pas éloigné de l'opinion de II. Dillwyn et de celle des autres auteurs qui réunissent les deux espèces.

33. CONE CIVETTE. Conus obesus, Brog.

(Collect. Lam. et Mus.) Chenn. Conch. 10, t. 142, fig. 1318.

Pl. X, fig. 3.

C. testâ turbinatâ, coronatâ, niveo-roseâ, maculis punctis et nubeculis violaceis undulatâ ; spirâ concavo-obtusâ, mucronatâ.

Coquille épaisse, turbinée, un peu racwourcie et renflée. La spire est peu élevée, obtuse, mucronée au sommet; on y compte huit ou dix tours étroits, munis de sillons décurrents et dont l'angle externe est garni de tubercules très-peu marqués, ne formant même que de simples festons; la base du dernier tour est ornée de quelques sillons transverses. La coloration, extrêmement remarquable, consiste en taches ou nébulosités violàtres ou rosées, interrompues par d'autres taches d'un blanc mat; au milieu des premières sont placés un grand nombre de points noiràtres plus ou moins larges, arrondis, quadrangulaires, formant quelquefois des espèces de lignes transverses articulées; ces taches, points et nébulosités sont disposés de manière à produire des ondulations longitudinales imitant jusqu'à un certain point le jaspe : des fascies transverses assez larges sont obscurément tracées sur le dernier tour par la teinte un peu plus foncée des nébulosités. L'ouverture est étroite en haut, 
large au bas. La columelle, convexe à sa partie supérieure et concave à l'inférieure, porte vers cette partie un pli de torsion assez marqué.

Long. 56 millim.

Habite la mer de l'Inde, les côtes de Ceylan.

Jolie espèce que sa coloration rend bien distincte; par sa forme, elle est voisine du Conus pulicarius. Chemnitz lui a donné le nom de Conus ceylonicus, et Gmelin, celui de Conus zeylanicus. Vulgairement la Peau de civelte.

34. CONI MIIIAIRE. Conus miliaris, BRtg.

(Collect. Lam.) Encyclop. pl. 319, fig. 6. Pl. XIII, fig. 1.

C. testâ turbinatâ, coronatâ, carneâ, albo-zonatâ; fasciis duabus lividis ; lineis transversis fusco-punctatis; spirâ obtusâ.

Coquille conique, à spire obtuse, composée de onze tours qui sont garnis de tubercules saillants et convexes, se prolongeant d'une manière très-distincte depuis la pointe du sommet jusqu'au bord de l'ouverture. Ces tours sont striés circulairement. La superficie de la coquille est luisante; sa moitié supérieure est lisse, et le reste, depuis le milieu jusqu'au bas, est strié circulairement. L'ouverture est simple à sa base, échancrée à son extrémité supérieure; la columelle est arrondie, légèrement oblique et contournée au dehors par une côte saillante bien marquée. La couleur de la coquille consiste en une teinte incarnate, sur laquelle sont tracées deux fascies blanches ou mouche- 
tées, de même couleur que le fond; en outre, elle est ornée de lignes circulaires très-finement ponctuées de brun. L'ouverture est olivâtre ou livide dans le fond.

Long. 38 millim.

Habite les côtes de la Chine.

Espèce assez commune, qui doit son nom aux lignes circulaires finement ponctuées de sa surface, et peut-être aux petits grains dont sa partie inférieure est garnie.

35. CONE GOURGOURAN. Conus barbadensis, BRdG.

(Collect. Laм.) Encyclop. pl. 322, fig. 8.

Pl. XIII, fig. 2.

C. testâ turbinatâ, coronatâ, roseâ aut rufescente; lineis transversis fusco alboque articulatis; fasciis duabus albidis ; spirâ obtusâ.

Coquille conique, renflée vers son sommet, à spire obtuse, composée de huit ou neuf tours dont la partie supérieure, légèrement canaliculée, est entourée de plusieurs stries circulaires, et dont la moitié inférieure est garnie de tubercules. Le dernier tour est luisant, quoique sillonné circulairement sur toute son étendue, et granuleux à sa base. Quant à la couleur de la coquille, on aperçoit d'abord une fascie blanchâtre vers la naissance des tubercules de la spire, puis deux larges ceintures de couleur fauve ou rosée, séparées entre elles par une seconde fascie blanche. En ou- 
tre, toute la surface est ornée de lignes transverses, articulées de brun et de blanc. L'ouverture est d'un blanc violacé dans le fond.

\section{Long. 38 millim.}

Habite les mers des Antilles.

Nous pensons que cette espèce doit être réunie au Conus miliaris; ces deux coquilles offrent, en effet, très peu de différences entre elles, et se réunissent par un grand nombre de variétés. MM. Sowerby et Reeve ont donné, dans leur publication, le nom de Conus barbadensis à une variété du Conus nebulosus.

36. CONE PAPIER-TURC. Conus minimus, Lix.

(Collect. LaM.) Martini, Conch. 2, t. 63, fig. 703-705.

Pl. XIV, fig. 1 à 1 c.

C. testâ turbinatâ, coronatâ, glaucinầ, fulvo-maculatâ; lineis transversim fusco et albo articulatis; spirâ brevi, obtusâ.

Coquille conique, élargie à sa partie antérieure; la spire est obtuse, arrondie ou légèrement rétrécie vers la naissance des tubercules; elle est composée de huit ou neuf tours dont la superficie, en biseau, est garnie de plusieurs stries circulaires, et le bord extérieur, d'un rang de tubercules transverses, lisses et petits, mais bien marqués. La coloration de cette coquille est glauque ou d'un cendré bleuâtre; elle est garnie de quinze ou seize lignes transverses, finement articulées de blanc et de brun, avec quelques larges taches 
de forme variée et de couleur fauve; souvent aussi on remarque sur la surface une fascie fauve, et au-dessous, une seconde fascie blanche dont la trace s'aperçoit à l'intérieur. La spire offre ordinairement des taches brunes, alternant avec les tubercules blancs dont elle couronnée; quelques taches semblables sont parsemées sur la sup̣erficie des tours.

\section{Long. 34 millim.}

Habite les mers des grandes Indes.

Cette jolie espèce, très-commune, présente un grand nombre de variétés dans la coloration des taches et dans le plus ou moins de développement des tubercules de la spire; nous en avons fait représenter trois principales (même pl., fig. 1. à $1^{c}$ ). M. Reeve a donné dans son. Conch. icon. pl. 16, fig. 86, une variété très-remarquable de ce Cône sous le nom de Conus abbreviatus.

37. CONE híBRAIQUe. Conus hebrous, Lin.

(Collect. Lam. et Mus:) Lister, Conch. t. 779, fig. 25.

Pl. IV, fig. 2, et Pl. VIII, fig. 3, 3a var.

C. testâ turbinatâ, coronatâ, albâ; maculis nigris subquadratis fasciatìm digestis, aut flammis longitudinalibus perangustıs ; striis transversis; spirâ convexoobtusâ.

Coquille conique, élargie vers le haut, rétrécie à sa base. La spire est p'u élevée, obtuse, arrondie et légèrement mucronée au sommet; on y compte une dizaine de tours faiblement striés en travers et dont l'angle externe est pourvu de petits tubercules arrondis; ces 
GENRE CÔNE.

tubercules sont plus apparents sur les deux ou trois premiers tours. Le dernier est marqué de stries transverses à peine apparentes, excepté à la base où elles forment des sillons quelquefois granuleux. La coquille est blanchâtre ou légèrement teintée de rose; son dernier tour est traversé par trois ou quatre fascies plus ou moins larges, formées par des séries de taches noires, quadrangulaires, plus longues quelarges; des taches semblables sont distribuées sur la spire où elles occupent les interstices des tubercules. L'ouverture est étroite; l'intérieur est coloré de violet ou de noirâtre.

\section{Long. 40 millim.}

Habite les mers des climats chauds de l'Asie, de l'Afrique et de l'Amérique.

Cétte espèce, très-commune, offre un grand nombre de variétés, dont quelques-unes sont assez constantes. La variété de notre pl. 8, fig. 3, avait été établie comme espèce par Lamarck, sous le nom de Conus vermiculatus; mais l'examén des variétés intermédiaires nous a permis de la réunir au $C$. hebrous; elle n'en diffère que par la forme de ses taches qui sont longitudinales et réunies entre elles, souvent anguleuses ou rameuses et noires sur un fond blanc. La variété, même plauche 8 , fig. $\mathbf{5}^{a}$, est d'une teinte tout à fait rosée, et n'a point les deux fascies du milieu du dernier tour : elles sont remplacées par des suites circulaires de points noirs. 
GENRE CÔNE.

38. CONE NOISETTE. Conus nux, BRod.

(Collect. du Mus.) Sow. Conch. illust. pl. 5, fig. 31.

PI. XI, fig. 3.

C. testâ obeso-turbinatâ, lævi, basim versùs granuloso-striatâ, granulis subobsoletis, albâ, maculis bruneis undatis bifasciatâ ; spirâ depresso-convexâ; apice subobtuso, basi et aperturæ fauce violaceo-nigricante.

Coquille courte et turbinée. Le sommet du dernier tour est large; la spire. très-courte, est composée d'un petit nombre de tours étroits, couronnés d'une rangée de tubercules le plus souvent de grosseur irrégulière. Le dernier tour est très-rétréci à la base; et, vers cette partie, on remarque quelques petites côtes transverses granuleuses. L'ouverture est fort étroite, à bords parallèles; le bord droit est mince et séparé de la spire par une échancrure étroite et profonde. La coquille est d'un fond blanc grisâtre, ornée de deux zones transverses et inégales de taches brunes. La zone supérieure est formée de flammules irrégulières, plus ou moins rapprochées entre elles et découpées, se confondant vers le milieu de la coquille. La seconde zone est située près de la base; elle est également formée de flammules, mais plus simples. Entre chaque tubercule de la spire, il y a une tache brune. L'ouverture est teintée d'un beau violet, surtout vers la base, où cette couleur passe au dehors.

\section{Long. 25 millim.}

Habite l'océan Pacifique, les îles Gallopagos.

Petite espèce très-distincte. Il faudra y rapporter, comme variétés, 
deux coquilles établies comme espèces par M. Broderip et figurées par M. Sowerby dans son Conch. illust. fig. 25 et 6 . La première, nommée Conus maculiferus, ne diffère de notre type que par les taches de sa surface qui sont un peu plus confluentes, et par la base de l'ouverture qui, au lieu d'être de couleur violette, est rosée. La seconde, que le même auteur a nommée Conus nanus, paraît être un individu plus petit et roulé, dont la partie supérieure est blanche et la base d'un violet obscur.

39. CONE ÉPOUX. Conus sponsalis, BRtG.

(Collect. LaM.) Chemn. Conch.11, t. 182, fig. 1766-1767.

Pl. XIV, fig. 4.

C. testâ ventricosâ, coronatâ, infernè granulatâ, luteâ, maculis fulvis oblongis distinctis bifasciatâ ; spirî̀ convexo-acutâ; fauce violaceo-nigricante.

Coquille petite, ventrue et arrondie vers sa moitié supérieure; sa base est étroite, un peu échancrée et noirâtre sur les deux faces; la spire est convexe, saillante, terminée en un sommet pointu : elle estcomposée de neuf ou dix tours, couronnés par des tubercules arrondis, également distants entre eux. La surface de son dernier tour est lisse, marquée de quelques stries d'accroissement; sa moitié inférieure est garnie de stries circulaires, granuleuses. L'ou verture est étroite, colorée intérieurement d'un violet très-foncé. Le fond de coloration de la coquille est jaunâtre, orné de deux fascies composées de taches fauves ou rouges, inégales et oblongues; de ces deux fascies, celle dont les taches sont les plus grandes, est placée vers le milieu de la coquille; la seconde nccupe les tours de 
GEXRE CÔNE.

sée en points subarrondis dans les interstices des tubercules.

Long. 22 millim.

Habite la mer Pacifique, dans les parages des îles Saintfreorges.

Ce petil Còne, rncore assez rare, ressemble beaucoup au Conus nux; il es! cependant d'une forme plus courte et plus arrondie

40. CONI DES MOLUquxs. Conus moluccensis, Chems.

(Collect. de M. Cuning.) Chenr. Conch. t. xi, pl. 183 , fig. $1780-1781$.

Pl. LXXV, fig. 2.

C. testâ conico-turbinatâ, albâ, vel carneâ, maculis rufescentibus longitudinalibus nubeculatâ, transversim densè sulcatâ, sulcis pertusis, striis subgranulatis; spirâ mediocriter convexâ, tuberculis regulariter coronatâ ; apice mucronato.

Coquille conique, turbinée, à spire élevée en angle obtus, composée de sept ou huit spirales sillonnées transversalement et finement granuleuses; les tours sont couronnés par une série de tubercules réguliers, saillants, pointus sur le dernier; cenx du sommet ne sont pas visibles. Le dernier tour est muni de dix-huit à vingt lignes circulaires brunes, formées en partie de légères granulations qui deviennent beaucoup plus apparentes sur les sillons transverses placés à la base du tour. La coquille est d'un fond blanc ou couleur de chair ; toute sa surface est ornée de larges flammules 
longitudinales brunes ou rougeàtres qui se réunissent quelquefois dans leur trajet, et forment un très-léger réseau entre les mailles duquel on voit les séries de lignes brunes granuleuses.

Long. 40 millim.

Habite les mers des Moluques.

Cctte jolic coquille, que II. Recve a nommée Conus Stainforthii (Proceedings, part. XI, 18:5, page 12 ), avait déjà été décrite et figurée par Chemnitz, t. Xl, page 63, pl. 185, fig. $1780-4781$, sous lc nom de Conus moluccensis, que nous lui avons conservé, comme étant le premier qui lui ait été donné. Cctte espèce est encore fort rare dans les collections.

41. CONE IIARE. Conus tiaratus, Brop.

Sow. Conch. illust. fig. 10.

Pl. XI, fig. 2.

C. testâ turbinatâ, albâ, monilibus castaneo-albis tessellatis basim versùs pallidè bifasciatâ; spirâ subproductà, conicâ, coronatâ; ultimo transversim striato, interstitiis bruneo-maculatis; aperturâ fuscâ, albo-bifasciatâ.

Coquille turbinée, à spire large, assez élevée, conique et pointue; on y compte huit ou neuf tours garnis de tubercules convexes et saillants qui se prolongent d'une manière très-distincte du sommet à l'ouverture. Le dernier tour est garni de quatorze ou quinze stries transverses granuleuses, régulièrement espacées entre elles. Le fond de coloration de la co- 
quille esı blanc, traversé par deux bandes d'un brun marron; l'une est siluée à l'extrémité supérieure du dernier tour, l'autre un peu au-dessous de son milieu; la bande supérieure est très-large et garnit presque la moitié de la convexité du tour; la seconde n'occupe qu'une partie de la moitié inférieure. La spire est blanche et offre dans les interstices des tubercules des taches brunes qui se continuent en formant une bande circulaire autour des spirales. L'intérieur del'ouverture est brun, marqué de deux fascies blanches correspondant aux fascies semblables qui sont placées sur la superficie.

\section{Long. 32 millim.}

Habite la mer Pacifique, les côtes des îles Gallapagos.

Nous avons fait représenter cette eoquille d'après la figure qu'en a donnée M. Sowerby. Elle a été déerite pour la première fois par M. Broderip dans les Proceedings, 1853, page 52; depuis, elle a été envisagée par M. Reeve comme une variété du Conus minimus, ce qui nous paraitrait assez probable en la eomparant avee la variété de eette dernière espeee que nous avons fait représenter sur notre planche 14, fig. ic, et dont elle se rapproche le plus. Du reste, comme nous ne eonnaissons eette coquille que d'après la deseription de M. Sowerby, nous ne potuvons rien affirmer à son sujet. La variété de notre même planche 1:, fig. $2^{\mathrm{a}}$, duit être reportée eomme jeune du Conus hebraus. 
42. CONE MURIC JIÉ. Conus muriculatus, Sow

(Collect. de $M^{\text {me }}$ Dupont.) Sow. Conch. illust. fig. 1.

Pl. LXXII, fig. 2.

C. testâ turbinatâ, albâ, fasciis dwabus latis, luteo-fuscis, lineolatis circum cinctâ, muriculato-granulatâ; granulis prominentibus, subdistantibus, seriatìm digestis; spirâ depresso-convexâ, coronatâ, rubido-fusco maculatâ ; basi et aperturæ fauce violaceis.

Coquille oblongue, turbinée, à spire courte ou surbaissée ; elle se compose de huit ou neuf tours couronnés d'une rangée de tubercules comprimés et obliques; le dernier est chargé de douze ou treize sillons transverses sur lesquels sont rangées de grosses granulations assez distantes entre elles; ces sillons sont égaux sur la plus grande partie de la coquille ; ceux de la base sont plus rapprochés les uns des autres. L'ouverture est étroite, d'un beau violet; la base de la coquille est de la même couleur, tandis que le reste est d'un fauve foncé séparé en deux larges zones par une fascieblanche; une autre fascie, également blanche, règne au sommet du dernier tour; sur les zones fauves on remarque des linéoles filiformes plus foncées. La spire est tachetée de brun rougeâtre.

\section{Long. 24 millim.}

Habite les mers des îles Philippines.

Cette espèce, qui n'acquiert qu'un petit volume, rappelie encore dans quelques-uns de ses caractères le Conus varius. 
43. Cone spiezis. Conus tabidus, Reeve.

(Collection du Mus.) Reeve, Conch. iconica, pl. 44, fig. 243.

Pl. L.XVI, fig. 2.

C. testà turbinatâ, leviter pyriformi, nitidà, undiquè striatà, albidâ, cincreobizonatâ, sulcis basalibus laterioribus, subprofundis; spirâ subobtuso-convexà, obsoletè coronatâ, interstitiis fulvo-maculatis.

Coquille turbinée, pyriforme, épaisse, luisante, a spire obtuse, généralement peu saillante et composée de huit ou neuf tours étroits, séparés les uns des autres par une suture onduleuse; les tubercules sont larges et peu saillants; on les voit à peine sur la moitié supérieure du dernier tour, et pas du tout sur les autres. Le dernier tour est garni de sillons très-marqués à sa base et de stries circulaires peu élevées, beaucoup moins visibles vers son sommet; quelques sillons longitudinaux, peu profonds, accompagnés de stries parallèles très-déliées, indiquent les accroissements successifs. Le fond de la coquille est blanchâtre, orné de deux zones d'un gris cendré ; l'une placée vers le haut du dernier tour, l'autre située un peu au-dessous de son milieu. Les interstices des tubercules de la spire présentent des taches fauves ou roussâtres. L'épiderme est d un fauve très-intense, les stries et les sillons de la surface en restent souvent marqués.

Long. 55 millim.

Habite

Coquille assez ambizuë et que $\mathrm{M}$. Reeve a distinguéc comme espece; 
elle a par sa forme de l'analogie avec le Conus lividus, elle en est principalement distincte par la coloration de son ouverture aui riest pas de teinte violette comme celle de ce dernier.

44. CONE ÉMAIILE். Conus encrustus, Nopis.

(Collect. de M. Prevost.)

PI. XIV, fig. 2.

C. testâ oblongo-turbinatâ, transversim striatâ, fulvâ ,aut rubescente, punctis albis lincolisque fuscescentibus vicissim aspersâ, albo-bizonatâ; spirâ mucirunatâ; sulcis prominentibus.

Coquille conique, turbinée, à spire peu élevée, mucronée; les tours, au nombre de sept, sont étroits, striés circulairement; leur angle externe est pourvu d'une rangée de tubercules arrondis et très-prononcés; le dernier tour est luisant; sa moitié supérieure est striée transversalement, et sur le reste jusqu'à la base, ces stries se changent en sillons élevés. L'ouverture est fort étroite, colorée d'un brun fauve dans le fond. A l'extérieur, la coquille est de couleur fauve ou rougeàtre, parsemée de points blancs allonyés, souvent irréguliers de forme, disposés en séries transverses, trèsrapprochés les uns des autres et alternés par de petits traits bruns. Les taches blanches forment deux zones; l'une placée vers la partie supérieure du dernier tour; l'autre au-dessous du milieı du même tour. Des maculations brunes ornent les interstices des tubercules.

Long. 26 millim.

Habite

Malgré l'analogie que cette coquille parait avoir avec plusieurs varié- 
tés du Corus minimus, elle doit cependant consiluer une espere par. ticulic̀re; elle est surtout remarquable par la disposition te ses taches +t sq couleur qui lui donnent l'aspect d'une mosaïque.

45. CONE VARTOLI. Conus verrucosus, BuUt.

(Collect. Lay.) Favaxie, Conch. pl. 18, fig. H.

Pl. LXVI, fig. 6, 6a var

Ci. testâ turbinatâ, sulcatâ, granulatà, albidâ vel flavidâ, fulvo-variegatâ; spirâ acumininatâ, granosâ.

Coquille conique, turbinée, à spire élevée, pointue, composée de dix spirales dont la superficie est légèrement marquée de stries circulaires, et le bord extérieur d'une série de tubercules médiocres et très-rapprochés entre eux; sur les premiers tours, ces tubercules n’offrent qu'une carène simple et aiguë; la superficie du dernier porte quatorze ou quinze cordelettes convexes, assez distantes entre elles, chargées de grains saillants; leurs intervalles sont ornés de traits transverses d'un brun plus ou moins foncé, qui deviennent plus fins et plus serrés vers l'extrémité de la base. L'ouverture est profondément échancrée vers le haut, colorée à l'intérieur d'un blanc nuancé de violet ou de brun. Cette coquille est blanche et marquée de deux zones fauves plus ou moins foncées; ou bien elle est roussàtre, flambée sur sa longueur de traits fauves et bruns. La spire offre quelques taches brunes ou fauves, ou de couleur citron sur la su- 
perficie des spirales; on voit un rang de points bruns placés un à un dans les interstices de leurs crénelures.

Long. 27 millim.

Habite les mers d'Afrique, les côtes du Sénégal et de Nozámbique.

Ce Còne, de taille moyenne, est remarqquable par ses granulations et se rapproche beaucoup, sous ce rapport, du Conus varius. La variété de notre pl. 66, fig. $6^{a}$, est ornée de larges taches on flammules d'un brun foncé, coloration qui appartient généralement aux jeunes individus de cette espèce; on trouve quelquefois d'autres intlividus enttèrement blancs.

46. CONE TACeETÉ DE BLANC. Conus albomaculatus, Refve.

(Collect. de $M^{\text {me }}$ Dupont.) Sow. Conch. illustr. fig. 2.

Pl. LXXXIII, fig. 2.

C. testâ minutâ, turbinatâ, granulatâ, aurantiâ, macularum albarum seriebus duabus vividè ornatâ; granulis prominentibus, subdistantibus; spirâ convexâ, ohsoletè coronatâ; apice mucronato, elato.

Coquille petite, turbinée, granuleuse; sa spire est aiguë, légèrement aplatie sur les côtés, couronnée de très-petits tubercules comprimés et obliques : elle est parsemée de blanc et de brun; la superficie de son dernier tour est marquée de dix ou onze stries circulaires, munies de granulations assez saillantes. Le fond de la coloration de cette coquille est blanc, marbré de 
grandes taches de couleur fauve ou orange; quelquefois ces taches forment deux fascies distinctes, ou bien elles se réunissent pour former un large réseau.

Long. 22 millim.

\section{Habite}

Quoiqu'il existe beancoup danalogie entre le Conus albomaculatus et le Conus verrucosus, on ne saurait les confondre ; leur spire th teur roloration sont différentes, mais la disposition des stries est la mème. quoique moins saillantes dans celui que nous venons de déerire.

47. CONI TURBAN, Conus cidaris, Nonss.

(Collect. du Mus. et de $\mathbf{M}^{\text {me }}$ Dupont).

Pl. LXIII, fig. 1, 1a.

C. testâ conicâ, coronatà, citreâ, fulvo-zonatâ, albo-maculatậ; spirâ depressâ, obsoletiè sulcatâ; aperturâ intùs roseâ.

Coquille conique, peu épaisse, très-luisante sur sa superficie, marquée de quelques sillons transverses à peine visibles : ceux de la base sont plus saillants. La spire est obtuse, légèrement aplatie, composée de neuf spirales dont les sutures sont bien marquées, quoique peu profondes; le bord de ces spirales est couronné d'un rang de petits tubercules qui tendent quelquefois a disparaître et rendent les tours subanguleux. L'ouverture est étroite, d'un blanc rosé dans l'intérieur. L'échancrure de son sommet est peu profonde. La co- 
quille est lisse, portant, sur un fond d'un jaune citron ou nuancé d'orange, une fascie assez large placée vers le milieu du dernier tour; cette fascie est de couleur fauve, piquetée de petits points bruns, et interrompue par de larges taches blanches dont les bords sont déchiquetés; une seconde fascie, reinée de même couleur que la précédente, mais plus étroite, occupe le sommet du dernier tour et toute la superficie de la spire.

Long. 25 millim.

Habite l'océan Indien.

Nous ue connaissons encore que pea dindividus de celte jolie petite espèce de Cône : l'un d'eux se trouve dans la collection du Huséun ; un autre nous a été communiqué par $\mathbb{I}^{\text {me }}$ Pupont; e’cst la variété de notre même pl. 63 , fig. $1^{\mathrm{a}}$; clle est runarquable par un fond de coloration plus orangé et par des flammules étroites, longitudiuales, légìre. ment ondulées qui garmissent la surface de son dernier tour.

48. CONE JAUNATRE. Conus flavescens, Griy.

(Collect. de $\mathrm{M}^{\mathrm{me}}$ Dupost.) Sow., Conch. illust. fig. 68. Pl. LXVIII, tig. 1 .

C. testâ turbinatâ, leviter striatâ, basim versùs sulcatà, flavescente, maculis albis irregularibus perpaucis biseriatim ornatâ ; spirâ acutâ, coronatà : apice mucronato, elato.

Coquille conique, obtuse, rétrécie vers sa base; ses tours de spire sont au nombre de huit, légèrement 
convexes ou aplatis; leur bord est muni d'une série de petits tubercules irréguliers, plus ou moins rapprochés les uns des autres. Le sommet du dernier tour est peu aigu; sa surface offre quelques légères stries transverses : celles de la base sont saillantes et onduleuses. L'ouverture est fort étroite, blanchàtre, violette dans le fond. La coloration de la coquille est jaune mêlé d'orange; deux fascies l'entourent; l'une, composée de larges taches blanches à bords déchiquetés et rarement de couleur fauve, est située vers le milieu du dernier tour; l'autre est formée par les tubercules qui sont blancs. De petites linéoles fauves se font distinguer aussi cians les interstices des tubercules et à leur base.

Long. 20 millim.

\section{Habite}

Cette petite cofuille, que lion rencontre rarement dans les collections, a quelques rapports avec la précédente par sa forme el sa coloration : olle en est divtiute par des caracteres assez constants.

49. CONE CHINGUIAIS. Conus ceylanensis, Brtg.

Collect. du Mus. et de M. Déessert.) Encyclop. pl. 312. fig. 10.

PI. XIV, fig. 5

đ. tetâ turłinatâ, coronatâ, basi granosâ, flavidâ, fasciâ intermediâ ramosâ, pallidè cxsiù, supernè zonâ albâ, lineis fulvo-punctatis distinctâ ; spirâ obtusâ ; fưre violaceâ.

Coquille perite, conique, à spire obtuse, composée 
de huit tours couronnés de petits tubercules rapprochés entre eux; la moitié supérieure du dernier tour est lisse, l'autre moitié est garnie de séries transverses de petites granulations. L'ouverture est étroite ; le bord droit est mince, son extrémité supérieure est profondément échancrée, sa base est colorée intérieurement de violet mêlé de blanc. La coquille offre, sur un fond jaunâtre, une fascie blanche placée vers l'extrémité supérieure du dernier tour et accompagnée de deux ou trois lignes circulaires ponctuées de fauve, également distantes entre elles; une seconde fascie blanche est située un peu au-dessous du milieu du même tour; elle est plus étroite que la première et est jointe à celle-ci par des lignes en chevrons qui se renouvellent à la partie inférieure du tour; enfin la base de la coquille est colorée au dehors de la même teinte violette qui nuance l'intérieur.

Long. 18 millim.

Habite les côtes de l'île de Ceylan.

Petite coquille fort élégante qui a de l'analogie avee le Conus sponsalis, mais qui en est distincte par des caractères constants. 
30. Cone musique. Conus musicus, Bricg.

(Collect. Lay.) Encyclop, pl. 522, fig. 4.

PI. XIII, fig. 6, 6 var.

C. testà turbinatâ, coronatâ, albâ; zonâ cæruleâ, lineis transversis fusco-punclatis; spirà obtusâ, nigro-maculatà ; fauce violaceâ.

Coquille petite, conique, mince, effilée, à base tronquée, à spire obtuse, composée de huit tours peu conrexes et couronnés de tubercules arrondis; ces tubercules ne sont bien visiblesque sur les deux ou trois derniers tours. Le dernier est luisant, uni ; son extrémité inférieure est marquée de plusieurs stries profondes. L'ouverture est étroite, colorée d'un violet foncé à sa base et dans l'intérieur. La superficie de la coquille est blanche, ornée d'une zone grise ou noirâtre qui est placée un peu au-dessus du milieu du dernier tour ; neut ou dix lignes ponctuées de brun la traversent : ces lignes sont assez régulièrement espacées entre elles; en outre, on voit au liaut du même tour un rang de taches brunes très-foncées, figurant des clievrons et se prolongeant sur la spire dans les interstices des tubercules, jusqu’à proximité du sommet.

Long. 18 millim.

Habite les côtes de la Chine.

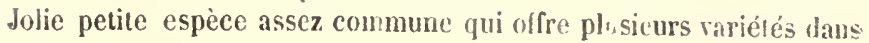


le nombre et l'écartement inégal de ses lignes ponctuées. Notre lig. $t_{2}$ (même planche) est remarquable en ce que ces lignes ne passent jamuis sır la zone bleuâtre.

51. CONE EXIGU. Conus exiynus, I.M.

\author{
(Collect. Lav. )
}

Pl. XI, fig. 1.

C. Icitì oblongo-turbinatâ, coronatâ, albâ; maculıs fuscis longitudintiinu striis transrersis laxis; spirâ convexo-acutà.

Coquille petite, oblongue, turbinée, à spire con vexe, peu élevée, formée de six ou sept tours étroits. à peine creusís; leur bord est couronné d'une ranger de tubercules assez réguliers; la surface du dernier est garnie de stries transverses fines, de couleur brune of régulièrement distantes entre elles. Le fond de coloration de la coquille est blanc, varié de larges taches ou flammules brunes, peu régulières, se continuant le plus souvent sur toute la surface du dernier tour. La spire et les tubercules sont blancs; une bande brume borde la suture; l'intérieur de l'ouverture est olivàtre.

\title{
Long. 18 millim.
}

Habite les mers de l'Asie.

Petite coquille foit élégante ê qui se rapproche par ses caractères du Conus varius; peut-êtıe bien ne devra-t-elle figurer plus taril que comnie jenne indivilu de ce dernier, ses granulations n’étant pas encor. apparentes. 
52. CONE KAIN. Conus pusillus, ChenN

(Collect. de il. Delessert.) Chemn. Conch. xı. t. 1850.

fig. 1788-1789.

Pl. LV, fig. 7, 7a

C. tustà conico-turbinatâ, fitsciis longitudinalibus et punctis rufescentibus in fundo albo ornatâ; spirâ subconvexâ, subtiliter coronatâ; basi et fauce violaceis.

Coquille petite et lisse, excepté à sa base où il existe quelques sillons transverses légèrement prononcés; la spire est courte, obtuse, composée de six ou sept tours dont la superficie est étroite; ces tours sont garnis d'un rang de petits tubercules se prolongeant quelquefois en forme de plis. L'ouverture est étroite, colorée dans l'intérieur et à sa base d'un violet trèsfoncé. Le fond de coloration de la coquille est blanc; elle est constamment garnie d'un grand nombre de points bruns ou noirs, disposés en ligrnes circulaires, assez variables dans leur forme et leur nombre; outre ces points, elle est aussi ornée de flammules de même couleur qui forment șouvent des zigzags longitudinaux, variables dans leur largeur et leur intensité.

Long. 18 millim.

Habite les còtes des îles Séchelles et de Madagascar.

Nous arons donné sur notre planche 43, fig. 2 , une jeune coquille du 
Conus calus sous le nom de Cones pusillus, parce que c'est l'iudividi que Lamarck a ćtabli ainsi dans sa collection; depuis, nous arous Ittroure des individus tout à fait semblab!es à la figure qua donnée chrmnitz, mais n’ayant aucun rapport avec la coquille de Lamarck; il fudra donc remarder comme jeune du Conus cat's la figure 2 de notre planche 43.

La fignre $7^{n}$ de notre planche $\dddot{3}$; représente mn indi idu du Conus pusillus, remarquable par st spire phis acuminee et ses tuberenles phu, saillants; le nombre des points de la surface de son dernicr tour cst anssi moins consilérable.

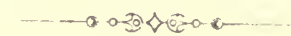

\section{Coquille non couronnée.}

53. CONE TIGRE. Conus millepunctutus, LaN.

(Collect. Las.) Encyclop. pl. 325, fig. 5.

Pl. XVIII, fig. 1.

C. testâ turbinatà, albà, maculis fuscis aut nigris seriatim cinctâ; spirâ planoobtusâ : anfractihus subcanaliculatis.

Coquille épaisse, pesante, conique; la spire est obtuse, souvent aplatie, anguleuse : elle est formée de huit ou neuf tours légèrement canaliculés et sillonnés circulairement; sa suture est un peu enfoncée, son bord est accompagné d'un petit bourrelet arrondi; sa superficie paraît lisse, mais elle est garnie de stries longitudinales très-fines et très-serrées, et d'autres stries transverses un peu onduleuses; celles-ci sont plus visibles vers la base du dernier tour. L'ouverture occupe 
toute la longueur de la coquille : son sommet est terminé par une échancrure oblique, le fond de coloration de cette espèce est toujours d'un beau blanc, couvert de lignnes circulaires composées de tâches noirâtres ou bleuàtres sur leur bord postérieur et d'une forme arrondie ou ovalaire; quelques lignes circulaires de points rougies ou bruns sont rangés dans les mêmes séries que les taches et n'en sont distinctes que par leur petitesse. La spire est variée de larges taches brunes très-foncées qui garnissent aussi le sommet.

\section{Long. 12 cent.}

\section{Habite l'océan Asiatique.}

Cette espèce, qui prend souvent un accroissement considérable, a été établie par Lamarck, car Bruguières l'avait rangée parmi les variétés du Conus litteratus. Elle offre plusieurs variétés dans le nombre des séries de ses taches et dans leur forme; la spire est aussi plus ou moins élevée; cependant, le plus souvent, on la voit aplatie et son dernier tour anguleux.

54. CONE ARABE. Conus litteratus, LiN.

(Collect. L am.) Bonann, Recreat. 3, fig. 365.

Pl. XIX, fig. 1, 1*.

G. testâ turbinatâ, albâ, maculis fuscis aut nigris seriatim cinctâ; zonis tribus luteo-aurantiis; spirâ planâ, truncatâ ; anfractibus canaliculatis.

Coquille épaisse, turbinée, à tours de spire concaves, lisses, sans stries circulaires; ses trois derniers sont 
bordés d'un talus arrondi plus ou moins prononcé; la suture des tours est bien marquée et ressemble à un sillon profond. Leur superficie paraît lisse; cependant on y remarque des stries longitudinales d'accroissement assez sensibles, et des stries circulaires onduleuses très-fines et très-serrées, plus apparentes, vers la base. L'ouverture occupe toute la longueur de la coquille; son sommet est terminé en une coupe oblique et profonde. Le fond de la coloration est ordinairement blanc, moucheté de taches ovales, carrées ou oblongues, d'un brun très-foncé, presque noirâtre, diversement rapprochées les unes des autres et rangées en lignes circulaires; deux ou troís zones plus ou moins apparentes, d'un jaune orangé ou couleur citron, garnissent aussi la surface. La spire est constamment variée de taches brunes très-foncées sur un fond blänc, ces taches occupent la largeur des tours et partent du sommet.

\section{Long. 9 cent.}

Habite la mer des Indes.

Cette espèce, que l'on a considérée longtemps comme une variété de la précédente, offre par le nombre et la forme de ses taches un bon nombre de variétés. La forme de la spire est aussi peu constante, et présente plus ou moins de saillie. L'individu que nous avons fait représenter, même planche, $f g$. 1 $^{\text {a }}$, est remarquable par les rangs serrés de taches longitudinales, presque quadrangulaires et bleuâtres, qui occupent toute sa superficie et rarement sont disproportionnées entre elles. 
GENRE CÔNE.

55. CONI PAVÉ. Conus eburneus, Brug.

(Collect. Lam.) Lister, Conch. t. 774, fig. 20.

Pl. XVII, fig. 2.

C. lestâ turbinatâ, basi sulcatâ, albâ, maculis fulvis aut nigris subquadratis seriatìm cinetâ; faseiis luteo-aurantiis subternis; spirâ obtusâ, striatâ, acuminatâ.

Coquille conique, arrondie à son sommet. La spire, légèrement aplatie, est composée de dix tours un peu élevés à leur centre et à sommet pointu; on distingue sur chacun d'eux une ou deux stries circulaires bien marquées, et à la base du dernier tour, neuf ou dix sillons inégaux dans leur profondeur et leur distance entre eux ; le reste de la superficie paraît lisse, quoique marqué par un grand nombre de stries transverses, mais qui sont à peine visibles. La coloration de cette coquille consiste en plusieurs rangs inégaux et transverses de taches noires ou fauves, plus ou moins quadrangulaires, placées sur un fond blanc qui est diversifié de plusieurs fascies d'un jaune tirant sur le jonquille. La spire est blanche et ornée d'un seul rang de taches fauves ou noires, situées près du bord extérieur de chaque tour.

Long. 56 millim.

Habite les mers des Indes orientales.

Cette coquille est toujours beaucoup plus petite que celle qui précède, et en est bien distincte. Elle offre plusieurs variétés remarqua. bles en ce qu'elles n'ont point de fascies, et que leurs taches sont de forme arrondie et de couleur marron. 
GENRE CONNE.

56. Cone mosaique. Conus tessellatus, Brug.

(Collect. Lam.) Lister, Conch. t. 767, fig. 17.

Pl. XVII, fig.: 1 .

C. testå turbinatâ, albâ ; maculis coceincis quadrangulis seriatis; basi sulcatâ, violaceâ ; spirâ plano-obtusâ, acuminatâ.

Coquille conique, turbinée; sa spire est aplatie à la circonférence ; son sommet est élevé ; elle est composée de dix ou douze spirales étroites, légèrement concaves, marquées d'une ou de deux stries circulaires et bordées d'un cordon lisse et convexe. La superficie dı dernier tour offre des stries circulaires extrêmement fines et serrées, coupées par d'autres stries longitudinales plus apparentes. La base est profondément striée extérieurement; l'intérieur est coloré de violet; la même nuance s'étend sur le cordon oblique de la columelle et quelquefois même se prolonge sur sa convexité. Le fond de la coquille est presque tonjours d'un beau blanc; on y compte depuis dix jusqu’à vingt-quatre rangs circulaires de taches écarlates ou d'une teinte orangée tirant sur le rougeâtre; ces taches, plus ou moins régulières, sont assez souvent rapprochées entre elles par des rangs circulaires de taches plus petites et plus distantes les unes des autres que les premières.

Long. 60 millim.

Habite l'océan des grandes Indes.

Cette coquille, qui n'est pas rare, se rapproche beaucoup de l'espèce 
précédente par sa forme, mais elle en est distincte par ses rangs transverses de taches rougeâtres et sa base, dont l'intérieur est constamment teinté de violet; elle offre souvent des variétés : les unes ont les taches plus grandes, plus allongées; les autres ont ces taches réunies en forme de caractères d'écriture.

57. CONE PAPIIIONACÉ. Conus papilionaceus, BRtG.

(Collect. Lam.) Bonaxi, Recr. 3, fig. 132.

Pl. XXIV, tig. 1.

C. testâ turbinatâ, crassâ, ponderosâ, albâ ; punctis et maculis fulvis subquadratis vel oblongo-verticalibus transversim sèriatis; spirâ convexâ, subcanaliculatâ, mueronatâ.

Coquille conique, à spire formée de douze ou treize tours assez larges, légèrement concaves, à bords arrondis et placés de manière que le bord supérieur de chacun d'eux est plus saillant et plus élevé que le bord inférieur du tour qui suit; la ligne des sutures est profonde et bien marquée. La superficie est finement treillissée de stries longitudinales un peu onduleuses, produites par les accroissements et qui sont croisées par d'autres stries circulaires aussi fines, quelquefois même par des sillons peu prononcés et distants entre eux. La coloration de la coquille consiste en zones et en lignes circulaires de taches et de points fauves ou rouges, placées sur un fond blanc; les zones, beaucoup plus larges que les lignes, sont composées de taches irrégulières d'un fauve teinté de lilas; les points des 
lignes sont de forme carrée ou allongée. La spire est blanche et flammiulée irrégulièrement de fauve.

Long. 10 cent.

Habite l'océan Asiatique, les côtes de la Guinée.

Ce Cône, que l'on nomme vulgairement la Fausse aile de papillon, devient quelquefois très grand; il offre des variétés remarquables par la différence de largeur des zones, par leur nombre, l'irrégularité de leurs taches, la distribution de leurs couleurs. Sur quelques individus on remarqque quelques handelettes jaunâtres, et les taches y paraissent assez semblables à des caractères d'écriture.

58. CONa sxamors. Conus siamensis, Brug.

( Colléct. Lam.) Rumpr. Mus. t. 34, fig. E.

Pl. XCI, fig. 1.

C. testâ oblongo-turbinatâ, albidâ, fulvo-fasciatâ ; lineis transversis numerosis, fulvo aut fusco et albo-articulatis; spirâ convexo-obtusâ, mucronatâ, aurantio alboque variegatâ:

Coquille oblongue, turbinée, légèrement rétrécie vers son milieu et bombée à son extrémité supérieure; on compte onze ou douze tours à la spire; ces tours sont larges, un peu concaves, élevés en angle trèsobtus; le dernier paraît lisse, quoique marqué de quelques stries longitudinales peu prononcées et de stries transverses qui ne sont visibles qu'à son extrémité inférieure. Son ouverture est terminée par une échancrure peu profonde : elle est-blanche intérieurement; son bord droit est assez souvent liséré de 
points fauves et même d'un rang de taches brunàtres. La coquille est d'un fond jaune, flambé longitudinalement de fauve nuancé d'orange et orné de plusieurs zones qui sont composées de points d'un fauve clair, ou de portions de lignes transverses d'une teinte tirant sur le marron foncé; elle porte encore trois fascies blanches : la première, située vers son tiers supérieur, a deux ou trois rangs de lignes ponctuées; ces lignes sont inégales entre elles par la grandeur ou la petitesse de leurs points; on compte quatre ou cinq rangs de lignes semblables sur la fascie intermédiaire, et quelquefois plus de quatre autres rangs formés de petits points sur celle qui occupe la base. La spire est blanche et ornée de flammes fauves et orangées.

\section{Long. 11 cent.}

Habite l'océan Asiatique.

Ce Cône, qui devient assez grand et épais, paraitt tenir le milieu entre l'espèce précédente et celle qui suit; néanmoins, il est beaucoup plus voisin de la première par sa forme et sa coloration.

59. CCNE RROMŕthíE. Conus Prometheus, BRug.

(Collect. LaM.) Lister, Conch. t. 771, fig. 17, D.

'Pl. XCII, fig. 1, et pl. XXV, fig. 1 var.

C. testâ oblongo-turbinatâ, albâ, ferrugineo-interruptâ zonatâ ; spirâ convexâ, subcanaliculatâ, mucronatâ, aurantio et albo-variegatâ.

Coquille oblongue, turbinée, légèrement rétrécie au milieu; sa superficie est marquée le plus ordinai- 
rement de fines stries transverses et de stries longyitudinales d'ac'croissement assez sensibles; sa spire, médiocrement élevée en angle obtus, est formée de douze ou quatorze tours assez larges, légèrement concaves, et dont les sutures forment un sillon bien prononcé. Le fond de la coquille est blanchâtre, orné de deux ou trois larges zones de marbiures ou de veines irrégulières et très-serrées d'un fauve roussàtre qui laissent paraître les veines blanches du fond; ces zones sont elles-mêmes souvent tachetées d'un fauve plus vif. quelquefois des portions de lignes transverses de la même teinte les coupent circulairement. Outre ces zones, on remarque encore sur la surface plusieurs rangées de points d'un fauve plus foncé. La spire est blanche, marbrée de grandes taches jaunes; l'intérieur de l'ouverture est blanc.

\section{Long. 12 cent.}

Habite l'océan Africain et la mer des Indes.

Ce Cône, que l'on nomme vulgairement la Spéculation, devient fort grand et d'une couleur presque uniforme, d'un blanc jaunâtre. La variété que nous avons fait représenter pl. 25 , fig. 1, est remarquable par l'aplatissement de la spire et par ses lignes ponctuées.

60. CONE IÉONINS. Conus leoninus, Breg.

(Collect. Lam. ) Gualt. Test. t. 21, fig. D.

PI. XIX, fig. 2, 2a.

C. testâ turbinatâ, albâ ; punctis numerosis, seriatis fulvis aut fuscis et maculis longitudinaliter confluentibus, interdùm suhiconnatis ; spirâ planâ, canaliculatâ, mucronatâ.

Coquille conique, turbinée, à spire mucronée, peu 
élevée en angle obtus; on y compte dix.ou douze tours à superficie lisse, concave, garnis extérieurement d'un léger bourrelet; le dernier offre quelquefois des stries longitudinales assez prononcées, plus ou moins nombreuses, mais les stries circulaires qu'on y apercoit y sont toujours extrêmement fines, excepté à sa base, où elles deviennent fort apparentes. La coquille est d'un fond blanc, tout parsemé de lignes circulaires serrées, composées de points carrés d'inégale grosseur; deux larges zones occupent le lernier tour : l'une est située vers sa moitié supérieure, l'autre, vers sa base. Elles offrent, indépendamment de leurs taches, des mouchetures longitu:linales, diversement figurées. La couleur de ces taches, comme celle des points, est d'un brun rougeàtre très-foncé, souvent noirâtre. L'intérieur de l'ouverture est d'un blanc nuancé de rose ; un rang de taches brunes ou violattres orne le bord droit.

Long. 60 millim.

Habite les mers de l'Amérique.

Ce Còne est si voisin du Conus proteus, que Bruguières, dans son article de l'Encyclopédie, paraît hésiter à l'établir comme espèce, et dit quil ne differe du Conus proteus que par ses couleurs qui sont très-inconstantes. La variété (même planche, fig. $\mathbf{2}_{a}$ ) est ornée de séries circulaires de portions de lignes plus ou moins interrompues, de couleur marron ou noirâtre, avec de larges taches découpées, de même couleur. 
61. CoNE TINE. Conus betulinus, Liv.

(Collect. Lam.) Sebs, Mus. 3, t. 45; fig. 4.

C. testâ turbinatâ, supernè latissimà, basi rugosâ, citrinâ ; maculis fuscis transversim seriatis ; ultimi anfractùs angulo rotundalo; spirâ convexiusculâ, mucronatâ.

Coquille épaisse, s'élargissant et s’arrondissant insensiblement vers son sommet; sa spire est formée de quatorze tours convexes, lisses et élevés en un sommet saillant. La surface est marquée de lignes d'accroissement en général assez fines, mais dans quelques endroits très-prononcées; ses stries circulaires, inégales et assez serrées, sont aussi plus ou moins sensibles, mais celles de la partie inférieure du dernier tour sont ordinairement très-marquées, et la côte oblique que la columelle forme en cet endroit est bien saillante. La coloration consiste en un fond citron sur lequel on compte un grand nombre de rangs circulaires de taches brunes ou noirâtres; ces taches, plus ou moins larges, sont quelquefois assez distantes entre elles. I.a spire est panachée de grandes taches un peu ondées, de même couleur que les précéden:es.

Long. 12 cent.

Habite les mers des grandes Indes, depuis Madagascar jusqu'en Chine.

Cie cône parvient à un très-grand volume, il présente beancoup de 
variétés, non dans sa forme, qui est eonstante, mais dans le nombre et la figure de ses taehes. Nous en avons fait représenter deux des prineipales : la première, fig. 1a, diffère de notre type par le nombre plus considérable de rangs eirculaires de taches, par leur dimension, alternativement grandes et jetites, enfin par leur eouleur et leur arrangement : les grandes étant brunes ou de eouleur marron, et les plus petites offrant seulement de simples séries de points fauves. La fig. $1^{b}$ est bien remarquable par le manque presque complet des taehes de la surfaee.

62. CONE DE SURATE. Conus suratensis, Brug.

( Collect. Lam.) Chemn. Conch. 11, t. 181, fig. 1752-1753.

PI. XXXVII, fig. 4.

C. testà turbinatâ, anteriùs rotundato-turgidâ, basi st riatâ, flavidulâ, maculis fuscis linearibus seriatim cinctâ; spirâ convexiusculâ, mucronatâ, fusco-maculatâ.

Coquille turbinée, conique, arrondie, un peu bombée au sommet ; sa spire est légèrement convexe, formée de neuf tours lisses et dont le bord supérieur fait saillie d'une manière sensible sur le bord inférieur du tour suivant; leur sommet est peu élevé. La superficie du dernièr tour est lisse, excepté vers son tiers inférieur où elle est striée; les stries de cette partie sont profondes et distantes entre elles; les intervalles qui les séparent sont un peu convexes et semblables à des cannelures. Le fond de la coquille est fauve; un rang de taches allongées, distantes eutre elles, d'un fauve plus foncé, garnit le bord supérieur; le reste de la superficie est couvert d'un grand nombre de séries circulaires de points ou mouchetures d'un fauve très- 
GENRE CÔNE.

foncé, 'tirant sur le brun; ces mouchetures, rarement égales entre elles, sont souvent rétrécies aux deux bouts, et l'on remarque que celles qui offrent cet aspect ont leur centre muni d'une tache fauve qui les fait paraître comme œillées. La spire est ornée de larges flammules brunes.

Long. 70 millim.

Habite les mers des grandes Indes.

Ce Cône, voisin du précédent par sa forme, en est distinct par ses taches ct sa coloration; il a cependant quelques variétés qui tendraient à le réunir au Conus betulinus.

63. CONE MiNIME. Conus figulinus, Liv.

(Collect. Lam.) Lister, Conch. t. 785, fig. 32.

Pl. XXVIII, fig. $1,1^{\mathrm{a}}, 1^{\mathrm{b}}$.

C. testâ turbinatâ, supernè ventricoso-rotundatâ, rubiginoso-fuscâ, filis rufis circumligatâ ; spirâ convexâ, mucronatâ.

Coquille épaisse, renflée vers le milieu; le sommet de son dernier tour est arrondi. La spire est convexe, élevée en angle obtus, à sommet pointu ; ses tours, un peu bombés, sont légèrement marqués de stries lonyitudinales, nombreuses et un peu arquées; les stries d'accroissement du dernier tour sont souvent très-prononcées à sa partie inférieure où il se rétrécit. Les sillons circulaires et onduleux sont aussi très-mar- 
qués. La coloration générale est d'un rouge brun ou d'un fauve cannelle; mais cette teinte est toujours plus vive et plus foncée sur les tours de la spire où elle forme une large zone, soit continue, soit interrompue. Le dernier tour est d'une coloration plus claire; son sommet est muni d'un liséré roux, contigu à la zone supérieure, et sa convexité rembrunie est couverte d'un grand nombre de li:nes circulaires plus ou moins distantes entre elles, d'un brun foncé presque noiràtre qui tranche fortement sur la couleur du fond. L'intérieur de l'ouverture est blanchâtre, et son bord droit est terminé par un liséré fauve, ponctué de brun.

Long. 72 millim.

Habite les mers des grandes Indes, des Moluques et des Philippines.

Cette espèce n'est pas rare et n'acquiert qu'une moyenne grandeur; elle a beaucoup d'analogie par sa forme avec la précédente, mais les lignes transverses de sa superficie la font facilement reconnaitre. Il arrive cependant que certains individus ont leurs lignes transverses interrompues sur la convexité de la coquille et présentent des séries de petites taches allongées et comme articulées, avec deux zones blanches placées à la base du dernier tour. (Voir notre fig.1 1a.) Cette variété offre, par sa forme et la disposition de ses taches, infiniment de rapports avec le Conus glaucus. La variété $1^{\mathrm{b}}$ diffère du type par le fond de sa coloration qui est fauve, mêlé de gris et de bleuâtre. Les lignes circulaires y sont aussi moins apparentes. 
64. CONE GLAUQ⿱一⿻上丨⿹⿺㇉一灬. Conus glaucus, Lis.

( Collect. Lam.) Rumpr. Mus. 1. 35, fig. G. G.

PI. XXV, fig. 2.

C. testâ turbinatâ, , anteriủs rotundato-turgidâ, cinereo-cærulescente, lineis fuscis confertis interrụptis cinctâ; spirâ obtuso-convexâ, mucronatâ, fusco-maculatâ ; basi striatâ.

Coquille conique, à spire convexe et formée de six tours très-lisses' et légèrement arrondis, à sommet saillant et pointu. Le.dernier tour est bombé vers le haut ; sa convexité est luisante, striée profondément, et sa base est même sillonnée de lignes circulaires. L'ouverture est blanche, nuancée de bleuâtre, terminée par une échancrure oblique assez profonde; elle offre extérieurement une légère courbure vers le dos; l'intérieur de son bord droit est liséré de brun. La couleur de la coquille est un gris bleuàtre plus ou moins vif, souvent mêlé d'une teinte couleur de chair et de quelques veines longitudinales mélangées de fauve, et peu régulières. Le haut du dernier tour est ceint, le plus souvent, d'une bandelette blanchâtre; quelquefois une bandelette semblable est pla. cée sur le milieu du même tour. Tout le reste de la superficie est orné de lignes interrompues en séries circulaires de traits transverses, d'une couleur d'un brun marron. La spire, dont le fond est d'un gris plus clair que celui du dernier tour, est flambée de brun ou de roussâtre.

Long. 50 millim. 
Habite les iners des grandes Indes, les côtes dés Mo. luques et des Philippines.

Espèce bien distincte, peu commune dans les, collections, vulgairement le Minime bleu, car, à cause de ses rapports avec certaines variétés du Conus figulinus, elle a été considérée par les anciens conchyliologistes comme une variété de ce Cône.

65. CONE AUMUSsE. Conus vexillum, Mart.

(Collect. LaM.) Rump. Mus. t. 31, fig. 5.

PI. XXXIV, fig. 1.

C. testâ turbinatâ, fulvâ aut fulvo-virescente, albo-fasciatâ, basi nigricante, lineis irregularibus longitudinalibus venulatâ ; spirâ obtusâ, albo fưlvoque variegatâ.

Coquille conique, assez régulière, à spire obtuse, plus ou moins élevée, composée de dix ou douze larges tours, peu concaves et garnis de fines stries circulaires onduleuses, mais bien distinctes ; le bord supérieur de ces stries forme une légère saillie tout le long des sutures; sur le dernier, les-stries longitudinales d'accroissement sont très-rapprochées entre elles et trèsapparentes ; les sillons on cordons obliques de sa base sont nombreux, distants les uns des autres et bien prononcés, ce qui la rend légèrement raboteuse. L'ouverture est d'un blanc uniforme; sa partie supérieure offre une échancrure assez profonde. La coquille est d'un fond de couleur fauve, nuancé de roux ou de jaunâtre et veiné longitudinalement d'un fauve brun; elle est ornée de deux fascies blanches : l'une est placée 
vers son sommet, l'autre sur son milieu; ces fascies sont quelquefois accompagnées de taches blanches longitudinales qui les dépassent de chaque côté, et y forment comme autant de croix ; ou bien elles sont jaunâtres et interrompues par de grandes taches blanches, distantes entre elles et plus.ou moins régulières. De ces deux fascies, il arrive souvent que la supérieure est composée de grandes taches brunes et blanches: dans ce cas, elle est un peu plus large que celle du milieu. La spire est marbrée de taches alternativement blanches et brunes, ou variées de fauve.

Long. 86 millim.

Habite l'océan Asiatique, dans les parages des Moluques, et les mers Australes.

Ce Cône acquiert un assez grand volume; il est cependant peu épatis et est remarquable par les flammules longitudinales dont il est veiné. Une variété de cette espèce diffère du type en ce que son dernier tour n'offre aucune trace de fascies transverses.

66. CONI rodp. Conus sumatrensis, Brog.

(Collect. LaM.) Lister, Conch. t. 781, fig. 28.

Pl. XXXVI, fig. 3.

C. testâ turbinatâ, albidâ vel lutescente; lineis fuscis ramosis longitudinalibus confluentibus; spirâ obtusâ, variegatâ.

Coquille turbinée, renflée, à spire formant un angle très-obtus, composée de onze tours aplatis et marqués 
de plusieurs stries circulaires assez apparentes ; la convexité du dernier paraît lisse, quoique garnie de stries transverses tremblotantes, et d'autres stries longitudinales plus profondes qui sont les traces des accroissements successifs. Vers le tiers inférieur du tour, ces stries sont beaucoup plus sensibles et leurs intervalles sont un peu convexes, sans être raboteux. L'ouverture est d'un blanc violacé; son extrémité supérieure est coupée obliquement par une échancrure peu profonde. Le fond de coloration de la coquille est blanchâtre et coupé par deux larges zones fauves, dont l'une est située vers son tiers supérieur et l'autre vers sa base. Toute la coquille est ornée de lignes longitudinales larges, onduleuses, ramifiées, souvent réunies les unes aux autres par divers points de leur longueur; elles sont d'un brun très-foncé, tirant sur le noirâtre, et leurs bords sont diversement nuancés, sur toute la moitié supérieure du tour, de fauve et de violet. La base est rousse ou jaunâtre et sans taches. La spire offre des taches brunes, élargies, plus ou moins foncées, qui sont les prolongements des lignes ramifiées dont nous venons de parler.

Long. 75 millim.

Habite la mer Rouge et la mer des Indes:

Coquille qui par sa forme se rapproche de la précédente; elle est reconnaissable surtout par ses lignes longitudinales ramifiées. Elle n'est plus rare dans les collections. 
67. CONE BOIS-DE-FRÊNE. Conus nemocanus, BRtg.

(Collect. du Mus.) Encyclop. pl. 338, fig. 5.

Pl. XXXv, fig. 3.

C. testâ turbinatâ, lutescente, zonis filisque tenuissimis undulatis approximatis fulvis cinctâ; spirâ obtusâ, striato-punctatâ, fusco-maculatâ; fauce subcæruleâ.

Coquille effilée à sa base et légèrement rétrécie vers son milieu ; la spire est obtuse, composée de dix ou onze tours un peu concaves, excepté le-dernier qui est bombé; tous sont marqués de plusieurs stries circulaires, finement piquées de points enfoncés ; ces piquetures sont souvent peu senșibles. L'extrémité supérieure de l'ouverture est terminée par une échancrure assez profonde, et l'intérieur de son bord droit est nuancé d'une teinte bleuâtre sur un fond blanc. La coloration de la coquille est jaunâtre ou verdàtre; elle est environnée d'un grand nombre de zones fauves onduleuses et de fils ou lignes circulaires également onduleuses qui occupent les interstices des zones; une fascie blanchâtre garnit l'extrémité supérieure de son dernier tour; on en distingue une seconde, souvent plus apparente que la première, un peu au-dessous du milieu du même tour; cette fascie consiste en un rang de taches assez larges, quelquefois allongées et dentelées, d'une couleur d'un brun marron. Ces taches bordent la zone en dessus. La spire, ornée de taches 
galement d'un brun marron, est distincte par une ligne suturale assez profonde.

$$
\text { Long. } 70 \text { millim. }
$$

Habite la mer des Indes, les côtes de Madagascar et des Séchelles.

On donne le nom de Bois-de-frêne à cette coquille, parce qu'effectivement les fils fauves et onduleux dont elle est ornée sur un fond jaunâtre représentent assez fidèlement les courbes et les fibres qui distingu ent cette cspèce de bois.

68. CONE HYìñ. Conus hycena, Brog.

(Collect. de M. Delessert.) Encyclop. pl. 327, fig. 5.

Pl. XXXV, fig. 4.

C. testâ turbinatâ, lutescente; flammis fulvis longitudinalibus; spirâ convexâ, mucronatâ.

Coquille conique, turbinée, à spire mucronée, formée de onze tours convexes, à sommet pointu ; chacun de ces tours est marqué de stries circulaires très-fines et distinctes les unes des autres par un sillon très-mince. Le dernier tour est muni de stries superficielles dont quelques-unes sont longitudinales et assez sensibles. On voit encore sur ce tour des cannelures augmentant en nombre à sa base et légèrement onduleuses. La coloration de la coquille consiste en une teinte jaunâtre, variée de flammes étroites et longitu- 
dinales, de couleur fauve, et de séries longitudinales de points ou de portions de lignes d'un fauve plus foncé. Une fascie ou zone blanche est placée un peu au-dessous du milieu du dernier tour; elle est interrompue ou traversée par des flammules de couleur fauve. Une fascie semblable se dessine au sommet du même tour; mais celle-ci est rarement entière et moins distincte que la prenière.

\section{Long. 64 millim.}

Habite les mers de la côte ouest d'Afrique.

Cette espèce a beaucoup d'analogie avec la précédente, sa forme est la même. Les seuls caractères distincts qu'elle offre consistent dans les flammes longitudinales et onduleuses dont elle est ornée.

69. CONE PIQUETÉ. Conus pertusus, BRtG.

(Collect. du Mus.) Encyclop. pl. 556, fig. 2.

Pl. XXXV, fig. 1, 1a.

C. testâ oblongo-turbinatâ, roseâ, incarnato-fasciatâ, albido-cærulescente nebula tâ ; striis transversis pertusis; spırâ convexâ.

Coquille oblongue, turbinée, à spire élevée et formée de onze tours convexes, séparés par des sutures onduleuses très-prononcées; cliacun des tours offre vers son milieu trois stries circulaires composées de très-petits points enfoncés, semblables à des piquetures d'épingle; celles qui garnissent le dernier tour sont très-écartées entre elles et peu apparentes vers le haut 
du tour; elles sont, au contraire, plus serrées et leurs piquetures sont plus distinctes sur la moitié inférieure où l'on aperçoit aussi quelques cordelettes saillantes, lisses et distantes entre elles. L'ouverture est blanche, l'éclıancrure supérieure peu profonde. La couleur de cette coquille consiste en un fond rose, sur lequel se détachent une ou deux fascies incarnates qui sont munies de quelques lignes circulaires d'un rouge orangé et de taches du même rouge, interrompues par des nébulosités d'un blanc mat mêlé de rose ; enfin, de très-petits points blanchâtres sont parsemés, sans trop de régularité, sur toute la surface.

Long. 54 millim.

Habite les mers des grandes Indes.

Cette espèce, encore assez rare, se distingue aisément de toutes les autres du même genre. Nous y réunissons, comme variété, une coquille que Lamarck avait établie sous le nom de Conus amabilis, et dont Chemnitz a décrit et figuré un jeune individu sous le nom de festivus. ( Voir même planche, fig. 1a var.)

70. Conz Capitarag. Conus capitaneus, LiN.

(Collect. Lam.) Lister, Conch. t. 780, fig. 27.

Pl. XX, fig. 1.

C. testâ turbinatâ, olivaceo-flavidâ; fasciis duabus albis fusco-maculatis ; lineis transversis punctatis ; spirâ convexâ, fusco-maculatâ.

Coquille conique, turbinée, à spire élevée en angle obtus, formée de dix ou onze tours un peu aplatis, dont la superficie est striée circulairement et dont la 
suture est peu profonde, mais bien apparente; sur l'avant-dernier tour, les stries consistent le plus souvent en séries de petits points enfoncés, semblables à des piqûres; la moitié supérieure du dernier est lisse, la partie inférieure est striée comme le tour précédent; les interstices des stries sont convexes et élevés comme des cordelettes, surtout vers la base. La coquille est jaune, quelquefois verdâtre, ou d'une teinte olivâtre légèrement rembrunie; outre les points bruns de ses stries circulaires, elle est ornée de veines longitudinales et onduleuses de la même couleur, qui sont ordinairement réunies sur sa moitié supérieure. Le fond de coloration est interrompu par deux fascies blanches, dont l'une occupe la partie supérieure de la coquille et se prolonge sur la spire, l'autre est située un peu au-dessous de sa partie moyenne. La première est la plus étroite : elle est bordée en dessous d'un rang de taches inégales d'un brun noirâtre et traversée par.le prolongement de quelques flanmmes de la spire; celle du milieu est bordée de chaque côté par un rang de taches semblables à celles de la première fascie et dont la forme est irrégulière, ovale ou carrée : cette fascie est quelquefois traversée par des veines ou des flammes d'une teinte plus claire. La spire est blanche, flambée d'un brun foncé ou rougeâtre. L'intérieur de l'ouverture est d'un blanc violacé.

$$
\text { Long. } 65 \text { millim. }
$$

Habite l'océan Asiatique.

Coquille commune, qui offre plusieurs variétés remarquables dans 
l'ordre ou la distribution de ses taches, ou par le manque des séries ponctuées et des veines longitudinales de sa surface.

71. CONE MATELOT. Conus classiarius, Brtg.

(Collect. Lay. et de M'me Dupont.) Encyclop. pl. 355, fig. 7.

PI. LXIII, fig. 3.

C. testâ turbinatâ, ferrugineâ, aut castaneâ, fasciâ albâ marginibus fusco-ma culatis cirictâ ; spirâ obtusâ, albâ, fusco-maculatâ.

Coquille conique, à spire convexe, obtuse, formée de sept tours striés circulairement et à sutures bien marquées; la partie supérieure du dernier est lisse, mais tout le reste du même tour est garni de stries transverses également espacées entre elles et formées de rangées de petites piquetures enfoncées ; la coquille est d'un fond couleur de rouille mêlée de marron; elle est traversée, un peu au-dessous de son milieu, par une fascie blanche garnie de deux rangs de taches d'un brun noirâtre, et de quelques lignes fauves; une seconde fascie borde le sommet du dernier tour et occupe toute la superficie de la spire. Cette fascie est blanche et flambée de rouge brun ou de brun foncé.

\section{Long. 35 millim.}

Habite l'océan Asiatique.

Ce Cône est plus petit que le Conus capitaneus; mais il a tant de rapports avec celui-ci, que nous pensons qu'il'devra en être considéré comme une simple variété. 
72. CONa Changeant. Conus mutabilis, Chens.

(Collect. de $\mathrm{M}^{\mathrm{me}}$ Dupont.) Griesn. Conch. XI, t. 182, fig. 1738-1759.

\author{
Pl. LXX, fig. 1.
}

C. testâ turbinatâ, subpyriformi, lævigatâ, basim versus undulatim sulcatâ ; fuscescente in medio sæè pallidissimâ, fusco irregulariter virgatâ, lineisque fuscis interruptis cinctâ; spirâ convexâ, spiraliter striatâ, suturis rudibus, apice elato.

Coquille turbinée, subpyriforme, à spire peu élevée en angle obtus, composée de dix tours distincts, à bord élevé; leur suture est peu profonde, mais bien apparente. Toute la surface de cette coquille est finement striée circulairement ; ces stries, très-nombreıses, sont tremblotantes et à peine visibles. D'autres stries longitudinales, qui sont la trace des accroissements successifs, se montrent plus profondes et irrégulièrement espacées entre elles. L'ouverture est arquée, blanche à l'intérieur, marquée de deux larges fascies violâtres. Le bord droit est mince et tranchant. La coloration extérieure est d'un jaune olivâtre, traversée par un grand nombre de linéoles circulaires fauves. Une large fascie blanche occupe le milieu du dernier tour : elle est accompagnée de plusieurs séries ponctuées de points bruns ; la spire est décorée de taches allongées brunes ou fauves.

Long. 60 millim.

Habite 
Cette coquille avait été considérée par Lamarck comme une varièté du Conus vexillum; elle paraît avoir plus d'analogie avec le Conus capitaneus, par sa forme et même par sa coloration, quoiqu'elle en soit bien distincte sous d'autres rapports. Nous ne connaissons encore qu'un petit nombre d'individus de cette espèce.

73. CONE ACAJOU. Conus badius, NoBIs.

\section{(Collect. Verreaux.)}

PI. XXXIII, fig: 3.

C. testâ turbinatâ, albo-violaceà, transversim striatâ ; striịs tenuibus, numerosis, undulatis, fulvis vel aurantiis; longitudinaliter flammulatis; spirâ planoobtusâ, albâ, fusco-maculatâ ; apice truncato ; aperturâ albo-violaceâ.

Coquille ayant la figure d'un cône renversé, à spire composée de douze tours aplatis; ceux du sommet sont presque confondus ensemble et forment un bouton blanc à peine saillant; leur suture offre un sillon bien prononcé. Toute la surface de cette coquille est munie de stries transverses : celles de la spire sont plus saillantes que celles du dernier tour qui sont plus ou moins fines et très-nombreuses; elles deviennent beaucoup plus rapprochées et plus visibles à la base du tour. Ces stries sont parallèles et onduleuses. L'ouverture est blanche, nuancée de violet; son échancrure supérieure est arrondie; peu profonde : son bord droit est tranchant et liséré de fauve. Le fond de la coquille est d'un blanc violacé; les stries sont fauves ou d'un rouge orangé : elles sont traversées par des veines ou flammules longitudinales de même couleur et qui sont souvent réunies; une fascie 
blanclie est située un peu au-dessous de la partie moyenne du dernier tour : cette fascie est rarement interrompue ou traversée par les flammules. La sipire est blanche et flambée de taches d'un brun noirâtre ou d'un marron foncé.

Long. 60 millim.

\section{Habite}

Quoique voisine du Conus capitaneus, sous plusieurs rapports; cette espèce en est dictincte par sa spire très-aplatie et d'autres caractères.

74. CONב HERMres: Conus mustelinus, Brug.

(Collect. LaM.) Seba, Mus. 3, t. 42, fig. 31 .

Pl. $X X$, fig: $2,2^{\mathrm{a}}$.

C. testâ turbinatâ, pallidè luteâ vel virescente; fasciis duabus albis ; superiore nigro-variegatâ ; inferiore serie duplici macularum nigricantium; spirâ planoobtusâ.

Coquille turbinée, allongée, à spire obtuse, conique, composée de dix tours peu élevés, striés circulairement; ces tours sont veinés et flambés sur un fond blanc, d'un brun noirâtre souvent très-foncé. Le dernier tour est lisse, excepté vers son tiers inférieur où il est strié; sa coloration est d'un fond verdâtre, quelquefois passant au citron; il est orné de deux larges bandes blanches ou fascies circulaires. dont l'une occupe sa partie supérieure; elle est ornée de flammules brunes ou d'un brun noiràtre, qui sont la continuation de 
- celles de la spire; la seconde fascie est placée un peu au-dessous du milieu du tour : elle est tacheté ou ponctuée sur ses deux bords, de deux rangs de taches noires, irrégulières dans leur grandeur.

\section{Long. 70 millim.}

\section{Habite l'océan Asiatique.}

Cette espèce est bien distincte de la précédente par sa forme plus allongée, les strics circulaires de sa spire, 'sans piqûreș; et surtout par sa coloration toute différente. La variété que nous avons fait représenter même planchc, figure $2^{a}$, est remarquable par une troisième fascie située dans l'intervalle des deux autres et beaucoup plus étroite : il n'y existe qu'une seule rangée de points.

75. CONE DE IOROIS. COnus Loroisii, NoBIS.

(Collect. de MM. Lorois et Borvix.)

Pl. LXV, fig. 1.

C. testâ turbinatâ, crassâ, cinereo-virescente, transversim lineis distantibus, viridibus circumcinctâ; spirâ convexâ; ultimo anfractu suprà lævigato, infrà striato; aperturà griseo-violaceâ.

Coquille turbinée, épaisse, arrondie et bombée vers le haut. La spire est ordinairement convexe, peu élevée, composée de dix tours assez aplatis; les supérieurs sont presque granuleux; leur suture est peu profonde, ondulée èt bien marquée jusqu'au sommet, qui est légèrement saillant et pointu ; la moitié supérieure du dernier tour est lisse; la partie inférieure présente des stries circulaires, rares d'abord, écartées 
entre elles, peu apparentes, mais grossissant et se resserrant à mesure qu'elles approchent de la base. L'ouverture est d'un gris violacé dans le fond; son extrémité supérieure offre une échancrure assez profonde et sa base un bourrelet oblique et saillant; le bord droit est tranchant, marqué dans toute sa longueur d'un liséré fauve. Toute la surface de la coquille est d'un cendré verdâtre, traversé par des lignes plus foncées que le fond de la coloration; ces zones sont étroites, assez régulièrement espacées entre elles, le plus souvent traversées par des stries d'accroissement arquées, très-rapprochées les unes des autres sur.la spire et plus espacées sur le reste de la coquille:

\section{Long. 70 millim:}

Habite la mer de l'Inde.

Nous ne connaissons encore qu'un petit nombre d'individus appartenant à cette éspèce. Quoique très-voisins, sous beaucoup de rapports, du Conus minimus, ils ont des caractères qui nous semblent suffisants pour les distinguer de celui-ci. C'est à M. Lorois, préfet du Morbihan, que nous avons du la connaissance de cette espèce, et nous nous sommes empressé de lui douner le nom d'un amateur dont les recherches assidues contribueront à compléter les richesses conchylio : logiques. 
76. CONE IINÍÉ. Conus quercinus, BRtg.

(Collect. Laм.) Kronn, Vergn. 3, t. 11, fig. 2.

Pl. XXXII, fig. 1, et pl. XXXIII, fig. 2 var.

C. testâ turbinatâ, pallidè luteâ, filis tenuissimis circumdatâ ; spirâ planoobtusâ, striatâ ; basi rugọ̣â.

Coquille conique, turbinée, à spire formant un angle obtus peu élevé; elle est ordinairement aplatie sur toute sa circonférence, saillante et mucronée au centre ; elle est formée de douze tours striés circulairement ; les stries du dernier ne sont bien sensibles que vers sa partie inférieure : elles s'y montrent moins serrées et onduleuses. L'ouverture est étroite, tronquée. obliquement vers son sommet; le bord droit est mince, accompagné d'un liséré jaunậtre; la couleur de là coquille est d'un jaune orangé ; elle est couverte de lignes très-fines et très-serrées, d'une nuance fauve; on remarque aussi sur le dernier tour deux zones blanchâtres.

\section{Long. 68 millim.}

Habite l'océan des grandes Indes, les côtes de Timor.

Ce Cône n'est pas rare; il est surtout remarquable, dans son jeune àge, par les lignes très-apparentes de sa surface ; ces lignes disparaissent ou deviennent peu sensibles lorsque la coquille a atteint un certain volume. (Voir notre pl. 53, fig. 2.) 
77. CONE INAVET. Conus miles, Liv.

(Collect. Lam.) Listen, Conch. t. 786; fig. 34.

Pl. XXXVIII, fig. 2.

C. testâ turbinatâ, pallidè flavescente, suprà medium fasciâ fusco-ferrugineầ cinctâ , basi nigricante; filis fulvis longitudinalibus flexuosis ; spirâ plano-obtusâ.

Coquille turbinée, à spire peu élevée, dont les tours, au nombre de douze, sont étroits, aplatis ou très-légèrement concaves et striés circulairement, excepté le dernier dont les deux tiers supérieurs sont lisses; le. reste est garni de plusieurs stries élevées et transverses. L'ouverture est étroite, le bord droit mince, marqué de deux larges bandes noirâtres. La coloration de la coquille est fauve ou d'ún jaune pàle, mêlé de veines, de fils ou lignes longitudinales onduleuses, d'un fauve orangé, quelquefois très-foncé; deux fascies, d'un brun noirâtre ou couleur de bistre, ornent le dernier tour ; la plus largé est placée vers son tiers inférieur ; l'autre, située vers le tiers supérieur, semble être placée au milieu d'une grande bande fauve. La spire présente par intervalles, outre le fauve clair et les veines de fauve orangé dont elle est colorée, quelques taches d'un fauve rougeâtre, entremêlées de parties jaunes ou tirant sur le roux:

Long. 70 millim.

Habite l'océan des grandes Indes et des Moluques.

Cette espèce, très-commune dans les collections, offre quelques 
légères variétés: une d'entre elles ne présente d'autre différence avec le type que la privation de la fascie noirâtre supérieure qui y est remplacée par des lignes circulaires orangées.

78. CONE CIERGE. Conus virgo, LiN.

(Collect. Lasr.) Listèn, Conch. t. 754, fig. 2.

Pl. XXXVI, fig. 1.

C. testâ turbinatâ, pallidè luteâ, basi cæruleo-violacescente; striis transversis tenuissimis obsoletis ; spirâ plano-convèxâ, obtusâ.

Coquille turbinée, allongée, à spire très-peu élevée en angle obtus; on y compte neuf ou dix tours aplatis, striés circulairement, à peine saillants les uns au-dessus des autres; les stries du dernier sont très-légères, plus fortement prononcées à sa base. L'ouverture est étroite; son intérieur est d'un blanc nuancé de violet clair, qui devient un violet vif et foncé à son extrémité inférieure. Le bord droit est mince, tranchant; l'échancrure de son sommet est peu profonde. La couleur de la coquille est jaune ou couleur de soufre ; sa base est décorée d'une large tache violette.

\section{Long. 75 millim.}

Habite les mers des Indes orientales.

Cette espèce devient souvent très-grande et épaisse; elle est fort commune, et, dans les collections, on la voit le plus ordinairement dépouillée de sa première couche : alors elle a perdu cette couleur soufrée qui la distingue, et elle se montre d'un beau blanc de porcelaine, mais la base reste constamment violette. 
79. CONE BLONDIN. Conus favidus, LAM.

(Collect. Lan.) Reeve, Canch. icon. pl. 58, fig. 207.

Pl. XXVI, fig: 4 .

C. testâ turbinatâ, fla vo-rubente, fasciis duobus albis cinctâ, basi fusco-violaceâ ; striis transversis, inferioribus subgranosis ; spirâ obtusâ, immaculatâ.

Coquille turbinée, formant un cône assez régulier ; elle est un peu resserrée vers le milieu, à spire obtuse, très-peu saillante, composée de dix ou onze tọurs étroits, aplatis, assez creusés en gouttière et distincts les uns des autres par une suture bordée et onduleuse. Le dernier tour, fort rétréci à sa base, paraît lisse; cependant il est couvert de stries circulaires extrêmement fines qui deviennent plus saillantes vers la base et plus ou moins granuleuses. L'ouverture est étroite, un peu plus dilatée vers ses deux extrémités. Le bord droit est mince, tranchant, faiblement échancré à son sommet, simple et arrondi à sa base, marqué dans l'intérieur de deux larges bandes violettes. La couleur de la coquille consiste en un fond blanc rougeâtre, traversé par une ou deux zones blanchâtres, dont l'une est placée-le plus souvent vers le haut du dernier tour, et l'autre, plus large, un peu au-dessous de son milieu; la base de ce tour est constamment colorée de violet foncé.

\section{Long. 60 millim.}

Habite les côtes des îles de la Polynésie.

Espèce voisine de la précédente, et que M. Dillwyn a confondue arec elle; elle a cependant des caractères constants qui peurent servir à la distinguer, ce qu’a fait Lamarck en l'établissant comme espèce. 
GENHE CÔNE.

30. CONE CONCOZOR. Conus concolor, Sow.

(Collect. du Mus.) Sowerbx, Conch. illust. fig. 59.

PI. XLV, fig. 2.

C. testâ subpiriformi-turbinatâ, basim versủs subtiliter liratâ, cinnamomeả, lineis fuscis irregularibus, nunc confertis, nunc distantioribus, cinctà ; spirâ conrexâ, spiraliter sulcatâ; suturis rudibus; apice elato.

Coquille subpiriforme, à spire conique, pointue, composée de dix tours médiocrement convexes; l'angle du dernier est très-obtus. Toute la surface de ces tours est garnie de stries transverses, obscurément treillissées par des stries longitudinales; sur le dernier, les stries transverses sont ondulées et fort irrégulièrement espacées entre elles; celles de la base forment. des sillons assez réguliers. L'ouverture est étroite, blanche à l'intérieur. Toute la coquille est d'un brun rougeâtre plus ou moins foncé; quelquefois on voit sur sa surface des zones irréģulières, longitudinales et blanchàtres.

\section{Long. 80 millim.}

Habite la mer de Chine.

Ce Cône, encore assez rare, se rapproche beaucoup de la variété du Conus quercinus; il en est distinct crpendant par sa forme beaucoup plus piriforme et sa spire plus élevée. 
81. CONE CAROTrE. Conus daucus, Bete

(Collect. Lam.) Favane, Conch. pl. 15, fig. 0.

Pl. XXVI, fig. $1,1^{\mathrm{a}-1^{\mathrm{b}}}$.

C. testà turbinatâ, hasi sulcatâ, aurantio-rubrâ, interdùm pallidè luteà ; spirà plano-obtusâ, subcanaliculatâ, obsoletè maculatâ.

Coquille turbinée, à spire obtuse, composée de dix ou douze tours, légèrement concaves, formant saillie les uns an-dessus des autres par des stries arquées et d'autres stries circulaires très-peu apparentes; la superficie du dernier est lisse ou marquée de stries circulaires extrêmement fines; à sa base, elles forment des sillons convexes, souvent un peu granuleux. L'ouverture est étroite, plus large vers sa base, nuancée intérieurement d'une belle teinte rosée. La couleur extérieure est d'un beau rouge, nuancé d'orangé et traversé par une ou plusieurs zones blanches simples; celle de la partie supérieure est composée de taches plus foncées que le fond de la coloration générale. La spire, d'un rouge plus orangé, offre des taches rares, irrégulières, blanches ou nuancées de rose vif.

$$
\text { Long. } 50 \text { millim. }
$$

Habite les mers de l'Amérique.

Cette espèce est moins grande que le Conus flavidus, avec lequel elle 
GENRE CÔNE.

a le plus de ripport par sa forme et même par sa coloration; mais elle s'en distingue surtout parce qu'elle n'a pas celte belle teinte violette qui colore la base et l'ouverture de cette dernière espèce. Le Conus daucus offre plusieurs variétés remarquahles; la première (fig. 1a) n'a pas de bandes blanehes et est traversée par des séries de petits points bruns très-rapprochés les uns des autres. La fig. $I_{b}$ est un jeune individu qui présente deux larges fascies blanches; le fond de sa coloration est plus pâle et sa surface est garıie de lignes circulaires ponetuées de brun.

82. CONE MAGELIANIQUE. Conus magellanicus, Brug.

(Collect. de M. Delessert.) Favanne, Conch. pl. 16, fig. H.

Pl. XXIX, fig. 3.

C. testâ turbinatâ, aurantiâ, fasciâ albo fulvoque punctutâ ; spirâ plano-obtusâ ; apice subtruncato.

Coquille turbinée, à laquelle on compte neuf tours de spire un peu élevés les uns au-dessus des autres, légèrement concaves et dont le bord extérieur est terminé par un talus prononcé. Les sutures sont profondes ou semblables à un sillon onduleux ; le sommet est terminé par un bouton saillant. Le dernier tour est garni de quelques stries circulaires peu apparentes; sa base et son extrémité supérieure en laissent voir une seule bien prononcée. L'ouverture est fort étroite, nuancée de rose. La couleur de la coquille est orangée; une fascie blanche, articulée par des points fauves, orne son milieu ; cette fascie est munie de taches blanches irrégulières qui renlent ses bords sinueux; l'extrémité supérieure est également ornée d'une autre 
fascie dont le bord inférieur est déchiqueté, nuancé de fauve et quelquefois veiné.

Long. 26 millim.

Habite les parages du détroit de Magellan.

Cette espèce est constamment de petite taille; elle est assez rare. Bruguières l'avait rapprochée du Conus cardinalis. Comme l'individu qui nous a servi de type n'est pas couronné, nous pensons que ce cône doit naturellement venir se placer près du Conus daucus avec lequel il parait avoir le plus d'analogie.

83. CONe ranaIs. Conus pastinaca, Lan.

(Collect. Lamarck et de M. Delessert.)

Pl. XXVI, fig. 2.

C. testâ turbinatâ, transversìm tenuissimè striatâ, basi sulcatâ, pallidâ, spirâ obtusâ, fulvo-maculatâ, submucronatâ.

Coquille turbinée, à spire élevée en angle obtus, composée de dix tours légèrement aplatis, formant saillie les uns au-dessus des autres. La surface du dernier offre de légères stries circulaires, plus saillantes a sa base. L'ouverture est étroite, blanche à l'intérieur. La coquille est d'un blanc pâle, quelquefois jaunâtre; 
elle est traversée vers son milieu par une large fascie blanche; la spire est parsemée de taches fauves.

$$
\text { Long. } 48 \text { millim. }
$$

\section{Habite}

Dans Ics collections, on voit rarement cette cspèce bien conservée, et on l'indique comme toute blanche. Lindividu qui nous a scrvi est en état parfait de conservation et fait partie de la riclıe collection de II. Delesscrt.

84. CONE CONSORT. Conus consors, Sow.

(Collect. de M. Largilliert.) Reeve, Conch. icon. pl. 21, fig. 121.

PI. LXXIII, fig. 5.

C. testâ turbinatâ, lævi, hasim versùs sulcatâ, luteolâ, luteo-fuscescente, transversim et longitudinaliter variè fasciatâ; spirâ subobesâ, convexo-elatâ, apicem versus subtilissimè coronatâ; apice acuto.

Coquille turbinée, lisse, à spire convexe, terminée par un sommet pointu; elle est formée de neuf tours convexes; chaque tour est distinct du précédent par un léger sillon, un peu irrégulier et à bord rugueux. Le dernier tour est lisse sur presque toute son étendue, seulement on voit à sa base quelques cannelures circulaires. L'ouverture est étroite, d'un blanc uuancé de violet dans le fond. Le bord droit est mince, Irancluant; l'échancrure de son sommet est peu profonde. La coloration de la coquille est jaunâtre, tra- 
versée par des lignes et des bandes plus foncées que le fond et quelquefois d'un brun pâle.

\section{Long. 54 millim.}

Habite la mer de Chine.

Ce Cône ressemble beaucoup au $C$. pastinaca de Lam. Il en a à peu près la forme, mais il en est distinct au premier aspect par sa coloration.

85. CONב FTÉ'RI. Conus sugillatus, REEE.

(Collect. de M. Delessert.) Léeeve, Conch. icon. pl. 45, fig. 247.

Pl. XXVI, fig. 3 .

C. testâ turbinatâ, lævigatâ, basim versùs subobsoletè noduloso-liratâ, albidâ, fasciis duobus latissimis livido-olivaceis, lineisque exilibus fuscescente-punctatis, cinctâ ; spirâ obtusâ; apice mucronato, elato; ultimo anfractu basi et apertura fauce violaceo-tinctâ.

Coquille allongée, conique, étroite, à spire surbaissée, composée de dix tours subnoduleux, à surface finement treillissée par l'entre-croisement de stries longitudinales et transverses. Le dernier tour est lisse, excepté à sa base où il porte quelques sillons transverses et obliques; cependant on remarque quelquefois sur la surface de ce tour le fin réseau qui existe sur la spire, mais il s'y montre moins régulier, à cause des stries d'accroissement. L'ouverture est fort étroite, d'un beau violet foncé à l'intérieur ; cette nuance est 
interrompue dans le milieu et au sommet par des zones blanches assez larges. Le dernier tour porte sur un fond d'un blanc bleuâtre ou grisâtre deux larges zones d'un jaune verdâtre plus ou moins foncé; la base est colorée par une zone oblique d'un violet obscur.

$$
\text { Long. } 38 \text { millim. }
$$

Habite

Ce Cône a de l'analogie avec le $C$. flavidus, mais il est beatcoup plus petit et se distingue encore de celui-ci par certains individus qui ont les tours de spire noduleux; peut-être devra-t-on le rapprocher du Conus lividus, avec lequel il paraît avoir le plus de rapport.

86. CONב CORDEIIER. Conus fumigatus, Bnug.

(Collect. de M. Delessert.) D'Argenville, Conch. pl. 12, fig. D.

Pl. L, fig. 2, 2a, et pl. LXXIX, fig. 2.

C. testâ turbinatâ, lævi, rufo-castaneâ, albo-zonatâ ; spirâ obtusâ, canaliculatâ, albo castaneoque maculatâ.

Coquille conique, luisante, à spire obtuse, formée de huit tours dont les sutures sont bien marquées, quoique peu profondes, et dont la superficie est lisse et légèrement canaliculée; le sommet est pointu, mais peu saillant. Le dernier tour est lisse; sa base est marquée de plusieurs stries écartées et peu élevées. L'ouverture est assez large, violâtre dans l'intérieur, 
ornée de deux fascies qui correspondent à deux fascies semblables placées sur la superficie. Le fond de coloration extérieure est d'un brun tirant sur le marron. nuancé de quelques traits longitudinaux plus foncés, et traversé par deux fascies blanches, dont l'une est située à l'extrémité supérieure de la coquille, et l'autre un peu au-dessous de son milieu. La fascie supérieure est droite, veinée de faure ou de marron, et se prolonge sur les tours de la spire; celle du milieu est bordée de chaque côté par une ligne rougeâtre. La spire offre des veines mêlées de taches marron sur un fond blanc.

$$
\text { Long. } 45 \text { millim. }
$$

Habite les mers de l'Amérique.

Cette coquillc, à laquelle Gmelin, avant Brugnières, avait domé le nom de Conus coffea, offre plusieurs variélés; l'une, que $\mathbf{H}$. Broderip a nommée Conus orion, est l'individu que nous avons fait représenter (pl. 50 , fig. $2^{\mathrm{a}}$ ) Il ne diffère du type que par une coloration plus claire et des taches plus larges situées sur les zones blanches. La seconle (pl. 79, fig. 2), est un individu presque cntièrement décoloré et anţıel M. Reeve a donné le nom de Conus incarnatus.

87. CONE SínATEUR. Conus senator, GMel.

(Collect. Lam.) Bonv. Mus. t. 7, fig. 13.

PI. XXVII, fig. 1, 1.

C. testâ turbinatâ, rufâ, pallidè fasciatâ, basi fuscatâ; filis fulvis obsoletis, inferioribus subgranosis; spirâ obtusâ, striatâ, fusco-maculatâ.

Coquille conique, à spire légèrement convexe, com- 
posée de onze tours à peine concaves, garnis de stries circulaires rugueuses. Les rugosités sont formées par des stries arquées très-serrées qui, croisaht les stries circulaires, rendent cette partie finement treillissée. Chez certains individus, le dernier tour est traversé par de légères cordelettes qui, vers sa base. deviennent plus élevées et un per granuleuses. L'ouverture est colorée dans le fond d'un violet très-pàle. Le bord droit est profondément échancré vers son sommet et liséré de fauve rougeâtre. La coquille est de couleur fauve, ornée de deux zones d'un roux clair, dont la plus étroite occupe le sommet du dernier tour et l'autre le milieu; on aperçoit encore sur la convexité du même tour des lignes circulaires, tremblotintes et d'un fauve plus foncé que celıi du fond : elles ne sont bien apparentes que sur les deux zones rousses, mais celle du sommet est le plus souvent garnie de flammes brunes irrégulières qui se prolongent quelquefois sur le reste de la coquille. La spire est d'un fauve très-clair, et les taches dont elle est variée sont arquées d'un brun noirâtre.

\section{Long. 55 millim.}

Habite les côtes de la Guinée.

Ce Cône, nommé vulpinus par Bruguières, ofîre des lifférences dans sa coloration et erlle de ses lignes transverses plus ou moins foneées. Une variété bien distincte, que nous avons fait représenter (mème planche, fig. 1a), est surtont remarquable par lles séries circulaires granuleuse; distantes entre elles et élevées, garnissant toute la convexité de la coquilte. 
GENRE CÔNE.

88. CONE VITULIN. Conus vitulinus, Brug.

(Collect. Lay.) Encyclop. pl. 326, fig. 3.

Pl. XXII, fig. 1.

C. Lestâ oblongo-turbinatâ, basi granosâ, fulvâ ; maculis flammeis fuscis fascias alhas longitudinaliter intersecantibus; spirâ obtusâ, fusco-maculałâ.

Coquille conique, à spire obtuse, peu élevée et conposée de onze ou douze tours légèrement concaves et marqués de plusieurs stries circulaires fines, serrées et pointillées. Les deux tiers supérieurs du dernier tour sont lisses, et sa partie inférieure est munie de cordelettes circulaires, distantes entre elles et plus ou moins granuleuses. L'ouverture est étroite, blanche intérieurement; la couleur de la coquille consiste en une grande zone fauve très-foncée, que l'on doit considérer, à cause de sa largeur, comme le fond; cette zone rst coupée cirrulairement par des lignes écartées entre elles et d'un fauve clair; des flammes brunes onduleuses la sillonnent longitudinalement; deux fascies blanches et flambées de brun d'une manière irrégulière la garnissent, l'une vers les tours de la spire, l'autre vers le milieu de la convexité. Les cordelettes granuleuses de la base offrent la même teinte fauve clair que les lignes circulaires du sommet. Ln spire est 
GENRE CÔNE.

$10 \pi$

blanche, marquée de taches d'un brun foncé et arqué.

Long. 58 millim.

Habite l'océan Asiatique.

Ce Cône, qui ressemble par sa forme au precédent, en est distiuct par son système de coloration. Chez certains individus, les lignes longitudinales brunes sont plus fines, plus rapprochées entre elles et se prolongent sur presque toute la convexité du tour.

89. CONE FIIEUR. Conus lineatus, Cineys.

(Collect. Lam.) Chems. Conch. 10, t. 138, fig. 1285.

Pl. XVIII, fig. 4.

C. testâ oblongo-turbinatâ, basi granosâ, albâ ; maculis fuscis longitudinalibus filisque numerosis transversis interruptis; spirâ obtusâ.

Coquille oblongue et turbinée; on compte à sa spire dix ou onze tours étroits, peu concaves, marqués de trois ou quatre stries circulaires serrées et bordées d'un très-petit talus. La suture est peu profonde, mais bien marquée. La superficie du dernier tour est très. finement striée circulairement, mais, vers sa base, les stries sont fort sensibles : plusieurs sont saillantes et granuleuses. L'ouverture est d'un blanc violacé, le bord droit mince et tranchant, liséré de fauve. La coquille est blanche, coupée par deux larges ceintures ou par deux rangs de grandes taches longitudinales, 
d'un brun tirant sur le marron, qui occupent presque toute sa superficie : ces taches, semblables à des flammes irrégulières, sont onduleuses et sinueuses sur leurs bords, se rétrécissant vers leurs extrémités et traversées par des fils ou des lignes nombreuses et serrées; la couleur de ces lignes est d'un brun plus foncé que celui des taches. Le fond blanc de la coquille forme comme trois fascies distinctes; l'une est placée au sommet du dernier tour, l'autre vers son milieu, la troisième, moins apparente, à sa base; ces fascies présentent aussi des stries circulaires peu visibles, souvent interrompues et composées de petits points fauves. La spire est blanche, flambée de taches arquées, d'un brun noirâtre.

Long. 58 millim.

Habite l'océan Asiatique.

lie Cône, très.commun darrs les colleetions, offre dans la disposition de ses taehes et de sa coloration plusieurs variétés remarquables. Chez les unes, la eoloration est plus intense et les zones formées par le fond sont moins apparentes; ehez les autres, le fond blanc est bien plus visible, les zones brunes sont etroites et flammulées sur tonte la surfaee. Nous avons fait représentel (pl. 102, fig. 3) une très-jolie variété qui est presque complétement blanehe, et dont la surface n'est interrompue que par quelques larges taches ou flammules diun brun foncé. Cette coquille nous a été eonliée par M. Bernardi, amateur zélé qui a contribué à enriehir notre monographie des Cônes. 
90. CONE AGRÉaBLE. Conus pulchellus, Siwains.

(Collect. de M. Delessert.) Swarson, Zool. illust. $1^{\text {re }}$ série, t. 2 , pl. 65 .

Pl. LIX, fig. 1, 1a.

C. testâ oblongo-turbinatâ, in medio leviter coarctatâ, fulvo-aurantiâ, macu lis grandibus sinuatis medianè et supernè ornatẩ, punctisque fuscis numerosis ubiquẻ seriatim cinctâ ; spirâ depressâ, striatâ, basi pallidè purpureâ, leviter nodulosâ ; fauce purpureâ.

Coquille allongée, turbinée, à spire très-courte, finement striée, composée de dix tours un peu creusés; la suture est bien distincte. Le dernier tour paraît lisse, quoique légèrement strié, et, vers la base, il présente plusieurs rangées distantes et transverses de petites granulations. L'ouverture est étroite, d'un blanc jaunàtre ou d'un rose pâle, passant au rose pourpré à la base. La couleur de la coquille consiste en deux zones d'un hrun marron rougeâtre, découpées sur leurs bords en taches ou flammules étroites; ces taches les réunissent souvent sur le milieu du dernier tour. Les flammules de la zone supérieure se prolongent sur le bord de la spire; ses tours sont d un rose pourpré, ornés de petites taches longitudinales brunes. On remarque de plus sur la surface de cette coquille des linéoles transverses plus ou moins nombreuses et 
irrégulières, formées d'un grand nombre de petits points allongés, d'un brun noir.

$$
\text { Long. } 45 \text { millim. }
$$

\section{Habite}

Ce Cône, encore assez rare, parâtt intermédiaire entre le $C$. vitulinus et le $C$. linealus. La variété que nous avons fait représenter (même planche, fig. $1^{a}$ ) est distincte du type par des zones moins larges, de couleur marron, et par le peu d'apparence des linéoles.

91. CON E CERCLÉ. Conus vittatus, Bhug.

(Collect. du Mus.) Krorn, Vergn. 5, t. 11, fig. 5.

Pl. LXIII, fig. 5.

C. testà turbinatâ, luteâ aut fulvâ ; zonâ albâ supernẻ laciniatâ et maculatâ ; spirâ convexâ, mucroratâ.

Coquille turbinée; son extrémité supérieure est légèrement arrondie, sa base un peu rétrécie. La spire est composée de neuf tours peu élevés, convexes, traversés par des stries circulaires fines et nombreuses. Les deux tiers supérieurs du dernier tour sont lisses et le tiers inférieur muni de stries convexes et inégales. L'ouverture est étroite et blanche. Le fond de coloration de la superficie, fauve ou jaunâtre, quelquefois nuancé d'orangé, est traversé sur toute sa longueur par des traits blanchâtres peu marqués et par des lignes très-fines ponctuées de brun; une fascie blanche assez large se laisse voir un peu au-dessous du milieu de la 
coquille; cette fascie est veinée, tachetée et ponctuée de brun; ses bords sont souvent déchiquetés. Une seconde fascie à marbrures brunes sur un fond blanchâtre occupe l'extrémité supérieure du dernier tour et toute la superficie de la spire dont les sutures, ponctuées d'orangé, paraissent comme crénelées.

Long. 48 millim.

Habite l'océan Asiatique.

Ce Cône est eneore un de ceux qui ont de l'analogie avec le $C$. lineatus. II se rapproche de celui-ci par sa forme et un peu par la dispositiuu de ses eouleurs; mais il en est distinet prineipalement par le sommet de sou dernier tour qui est arrondi, et par sa fascie médiant? blanche reinés de taches et de points bruns.

92. CONE CARÉNÉ. Conus carinatus, Swarss.

(Collect. de M. Delessert.) Swainson, Zool. illust. $1^{\text {re }}$ série, pl. 112.

Pl. XXVII, fig. 2, $2^{\text {a }}$.

C. testâ elongatã, turbinatâ, subcylindraceâ, supernè carinatà, fuscâ, transversìm lineis minutissimè articulatis ; spirâ subdepressâ, spiraliter striatâ, fuscovariegatâ.

Coquille allongée, turbinée, subcylindracée, à spire subdéprimée, composée de dix tours striés circulairement; les stries sont fines et pointillées. Le dernier tour est finement strié; sa base est munie de sillons assez profonds et rapprochés entre eux. L'ouverture est étroite, d'un blanc violacé intérieurement; ses 
extrémités sont élargies. Le bord droit est très-mince, liséré de fauve clair. La coquille est d'un fond fauve clair, garnie de zones plus ou moins larges, d'un fauve plus foncé; sa convexité est aussi couverte de petites lignes brunâtres le plus souvent interrompues et comme articulées. La spire est variée de taches longitudinales arquées, d'un brun noirâtre.

Long. 70 millim.

Habite la mer de l'Inde.

- Ce Còne aveisine quelques variétés du Conus senator ; néanmoin; il est plus grand et plus allongé. M. Reeve, dans son Concholog. icon. (pl. 44, fig. 239), a fait représenter une coquille sous le nom de $C$. usıulatus, qui ne parait offrir pour tonte différence avec le $c$. carinatus qu'une dimension plus petite et une ceinture blanche sur le nilieu du dernier tour. Nous avons donp̣é une variété de cette même espèce (pl. 27, fig. $2^{a}$ ), qui est remarquable par sa spire plus saillante, ses linéoles plus jrononcées et des flammules longitudiuales brunes.

93. CONE IIGNí. Conus lignarius, REEvE.

(Collect. de M. Delessert.) Reeve, Conch. icon. pl. 24, fig. 136.

Pl. XXVII, fig. 3.

C. testâ oblongo turbinatâ, basim versùs subtiliter sulcatâ, luteo-fuscâ, fusco indistinctè bifasciatâ, filis tenuissimis fuscis densissimè cingulatâ ; spirâ planiusculâ, leviter canaliculatâ ; suturâ subirregulari ; apice elato, acuto.

Coquille allongée, conique, très-finement treillissée parl'entre-croisement de stries longitudinales et transverses. La spire est médiocre, très-pointue au sommet ; 
on y compte dix tours étroits, un peu concaves; le dernier, dont la base est sillonnée, est circonscrit par un angle aigu. La suture est profonde. L'ouverture est étroite, blanche dans le fond, un peu dilatée vers sa base; la columelle est un peu rentrante à son extrémité inférieure et porte un pli tordu. Le bord droit est mince et brunâtre. La coloration de la surface est d'un brun cannelle un peu foncé; elle est couvertir de linéoles transverses brunes, fort rapprochées entre elles; une ou deux zones plus pàles sont distinctes sur le dernier tour.

\section{Long. 50 millim.}

Habite les mers des îles Philippines.

Ce Cône a de l'analogie avec le Conus figulinus par ses linéoles transverses; mais elles sont, sur sa surface, plus fines, plus nombreuses et beaucoup moins apparentes; il est plus petit et d'une forme plus rétrécie. Un individu un peu plus petit que notre espèce, et qui n'a pas, comme celui-ci, les tours de spire légèrement concaves, a été établi comme espèce par M. Réeve, sous le nom de $C$. buxeus (Conch. icon. pl. 47, fig. 265); mais il ne doit être envisagé que comme une simple variété du $C$. lignarius.

94. CONE SUTURE. Conus suturatus, REEve

(Collect. de $\mathrm{M}^{\mathrm{me}}$ Dupont.) ReEve, Coneh. veon. pl. 45, fig. 250 .

Pl. LXXXVIII, fig. 1 .

C. testâ turbinatâ, lævigatâ, basim [versùs sulcatâ, sulcis latiusculis, distantibus, alhâ, basi pallidè rosaceâ; spirâ plano-convexâ, profundè suturatâ, spiraliter liratâ et striatâ ; apice minuto, acuto.

Coquille conique, turbinée; sa spire est peu élevée 
GENRE CÔNE.

en angle obtus, formée de dix tours légèrement aplatis, munie destries transversés et longitudinalesqui forment par leur entre-croisement un treillis assez fin. La suture est bien distincte. Le dernier tour est peu convexe dans ses contours; il est lisse et présente à sa base des sillons obsolètes. L'ouverture est étroite; sa base, un peu dilatée, est d'un blanc violacé. La coloration de cetté espèce est assez uniforme ; sur un fond d'un blanc quelquefois mêlé de jaunàtre, sont tracées de légères fascies circulaires d'une nuance un peu plus foncée. La basè est d'un rose pâle.

\section{Long. 56 millim.}

Habite

Ce Còne, qui est voisin par sa forme du $C$. pastinaca, est d'un aspect remarquable par ses tours de spire treillissés.

95. CONE GRISATRE. Conus griseus, NoBis.

(Collect. de $M^{\text {me }}$ Dupont.)

PI. $\mathbf{e X I I I , ~ f i g . ~} 2$.

C. testâ oblongo-turbinatâ, basim versùs subtiliter sulcatâ, griseâ, longitudinaliter fulvo-lineatâ : sulcis æqualiter distantibus ; spirâ depressiusculâ, maculis brunneis inæqualibus tinctâ; suturâ lineali undulosè marginatâ.

Coquille oblongue, turbinée, à spire conique et peu élevée. On y compte dix tours médiocrement concaves dont la suture linéaire est bordée d'un petit bourrelet onduleux. La surface est lisse, excepté vers la base, où l'on voit un petit nombre de sillons trans- 
verses, égaux, également distants entre eux. L'ouverture est étroite, blanche', un peu dilatée à sa bace; le bord droit est mince et tranchant, arqué dans sa longueur; son sommet est terminé par une échancrure assez profonde. Cette coquille, sur un fond d'un blıne grisàtre, présente quelques lignes longitudinales irrégulières, nuancées de fauve. La spire èst tachetée de maculations brunes ou fauves, inégales et allongées.

$$
\text { Long. } 40 \text { millim. }
$$

Habite les côtes septentrionales d'Afrique.

Ce Còne a beaucoup d'analogie avec le $C$. sugillatus; mais il en est constamment distinct par sa spire plús élevée et par la coloration presque uniforme de son dernier tour.

96. CONE DE RIEVE. Conus Reevei, NoBIs.

(Collect. de $\mathrm{I}^{\mathrm{me}}$ Dupont.) Reeve, Conich. icon. pl. 24, fig. $133 \mathrm{~b}$.

PI. XLIV, fig. 2.

C. testâ conicâ, crassâ, apice ventricosâ, basim versus angustatâ, reticulatim striatâ ; spirâ obtusâ, maculis brunneis albisque vicissìm distinctâ ; ullimo anfractu confertissimè lineato, ad medium albo-fasciato.

Coquille conique, épaisse, hombée à son extrémité supérieure, légèrement arrondie vers la naissance de la spire et rétrécie à sa base. La spire est peu élevée, obtuse, composée de neuf ou dix tours étroits, mediocrement aplatis. Liouverture est étroite, d'un blanc rosé. Cette coquille est couverte d'un grand 
nombre de fines stries longitudinales et transverses dontl'entre-croisement forme un réseau extrêmement serré. Le dernier tour, quelquefois de couleur olivâtre, est traversé dans toute son étendue par un grand nombre de lignes également distantes entre elles, plus saillantes vers la base de la coquille. Ces lignes sont formées de petits points allongés très-rapprochés entre eux et d'un fauve foncé. Une étroite fascie blanche, pointillée de même, est placée un peu au-dessous du milieu du dernier tour. La spire est marquée de larges taches d'un brun foncé, alternant avec d'autres taches blanches à peu près égales.

\title{
Long. 46 millim.
}

\section{Habite}

Ce Cône a été signalé pour la première fois par M. Reeve qui l'a indiqué comme variété du $C$. punclatus, en proposant de le réunir au C. hycna. Pour nous, ces deux espèces sont bien distinctes l'une de l'autre et he peuvient être confondues. Le Cône auquel nous avons donné le nom de M. Reeve est une coquille bien différente du $C$. punctatus de Bruguières: il en est distinct, alt premier aspect, en ce que la spire n'est jamais couronnée.

97. CONE PICOTÉ. Comus augur, Brug.

\author{
(Collect. Lam. ) Lister, Conch.t. 755, fig. 7.
}

Pl. XVIII, fig. 3 .

C. testâ turbinatâ, albido-flavescente; fasciis duabus fulvo-nigricantibus punctisque rutis transversìm seriatis ; spirâ obtusâ, striatâ, maculis brunneis variegatâ.

Coquille conique, à spire obtuse, peu élevée, compo- 
sée de dix ou douze tours étroits, très-légèrement concaves et garnis de plusieurs stries circulaires peu prononcées. La surface du dernier tour paraît lisse, quoiqu'elle soit munie de quelques stries circulaires et d'autres stries longitudinales, mais à peine distinctes. Les stries transverses de la base sont saillantes, alternativement prononcées. L'ouverture est étroite, blanche en dedans; le bord droit est mince, accompagné d'un liséré ponctué et tacheté de brun. Le fond de la coquille offre une teinte rousse ou légèrement jaunàtre, parsemée d'un bout à l'autre de très-petits points rougeàtres disposés en rangées transverses : elle est ornée de deux fascies d'un brun noir, quelquefois de couleur marron. L'une de ces fascies est située un peu au-dessus du milieu de la coquille; l'autre, vers le tiers inférieur. La fascie supérieure est toujours formée de flammules longitudinales plus ou moins distantes entre elles. La spire offre, sur un fond blanchâtre, un rang de mouchetures fauves ou brunes qui se prolongent sur le bord supérieur des tours.

$$
\text { Long. } 60 \text { millim. }
$$

Habite l'océan Asiatique, les côtes de Ceylan.

Espèce bien distincte et peu commune, qui a beaucoup de la forme du $C$. lineatus; elle est remarquable par le grand nombre de ses séries circulaires de petits points et par ses deux zones transverses. 
98. CONE GRAND AMIRAT. Conus thalassiarchus, Grar.

(Collect. de M. Delessert et du Mus.) Sowerby, Conch. illust. fig. 80 et 85 .

Pl. XXII, fig. 3, $3^{n}-5^{b}$.

C. testâ cylindraceo-conicâ, albidâ, lineis furvo-nigricantibus, acutissimè el triangulariter undulatis, prófusè pictâ; lineis sæè in medio quasi fasciâ interruptis; spirâ minuvè depressâ.

Coquille conique, a spire très-courte et presque plane, composée de dix ou onze tours légèrement concaves, bordés d'un talus peu saillant. Le dernier tour est lisse, garni seulement à la base de stries transverses obsolètes. L'ouverture est étroite, un peu dilatée à sa base; elle est d'un blanc jaunàtre: le bord droit est mince, il se projette en avant, détaché à son sommet par une échancrure profonde. Cette coquille est toute marbrée et panachée d'un grand nombre de veines d'un brun foncé, descendant en zigzag et formant par leur entrelacement un réseau ì mailles inégales. Ce rés'au est quelquefois interrompu par deux ou trois zones blanches comme le fond, mais garnies de séries circulaires de petits points bruns. La spire, comme le reste de la superficie: est panachée de bran.

\section{Long. 68 millim.}

Habite la mer des îles Philippines et de Luçon.

Ce Cône, encore assez rare dans les collections, a une coloration 
très-variable. L'individu (fig. $3^{\text {" }}$ ) est remarquable par le grand nombre de ses lignes d'un brun foncé, descendant en zigzag du sommet à la base, s'entre-croisant souvent de manière à former des taches triangulaires. Cette variété n'a pas de zones. La variété $3^{\text {b }}$, au contraire, a sa surface occupée par de larges zones fauves, chargées de lignes ponctuées; les flammules longitudinales ne s'y montrent plus đุu'au sommet, sur le milieu et à la base du dernier tour.

99. CONE DE MAIACA. Conus malacanus, BRtG.

(Collect. Las.) Chemn. Conch. 11, t. 181, f. 1748-1749.

Pl. XXII, fig. 2, et pl. GI, fig. 5 var.

C. testâ oblongo-turbinatâ, basi sulcatâ, albâ, helvaceo-fasciatâ, maculis et lineis paucis albo fulvoque articulatis, concatenatis; spirâ convexiusculâ, marg̣inatâ, apice mucronatâ.

Coquille oblonģue, turbinée, peu épaisse, à spire composée de dix ou onze tours. Cette spire est trèsobtuse. terminée par un sommet pointu et saillant; chacun de ces tours, considéré séparément, forme une surface aplatie, żarnie de trois ou quatre stries circulaires dont le bord extérieur s'élève en vive arête; au quatrième tour, elle cesse d'être aperçue. L'ouverture est étroite, profondément échancrée vers sa partie supérieure. Le bord droit est mince, teinté de fauve, émaillé de blanc dans tout le reste de sa cavité. Le fond blanc de cette coquille est orné de deux fascies d'un rougge pâle ou safran, et de quelques flammes irrégulières brunes; la fascie supérieure est située un peu au-dessus du milieu de la coquille : elle est bordée de chaque côté par une zone composée de deux ou trois lignes brunes articu- 
lées de fauve et de blanc, plus ou moins rapprochées entre elles. Une liğne sémblable existe au milieu, mais isolée. La seconde fascie est située un peu au-dessous de la moitié inférieure de la coquille; ses lignes articulées sont quelquefois peu marquêes. Le reste de la coquille est blanc, marqué de taches d'uı roux brun flammulées irrégulièrement; celles de la spire sont plus rares.

\section{Long. 58 millim.}

Habite près du détroit de Malaca.

Coquille agréablement panachée, peu commune, recherchée dans les collections. La variété que nous avons fait représenter $y \mathrm{l} .101$, fig. s̆, est remarquable par la coloration de son dernier tour qui est presque généralement d'un roux verdâtre, traversé vers son milieu d'une ceinture brune et accompagné au-dessous de deux lignes brunes peu espacées entre elles et articulées de petits points blanes allongés. Cet individu fait partie de la collection de $\mathrm{M}$. Bernardi.

100. CONe AMadis. Conus Amadis, CHemr.

(Collect. Lam. et de M. Deleessert.) D'Argenvilue, Conch. append. pl. 1, fig. S.

PI. XLI, fig. 1-1², et PI. LXXXIV, fig. 2 var.

C. testâ turbinatâ, basi punctatim sulcatâ, aurantio-fuscâ ; maculis niveis trigono-cordatis inæqualibus ; lineis transversis raris albo fulvoque articulatis ; spirâ canaliculatâ, acuminatâ.

Coquille turbinée, peu épaisse, à spire élevée, pointue, composée de dix ou douze tours assez larges, concaves, à stries fines, circulaires, légèrement ondu- 
leuses, presque treillissées et bordées d'un talus saillant dont les sutures sont peu profondes et régulières. Le dernier tour est lisse, excepté vers sa partie inférieure où l'on compte un nombre assez considérable de stries circulaires profondes, garnies de points concaves ou de piqûres plus ou moins apparentes. Ces piqûres disparaissent sur les dernières stries. L'ouverture est blanche, fortement échancrée à son sommet. Le bord droit est très-mince, projeté en avant. Toute la superficie de la coquille est marbrée, sur un fond blanc de traits en zigzag, d'un fauve plus ou moins brun cu tirant sur l'orangé, qui laissent paraître dans leurs interstices des parties blanches du fond en forme d'écailles triangulaires ou cordées; des taches brunes ou fauves sont parsemées entre les mailles de ce réseau et souvent réunies en deux espèces de zones. La spire est garnie de grandes taches brunes ou marron sur un fond blanc.

\section{Long. 72 millim.}

Habite les mers des grandes Indes, les côtes de Java et de Bornéo.

Cette espèce, commune dans les collections, offre chez certains individus des différences de coloration. La coquille que nous avons fait représenter. même planche, fig. $1^{2}$, est d'une teinte beaucoup plus orangée, garnie, au-dessus et au-dessous de soll inilieu, de cordons circulaires de petits points inégaux entre eux, d'une forme ronde ou ovale. Notre seconde variété ( pl. 84, fig. 2), qui fait partie de la magnifique collection de 11 . Delessert, est bien remarquable par sa coloration presque uniforme, d'un roux tirant quelquefois sur le verdâtre, avec une large fascie réticulée siluée un peu au-dessous du milieu du der-. nier tour. 
101. CONE FLA MBLOYANT. Conus generalis, Lix.

(Collect. Lam.) Lister, Conch. t. 786, fig. 35. Pl. XXX, fig. 1, 1" à $1^{c}$; pl. XXXI, fig. 2, $2^{\text {s }}$.

G. testâ oblongo-turbinatâ, fuscâ vel citrino.aurantiâ, basi nigrâ; fasciis albis interruptis; spirâ planâ, marginatâ, apice acuminatâ, fusco-flammulatâ.

Coquille oblonģne, turbinée, rétrécie vers la base. La spire est composée de douze tours étroits; son sommet est élevé, pointu : il forme, avec les tours qui le composent, un angle aigu, tandis que les suivants sont légèrement aplatis et un peu concaves. Le dernier est luisant, quoique garni de stries d'accroissement longitudinales et même de stries circulaires peu apparentes, excepté celles de la base qui sont assez grosses, distantes entre elles, quelquefois même léz̧èrement granuleuses. L'ouverture est étroite, blanche; son extrémité in férieure est noirâtre. Le fond de la coquille offre une couleur fauve ou brune très-vive, ornée de trois ou quatre fascies transverses blanches, flambées de brun noirâtre; les flammules sont inégalement disposées ; la fascie qui occupe le milieu de la coquille est la plus large; celle de la base la plus étroite. La spire est blanche, panachée de flammes arquées d un brun trèsfoncé.

$$
\text { Long. } 58 \text { millim. }
$$

Habite l'océan des grandes Indes.

Belle coquille, mais dont la couleur n'est pas toujours telle que nous 
venons de la décrire; ii est mềne assez rare de rencontrer les individus complétement semblables: on en trouve qui sont tout bruns, d'autres de même couleur avec trois fascies interrompues (Voir notre pl. 30, fig. $1^{\mathrm{b}}$ ), d'autres, d'une coloration rosée avec des flammules d'un brun clair ( Voir pl. 31, fig. 2²); MM. Dillwym et Deshayes pensent que le $C$. maldivus n'est qu'une variété du $C$. generalis. Le $C$. maldivus se distingue par des lignes brunes transverses et des lignes ponctuées à la base. M. Deshayes possède un individu dont une noitié du dernier tour porte ces caractères, tandis que l'autre offre ceux du C.generalis. Ce fait prouve évidemment la complète analogie des deux coquilles; aussi les avons-nous réunies en en donnant plusieurs figures ( pl. 30, fig. $1^{2}$ à $1^{\mathrm{c}}$, et pl. 31, fiğ $2,2^{2}$ ), afin de montrer les nombreuses variétés de coloration de celte espèce.

102. CONE FAISAN. Conus monile, Brug.

(Collect. Laм.) Knorr, Vergn. 3, t. 6, fig. 3 .

PI. XXXI, fig. 1, 1*, $1^{\text {b. }}$

C. testâ oblongo-turbinatâ, albo-rubellâ; lineis maculisque rufis transversim seriatis ; fasciâ albâ, punctatâ ; spirâ plarâ, canaliculatâ, apice acuminatâ.

Coquille allongée, étroite, à spire élevée en angle aigu, composée de douze tours; elle ressemble à celle du Cône flamboyant par son aplatissement vers la circonférence, par le talus intérieur des tours et par la saillie du sommet. Le dernier tour est lisse, rétréci, strié à sa base, quelquefois marqué de stries longitudinales d'accroissement assez apparentes. La coloration de la coquille consiste en un fond blanc mêlé d'une teinte rougeâtre souvent très-légère, ou d'un fauve extrèmement clair sur lequel on compte plusieurs suites circulaires de taches et de portions de lignes brunes ou d'un rouge foncé, de grandeur et de 
distances inégales; une ou deux fascies blanches, garnies de plusieurs séries de points de la même nuance que les taches, occupent aussi le fond de coloration. S'il ne se trouve qu'une fascie sur la coquille, cette fascie est placée vers sa partie moyenne; si l'on en voit deux, la seconde est située à sa base. La spire est blanche, flambée de taches brunes arquées.

Long. 60 millim.

\section{Habite l'océan Asiatique.}

Cette coquille rappelle la forme du $C$. generalis et il est vraisemblable qu'elle n'en est qu'une variété, puisqu'elle offre avec toutes les parties de ce Cône la plus grande analogie. L'une des deux variétés que nous avons fait représenter ( fig. 1") présente une autre disposition des taches qui y sont plus larges et placées longitudinalement. La seconde ( fig. $1^{\text {b }}$ ) est remarquable en ce que les taches se prolongent sur toute sa surface en flammes onduleuses.

103. CONE RÉGUIIER. Conus regularis, Sow.

(Collect. de M. Delessert et du Mus.) Sowerby, Conch. illust. fig. 29 et 45 .

PI. XXIII, fig. $3, \mathbf{3}_{\mathbf{2}}$.

C. testâ suboblongo-turbinatâ, propè basim paululùm attenualâ, lævi, albidâ, rubido-fusco plus minùsve pallidè tinetâ, fasciis fuscis angustis, numerosis, interruptis cinctâ; spirâ acuminato-exsertâ, fusco profusè maculatâ.

Coquille allongée, étroite, à spire assez longue, trèspointue, à angle aigu, composée de dix tours étroits légèrement concaves. Le dernier est circonscrit vers 
son sommet par un angle vif et atténué à sa base qui est chargée de stries fines et onduleuses. L'ouverture est très-étroite, blanche ou d'un brun brunàtre. Le bord droit est mince, liséré de petites taches fauves. Le fond de coloration de cette coquille est blanchâtre, teinté de violet, et traversé par six ou huit fascies formées de tachesirrégulières d'un brun noiràtre assez rapprochées entre elles, quelquefois interrompues par de courtes flammules; ces fascies sont souvent alternées par des lignes étroites de petits points bruns. La spire est maculée de linéoles brunes.

Long. 50 millim.

Habite les îles Philippines.

Ce Còne ressemble beaucoup par sa forme au $C$. monile; il est à peu près de la même taille, mais il en est distinct, au premier aspect, par sa coloration. Il offre plusieurs variétés. Celle que nous avons fait représenter(même planche, fig. 3") est remarquable par une coloration d'un fauve obscur parsemée de flammules sur les deux tours supérieurs de la coquille; le reste du dernier tour est traversé par des séries de taches de même couleur d'un brun foncé.

104. CONE PIULE D'OR. Comus japonicus, Brug.

Encyclop. méthod. pl. 330, fig. 3.

PI. LXXIX, fig. 4.

C. testâ turbinatâ, basi sulcatâ, luteâ, albo-interspersâ ; lineis fuscis interruptis punctatis; spirâ acuminatâ.

Coquille petite, conique, turbinée, composée de dix 
tours étroits, légèrement aplatis, a bords arrondis et peu saillants. La spire est élevée, presque aiguë; ses sutures sont profondes. Le dernier tour est lisse; sa base seulement est marquée de quelques stries. L'ouverture est étroite, bien échancrée à son sommet, colorée de fauve à l'intérieur; son bord droit est mince, peu tranchant. Le fond dela coquille est jaune, flambé de blanc, de fauve ou d'orangé et garni de nombreuses lignes circulaires brunes ou d'un fauve foncé, interrompues par des points blancs, ce qui leur domne l'aspect de pretites chaînes. Unt peu au-dessous du n!ilieu du dernier tour, on remarque une fascie blanche bordée d'une ou de deux lignes circulaires à points plus gros et d'une teinte plus foncée que ceux des autres rangs. La spire est tachetée de fauve orangé sur un fond blanc.

Long. 30 millim. .

Habite les côtes du Japon.

Bruguières dit que cette jolie petite coquille a une grande analogie avec le $C$. mindanus, et que Favanne avait réuni ces deux espèces. Cependant, d'après la figure de l'Encyclopédie méthodique que nous avons copiée, ainsi que la description, notre coquille ici décrite parait bien distincte. N'ayant pas vu d'individus en nature et ne connaissant que celui qui est cité de la collection de M. Hwass, nous ne pouvons nous prononcer à ce sujet; toutefois, nous avons cru devoir représenter cette espèce afin de l'indiquer seulement aux conchyliologistes. 
105. CONE ÉTOURNEAU. Conus lithoglyphus, Brug.

(Collect. Lam.) Seba, Mus. 3, t. 42, fig. 40-42.

PI. XXIX, fig. 1, $1^{2}$.

C. testâ turbinatâ, basi granulatâ, rubro-fulvâ, infernè nigricante; fasciis duabus niveis distantibus ; superiore fulvo-variegatâ ; spirâ ohtusâ.

Coquille turbinée, un peu bombée vers son extrímité supérieure, également décroissante jusqu'à sa base; les tours de spire sont au nombre de dix : ils sont ou légèrement convexes, ou aplatis; la ligne de leurs sutures est profonde, peu régulière, presque toujours festonnée sur son bord supérieur. La spire est obtuse, terminée par un sommet peu aigu. La superficie du dernier tour offre des stries longitudinales extrêmement fines et des cordelettes écartées au nombre de neuf ou dix, dont les supérieures sont peu apparentes, tandis que celles de la base sont souvent saillantes et quelquefois granuleuses. L'ouverture est étroite, d'un blanc orné de violâtre, excepté vis-à-vis les fascies extérieures où elle est tout à fait blanche, et à sa base, où elle est entièrement noirâtre. Le fond de la coloration extérieure est d'un beau rouge, quelquefois tirant sur le fauve ou l'orangé. On y aperçoit des bandelettes circulaires un peu plus obscures, et deux fascies, dont l'une, composée de grandes taches blanches variées de fauve, occupe le haut de la coquille, et l'autre, entièrement blanche et déchiquetée sur ses 
bords, est placée un peu au-dessous du milieu. La spire est tachetée de blanc sur un fond rouge ou fauve.

$$
\text { Long. } 60 \text { millim. }
$$

Habite les mers des grandes Indes, les côtes des îles Philippines.

Ce Cône est assez commun, très-facile à riconnaître par sa coloration. La variété de notre pl. 29 (fig. $1^{2}$ ) est remarquable par sa couleur presque uniforme d'un rouge foncé, arec une seule tache blanche vers le haut du dernier tour; la fascie placée au-dessous du milieu est peu apparente et n'est pas déchiquetée sur ses bords.

106. CONE JANUS. Conus Janus, BRvg.

(Collect. Lam.) Lister, Conch. t. 785, fig. 35.

Pl. XXIX, fig. 2, 2a, $2^{b}$.

C. testâ oblongo-turbinatá, basi sulcatâ, albâ, fulvo et castaneo-undatâ ; spirả subcanaliculatâ, exserto-acutâ.

Coquille oblongue et turbinée ; sa spire est composée de douze tours légèrement concaves, garnis de trois ou quatre stries circulaires bien prononcées, quelquefois ridées ou onduleuses. Le dernier tour est uni, luisant, quoique marqué de stries d'accroissement assez sensibles jusque vers son tiers inférieur où l'on aperçoit des sillons obliques et écartés, dont la cavité est linement striée et quelquefois ponctuée par des piquires longitudinales semblables à de petites rides. L'ouverture est assez large; son extrémité supérieure 
est peu échancrée; son bord droit est peu épais, marqué d'un liséré taché de brun sur un fond roussâtre ou jaune clair qui occupe toute sa cavité. La coquille est ornée, sur un fond blanc, de flammes longitudinales un peu obliques, onduleuses ou en zigzag, de couleur fauve ou brune plus ou moins foncée. Ces flammules, ordinairement peu écartées entre elles, sont quelquefois interrompues par deux ou trois rangs circulaires de grandes taches brunes mêlées de fauve, avec lesquelles elles se confondent et qui y forment comme autant de zones d'une largeur très-sujette à varier. La spire est maculée de flammes brunes ou jaunâtres sur un fond blanc.

\section{Long. 60 millim.}

Habite l'océan Asiatique, les côtes de la NouvelleGuinée et celles d'Otaïti.

Coquille commune dans les collections. Elle offre plusieurs variétés remarquables dans sa coloration. La fig. $2^{a}$, dont le fond est fauve ou d'un jaune orange, est traversée de deux fascies blanches assez larges, profondément déchiquetées sur leurs bords, La fig. $2^{\text {b }}$ est un jeune individu dont la surface est toute sillonnée en travers et panachée de taches rousses ou d'un brun fauve. 
107. CONE SOUFRÉ. Conus sulphuratus, NoBrs.

( Collect. de M. Borvis et du Mus.)

Pl. LXVI, fig. $\mathbf{3}$, et pl. LXXVIII, fig. 4.

C. testâ conicâ, turbinatâ, obsoletè striatâ, sulphuratâ, seriatim fusco-maculatâ; spirâ obtusâ, depressiusculâ; ultimó anfractu supernè lævigato; aperturå flavescente-albidâ.

Coquille petite, conique, assez mince, à spire obtuse, peu élevée, composée de huit ou neuf tours faiblement aplatis, marqués de plusieurs stries circulaires. La moitié supérieure du dernier est lisse; sa partie inférieure présente des stries transverses régulièrement espacées entre elles, peu apparentes, mais se rapprochant et devenant plus distinctes vers la base. L'ouverture est blanche, nuancée de jaunâtre; son échancrure supérieure est arrondie et peu profonde. La couleur de cette coquille est d'une belle couleur de soufre; une série circulaire de petites taches brunes arrondies ou oblongues se détache sur le milieu dı dernier tour; des taches semblables, mais beaucoup plus grandes, ornent les tours de spire.

$$
\text { Long. } 28 \text { millim. }
$$

\section{Habite}

Cette jolie petite espèce, que nous a communiquée M. Boivin, parait se rapprocher du Conus mustelinus avec lequel on pourrait même la confondre; tout au moins on pourrait la considérer comme un jeune individu de ce dernier, ainsi que l'a déjà fait $M$. Sowerby dans son Concholog. illustr., fig. 77. Cependant elle en est distincte par sa forme 
plus acuminée à la base, par le manque de fascies blanches et de flammules; en outre, elle n'a qu'un rang de taches sur le milieu du dernier tour, tandis que le $C$. muslelinus en a deux. L'individu que nous arons fait représenter pl. 78, fig. 4, sous le nom de $C$. citrinus, nous parait être l'adnlte du $C$. sulphuratus; lindividu de notre pl. 66, fig. $\mathbf{3}$, est jeune.

108. CONE ÉMARGINÉ. Conus emarginatus, REEve.

(Collect. du Mus.) Reeve, Conch. icon. pl. 43, fig. 232.

$$
\text { Pl. XXIII, fig. } 4 .
$$

C. testâ subfusiformi turhinatâ, lævi, ad basim leviter sulcatâ, alhidâ, strigis fuscis latiusculis undatis vividè variegatâ ; spirâ elatâ, subcanaliculatâ, apice mucronato; labro arcuato, juxta spiram emarginato.

Coquille subfusiforme, turbinée, lisse, sillonnée à sa base, à spire conique, longue, pointue, composée de douze tours faiblement canaliculés en dessus, bordés par un petit talus caréniforme; le dernier est circonscrit par un angle vif à son sommet et fortement. atténué à sa base. L'ouverture est étroite, un peu rétrécie vers le milieu; le bord droit est mince, tranchant et arqué, détaché de la spire par une échancrure arrondie et peu profonde. Cette coquille, sur un fond d'un blanc grisâtre, est traversée par des veines ou des flammules irrégulières brunes, souvent arquées et entrelacées. La base est marquée de plusieurs séries transverses de petites taches allongées; la spire elle-même est tachetée de brun.

$$
\text { Long. } 50 \text { millim. }
$$

Habite l'océan Pacifique.

Cette espèce est très-différente du Conus regularis, avec lequel 
cependant on pourrait la confondre. Elle est plus étroite; sa spire est plus longue, la disposition de sa coloration n'est pas la mệme.

\section{CONE RECOURBÉ. Conus recurvus, Brod.}

(Collect. de M. Bernardi.) Sowerby, Conch. illust. fig. 36.

Pl. XCVII, fig. 4,4 .

C. testâ elongato-conicâ, subrecurvâ, albâ, rubro-castaneo nebulosâ et vittatìm punctatâ ; spirâ prominente, acutâ, albo castaneoque maculatâ.

Coquille étroite, allongée, conique, lisse, mais striée à sa base, légèrement recourbée, à spire composée de dix tours un peu aplatis, dont la suture est bordée d'un petit cordonnet; le sommet est assez élevé et pointu; la partie supérieure du dernier tour est subcarénée, sa base est très-rétrécie. L'ouverture est fort étroite ; l'échancrure du haut est à peine apparente. La coloration de cette espèce consiste en un fond blanc sur lequel on remarque un assez grand nombre de séries transverses de points allongés ou de portions de lignes d'un roux marron, et quelquefois de larges maculations ou flammules d'une teinte moins foncée que les taches, couvrant une petite partie de celles-ci, qui sont toujours plus larges dans la moitié supérieure de leur convexité; celles de la base sont plus petites et de forme plus régulière. La spire est tachée irrégulièrement de blanc et de fauve.

Long. 42 millim.

Habite les mers des Antilles.

Celle-ci n'est pas moins rare que la précédente, et s'en rapproche 
GENRE CÔNE.

133

beaucoup par sa forme; mais elle est plus petite et en est surtout distincte par sa coloration, composée de séries transverses de points plus ou moins allongés qui n'existent pas sur le $C$. emarginatus. La figure $4^{*}$ est un jeune individu.

110. CONE DE NEPTUNE. Conus Neptunus, ReEve.

(Collect. de M. Larghliert.) Reeve, Conch. icon. pl. 6, fig. 30 .

PI. XCIX, fig. 5 .

C. testâ elongato-conicâ, nitidà, 'pallidè fulvâ, lineis maculisque rubidis ubiquè nebulosâ et verrosâ : spirâ acuminatâ, striatâ, apice acutâ, versùs basim leviter sulcatâ, sulcis distantibus; columellâ et aperturæ fauce subrosaceis.

Coquille allongée, conique, étroite, luisante, à spire élevée, composée de onze ou douze tours étagés, concaves, à stries circulaires assez saillantes et bordées d'un talus saillant; la suture est peu profonde et trèsrégulière; le sommet est pointu, les tours sont serrés, arrondis et lisses; le dernier est muni de sillons transverses réguliers, assez nombreux et espacés entre eux ; ceux de la base sont plus fins et beaucoup plus rapprochés les uns des autres. L'ouverture est blanche, teintée de rose, régulièrement étroite dans sa longueur; le bord droit est mince, bordé d'un liséré fauve, l'échancrure du haut est à peine sensible. La coquille, d'un fauve clair, porte deux ou trois fascies blanchâtres qui laissent paraître, dans leurs interstices, un réseau formé de petites taches triangulaires ou cordées ; la fascie qui est: placée au sommet du dernier tour est toujours plus large que celle du milieu; celle de la 
base est à peine distincte. La spire est tachée régulièrement de blanc jaunâtre et de fauve.

$$
\text { Long. } 40 \text { millim. }
$$

Habite la mer des îles Philippines.

Ce Cône a beaucoup d'analogie avec le Conus generalis. Sa forme est la même, seulement sa spire est plus acuminée; mais ce qui le rend surtout distinct de celui-ci, c'est la disposition des mailles du réseau qui forme les fascies. La figure que nous avons représentée comme variété de cette espèce, pl. 92, fig. 5 , doil être au contraire reportéc au $C$. acuminatus, comme variété.

111. CONE AMIRAT Conus amiralis, Liv.

(Collect. Lam. et de M. Delessert.) Rumph. Mus. t. 34, fig. B.

PI. XXI, fig. 1 à $\mathbf{1}_{\mathrm{d}}$.

C. testâ turbinatâ, citrino-fulvâ : maculis albis trigonis fasciisque flavis subtilissimè reticulatis; spirâ concavo-acutâ, aurantio-marmoratâ.

Coquille turbinée, à spire élevée le plus souvent en angle aigu et terminée par un sommet pointu; elle est composée de onze tours légèrement concaves; on aperçoit un léger talus sur les derniers de ces tours et quelquefois même des stries circulaires serrées, peu distinctes; la superficie du dernier est presque toujours dépourvue de stries, excepté vers sa base où elles devienment très-prononcées. Le bord droit est tranchant; l'échancrure de son sommet est médiocre. Le fond de coloration de la coquille est un jaune orangé ou marron parsemé de taches trigones d'iné- 
gale grandeur et d'un blanc de lait; des lignes brunes transversales et longitudinales avec quelques zones plus ou moins larges, finement réticulées, de couleur blanche ou d'un jaune citron, ornent également toute la surface; le plus souvent ces zones sont divisées en deux parties par un cordon ponctué de marron qui les fait paraître doubles. Toute la spire, dont le fond est blanc, est marbrée de taches arquées ou en croissant, d'un très-beau fauve orangé.

\section{Long. 58 millim.}

Habite les mers des grandes Indes, celles des Moluques et de la mer du Sud.

Cette espèce est une des plus belles et des plus élégantes du genre; ses nombreuses variétés, dont quelques-unes sont rares et précieuses, sont recherchées avec empressement. Ces variétés offrent principalement les différences que nous indiquons ici : les fascies treillissées plus ou moins nombreuses, les places diverses qu'elles occupent sur la coquille, l'existence et le nombre des cordons, ou leur absence; la division des fascies en deux ou trois (voir les figures $1^{a}, 1^{b}$ ), les tubercules dont la superficie est quelquefois ornée; dans ce cas, la coquille est plus petite: elle est munie de stries circulaires très-prononcées qui sont chargées de petits grains plus ou moins saillants (fig. 1 ${ }^{\mathrm{d}}$ ). Enfin la figure 1. a pour signe distinctif les tubercules qui couronnent ses tours de spire, contradiction qui se rencontre assez fréquemment sur certains individus de la section établie des espèces non couronnées. C'est cette variété que M. Vignart a décrite sous le nom de Conus Blainvillei. Elle n'est plus très-rare dans les collections. 
GENRE CÔNE.

112 CONE LLEUTENANT. Conus vicarius, LAY.

(Collect. du Mus.)

Pl. XXXVII, fig. 3.

C. testâ turbinatâ, citrinâ, maculis albis subtrigonis inæqualibus; majoribus fasciatim congestis; lineis fulvis decussatis cingulisque articulatis; spirâ acutâ, apice roseâ.

Coquille turbinée, conique, anguleuse à sa naissance; sa spire est composée de neuf tours lisses et légèrement arrondis qui sont terminés par un sonmet peu saillant et pointu; le dernier est subanguleux à sa circonférence ; on remarque à sa base quelques sillons transverses : tout le reste de la surface est parfaitement lisse. C'ette coquille présente, sur un fond citrin ou blanchâtre, une grande quantité de taches inégales, ovoïdes ou trigones; les plus grandes de ces taches sont rapprochées entre elles et souvent confluentes, affectant alors la forme de zones transverses et longitudinales. Dans les interstices de ces zones, on remarque d'autres petites taches blanches, des lignes rousses ou marron qui se croisent et des cordelettes étroites, articulées. La spire est panachée de blanc et de fauve marron; le sommet est rose.

Long. 44 millim.

Habite l'océan Indien.

L'aspect de ce Cône est celui du C. amiralis à zones très-blanches, irrégulières, et presque sans réseau. Déjà Linnée, dans son Systema 
natura, avait donné, sous le nom de $C$. vicarius, une variété du Conus amiralis, que M. Dillwin a mentionnée dais son catalogue en la reportant à sa place. Nous pensons de même que le Conus vicarius de Lamarck n'est autre qu'une variété du Conus amiralis. On retrouve tous les caractères de celui-ci dans cet individu qui, cependant, ut' paraît pas être en état parfait de conservation.

1r3. CONE DE RUMPrIUS. Conus acuminatus, Bheg.

(Collect. Lam.) Rumpr. Mus. t. 54, fig. F. Pl. XXXIX, fig. 1-1, $1_{b}$.

C. testâ turbinatâ, albâ, fusco-reticulatâ, subfasciatâ; maculis albis trigonis ; spirâ subcanaliculatâ, acutâ.

Coquille turbinée, à spire élevée en angle aigu, composée de neuf tours lisses, subcanaliculés, formant une légère saillie les uns au-dessus des autres; la suture est assez profonde et ondulée; la surface du dernier tour est presque lisse et l'on n'y voit les stries circulaires qu'à la base. L'ouverture est plus étroite vers son milieu, l'échancrure supérieure est profonde, le bord droit tranchant; il est ponctué de brun sur toute la longueur. Les couleurs qui ornent cette coquille consistent en veines très-fines formant un réseau à mailles médiocres et triangulaires d'un brun fauve ou marron foncé, quelquefois d'un brun violâtre sur un fond blanc. Sur ce réseau on aperçoit quelques taches longitudinales plus foncées et composées de mailles beancoup plus petites que celles du réseau : ces mailles sont rondes ou ovales. Les taches, ordinairement disposées en deux zones, dont l'une est placée un peu au-dessus du milieu de la coquille et 
l'autre, plus étroite, vers le tiers inférieur, sont séparées entre elles par la zone treillissée du fond, marquée de traits bruns arrondis qui forment des séries transverses. La spire est marbrée de blanc et de brun noirâtre.

\section{Long. 43 millim.}

Habite les mers des grandes Indes, surtout celles des Moluques.

Espèce de grandeur médiocre, commune dans les collections, assez variable dans la disposition de ses couleurs. La variété fig. 1a, ressemblant à la précédente dans toutes ses parties, n'en est distincte que par le réseau de sa surface, qui est plus lâche avec de larges taches fauves le cachant en partie. La fig. 1b a une forme plus étroite; la coloration du fond est roussâtre, traversée par plusieurs cordons ponctués de blanc. Les mailles du réseau y sont à peine visibles.

114. CONE ÉCLATR. Conus flammeus, LAM.

$$
\text { (Collect. LaM.) Encyclop. pl. 336, fig. } 1 .
$$

Pl. XXIII, fig. 1.

C. testấ turhinatâ, basi striatâ, lineisque punctatis notatâ, albidâ vel flavescente; flammis longitudinalibus fulvis ; spirâ obtusâ.

Coquille conique, à spire élevée en angle obtus, aplatie vers sa circonférence et mucronée au centre; on y compte dix tours dont la superficie est lisse et luisante et bordée d'un léger talus. Les deux derniers sont légèrement concaves; le dernier est très-atténué à sa base, lisse sur sa moitié supérieure; le reste de la surface est marqué de stries circulaires bien distinc- 
tes et comme tremblées, plus serrées vers le bas. L'ouverture est étroite, blanche dans le fond; l'échancrure supérieure est faible et arrondie. La coquille est d'un fond blanc orné d'un grand nombre de lignes transverses de points fort rapprochés, de couleur marron ou jaunâtre ; ces lignes sont presque constamment traversées dans leur longueur par des flammules de la même teinte, onduleuses et irrégulières. Ces flammules occupent le plus souvent toute la longueur du dernier tour, mais il arrive aussi qu'elles s'interrompent à la base et.laissent voir alors distinctement les rangs circulaires de taches. La spire est marquée de taches plus ou moins larges d'un brun mêlé de fauve.

$$
\text { Long. } 50 \text { millim. }
$$

Habite les mers d'Afrique.

Ce Cône est fort rare. Lamarck y a vait rapporté la figure du Conus lorenzianus de Chemnitz, ce qu'ont fait aussi dernièrement MM. Reeve et Deshayes; cependant le Conus lorenzianus se distingue surtout du Conus flammeus, en ce que sa surface n'est pas traversée par des lignes nombreuses de points; ses flammules sont moins nombreuses et plus distinctes; en outre, il est généralement plus petit.

115. CONE DE LORENz. Conus lorenzianus, GHEM.

(Collect. de M. Delessert.) Chemn. Conch. vol. ii, pl. 181, fig. 1754, 1750.

Pl. LV, fig. 1.

C. testâ oblongo-turbinatâ, transversim striatâ, albidâ , lineis longitudinalibus rufescentibus notatâ; spirâ exsertâ, et basi punctis rubicundis punctatâ.

Coquille oblongue, turbinée, à spire élevée, mu- 
cronée, composée de neuf tours lisses, séparés les uns des autres par une suture onduleuse bien prononcée; le dernier est garni de stries transverses superficielles; celles de la base qui est très-étroite, sont plus espacées et plus profondes. L'ouverture est très-étroite, à bords parallèles dans toute sa longueur ; son échancrure sıpérieure est peu profonde. Cette coquille est d'un fond blanc grisâtre sur lequel sont tracées de grrandes flammules longitudinales étroites, ondulées et irrégulières, d'un roussâtre un peu foncé. Ces flammules sont rarement réunies entre elles; des taches inégales de même couleur se montrent sur la spire.

\section{Long. 38 millim.}

Habite la mer du Sud, les côtes d'Acapulco.

Cette coquille a beaucoup d'analogie avec la précédente; cependant elle en est distinctè par des caràctères constants et par sa coloration.

116. CONE ÉTAGÉ. Conius gradatus. Grax.

(Collect. de M. Largluert.) Reeve, Conch. icon. pl. 25. fig. 140.

Pl. XCIV , fig. 6.

C. testâ elongato-turbinatâ, læviusculâ, albidâ, rubido-fusco longitudinaliter inquinatâ ; spirâ turrito-exsertâ ; apice valdè elato.

Coquille turbinée, lisse, à spire très-allongée, turriculée, formée de onze ou douze tours graduellement étagés, carénés dans le milieu, subcanaliculés en dessus; 
la partie supérieure du dernier est large et carénée ; la base est atténuée; sa superficie n'offre que des stries longitudinales d'accroissement. Le bord droit est mince et tranchant, arqué dans sa. Iongueur; son échancrure supérieure est assez profonde. La coquille offre, sur un fond blanc, de grandes marbrures ou flammules longitudinales irrégulières, onduleuses, quelquefois ramifiées. Ces flammules sont d'un brun caunelle, bordées de jaunâtre. La spire, comme le reste de la superficie, est marquée de taches oblongues qui sont le prolongement des flammules.

\section{Long. 80 millim.}

Habite les côtes du Mexique.

Cette espèce, très-remarquable, semble se rapprocher du Conus generalis; elle est plus grande, la spire plus allongée et forme plus du tiers de la longueur totale; sa base est plus large. Nous devons à l'obligeance de M. Largilliert, de Rouen, la connaissance d'un individu plus petit que celui que nous avons fait représenter. Celui-ci est une copie du type de M. Reeve.

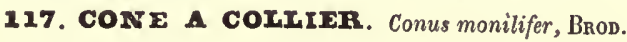

(Collect. de M. Delessert.) Sowerby, Conch. illust. fig. 37. PI. XCIII, fig. 1.

C. testâ subfusiformi, turbinatâ, transversim striatâ, albicante, castaneo-variegatâ, punctis castaneis numerosis seriatìm cinctâ; spirâ valdè acuminatâ, cas-
taneo-maculatâ.

Coquille subfusiforme, turbinée, à spire très-élancée, conique, composée de onze tours légèrement con- 
caves dont le dernier est circonscrit par un angle assez aigu. Ce tour, légèrement ventru vers sa partie supérieure, s'atténue presque subitement à sa base ; toute sa surface est striée. Cette coquille, dont le fond est d'un blanc gris, est ornée d'un assez grand nombre de lignes transverses, composées de petites taches d'un brun assez foncé; affectant quelquefois une forme en croissant; outre ces lignes, le dernier tour porte un petit nombre de larges taches ou de flarnmules d'un brun roussâtre, irrégulièrement distribuées. La spire est marquée de taches allongées, d'un brun foncé, alternant avec les tảches plus grandes du fond de la coquille.

Long. 40 millim.

Habite Salango dans l'Amérique du Sud.

Cette espèce, assez rare encore dans les collections, est très-différente des précédentes par la disposition des séries nombreuses de petits points dont elle est munie, et par sa coloration.

118. CONE SANGIÉ. Conus cingulatus, Lam.

(Collect. de M. Delessert.)

Pl. XCIII, fig. 2.

G. testâ turbinatâ, transversim striatâ, albidã, fulvo-maculatâ, flammis fulvis longitudinalibus pictâ ; cingulis transviersis albo fulvoque articulatis; spirâ acuminatâ variegatâ.

Coquille conique, turbinée; la spire est lisse, aiguë, composée de dix tours légèrement arrondis et à suture 
bien distincte. Toute l'étendue du dernier est garnie de stries tranversales un peu espacées, dont les intervalles forment de petites cordelettes aplaties; la partie supérieure de ce tour est circonscrite par un angle obtus et sa basè est atténuée. Les stries sont plus prononcées vers cet endroit. L'ouverture est fort étroite, d'un blanc violacé. La coloration de cette espèce est blanchâtre : elle présente un très-grand nombre de séries transverses de points fauves, subquadrangulaires et comme articulés. Ces séries sont alternées par d'autres lignes depoints beaucoup plus fins; des flammules ou des maculations longitudinales anguleuses, de même couleur que les points, garnissent tout le dernier tour du haut en bas. La spire est maculée deblanc etdemarron.

\section{Long. 45 millim.}

Habite l'océan Indien.

II. Reeve, dans son Conch. illustr., pl. 27, fig. 158, a donné comme C. cingulatus de Lam. une coquille toute différente de l'espèce type et à laquelle nous avons donné le nom de $C$. undatus, à cause de la disposition des lignes dont elle est ornée.

119. CONE CarNoIS. Conus sinensis, Sow.

(Collect. de M. Borviv.) Sow. Conch. illust. fig. 56.

Pl. LXXI, fig. 1.

C. testâ obtuso-fusiformi, transversìn sulcatâ, sulcis interdùm latis, subtilissimè pertusis; albidâ, fusco pallidè maculatâ et variegatâ; labro tenui, acuto, juxtà spiram emarginato; spirâ valdè elatâ, striatâ, angulato-carinatâ; apice mucronato.

Coquille turbinée, à spire élancée, conique, très- 
pointue au sommet, composée de dix ou douze tours, dont les premiers sont légèrement carénés au milieu ; les suivants sont un peu aplatis, formant saillie les uns au-dessus des autres; le dernier est conique, très-atténué à sa base; sa surface est garnie presque entièrement de stries assez larges et peu profondes. L'ouverture est étroite, blanchâtre dans l'intérieur. Le bord droit est mince et tranchant; il s'arrondit en avant et se détache, vers sa partie supérieure, par une échancrure profonde. La coloration de cette coquille consiste en un fond blanchâtre, varié d'un grand nombre de séries transverses de points bruns, plus on moins allongés, formant quelquefois des lignes interrompues et des flammules longitudinales nuagenses, souvent peu apparentes. La spire est tachetre de brun et de blanc: les taches sont alternées et à peu près égales.

$$
\text { Long. } 52 \text { millim. }
$$

Habite les mers de la Chine.

Ce joli petit Cône a tant d'analogie avec le précédent, qu'il ne pariłt en être distinct que par sa taille, qui est moindre, et par l'échancrure du sommet de l'ouverture, qui est plus large et plus profonde. Aussi pensons-nous que l'on devra réunir ces deux espèces. 
120. CONE RÉTrcuxé. Cónus reticulatus. Sow.

(Collect. de $\mathrm{M}^{\mathrm{me}}$ Dupont.) Sow. Conch. illust. fig. 86.

Pl. LXVI, fig. 5.

C. testâ turbinatâ, solidâ, albido-griseâ, lineis transversim bruneis aut fuscis, subdistantibus interdùm interruptis, interstitiis lineis longitudinalibus brevibus, arcuatis, subirregulariter reticulatâ ; ultimo basi suleato ; spirâ convexo-obtusâ, lævi, maculis fuscis tessellatis.

Coquille turbinée, assez épaisse, lisse, à spire conique, pointue au sommet, formée de neuf ou dix tours étroits, dont les derniers sont légèrement creusés. La suture est simple et bien distincte. Le dernier tour est régulièrement conique, muni seulement à sa base de plusieurs sillons transverses espacés entre eux. La coloration de cette coquille est très-agréable; le fond grisblanc est orné d'un réseau formé de lignes círculaires bien distinctes d'un brun rougeâtre, et d'un grand nombre de petites linéoles longitudinales de couleur fauve, droites ou obliques, assez fines, souvent arquées: elles n'ont rien de régulier ni de constant dans leur forme ou leur longueur; le plus ordinairement elles sont circonscrites dans l'intervalle des lignes circulaires qui sont quelquefois interrompues par le prolongement de ces linéoles; des taches de forme irrégulière et d'un brun violacé ornent aussi la convexité du dernier tour. La spire est marquée de quelques maculations et de linéoles fauves ou d'un brun violacé.

Long. 40 millim.

Habite 
Cette jolie espèce, encore rare, est bien facile à reconnaître par la disposition particulière de sa coloration.

121. CONE MAGISTRAT. Conus archon. Brod.

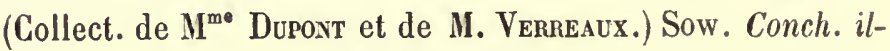
lust. fig. 38 .

Pl. LXXV், fig. 3, et pl. GIV̄, fig. 4 .

C. testâ conicâ, albâ, maculis grandibus flavo-castaneis longitudinaliter nebulosâ, puncticulis albis subdistantibus tœeniatis; spirâ subconcavo-exsertâ, apice acutissimè acuminato.

Coquille conique, lisse, à spire aiguë, légèrement comprimée sur les côtés et composée de neuf ou dix tours plus ou moins canaliculés; il existe quelques stries transverses peu profondes et granuleuses à la base du dernier. La coloration de cette coquille est d'un fond blanc, couvert en grande partie de larges taches ou flammules déchiquetées, d'un fauve clair ou marron ; ces taches se prolongent du haut en bas du dernier tour en se rétrécissant vers différents points. La surface est en outre traversée par un grand nombre de cordons étroits, bruns, articulés de points blancs arrondis; le dernier tour est aussi orné de plusieurs fascies transverses dues à la coloration du fond, la fascie du milieu de la convexité est toujours la plus large : toutes sont traversées par les taches réduites en flammules étroites. La coloration de la spire diffère peu de celle du dernier tour : elle est variée de taches blanches ou d'un brun fauve, mais elle n'a pas de lignes articulées. 
Long. 42 millim.

\section{Habite les côtes du Mexique.}

Cette espèce est l'une des plus rares du genre. Elle a tellement de ressemblance avec le Còne cedonulli, qu'on serait tenté de la regarder comme une simple variété de celui-ci. La seule différence véritable qui peut l'en séparer est de n'avoir jamais sa spire couronnée. Ses cordons articulés présentent aussi quelques changements. Nous avons fait représenter sur notre pl. 104, fig. 4, un individu d'une très-grande dimension que nous devons à l'obligeance de M. Verreaux, et qui depuis, a été acquis par M. Wilson:

122. CONE SPIINDIDE. Conus splendidulus. Sow.

(Collect. Masséna.) Sowerby. Conch. illust. fig. 53.

Pl. XXXV, fig. 2.

C. testâ turbinatâ, solidiusculâ, luteo-fulvâ albogue alternatim fasciatâ, lineis fuscis subflexuosis, plùs minùsve interruptis, vividè cinctâ; spirâ conicâ, acutâ, arfractuum marginibus nigro-flammeâ.

Coquille turbinée, dilatée à sa partie supérieure ; sa spire est conique, pointue au sommet, formée de neuf ou dix tours légèrement convexes, à sutures peu profondes. Toute la coquille est lisse, excepté la base du dernier tour qui est ornée de quelques stries transverses. L'ouverture est étroite, à bords parfaitement parallèles; le bord droit est mince et tranchant, détaché vers son sommet de l'avant-dernier tour par une échancrure peu profonde. La coquille est 'd'un fond jaune plus ou moins foncé; le dernier tour est traversé par un grand nombre de lignes interrompues le plus souvent par des portions de lignes blanches; 
on remarque aussi trois zones blanches sur ce tour; la première est située vers sa partie supérieure, la seconde au-dessus de son milieu, et la troisième audessus de sa base qui est brune. La spire est blanche et ornée de larges taches ou flammules noires.

\section{Long. 54 millim.}

\section{Habite}

L'ensemble de cetle espèce lui donne la plus grande analogie avec la suivante ; cependant elle est d'une taille moins considérable, et les lignes transverses interrompues de son dernier tour sont tout à fait différentes.

123. CONE CENTURION. Conus centurio. BonN.

( Collect. Lam.) Bonn. Mus. t. 7, fig. 10.

Pl. XXXVI, fig. 2-2*.

C. Testâ turbinatâ, supernè dilatatâ, basi sulcatâ, albâ, fasciis tribus rufo-fuscis ramosis undulatis; spirâ concavo-convexâ.

Coquille turbinée, large vers le haut, très-atténuée à sa base; la spire est élevée en angle obtus et composée de dix ou douze tours légèrement concaves et à hords carénés, graduellement élevés les uns au-dessus des autres. La coquille est lisse, excepté la base du dernier tour qui présente des sillons circulaires dont les interstices ressemblent assẹz, par lẹr saillie, à de grosses cordelettes aplaties. L'ouverture est étroite, d'un blanc grisâtre; le bord droit très-mince et tranchant, arqué en avant et détaché des tours, vers sa 
partie supérieure, par une échancrure profonde. La coquille est d'un fond blanc, orné de trois fascies d'un jaune plus ou moins foncé; la première occupe lehaut du dernier tour, la seconde est située vers son milieu, la troisième vers sa base; celle-ci est la plus large : ces fascies sont marbrées de veines ou flammules irrégulières, souvent entrelacées ou rameuses, et d'un rouge brun.

Long. 43 millim.

Habite les mers des Antilles.

Cette espèce est remarquable par sa forme turbinée et la disposition de sa coloration. Elle offre une variété dont la forme est moins turbinée et le fond de coloration roussâtre. Les fascies sont souvent interrompues sur cette variété par des flammules beaucoup plus étroites et plus nombreuses. (Yoir même planche, fig. 2a. )

124. CONE A TACEES ROUSses: Conus lentiginosus. Reeve.

(Collect. de $\mathbf{M}^{\mathrm{me}}$ Dupont.) Ftreve. Conch. icon.pl. 44, fig. 245.

Pl. LXXXVIII, fig. 3.

C. testâ subfusiformi turbinatâ, tenuiculâ, lævi, basim versus sulcatâ, sulcis latiusculis, profundis ; albidâ, fuscescente lentiginosâ et punctatâ ; spirâ elatâ ; anfractibus acutangulis.

Coquille subfusiforme, turbinée, à spire lisse, régulièrement conique, composée de dix tours étroits, à peine creusés en gouttière; 'leur bord.inférieur est légèrement caréné. La surface du dernier est occupée par des stries transverses régulières, distantes entre elles, au nombre de douze ou quatorze; la base de ce 
tour est munie de plusieurs larges sillons.-L'ouverture est étroite, le bord droit mince et tranchant, légèrement arqué dans sa longueur. Le fond de coloration de cette coquille offre une teinte blanchâtre, ornée d'un grand nombre de petits points bruns qui sont placés sur les stries circulaires. On voit encore sur toute la surface, de larges taches rousses se prolongeant quelquefois en flammules. Les taches de la spire sont brunes et de forme quadrangulaire.

Long. 30 millim.

\section{Habite}

Cette Coquille est très-voisine de la précédente ; on pourrait même la prendre pour un jeune individu de cette dernière; cependant elle parait offrir des différences assez constantes : elle est toujours plus petite et sa coloration toujours distincte.

125. CONE AMBIGU. Conus ambigurs. ReEve:

(Collect. de M. Delessert.) Reeve. Conch. icon. pl. 44.

fig. 244 .

Pl. LXX, fig. 3.

C. testâ turbinatâ, lævi, basim versùs lirata, lineis subtilissimis, undatis, longitudinalibus, subobsoletè incisis; albâ, pallidè fuscescente tinctâ; spirâ obtusoconvexâ, leviter canaliculatâ, maculis arcuatis fuscescentibus ornatâ, apice mucronato, elato.

Coquille régulièrement conique, à spire assez large, convexe, formée de dix ou douze tours un peu concaves dans leur milieu, séparés entre eux par une suture linéaire assez profonde; le sommet est saillant, fort 
pointu. La surface paraît lisse, quoique très-finement striée; seulement à la base l'on remarque des sillons tranverses égaux, également distants entre eux; les bords de l'ouverture sont parallèles; le bord droit est mince, tranchant, faiblement arqué dans sa longueur. Sous un épiderme verdâtre, cette coquille est blanche, marquée de plusieurs zones transverses inégales, d'une teinte plus pâle. La spire est souvent ornée de petites zones obliques d'un brun pâle.

$$
\text { Long. } 34 \text { millim. }
$$

\section{Habite}

Ce Cône, par sa forme, ressemble beaucoup au $C$. Largillertii, mais il s'en distingne, au premier aspect, par sa coloration uniforme.

126. CONE TBEIrIISSÉ. Conus cancellatus. Brug.

(Collect. de M. Delessert.) Encyclop. méth. pl. 338. fig. 1. Pl. LXXVI, fig. 4.

C. testà turbinatâ, sulcis transversis striisque profundis longitudinalibus decussatim cancellatâ, albâ, spirâ acuminatâ.

Coquille allongée, turbinoïde, fortement rétrécie vers la base; sa spire est conique, subturriculée, formée de douze ou quatorze tours étroits, un peu élevés les uns au-dessus des autres, légèrement concaves vers leur milieu et bordés par un talus assez aigu. Chacun de ces tours offre quatre ou cinq stries circulaires saillantes et serrées, traversées par d'autres stries longitudinales plus fines; le dernier est régulière- 
ment conique; toute sa surface est traversée par des stries circulaires onduleuses, et présente aussi des stries longitudinales d'accroissement. L'ouverture est assez étroite, le bord droit, mince, tranchant, faiblement arqué vers sa partie supérieure, qui est terminée par une échancrure peu profonde. La coloration de cette espèce est d'un blanc grisâtre uniforme.

\section{Long. 42 millim,}

Habite l'océan Pacifique sur' les côtes de l'île d'Owhyhée.

Bruguières regarde ce Còne comme l'analogue vivant du $C$. perdu, que l'on trouve en France dans l'état fossile. Il a cependant des caractères qui paraissent suffisants pour l'en rendre distinct: ses stries sont plus nombreuses, plus apparentes, et la saillie des tours est différente.

127. CONE INTERROMPU. Conus interruptus. BRodERIP.

(Collect. du Mus.) Gray. Zool. Bech. Voy. pl. 55, fig. 2.

Pl. LIV, fig. 2.

C. testâ subgracili, albidâ, spadiceo-nubilâ, tæniis frequentibus spadiceis albointerruptis cinctâ, ad basim striatâ; spirâ mediocri, simplici; labro recto, crenulato.

Coquille allongée, subcylindracée, à spire régulièrement conique, formée de dix tours conjoints et légèrement aplatis; le dernier circonscrit la base de la spire par un angle obtus. Toute la coquille est lisse, excepté la base du dernier tour qui est garnie de sillons transverses dont les derniers sont très-profonds. L'ouverture est étroite, un peu arquée dans sa lon- 
gueur, d'un rose pourpré en dedans. Le fond de coloration de cette coquille est blanc, et il s'y détache un grand nombre de lignes transverses formées de points bruns plus ou moins allongés ou subquadrangulaires ; souvent des lignes de points beaucoup plus petits, alternent avec les premières; outre ces lignes, la surface est aussi munie de grandes taches longitudinales et transverses, nuageuses sur leur bord et d'un brun assez foncé.

\section{Long. 52 millim.}

\section{Habite l'océan Pacifique.}

Cette espèce est facilement distincte par sa coloration, quoiqu'elle ne manque pas d'analogie avec le $\boldsymbol{C}$. puncticulatus de Bruguières, mais celui-ci est bcaucoup plus petit et de forme différente.

128. Cons IOUPIE. Conus tornatus. Broderip.

(Collect. de M. Delessert.) Sowerby. Couch. illust. fig. 25. Pl. LIX, fig. 5.

C. testâ elongato-turbinatâ, subfusiformi, leviter sulcatâ; spirâ valdè elatâ, turrito-acuminatâ, apice acuto; albâ, fusco-nigricante bifasciatìm nebulosâ, punctis fuscis irregularibus ubiquè cinctâ.

Coquille allongée, étroite, à spire très-proéminente et fort aiguëau sommet, régulièrement conique, formée de neuf ou dix tours légèrement concaves et subanguleux à leur base; la suture est bien distincte et enfoncée. Le dernier tour est atténué et strié à sa base; le reste de la coquille est lisse. La coloration consiste 
GENRE CÔNE.

en lignes transverses nombreuses, formées de points d'un brun violacé; ces lignes ressortent sur le fond de la coquille qui est d'un blanc légèrement violet; en outre, un grand nombre de taches ou flammules longitudinales, également d'un brun violet, se prolongent d'une extrémité à l'autre de la surface et sont interrompues vers le milieu du dernier tour par une zone blanche.

\section{Long. 58 millim.}

Habite l'océan Pacifique.

Ce Cồne, publié pour la première fois par M. Broderip dans les Proceedings, 1833, page $\mathbf{5 3}$, a infiniment de ressemblance avec le précédent; il ne devra sans doute être envisagé que comme une variété de ce dernier. Les seuls caractères différents qu'on y puisse trouver sont ceux-ci : la spire plus proéminente et les tours plus détachés; sa coloration est presque semblable.

129. CONE DE IA MER ROUGE. Con ss erythrcensis. Веск.

(Collect. de $\mathrm{M}^{\mathrm{me}}$ Dupont.) Reeve. Conch. icon. pl. 24. fig. 127.

PI. LXXI, fig. 4.

C. testâ turbinatâ, lævi, albidâ, maculis rubido-fuscis numerosis, irregulariter subquadratis, interdùm bifasciatim confluentibus, seriatim cinctâ; spirâ exsertâ, læviter canaliculatâ, rubido-fusco densissimè tessellatâ; apice acuto, aperturæ fauce violaceâ.

Coquille turbinée, un peu ventrue, à spire conique, composée de neuf ou dix tours; les premiers sont carénés, les suivants sont conjoints et à peine concaves : ils portent un petit nombre de stries concentriques. Le dernier présente à sa base quelques sillons peu 
profonds dont quelques-uns remontent jusque vers le milieu du tour, mais ceux-ci sont plus fins etplus écartés entre eux. L'ouverture est étroite, un peu dilatée à sa base, d'un blanc rosé ou d'un fauve très-pâle. Le bord droit est mince et tranchant, son échancrure supérieure est peu profonde. La spire est ornée de taches brunes, étroites, longitudinales, également espacées entre elles; sur le dernier tour, ces taches franchissent l'angle et viennent s'arrêter un peu au-dessous. Le reste de la surface est orné sur un fond blanc de lignes transverses formées par des ponctuations d'un brun roux assez foncé ; souvent la base est munie de taches confluentes.

$$
\text { Long. } 26 \text { millim. }
$$

Habite la mer Rouge.

Jolie petite espèce qui avoisine quelques variétés du Conus puncliculatus, mais très-distincte par des caractères constants.

130. CONE ACUTANGIE. Conus acutangulus. ChEnN.

(Collect. du Mus.) Chemv. 11. t. 182. fig. 1772-1773.

Pl. LXXII, fig. 1.

C. testâ oblongo-turbinatâ, subfusiformi, transversim sulcatâ, albidâ, fulvo vel rubro maculatà ; sulcis punctato pertusis; spirâ elevatâ, peracutâ.

Coquille petite, oblongue, turbinée, fusiforme, à spire conique, très-pointue', composée d'un grand nombre de tours striés circulairement, bordés par un angle plus ou moins granuleux; le dernier est 
très-atténué vers sa base et toute sa surface offre des sillons transverses munis de points enfoncés. L'ouverture est fort étroite, le bord droit, arqué dans sa longueur, peu échancré à son extrémité supérieure. La coquille est blanche, ornée de taches ou de flammules longitudinales de couleur orangée ou rougeâtre; ces taches sont quelquefois assez larges et forment deux zones interrompues sur le dernier tour.

\section{Long. 28 millim.}

\section{Habite les mers du Japon.}

Les plus grands rapports existent entre cette 'coinuille et le $C$. sinensis, de Sowerby; elle a à peu près la même forme, mais elle est toujours plus petite et plus acuminée à ses deux extrémités; en outre, ses tours de spire et ses sillons circulaires sont propres à la faire parfaitement distinguer.

131. CONE DExesser. Conus Delessertii. Recluz.

(Collect. de M. Delessert.) Magasin de Zoologie, 1845, pl. 72.

PI. XXIII, fig. 2.

C. testâ obeso-fusiformi, ad basim sulcatâ, sulcis prominentibus; albido lutescente, fasciis tribus rubido aurantiis cinctâ, maculis rubidis rhomboidibus minutis per totum aspersâ, maculis super fuscias majoribus, interdùm longitudinaliter confluentibus; spirâ valdè elatâ, subcanaliculatâ; maculis rubidis vividè aspersâ, apicc mucronato, acuto ; labro tenuisculo, arcuato, juxtà spiram emarginato.

Coquille turbinée, fusiforme, à spire conique, trèsallongée, à sommet aigu, formée d'un grand nombre de tours anguleux à leur base et légèrement creusés 
dans leur milieu; les premiers sont granuleux, le dernier est atténué à sa base, qui est sillonnée transversalement. L'ouverture est blanche, très-étroite, surtout vers son milieu; le bord droit, mince et tranchant, est fortement arqué en avant et détaché de l'avant-dernier tour à sa partie supérieure par une échancrure profonde. La coloration de la surface est d'un rose arrivant au roussâtre ou au jaunâtre, peinte de points plus ou moins carrés, de couleur marron, devenant quelquefois confluents et formant alors des flammes longitudinales obliques; ces flammules sont coupées sur le milieu du dernier tour par deux larges fascies blanches marquées de points, également de couleur marron. La spire est d'un jaune orangé, flammulée de marron foncé.

\section{Long. 60 millim.}

Habite la mer Rouge, près des côtes de l'île de Socotora.

Cette Coquille est une des plus belles connues du genre cône; elle est bien distincte par sa forme toute particulière.

132. CONE $\triangle$ RQUÉ. Conus arcuatus. Brod.

(Collect. de $\mathrm{M}^{\text {me }}$ Dupontr.) Sowerby. Conch. illust. fig. 9. Pl. LXXII, fig. 5.

C. testâ fusiformi, albidâ, castaneo-marmoratâ ; striis et labio spiram versủs marginato-arcuatis, spirâ mediocri, carinatâ.

Coquille conique et ventrue vers son milieu, atténuée vers ses deux extrémités, à spire allongée, très- 
pointue, formée d'un grand nombre de tours un peu concaves, carénés à leur circonférence et au-dessus de la suture qui est linéaire et à peine apparente; toute la surface du dernier est ornée de stries transverses assez profondes, étroites, également distantes entre elles. L'ouverture est très-étroite; le bord droit mince, arqué dans sa longueur et échancré à son sommet près de la spire. La coquille est d'un fond blanchâtre orné de flammules anguleuses, irrégulières, peu nombreuses et d'un brun marron; ces flammules se continuent quelquefois du haut en bas du dernier tour; souvent elles sont interrompues, vers son milieu, par des ponctuations de même couleur.

Long. 55 millim.

Habite l'océan Pacifique.

Cette espèce fort remarquable est rare encore dans les collections. Elle est parfaitement distincte de toutes ses congénères, quoiqu'il existe cependant un peu de ressemblance de forme entre elle et la précédente.

133. CONE A SPIRAIE. Conus scalaris. Valesc.

(Collect. du Mus.)

Pl. LXXXVIII, fig. 5.

C. testâ oblongâ, fusiformi, subtiliter costigerâ, albidâ, rufo longitudinaliter variegatâ; anfractibus ad basim angulatis, et in spiram scalarim decurrentibus; spirâ conicâ, acutâ.

Coquille allongée, fusiforme, à spire très-pointue, composée de neuf tours étroits, carénés à leur base en 
rampe spirale aplatie, séparés par une suture légèrement creusée. Le dernier tour est faiblement ventru vers le haut. Toute.la surface de la coquille est munie de stries verticales peu distinctes et de stries transverses pointillées, étroites, également distantes entre elles. L'ouverture est fort étroite; le bord droit mince et arqué. La coquille, d'un fond blanc, est maculée de grandes taches jaunâtres plus ou moins irrégulières; quelques-unes forment des flammules longitudinales. Sur la spire, les taches sont plus foncées et plus régulières.

\section{Long. 28 millim.}

Habite la mer Pacifique, sur les côtes d'Acapulco.

Cette espèce, décrite pour la première fois par M. Valenciennes (Coquilles vivantes, Voyage de MM. Humboldt et Bompland, p. 338), a beaucoup d'analogie avec le Conus acutangulus; elle en est distincte cependant par sa forme, plus étroite et plus élancée.

134. CONE FOODROYANT. Conus fulgurans. BRUG.

Encyclopédie. pl. 537. fig. 3.

Pl. CI , fig. 4.

C. testâ ovato-turbinatâ, basi scabrâ, albidâ; maculis longitudinalibus flexuosis guttisque ferrugineis transversis ; spirâ convexo-acutâ.

Coquille ovale, turbinée, élevée en aigle aigu, composée de onze tours bien distincts, ordinairement lisses, un peu concaves et un peu saillants les uns audessus des autres; le dernier se rétrécit à sa base, qui 
est garnie de sillons bien distincts, ce qui la rend raboteuse. L'ouverture est échancrée à son extrémité supérieure, blanche dans le fond; le bord droit est mince et tranchant; il est marqué d'une ligne fauve tachetée de brun. La coloration de la coquille est d'un fond blanc, peint de plusieurs rangs circulaires de points ronds ou ovales, de couleur brune ou marron foncé; ces rangs sont rapprochés entre eux et traversés, dans toute leur longueur, par des flammules souvent entrelacées ou en zigzags, de même couleur que les points. Souvent ces flammules ornent toute la coquille; d'autres fois elles s'interrompent à quelque distance de la base, où l'on aperçoit alors plus distinctement les rangs circulaires de points. La spire est marbrée de marron sur un fond blanc ou de brun mêlé de fauve; le bord de ses tours offre un rang de taches semblables aux flammules, mais beaucoup plus petites.

\section{Long. 40 millim.}

Habite les côtes d'Afrique.

Cette coquille, qui a été décrite et figurée pour la première fois par Bruguières dans l'Encyclopédie, paraît extrêmement rare, puisque depuis cette époque on ne la voit citer dans aucune autre collection que celle de M. Hwass. Aussi, pour la reproduire ici, nous avons été forcé de copier la figure et la description de Bruguières. La figure citée de l'ouvrage de Martini, t. II, pl.š, fig. 644, parait plutôt appartenir au Conus fammeus de Lamark. 
135. CONJE NARCISSE. Conus narcissus, LaMaRCK.

(Collect. Lam.) Réve, Conch. icon. pl. 27, fig. 155.

Pl. LII, fig. 4.

C. testâ turbinatâ, aurantiâ, albo-maculatâ; fasciâ albâ; interruptâ ; spirâ obtusâ, striatâ, variegatâ.

Coquille turbinoïde, à spire peu élevée, conique, composée de huit ou neuf tours légèrement aplatis, et striés; le dernier est conique, élargi vers son sommet et rétréci à son extrémité inférieure qui est munie de stries assez nombreuses et profondes; le reste de la surface est lisse. Le fond de la coquille, d'un jaune orangé, est orné de taches d'un blanc de lait, de forme variable, arrondies ou oblongues: ces taches sont assez nombreuses, espacées entre elles et presque disposées en bandes, soit transversales, soit longitudinales, le plus souvent réunies par de petits filets fauves; une large fascie, formée de taches irrégulières blanches, déchiquetées sur leur bord, est placée audessous du milieu du dernier tour. La spire est blanchâtre, flambée de fauve et d'orangé.

\section{Long. 48 millim.}

Habite les mers des îles Philippines.

Joli cône bien distinct par śa coloration ; il est encore rare dans les collections. Sa forme parait se rapprocher de celle du Conus consort. 
136. CONI SAFrañ́. Conus crocaius. Lam.

(Collect. Lam.) Reeve, Conch. icon. pl. 1, fig. 6.

Pl. LII, fig. 3.

C. testâ oblongó-turbinatâ, aurantiâ, mạculis albis subtrigonis fasciatim sparsis; striis transversis obsoletis; spirâ convexo-acutâ.

Coquille subfusiforme, à spire conique, saillante, composée de neuf tọurs convexes, bien distincts les uns des autres, finement striés circulairement; le dernier est conique, aplati yers son extrémité supérieure, effilé dans sa longueur; presque toute sa surface est garnie de stries transverses fines et serrées; celles de la base sont plus profondes. Le fond de la coquille est d'un beau jảunẹ orangé, parsemé de taches blanches, les unes trigones, les autres arrondies ou ovales; ces taches sont éparses, peu nombreuses, quelquefois groupées; les taches de la spire sont plus grandes et allongées.

\section{Long. 50 millim.}

\section{Habite l'océan Américain.}

Cette espèce a beaucoup d'analogie avec la précédente; elle en est cependant bien nettement distincte par sa forme plus étroite, et surtout par ses taches moins nombreuses et plus petites. 
137. CORE AILE DE PAPITLON. Conus genuanus. Lix:

( Collect. Lam.) Listek, Conch. t. 769, fig. 17, B.

Pl. XVIII, fig. 2.

C. testâ turbinatâ, albido-roseâ, tæniis inæequaliḅus fusco alboque articulatis cinctâ ; spirâ plano-obtusầ, mucronatâ.

Coquille turbinée, épaisse, lisse; la spirè, élevée en angुle obtus, a son sommet pointu et mucroné; elle est formée de douze ou quatorze tours dont la superficie, très-légèrement concave, s'arrondit vers le bord supérieur; le sillon des sutures est peu profond, l'ouverture blanchâtre, assez étroite. L'échancrure supérieure est peu profonde et le bord droit tacheté de marron à l'intérieur. La coquille est d'un fond blanchàtré, orné d'une 'teinte rose très-délicate ou quelquefois d'un fauve clair; elle est entourée de zones circulaires inégales, nombreuses, d'un beau blanc, assez régulièrement mouchetées de petites taches brunes, plus longues que larges et inégalement distantes entre elles; ces zones sont disposées de manière qu'une large zone est suivie d'une zone plus étroite, formée de points rapprochés les uns des autres et le plus souvent arrondis: La spire est ornée de quelques taches de couleur amaranthe et d'un cordon blanc ponctué de marron, situé sur le bord supérieur de chaque tour. 
GENRE CO̊NE.

Long. 58 millim.

Habite les mers des grandes Indes, des Moluques et du Sénégal.

Espéce très-belle, peu commune, recherchée à cause de l'élégance et de la vivacité de ses couleurs.

138. CONE BÜBANí. Conus toniatus. Brug.

(Collect. Lam.) Lister, Conch. t. 763, fig. 12.

'Pl. VIII, tig. 4.

C. testâ turbinatå; albâ, amethystino-zonatâ; lineis fusco albơque articulatis spirâ obtusâ; aperturâ cœrulescente.

Coquille turbinée; épaisse, lisse, un peu renflée vers son milieu; sa spire est obtuse, formée de neuf tours légèrement convexes. Le sillon des sutures est assez profond et bien distinct. L'ouverture est étroite et blanche, mêlée d'une légère teinte bleuâtre. Le bord droit est liséré de brun, son extrémité süpérieure est terminée par uné échancrure peu profonde et oblique. La coquille est blanche, marquée de trois fascies d'un violet clair; ces fascies et tout le fond de coloration sont garnis de douze ou quinze lignes transverses articulées de taches blánches d'un brun noirâtre, plụ écartées les unes des autres sur les parties blanches de la coquille que sur les fascies; le plus sonvent, les taches brunes sont larges et flammulées; quelquefois une série de petits points bruns alternent 
ces lignes transverses. La spire est d'une teinte plus claire.

Long. 45 millim.

Habite les mers de Chine.

Coquille fort jolie et peu commune; ses petites taches noires et carrées, disposées en lignes transverses, ont été comparées à des notes de musique.

139. CONE PROTÉE. Conus proteus. BRvG.

(Collect. Lay.) Rumpr. Mus. t. 54, fig. M.

Pl. XLII, fig. 2, 2a.

C. testâ turbinatâ, albâ; guttis aut lineolis fuscis vel fulvis laxis transversim seriatis maculisque irregularibus separatis fasciatim digestis; spirà canaliculatâ, subacuminatâ, variegata.

Coquille conique; sa spire est élevée en angle obtus, mucronée au centre; sa circonférence est aplatie; on y compte onze ou douze tours lisses, un peu concaves et bordés d'un léger talus; le dernier, ordinairement lisse, offre quelquefois cependant, des stries circulaires très-fines; celles de la base sont toujours plus apparentes, quelquefois très-prononcées. Lebord droit présente vers l'intérieur de l'ouverture une suite de taches peu apparentes qui correspondent à celles de l'extérieur; son sommet est muni d'une échancrure profonde. Le fond de la coquille est d'un beau blanc, orné de trois ou quatre rangs circulaires de grandes taches de forme 
bizarre et irrégulière; au-dessous de chacun deces rangs se trouve une ligne d'autres taches beaucoup plus petites, rondes ou ovales; toutes ces taches sont d'un marron brun ou noirâtre. La spire est panachée de taches semblables.

Long. 60 millim.

Habite l'océan Atlantique et les mers d'Amérique.

Ce cône a beaucoup de rapports avec le Conus leoninus; cependant on l'en distingue facilement, à cause de ses larges taches irrégulières. La variété représentée même planche, fig، $\mathbf{2}^{a}$, diffère du type par un plus grand nombre de séries de taches, moins grandes; elles varient aussi d'aspect : il y en a en forme de zigzags ou de flammules.

140. CoNs AIvíoxÉ. Conus alveolus. Sow.

(Collect. M. Delessert.) Sowerbì, Conch. illust. fig. 11 .

PI: LIX, fig. 2.

C. testâ oblongo-turbinatâ, subcylindraceâ, basim versùs sulcatâ, sulcis distantibus, subtilissimè striato-cancellatis; allbâ, maculis quadrangularis bruneis, bifasciatim confusis cinctâ ; spirầ concavo-elâtâ.

Coquille oblongue, turbinée; la spire est composée de dix ou onze tours étroits, légèrement concaves et bordés d'un tạlus assez saillant; ces tours sont marqués de plusieurs stries circulaires bien distinctes; le dernier paraît lisse et luisant, quoique orné d'un grand nombre de stries transverses et longitudinales extrêmement fines; sa base porte de longs sillons égaux 
dans leur écartement et leur profondeur et sur lesquels les stries sont plus apparentes. L'ouverture est étroite, d'un blanc teinté de violet. Le bord droit est. mince, à peine échancré vers le haut; il est bordé de taches interrompues, d'un fauve clair ou brun. Le fond de la coquille est blanc et on y voit treize ou quatorze rangs circulaires de taches brunes ou légèrement teintées de fauve; ces taches sont plus ou mioins régulières dans leur forme; celles de la première rangée sont toujours plus grandes et allongées; quelquefois les taches de plusieurs rangs se réunissent et présentent alors des espèces de fascies interrompues au-dessus et au-dessous du milieu du dernier tour.

\section{Long. 38 millim.}

Habite les mers des Moluques et des Philippines.

Cette espèce, àu premier aperçu, paraîtrait appartenir à quelques variétés du Conus proteus, mais elle en diffère d'une manière essentielle tant par sa forme plus cylindrique que par-le nombre de taches de sa coloration.

141. CONE MAIILOT. Conus voluminalis. Hinds.

(Collect. de M. Borvis) Reeve,Conch. icon. pl. 37, fig. 206.

PI. LXXI, fig. 5.

C. testâ turbinatâ, supernè validè acutangulâ, lævi, basin versủs sulcatâ, albâ, mraculis fuscis, perpaucis grandibus hieroglyphiis ḅiseriatim cinctâ ; spirâ concavodepressâ, striatâ.

Coquille conique, turbinée, à spire ássez large, courte, composée de douze tours étroits, légèrenent 
concaves et striés circulairement; le dernier est fort rétréci vers sa base qui est munie de sillons transverses, rapprochés les uns des autres; ceux qui garnissent la convexité de ce tour sont plus distants entre eux; lebord droit est mince, tranchant, sa partie supérieure est terminée par une échancrure profonde. La coloration de cette coquille consiste en séries transverses assez régulières de petites taches de forme plus ou moins carrée, d'un fauve pấle sur un fond blanc souvent aussi elle est ornée de quelques larges taches allongées d'un brun roux, ordinairement disposées en deux zones transverses.

\section{Long. 38 millim.}

Habite la mer des Indes, les côtes de Malaca.

Cette espèce ne manque pas d'analogie avec la variété du Conus proteus; sa forme est la même; seulement elle est plus petite et sa base est plus rétrécie; elle diffère surtout de ce cône par sa coloration.

142. CONב DE CI'्xaY. Conus Clerii. ReEv.

(Collect. M ${ }^{\text {me }}$ Dupont.) Reeve, Conch.icon., pl. 45, fig. 229.

PI. XCXIV, fig. 2.

C. testâ turbinatâ, supernè acutangulâ, tenuisculâ, per totam superficiem subtilissimè liratâ, albâ, strigis fuscescentibus, longitudinaliter undatis subirregulariter variegatâ ; spirâ depressiusculâ, leviter canaliculatâ, apice elato, mucronato.

Coquille turbinée, étroite, à spire peu élevée, à sommet aigu, composée de huit ou neuf tours étroits, 
à peine convexes et bordés d'un léger talus; le dernier est légèrement canaliculé; sa partie supérieure est carénée; sa base très-atténuée. Presque toute la surface de cette coquille est couverte de stries transverses superficielles à peine visibles, excepté vers la base du dernier tour où elles sont fort apparentes et très-rapprochées les unes des autres. L'ouverture est étroite, à peine échancrée à son sommet. La coloration de la coquille est blanche, et toute sa surface est parsemée d'un grand. nombre de linéoles on taches étroites, longitudinàles, onduleuses, irrégulièrement distribuées et d'un brun fauve; ces taches se confondent quelquefois et forment alors de véritables flammules qui se prolongent sur toute la longueur du tour.

Long. 32 millim:

Habite

Pctite coquille qui, par ses caractères, se rapproche du Conus emarginalus, et devra sans doute, par la suite, être regardée comme variété ou jeune individu de ce dernier.

143. CONE ANDATOUS. Conus Bœticulus. ReEve.

(Collect. de $\mathrm{M}^{\mathrm{me}}$ Dupont) líeeve; Conch. icon. pl. 42, fig. 226.

Pl. LV, fig. 2.

C. testâ turbinatâ, solidiusculâ, læevi, basim versùs granulosâ, albá, punctis maculisque grandibus vividè pictâ; spirâ subobtuso-convexâ, sulcatâ et striatocancellatâ.

Coquille turbinée, un peu effilée, à spire convexe, dont le sommet est saillant et pointu; elle est compo- 
sée de dix ou onze tours légèrement aplatis, marqués de stries transverses et longitudinales souvent peu apparentes. Le dernier tour est subanguleux vers sa partie supérieure, lisse sur presque toute sa convexité; sa base est étroite, traversée par des sillons profonds et granuleux. La coquille, d'un fond blanc, est garnie d'un grand nombre de lignes circulaires interrompues, composées de séries de petits points bruns allongés ; sur le dernier tour, on remarque deux zones interrompues, formées de larges taches transverses et longitudinales, d'un brun foncé.

$$
\text { Long. } 40 \text { millim. }
$$

Habite

Coquille qui tient du Conusinterruplus par sa forme et sa couleur ; elle n'en est véritablement distincte que par sa spire un peu plus courte, ses tours un peu carénés et quelquefois couronnés de petites nodosités; les taches ou flammules longitudinales de sa coloration sont aussi plus nombreuses.

144. CONI MAHOGAII. Conus mahogani. ReEve.

(Collect. de M. Borvin.) Réeve, Conch. icon., pl.22, fig. 126.

Pl. LXXIV, fig. 3.

C. testâ elongato-turbinatầ, subcylindraceâ, basim versùs sulcatâ, albidầ, spàdiceo profusè tinctâ, tænïs frequentibus spadiceo alboque articulatis cinetâ; spirâ valdè elatâ; aperturæ fauce albâ.

Coquille allongée, étroite, à spire régulièremènt conique et pointue; on y compte neuf ou dix tours 
obliques à suture bien distincte; le dernier est conique, un peu rétréci vers son extrémité inférieure qui est garnie de stries transverses; le reste de la surface est lisse. L'ouverture est étroite, à bords parallèles; son échancrure supérieure est peu profonde. Toute cette coquille est peinte de petits points oblongs ou arrondis, d'un brun foncé, disposés en séries transverses très-rapprochées les unes des autres, et comme articulées; de larges bandes ou flammules longitudinales, quelquefois ramifiées, d'un beau brun rouge, sillonnent aussi sa surface. La spire est blanchâtre, marquée de larges taches brunes irrégulières.

$$
\text { Long. } 42 \text { millim. }
$$

Habite l'océan Pacifique, les côtes de la Colombie.

Cône qui, par ses caractères, se rapproche du Conus zebra de Lam.; il a aussi beaucoup d'analogie avec le $C$. interruptus de Broderip, et pourrait bien n'être qu'une variété de celui-ci.

145. CONE zìBRE. Conuś zebra. LAM.

(Collect. du Mus.)

Pl. LXXVI, fig. 2.

C. testâ oblongo-turbinatâ, angustatâ, albidâ, flammis fulvo-rubris longitudinalibus angustis lineatâ ; basi sulcis distantibus ; spirâ convexâ, non striatâ.

Coquille oblongue, turbinéé, à spire courte, pointue au sommet, composée de onze ou douze tours très-étroits, médiocrement convexes; le dernier est renflé et un peu anguleux vers son sommet; sa moitié 
supérieure est lisse, le reste porte des sillons transverses assez réguliers et distants entre eux; sa base est atténuée. L'ouverture est un peu arquée dans sa longueur, un peu large à sa base; elle est d'un blanc violacé; le bord droit est mince, ponctué de brun en dedans. Cette coquille, d'un fond blanchâtre, est ornée de lignes ou flammules longitudinales plus ou moins larges, d'un rougé un peu fauve; et qui descendent du sommet à la base; ces flammules se changent quelquefois en marbrures' ou veines rameuses irrégulières.

\section{Long. 32millim.}

\section{Habite l'océan Asiatique.}

Espèce assez facile à distinguer parmi ses congénères par ses belles lignes longitudinales d'un rouge brun.

146. CONE POINTIIEE. Conus puncticulatus. BRUG.

(Collect. Lam.) Sebá, Mus. 3, t. 48, fig. 46, 47. PI. LX, fig.1, 1s, 1b; ?

C. testâ turbinatâ, basi sulcatâ, albidâ, seriebus approximatis punctorum fuscorum cinctâ; spirâ convexo-acutâ.

Coquille conique, turbinée; sa spire est élevée en un angle obtus et composée de huit ou neuf tours dont le bord extérieur est terminé par un talus assez saillant, et dont la superficie, légèrement concave, est marquée de stries longitudinales, ou arquées; très- 
fines. La moitié supérieure du dernier tour est lisse ; et le reste strié circulairement; les stries sont convexes, plus ou moins saillantes, toujours séparées les unes des autres par des sillons larges et aplatis dont la cavité est garnie dé stries longitudinales. L'ouverture est blanche, nuancée de violâtre. Le fond blanc ou rose de cette coquille est orné d'un grand nombre de rangs circulaires de points bruns; les points de la rangée qui óccupe, le haut du dernier tour sont plus grands et se prolongent sur le bord des autres tours.

Long. 32 millim.

Habite les côtes de la Chine.

Jolie espèce, répandue dans les collections et qui offre plusieurs vàriétés; la première que nous avons fait représenter même planche, fig. $1^{a}$ est de même grandeur que notre type ; elle en diffère par les stries saillantes de sa partie infẻrieure qui sont plus convexes et sollvent granuleuses et par des flammes longitudinales, brunes; onduleuses ou en zigzags formées par la réunion des points, qui ornent le fond blanc de sa superficie. La variété 16 est distincte de la précédente par la teinte fauve ou orangée des flammules et des points dont elle est ornée.

147. CONE CEINÉ. Contis mátritianus. BRug.

$$
\text { (Colleci. Lam.) Encyclop. pl. 330, fig. } 9 .
$$

PI. LXIX, fig. 2.

C. testâ turbinatâ, basi sulcatâ, albâ, fulvo-maculatâ,- punctis fusçis' lineatis cinctầ; spirâ obtusâ, depressâ, striatâ, fusco-marmoratâ.

Coquille turbinée, un peu ventrue; sa spire est conique, obtuse au sommet; : ses tours sont aplatis 
et même un peu concaves, garnis de stries arquées; la moitié supérièure dú dernier est lisse, l'autre moitié sillonnée. Cette coquille, d'un fond blanc, offre un grand nombre de séries circulaires de petits points bruns, fort rapprochés les uns des autres, quelquefois arqués en croissants ; des flammúles longitudinales, de couleur fauve nuancée de brun et de violâtre, traversent ces lignes ponctuées. La spire est marbrée de brun sur le fond blanc; le bord inférieur des tours est orné d'un rang de petites lignes arquées.

\section{Long. 38 millim.}

\section{Habite les mers d'Afrique.}

Cette espèce, distinguée par M. Hwass, et décrite par Bruguières dans l'Encyclopédie, n'est bien certainement qu'une variété du C. puncticulatus; elle a ńon-sèulement la même forme, mais encore la même disposition de rangs circulaires de points traversés de flammules longitudinales, comme dans les deux variétés que nous avons fait représenter $p l .60, f g .1^{a}, 1^{b}$; elle ne diffère de ce cône que par la nuance de coloration.

148. CONIz PEMÉz. Conus pygmaus. Reeve.

( Collect. de M. Delessert.) Reeve, Conch. icon. pl. 47 , fig. 260 .

Pl..CII, fig. 1, 1, $1^{\mathrm{b}}$.

C. testâ subabbreviato-turbinatâ, lævi, infernè sulcatâ, sulcis .prominentibus. subdistantibus; pallidè violaceo-albâ, strigis fuscis longitudinalibus, latis, undatis, punctorumque seriebus transversim ornatâ; spirâ obtúsâ.

Coquille conique, assez courte, lisse, à spire peu élevée, composée de huit tours subaplatis, à peine 
creusés, dont les bords sont peu aigus; le dernier est large et subanguleux à sa partie supérieure, rétréci à sa base qui est garnie de sillons larges et profonds; le reste de la surface est lisse. L'ouverture est d'un beau rose violacé. Le bord droit, très-mince et tranchant, est arqué en avant et détaché à son sommet par une légére échancrure. Le fond dé la coquille est d'un blanc violacé : toute sa surface est ornée d'un grand nombre de lignes circulaires très-fines; formées de ponctuations allongées d'un brun rouge; sa spire est flammulée de brun rouge plus foncé que la couleur des points ; ces flammules, anguleuses et irrégulières, se prolongent plus ou moins sur la convexité du dernier tour.

Long. 22 millim.

Habite le golfe du Mexique.

Cette petite coquille, très-variable dans sa coloration; a de l'analogie avec le $C$. puncticulatus, par quelques-unes de ses variétés; néanmoins, elle reste toujours plus petite. Nous avons fait représenter même planche 102 , fig. $1^{\prime \prime}, 1^{b}$, deux variétés; la première, fig. $1^{a}$, n'a pas de stries circulaires et sa convesité est ornée de larges flammules rougeâtres qui de scendent du sommet à la base de la coquille; la seconde, fig. $1^{6}$, est presque semblable au type, mais beaucoup plus petite. 
149. CONE DORANGE. Contus autisiaeus. LiN.

(Collect. Las.) Rumpr. Mü. t. 34, fig. A.

PI. XLIX, fig. 2, 2"

C. testâ oblongo-turbinatâ, basi emarginatâ, incarnatâ, albo-zonatâ, striis elevatis albo fuscoque tessulatis; spirâ obtusấ; canaliculatâ, maculatâ.

Coquille allongée, turbinée; sa superficie est garnie de cordelettes tranșverses nombreuses, inégales et assez distinctes entre elles, excepté vers la base où elles sont plus fines et p̀lus serrées. La spire est obtuse, composée de dix tours concaves ou creusés en gouttière, garmis de quelques stries circulaires et d'autres stries longitudinales moins mảrquées, bordées de chaque côté d'un talus légèremènt arrondi. La suture est fine, quoique bien apparente, régulière et munie d'un petit sillon. L'ouverture est, dans l'intérieur, d'un beau blanc; bien échancrée à son extrémité supérieure. Le fond de coloration est une belle couleur incarnate, ornée de trois fascies d'un blanc nuancé de rose tendre ; la convexité - est garnie de cordeleites et de lignes circulaires d'un blanc pur, interrompues par des points ou des portions de lignes d'un brun trèsfoncé ; de ces trois fascies, l'une est située vers le tiers supérieur du'dernier tour, la seconde un peu audessous de son milieu, la troisième vers son tiers inférieur. Les points bruns des cordelettes y sont un peu moins gros et plus distants entre eux que sur les parties du fond; enfin, au sommet du même tour, 
on remarque un cordon de taches plus ou moins larges, alternativement brunes et blanches, et qui se retrouve sur le bord inférieur des tours de la spire.

Long. 58 millim.

Habite les mers des Moluques.

Ce Cône est sans contredit un des plus beaux du genre. La variété, même planche, fig. $2^{a}$, est d'une teinte plus jaune; la fascie du milieu conserve seule la nuance incarnate; les taches y sont plus marquées et les stries de la base beaucoup plus profondes.

150. CONE PEA U-DE-SERPENT. Conus testudinarius, MartisI.

(Collect. Las.) Ruмp. Mus. t. 34, fig. K.

Pl. LVII, fig. 1 à $1^{c}$.

C. testâ turbinatâ, albâ, furvo et pallidè cæsio-nebulatâ ; maculis fulvis aut fuscis per fascias albas dispersis ; spirâ obtusiusculâ.

Coquille turbinée, épaisse, légèrement ạrondie vers son extrémité supérieure qui est terminée en une sphère conique, un peu obtuse, composée de onze ou douze tours assez larges, légèrement concaves et marqués le plus souvent de quelques stries circulaires. On remarque sur le dernier tour quelques stries transverses assez distantes entre elles; celles de la base sont beaucoup plus apparentes, plus rapprochées et granuleuses. Le fond blanc de cette coquille, nuancé de bleuâtre ou de violacé, offre deux rangs de taches brunes ou marron foncé, dont la forme, très-irrégulière, est entrelacée avec les parties blanches du fond, 
et dont les bords sont très-déchiquetés. Le premier de ces rangs occupe à lui seul la moitié supérieure du dernier tour et s'y prolonge en flammules de même couleur. Vers le milieu du tour, ces flammules s'interrompent et laissent voir une fascie blanche, ponctuée de petites taches d'un marron brun, disposées en lignes circulaires. A la base du même tour, on distingne aussi une seconde fascie blanche également ponctuée. L'ouverture est d'un blanc nuancéde'violet dans l'intérieur.

- dil cimang no

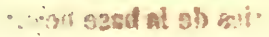

Long. 74 millim.

Habite l'océan des Antilles.

Le Cône peau-de-serpent a été ainsi nommé à cause des taches dont sa cợuille est marbrée et qui offrent une vague ressemblance avec celles de là peau de quelques serpents. Cette espèce présente un grand nombre de variétés qui dépendent souvent de l'âge ou des divers degrés de conservation des individus; nous avons fait représenter plusieurs de ces variélés sur notre planche 57. La première, fig. 1a, ressemble beaucoup au type; mais ses taches, d'un brun rougeâtre, sont plus foncées et tellement confondues ensemble, qu'elles forment deux larges fascies transverses. La fig. $1^{b}$ a toute sa surface marbrée de taches plus ou moins larges, déchiquetées et flammulées, le plus souvent réunies entre elles, ce qui fait paraître la coquille presque entièrement de couleur marron. Au contraire, la fig. $1 c$ montre un individu en grande partie- dépourvu de taches, et dont le fond de coloration est d'un blanc fortement violacé. C'est avec une variété semblable à celle-ci que M. Reeve a établi son Conus fulmen; le même auteur a également distingué un jeune individu de cette espèce sous le nom de Conus Grayi. 
151. CONE DE PORTO-RICco. Conus portoricanus, Brug.

(Collect. de M. Largiluert.) Encyclop. pl. 338, fig. 4 .

Pl. LXXXIV, fig. 1.

C. testâ turbinatâ, granulatâ, albâ, fulvo-maculatâ ; spirâ convexo-mucronatâ.

Coquille conique, turbinée, à spire convexe, mucronée au centre; on y compte neuf tours marqués de stries circulaires. Le bord de ces tours est muni d'une cordelette subgranuleuse qui les fait paraître un peu couronnés, surtout les six premiers; leurs sutures sont bien prononcées et un peu canaliculées. Le dernier est bombé vers son sommet, effilé à sa base; il est chargé de petites cordelettes granuleuses également distantes entre elles, et dont les intervalles sont garnis de stries circulaires onduleuses extrêmement fines. Ces cordelettes disparaissent souvent vers le haut du tour, mais sont toujours trè̀-prononcées à sa base. L'ouverture est étroite, un peu arquée dans sa longueur, légèrement échancrée à son sommet, blanchâtre dans l'intérieur. Cette coquille, d'un fond blanc, offre plusieurs rangs de taches irrégulières de couleur fauve ou marron. Ces taches sont ordinairement distantes entre elles, déchiquetées sur leurs bords. Les lignes circulaires sont articulées de petits points sagittés. Le milieu du dernier tour porte șouvent deux zones très-rapprochées l'une de l'autre et de même couleur que les taches. La spire est marbrée de fauve et de brun. 
Long. 42 millim.

Habite les mers des Antilles, vers les côtes de PortoRicco.

Cette coquille est encore fort rare dans les collections : nous n'en avons vu jusqu'à présent qu'un petit nombre d'individus. Celui-ci nous a été communiqué par M. Largillicrt; il fait partie de la magnifique collection de cet amateur. Néanmoins ce Cône, par sa forme et sa coloration, parait avoir beaucoup de rapports avec de jeunes individus du Conus cestudinarius.

152. CONE VExoURs. Conus luzonicus, BrvG.

Encyclopédie, pl. 338, fig. 6.

Pl. LXXXIII, fig. 3.

C. testâ turbinatâ, albidâ, fusco-interruptè fasciatâ punctisque sagittatis lacteo-articulatis lineatâ; spirâ convexâ, mucronatâ.

Coquille conique, turbinée, à spire convexe et mucronée au centre, composée de dix tours étroits; leur superficie, légèrement bombée, a quelques stries circulaires ordinairement peu apparentes. Les six premiers sont garnis d'un rang de granulations qui n'existe pas sur les derniers. La lignedes sutures est fine, quoique peu régulière. La superficie du dernier tour est lisse, excepté vers sa base où l'on remarque quelques stries circulaires 'grosses et assez serrées; il est très-renflé vers son sommet, rétréci à sa base. L'ouverture est colorée de bleuâtre à l'intérieur; son bord, peu tranchant et peu échancré à son extrémité supérieure, est veiné de brun-marron. Le fond de coloration de la coquille est blanchâtre, garni de lignes circulaires fines et nom- 
breuses d'un blanc de lait. Ces lignes sont interrompues à distances inégales par des points ou piqûres sagittées, de grandeur variable; en outre, de larges taches inégales, fauves ou d'un brun-marron, très-découpées sur leurs bords, garnissent la surface et sont également traversées par les lignes piquetées. La spire est tachetée de brun ou de fauve clair sur un fond cendré ou mêlé de bleuâtre. Les sutures sont bordées d'un liséré étroit, moitié blanc et moitié brun.

Long. 40 millim.

Habite l'océan Austral, les côtes des îles Philippines.

Nous soupçonnons que cette espèce, désignée par Bruguières sous le nom de $C$. luzonicus, n'est qu'une variété en mauvais état du précédent. Elle paraît en posséder tous les caractères, excepté les séries de granulations; mais même sur le $C$. portoricanus du même auteur on ne les retrouve pas toujours. Comme nous n'avons pas vu l'individu qui a été décrit comme type, et que nous nous sommes servi de la figure de l'Encyclopédie et de la description de Bruguières; nous ne pouvons nous prononcer à ce sujet. Lamarck a donné, comme variété $\boldsymbol{B}$ du $C$. luzonicus, une coquille de sa collection qui a un aspect tout particulier, ce qui nous a engagé à l'établir comme espèce, en lui donnant le nom du savant illustre auquel elle appartenait.

153. CONE GIÉROGLYPHIQUE, Conus hieroglyphicus, Dvelos.

(Collect. de M. Borvis.) Magasin de zoologie, 1833, pl. 23.

Pl. LXXIII, fig. 1-12.

C. teśtâ cylindraceo-ovatâ, cinereo-violaceâ, macularum fasciis duabús ornatâ, maculis niveis peculiariter sinuosis, granulosá, granulis pallidis; spirâ convexo-acutâ, variegatâ; basi striatâ.

Coquille turbinée, un peu ovale. Sa spire est peu 
élevée, formée de sept tours convexes sur lesquels se montrent de fines stries concentriques; le dernier est un peu ventru, strié à sa base. L'angle de la spire est strié et arrondi ; la surface est garnie de rangées transverses de fines granulations blanchâtres, également distantes entre elles. L'ouverture, assez ouverte, est nuancée de violet cendré dans l'intérieur. La coloration de la coquille est d'un blanc violacé; le dernier tour est orné de deux fasciés de taches brunes flammulées et irrégulièrement découpées : la spire est aussi maculée de larges taches inégales.

$$
\text { Long. } 22 \text { millim. }
$$

\section{Habite}

Petite espèce remarquable par la forme et la disposition des taches de sa coloration qui semblent rappeler des caractères hiéroglyphiques. Sur certains individus, le blanc est plus apparent, et la coquille est ornée de larges lignes longitudinales, onduleuses et ramifiées, d'un brun rougeâtre. (Voy. fig. 1a.)

154. CONE VIIN غ̇. Conus venulatus, BRvg.

(Collect. Lam.) Favanne. Conch., pl. 14, fig. D, 1.

PI. LXIX, fig. 1.

C. testâ turbinatâ, albidâ, flavo vel aurantio-renulatâ; spirâ convexâ, variegatâ.

Coquille conique, turbinée, élargie vers le haut. La spire est convexe, composée de neuf tours dont la superficie est lisse; les deux derniers sont plutôt un peu concaves. Les bords sont saillants et renflés. On distingue sur la base du dernier tour des cordelettes 
circulaires bien prononcées. L'ouverture est blanche, l'échancrure supérieure peu profonde; le bord, étroit, mince, tranchant, liséré de fauve. La surface de la coquille, d'un fond blanchâtre, est presque entièrement veinéẻ par une multitude de traits ou flammules d'une couleur orangée mêlée de rouge-brun, et qui la font paraître réticulée. L'interruption de ces flammules forme une zone blanchâtré un peu au-dessous du milieu du dernier tour. La spire, d'une teinte légèrement rose, est tachée de jaune orangé et de fauve clair.

Long. 38 millim.

Habite les mers d'Amérique.

Espèce encore rare. L'ensemble de ses caractères la rapproche du C. guinaicus.

155. CONE DE GUINÉE. Conus guinaicus, BRug.

(Collect. Lam.) Encyclop. pl. 337, fig. 4.

Pl. LII, fig. 1, 1a, $1^{\text {b. }}$

C. testâ turbinatâ, rubiginosâ, albo-cœrulescente nehulosâ, obsoletè fasciatâ; spirâ convexo-obtusâ, maculatâ.

Coquille turbinée, renflée vers son sommet et fort rétrécie à sa base; la spire est conique et obtuse, composée de neuf tours légèrement convexes qui paraissent lisses et sont néanmoins garnis de fines stries circulaires; ces stries quelquefois même deviennent assez distinctes. La ligne des sutures est bien marquée et peu régulière. Les stries de la base du der- 
nier tour sont saillantes et serrées. L'ouverture est assez étroite, légèrement échancrée vers son extrémité supérieure; elle est colorée de blanc violacé dans l'intérieur; le bord droit est liséré de fauve. La coquille, d'un fond brun rougeâtre, offre de grandes taches d'un blanc nuancé de bleu; celles qui sont situées vers le milieu de la coquille sont longitudinales ou obliques, séparées entre elles par des traits bruns et étroits, tandis que celles qui occupent l'extrémité supérieure sont plus petites, transversales, et presque ovales. Ces taches sont disposées de manière que la teinte du fond y forme deux ou trois zones plus ou moins distinctes; on aperçoit souvent encore une autre petite zone blanche qui coupe circulairement les taches du milieu de la coquille. La spire est marbrée de blanc sur un fond d'un fauve nuancé de brun

$$
\text { Long. } 52 \text { millim. }
$$

\section{Habite les côtes de Guinée.}

Cette coquille, assez commune, qui, en apparence, semble facile à distinguer, offre cependant d'assez grandes différences dans son système de coloration. La varièté fig. 1 a est toujours plus petite : elle est remarquable en ce que ses taches sont moins nombreuses et d'un brun foncé. L'individu de la variété fig. $1^{b}$ a ses deux fascies un peu plus largés et d'une coloration plus intense. 
156. CONE CHAT. Conus catus, Brug.

(Collect. Lam.) Martini, Conch. 2, t. 5̃5, fig. 609, 610.

Pl. XLIII, fig. $1-1^{a}-1^{d}$.

C. testâ turbinatâ, albidâ, fulvo vel fusco-variegatâ; striis transversis elevatis numerosis ; spirâ convexo-obtusâ, striatâ, variegatâ.

Coquille épaisse, courte, bombée; sa spire, de forme obtuse, est composée de dix tours dont les inférieurs sont légèrement concaves, garnis de plusieurs stries circulaires bien prononcées. Le dernier est arrondi vers le haut, quelquefois lisse sur cette partie, mais plus ordinairement sillonné d'un bout à l'autre et garni de cordelettes saillantes: ces cordelettes sont convexes sur la moitié inférieure du tour, souvent granuleuses, plates ou peu élevées sur la moitié supérieure. La coquille, d'un fond blanchâtre, est ornée de deux ou trois rangs circulaires de taches irrégulières de couleur fauve; ces taches, assez souvent distinctes et séparées, se confondent quelquefois par des nuances qui participent également de la couleur fauve et de celle du fond. En outre, les cordelettes sont ponctuées alternativement de fauve et de blanc, et, sur la moitié supérieure du tour, souvent marquées de portions de lignes fauves et blanches, dans les interstices desquelles se voient d'autres rangs de lignes semblables, mais plus étroites. La spire est tachetée de marron et de fauve sur un fond cendré. 


\section{Long. 40 millim.}

Habite l'océan des Antilles, les côtes du Sénégal, de l'île de France, etc.

Cette espèce, extrêmement commune, offre un grand nombre de variétés dans la coloration, jamais dans la forme. (Voir les figures $1 a$ à 1d.)

157. CONE RAT. Conus rattus, Brug.

(Collect. Lay.) Encyclop. pl. 338, fig. 9.

Pl. XLIV, fig. 3.

C. testâ turbinatâ, olivaceâ vel cịnereo-violaceâ, fasciâ punctisque albis sparsis notatâ ; spirâ obtusâ ; fauce violaceo-roseâ.

Coquille turbinée, dilatée vers sa partie supérieure. La spire est obtuse, composée de dix tours légèrement convexes, traversés par des'stries circulaires et marqués d'accroissements multipliés. La suture des tours est bien prononcée; la-superficie du dernier paraît lisse, mais elle est chargée de stries circulaires très-fines qui ne se voient bien qu'à son extrémité inférieure. Les couleurs de cette coquille consistent en un fond cendré ou violacé, nuancé d'olivâtre, sur lequel se détachent deux fascies inégales. La première de ces fascies, située vers le haut du tour, est blanche, assez large, interrompue par des flammules; la seconde, un peu plus étroite, est placée un peu au-dessous du milieu du tour; elle est ordinairement couleur d'agathe, nuancée de violet, et toute parsemée de poịnts blancs ou couleur de chair, et de quelques nébulosités blanchâtres. La spire est marbrée de fauve ou de roux sur un fond 
GENRE CÔNE.

blanc; toute la cavité de l'ouverture est colorée d'une nuance violacée qui s'étend aussi sur la columelle.

Long. 43 millim.

Habite les mers de l'Amérique.

Espèce très-commune et peu variable dans sa coloration. La plupart des conchyliologistes la confondent avec le $\boldsymbol{C}$. taitensis de Bruguières, mais toutes deux sont assez distinctes pour être séparées.

158. CONI VIOLET. Conus taitensis, Brug.

(Collect. LaM.) Encyclop. méthod. pl. 336, fig. 9.

Pl. LXVI, fig. 4.

C. testâ turbinatâ, transversim st $\mathbf{r}$, violaceo-nigricante; maculis et punctis raris albis; spirâ obtusâ, striatâ.

Coquille turbinée, assez courte, bombée vers sa partie supérieure, très - rétrécie à sa base. La spire est composée de neuf tours aplatis, marqués de plusieurs stries circulaires bien prononcées et d'autres stries longitudinales nombreuses et très-fines. La ligne des sutures est régulière et distincte; le dernier tour est garni d'un bout à l'autre de stries transverses légèrement onduleuses et beaucoup moins prononcées vers son tiers supérieur. L'ouverture est étroite, blanchâtre dans le fond de la cavité, d'un violet bleuâtre près du bord droit qui est mince, un peu onduleux à sa base et liséré de marron foncé. La coquille est de couleur marron ou d'un violet très-foncé. Vers le haut du dernier tour et un peu au-dessous de son milieu, on remarque une suite de nébulosités bleuâtres, pointillées de blanc, et un rang 
de taches peu régulières, mais bien distinctes, d'un blanc mêlé quelquefois de bleu clair. La spire est marbrée de taches livides ou de couleur marron sur un fond plus ou moins blanc.

\section{Long. 38 millim.}

Habite l'océan Pacifique, vers les côtes de l'île d'Otaïti.

M. Reeve considère ce Cône comme une variété du $C$. rattus; cependant on y trouve des caractères constants de forme et de couleur qui semblent le distinguer de celui-ci, quoiqu'il y ait entre eux une grande analogie.

159. CON2 AGATEE. Conus achatinus, ChEMN.

(Collect. Lam.) D'Arg̣envilue, Conch. pl. 13, fig. B.

Pl. XL, fig. 1-1's à $1^{\mathrm{c}}$.

C. testâ oỷato-turbinatâ, basi subgranulatâ, furvâ, albo-cœruleoque nebulosâ, lineis punctatis interruptis cinctâ ; spirâ acutâ.

Coquille ovale, turbinée, à spire assez aiguë, composée de onze tours dont la superficie est striée circulairement. La ligne de leurs sutures est peu profonde, sensiblement onduleuse ; la partie supérieure du dernier tour est légèrement concave. Il porte sur toute sa convexité un grand nombre de stries circulaires bien distinctes, devenant plus prononcées et quelquefois granuleuses à la base de la coquille. L'ouverture est dilatée vers sa partie inférieure; elle est un peu arquée. Son sommet est terminé par une légère échancrure. Les couleurs de cette coquille consistent en de larges flammules longitudinales d'un fauve brun sur un fond blanchâtre, mêlé de teintes bleues et orné de lignes 
GENRE CÔNE.

circulaires composées de traits transversaux noirs et de points de couleur marron ou cramoisie. Les flammules brunes sont onduleuses, déchiquetées sur leurs bords. La spire présente le même fond et les mêmes.marbrures que le dernier tour, mais on n'y aperçoit pas de lignes ponctuées.

Long. 68 millim.

Habite l'océan Asiatique.

Ce Cône, que l'on nomme vulgairement la T'ulipe, offre plusieurs variétés de coloration : la fig. $1^{a}$ diffère du type par son fond blanchâtre marqué de grandes taches d'un brun noir, qui y sont divisées en deux grandes fascies; les lignes circulaires qui les traversent sont moins ponctuées, excepté trois ou quatre qui garnissent le milieu de la convexité de la coquille et sa base. La variété $1^{b}$ est entièrement de conleur uniforme d'un fauve clair qui ne laisse apercevoir que quelques petites taches éparses du fond blanc de la coquille; 'une iuance plus claire forme une zone transverse sur le milieu de la convexité du dernier tour, et à la base du même tour se retrouvent les séries de points et de traits que nous avons déjà indiquées. La variété $1^{c}$ appartient à l'espèce établie par Bruguières, et connue des auteurs modernes sous le nom de $C$. ranunculus. Elle est évidemment une variété du $C$. achatinus; une suite d'individus de ces coquilles le démontre d'une manière incontestable, car on les voit se fondre dans des nuances insensibles.

160. CONI ROURRRÉ. Conus purpurascens, BROD.

(Collect. de M. Delesserit.) Sow. Conch. illust. fig. 13.

PI. XXXIX, fig. 2, et pl. LXI, fig. 3.

C. testà subobeso-conicâ, interdùm leviter granulosâ; violaceâ, purpureo-variegatâ et nebulosâ, monilibus purpureis et albis frequentibus cingulatâ; aperturầ subamplâ, ; spirâ convexâ, subcanaliculatâ, spiraliter striatâ.

Coquille turbinée, épaisse, à spire large, peu proé- 
minente, régulièrement conique, composée de dix ou douze tours médiocrement concaves, et dont la surface est occupée par des stries transverses, égales et régulières. L'angle supérieur du dernier tour est aigu; ce tour est un peu ventru, substrié sur presque toute son étendue. Les stries sont fines et plus rapprochées entre elles vers la base, légèrement saillantes vers le sommet du tour. L'ouverture est assez large, d'un beau blanc; la coloration de la coquille est un gris violacé, avec de larges taches d'un brun rougeâtre foncé, interrompues vers le milieu du dernier tour par une zone d'un blanc pourpré, irrégulièrement découpée sur ses bords et assez souvent ponctuée de blanc. En outre, la surface est encore ornée d'un nombre assez considérable de lignes transverses d'un hrun rouge très-intense. La spire est garnie de taches subquadrangulaires brunes, alternant avec d'autres taches blanches.

Long. 65 millim.

Habite la côte de Panama.

Ce Cốne ne manque pas d'analogie avec certaines variétés du $C$. lestudinarius de Brug; mais plusieurs caractères constants de forme et de coloration l'en distinguent. Nous avons fait représenter (pl. 61, fig. 5) la variété d'un petit individu qui diffère du type par sa spire plus courte, les lignes de sa coloration plus fines et formées de petits points bruns; sur cette variété les taches sont beaucoup moins grandes et moins nombreuses. 
161. CONE PLUIE-D'ARGENT. Conus mindanus, BRgG.

(Collect. LaM.) Encyclop. pl. 330, fig. 7.

Pl. LIX, fig. 3.

G. testâ turbinatâ, basi sulcatâ, albâ, puniceo-variegatâ, lineis numerosis puncticulatis cinctâ; spirâ acuminatâ.

Coquille turbinée, rétrécie à son extrémité inférieure, assez arrondie au sommet. La spire est élevée, composée de neuf tours un peu concaves, légèrement marqués de stries en croissant, et dont le bord inférieur est terminé par un talus saillant: La superficie est lisse, mais la base du dernier tour est marquée de stries nombreuses et profondes. Cette coquille, d'un fond blanc, offre de grandes taches nébuleuses déchiquetées, ordinairement longitudinales, soit d'un rouge écarlate, soit verdâtres; en outre, elle est ornée de nombreuses lignes circulaires d'un blanc de lait, munies de points ou piqûres transverses d'un rouge vif. La spire, dont le sommet est terminé en une pointe rose, présente aussi, sur le fond blanc de ses tours, des taches écarlates et deux rangs de points rouges plus gros que ceux des lignes du dernier tour.

Long. 34 millim.

Habite les côtes des îles Philippines.

Il arrive quelquefois pour cette espèce que certains individus ont leurs tours très-légèrement couronnés d'une série de petites nodosités; c'est avec une variété semblable que M. Duclos a établi son Conus elventinus. (Magasin de Zool. 1833, pl. 19.) 
162. CONE FRANCISCAIN. Conus franciscanus, BrgG.

(Collect. Lam.) Encyclop.pl. 337, fig. 5.

Pl. LII, fig. 2.

C. testâ turbinatâ, castaneâ, albido-bifasciatâ; fasciâ superiore anfractus decurrente; spirâ convexo-acutâ.

Coquille conique, arrondie vers sa partie supérieure qui est terminée par une spire convexé, aiguë, formée de huit tours assez larges, lisses, dont les sutures sont bien distinctes et raboteuses: La superficie de cette coquille est pourtant munie, malgré son apparence lisse, de quelques stries circulaires; ces stries deviennent plus saillantes et pluś rapprochées entre elles à la base. Quelques stries longitudinales d'accroissement, tantôt plus foncées, tantôt plus claires, se montrent aussi sur la surface. L'ouverture est assez largé, peu échancrée vers son extrémité supérieure, d'un blanc nuancé de violet dans l'intérieur et liséré de marron clą̣r sur le tranchant du bord droit. La coloration de la coquille est d'un brun-marron, sur lequel on peut apercevoir les lignes circulaires assez écartées les unes des autres, et d'un brun plus foncé. Trois petites zones blanchâtres occupent le dernier tour : la première est située vers son extrémité supérieure ; la seconde un peu au-dessous du milieu de la convexité du tour; et la troisième à la base.

Long. 60 millim.

Habite les mers d'Afrique et la Méditerranée.

Ce Cône, assez commun, qui a été établi comme espèce par Bruguières, n'est très-probablement qu'une variété, ou mieux encore un individu roulé du $C$. mediterraneus; aussi pensons-nous qu'il devra être supprimé des catalogues comme espèce. 
163. CONE MÉDITERRANEEN. Conus mediterraneus, BRug.

(Collect. Lam.) Seba, 5, t. 47, fig. 27.

Pl. LVI, fig. 1 à 1 .

C. turbinatâ, cinereo-virescente vel rubellâ, fụlvo aut fưsco nebulatâ; lineis transversis albo fuscoque articulatis; fasciâ albidâ; spirâ convexo-acutâ, maculatâ.

Coquille conique; tưbinée, renflée vers son extrémité supérieure; sa spire est élevée, presque aiguë, formée de neuf tours légèrement convexes ; les derniers sont traversés par quelques fines stries circulaires; leurs sutures sont bien distinctes. Quelques stries transverses, extrêmement fines, paraissent visiblement sur la base du dernier tour, tandis que le reste de la surface semble tout à fait lisse, quoique également garni de fines stries. L'ouverture est étroite, colorée de fauve violacé dans l'intérieur, avec deux fascies blanches; l'une située vers son extrémité supérieure, l'autre vers son milieu; ces fascies correspondent à celles de la superficie. Le fond de coloration de la coquille est d'un vert olivâtre; toute sa surface est garnie d'un grand nombre de lignes circulaires très-fines, ponctuées de brun et parsemées, sans régularité, de taches ou mouchetures transverses, blanchâtres ou cendrées ; une fascie d'un blanc cendré, le plus souvent ponctuée comme le reste de la coquille, est située un peu au-dessous du milieu du dernier tour. La spire est maculée de taches blanches et noirâtres. 
Habite la Méditerranée et la mer des Antilles.

Cette coquille est très-commune; on y pourrait compter presque autant de variétés que d'individus, si l'on ne suivait les intermédiaires depuis l'espèce type jusqu'à la dernière variété. Nous n'avons fait représenter que les principales. Nous avons réuni à cette espèce le C. jamaicensis et madurensis de Brug., qui ne sont que des variétés de localité. (Voir la fig. 1a, même pl. 56, pour le premier de ces cônes; le second (fig. 1c) est plus petit que le précédent, et c'est la seule différence qui l'en distingue. La fig. $1^{b}$ est de forme plus courte; les séries de points y sont à peine apparentes, et les taches plus brunes et plus prononcées. La fig. $1 d$ ressemble beaucoup au type, elle est seulement plus petite. La fig $1 e$ n'a plus de taches visibles, elle est garnie de séries de petites ponctuations: La fig. 1 f est remarquable par les lignes circulaires brunes et continues. qui remplacent les séries de points.)

164: CONE EN FUSEAU. Conus fusiformis, LAM.

(Collect. LaMr.)

\section{PI. LXXVI; fig. 3.}

C. testâ turbinato-fusiformi, strús tenuissimis transversis et longitudinalibus obsolétè cancellatâ, pallidè albo-rufescente; spirâ. elevatâ, : acutâ ; anfractibus convexis.

Coquille turbinée, fusiforme, à spire conique, élargie'vers sa base et formée de dix tours anguleux sur leur milieu; leur partie supérieure est oblique et légèrement creusée. Ces tours sont garnis de stries transverses assez fines : le dernier est régulièrement conique, anguleux vers son sommet; il est chargé de stries transverses qui deviennent plus espacées entre elles et plus profondes vers sa base; d'autres stries longitudi- 
nales très-fines coupent ces stries transverses, et leur entre-croisement forme un treillis si fin qu'il est à peine visible. L'ouverture est étroite, le bord droit mince et arqué. La coloration est d'un blanc roussâtre uniforme.

\section{Long. 48 millim.}

\section{Habite l'océan Pacifique?}

Ce Cône, très-rare, paraît se rapprocher infiniment de plusieurs espèces fossiles, entre autres du Conus deperditus de Bruguière.

165. CONE ACULEIFOEME. Conus aculeiformis, REEVE.

(Collect. de $\mathrm{M}^{\text {me }}$ Dupont.) Reeve, Conch. icon. pl. 44, fig. 240.

Pl. XCII, fig. 4.

C. testâ elongato-turbinatâ, subfusiformi, undiquè súlcatâ, sulcis subtilissimè striato-cancellatis; albidâ, fuscescente punctatâ, maculis fuscescentibus biseriatìm cinctâ; spirâ acuminatâ, apice elato, acuto.

Coquille petite, allongée, subfusiforme, étroite, à spire longue dont le sommet est très-aigu; composée de dix tours obliques et distincts. Le dernier est conique, caréné vers sa partie supérieure, très-atténué à sa base ; toute la surface de ce tour est garnie de sillons transverses pointillés, également distants entre eux et traversés par de fines stries longitudinales: L'ouverture est étroite, à peine échancrée à son sommet; le bord droit est mince et arqué. La coloration de la coquille est blanche, traversée de lignes' nombreuses formées de petits points bruns. Deux larges 
taches brunes, de forme irrégulière, sont placées sur le milieu du dernier tour. La spire est ornée de taches longitudinales irrégulières.

Long. 22 millim.

Habite les côtes de Mindanao et des Philippines.

Très-jolie petite espèce, qui par l'ensemble de ses caractères se distingue facilement des autres cônes.

166. CONI JAUNATR2. Conus flavescens, Sowerby.

(Collect. de $\mathrm{M}^{\text {me }}$ Dupont.) Sow, Conch. illust. fig. 68.

$$
\text { î. XCII, fig. } 2 .
$$

C. testâ turbinatâ, lævi, basim versùs sulcatâ ; albidâ, maculis flavescentibus ir regularibus perpaucis biseriatìm ornatâ ; spirâ acutâ, angulatâ, apice mucronato, elato.

Coquille petite, turbinée, lisse, à spire allongée, régulièrement conique et pointue. On y compte dix tours étagés, à surface concave et dont la base est bornée par un angle aigu. La partie supérieure du dernier tour est anguleuse et sa base très-atténuée ; sa surface est lisse, excepté la partie inférieure qui est striée. L'ouverture. est étroite, blanche en dedans; le bord droit se projette en avant, sous une courbure assez forte et se détache de l'avant-dernier tour par une échancrure large et profonde. La coloration de ce cône est blanchâtre; son dernier tour est orné de larges taches irrégulières, d'un jaune orangé, et dispo- 
sées en deux fascies transverses. La spire est maculée de taches longitudinales de même couleur.

Long. 26 millim.

Habite

Nous ne connaissons encore qu'un petit nombre d'individus appartenant à cette espèce, quoique voisins, sous certains rapports de forme, du Conus emarginatus.

167. CONE OCRACÉ. Conus ochraceus, LAM.

(Collect. du Mus.)

Pl. XXXVII, fig. 2-2a.

C. testâ turbinatâ, flavâ, albo-fasciatâ et maeulatâ; fasciis luteo-punctatis; spirâ planiusculâ, mucronatâ: anfractibus canaliculatis.

Coquille turbinée, à spire conique, très-surbaissée, formée de neuf ou dix tours étroits, lisses, un peu convexes, à sutures assez profondes. Le dernier tour, obtus à sa circonférence, est sillonné à sa base. L'ouverture est légèrement arquée, blanche en dedans; l'échancrure du bord droit est peu profonde. Cette coquille, d'un fond jaunâtre, présente de longues marbrures longitudinales blanches et irrégulières; le milieu du dernier tour' est orné d'une zone blanche irrégulièrement.découpée sur ses bords et ornée de taches ou de points subquadrangulaires. La spire est maculée de taches fauves alternant avee le fond blanc.

Long. 40 millim.

Habite 
Cette coquille se rapproche beaucoup, par sa forme, du Conus tessel. latus : elle en est distincte par ses couleurs. La variété que nous avons fait représenter (fig. $2^{\omega}$ ) est plus grande que le type de la collection Lamarck; elle offre aussi la différence d'une fascie blanche située sur le dernier tour, et semée de plusieurs rangées transverses de points d'un fauve brun.

168, CONE D'ALGOA. Conus algoensis, SOWERby.

(Collect. de $\mathrm{M}^{\text {me }}$ Duponr.) Sow., Conch. illust. fig. 66.

Pl. LXVIII, fig. $\mathbf{3}$.

C. testâ subcylindraceo - turbinatâ, tenuiculâ, castaneo-fuscâ, fasciâ unicâ, fasciisve duabus albis, peculiariter interruptis, ornatâ; spirâ brevi, convexâ, fusco alboque articulatâ.

Coquille petite, subcylindrique, turbinée, à spire courtê, légèrement convexe, formée de sept tours un peu aplatis et subanguleux. Toute la surface de cette coquille est garnie de fines stries longitudinales d'accroissement, très-rapprochées entre elles, traversées par d'autres stries à peine visibles d'abord, mais plus apparentes et rugueuses sur la base du dernier tour. L'ouverture est étroite, d'un blanc nuancé de violet dans l'intérieur. Le fond de coloration de cette coquille est d'un marron clair; deux zones formées de taches irrégulières de forme et de grandeur ornent la convexité du dernier toúr. Ces taches se réunissent quelquefois, et ne forment plus alors qu'une seule et large zone. Une autre fascie, à marbrures allongées d'un marron foncé sur un fond blanc, occupe l'extrémité supérieure du dernier tour et le reste de la spire. 
Long. 28 millim.

Habite les côtes du cap de Bonne-Espérance et la baie d'Algoa.

Joli petit Cône bien distinct des autres cônes par sa coloration. Il est encore rare dans les collections, et parait avoir quelques rapports de forme avec le $C$. narcissus de Lamark; mais il est beaucoup plus petit.

169. CONI B BITXANT. Conus nitidus, ReEve.

(Collect. de M. Delessert.) Reeve, Conch. icon. pl. 47, fig. 266.

PI. LXIII, fig. 4-ín

C. testâ parvâ, turbinatâ, lævi, nitidâ, prope basim subtilissimè liratâ; aurantio-fucescente, supernè et medianè exiliter albimaculatâ, lineis fuscis interruptis subdistantibus undiquè cinctâ ; spirâ subelatâ, spiraliter striatâ, apice pallidè rosaceo.

Coquille petite, turbinée, subcylindracée. La spire est courte, pointue, d'un rose pâle au sommet, et composée de dix tours étroits, un peu aplatis, dont la surface est munie de plusieurs stries circulaires finement granuleuses. La suture est bien distincte, subcanaliculée. Le dernier tour est légèrement arrondi vers sa partie supérieure; sa base est rétrécie et munie de petits sillons élevés; tout le reste de la surface est lisse et luisant. L'ouverture est étroite, blanche en dedans; le fond de coloration de la coquille est jaunâtre, nuancé d'orangé; elle est traversée dans toute sa longueur par des traits bruns rarement interrompus ; une 
fascie blanche assez large et ponctuée de brun est placée un peu au-dessous du milieu du deruier tour; une autre fascie à marbrures fauves sur un fond blanc occupe l'extrémité supérieure du même tour et toute la superficie de la spire.

\section{Long. 24 millim.}

\section{Habite les côtes des îles Philippines.}

Petite coquille très-élégante, qui se distingue de ses congénères par sa forme et sa coloration. La variété que nous avons fait représenter même planche, fig. $4^{a}$, présente sur toute sa surface, au lieu de traits bruns, des séries de petits points très-rapprochés entre eux. La coloration de celle-ci est d'un jaune pâle.

170. CONI ASPERGÉ. Conus conspersus, REEVE.

(Collect. de' M. Delessert.) Reeve, Conch. illust. pl. 47, fig. 262.

Pl. LXXXVIII, fig. 2.

C. testâ turbinatâ, læviter inflatâ, læevi, basim versủs sulcatâ; paliidè luteolâ, maculis aurantio-fuscis varïsque irregulariter conspersis, lineis capillaribus confertis undiquè cinctâ; spirâ convexâ, aurantio-fusco-maculatâ.

Coquille conique, turbinée, un peu rentlée vers le milieu. La spire est peu proéminente, composée de huit ou neuf tours légèrement aplatis, garnis de fines stries circulaires. La base du dernier tour est fort rétrécie et offre un petit nombre de sillons transverses, étroits, très-écartés entre eux, finement ponctués. L'ouverture est assez large, d'un jaune safrané très- 
tendre. La coloration de cette coquille consiste en taches plus ou moins allongées d'un brun fauve; ces taches sont irrégulières, imitant des marbrures; elles se dessinent nettement sur le fond d'un blanc jaunâtre et sont interrompues sur le milieu du dernier tour par une zone blanchâtre. En outre, toute la surface est ornée d'un très-grand nombre de linéoles transverses extrêmement fines et qui se montrent aussi bien sur les taches que sur le fond de la coquille.

$$
\text { Long. } 30 \text { millim. }
$$

\section{Habite}

Espèce rare, qui, par sa forme et sa coloration, ne manque pas d'analogie avec plusieurs autres du même genre auxquelles on devra sans doute la rattacher lorsqu'on aura un plus grand nombre d'individus à examiner.

171. CONE FÉ VRROLE. Conus fabula, Sow.

(Collect. de M. Borvin.) Sowerby, Conch. illust, fig. 5.

PI. LXXVIII, fig. 2-2a.

C. testâ pyriformi-turbinatâ, supernè solidâ, transversè striatâ, striis subtilissimè granulosis, granulis æquidistantibus regularibus; albâ, fusco hic et illic longitudinaliter confluente, bifasciatim inquinatâ; spirâ obtuso-rotundatâ; apice parro, elato, acuto.

Coquille petite, pyriforme, turbinée, à spire convexe et à sommet pointu. L'angle de sa circonférence est arrondi : les tours sont étroits, au nombre de dix. On $\dot{y}$ remarque quelques stries concentriques. Ces tours sont séparés par une suture bien distincte et as- 
sez profonde. Le dernier est strié transversalement dans toute son étendue; les stries de sa base sont profondes et le plus souvent granuleuses. L'ouverture est très-étroite, un peu plus large vers sa partie inférieure; elle est d'un violet pâle, interrompu vers le milieu par une zone blanche. Le fond de coloration de la surface est blanc. orné de grandes taches d'un brun cannelle de forme quadrangulaire ou rameuse, irrégulièrement disposées; souvent ces taches se réunissent et ont alors l'aspect de larges ceintures déchiquetées sur leurs bords.

\section{Long. 30 millim.}

Habite les côtes des îles Philippines.

Coquille assez rare dans les collections. Nous en dévons la communication à $M$. Boivin, de même que de la variété (fig. $\left.2^{a}\right)$. Celle-ci a moins de taches que l'espèce type; elle est surtout remarquable par les nombreuses séries transverses de granulations qui garnissent son dernier tour.

172. CONב AmBAss ADEUR. Conus tinianus, Brog.

(Collect. de M. Bellanger.) Encyclop. pl. 338, fig. 2.

Pl. LXI, fig. 1.

C. testâ turbinatâ, cinnabarinâ, maculis pallidè cæsiis nebulatâ ; punctis fulvis interspersis; spirâ convexâ.

Coquille conique, ovale, bombée vers son extrémité supérieure, effilée vers sa base qui est garnie de stries circulaires; le reste de la superficie est lisse: La spire est convexe, composée de huit tours un peu bombés, 
assez larges, et dont les sutures consistent en une ligne simple et peu profonde. L'ouverture est plus élargie vers la base; elle est d'un blanc nuancé de rose à l'intérieur. Le bord droit est mince, l'échancrure supérieure peu profonde. La coquille est d'un rouge vif, analogue à celui du cinabre; le dernier tour est traversé par plusieurs rangées de taches d'un bleu cendré pâle. L'une est située vers la partie supérieure de la coquille, l'autre un peu au-dessous de son milieu, et la dernière vers la base. Ces taches offrent, dans leurs intervalles, des points plus ou moins allongés, de couleur fauve ou blanchâtre, formant le plus souvent des séries circulaires qui se confondent avec le fond rouge de la coquille. La spire, nuancée de rose sur un fond cendré, a quelques taches irrégulières de couleur fauve ou marron.

$$
\text { Long. } 50 \text { millim. }
$$

Habite l'océan Pacifique vers les côtes de l'île de Tinian.

Coquille fort rare dans les collections. Elle se distingue facilement de toutes les espèces connues.

173. CONE QUESTEUR. Conus characteristicus, GHEN.

(Collect. du Mus.) Chematrz, Conch. t. 11, pl. 182, fig. 1760,1761 .

Pl. XLII,jfig. 1, 1a, $1^{\text {b. }}$

C. testâ turbinatâ, alhâ ; maculis aurantin-fulvis Iongitudinalibus flexuosis 'subramosis; spirâ planâ, maculatâ.

Coquille turbinée, à spire élarpie, presque plane, 
composée de dix tours un peu élevés à leur centre et formant un sommet obtus. La partie supérieure de ces tours présente le plus souvent des stries variables en nombre et en grosseur. Les stries sont bien distinctes, rarement onduleuses. Le dernier tour est conique, un peu rétréci vers sa base où l'on remarque plusienrs sillons obliques; le reste de la surface est lisse. L'ouverture est plus dilatée à sa base qu'à son sommet. L'échancrure du bord droit est étroite et peu profonde. La coloration de ce cône est un fond blanc tout parsemé de flammules fléchies en zigzags et de lignes longitudinales irrégulières, un peu rameuses et d'un brun orangé. De larges taches de même couleur, peu distantes les unes des autres, forment comme deux zones sur la convexitẻ du dernier tour.

Long. 50 millim.

Habite l'océan Indien.

Ce Cône, que Lamarck avait établi sous le nom de $C$. questor, est le mème que le Characteristicus de Chemnitz. Il est encore assez rare dans les collections. Il offre certaines variétés remarquables : la première, que nous avons fait représenter (fig. 1a) est distincte par son mode de coloration, dont les flammules plus ou moins larges, déchiquetées en zigzags, descendent sans interruption du sommet à la base du dernier tour; la seconde variétẻ (fig. $1^{b}$ ) avait été établie comme espèce, par Lamarck, sous le nom de $C$. muscosus; cet individu a tous les caractères du $C$. characteristicus de Chemnitz; cependant, les deux premiers que nous venons de" décrire ont généralement la spire plus large et plus surbaissée; la coloration de celui-ci est un peu différente; elle consiste en un fond blanchâtre parsemé de petites taches trigones, de couleur fauve ou d'un roux brun, la plupart'réunies en petites flammules onduleuses et longitudinales. 
GENRE CÔNE.

174. CONE APLUSTBE. Conus aplustre, REEVE.

(Collect. de M. Delessert.) Reeve, Conch. icon. pl. 30 ,

fig. 170.

Pl. LXXIV, fig. 2.

C. testâ turbinatâ, tenui, subinflatâ, lævi, basim versủs liratâ ; rubido-fusco et cœruleo pallidè et subirregulariter zonatâ, tæniis fusco-articulatis angustis numerosis subtilibus ornatâ ; spirâ depresso-convexâ, apice mucronato.

Coquille petite, turbinée, élargie vers son sommet; sa spire est peu élevée, obtuse à sa partie supérieure, formée de sept. ou huit tours aplatis et bordés d'un léger talus arrondi; ces tours sont garnis de plusieurs stries fines et circulaires. Le dernier est large, subanguleux vers son sommet, fort rétréci à sa base qui est garnie de sillons élevés; le reste de la surface est lisse. L'ouverture est étroite, d'un rose violacé; le bord droit est mince et arqué. Le fond de la coquille est jaunâtre ou rougeâtre, nuancé de cendré pâle, orné sur toute son étendue de lignes circulaires qui sont formées de ponctuations souvent allongées et d'un brun rouge. Une fascie d'un blanc violacé est située sur le milieu du dernier tour. La spire est flammulée de brun sur un fond blanc.

Long. 20 millim.

Habite

Par sa coloration cette jolie espéce a beaucoup d'analogie avec le $C$. splendidus; mais elle est beaucoup plus petite. 
175. CONE DRAR-D'ARGENT. Conus stercus-muscarum, Lix.

(Collect. Lam.) Lister, Conch. t. 757, fig. 9.

Pl. LVIII, fig. 3

C. testâ cylindraceo-turbinatâ, albâ, fusco-maculatâ; punctis nigris cingulatis identidem coacervatis; spirâ convexo-obtusâ, subcanaliculatâ.

Cône cylindrique, turbiné, assez épais, à spire lisse, obtuse, composée de dix ou onze tours dont les denx ou trois derniers sont concaves et légèrement arrondis sur leurs bords; toute la superficie de la coquille est garnie de stries circulaires extrêmement fines. Mais sur le tiers inférieur elles ont plus de saillie et forment souvent des cordelettes. L'ouverture est plus large vers sa base; elle est blanche en dedans; le bord droit est tranchant, liseré à l'intérieur de petites piquetures noires. Cette coquille, d'un fond blanc nuancé de rose clair, présente un très-grand nombre de points noirs ou bruns rangés en lignes circulaires très-serrées ; ces points, ordinairement arrondis, mais qui varient en grosseur sur la même ligne, sont entremêlés, à distances inégales, de mouchetures transverses blanches. En outre, on voit sur la surface deux zones de taches qui sont elles-mêmes composées ou de points plus nombreux, plus rapprochés entre eux, on de petites lignes longitudinales onduleuses ou noirâtres. La spire est ordinairement d'un blanc roux, mouchetée de lignes allongées d'un marron noir. 
Long. 52 millim.

Habite l'océan Asiatique, les côtes de Ceylan et d'Amboine.

Espèce assez commune dans les collections; au premier aspect elle paraît se rapprocher, par sa forme et sa coloration, des $C$. arenatus et pulicarius. Mais on la distingue facilement de ceux-ci par sa spire, qui n'est jamais couronnée.

176. CONE SATINTE. Conus timorensis, BRdG.

(Collect. LaM.) Encyclop.pl. 341 , fig. 3.

Pl. LXXV, fig. 4.

G. testâ cylindraceo-turbinatâ, gracili, incarnatâ, albo-undatâ; zonâ obsoletâ intermediâ ; spirâ subcanaliculatâ, acuminato ; aperturâ hiante.

Coquille cylindrique, turbinée, étroite; sa spire est conique, à peine élevée, composée de dix tours finement striés, un peu concaves, et dont le bord extérieur forme un talus aigu très-prononcé. Le dernier tour est conique, atténué vers sa base qui porte un petit nombre de stries larges et peu profondes; le reste de la surface est lisse. L'ouverture est étroite, blanche à l'intérieur, tachetée d'incarnat ou de rose vif. Le bord droit est mince et tianchant; son extrémité supérieure est terminée par une échancrure profonde. La coquille est d'un fond incarnat ou rose mêlé de blanc, sur lequel se dessinent des rangées transverses de taches blanches et allongées, assez écartées entre elles, interrompues par des mouchetures de couleur incar- 
nat et comme articulées. La spire est d'un blanc rosé, tacheté d'incarnat.

\section{Long. 43 millim.}

Habite les mers des grandes Indes, des Moluques, les côtes de Timor.

Cette jolie espèce est bien distincte de ses congénères par sa forme et sa coloration.

177. CONE PEINT. Conus pictus, ReEve.

(Collect. Stalnforth:) Reeve, Conch. icon. pl. 18, fig. 98. Pl. LXVIII, fig. 4.

C. testâ oblongo-turbinatâ, tenuiculâ, subventricosâ, puniceo-bruneove et albo aiternatìm fasciatâ, fasciis interstitiisque fusco alboque identidem tœniatis et variegatis ; spirâ convexo-elatâ, ad marginem peculariter strigatâ.

Coquille petite, oblongue, turbinée, à spire peu élevée en angle obtus, composée de six ou sept tours étroits, striés transversalement; ils sont nettement séparés entre eux par un bourrelet décurrent qui s'élève au-dessus de la suture. Le dernier tour est large ; sa partie supérieure est carénée ; son extrémité inférieure est rétrécie : on y remarque quelques stries obliques. Tout le reste de la surface est lisse. L'ouverture est étroite, elle s'élargit insensiblement à son sommet; où elle est terminée par une échancrure profonde. Le fond de coloration est d'un rouge écarlate plus ou moins foncé; le dernier tour est orné de 
deux ou trois fascies transverses blanches, dont celle du milieu est la plus étroite; ces fascies sont peintes de petites taches irrégulières flammulées ou en zigzags, et de points bruns foncés. Une autre fascie de même disposition est placée à la base du tour. La spire est blanche, panachée de flammules plus ou moins arquées et d'un brun très-foncé.

Long. 26 millim.

Habite

La coloration de cette jolie Coquille est d'un caractère si particulier, qu'elle se distingue netlement des espèces qui en sont le plus voisines.

178. CONI MARRON. Conus castaneus, NoBts.

(Collect. de M. Gubba.)

Pl. CIV, fig. $\mathbf{3}$.

C. testâ turbinatà, supernè turgidâ, infrậ-coarctatâ; castaneâ, maculis albis irregulariter sparsis ; fasciâ obscurâ subspirali; spirâ exsertâ, mucronatâ.

Coquille turbinée, épaisse, formant un cône à base très-élargie, environ quatre fois plus large que son sommet ; les plans latéraux sont très-convexes, surtout vers leur milieu, au-dessous duquel existe un rétrécissement remarquable. L'angle spiral du dernier tour est saillant, quoique obtus, et on le retrouve sur les tours précédents. La spire est très-élevée, conique; étagée ; on y compte environ neuf tours obliquement aplatis en dessus. Cette coquille est d'un brun foncé ou marron, ornée d'une fascie étroite plus foncée au-dessous 
de l'angle spiral ; elle est en outre parsemée de taches blanches irrégulières, quelquefois très-ällongées, mais généralènent peu nombreuses, excepté sur la spire où elles, sont plus petites et en plus grande quantité.

\section{Long. 45 millim.}

\section{Habite}

Cette espèce est remarquable par sa forme très-élargie vers sa partie supérieure et rétrécie au contraire à sa base; sa couleur marron, parsemée de taches blanches, et sa spire assez élevée, servent encore à la distinguer.

179. CONE ONDÉ. Coñus undatus,' NoBls.

( Collect. de M. Delessert.)

Pl. XCXIV, fig. 1.

C. testâ turbinatâ, supernè inflatâ, transversim sulcatâ ; albidâ, flammulis castaneis undatis vividè pictâ; spirâ elatâ, acuminatâ, fusco variegatâ.

Coquille turbinée, très-élargie vers sa partie supérieure, ạtténuẹe et rétrécie à l'inférieure, à plans latéraux très-convexes. La spire est fort élevée, conique, acuminée et pointue vérs son sommet; elle est formée de dix tours environ, étroits et aplatis ; le dernier est légèrement aplati au-dessous de l'angle spiral qui est saillant et bien marqué. Sa superficie est traversée par des sillons qui deviennent plus rares et disparaissent même quelquefois sur le tiers supérieur de la coquille. La coloration consiste en un fond blanchâtre sur lequel se détachent de grandes maculations longitudi- 
nales assez larges, irrégulièrement contournées, et se transformant en zigzags sur la partie supérieure de la coquille; elles sont interrompues vers la base, et deviennent plús rẻgulièrement parallèles. La spire est également maculée de brun.

\section{Long. 32 millim.}

Habite l'océan indien.

Jolie espèce qui rappelle un peu par sä forme le Conus sinensis mais qui en diffère par ses sillons transvêrses, ainsi que par ses grandes flammules longitudinales brunes se détachant d'une manière bien nette sur le fond blanchàtre de la coquille.

M. Reeve a commis une erreur daus son Couch. icon. pl. 27, fig. 158 , en prenant cette coquille pour le Conus cingulatus de Lamarck.

180. CONE DISPARATE. Canus dispar, Sow.

(Collect. de M. Beraradi.) Sowerby, Conch. illust. fig. 57.

PI. CI, fig. 3.

C. testâ elongatâ, subcylindricâ, infernè angustâ; albâ, maculis castaneis irregulariter fasciatâque seriatịn punctatâ ; spirâ conicâ, flammulis nigris longitudinalibus pictâ.

Coquille petite, très-aHongée, subcylindrique, trèsétroite vers sa partie inférieure; les plans latéraux sunt irrégulièrement et légèrement convexes; celui qui correspond au bord droit est un peu concave. La spire ést médiocrement élevée et conique. Lả coquille est blanche avec de larges taches brunes irrégulières, formant 
des espèces de fascies ; entre ces taches on remarque des séries transverses de petits points bruns. La spire est de même maculée de brun, seulement les taches y sont plus petites et irrégulièrement quadrilatères. L'ouverture est de couleur fauve dans l'intérieur.

\section{Long. 24 millim.}

Habite la mer des Indes.

Jolie petite espèce remarquable par sa forme allongée, et surtout par ses grandes taches brunes et ses séries de petits points qui se détachent d'une manière très-nette sur le fond blanchâtre.

181. CONE DE IARGIhIIERT. Conus Largillierti, Nobis.

(Collect. de M. Largilliert.)

P1. XGVIII, fig. 3, et pl. CI, fig. 1-1^.

C. testâ ovatâ, basi' attenuatâ, coarctatâ; aurantio-fuscâ, medio-albifasciatâ, teniis angustis rưfo-fusco alboque articulatis undiquè cingulatâ; spirâ elatâ, acutâ, irregulariter tessellatâ.

Coquille un peu épaisse; à plans latéraux convexes et resserrés vers la naissance du canal; la spire est très-élevée, acuminée et pointue ; l'anğle spiral du dernier tour est bien marqué. Toute la surface est lisse à l'exception de la base qui porte trois ou quatre sillons transverses. La coquille est fauve ou roussâtre, avec des lignes transverses de petits points rouges ou orangés, très-rapprochés entre eux, commé articulés, et se confondant mêmé quelquefois ; ces lignes 
alternent avec d'autres lignes plus petites. Vers le tiers inférieur de la coquille, on aperçoit une fascie transverse formée dé taches blanchâtres irrégulières. La spire est maculée de taches rouges irrégulièrement quadrilatères.

\section{Long. 34 millim.}

Habite les côtes du Mexique.

Espèce fort remarquable, ayant quelque ressemblance avec le Conus japonicus, mais qui s'en distingue surtout par sa forme moins élargie vers la partie supérieure; elle présente d'ailleurs des variations assez notables ; ainsi, chez certains individus, les rangées de points sont beaucoup moins nombreuses et móins rapprochées entre elles, et quelquefois la coquille prend une teinte générale grisâtre. (Voir notre pl. 101, fig. 1, $1^{a}$.)

Nous avons dédié cette belle espèce à M. Largilliert, connu depuis longtemps par sa riche collection de coquilles.

182. CONE DE PEIIIPPI. Conus Philippii, NoBIs.

\section{(Collect. de M. Largiluert.)}

Pl. XGVIIl, fig. 2.

C. testâ turbinatâ, basi attenuatâ, albo-luteâ, punctis rubris transversìm seriatìm ornatâ; spirâ elatâ, exsertâ, fusco-maculatâ.

Coquille turbinée, très-régulièrement conique et très-atténuée vers sa partie.inférieure. L'àngle spiral, bien marqué et saillant sur les premiers tours, s'efface le plus souvent sur le dernier où il est obtus et ar. rondi. l.a spire est élevée, acuminée et pointue; on y 
compte neuf ou dix tours étagés. La coloration consiste en un fond blanc ou jaunâtre sur lequel sont disposées trạnsversalement des séries nombreuses et régulièrés de petits points rouggeâtrés. Ces séries sont plus rapprochées entre elles sur quelques parties de la coquille et ont tendance à former des fascies. L'angle spiral offre au lieu de points, des maculations brunes irrégulières quel'on retrouve sur la spire; celleci est généralement plus claire que le reste de la coquille.

\section{Long. 36 millim.}

Habite les côtes du Mexique.

Jolie espèce voisine de notre Conus Largillierti par son mode de coloration, mais qui en est fort distincte par sa forme générale. Nous l'avons dédiée à M. Philippe de Cassel, amateur fort distingué. Cette rare coquille nous a été communiquée par M. Largilliert.

183. CONY CANTIDE. Conus candidus, NobIS.

(Collect. de M. Bernardi.)

Pl. XCVII, fig. 1.

C. testâ elongato-tarhinatâ, ad basim attenuatâ; albâ, punctis minimis fuscis regulariter seriatis; spirâ elatâ, acutâ, variegatâ, apice fusco.

Coquille élancée, très-atténuée vers sa partie inférieure óu elle paraît comme étranglée. La spire est fort élevée, acuininée et pointue ; on y compte onze ou douze tours étroits, étagés entre eux, portant un 
angle bien marqué sur leur partie externe. La suture est finement marquée; le dẹrnier tour est lisse jusqu'à sa base qui offre cinq ou six gros sillons transverses. Cette coquille est blanche avec des séries transverses de petits points bruns très-régulièrement espacés entre eux: La spire est parsemée de taches brunes et obliques. Le sommet est entièrement coloré de brun.

\section{Long. 31 millim.}

\section{Habite}

Cette espèce, de forme élégante, est remarquable par les séries transverses de petits points bruns dont elle esst ornée.

184. CONE CHAGRINE⿱一. COnus granarius, NoBLS.

(Collect, de M. Bernardi.)

Pl. XGVIII, fig. 1 .

C. testâ oblongâ, supernè dilatatâ, subinflatâ, infernè coarctatâ; granulis creberrimis seriatim dispersis ornatâ; fuscâ, maculis obscuris pictâ; spirâ exsertâ, acuminatâ, medio subnodulosâ.

Coquille turbinée, large vers sa partie supérieure, atténuée vers sa base; la-spíre est très-élevée; acuminée, puintue au sommet, un peu étagée. On y compte une dizaine de tours étroits et anguleux; les premiers et les derniers sont lisses, les autres sont couronnés sur leur angle d'une rangée de petits tubercules. Toute la surface du dernier tour est chargée de petits 
grains saillants disposés en séries transverses trèsnombreuses et comme articulées. La coquille est d'un blanc verdàtre, parsemé de grandes taches brunes irrégulières; la spire est pourvue des mêmes taches, à l'exception des premiers tours 'qui sont d'un brun clair uni.

$$
\text { Long. } 35 \text { millim. }
$$

\section{Habite}

Cette jolie espèce est très-facile à distinguer à cause des séries de granulations dont elle est ornée. Ses grandes maculations brunes ont quelquefois tendance à former des fascies.

Nous devons la connaissance de cette nouvelle espèce à M. Bernardi, dont nous ne pourons trop louer l'obligeance.

185. CONE AUUCRONÍ. Conus mucronatus, ReEve.

(Collect. de M. Delessert.) Reeve, Conch. icon. pl. 57 , fig. 204.

Pl. XCII, fig. 1.

C. tẻstâ acuminato-turbinatâ, basim versùs attenuatâ, transversim sulcatâ, striis longitudinalibus, subcancellatis; albidâ, maculis fulvis minimis ornatâ ; spirâ acuminatâ, fuscọ palidè maculatâ.

Coquille subcylindrique, allongée, à peu près régulièrement conique. La spire est élevée, excavée, acuminée et mucronée au sommet; on y compte dix ou douze tours légèrement convexes, marqués de stries fines et décurrentes. L'angle supérieur du dernier est obtus et un peu arrondi, toute la surface est traversée par des sillons parallèles et espacés entre eux, au nom- 


$$
\text { GENRE CÔNE. }
$$

bre de vingt environ : ces sillons sont coupés par des stries longitudinales qui donnent à la coquille une apparence cancellée. La coloration, extrêmement simple, consiste en un fond blanchâtre parsemé de petites taches d'un jaune pâle. La spire est marquée de taches plus pâles.

\section{Long. 28 millim.}

IIabite les côtes des îles Philippines.

Par sa forme, cette espèce se-rapproche du Conus Lorenzianus, mais elle est beaucoup plus petite et son système de coloration est atussi bien différent.

186. CONE ĹPER VISR. Conus nisus, Chexs.

(Collect. de M. Deuesserr.) Chemnitz, t. XI, pl. 185, fig. 1786-1787.

PL. LIX, fig. 4

C. testâ turbinatâ, basi angustiore; cinerascente, maculis margis et rufis tinctâ, fasciatâ, lineis transversis punctatâ; spirâ conícâ, . exsertâ, maculatâ, fauce brunneâ.

Coquille turbinée, très-large vers sa partie supérieure, atténuée à sa base et légèrement rétrécie vers son milieu. La spire est assez élevée, régulièrement conique, formée de huit tours un peu convexes et faiblement étagés. La surface est lisse, à l'exception de la base du dernier tour qui présente sept ou huit sil- 
lons transverses et parallèles entre eux. La coloration consiste en un fond grisâtre articulé de petits points bruns disposés par séries transverses, très-rapprochés les uns des autres, et de grandes taches fauves ou rougeâtres nuageuses disposées sur le dernier tour de manière à former trois fascies transverses. L'angle supérieur de ce tour est orné d'une série de points noirs assez distants entre eux et que l'on retrouve sur les tours précédents ; ceux-ci sont, en outre, parsẹmés de petites taches fauves. L'auverture est itroite et colorée de brun.

\section{Long. 35 millim.}

Habite les côtes de Madagascar.

Cette espèce rappelle un peu par sa forme le Conus cedonulli, mais elle n'est pas couronnée; sa coloration aussi olfre quelque ressemblance avec celui-ci, mais elle est beaucoup plus compliquée et les. taches qui la constituent sont plus larges et plus rares.

187. CONE jJASPÉ, Conus jaspideus, NoBts.

(Collect. Masséna.)

PI. LV, fig. 4.

C. testâ turbinatâ, ovato-conicâ,' basi attenuatâ, crebérrimè sulcatâ, punctis seriatim dispositis, flammulis undulatis characteribus aurantio-fuscis ornatâ, fasciâ aurantiầ supernẻ cingulatâ ; spirâ conicâ, fuscọ radiatim strigatâ ; apicẹ roseo.

Coquille ovale, conique, turbinée, atténuée vers la 
partie inférieure et légèrement renfléé au milieu ; elle est formée de six tours ; l'angle supérieur du dernier est un peu obtus. La spire est médiocrement élevẻe, conique; la suture est profonde et bien marquée Le dernier tour est lisse jusqu'à la partie inférieure qui est garnie d'une douzaine de sillons transverses trèsfins et parallèles entre eux. Le fond de coloration est blanc avec des séries transverses de petits points et des flammules longitudinales irrégulièrement onduleuses, d'un brun fauve ou orangé, formant des espèces de fascies. La partie supérieure du dernier tour est ceinte d'une fascie assez large, bien nettement accusée et d'un jaune orangé. La spire est veinée de flammules longitudinales de couleur fauve et disposées en rayons. Le sommet a une teinte rosée.

\section{Long. 33 millim.}

Habite la baie d'Algóa.

Cette jolie espèce a la forme générale du Conus mediterraneus, mais sa coloration la rend aussi distincte de ce cóne que de tous les autres. Elle est surlout remarquable par la fascie orangée bien marquéc qui entoure la portion supérieure de son dernier tour.

188. CONg pLovieuX. Conus nimbosus, Breg.

(Collect. LaM.) Encyclop. pl. 341 , fig. 5.

Pl. XLV, fig. 4.

C. testâ subcylindraceâ, tứrbinatâ, transversìm sulcatâ; albido roseâ, punctis lineolisque rufo purpureus aut fuscis fasciiis ọbsoletis; spirâ subdepressâ, striatâ; mucronatâ.

Coquille turbinée, subcylindrique, renflée vers le 
milieu, rétrécie vers sa partie: supérieure. La spire est peu élevée, acuminée. On y compte huit ou neuf tours étroits, Iisses, très-légèrement striés et creusés d'une sorte de gouttière peu profonde. Toute la surface du dernier est traversée par des stries assez fines, parallèles entre elles et comme articulées par de petits points bruns ou pourpres plus ou moins rapprochés les uns des autres. Deux grandes taches fauves formant deux fascies assez larges et, obscures, occupent le dernier tour. Le fond de la coquille est d'un blanc rosé.

$$
\text { Long. } 50 \text { millim. }
$$

Habite les mers des grandes Indes, les côtes de Ceylan.

Cette espèce, assez rare dans les collections, est d'une coloration remarquable par son élégance et sa simplicité.

189. CONE DE BRRMARDI. Conus Bernardii, Nóbis.

\section{( Collect: de M. Bernardi.)}

Pl. C, fig. 2.

C. testâ turbinatâ, subcylindricâ, transversim sulcatâ; fulvâ, maculis albis sparsis vel supernè aggregatis in fascio fusco; spirâ striatâ, apice mucronatâ.

Coquille allongée, subcylindrique, à plans latéraux très-légèrement convexes, à angle spiral arrondi et obtus. La - spire est conique, médiocrement élevée et mucronée au sommet. Toute la surface du dernier 
tour est traversée par des sillons distants entre eux, surtout vers sa partie inférieure. La coquille est de couleur fauve, avec des maculations irrégulières blanchâtres et peu nombreuses, si ce n'est vers l'angle spiral où elles couronnent une fascie brune qui se retrouve sur les premiers tours. En outre, la spire est chargée de stries longitudinalès parallèles à l'axe de la coquille.

\section{Long. 44 millim.}

\section{Habite}

Jolie espèce bien distincte de ses congénères par sa forme élégante, par les sillons dont elle est traversëe et par la fascie brune tachetée de blanc qui décore la partie supéricure de son dernier tour.

Nous nous faisons un plaisir de la dédier à M. Bernardi, bien connu par son zèle pour la conchyliologie.

I90. C,ONY DE BRUGUIHRE. Conus Bruguieri, NoBIs.

$$
\begin{gathered}
\text { (Collect. de } \mathrm{M}^{\mathrm{m} \theta} \text { Dupont.) } \\
\text { Pl. LVI, fig. } 2 .
\end{gathered}
$$

C. testâ subcylindricâ, elongatâ, basi'coarctatâ ; olivaceo-fuscâ, cum lineis obscuris et punctis albis articulatâ; fasciâ angustâ superiore ultimo anfractu obscurâque albo variegatâ in parte inferiore; spirâ conicâ, maculatâ.

Coquille subcylindrique, étroite, allongée, légèrement renflée vers le milieu, très-rétrécie à sa base; elle se compose de six ou sept tours faisant légèrement saillie les uns sur les autres. Le dernier est à peine anguleux vers son sommet; il est lisse jusqu'au 
canal où quatre ou cinq sillons sont faiblement indiqués. La coquille est d'un brun olivâtre plưs ou moins foncé, quelquefois presque noir, avec des lignes transverses étroites et en grand nombre, de couleur obscure et articulées de petits points blancs. Vers le tiers inférieur de la coquille on voit une fascie étroite blanchâtre sur laquelle sont disposées des taches irrégulières d'un blanc de lait et dans leur intervalle d'autres taches de couleur fauve. L'angle supérieur du dernier tour est également pourvu d'une ligne blanchâtre ou brune plus étroite et maculée. La spire offre aussi des taches blanchàtres, mais moins afférentes. La suture est liserée de fauve.

$$
\text { Long. } 38 \text { millim: }
$$

\section{Habite}

Espèce confondue par Bruguière avec le Conus jamaicensis, et constituant sa variété $\mathrm{B}$. Sa forme plus allongée, cylindracée, sa spire conique ainsi que sa coloration la rendent facilement distincte. Elle a d'ailleurs assez l'aspect du Conus mediterraneus.

Nous dédions ce Cônè au savant auquel: la science est redevable d'articles si remarquables sur la conchyliologie, dans l'encyclopédie méthodiqué.

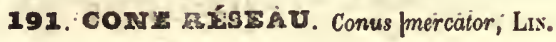

(Collect. Lam.) Lister, Conch. f. 788, fig. 41.

Pl. LIV், fig. $3 \dot{d} \mathbf{z}^{\mathrm{d}}$.

C. Testâ ovato-oblongâ, angulo spirali obtuso; albo-luteâ, fasciis reticulatis flavis aut nigris cinctâ; spirâ subdepressâ, apice mucronatâ.

Coquille ovale, oblongue, conique, à plans latéraux 
légèrement convexes. L'angle supérieur du dernier tour est arrondi et obtus. La spire est peu élevée, conique et nucronée au sommét. La partie súpérieure du canal porte quelques larges sillons. Le fond de la coloration est jaunâtre avec des linéoles très-régulièrement entrelacées de manière à former un réseau plus ou moins fin; ce réseau. est disposé par fascies transverses, en général au nombre de deux : l'une plus large et occupant la partie supérieure du dernier tour; l'autre située vers le tiers inférieur. Dans certaines variétés ce réseau est très-irrégulier et ne forme pas de fascies bien déterminées; dans d'aütres il se réduit à de simples taches disposées en fascies; le reste de la coquille étant d'ailleurs d'un brun foncé.

Long. 36 millim:

Habite les côtes d'Afrique et la mer de Indes.

Cette jolie petite espèce, fort commune dans les collections, est trèsremarquable par le réseau de linéoles brunes dont elle est ornée, réseau tantôt très-tin, tantôt à mailles assez larges, perdant quelquefois toute sa régularité en même temps que le fond, ordinairement jaunâtre, devient d'un brun foncé. (Voir, pour les variétés, les figures $\mathbf{3}^{\mathfrak{a}} \mathbf{a ̀ ~}^{\mathbf{d}}$.) 
192. CONE PETIT COIN, Conus cuneolus, ReEvE.

(Collect: de M. Gubba.) Reeve, Conch. icon. pl. 57, fig. 205. $a-b$.

Pl. XCII, fig. 3-3".

C. Testâ abbreviato-turbinatâ, supernè obesâ, subinflatâ; fuscâ; maculis albidis paucis parvis, irregulạribus, subtrigonis, fasciatim aspersâ ; fasciâ albidâ, fusco pallide strigatâ ; spirâ convexo-obtusầ.

Coquille turbinée, large et renflée vers sa partie supériẹre, atténuée vers la base; , elle est formée de six tours légèrement convexes en dessus. Le dernier, dont l'angle est árrondi, est lisse jusqu'à sa base qui est garnie de sept ou huit sillons obliques et parallèles. La coloration consiste en un fond d'un blanc jaunâtre ou rouge sur lequel se détachent de petites: taches blanches formant des fascies transverses et produisant, dans certains cas, un véritable réseau ; l'une de ces fascies est située au-dessous de l'angle spiral, l'autre occupe le tiers inférieur de la coquille; entre celles-ci, il en existe une troisième moins bien limitée, formée de taches plus rares et plus espacées entre elles. La spire est quelquefois aussi tantôt maculée de blanc, tantôt d'un brun trếs-clair uni.

\section{Long. 34 millim.}

\section{Habite}

Cette espèce est très-voisine du Conus mercator, soit par sa forme, soit par son mode de coloration; elle est cependant plus renflée vers son sommet, et le réseau que forment ses taches n'est pas aussi nettement dessiné. 
193. CONE ÉTOIIÉ. Conus stellatus, NoBss.

\section{( Collect. de M. Beríardi.)}

PI. XCIX, fig. 3.

C. testâ turbinatâ, subcylindricâ; fuscâ, lineis tenuissimis reticulatis passìm obscuris ornatâ; spirâ convexâ, apice mucronatâ.

Coquille subcylindrique, légèrement renflée, à angle spiral arrondi et obtus. La spire est un peu élevée, arrondie et mucronée au sommet; toute la surface est lisse, à l'exception du tiers inférieur qui porte une douzaine de stries transverses parallèles très-fines. La coloration consiste en un fond d'un brun foncé, sur lequel se détache un réseau de linéoles extrêmement fines, peu distinctes, dans certains endroits, du fond lui-même, et laissant voir, dans d'autres parties, des taches blanches un peu plus grandes et irrégulièrement triangulaires. La spire offre le même système de coloration, mais un peu plus foncé, excepté cependant sur son sommet dont la teinte est plus claire. L'ouverture est b!anclıe dans l'intérieur.

$$
\text { Long. } 20 \text { millim. }
$$

Habite

Cette charmante petite espéee a beaucoup d'analogie avec le Conus mercator; elle est cependant plu; petite; sa forme est un pelı plus allongée, et le réseau qui l'enveloppe est beaucoup plus fin et ne forme pas de fascies transverses. 
194. CONE FEIGEUX. Conus nivosus, LAM.

\author{
( Collect. LaM.) \\ Pl. LXXXI, fig. 1 à 1f.
}

C. testâ crassâ, turbinatâ, pallidè luteâ aut fuscâ, maculis niveis quadrangularibus vel triangularibus sparsis ; spirâ brevi, plano-obtusâ, leviter mucronatâ.

Coquille épaisse, turbinée, légèrement renflée vers sa partie supérieure; la carène du dernier tour est un peu obtuse. La surface est lisse, à l'exception de la base qui est marquée de sept sillons transverses et parallèles. La coloration, extrêmement variable, consiste ordinairement en un fond jaunâtre ou citron très-pâle, sur lequel se détachent des maculations ovales ou quadrangulaires assez larges et blanchâtres; quelquefuis ces maculations ont une forme irrégulièrement triangulaire et sont disposées en fascies transverses vaguement indiquées; mais dans les jeunes individus elles sont plus nombreuses, mieux marquées et d'une couleur brune ou jaunàtre uniforme. Chez quelques individus, le fond de coloration est sillonné de quelques lignes étroites, brunes, interrompues par les maculations blanchàtres qui alors sont plus allongées et produisent des espèces de flammules. La spire est surbaissée, légèrement acuminée et mucronée au sommet. Dans les jeunes individus elle est plus obtuse.

Long. 48 millim.

Habite les mers d'Amérique. 
Cette eśèce, extrêmement variable de coloration, a été établie sur des individus d'un jaune citron très-pâle, avec des taches d'un blanc de lait, mais le plus ordinairement le fond est beaucoup plus foncé, jauıàtre ou brunâtre.

Dans une note de la deuxième édition du système des animaux sans vertèbres de Lamarck, M. Deshayes dit, à l'occasion de cette espèce, qu'elle est la même que le $\boldsymbol{C}$. venulatus du Bruguières; nous ne partageons pas cette opinion, et nous croyons les deux espèces bien distinctes. Le $C$. venulalus est beaucoup moins large vers sa partie supérieure qui est arrondie; sa spire est plus obtuse, conique et non acuminée; sa coloration est aussi très-différente. 11 n'en est pas de même du $C$. nivifer de Broderip, que nous regardons comme une simple variété du C. nivosus.

(Voir, pour les variétés de coloration de ce dernier Cône, nos fig. $1_{\text {“ }}$ à $1 f$, même planche 81 .)

195. CONE hÉPATIQUE. Conus hepaticus, NoBrs.

\section{(Collect. de $\mathrm{M}^{\mathrm{me}}$ Dupont. )}

Pl. XCVII, fig. 3.

C. testâ turbinatâ, crassâ, transversìn sulcatâ; luteo-virescente; spirâ depressâ, mucronatâ.

Coquille turbinée, formant un cône assez régulier, à plans latéraux, très-légèrement convexes. La spire est très-surbaissée, à peine mucronée : elle est formée de sept tours légèrement excavés et canaliculés el. dessus. Toute la surface du dernier est traversée de stries fines et parallèles, groupées par faisceaux, de manière à laisser voir un intervalle assez large entre chacun des groupes. La coquille est verdâtre ou légèrement jaune en certains endroits. 
Long. 40 millim.

Habite

Espèce bien facile à distingúer à cause de sa forme régulière, de la disposition des stries de sa surface, el surtout de sa teinte uniforme.

196. CONE MODIFER. Conus nodiferus, NoBIs.

(Collect. de M. Bernardi.)

Pl. C, fig. 4.

G. testâ elongato-turbinatâ, transversim sulcatâque granulosâ ; spirâ elatâ, acuminatâ, angulatâ ; angulo maeulis fuscis articulatâ.

Coquille allongée, formée de deux cônes oppo̊sés base à base : l'un, plus grand, constitue le dernier tour ; il est assez régulier, très-atténué vers sa base, et porte, sur toute son étendue, des sillons transverses dans l'intervalle desquels il existe des séries de petites granulations; l'autre, plus petit et formant plus du tiers de la longueur totale, constitue la spire; celle-ci est très-élevée, conique et acuminée; on y compte sept ou huit tours un peu étagés , aplatis en dessus et marqués, sur leur partie externe, d'un angle assez saillant; cet angle a uné teinte blanche et est articulé de petites taches brunes, rougeâtres, qui le font paraître noduleux. Tout le reste de la coquille est jaunåtre.

Long. 38 millim.

Habite la mer des Indes. 
Charmante petite espèce, remarquable par sa torme réguliere, par l'élévation de sa spire, sa surface grenue et les sillons de son dernier tour.

197. CONE RAYÉ. Conus scalptus, REEve.

(Collect. de M. Galluadd.) Reeve, Conch. icon. pl. 37, fig. 203.

Pl. LV, fig. 3.

C. testâ turbinatâ, solidiusculâ, politâ ; albidâ, filis rubidis numerosis cinctá, spirâ conico-obtusâ, spiraliter striatâ, rubro fuscoque variegatâ.

Coquille épaisse, turbinée, formant un cône peu élevé, à plans latéraux légèrement convexes, principalement vers l'angle spiral, qui est arrondi et obtus. La spire est médiocrement élevée, conique, composée de six tours marqués en dessus de légères stries décurrentes. La coloration consiste en un fond blanchâtre, sur lequel se détachent un grand nombre de petites lignes transverses rouges. La spire présente de grandes maculations généralement allongées, et d'un brun rouge.

$$
\text { Long. } 30 \text { millim. }
$$

Habite

Espèce bien remarquable et bien distincte de ses congénères à cause des lignes transverses rougeâtre dont elle est ornée. 
198. CONE INFO

(Collect. Lam.) KNorr. Vergn. 2. t. 1, fig. 6.

Pl. LI, fig. 2, 2a.

C. testâ oblongo-turbinatâ, sæpiùs informi, albâ, maculis elongatibusque irregularibus castaneis ornatâ ; spirâ convexo-acutâ maculatâ.

Coquille turbinée, cylindracée, de forme variable, à angle spiral quelquefois saillant et un peu arrondi, quelquefois effacé en se confondant plus ou moins avec les plans latéraux qui sont alors légèrement convexes. La spire est assez élevée, conique et un peu renflée; quelquefois elle est un peu excavée et acuminée au sommet. La partie inférieure du dernier tour porte quinze sillons transverses parallèles et bien accusés. La coloration consiste en un fond blanchâtre légèrement nuancé de rosé ou fauve, sur lequel se détachent de grandes flammules longitudinales très - irrégulières, d'un brun foncé, formant tantôt des zigzzags, tantôt des espèces de lignes transverses articulées; la spire est de même maculée de brun.

Long. 62 millim,

\section{Habite l'océan Américain.}

Ce Cône, dont la forme est encore plus irrégulière que celle du Conus mozambicus, a la plus grande ressemblance avec un jeune strombe, et Bruguières avait été tenté de le considérer comme tel; mais il appartient réellement au genre cône. Il présente, chez quelques individus, une particularité bien remarquable; c'est la présence d'un renflement qui le rend comme bossu. 
GENRE CÔNE.

199. CONa mozambiQUE. Conus mozambicus, Brug.

(Collect. Lam.) Chemn. Conch. 10, t. 144; , fig. I. K.

Pl. LI, fig. 1 à $1^{\mathrm{c}}$.

G. testâ oblongu-turbinatâ, supernè inflatâ; fuscâ aut fulvâ, maculis albisque fuscis fasciatâ, lineis transversis articulatis; spirầ convexiusculâ sæepiùs striatâ.

Coquille oblongue, subcylindrique, renflée vers sa partie supérieure, à plans latéraux léģèrement convexes. La spire est médiocrement élevée et conique; on y compte cinq ou six tours un peu convexes, marqués le plus souvent de stries fines et décurrentes. L'angle supérieur du dernier tour est arrondi et obtus. Toute sa superficie est lisse, à l'exception de sa partie inférieure qui porte une quinzaine de sillons transverses, fins et parallèles. La coijuille est brune ou de couleur fauve, parsemée de taches blanches et brunes, formant, un peu au-dessous du milieu du dernier tour, une fascie tantôt simple, tantôt divisée. Le plus souvent le reste du dernier tour est traversé par des lignes articulées de blanc et de brun, et les points bruns, bien régulièrement disposés les uns au-dessus des autres, se confondent et forment des espèces de flammules longitudinales. La spire est ornée, en général, de maculations allongées, alternativement brunes et blanches.

Long: 50 millim.

Habite la côte occidentale de l'Afrique vers le cap de Bonne-Espérance. 
Cette espèce présente d'assez grandes variations de forme el de coloration; cependant celle-ci se réduit, en dernière analyse, à des maculations brunes et blanches formant la fascie du dernier tour et des lignes transverses articulćcs de blanc et de brun. (Voir, pour les variétés, nos fig. $1 a$ à $1 c$, même planche š1.)

200. CONI BACHeiter. Conus coelebs, Hinds.

(Collect. de M. Delessert.) Reeve. Conch.icon. pl. 1 5. fig. 64 .

Pl. LI, fig. 5.

C. testâ oblongâ, subpyriformi, albâ, ad apicem basimque violaceâ obscurè fasciatâ ; epidermide corneâ, olivaceo, crasso, transversim lineato.

Coquille turbinée, très-élarggie à sa partie supérieure; atténuée à sa base, à plans latéraux à peine convexes. L'angle du dernier tour est obtus. La spire est très-surbaissée et mucronée au sommet; toute la coquille est blanchâtre, excepté le sommet de la spire et la partie inférieure du dernier tour qui sont viola. cés; vers le milieu du même tour on aperçoit une fascie transverse brune assez large. Cette coquille est ordinairement recouverte d'un épiderme olivâtre, épais, relevé de lignes transverses squammeuses assez saillan. tes et à distances égales entre elles.

Long. 28 millim.

Habite les mers des Moluques.

C'est avec le Conus mozambicus que cette espèce a le plus de ressemblance par sa forme. Elle rappelle aussi le Conus mercator, mais elle est plus allongée, et d'ailleurs sa coloration l'en distingue. 
201. CONI TAUPIN. Conus cinereus, But.

(Collect. Lam.) Rumph. Mus. t. 32, fig. R.

PI. XLVI, fig. 1 à̀ 1 .

C. testâ oblongo-turbinatâ, supernè retusâ, infernè attenuatâ, basi „sulcis distantibus cinctâ ; cinereo-cærulescente, fasciatâ, maculis fuscis lineisque punctatis ; spirâ convexâ, mucronatâ aliquandò acuminatâ.

Coquille oblongue, turbinée, large et obtuse vers. sa partie supérieure, atténuée à sa base. Les plans latéraux sont irrégulièrement convexes. L'angle spiral du dernier tour est arrondi et obtus; la moitié inférieure de ce tour est marquée de sillons transverses très-espacés entre eux. La spire est ordinairement surbaissée, convexe, mucronée au sommet ; quelquefois elle est plus élevée, conique et légèrement acuminée. La color tion est assez variable; elle consiste, le plus souvent, en un fond cendré ou tout à fait fauve, sur lequel se détachent des maculations irrégulières, brunes, disposées par fascies, et dans l'intervalle desquelles sont placées des lignes ponctuées de même couleur. La spire est également munie de grandes taches brunes, allongées et comme radiées.

\section{Long. 36 millim.}

Habite l'océan Asiatique et les côtes des îles Philippines.

Cette espèce, variable dans sa coloration, l'est aussi dans sa forme, qui est plus ou moins allongée. Chez certains individus, la coloration est plus foncée, les taches plus grandes, moins arrêtées, et les fascies 
peu ou point marquées; voir notre fig. $1^{b}$. Chez d'autres, au contraire, les points sont très-petits, peu nombreux, et la coquille est presque entièrement d'un gris cendré ( fig. $1^{c}$ ). Dans la fig. $1^{a}$ les taches, larges et régulièrement espacées, sont d'une teinte roussâtre. Le caractere qui sert le plus particulièrement à distinguer cette espèce consiste dans les sillons transverses du dernier tour.

202. CONI RAIELET. Conus stramineus, LAM.

(Collect. du Mus )

PI. XLVI, fig. 2.

C. testå oblongo-turbinatấ, albidâ, maculis subquadratis, pallidè fulvis ornatâ : basi sulcis transversis distantibus ; spirâ subdepressâ, acutâ, acuminatâ ; spiralites striatâ, maculis fuscis nuajoribus pictâ.

Coquille oblongue, de forme régulière, légèrement rétrécie vers sa partie inférieure. La spire est peu élevée, concare et acuminéê : on y compte huit ou neuf tours aplatis en dessus et marqués de stries décurrentes; le dernier porte à sa base quelquess sillons trèsespacés entre eux. Sur un fond blanclıàtre cette coquille est garnie de peitites taches quadrangulaires jaunâtres on d'un brun pâle, régulièreinent disposées en séries transverses; vers le tiers inférieur du dernier tour, ces séries, étant plus espacées entre elles, produisent une sorte de fascie divisée par un rang de taches. Les premiers tours de la spire sont fanves ou brunàtres; le dernier est marqué de taches quadrangulaires plus grandes que toutes les autres, et d'un brun plus foncé.

Long. 38 millim.

Habite l'océan Asiatique. 
Espèce remarquable par la légularité parlaite de sa forme et par son angle spiral bien marqué, mais surtout par les séries de taches quadrangulaires qui la couvrent. Elle se rapproche du $C$. cinereus de Lamarck, mais elle esı plus étroite et plus régulièrement conique.

203. CONE ANÉmON Z. Conus anemone, LAM.

(Collect. Lam.) Reeve, Conch. icon. pl. 25, fig. $139^{a-b}$.

Pl. XLVI, fig. $\mathbf{3}$ à $\mathbf{3}$ b.

C. testâ oblongo-turbinatâ, striiis transversis crebris elevatis; albido-cinereâ vel cinnamomeâ, maculis fuscis aut castaneis undatâ, fasciâ albidâ; spirâ brevi, conicâ, tenuissimè striatâ.

Coquille oblongue, turbinée, légère, formant un cône un peu irrégulier, à plans latéraux presque droits, mais arrondis et obțis vers l'angle spiral. Toute la surface est traversée par des stries extrêmement fines et nombreuses; celles de la partie inférieure sont un peu plus fortes et plus espacées entre elles. La spire est médiocrement élevée, conique et acuminée.

Cette coquille est, ordinairement d'un gris cendré, avec des taches allongées, irrégulières, d'un brun plus ou moins foncé; il reste assez souvent une partie blanchâtre vers le tiers inférieur du dernier tonır, et il n'est pas rare d'en voir une astre un peu plus étroite au-dessus de celle-ci.

$$
\text { Long. } 45 \text { millim. }
$$

Habite les côtes de la Nouvelle-Hollande.

Cette espèce est d'une forme légèrequi suffirait à la distinguer; mais elle est encore remarquable par les stries fines et nombreuses qui cou- 
vrent sa surface. Dans certaines variétés les fascies manquent complétement, et la coquille prend une teinte générale brunâtre ou jaunàtre, sur laquelle les maculations se détachent en blanc. (Voir fig. $3^{a}, 3^{b}$, même planchc 46. )

204. CON I MOINE. Conus monachus, Lis.

(Collect. Lam.) KnorR, Vergn. 3, t. 16, fig. 2.

Pl. L, fig. 1 à $1^{d}$.

C. testâ oblongâ, subcylindricâ, basi sulcatâ, fusco et albo-cærulescente undatâ ; spirâ brevi conicâ, obtusiusculâ.

Coquille oblongue, subcylindri ${ }_{1} u e$, à plans latéraux convexes; elle est formée de six ou sept tours marqués de stries décurrentes; l'angle du dernier est arrondi et obtus. La spire est un peu élevée, conique et plus ou moins mucronée au sommet. La coloration consiste en maculations brunes et blanchâıres irrégulièrement entremêlées et donnant à la coquille un aspect nébuleux. Le plus souvent il existe, vers l'angle spiral, une fascie étroite; articulée de taches blanchâtres.

\section{Long. 45 millim.}

Habite l'océan Asiatique.

Cette espèce est remarquable par sa forme oblongue et surtout par scs nébulosités brunes ct blanches qui présentent des variétés assez notables; tantôt ce sont les maculations blanches qui dominent, tantôt ce sont les bruncs; chez cẹrtains individus elles sont plus petitcs, plus pâles, quelquefois presque nulles, et toute la superficie du dernier tonr est traversée par des lignes brunes articulées de petits points blancs. (Voir les fig. 1a, 1d, même planche šo.) 
GENRE CONNE.

205. CONE ROXAUTÉ. Conus regalitatis, Sow.

(Collect. du Mus.) Sowerby, Conch. illust. fig. 87.

PI. XXXIX, fig. 3.

C. testâ ovato-turbinatâ, lævi, crassiusculâ, supernè ventricosâ; spadiceâ, fasciâ albo-cærulescente, punctis fuscis articulatâ, maculis cærulescentibus passim variâ; spirâ depressiusculâ, spiraliter sulcatâ; basi lineis elevatiusculis paucis subgranosis.

Coquille épaisse, turbinée, lisse, très-renflée vers sa partie supérieure, à plans latéraux légèrement convexes. La spire est très-surbaissée et marquée de stries décurrentes; l'angle spiral du dernier tour est arrondi et obtus; vers la base de ce tour on observe quelques stries obliques un peu granuleuses. La coquille, d'un rouge brun foncé, est traversée par des lignes nombreuses plus obscures; vers le tiers inférieur du dernier tour, il existe une fascie d'un blanc bleuâtre, à bords festonnés, au milieu de laquelle sont tracées deux lignes brunes articulées ; la partie supérieure du canal est d'un blanc bleuâtre; des taches de même couleur sont éparses sur différentes parties, mais forment quelquefois, au-dessous de la spire, une série transverse; l'angle spiral et le sommet de la coquille sont d'une teinte plus claire et sont parsemés de taches semblables.

Long. 62 millim.

Habite l'océan Pacifique, les côtes du Pérou. 
Ce Cône a quelque analogie avec le Conus prarpuraceus de Broderip, mais il est plus raccourci ; sa spire est aussi plus courte, sa coloration plus uniforme et plus foncée, les taches nuageuses qui existent dans le Conus purpuraceus n'étant représentées dans celui-ci que par une fascie et quelques maculations isolées.

206. CONE CaÉTIF. Conus pauperculus, Sow.

(Collect. de M. Stainforth.) Sowerby, Conch. illust. fig. 78.

PI. LXXIl, thg. 3.

C. testâ subcylindraceâ, conico-elongatâ ad basim coarctatâ; fusceâ, punctis nigris minimis seriibus transversis dispositiš, fasciâ albâ, submediâ; spirâ conicâ. læviter acuminatâ, maculis nigris elongatis pictâ.

Coquille subcylindrique, allongée, à plans latéraux légèrement convexes vers leur partie moyenne, concaves et resserrés à leur base. La spire, médiocrement élevée, est conique et acuminée; l'angle spiral du dernier tour est obtus; vers la base de ce tour on aperçoit quelques légers sillons obliques. La coquille, d'un fond brun clair, est couverte de séries transverses de très-petits points noirâtres; un peu au-dessous du milieu du dernier tour, il existe une fascie blanchâtre faiblement indiquée. La spire est marquée de taches noirâtres, allongées et très-rapprochées entre elles.

$$
\text { Long. } 23 \text { millim. }
$$

Habite

Cette jolie petite espèce, que nous ne connaissons que par la figure qu'en a donnée M. Reeve, est remarquable par sa forme allongée et surtout par ses séries de petits points noirs. 
207. CONE SILCOINIE. Conus exaratus, REEVE.

(Collect. de $\mathrm{M}^{\mathrm{me}}$ Dupont.) Reeve, Conch. icon.pl. 44, fig. 238.

Pr. LXXII,-fig. 6.

C. testâ turbinato-conicâ, elongatâ, supernè inflatâ, ad basim attenuatâ ; transversim sulcutâ, sulcis regularibus latiusculis, interstitiis, subtilissimè striatocancellatis ; pallidè cærulẹo-purpureâ, punctis minimis, seribus transversis maculis ferruginosis albo-nebulatis sparsim ornatâ; spirâ elatior, acuminatâ.

Coquille turbinée, conique, très-atténuée vers sa base; toute sa superficie est couverte de sillons transverses espacés entre eux, coupés par des stries longitudinales très-fines. La spire est fort élevée et acuminée; elle forme au moins le tiers de la longueur totale; on y compte huit tours étroits; l'angle spiral du dernier est obtus et arrondi. La coquille est rougeâtre ou faiblement pourprée, mnnie de taches plus foncées, ferrugineuses, quelquefois nébuleuses, formant une espèce ‘e fascie irrégulière vers le tiers inférieur du dernier tour, et une autre moins distincte vers l'angle spiral du même tour. Toute la suiface est en outre traversée par des séries de petits points rougeâtres.

Long. 20 millim.

Habite

Petite espèce fort remarquable par'sa forme atténuée à la base, l'élévation de sa spire, et surtout par les sillons dont elle est traversée. 
208. CONE DE LAMARCK. Conus Lamarckii, NoBIS.

\section{(Collect. Laм.)}

Pl. LXXXIII, fig. 4.

C. testâ turbinatâ, crassâ, supernè turgidâ; luteâ, duobus fascibus, maculis albis reticulatis ; spirâ rotundâ, obtusâ, mucronatâ, decurrente excavatâ, albo maculatâ.

Coquille épaisse, turbinée, renflée vers sa partie supérieure, à plans latéraux légèrement convexes, surrout vers l'angle spiral, qui est arrondi ; la spire, médiocrement élevée, est convexe, obtuse, mucronée au sommet; on y compte six tours marqués au-dessous de la suture d'une gouttière superficielle décurreute; la base du dernier offre une dizaine de petits sillons assez rapprochés les uns des autres. La coloration est élégante; elle consiste en un fond d'un jaune orangé traversé par deux fascies formées de petites taches blanches disposées en réseau; la fáscie qui occupe la partie supérieure est la plus étroite et la mieux limitre; l'autre, plus large, s'étend plus ou moins vers la partie inférieure. La spire, d'une coloration plus foncée, est marquée de taches brunes et blanches.

$$
\text { Long. } 38 \text { millin. }
$$

\section{Habite}

Jolie espèce confondue par Lamarck avec le Cònus luzonicus, et constituant sa variété $b$. Mais il suffit de jeter les yeux sur les figures qui représentent ces deux espèces pour constater leurs différencés, soit de forme, soit de coloration. 
209. CONE TACEETÉ D'ÉCABIATE. Conus coccers, REEvE.

(Collect. de M. Gubba. ) Reeve, Conch. icon. pl. 42, fig. 228. Pl. CVII, fig. 1-1a.

C. testâ oblongo-turbinatâ, supernè angulo-obtusâ in medio subinflatâ, ad basim latè sulcatâ ; albâ, maculis subquadratis pallidè cocceis, serïbus transversis dispositis, sparsim tæniatis ; spirâ obtusiusculâ, apice mucronato.

Coquille turbinée, oblongue, subcylindrique, à plans latéraux convexes; l'angle spiral du dernier tour est légèrement arrondi et obtus; sa base est traversée par huit sillons bien marqués et espacés entre eux. La spire est peu élevée et obtuse ; son sommet est légèrement mucroné; on y compte sept ou huit tours aplatis en dessus, marqués de quelques stries décurrentes. L'ouverture s'élargit un peu vers sa base. La columelle est légèrement tordue à sa partie inférieure; le bord droit mince et tranchant, offre vers son sommet une échancrure profonde. La coquille est blanche avec des taches jaunâtres ou oranģes, de forme généralement quadrangulaire, mais quelquefois irrégulièrement dispersées en séries transverses plus ou moins nettement dessinées. La spire offre également des taches jaunâtres, mais elles sont plus irrégulières et le plus souvent allongées.

\section{Long. 40 millim.}

Habite les mers de la Nouvelle-Hollande. 
Cette espèce a un peu l'aspect du Conus stramineus, mais elle en est distincte par sa forme moins régulièrement conique, par son angle spiral moins marqué et par ses taches plus larges et plus irrégulières. La variété 1* est surtout remarquable par sa forme qui est plus rétrécie et sa spire qui est beaucoup plus élevée.

210. CONE DE CIBIEI. Conus Cibielii, NoBrs.

(Collect. de M. Comsel. )

Pl. CVII, fig. 2.

C. testâ turbinatâ, valdè conicâ , supernè latissimâ, infernè attenuatâ, striis transversis minutissimis ornatâ, ad basim sex elatioribus; viridè pictâ, fascis fuscis bicinctâ ; spirá conico-obtusâ, spiraliter striatâ.

Coquille turbinée, très-élargie vers sa partie supérieure, atténuée et un peu rétrécie à sa base; l'angle spiral du dernier tour est bien marqué et légèrement tuberculeux; toute la surface est traversée par des stries extrêmement fines; vers la base on en distingue six plus saillantes et plus espacées entre elles. L'ouverture est étroite, les bords sont presque parallèles; le bord droit, mince et tranchant, est échåncré vers son sommet. La spire est conique, très-surbaissée ; on y compte six tours aplatis garnis de stries décurrentes La suture en est bien marquée. La coloration consiste en un fond verdâtre sur les individus très-frais ou quelquefois blanchâtre et sur lequel se détachent deux larges fascies brunes vaguement indiquées. La spire est brune, avec quelques petites taches un peu plus foncées. L'ouverture est violette dans l'intérieur. 
Long. 28 millim.

\section{Habite}

Petite espèce bien remarquable par sa forme élargie vers sa spire qui est couronnée d'une rangée de très-petits tubercules.

Nous devons la connaissance de cette espèce à l'obligeance de $\mathrm{M}$. Cibiel, amateur au Havre.

211. CONE SUBULE. Conus subulahs, NoBss.

\section{(Collect. de $\mathrm{M}^{\mathrm{me}}$ Dupont.)}

Pl. LXX, lig. 2.

C. testầ turbino-elongatâ, subfusiformi ad basim inflexà ; spirâ elatâ, acuminatâ, circiter striatâ ; ultim anfractu supernè angulato, sulcis latis ornatc, inferioribus creberrimis; albâ, maculis fuscis quadrangularibus sparsis; aperturâ infernè dilatatâ, intùs violaceâ.

Coquille allongée, subfusiforme, légèrement infléchie ou rétrécie vers la partie inférieure. La spire est très-élevée, acuminée et pointue ; on y compte douze tours aplatis et ornés de quelques stries décurrentes; l'angle spiral du dernier est bien marqué; toute son étendue est couverte de larges sillons transverses moins prononcés vers la partie supérieure, mais devenant plus rapprochés et cancellés vers la base; l'ouverture est un peu dilatée à sa partie inférieure, le bord droit tranchant et sinueux est fortement échancré à son sommet. La coquille offre sur un fond blanchâtre des taches brunes éparses, peu nombreuses, le plus souvent quadrangulaires, mais occupant presque toujours l'intervalle des sillons. La spire est ornée de taches 
semblables, mais plus petites et tout à fait irrégulières. L'ouverture est violette en dedans.

Long. 34 millim.

Habite

Jolie espèce d'une forme très-élancẻe et comme flexueuse, remarquable par les larges sillons qui couvrent sa surface et les taches quadrangulaires qui y sont mêlées.

212. CONE AURORE. Conus aurota, LaMarck.

(Collect. du Mus ) Chenn. Conch. 11, t. 181, fig. 1756-1757.

PI. XLV, fig. 1.

C. testâ oblongo-turbinatâ, subventricosâ, basi sulcatâ; coccinatâ, fasciis binis angustis albidis cingulatâ ; spirâ convexo-acutà.

Coquille assez mince, turbinée, oblongue. La spire est surbaissée et pointue; on y compte huit tours aplatis et marqués en dessus de quelques stries décurrentes. La suture est profonde et bien indiquée. L'angle spiral du dernier tour, qui est un peu renflé vers sa partie supériẹure, est arrondi et obtus; ce tour a sa base pourvue d'un assez grand nombre de sillons transverses, irréguliers et espacés entre eux. La coquille a une teinte générale rougeâtre ou aurore, s'affaiblissant un peu vers l'angle spiral et au milieu du dernier tour, de manière à former deux sortes de fascies un peu plus pâles que le fond lui-même. 
Long. 60 millim.

Habite

Belle espèce assez rare dans les collections et bien distincte de ses congénères par sa teinte presque uniformément aurore.

213. CONE D"ADAMSON. Conus Adamsonii, LaMarck.

(Collect. Lam.) Sowerby. Conch. illustr., fig. 20.

PI. XLIV, fig. 1.

C. testâ oblongo-turbinatâ, cinereo-flavescente, fasciâ albidâ, interruptà, líneis transversis purıctorum fuscorum numerosis; spirâ convexo-acutâ, decurrentè striatâ, maculosâ.

Coquille oblongue, turbinée, à plans latéraux assez réguliers, presque droits, si ce n'est vers l'angle spiral où ils s'arrondissent un peu. La spire est médiocrement élevée, conique; on y compte six ou sept tours aplatis en dessus et marqués de stries décurrentes fines et nombreuses. La suture est profonde et surmontée d'une sorte de petit bourrelet; le dernier tour, lisse sur presque toute son étendue, offre seulement vers sa base quelques sillons très-rapprochés entre eux. La coloration consiste en un fond jaunâtre trés-clair nuagé de taches blanches sur l'angle spiral et au-dessous du milieu du tour, ce qui produit deux fascies mal arrêtées. Toute la surface est en outre traversée par un grand nombre de petites lignes formées par des points très-fins et très-rapprochés les uns des autres, ces points sont d'un brun rougeâtre. La spire est radiée de maculations brunes et allongées. 
Long. 30 millim.

\section{Habite}

Cette espèce, bien distincte par sa forme et sa coloration, a été établie par Lamarck sous le nom de Conus Adamsonii, car ce savant pensait que le Chotin d'Adamson (Voy. au Sénégal, pl. 6, fig. 6.) se rapportait à cette coquille; mais l'espèce figurée par Adamson n'est qu'une variété du Conus medilerraneus. M. Reeve, dans son Conch. icon., pl. 43, fig. 193, a fait représenter un Conus mediterraneus pour le $C$. Adamsonii de Lamarck. M. Sowerby, dans son Conch. illust., fig. 20, a donné à l'espèce que nous décrivons le nom de $C$. unicolor; c'est sous ce nom que nous avions d'abord fait représenter ce cône (pl. 61, fig. 4), mais nous croyons devoir lui restituer le nom que lui avait d'abord donné Lamarck.

214. CONE CORALEIN. Conus corallimu, NoBis.

\section{(Collect. de $\mathrm{M}^{\mathrm{me}}$ Dupont. )}

\section{Pl. LXXnI, fig. 2.}

C. testâ cylindraceo-tarbinatâ, ad angulam spirale inflatâ, basim attenuatâ; subrubrâ, albo-fasciatâ, maculis rubris tinctâ, lineis fuseis transversis ornatâ; spirâ elatâ, striatâ rubro-maculatâ.

Coquille turbinée, cylindrique, renflée vers son angle spiral, atténuée à la base. La spire, très-élevée, forme environ le tiers de la longueur totale; elle est conique et un peu mucronée au sommet; on y compte neuf ou dix tours finement striés en dessus, portant vers leur angle externe les traces à peine visibles d'une petite carène marginale que l'on retrouve, assez pro- 
noncée sur le dernier tour; celui-ci est lisse à l'exception de sa base où l'on observe quelques stries obliques. La coquille est rose ou rougeâtre avec une fascie transverse blanche située un peu au-dessous du milieu du dernier tour ; cette fascie est accompagnée de maculations d'un rouge-brun; une fascie à peu près semblable occupe l'angle spiral, et enfin des maculations de inême couleur enveloppent le canal. Toute la surface est en outre traversée par des lignes brunes trèsfines. La spire offre de grandes taches rouges séparées par des intervalles blancs. L'ouverture est rosée à l'intérieur.

\section{Long. 24 millim.}

\section{Habite}

Jolie espece remarquable par sa forme allongée, subcylindrique, par l'élévation de sa spire et sa coloration rougeâtre fasciée de blanc et tachetée de rouge.

215. CONE IODOSTOME. Conus iodostomus, REEVE.

(Collect. de M. Delessert.) Reeve, Conch.icon. pl. 28, fig. 159.

PI. LXXII, fig. 7.

C. testâ subelongatâ, turbinatâ, leviter inflatâ, basim attenuatâ; albidâ, lutèofuscescente, sparsìm irregulariter maculatâque punctatâ : spirâ subelatâ, acutâ, subtilissimè striato-decussatâ.

Coquille allongée, turbinée, à plans latéraux légèrement renflés au milieu, atténuée à sa partie inférieure qui est sensiblement rétrécie. La spire est asse\%. élevée, elle forme un peu moins du tiers de la longueur totale; on y compte huit tours aplatis en dessus 
et finement décussés; le dernier porte vers sa partie inférieure quelques sillons obliques. La coloration consiste en un fond blanchâtre avec des taches ou des points d'un brun jaune très-irrégulièrement disposés, mais produisant dans certains endroits, soit des flammules longitudinales, soit une sorte de réseau, soit enfin simplement des lignes ou séries de points. La spire est variée de taches brunes. L'ouverture est légèrement teintée de violet.

Long. 25 millim.

\section{Habite}

Petite espèce remarquable par les petits points et les taches brunes dont elle est ornée. Par sa forme, elle a quelque analogie avec notre variété (C) du Conus cinereus, mais elle en est distincte par le manque de sillons sur le dernier tour.

216. CONE CITRIN. Conus citrinus, Nobis.

(Collect. Declera.)

PI. LIX, fig. 6 .

C. testâ turbinatâ, ventricosâ, supernè inflatâ, basi altenuatâ, angulo spirali rotundato; citrino-aurantiâ, maculis albis nebulosâque obscurè fasciatâ, lineis transversis fuscis et albis articulatis ; spirâ obtusâ apice conicâ.

Coquille turbinée, ovale, ventrue, renflée vers sa partie supérieure. La spire est peu élevée, conique; la suture est profonde et bien marquée; les tours, au nombre de sept, sont légèrement convexes en dessus; le dernier, dont l'angle spiral est arrondi, est lisse jusqu'à sa base qui porte un grand nombre de stries très- 
fines et très-rapprochées entre elles. Toüte la coquille est d'un jaune citrin assez vif avec de grandes maculations blanches, nuageuses, formant une sorte de fascie vaguement indiquée et située un peu au-dessous du milieu du dernier tour. Des maculations semblables existent également vers l'angle spiral et à la base du canal. Le dernier tour est aussi orné de lignes transverses brunes articulées de blanc, formant des fascies. La spire est garnie de taches nuageuses blanches et jaunâtres un peu plus foncées que le fond lui-même.

Long. 40 millim.

Habite la mer des Indes, les côtes de l'île de Ceylan.

Cette espèce est remarquable entre toutes celles du même genre par sa coloration orangée, ses fascies nuageuses peu arrêtées, et les lignes articulées de blanc qui la traversent.

217. CONE DE VIRREAOX. Conus Verreauxii, Nobis.

\section{(Collect. Verreaux.)}

Pl. LX, fig. 5 .

C. testâ ovato-turbinatâ, subinflatâ, subtilissimè transversìm striatâ, basi sex latisulcatâ; luteâ, transversim fasciatâ, maculis fuscis anguntisque irregularibus ornatâ.

Coquille turbinée, ovale, un peu renflée, à plans latéraux convexes. La spire est peu élevée, conique et pointue; les tours, au nombre de neuf ou dix, sont aplatis et striés; l'angle spiral du dernier est ar- 
rondi et obtus. Toute la surface est couverte de stries extrêmement fines et rapprochées entre elles. Vers la base, on observe six larges sillons distants entre eux. Le fond de coloration est d'un jaune de soufre assez vif avec des taches brunes irrégulières, anguleuses, interrompues un peu au-dessous du milieu de la coquille, et qui laissent voir le fond comme une fascie transverse à cet endroit. La spire offre des maculations à peu près semblables.

\section{Long. 40 millim.}

Habite les côtes du càp de Bonne-Espérance.

Cette jolie espèce est remarquable par les stries extrêmement fines dont sa surface est ornée, et par sa coloration d'un jaune de soul're. Elle a cependant, malgré ces différences, une légère analogie avec le Conus anemone.

218. CONE PARÉ. Conus lautus, REEvE.

(Collect. du Mus. brit.) Reeve, Conch. icon. pl. 46, fig. 255.

Pl. IXXXVIII, fig. 6 .

C. testâ turbinatâ, tenuiculâ, lævigatâ; luteâ, punctis grandibus fuscis trifasciatim confusis, seriatim cinctâ; spirâ obtuso-convexâ, strigis fuscis arenatis ornatâ.

Coquille turbinée, convexe et très-renflée vers son sommet, atténuée à sa base. La spire est obtuse et convexe, on y compte cinq ou six tours; l'angle spiral du dernier est très-arrondi et obtus, lisse sur toute son étendue. La coloration consiste en un fond jaune 
ou verdâtre şur lequel se détachent trois fascies transverses d'un rouge brun; ces fascies assez larges, sont formées de taches allongées, - simples ou bifides et rangées parallèlement; leurs intervalles sont en outre traversés par des séries de points de même couleur que les maculations et formant des lignes articulées. La spire offre également des taches allongées rougeàtres.

Long. 34 millim.

Habite

Espèce fort curieuse par sa coloration et sa forme générale ; elle est du petit nombre de celles qui manquent de stries vers la partie inférieure du canal.

219. CON E ÉmUIE. Conus cemulus, Reve.

(Collect. du Mus. brit.) Reeve, Conch.icon.pl. 46, fig. 256.

Pl. XCIV, fig. 3.

C. testâ turbinatâ, supernè tumidiusculâ, 'lævigatâ ; olivaceo-cœruleâ, olivaceofusco variegatâ, tæniatâ et maculatâ; spirâ subobtuso-elatâ, suturis rudibus ; aperturæx fauce olivaceo-fusco tinctâ.

Coquille turbinée, très-large et renflée vers son sommet, fortement atténuée à sa base qui est un peu rétrécie et infléchie. La spire est un peu obtuse, conique, formée de sept tours lisses et arrondis en dessus, réunis par une suture profonde et rugueuse. L'angle supérieur du dernier tour est très-arrondi et ol,tus; 
sa superficie est lisse, la base est seulement traversée par huit sillons assez espacés entre eux. La coquille, d'un gris olivâtre ou verdâtre, est ornée de maculations et de points bruns teintés également d'olivâtre; ces maculations, d'une forme très-irrégulière, offrent des espèces de fascies mal arrêtées. Les points, au contraire, sont régulièrement disposés en séries transverses. La spire est radiée d'une manière confuse, des mêmes maculations brunes. L'ouverture est colorée de brun olivâtre en dedans; cette teinte devient moins intense sur la partie tranchante du bord droit,

$$
\text { Long. } 32 \text { millim. }
$$

Habite

Cette espèce se rapproche par sa forme et par sa coloration du Conus cinereus de Brug, peut-être bien n'en est-elle qu'une variété?

220. CONE DE BRODERIP. Conus Broderipii, REEvE.

(Collect. de M. Borvin.) Reeve, Conch. icon., pl. 46, fig. 254 ?

Pl. LXXI, fig. 2.

C. testâ tenuiculâ, subinflatâ, transversìm sulcatâ, sulcis basim versủs distinctioribus subtilissimè pertusis; pallidissimè incarnato-albâ, maculis aurantiofuscescentibus inter sulcos ornatâ ; spirâ planiusculâ; spiraliter sulcatâ; apice elato mucronato, basi et aperturæ fauce pallidè incarnato-roseâ.

Coquille mince, bulloïde, un peu renflée. La spire est surbaissée, légèrement mucronée au sommet et 
marquée de stries décurrentes. Toute la surface du dernier tour est couverte de stries transverses généralement peu visibles, excepté vers la base où elles sont ponctuées et impressées. La coquille est d'un rose pâle avec une fascie transverse située vers le milieu du dernier tour; cette fascie est formée de petites maculations irrégulières blanches ou d'un brun orangé ; d'autres petites séries de taches couvrent certaines parties de ce tour, mais elles sont généralement peu visibles. La spire est également variée de taches orangées. L'ouverture est rosée en dedans.

Long. 26 millim.

\section{Habite}

Petite espèce assez jolie, fort voisine du Conus inflatus, cependant assez facile à distinguer à cause des stries extrêmement fines dont elle est traversée et aussi à cause de sa coloration incarnate, fasciée de taches rouges et blanches.

C'est à M. Boivin que je dois la connaissance en nature de cette espèce; il l'avait reçue d'Angleterre, désignée sous le nom de $C$. de Broderip.

221. CONב gNELÉ. Conus inflatus, Sow.

(Collect. de M. Delessert.) Sowerby, Conch. illust. fig. 41.

Pl. LXXI, fig. 3 .

C. testâ turbinatâ, tenui, subinflatâ, rubro-aurantiâ, bifasciatâ, fasciis albis nebulosisque venulatis ornatâ; spirâ conico-obtusâ, albo et fusco venulatâ ; aperturâ latâ, roseo linctâ.

Coquille turbinée, mince, un peu renflée, à spire obtuse, conique, peu élevée, formée de sept tours 
aplatis en dessus et ornés de stries décurrentes extrêmement fines. La suture est rugueuse et bien marquée. L'angle spiral du dernier tour est arrondi et obtus; il est lisse jusqu'à sa base où l'on observe quelques stries obliques fines et rapprochées entre elles. La coloration consiste en un fond rouge orangé trèsvif avec deux fascies transverses blanches; celle qui est située un peu au-dessous du dernier tour, est la plus large et la plus nettement dessinée; elle est formée d'un grand nombre de petits points d'un blanc laiteux, entremêlés de veinules rouģeàtres; l'autre fascie, placée au-dessus de la précédente, est plus étroite, interrompue et mal linitée; l'angle spiral est pour ainsi dire enveloppé par une troisième fascie également veinulée et tachetée : il en résulte que la spire est blanchâtre et simplement veinée de brun; enfin la base du canal offre aussi quelques maculations blanchâtres. L'ouverture est grande, large, rosée à l'intérieur.

$$
\text { Long. } 40 \text { millim. }
$$

Habite

Cette espèce, par sa forme mince et bulloïde, rappelle un peu te Conus Iulipa; elle en est bien distincte par ses autres caractères. 
222. CONE ÉCRIT. Conus inscriptus, REEv.

(Collect. de M. Larginuert.) Reeve, Conch. icon. pl. 29, fig. 164.

PI. CV, fig. 3:

C. testâ turbinatâ, solidiusculâ, lævi, basim versùs sulcatâ, sulcis latis, striatis; cœruleo-albidâ, maculis grandibus fuscescentibus, litteris sinensibus simillimis, trifasciatim inscriptâ ; spirâ mediocri, spiraliter striatâ, fuscescente variegatâ, apice acuto; aperturæ fauce violaceo-carneolatâ.

Coquille turbinée, épaisse, très-renflée à sa partie supérieure, atténuée vers sa base qui est un peu rétrécie. La spire est élevée, conique, pointue. On y compte huit tours marqués en dessus par des stries décurrentes; l'angle spiral du dernier est largement anguleux ; sa base est garnie de quelques sillons obliques assez larges et décussés. L'ouverture est un peu élargie vers sa partie inférieure; le bord droit est mince, sinueux et fortement échancré au sommet. Cette coquille offre, sur un fond gris cendré, de grandes taches brunes irrégulières contournées en zigzzag, de manière à simuler vaguement des caractères chinois. Quelquefois il existe un peu au-dessous du milieu du dernier tour une série transverse de petits points bruns. L'ouverture est colorée en dedans d'un violet foncé prenant une teinte rougeâtre sur le bord droit.

Long. 50 millim.

Habite 
Petite espèce remarquable par sa forme élargie, l'élévation de sa spire, et plus encore par les grandes taches irrégulières qui couvrent sa surface. Au premier aperçu, on pourrait la prendre pour un Conus guinaicus, mais en comparant avec un peu d'attention ces deux coquilles, on en reconnaît facilement les différences.

223. CONE HYBRIDE. Conus hybridus, NoBis.

\title{
(Collect. de M Delessert.)
}

\author{
Pl. LXXXIII, fig. 1.
}

C. testâ turbinatâ, tenui, supernè inflatâ, basi attenuatâ; cinereo-olivaceâ, submedio-fasciatâ, maculis irregularibus fuscis et punctis albis aspersâ ; spirâ. subulatâ, turgidâ, apice acuto, mucronato ; aperturâ intùs violaceâ.

Coquille turbinée, mince, très-renflée à son sommet, atténuée vers sa base. La spire, médiocrement élevée, est convexe dans une partie de son étendue. Le sommet'est saillant et mucroné. Les tours, au nombre de dix ou douze; sont aplatis et lisses; les premiers présentent quelquefois des stries fines et décurrentes; le dernier est très-renflé; l'angle spiral en est arrondi et obtus. Toute la surface est lisse jusqu'à la base qui présente quelques stries fines à peine visibles. L'ouverture, dilatée à la partie inférieure, offre des bords un peu flexueux; le bord droit, mince et tranchant, est profondément échancré à sa partie supérieure. La coloration consiste en un fond d'un gris olivâtre couvert de maculations brunes très-irrégulières entremêlées de petits points de même couleur et d'autres points d'un blanc laiteux. L'intervalle de ces taches et de ces points est un peu plus clair que le fond lui-mềme qu'on distingue bien en fascie trans- 
verse un peu au-dessous du milieu du dernier tour. L'ouverture est d'un violet devenant plus brun sur le bord droit.

$$
\text { Long. } 42 \text { millim. }
$$

\section{Habite}

Jolie espèce bien distincte, ayant un peu l'aspect du Conus mediterraneus : mais sa forme plus élargie et la disposition de sa spire suffiraient pour la faire reconnaitre.

224. COANE ZEBROIDE. Conus zebroides, NoBts.

$$
\text { (Collect. de M. Largilliert.) }
$$

$$
\text { Pl. CV, fig. } 5 .
$$

G. testâ turbinatâ, supernè - inflato-turgidà, ad basim attenuatâ; fulvâ, lineis fuscis longitudinalibusque flexuosis pictâ ; spầ brevi, obtuso-convexâ ; apice mucronato.

Coquille turbinée, large et renflée vers sa partie supérieure, atténuée à sa base qui présente un léger étranglement. La spire est convexe et peu élevée; on y compte six tours lisses et arrondis; l'angle spiral du dernier est très-obtus; toute sa surface est lisse, excepté sa base qui offre une douzaine de stries obliques peu marquées. La coloration, très-élégante, consiste en un fond jaunâtre clair, sur lequel se détachent de grandes lignes brunes longitudinales, un peu flexueuses, zébrant toute l'étendue du dernier tour; la spire est pourvue des mêmes lignes, mais elles y sont plus fines. 


\section{Long. 45 millim.}

\section{Habite}

Jolie coquille, très-remarquable par les grandes lignes brunes dont elle est zébrée ; sa forme élargie et obtuse à sa partie supérieure la rendent également facile à distinguer de ses congénères. C'est encore à l'obligeance de M. Largilliert que nous devons la connaissance de cette intéressante espèce.

225. CONI BUIBE. Conus bulbus, ReEve.

(Collect. de M. Delessert.) Reeve, Conch. icon. pl. 30, fig. a-b.

Pl. LXXVIII, fig. 3-3a.

C. testâ subobeso-turbinatâ, solidâ, supernè rotundatâ ; albâ, fusco longitudinaliter strigatâ, strigis irregularibus, obliquè undulatis, supernè et infernè diffusis ; spirâ brevi, conicâ, apice mụrợnato.

Coquille turbinée, épaisse, renflée et obtuse vers sa partie supérieure, atténuée et rétrécie à sa base. La spire, peu élevée, est acuminée et mucronée au sommet ; on y compte huit tours; l'angle spiral du dernier est arrondi; la partie inférieure de ce tour est pourvue de quelques stries fines et obliques. La coloration consiste en un fond brun sur lequel se détachent de grandes maculations blanches, allongées, un peu onduleuses et disposées parallèlement; ces maculations sont tantôt droites, tantôt obliques, quelquefois interrompues vers l'angle spiral du dernier tour et vers la base; d'autres fois elles se continuent sur toute la surface. 


\section{Long. 22 millim.}

Habite la côte occidentale d'Afrique.

Petite espècc très-remarquable par ses grandes maculations onduleuses. M. Reeve, qui l'a fait connaître, en indique une variété qui est entièrement brune.

226. CONE TRUTTÉ. Conus guttatus, NoBIs.

(Collect. de M. Largiluerr.)

Pl. CV ; fig. 4.

C. testâ turbinatâ, supernè inflato-turgidâ; fulvâ, maculis et punctis fuscis passim ornatâ; spirâ obtusâ.

Coquille turbinée, raccourcie, élargie et renflée vers sa partie supérieure. La spire est surbaissée et obtuse; on y compte six tours; l'angle spiral du dernier est très-arrondi et obtus; il est lisse sur toute son étendue, excepté vers sa base qui présente quelques petits sillons obliques. La coquille est d'un gris fauve, marquée de petits points bruns ou taches irrégulières éparses et peu nombreuses; ses points présentent quelquefois l'aspect de séries d'ailleurs fort irrégulières.

\section{Long. 32 millim.}

Habite

Cette espècc est très-singulière par sa coloration. Elle rappelle le Conus betulinus, mais elle est beaucoup plus petite. 
227. CONE AFRICAIN, Conus africanus, NoBIs

\title{
(Collect. de M. Largiluert.)
}

\author{
Pl. GIV, fig. 2.
}

C. testâ turbinatâ, supernè inflato-obtusâ; fuscâ vel nigrâ, maculis albis sparsis, in medio fasciatis, fasciâ irregulari lineis fuscis articulatâ ; spirâ obtusâ maculis albis guttatâ.

Coquille turbinée, renflée et obtuse vers sa partie supérieure. La spire est surbaissée et convexe, elle est formée de cinq tours étroits; le dernier a son angle spiral arrondi et -obtus; il porte vers sa partie inlérieure huit sillons obliques assez espacés entre eux. La coloration consiste en un fond d'un brun trèsfoncé ou noirâtre avec des points blanćcs épars sur la partie supérieure et des maculations également blanches, très-grandes, mais interrompues, formant, vers le milieu du derniêr tour, une large fascie irrégulière articulée par des séries transverses de points bruns.

Long. 30 millim,

Habite l'océan Atlantique, la côte de Guinée.

Charmante espèce, facile à distinguer à cause de sa -forme obtuse et renflée vers sa partie supérieure, mais surtout à cause de sa coloration brune très-foncée, parsemée de taches blanches. 
228. CONE MOUCEETE. Conus variegatus, NoBis.

\title{
(Collect. de M. Largiluert.)
}

\author{
Pl. GVI, fig. 1-1a.
}

C. testâ turbinatâ, supernè inflatâ, ad basim coarctatâ, transversim sulcatâ ; fuscâ vel luteâ, maculis albis minimis irregularị̣us sparsis, spirâ obtusâ, apice mueronato.

Coquille turbinée, obtuse et renflée vérs'sa partie supérieure, atténuée et rétrécie à sa base. La spire est surbaissée, mucronée au sommet; l'angle spiral du dernier tour est arrondi et obtus, toute la surface de ce tour est couverte de sillons transverses; ceux de la partie inférieure sont un peu plus espacés entre eux. La coquille est le plus souvent d'un brun foncé avec de petites taches ou des points blancs irrégulièrement épars; d'autres fois elle est fauve avec des séries de petits points bruns correspondant aux sillons transverses; l'angle spiral est articulé de petites taches alternativement brunes et blanches.

\section{Long. 25 millim.}

\section{Habite}

Petite espèce fort jolie, qui offre beaucoup d'analogie avec notre Conus africanus, mais qui en est distincte par sa forme plus atténuée vers sa base, et surtout par les sillons qui la traversent. Sa coloration est également très-différente; les taches sont beaucoup moins grandes. La variété fig. 1a est plus petite, et est remarquable par un fond de coloration d'un fauve clair; les séries de points transverses y sont aussi plus marquées. 
229. CONE SPECTRE. Conus spectrum, Lix.

(Collect. Lam.) Lister, Conch, t. 783, fig. 30.

Pl. XuIV, fig. 5-5a.

C. testå cylindraceo-turbinatâ, infernè sulcatâ; albâ, maculis rufo-fuscis tongitudinalibus flexuosis ; spirâ obtusâ, mucronatâ ; aperturâ dehiscente.

Coquille turbinée, subcylindrique, mince, à spire courte, excavée, pointue et mucronée au sommet. Le dernier tour est très-ample et pourvu vers sa partie supérieure d'un angle spiral arrondi et obtus; toute la moitié inférieure est traversée par des sillons larges et distants entre eux. L'ouverture est large, un peu évasée à sa base; le bord droit est mince, tranchant, profondément échancré. La coloration consiste en un fond blanc sur lequel se détachent de grandes flammules d'un brun roussâtre; ces flammules, irrégulières, flexueuses ou anguleuses, sont plus ou moins larges et étendues; elles laissent voir, par leur interruption, une sorte de fáscie transverse qui occupe le tiers inférieur de la coquille. La spire offre aussi quelques taches brunes.

Long. 48 millim.

Hahite l'océan Indien, les côtes des Moluques.

Cette espèce, remarquable par les larges sillons qui occupent la moitié inférieure de son dernier tour, ne l'est pas moins par sa coloration,

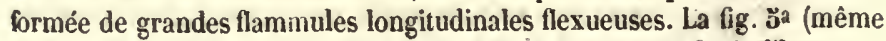
planche 44) est un jeune individı qui diffère du type en ce qu'il est en- 
GENRE CONNE.

tièrement couvert de stries, et que ses maculations sont nombreuses et très-petites.

230. CONE DÉCRĖTT. Conus decrepitus, NoBIs.

(Collect. de M. Bernardi.)

Pl. XCIX, fig. 4.

C. testâ oblongâ, tenui, bulloïdeâ, supernè inflatâ ; omnius minutissimè transversìm striatâ ; albâ, maculis elongatis, cinereo-fulvis, irregularibus passim areolatis ornatâ, punctis quadrangulis intermissis; spirâ conico-obtusâ, longitudinaliter flammulatâ.

Coquille turbinée, mince, bulloïde, renflée à sa partie supérieure, à plans latéraux arrondis et obtus vers l'angle spiral, légèrement convexes sur tout le reste. La spire est conique, un peu obtuse, elle est formée de cinq ou six tours. La superficie de la coquille est couverte de stries transverses extrêmement fines, égales entre elles; celles de la base du canal sont un peu plus grosses. La coloration consiste en un fond blanchâtre sur lequel on voit de nombreuses maculations de couleur fauve ou grise; ces maculations, de forme irrégulière, mais le plus souvent allongées, s'entrecroisent de manière à former sur certains points une sorte de réseau; dans d'autres parties, elles sont disposées à peu près parallèlement et produisent des espèces de fascies; enfin il existe dans leurs intervalles des séries transverses de petites taches quadrangulaires de la même couleur.

$$
\text { Long. } 38 \text { millim. }
$$

Habite l'océan Austral, _les côtes de la Nouvelle-Hollande. 
GENRE CÔNE.

Cette singulière espèce a un peu l'aspect du Conus anemone; elle est couverte comme lui de stries transverses très-fines, mais elle est encore plus mince, plus bulloïde, en même temps que sa spire est plus obtuse; enfin la coloration aussi est un peu différente.

231. CONE CRÉTACÉ. Conus cretaceus, Nobis.

(Collect. de M. Bernardi.)

Pl. XCIX, fig. 1.

C. testâ turbinatâ, subelongatâ, basim versùs liratâ : albidâ; spirâ conicâ, gradatâ ; ultimo anfractu subtùs concavo, punctis niveis in seriibus transversim dispositis ornato; labro dextro sinuato, in medio inflexo.

Coquille turbinée; assez régulièrement conique. La spire est médiocrément élevée; elle est formée de sept ou huit tours un peu étagés et lisses; l'angle spiral du dernier, qui est un peu excavé, est bien marqué; la moitié inférieure de ce tour porte une dizaine de sillons transverses assez larges et distants entre eux. L'ouverture est arquée dans sa longueur; elle s'élargit vers sa base; le bord droit est mince et il se détache de l'avant-dernier tour par une échancrure large et profonde. La coquille est d'un blanc grisâtre; le dernier tour est tacheté de points d'un blanc de lait, disposés par séries transverses.

\section{Long. 52 millim.}

Habite

Cette espèce, très-distincte de sè congénères, est remarquable par la disposition de sa coloration, où paraissent bien les petites taches blanches qui garnissent la surface de son dernier tour. 
GENRE CÔNE.

232. CONE ROSACE. Conus rosaceus, NoBis.

(Collect. de M. GubBa.)

Pl. CVII, fig. 4.

C. testâ turbinatâ, conicầ, ad basim subcoarctatâque recurvatâ, infernè sulcatâ, sulcis duodecim, latis ; cin€reâ, maculís roseis albisque irregularibus nebulosâ, obscurè bifasciatâ ; spirâ elatâ, acuminatâ ; ore roseo.

Coquille turbinée, régulièrement conique, offrant rers sa partie inférieure un léger rétrécissement suivi d'une faible inflexion dorsale. La spire est assez élevée, elle forme environ le quart: de la longueur totale. Elle est un peu-étagée, conique et très-acuminée; on y compte dix tours aplatis en dessus et portant quelques stries décurrentes très-fines. Toute la moitié supérieure du dernier tour est lisse, l'autre moitié est pourvue de douze gros sillons transverses espacés entre eux. L'ouverture est étroite, les bords en sont à peu près parallèles, le bord droit, mince et tranchant; offre vers sa partie supérieure une échancrure bien marquée. La coloration consiste en des taches irrégulières jaunâtres se détachant sur un fond blanc ou rosé: En outre, on distingue encore sur le fond d'autres petites taches d'un blanc mat formant deux sortes de fascies transverses vaguement indiquées. La spire est marquée de taches brunes et blanches. L'ouverture est rose dans l'intérieur.

\section{Long. 26 millim.}

Habite 
GENRE CÔNE.

Cette jolie espèce est remarquable par son aspect nébuleux dù aux différentes sortes de taches dont elle est ornée. C'est par erreur qu'elle est indiquée sur notre planche 107 , fig. 4 , sous le nom de $C$. roseus.

233, CONE STRTOxÉ. Conus striolatus, NoBrs.

\title{
(Collect. de M. Bernardi. )
}

\author{
Pl. CV, fig. 1.
}

C. testâ tarbinatâ, turgidulâ, ad basim coarctatâ; albâ, in medio bifasciatâ, fasciis luteis, alterấ canali circumdatâ ; striis transversalibus numerosis et punctulatis ornatâ, basi mucrosulcatâ; spirâ inflatâ, striis decurrentibus sculptâ, apice mucronato roseo.

Coquille épaisse, turbinée, à peine conique, à plans latéraux, légèrement convexes; formant vers la partie inférieure un étranglemẹnt bien nıarqué. $\mathbf{L a}$ spire, médiocrement élevée, est renflée et mucronée au sommet; on y compte six tours pourvus en dessus de stries fines et décurrentes; le dernier est légèrement creusé en gouttière; tout le reste de sa superficie est traversé par des stries fines et rapprochées entre elles, articulées de petits points noirs. La base présente quatre ou cinq gros sillons obliques. La coquille est toute blanche avec deux fascies étroites jaunâtres, placées vers le milieu du dernier tour ; une autre fascie plus large entoure le canal; sa spire est blanche, son sommel est coloré de rose.

Long. 28 millim.

Habite 
Petite espèce très-remarquable par sa forme peu conique, mais surtout par les stries fixes et pointillées dont sa surface est ornée.

\title{
234. CONE BOUGe. Conus rutilus, Merre.
}

(C.ollect. de M. Delessent.) Reve, Conch. icon.pl. 47, fig. 264.

\author{
PI. LXXIII, fig. 4 .
}

C. testâ turbinatấ, subpyriformi, tenui, inflatâ, ad basim coarctatâ, striis tenuissimis, subosoletis confertis cinctâ ; rutilâ, -unicolore ; spirầ depressiusculâ, versùs apicem subtilișsimè coronatâ, apice elato, acuminatọ.

Coquille turbinée, subpyriforme, mince, renflée à sa partie supérieure, atténuée et rétrécie vers la base. La spire est surbaissée et excavée; le sommet est élevé et acuminé : on y compte six ou sept tours aplatis en dessus et ornés vers leur suture d'une rangée de tubercules très-petits. L'angle spiral du dernier est très-saillant et caréné; toute la surface de ce tour est traversée par des stries extrêmement fines et rapprochées entre elles, un peu plus fortes sur le canal. L'ouverture est grande et ample : les bords sont un peu flexueux; le bord droit est profondément échancré vers sa partie supérieure. La coquille est uniformément teintée d'un gris clair, quelquefois traversée par plusieurs séries de petits points fauves.

\section{Long. 16 millim.}

Habite l'océan Austral, les mers de la Nouvelle-Hollande. 
GENRE CONNE.

Petite espèce pyriforme, très-distincte et facile à reconnaltre à cause de sa couleur rougeâtre et sa ténuité.

235. CONE IACTÉ, Conus lacteus, LaMarck.

(Collect. Lam.) Chemn., Conch. 10, 1. 140, fig. 1304.

Pl. LX, fig. 4.

C. testâ oblongo-turbinatâ, candidâ, sulcis distantibus undiquè cinctâ, superioribus obsoletis ; spirâ convexo-acutâ, mucronatâ, striatâ.

Coquille allongée, turbinée, à spire conique, légèreinent acuminée, formée de sept ou huit tours étroits marqués en dessus de stries fines et décurrentes; l'angle spiral du dernier est un peu obtus; toute la surface de ce tour est traversée par des sillons très-espacés entre eux; ceux de la partie supériemre sont moins prononcés que les autres. La coquille est entiprement blanche.

\section{Long. 38 millim.}

\section{Habite l'océan Indien.}

Espèce très-distincte de ses congénères, et remarquable par les sillons transverses qui occupent toute la surface de son dernier tour. 
236. CONE COLOMBE. Conus columba, Brug.

(Collect. Lam.) Guatr., test. 25, fig. G.

Pl. LXXVill, fig. 2.

C. testà turbinatâ, abbreviatâ ; albâ, vel roseâ ; spirâ elatâ, acuto-acuminatâ, ultimo anfractu lævi in parte inferiore, sulcatoque interdùm granulato.

Coquille turbinée, un peu raccourcie, à plans latéraux convexes. La spire, médiocrement élevée, est conique et très-acuminée ; on y compte une dizaine de tours marqués vers leur suture d'un petit bourrelet décurrent ; le dernier, lisse aux trois quarts supérieurs, est traversé à sa base de huit grośsillons, portant çà et là, dans leurs intervalles, quelques granulations. La coquille est toute blanche, quelquefois un peu teintée de rose plus ou moins purpurin: L'óuverture est violacée dans l'intérieur.

\section{Long. 25 millim.}

Habite l'océan Asiatique.

Petite espèce assez commune, remarquable par sa coloration d'un blanc rosé. Nous pensons que le Conus trochulus et le Conus tristis, de Reeve, n'en sont que des variếtés. 


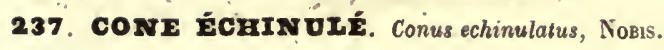

\author{
Pl. CV, fig. 2.
}

C. testâ minimâ, turbinatâ, elongatấ ; albâ ; spirâ elatâ, conico-acutâ, subgradatâ; anfractibus subtùs planibus octo; ultimo seriibus granulato, ad basim obliquè sulcato.

Coquille turbinée, petite, allongée. La spire, trèsélevée, forme près du tiers de la longueur totale; elle est conique et acuminée; on y compte huit tours étroits, lisses en dessus et un peu étagés; le derniẹ est orné, dans toute son étendue, de séries transverses de granulations assez saillantes et pointues; on voit encore vers sa partie inférieure sept ou huit sillons obliques bien prononcés. L'ouverture est étroite; régulièrement allongée et terebelliforme. La coquille est. entièrement blanche.

Long. 18 millim.

\title{
Habite
}

Petite espèce assez commune, remariquable par sa forme régulièrement conique, par sa spire trèsélevée et un peu étagée, mais surtout par les séries de granulations saillantes et pointues qui ornent la surface de son dernier tour. 
238. CONE PAPILIEUX. Comus papillosus, NoBis.

(Collect. de $\mathbf{M}^{\mathrm{me}}$ Dupont.)

Pl. LXXII, fig. 4.

C. testâ turbinatâ, abbreviatâ, supernè inflato-angulatâ; ad basim attenuatâ ; albâ, granulosâ, interstitiis granulorum punctulis fuscis seriatìn articulatis ; spirâ subelatâ, conico-acuminatâ, lævi ; ultimo anfractu gránulis, per seriibus dispositis ornato, infernè sulcato.

Coquille turbinée, raccourcie, large et renflée vers sa partie supérieure. La spïre, médiocrement élevée, est conique, acuminée et pointue; on y compte huit tours lisses et un peu étagés; l'angle spiral du dernier est bien marqué et entouré d'un large sillon au-dessous duquel commencent des séries transverses de granulations papilliformés, très-régulièrement disposées jusque vers la base où elles deviennent moins prononcées et sont même remplacées par de simples sillons. La coquille' est blanche; l'angle spiral est seulement articulé de petites pointes rougeâtres qui se retrouvent plus ou moins sur les premiers tours. L'intervalle dés yranulations est orné de points ou de petits traits, formant autant de lignes articulées qu'il y a de séries de granulations.

Long.' 25 millim.

\section{Habite}

Celte espèce a beaucoup d'analogic avec notre $C$. echinulatus, mais elle en est distincte par sa forme moins élanctêe, par ses granulations plus développées et surtout par les pointes rougeâtres et articulées qui occupent l'intervalle de ces granulations. 
289. CONב POSTULE. Conus pustulatus, NoBrs.

\author{
(Collect. de M. Bernardi.)
}

Pl. CI, fig. 2.

C. testâ minimâ, crassiusculâ, abbreviatâ, supernè inflato-angulatâ ; fuscâ, albo vel cinereo nebulatâ; spirâ conico-acuminatâ ; ultimo anfractu transversim sulcato, interstitiis tuberculiferis.

Coquille turbinée, petite, épaisse, raccourcie, à plans latéraux très-convexes, fort élargie vers sa partie súpérieure, atténuée et resserrée à sa base. La spire est médiocrement élevée, très-acuminée ; on y compte huit ou neuf tours aplatis'en-dessus et portant près de leur suture une rangée de petites granulations. L'angle spiral du dernier est saillant et fortement caréné: toute sa surface est traversée par de larges sillons dans l'intervalle desquels se dessinent des séries de tubercules assez saillants et arrondis. La coquille est brunàtre avec des parties blanches ou cendrées et comme nébuleuses. Les tubercules sont blancs.

$$
\text { Long. } 20 \text { millim. }
$$

Habite

Cette jolie espèce est surtout remarquable par les sillons qui la traversent et les rangées de tubercules qui entrecroisent ces sillous. 
240. CONE DE DUPONT. Conus Dupontii, NoBrs.

\section{(Collect. de $\mathbf{M}^{\mathrm{me}}$ Dupost.)}

PI. LXI, fig. 2.

C. testâ turbinatâ, brevi, supernè inflatissimâ, ad basin valdè attenuatâque coarctatâ, maculis albis et fuscis irregularibus pictâ; spirâ brevi obtusâ, apice mucronato.

Coquille turbinée, extrêmement élargie et renflée vers sa partie supérieure, atténuée et un peu étranglée à sa base; elle est formée de sept tours étroits, le dernier très-ample : son angle spiral est arrondi et obtus. Toute la surface est lisse, à l'exception de la partie inférieure qui est pourvue de sept ou huit sillons obliques très-fins et très-rapprochés entre eux. La spire est peu élevée, conique, mucronée au sommet. L'ouverture est sinueuse, un peu dilatée vers sa partie inféricure, la partie parallèle de la columelle offrant une sorte de pli oblique. Cette cóquille, d'un fond blanchâtre, est parsemée de grandes taches brunes très-irrégulières, comme lacérées et réduites, vers certaines parties, en petites linéoles.

$$
\text { Long. } 25 \text { millim. }
$$

\section{Habite}

Jolie espèce qui se distingue de toutes ses congénères par sa forme raccourcie. Elle offre pourtant une certaine analogie avec notre Conus africanus. 
GENRE CÔNE.

241. CONE CHEVArIER. Conus eques, Brug.

(Encyclop., p. 355, fig. 9.)

Pl. LXVI, fig. 1.

C. testâ turbinatâ, abbreviatâ, turgidè-inflatâ, albo-luteâ, lineis ramosis fulvis ornatâ, maculis fuscis obscurè bifasciatâ ; spirâ convexâ.

Coquille épaisse, turbinée, très-élargie, renflée vers sa partie supérieure, atténuée et rétrécie à sa base. La spire est surbaissée et obtuse. L'angle spiral du dernier tour est arrondi. Ce tour, lisse sur presque toute son étendue, offre seulement à sa base une dizaine de stries obliques fines et rapprochées entre elles. La coloration de la cóquille consiste en un fond d'un blanc jaunâtre presque entièrement couvert de taches linéaires étroites, comme rameuses et d'une teinte fauve; d'autres taches subquadrangulaires, d'un brun foncé, forment sur le dernier tour deux espèces de fascies transverses, distantes entre elles. La spire est couverte de maculations également fauves et brunes.

Long. 32 millim.

Habite l'océan Austral et les mers d'Amérique.

Espèce très-remarquable par sa forme raccourcie et sa coloration. N'ayant pu me procurer cette coquille en nature, j'ai fait représenter la figure de l'Encyclopédie. 
242. CONE PYRIFORME. Connus pyriformis, Rerve.

(Collect. de M. Delessert.) Reeve, Conch. icon. pl. 13, fig. 70 .

Pl. XLIV, fig. 4 .

C. testâ solidulá, valdè pyriformi, albidâ carneo eximiè tinctâ ; spirâ convexiusculâ, apice acuminato, anfractibus rotundatisque crenulatis, ultimo supernè inflatissimo, basi tenuissimè sulcato ; caudâ productâque paululùm recurvâ.

Coquille régulièrement pyriforme, très-renflée vers sa partie supérieure, atténuée et rétrécie à sa base qui forme un canal bien indiqué et légèrement recourbé vers le dos. La spire est peu élevée; son sommet est saillant et acuminé; on y compte une dizaine de tours très-étroits, arrondis en dessus et finement crénelés vers la suture; le dernier est lisse : son angle spiral est arrondi et obtus; il présente vers sa base un assez grand nombre de sillons transverses très-fins. La coquille est blanchâtre, nuancée de rose ou d'une teinte carnéolée.

\section{Long. 52 millim.}

Habite la mer des Antilles.

Espèce fort élégante, facile à distinguer par sa forme très-renflée à son sommet et au contraire très-étroite à sa base. 
243. CONE DE MABTINI. Conus martinianus, REEve.

(Collect. de M. Delessert.) Martini, Conch. vol. 2, pl. 55, fig. 584 .

PI. LX, fig. 2.

C. testâ cylindraceo turbinatâ, fuscâ, vel luteolo-fuscâ, ad basim et per spiræ naarginem albidâ; lævi, infrâ medium sulcatâ, sulcis latiusculis, subdistantibus, striis prominentibus, cancellatis ; spirâ convexâ, spiraliter multisulcatâ.

Coquille turbinée, subcylindrique, à spire peu élevée, convexe, acuminée au sommet, formée de sept tours marqués en dessus de stries décurrentes fines et nombreuses; l'angle spiral du dernier tour est arrondi et obtus : ce tour est pourvu un peu au-dessous de sa moitié inférieure d'une dizaine de sillons transverses larges et distants entre eux, cancellés par des stries fines et nombreuses. L'ouverture est assez ample; la columelle est un peu tordue à sa base, le bord droit échancré vers sa partie supérieure et légèrement infléchi vers son milieu. La coquille est brune ou jaunâtre; la spire un peu plus foncée; le dernier tour est orné vers son angle spiral d'une fascie blanchâtre étroite.

\section{Long. 38 millim.}

Habite les mers des îles Philippines et de Luçon.

Espèce remarquable par sa coloration uniforme sur laquelle tranche bien la fascie blanche de l'angle spiral ; par sa forme générale, elle offre une grande analogie avec le Conus lacteus de Lamark. 
244. CONE AIBATRE. Conus parius, ReEve.

(Collect. de M. Delessert.i) Cheman. Conch. t. 10, pl. 140, fig. 235.

Pl. LX, fig. 3.

C. testâ turbinatâ, solidâ, supernè obesâ, basim versủs sulcatâ, sulcis distantibus, latiusculis, densissimè striato-cancellatis ; marmore0-albidâ ; spirâ conicâ, lævi, apice mucronato, fuscescente.

Coquille épaisse, turbinée, légèrement renflée vers sa partie supérieure. La spire, médiocrement élevée, est conique, mucronée au sommet. On y compte neuf tours étroits et lisses; l'angle spiral du dernier est un peu obtus. Toute la superficie de ce tour est lisse, excepté sa partie inférieure qui présente huit ou neuf larges sillons transverses, espacés entre eux, coupés verticalement par de fines stries qui leur donnent une apparence cancellée. La coquille est entièrement blanche; le sommet de la spire est légèrement fauve.

Long 38 millim.

\section{Habite}

Cette espèce, voisine du Conus lacteus, a aussi une grande analogie avec le Conus martinianus; elle en est cependant distincte par sa forme plus renflée au sommet, par sa spire un peu plus élevée et conique, par son angle spiral qui est plus marqué, et enfin par sa coloration différente: 
245. CONE SUAIRE, Conus sindon, ReEve.

(Collect. de M. Prévost.) Reeve, Conch. icon., pl. 45, fig. $233 \mathrm{~A}-\mathrm{B}$.

P1. XCIV, fig. 4.

C. testâ subventricosâ, turbinatâ, læviusculâ; albidâ, vel rufâ, lineis rubidofuscis subtilissimis densissimè bifasciatim decussatâ ; spirâ subobtuso-convexâ, apice rosaceo.

Coquille turbinée, légèrement ventrué. La spire convexe, un peu élevée, est composée de six tours : le dernier est faiblement excavé en dessus; l'angle spiral en est bien marqué : ce tour est traversé, sur presque toute son étendue, par des lignes brunes extrêmement fines, rapprochées entre elles et groupées en deux espèces de fascies qui laissent voir un peu au-dessous du milieu du tour un intervalle assez étroit; la fascie supérieure, naissant un peu au-dessous de l'angle spiral, forme aussi vers cet endroit un cercle étroit plus clair.

\section{Habite}

\section{Long. 52 millim.}

Cette espèce rappelle par sa forme le Conus lacteus; elle a surtout de l'analogie avec le Conus martinianus; mais elle en diffère par plusieurs caractères, et notamment par le manque des larges sillons qui existent dans ces deux espèces. 
GENRE CONNE.

246. CONE MËLANCOIIQUE. Conus nolancholicus, LAy.

\author{
(Collect. du Mus.)
}

Pl. XLV, fig. 3.

C. testà elongatâ, subcylindricâ, in medio leviter inflatâ, strịis subtilissimis cancellatâ, rubro-aurantiâ ; fasciâ submedio interruptâ, maculis irregularibus flavidis ; spirâ plano-acutâ, marginatâ, striatâ.

Coquille allongée, subcylindrique, renflée vers sa partie moyenne. La spire est peu élevée, aplâtie sur une partie de son étendue, conique et acuminée au sommet; elle est formée de sept ou huit tours étroits, pourvus de quelques stries et d'un bourrelet décurrent qui, sur le dernier tour, est très-développé. Ce tour est couvert de stries longitudinales et transverses, composant un treillis extrêmement fin ; la partie supérieure du canal porte quelques sillons obliques. La coquille est d'un rouge fauve ou orangé avec des taches jaunâtres irrégulières formant, un peu au-dessous du milieu du dernier tour, une fascie transverse interrom-pue. Le bourrelet de l'angle spiral est pourvu d'une fascie semblable, mais beaucoup moins large.

Habite

\title{
Long. 52 millim.
}

Espèce encore peu répandue dans les collections, remarquable par sa couleur rougeâtre orangée, mais surtout par le bourrelet de l'angle spiral. 
247. CONY STRIÉ. Conus striatus, LIN.

(Collect. Lam.) Lister, Conch. pl. 760, fig. 6.

Pl. XLVII, fig. 1-1a.

C. testâ cylindraceo-turbinatâ, basi rugosâ, albâ vel albo-roseâ, fulvo aut fusco maculatâ : striis tenuissimis transversis, ad maculas albas interrụtis ; spirâ obtusâ canaliculatâ.

Coquille turbinée, cylindrique, épaisse, pesante, renflée et comme gibbeuse à sa partie supérieure, atténuée à sa base. La spire est peu élevée, conique, un peu obtuse : elle est formée de huit ou dix tours fortement excavés, canaliculés en dessus, réunis par une suture bien marquée et marginée; le dernier est rétréci vers son angle spiral qui est très-saillant et caréné. Toute la surface est couverte de stries transverses, extrêmement fines et rapprochées entre elles. La partie inférieure est munie de quelques gros sillons obliques bien marqués. La coloration consiste en un fond blanc ou légèrement rosé avec de grandes maculations brunes ou noirâtres, quelquefois bordées de blanc; ces maculations sont irrégulières, fortement dentelées ou découpées, formant sur certaines parties des espèces de fascies interrompues; quelquefois elles sont réduites à de simples flammules irrégulièrement onduleuses. La spire est maculée et veinée de la même couleur.

Long. 65 millim.

Habite l'océan des grandes Indes et des Moluques. 
Espèce extrềnement commune, facile à distinguer par sa forme, sa pesanteur, et surtout par les stries transverses dont elle est couverte. Ses grandes taches brunes, très-foucées et irrégulièrement découpées, ont fait nomner vulgairement ce Cône l'écorché. C'èst par crreur que sur notre pl. 47, consacrée à la représentation de cette cspèce, la fig. $1^{\text {b a }}$ até désignée comne variété du Cône strié; cette figure appartient an Conus gubernator et cst même une des variétés remarquables de cette espèce.

248. CONE GOUVERNEUR. Conus gubernator, BRug.

(Collect. Lan.) Encyclop. pl. 340 , fig. 5.

PI. XLVIII, fig. 1 à $1 d$; pl. XLVir; fig. 16 .

C. testâ turbinatâ, subcylindricâ, crassâ, supernè ventricosâ, in medio depressiusculà, lævè ad basim obliquè sulcatâ ; albido-roseâ, maculis fuscis majusculis seu irregulariter lineatis ornatâ ; spirâ obtuso-planatâ, canaliculatâ, apice acútomucronatâ.

Coquille épaisse, solide, turbinée, subcylindrique, renflée vers sa partie supérieure, légèrement rétrécie vers son milieu. La spire est peu élevée, conique, quelquefois obtuse et surbaissée : le sommet en est saillant et acuminé; on y compte luit ou dix tours fortement canaliculés en dessus ; l'angle spiral du dernier est obtus et caréné ; toute la surface de ce tour est lisse, excepté sa base qui offre quelques sillons obliques. La coquille est d'un bḷanc rosé tendre, avẹ de grandes maculations brunes, nombreuses, étendues et généralement irrégulières; quelquefois elles prennent la forme de linéoles longitudinales interrompues, de manière à produire de larges fascies ; d'autres fois ces taches sont ovales et transverses. La spire èst également veinée de brun. 


\section{Long: 64 millim}

\section{Hahite l'océan des grandés Indes.}

Cette espèce est voisine de la précédente par sa forme; sa coloration est aussi à peu près la même, mais elle en diffère essentiellement par le manque de stries transverses. Comme l'espèce que nous venons de citer, elle offre des variations assez remarquables, soit de forme, soit de coloration ; Iantôt les taches sont très-grandes et couvrent presque toute la surface, tantôt elles sont au contraire fort étroites et longitudinales : tantôt, enfin, elles sont éparses et en très-petit nombre. (Voir nos

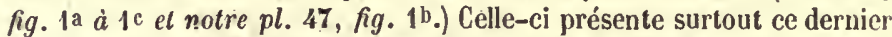
cas; clle y' a été désignée à tort sous lé nom de Conus strialus. Nous rapportons ćgalement à cette espèce, à titre de variété, le Cónus terminus de Linn. Il suffit, en effet, de jeter les yeux sur la tigure que nous en donnons; $p l .48, f g .1 d^{3}$, pour être convaincu de la justesse de ce rapprochement.

219. CONב DE BOIVIN. Conus Boivini, Nobis.

\section{(Collect. de M. Borvis.)}

Pl. LXIV, fig. 2.

C. testâ turbinatâ, cylindricâ, ponderosâ, supernè inflatâ, ad basim depressiusculâ; spirâ planatâ, apice mucronato ; albo-roseâ nebulatâ, obscurè fulvo-bifasciatâ, maculis rubro-fuscis sparsis ornatâ ; ultimo anfractu basi et șupernè crassisulcato.

Coquille épaisse, turbinée, cylindrique, légèrement renflée vers son sommet et un peu rétrécie à sa base. La spire est aplatie : le sommet seul en est saillant et mucroné. Le dernier tour offre un angle spiral anguleux et bien marqué; sa partie supérieure est ornée de húit gros sillons transverses distants les uns des autres; le milieu est très-finement strié èt sa base est pourvue de huit autres sillons obliques fort gros aussi 
et espacés entre eux. La coloration de la coquille consiste en un fond d'un blanc rose nébuleux orné de deux fascies transverses de couleur fauve, sur lesquelles sont éparses des maculations très-irrégulières, d'un brun foncé et le plus souvent longitudinales; ces maculations n'occupent pas exclusivement les deux zones transverses : on en retrouve d'autres plus petites sur le reste de la coquille et particulièrement sur la spire.

$$
\text { Long. } 62 \text { millim. }
$$

\section{Habite}

Belle espèce rappelant par sa lorme générale le Conus strialus, mais elle en est distincte par l'aplatissement complet de la spire et surtout par les gros sillons transverses de son dernier tour; sa coloration, et particulièrement les deux fascies qui la traversent, servent encore à la faire reconnaître.

250. CONE NF்BUIEUx. Conus magus, Lav.

(Collect. Lam.) D'Argent, Conch. append. pl. 2, fig. C.

Pl. LXXVII, fig. $1_{a}$ à $1 c$.

C. testâ elongato-turbinatâ, subcylindricâ; albâ, flammulis longitudinalibus fulvis aut fuscis subfasciatis, lineis transversis albo fuscoque articulatis ; spirâ convexo-acutâ, longitudinaliter maculatâ.

Coquille allongée, subcylindrique, à plans latéraux légèrement convexes, à spire peu élevée et faiblement conique; on y compte une dizaine de tours aplatis en dessus et le plus souvent pourvus de stries déeurrentes; le dernier est un peu concave et canaliculé 
en dessus; l'angle spiral en est obtus; il porte vers sa partie inférieure quelques sillons obliques peu apparents. Cette coquille est ordinairement blanchàtre avec un grand nombre de flammules longitudinales brunes ou fauves; ces flammules sont interrompues et forment des espèces de fascies; quelquefois les taches sont blanches, nuageuses et forment des fascies bien dessinées occupant les' extrémités et le milieu du dernier tour. Outre ces taches, toute la surface est traversée par un grand noinbre de lignes articulées composées de petits points alternativement bruns et blancs. La spire est veinée de maculations également brunes ou fauves.

\section{Long. 56 millim.}

Habite la mer des Indes et celles de l'Australie.

Cette espèce, très-commune, est l'uné des plus variables du genreCiône. Elle est le plus ordinairement couverte de flammules longitudinales brunes, mais quelquefois ces flammules sont remplacécs par de grandes taches blanches irrégulièrement découpées et formant des fascies trans-

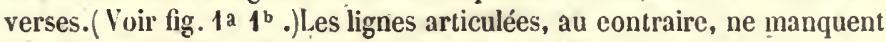
jamais ; seulement, elles sont plus ou moins fines et nombrcuses. C'est en raison de l'extrême variabilité de cette espèce que nous croyons devoir y réunir le Conus raphanus dé Brug, qui n'en diffère que par le manque de flammules longitudinales, ou tout au moins y sont-elles à peine marquées; même pl. 67, fig. 1 c . 
251. Cong DE Catrtaud. Conus Caillaudi, Nobis.

(Collect. de M. Címlaud.)

Pl. L'V, fig. 5 .

C. testâ elongato-turbinatâ, subcỵlindricấ, transversim omninò sulcatâ ; luteo - uurantiâ ; spirâ subplanatâ; rubro maculatâ, apice mucronato.

Coquille allongéé, turbinée, subcylindrique, un peu rétrécie vers le milieu. La spire est surbáissée ; le sommet, saillant, est mucroné. On y. compte six tours aplatis; les premiers sont pourvus, près de leur suture, d'une rangée de tubercules à peine visibles; l'anğle spiral du dernier est un pẹu émoussé; il porte, sur toute son étendue, des sillons transverses parallèlès et un peu onduleux. Toute la coquille est d'un jaune orangé assez vif, les sillonś transverses s'y détachent par leur couleur brune. La spire offre des maculations irrégulières rougeâtres.

\section{Long. 50 millim.}

Habite

Celte espèce est remarquable par sá belle couleur orangée et les sillons qui la couvrent. Elle nous a été communiquée par M. Caillaud, amafeur distingué, auquel nous nous faisons un plaisir de la dédier. 
252. CONE DE CÉCrIE. Conus Cecilei, NoBls.

(Collect. de M: Largilliért.)

Pl. XGVIII, fig. 4, et pl. CVII, fig. 3.

C. testâ èlongatâ, subcylindraceâ ; luteo-fuscâ obsccurè fasciatâ, punctis minimisque numerosis nigricantibus seriatis elegantissimè ornatâ; spirâ exsertâ, contabulatâ, conico-acutâ, lineis fuscis radiatâ, basi canali nigrescente=

Coquille allongée, subcylindracée, à spire assez élevée formant environ le quart de la longueur tótale ; elle est conique, acuminée et pointue; on y compte neuf tours étroits aplatis en dessus et légèrement étagés ; l'angle spiral du dernier est bien marqué: ce tour est lisse sur toute son étendue, excepté vers sa partie inférieure qui présente quelques sillons obliques extrèmement fins et rapprochés entre eux. La coloration de la coquille consiste en un fond d'un brun jaunàtre tout couvert de points très-fins et disposés en séries transverses fort rapprochées les unes des autres; ces points sont bruns ou noirâtres. On voit encore sur la surface une ou deux fascies transverses peu marquées, et la partie supérieure du canal est colorée de noir. La spire est couverte de petites linéoles brunes longitudinales et comme radiées.

\section{Long. 42 millim.}

Habite les mers de Chine.

Cette charmante espèce est extrêmemènt remarquable par sa coloration. Nous avons fait représenter, pl. 107, fig. 3, une variété de ce Cône, 
dont la coloration est beaucoup plus claire, les points moins apparents, les fascies transverses plus visibles, et dont la forme est plus pyramidale. Cette variété appartient à la collection de M. Gubba.

253. CONE EIOCONNEUX. Conus flocc tus, Sow.

(Collecl. de M. Gubba.) Sowerby, Conch. illus. fig. 112

Pl. Cvi, fig. 3, et pl. LXII, fig. 2.

C. testâ turbinatà, subcylindricâ, crassâ, olivæformi ; carneo-roseâ, fasciolis albidis interruptis transversim fasciolatâ, maculis fusco-rufis irregularibus quasi floccis inspersâ; spirâ obtusâ, subeanaliculatâ.

Coquille turbinée, subcylindrique, épaisse, oliviforme, presque aussi large à son sommet qu'à sa base. La spire est peu élevée, obtuse, convexe ; on y compte six ou sept tours étroits, "légèrement canaliculés en dessus et réunis par une suture profonde et bien marquée; l'angle spiral du dernier est obtus; ce tour est lisse sur toute son étendue, excepté vers sa base, où il est muni de quelques gros sillons obliques. La coquille, d'un fond rosé ou carnéolé, est pourvue de bandelette étroites et transverses, de couleur blanchâtre; ces bandelettes sont interrompues et peu apparentes. Toute la surface est, en outre, parsemée de taches irrégulières d'un brun rouge, généralement árrondies, mais formant, dans certains endroits, des espèces de flammules longitudinales. La spire est ornée des mêmes máculations. L'ouverture est.vivement colorée, dans l'intérieur, d'une belle teinte orangée; le bord droit et la base de la columelle sont d'un beau: blanc lacté. 
GENRE CôsE.

\section{Long. 62 millim.}

Habite les îles Philippines.

Espèce très-singulièrè par sa forme qui-lui donne l'aspect d'unc olive, et, en outre, par sa coloration, son fond rosé, ses petites fascies blanches interrompues et ses taches rougeàtres ressemblant à des gouttelettes. La figure que nous avons fait représenter, pl..62, fig. :2, est une variété très-remarquable de ce Cône, que M. Reeve a donnée dans son Conchol. icon. pl.5, fig. 4, comme type de l'espèce. Les taches y sont bien plus larges et d'une teinte plus foncée.

254. CONE D'ADAMSON. Conus Adamsoni, Broderit.

(Collect. de M. Délessert.) JaY, Cat.pl. 7, fig. 2-5.

Pl. XLIV; fig. 1

C. testâ solidâ, turbinatâ, subcylindraceâ, albidâ roseo pallido spadiceoque tessellatâ, fasciis tribus distantibus spadiceo puncticulatis ornatầ; spirâ brevi planatâ, anfractibus elevatis, spiraliter striatis, ultimo in extremitatibus transversím sulcato.

Coquille épaisse; turbinée, subcylindrique, à spire presque aplatie, dont le sommet est légèrement saillant; elle est formée de six ou sept tours convexes en dessus, faisant saillie sur les sutures et pourvus de stries décurrentes assez fines; le dernier porte à ses extrémités supérieure et inférieure de gros sillons transverses finement crénelés dans leurs interstices. La coloration de la coquille consiste en un grand nombre de petites iaches, la plupart roses, mêlées à d'autres taches blanchâtres ou jaunâtres et comme nuageuses; en outre, elle est traversée par trois fas- 
cies blanchâtres couvertes d'un très-grand nombre de petits points d'un brun jaunâtre ; ces fascies sont trèsdistantes les unes des autres; les deux supérieures; plus développées, sont placées sur la limite des sillons; la troisième, très-réduite, occupe la partie supérieure du canal. L'ouverture est blanche à l'intérieur.

\section{Long. 48 millim.}

\section{Habite les mers de l'Australie.}

Cette belle espèce, remarquable par sa forme bullée, l'est plus encore par l'élégance de sa coloration et aussi par les gros sillons transverses qui ornent les extrémités de son dernier tour. M. Sơwerby avait donné, dans le catalogue de Tankerville, le nom de $C$. cingulatus à cette espèce, et M. Jay dans son catalogue l'a désignée sous celui de Rhododendron.

255. CONE DE GUBBA. Conus Gubba, Nobis.

$$
\text { (Collect. de M: Gubba.) }
$$

Pl. CIV, fig. 1.

C. testâ elongatâ, subcylindricâ, fusco-nigrâ, spirâ conico-obtusâ, ultimo anfractu supernè obtuso, sulcis magnis transversis distantibusqué replentibus partem dimidiam inferiorum; aperturấ intùs violaceấ, fusco marginatâ.

Coquille allongée, subcylindrique, légèrement renflée vers le milieu. La spire est conique, obtuse au șommet; on y compte huit tours étroits, un peu convexes; l'angle spiral du dernier est arrondi et obtus, sa moitié inférieure est pourvue $d$ 'environ douze gros sillons transverses, très-distants entre eux. L'ouverture 
est assez grande, un peu. dilatée vers sa base, violacée dans le fond; le bord droit est bordé de brun foncé. Toute la coquille est d'un brun noirâtre à l'extérieur ; les jeunes individus sont tachetés de blanc.

\section{Habité}

$$
\text { Long. } 38 \text { millim. }
$$

Cette espèce se distingue de ses congénères par sa coloration entière ment noirâtre à l'extérieur. Elle nous a été communiquée par M. Gubba, amateur diștingué auquel nous nous faisons un plaisir de la dédier.

256. CONI MOBLI. Conus nóbilis, Lis.

(Collect. Lam.) Seba Mus., 3, t, 43, fig. 13-14.

Pl. XLIX, fig. $1 a$ à $1 e$.

C. testâ cylindraceo-turbinatâ ; luteo citrinâ, maculis albis trigono-rotundatis ornatâ, lineis transversis fulvo alboque articulatis, obscurè bifasciatâ; spirâ planoconcavâ, mucronatâ.

Coquille turbinée, subcylindrique, à spire déprimée, concave, mucronée au sommet, a yant les tours de spire creusés en dessus par une large gouttière décurrente; l'angle spiral du dernier est bien marqué; ce tour est caréné, lisse sur toute sọn étendue, excepté vers sa partie inférieure qui présente quelques sillons obliques peu prononcés. La coloration consiste en un fond d'un jaune-citron, quelquefois brunâtre, sur lequel se détachent de grandes taches blanches de forme irrégulièrement trigone, à angle obtus; ces taches sont 
très-nombreuse's et plus ou moins larges. Dans leurs intervalles sont placées des lignes transverses articulées de petits points bruns et blancs. Ces lignes ont l'aspect de deux espèces de fascies qui occupént, l'une le quart supérieur, l'autre le quart inférieur du dernier tour.

Long. 60 millim. .

Habite la mer des Indes et celle des Moluques.

Cette belle espèce, encore rare et recherchée dans les collections, est remarquable par la forme trigone de ses taches blanches qui rappellent celles du Cône damier; aussi est-elle connue vulgairement sous le nom de Damier chinois. Elle offre des variations assez notables, soit dans sa forme plus ou moins conique, soit dans sa coloration. Nous avons fait figurer, même pl. 49, fig. 1a, un individu dont le fond, au lieu d'être d'un jaune-citron comme il l'est le plus ordinairement dans les coquilles de cette espèce, est d'ü brun-marron assez foncé. La fig. $1^{\circ}$ est fort remarquable par ses lignes transverses articulées, groupées en deux fascies bien marquées. Cette variété constitue le Conus Victor de Broderip.

257. CONE D'OMA. Conus omaícus, BRUG.

(Collect. du Mus.) Martini, Conch. 2, t. 53, fig. 590.

C. testâ cylindraceo-elongatâ ; aurantiâ, albo-trifasciatâ, zonis et lineis numerosis fulvo alboque distinctis, sæpiùs notulis litterarum signatis ; spirâ conicoobtusâ, canaliculatâ, maculatâ.

Pl. XXXII, fig. 2.

Coquille médiocrement allongée, cylindrique, à spire peu élevée, conique, étagée ; on y compte neuf 
GENRE CÔNE.

ou dix tours anguleux et canaliculés en dessus; l'angle spiral du dernier est bien marqué; toute la surface de ce tour est lisse; seulement la partie supérieure du canal offre quelques petits sillons obliques. La coloration consiste en un fond orangé assez vif, marqué de trois fascies transverses blanches, distinctes entre elles, et portant des séries articulées de petits points orangés ressemblant à des notes de musique; entre les fascies on remarque de grandes taches blanches ou orangées, de forme irrégulière, mais affectant souvent une disposition de séries transverses. L'angle spiral de la spire, qui est blanche dans la gouttière, est garni de linéoles orangéés irrégulières plus ou moins anguleuses.

Long: 85 millim.

Habite l'océan Asiatique, vers les côtes de l'île d'Oma.'

Belle espèce encore fort rare et recherchée dans les collections, remarquable par la disposition de sa coloration.

258. CONE COMmAN DANT Conus dux, Brug.

(Collect. du Mus.) Martini, Conch. 2, t. 52, fig. 571-572.

C. testâ cylindraceo-elongatâ, transversìm striatâ, aurańtio-rubescente, violaceo-nubeculatâ, tæniis transversis angustis fuscoque albo-articulatis; spirâ convexo-exsertâ.

Pl. LXII, fig. 1 à $1^{\text {b. }}$

Coquille allongée, cylindrique, à pláns latéraux convexes. La spire est peu élevée, conique, formée de 
huit ou neuf tours légèrement convexes, subcanaliculés en dessus et munis de stries décurrentes; l'angle spiral du dernier est obtus; toute sa surface est ornée de stries transverses généralement fines; cependant quelques-unes sont plus fortes et comme cordelées. La coquille est d'un jaune orangé marqué de violet, et munie d'une ou de plusieurs fascies transverses plus claires, faiblement indiquées ; en outre, toute sa surface est pourvue de lignes transverses articulées de petits points bruns; ces lignes correspondent aux stries, et, comme celles-ci, elles sont plus ou moins grosses et en forme de cordelettes.

\section{Long. 68 millim.}

Habite la mer de Chine.

Espèce encore assez rare, remarquable par sa forme allongée, cylindrique, et surtout par sa coloration élégante. Dans certains individus, res taches sont plus larges, irrégulières, êt s'étendent plus ou moins en forme de flammules; la spire; plus claire que le reste de la coquille, offre aussi de grandes maculations irrégulières flammulées. (Voir nos fig. 1a $^{\text {, }}$ 1b, même planche 62.) On désigne'vulgairement ce Cône sous le nom de l'Amiral de Hollande.

259. CONE DE MADELEIN E. Conus Magdalena, Chenu.

(Collect. de M. Delessert.) Cheñu, Leçons élémentaires, pl. 12, fig. 7.

Pl. LXIX, fig. 4.

C. testâ subcylindraceâ, turbinatâ,, leviter inflatâ ; aurantiâ, infrà medio-fasciatâ, lineis transversis distantibus fuscorum punctorum articulatis ornatâ, maculis albis sparsis; spirâ conico-oblusâ, albo-maculatâ.

Coquille turbinée, subcylindrique, un peu renflée 
vers sa partie moyenne. La spire est obtuse et peu élevée; on y compte huit tours étroits ; le dernier est légèrement canaliculé en dessus; l'angle spiral en est obtus et arrondi ; toute la surface est lisse, à l'exception de quelques stries longitudinales d'accroissement qu'on y distingue. La coloration consiste en un fond d'un jaune orangé, sur lequel se dessine, un peu audessous de la partie moyenne du dernier tour, une fascie transverse blanchâtre articulée de points bruns ; d'autres lignes également articulées, mais plus fines et distantes entre elles, ornent le reste de la coquille; enfin des maculations blanchâtres y sont éparses, mais elles occupeńt plus particulièrement l'angle spiral du dernier tour.

$$
\text { Long. } 52 \text { millim. }
$$

\section{Habite}

Cette espèce ne paraît présenter áu premier aspect rien de particulier; mais la disposition de sa coloration la rend bien distincte de ses congénères; elle semble offrir ' pourtant quelques rapports avec certaines variétés du Conus ranunculus de Brug.

260. CONE GRANULEUX. Conus granulatus, Lis.

(Collect. LaM.) Lister, Conch.t. 760, fig. 5.

PI. LXVIII, fig. 5 .

C. testâ elongatâ, cylindraceo-turbinatâ, transversim crassisulcatâ ; coccineâ, obscurè albo-fasciatâ; sulcis subgranulosis purpureo-punctatis; spirâ convexoacutâ, fusco-variegatâ.

Coquille allongée, turbinée, cylindrique, à spire saillante, conique, formée de neuf ou dix tours con- 
vexes, réunis par une suture profonde et bien marquée; ces tours sont couverts d'un grand nombre de stries décurrentes; l'angle spiral du dernier est arrondi et obtus; toute sa surface est couverte de sillons transverses assez gros et granuleux. La coquille est d'un rouge écarlate, traversée d'une fascie blanchâtre faiblement indiquée ; lés stries sont la plupart des séries de petits points d'un brun pourpré. La spire, d'une teinte plus claire quéle reste de la coquille, est ornée de taches irrégulières flammulées dont la couleur est aussi d'un brun pourpré.

$$
\text { Long. } 65 \text { millim. }
$$

Habite l'océan Américain, les côtes de Surinam et celles du Brésil.

Belle espèce remarquable pär les cannelures qui la traversent et par sa belle couleur rouge. Encore rare et recherchée dans les collections, elle est connue vulgairement sous le nom de l'Amiral d'Angleterre.

261. CONz AUStrax. Conus australis, Giemn.

(Collect. du Mus.) Chems. Conch. 11, t. 183, fig. 1774-1775.

Pl. XLI, fig: 2.

C. testâ elongatâ, cylindrico-turbinatâ in medio inflatâ, transversìm sulcatâ; albido-roseâ, maculis fuscis aut fulvis subfasciatâ, lineis vel flammulis sparsis ornatâ ; spirầ elevato-acutâ, suturis marginatis.

Coquille allongée, cylindracée, renflée vers sa partie moyenne, atténuée à sa base. La spire est élevée, conique, acuminée; on y compte onze ou douze tours étroits, légèrement canaliculés, dont la suture est pourvue d'un petit bourrelet décurrent, et quii sont 
GENRE CÔNE.

couverts de stries égalemènt décurrentes. L'angle spiral du dernier tour est assez bien marqué, mais obtus ; toute sa surface est ornée de sillons transverses assez gros; la coquille présente, sur un fond d'un blanc rosé, un grand nombre de maculations brunes : les unes, assez grandes et irrégulières, forment deux zones interrompues et distantes entre elles : elleś occupent la partiemoyenne de la coquille; les autres, plus petites et allongées en forme de flammules ou réduites à de simples points, sónt éparses sur toüt le reste de la coquille. La spire est ornée de grandes maculations également brunes.

Long. 62 millim.

Habite l'océan Austral, les côtes de Botany-Bay.

Ce Cône ressemble beaucoup au précédent, il en a la taille; cependant il s'en distingue par la disposition de ses stries circulaires, par celle de sa spire qui est plus acuminée, et surtout par son système de coloration. Le nom de strigatus lui a été donné à tort sur notre planche 41. C'est le $C$ : australis de Chemnitz.

262. Conve PRÉTET, Conus profectus, Breg.

(Collect. du Mus.) Martin, Conch. 2, t. 52, fig. 573.

Pl. XLI, fig. 3.

C. testâ elongatâ, subcylindricâ; supernè inflatâ, infernè attenuatả et crassiśsulcatâ ; fulvâ, albido-pallidè fasciatâ ; spirâ subelatâ, acuminatâ, spiralitér striatâ, maculis aurantiis ornatâ.

Coquille allongée, subcylindrique, renflée vers sa 
partie supérieure, fortement atténuée à sa base. La spire, peu élevée, est conique et acuminée ; les tours, au nombre de douze environ, sont étroits, un peu étagés, et légèrement canaliculés en dessus; le dernier est très-renflé : sa partie supérieure est lisse, mais sa base est garnie de douze à quatorze sillons transverses très-distants entre eux. La coquille est d'un fauve pàle un peu rosé, elle porte au-dessous du milieu du dernier tour une fascie blanchâtre peu apparente; la spire est ornée de taches orangées occupant l'angle des tours.

$$
\text { Long. } 65 \text { millim. }
$$

Habite les mers de Chine.

Cette espèce, très-atténuée à sa partie inférieure, est distincte par ses larges sillons transverses et sa couleur fauve teintée de rose.

263. CONE JAUNE. Conus luteus, Sow.

(Collect. de M. Cuming.) Sowerbr, Conch. illust. fig. 8.

Pl. LXXIII, fig. 3, 3a.

C. testâ elongato-turbinatâ, basim attenuatâ ; luteâ, monilibus castaneis, exilibus cinctâ, maculis nigro-castaneis alboque limbatis in spiram et in anfractûs medium tessellatâ ; spirâ obtuso-produclâ ; apice mucronato.

Coquille allongée en forme de petite massue, trèsatténuée à sa partie inférieure. La spire, médiocrement élevée, est convexe et obtuse; le sommet est un peu mucroné; on y compte huit tours étroits réu- 
GENRE CÔNE.

nis par une suture bien marquée; l'angle spiral du dernier est obtus et à peine indiqué; il porte à sa base une douzaine de sillons transverses fins et réguliers. La coloration de la coquille consiste en un fond jaunâtre teinté de rose et parsemé de quelques taches irrégulières, brunes, bordées de blanc, formant deux fascies; l'une placée vers la partie supérieure des tours, l'autre au-dessous du milieu du dernier.

Long. 40 millim.

Habite l'océan Pacifique.

Cette jolie espèce se distingue par sa forme imitant une petite massue: sa coloration est élégante. Dans la variété $\mathbf{z}^{\mathrm{a}}$, le fond est rose, les taches brunes, plus petites, non bordées de blanc: la coquille est, de plus, traversée par de petites lignes interrompues et comme articulées.

* 264. Conz tarrihre. Conus terebra, Brog.

(Collect. Lam.) Favaje, Conch, pl. 17, fig. K, 2.

PI. XXXIV, fig. 2.

C. testâ cylindraceo-turbinatâ, terebriformi; albidâ vel albido-rubellâ; striis transversis elevatis asperatâ; fasciis binis flavescentibus obscurè tinctâ; spirâ convexo-obtusâ, subcanaliculatâ.

Coquille épaisse, turbinée, subcylindrique, régulièrement atténuée vers sa partie inférieure. La spire est un peu élevée, obtuse; elle est formée de cinq ou six tours; les premiers sont légèrement convexes, les. 
autres faiblement canaliculés; l'angle spiral du dernier est bien marqué,"mais obtus; toute son étendue est couverte de stries transverses assez saillantes et rugueuses. La coquille est blanchâtre ou légèrement teintée de rose ; elle est traversée par deux larges fascies fauves faiblement indiquées. La spire est toute blanche.

\section{Long. 64 millim.}

Habite la mer de Chine, les côtes des îles Philippines.

Espèce assez commune, facile à distinguer par sa forme régulièrement atténuée à sa base, mais surtout à cause des stries ruguetises qui la traversent. On la désigne vulgairement sous le nom de Bout de chandelle.

265. CONE NUSSATExTE, Conus nussatella, BRtG.

(Collect. Lam.) Lister, Conch. t. 744, fig. 35.

Pl. LIII, fig. 2.

C. testâ elongato-angustâ, subcylindricâ, transversim striatâ; albâ vel roseâ, fulvo aut aurantio nebulatâ, punctis fuscis aut nigris seriatim cinctâ; spirâ convexo-exsertâ, apice mucronato.

Coquille allongée, étroite, subcylindrique, un peu resserrée vers le canal. La spire est assez élevée, convexe, mucronée au sommet; on y compte cinq tours arrondis en dessus et marqués de stries décurrentes; l'angle spiral du dernier est peu saillant et arrondi ; toute sa surface est couverte de stries transverses. Le fond de la coquille est blanc ou légèrement rosé avec 
de grandes taches nuageuses orangées ou de couleur fauve, présentant l'aspect de fascies transverses; en outre, toute la surface est couverte de points bruns ou noiràtres. La spire est fasciée de fauve orangé avec une série de points occupant l'angle spiral. L'ouverture est rosée à l'intérieur.

\section{Long. 62 millim.}

Habite les côtes de la Chine et celles des îles Philippines.

Cette espèce est l'une des mieux caractérisées du genre ; elle est surtout remarquable par sa forme étroite et allongée et par les nombreux petits points qui la garnissent. Elle est connue vulgairement sous le nom de Drap piqueté.

266. CONI GIAND. Conus glans, BRUg.

(Collect. Lam.) D'Argent, Conch. append. pl. 2, fig. D.

Pl. LXXX, fig. 1 à 1 c.

C. testâ elongatâ, subcylindricâ , transversim striatâ ; fulvo-fuscâ aut violaceocastaneâ, fasciís albis interruptis fusco maculatis ; spirâ convex $\theta$ - exsertâ , obtusâ apice mucronato.

Coquille allongée, subcylindrique, renflée à sa partie supérieure, atténuée vers sa base en forme de petite massue. La spire est assez élevée, convexe, mucronée au sommet; on y compte une dizaine de tours légèrement convexes, lisses, à suture bien marquée. L'angle -spiral du dernier est à peine visible; vers cette partie, ce tour est lisse, mais le reste de son étendue est coúvert de fines stries transverses soit simples, soit rugueuses et même granuleuses. La co- 
loration est assez variable; elle est ordinairement d'un brun fauve, quelquefois marron, avec deux fascies transverses, blanchâtres, interrompues et tachetées de brun. L'une de ces fascies occupe la partie supérieure de l'angle spiral, l'autre est située un peu au-dessous du milieu du dernier tour. L'ouverture est d'un beau violet à l'intérieur.

\section{Long. 50 millim.}

Habite la mer des Indes et celle des Moluques.

Cette espèce est remarquable par sa forme, qui l'a fait comparer à un gland; non-seulement elle est variable de coloration, mais aussi de structure : elle est du petit nombre de celles qui présentent des variétés granuleuses constantes. La variété 12 est d'une couleur fauve, uniforme; les fascies y manquent compléternent. La variété $1^{\mathrm{b}}$, plus petite, a ses stries transverses granuleuses. La variété $1^{c}$ ressemble de forme à celleci, mais elle en diffère par ses stries circulaires, garnies de grains saillants, allongés transversalement, et par sa coloration d'un violet blanchâtre; les fascies y sont teintées de fauve.

267. CONE VÉRULEUX. Conus verulosus, BRug.

(Collect. Lam.) Favanne, Conch. pl. 15, fig. G. 3. Pl. LXIX, fig. 5.

C. testâ cylindraceo-turbinatâ, basim valdè attenuatâ ; albâ ; transversim sulcatâ; sulcis prominulis verrucosis, inferioribus majoribus et laxioribus; spirâ convexo-conicâ, subcontabulatâ.

Coquille turbinée, cylindrique, très-atténuée vers sa partie inférieure. La spire est peu élevée, conique, 
un peú étagée; elle se compose d'une dizaine de tours très-convexes, marqués en dessus de stries décurrentes; ces stries s'effacent sur le dernier tour dont l'angle spiral est arrondi, obtus et lisse, mais le reste du tour est. couvert de sillons transverses très - profonds et produisant de véritables côtes chargées de petites verrues. Ces sillons sont plus gros et plus espacés entre eux vers la base. La coquille est entièrement blanche.

\section{Long. 54 millim.}

Habite les mers de l'Amérique.

Espèce remarquable par les gros sillons qui la traversent et qui semblent souvent chargés de verrues.

268. CONT CYIINDRACE. Conus cylindraceus, BRod.

(Collect. de M. Delessert.) Broderip. Zooloyical Journ. t. 5 , pl. suppl. 40 , fig. 5 .

Pl. LXV, fig. 2.

G. testâ cylindraceo-fusiformi, lævigatâ ; fulvo-lutescente; strigis albis longitudinalibus ornatâ ; spirâ elatâ, rotundatò-pyrạmidatâ; apice mucronato.

Coquille allongée, cylindrique, fusiforme. La spire est élevée, convexe, pyramidale et mucronée au sommet. On y compte neuf ou dix tours subaplatis; le dernier est très-déclive vers sa partie supérieure, etson angle spiral est à peine marqué; il porte à sa base quel- 
ques petits sillons obliques; tout le reste de la coquille paraît lisse, mais à la loupe on aperçoit sur la surface des stries excessivement fines. La coquille est d'un brun jaunâtre plus ou moins foncé avec un grand nombre de lignes longitudinales, flexueuses, d'un beau blanc; ces lignes forment vers la partie inférieure une sorte de fascie interrompue. La spire est également veinée de blanc.

\section{Long. 38 millim.}

Habite les côtes des îles de la Société.

Cette jolie petite espèce, remarquable par sa forme élancée, très-régulièrement atténuée vers les extrémités à la manière d'un fuseau, ne l'est pas moins par sa coloration brune, élégamment ornée de lignes flexueuses blanches. Elle est voisine, par sa forme, de la suivante, mais celle-ci est couverte de granulations, et sa coloration est aussi très-différente.

269. CONE MIrRí. Conus witratus, Brug.

(Collect. Laм.) Encyclop. pl. 342, fig. 3.

Pl. LXXXVIII, fig. 7 .

C. testâ elongatâ, cylindrico-fusiformi, transversim striatâ, striis granulosis ; albâ, maculis fulvo-aurantiis fasciatâ ; spirậ elato-pyramidatâ, convexâ ; apice mucronato.

Coquille allongée, cylindrique, fusiforme, ornée de stries transverses qui sont surmontées de granulations assez saillantes. La spire est un peu élevée, pyramidale et mucronée au sommet. Les tours, au nombre de 
neuf ou dix, sont légèrement convexes; le dernier est un peu plus renflé vers l'angle spiral qui est à peine indiqué; les stries granuleuses dont ce tour est orné sont un peu plus distantes entre elles à sa base. La coquille est blanchâtre avec de grandes taches d'un brun jaunâtre formanttrois fascies interrompues, dontl'une, plus grande, occupe le milieu du dernier tour, et les autres ses extrémités. La spire est pourvue de taches de la même couleur.

Long. 40 millim.

Habite la mer des Indes et celle de Chine.

Cette espèce est facile à distinguer à cause de sa forme allongée qui rappelle tout à fait celle d'une mitre. Ses stries granuleuses et ses grandes taches rougeâtres servent également à la faire reconnaître.

270. CONE BATONNIT. Conus tendineus, Brtg.

(Collect. Lam.) Lister, Conch. t. 745, fig. 36.

Pl. LXXX, fig. 2-2a.

C. testâ elongatâ, cylindraceâ, transversìm striatâ, striis eleratiusculis, interdùm subgranulosis; albâ aut pallidè violaceâ, castaneo-fuscoque longitudinaliter inquinatâ vel fasciatâ ; spirâ convexo-elatâ; apice mucronato, violaceo ; basi intùsque extùs violaceâ.

Coquille épaisse, allongée, cylindrique, fusiforme, striée transversalement sur toute son étendue; les stries sont saillantes et un peu granuleuses en certains endroits. La spire est élevée, convexe, pyramidale, mucronée au sommet. On y compte neuf ou dix tours; 
l'angle spiral du dernier est à peine marqué ; ce tour est, en outre, pourvu, à de larges intervalles, de quelques profondes stries longitudinales d'accroissement, marquant des temps d'arrêt. La coloration consiste en un fond blanchâtre ou violacé sur lequel se détachent de grandes maculations longitudinales d'un brun marron, formant trois fascies assez larges et plus ou moins prononcées qui occupent le centre et les extrémités du dernier tour.

Long. 80 millim.

Habite la mer des Indes, les côtes de l'ile de France.

Cette espèce est voisinedu Conus glans, mais elle est un peu plus fusiforme et les stries de sa surface sont plus fortes; elle se rapproche également du Conus terebra, mais sa spire est plus élevée et sa coloration, d'ailleurs, est très-différente. La variété A est d'un violet plus intense que l'espèce type, et les fascies brunes ou pourprées y sont mieux arrêtées. L'intérieur et l'extérieur de la base du canal sont de conleur violette.

271. CONE ARTOPTE. Conus artoptus, Sow.

(Collect. de M. Stainforth.) Sowerby, Conch. illus. fig. 35.

PI. X́CIV , fig. 5 .

C. testâ cylindraceâ, angustâ, transversim granuloso-striatâ ; albidâ, aurantiofusco trifasciatim nebulosâ, interstitiis seriibus punctulorum instructâ ; spirâ conico-obtusâ.

Coquille cylindrique, étroite, à plans latéraux droits et parallèles vers le milieu, obliques ét atténués aux extrémités. La spïre est un peu élevée, subco- 
nique, obtuse. L'angle spiral du dernier tour est bien marqué, quoique obtus. Toute la surface est couverte de stries transvèrses extrêmement fines et granuleuses; ces stries sont un peu plus fortes sur la partie supérieure du canal. La coquille est blanchâtre avec trois larges fascies transverses formées par des taches allongées, irrégulières, d'un brun orangé ; les taches sont assez distantes entre elles, leurs intervalles sont ornés de séries transverses de très-petits points rougeâtres.

$$
\text { Long. } 40 \text { millim. }
$$

\section{Habite}

Cette espèce ressemble beaucoup au Conus nussatella, mais elle en diffère par sa forme moins élancée, par sa partie moyenne plane s'atténuant brusquement vers les extrémités, par sa spire moins élevée et son angle spiral mieux marqué; enfin, les fascies qui ornent sa surface sont plus larges et les taches sont aussi mieux accentuées.

272. CONE DACTYIE. Conus dactylosus, Nobis.

(Collect. de M. Bernardi.)

Pl. XCVII, fig. 2.

G. testâ angustâ, elongato-cylindraceâ, tenuissimè decussatim strìatâ; luteopallidâ, lineolis fulvis tenuissimisque areolatis quadrifasciatâ; spirâ convexo-obtusâ, apice mucronato.

Coquille allongée, étroite, cylindrique, atténuée vers sa partie inférieure. La spire est peu élevée, obtuse, mucronée au sommet ; on y compte neuf tours étroits, légèrement convexes en dessus; le dernier, au contraire, est un peu concave et canaliculé; son angle 
spiral est bien marqué. Toute la surface est couverte de stries transverses et longitudinales entrecroisées très-fines et très-régulières. La coloration consiste en un fond d'un jaune clair orné de quatre fascies transverses, distantes entre elles; ces fascies, blanchâtres, sont remplies par un réseau très-fin et très-délié qui est formé de petites linéoles fauves. La spire est un peu plus foncée que le reste de la coquille.

\section{Long. 36 millim.}

\section{Habite}

Petite espèce extrêmement élégante de forme et surtout de colorátion. Les quatre fascies alvéolées de son dernier tour la distinguent facilement de ses congénères.

273. COMS BRULE. Conus furvus, REEve.

(Collect. de M. Janelle.) Reeve, Icon. pl. 13, fig. 69.

Pl. LXXX, fig. 3.

C. testâ elongato-turbinatâ, angustâ ; luteolâ; fasciis duobus, furvo-fuscis, cingulatâ ; spirầ elatâ, conico-acuminatâ, suturis marginatis.

Coquille allongée, étroite, assez régulièrement conique. La spire est élevée, acuminée; on y compte neuf tours étroits en dessus et pourvus d'un sillon décurrent. La suture est légèrement marginée; l'angle spiral du dèrnier tour est assez marqué, mais un peu obtus. Toute la surface est couverte de stries transverses fines et régulières; celles de la base sont 
les plus prononcées. L'ouverture est étroite et linéaire; le bord droit fortement sinueux et profondément échancré à sa partie supérieure. La coquille est jaunâtre ou d'ụn brun ferrugineux; deux fascies plus claires se distinguent bien sur le dernier tour. La base est colorée de brun.

\section{Long. 52 millim.}

Habite les îles Philippines.

Cette espèce est distincte par sa forme allongée, sa spire un peu acuminée, et surtout par son bord droit sinueux au milieu, très-échancré au sommet.

274. CONE EFEIIÉ. Conus longurionis, NoBis.

(Collect. de M. Prevost.)

Pl. XGII, tig. 6.

C. testâ elongatissimâ, angustâ, utrinquè attenuatâ, subulatâ, transversim sulcatâ ; albo-luteâ, maculis rufo-aurantiis quadrangularis, transversim obsoletè bifasciatâ ; spirâ elatiore.

Coquille très-allongée, étroite, subulée. La spire est élevée, acuminée et forme environ le tiers de la longueur totale; on y compte quatorze ou quinze tours étroits, arrondis, légèrement étagés, réunis par une suture profonde; l'angle spiral du dernier est obtus; toute la surface de ce tour est couverte de sillons transverses assez gros; sa base est très-acuminée et largement recourbée vers le dos. La coquille est blanchâtre ou légèrement jaune, ornée de fascies trans- 
verses distantes entre elles ou interrompues, formées par des taches irrégulièrement quadrangulaires, de couleur rougeâtre ou orangée.

Long. 36 millim.

Habite

Cette jolie espèce, d'une forme extrêmement allongée, est remarquable par sa spire très-acuminée et par les sillons qui couvrent son dernier tour.

Par suite d'une erreur typographique, elle a été désignée à tort sur notre planche 92 , fig. 6 , sous le nom de $C$. subulatus.

275. CONE CISEIÉ. Conus insculptus, NoBts.

(Collect. de M. Largiliert.)

Pl. XCIX, fig. 2.

C. testâ longissimo-pyramidatâ, angustâ ; ferrugineâ ; spirâ elatâ, conico-acuminatâ ; anfractibus octo, supernè angulatisque spiraliter striatis : ultimo transversim undiquè sulcato; basi subrecurvâ.

Coquille très-allongée, pyramidale, effilée vers le canal, qui est légèrement infléchi en dessus. La spire est assez élevée, conique et acuminée ; on y compte huit tours étroits, marqués d'un angle caréné et de stries décurrentes; l'angle spiral du dernier est bien prononcé; ce tour est couvert de sillons transverses espacés entre eux et finement pointillés; sa partie inférieure se retrécit en une sorte de canal légèrement recourbé en dessus. L'ouverture est étroite, la colu- 
melle un peu sinueuse. Toute la coquille est d'un brun ferrugineux.

$$
\text { Long. } 25 \text { millim. }
$$

Habite la mer de Chine.

La forme très-effilée de cette coquille, son canal étranglé et infléchi en dessus, ses sillons transverses, la rendent bien facile à distinguer de ses congénères.

276. CONI PAGODE. Conus pagodus, Chend.

(Collect. de M. Delessent.) Chenu, Leçons élémentaires,

$$
\text { pl. 12, fig. } 2 .
$$

Pl. LXX, fig. 4 .

C. testâ fusiformi-turbinatâ, ventricosissimâ, basi coarctatâ, transversim undiquè sulcatâ, interstitiis sulcorum cancellatis; spirâ exsertâ, acuminatâ, spiraliter striatâ ; albâ, maculis quadrangularibus trifasciatis cinctâ.

Coquille turbinée, fusiforme, très-renflée et ventrue au milieu, atténuée vers ses extrémités; l'inférieure est étranglée et forme une sorte de canal assez long ; la supérieure constitue la spire qui est très-élevée et forme le tiers environ de la longueur totale de la coquille; on y compte quatorze tours étroits; légèrement étagés et pourvus de stries décurrentes; les premiers de ces tours portent ane série de petits tubercules à peine visibles; le dernier présente un angle spiral lisse, mais bien marqué ; toute son étendue est couverte de sillons transverses assez gros, dans l'interstice desquels on distingue de petites stries longitudi- 
nales qui font paraître ces sillons comme cancellés. La coquille, d'un fond blanc, est ornée de trois fascies transverses composées de taches rougeâtres irrégulière. ment quadrangulaires. Ces fascies sont distantes entre elles et de largeur inégale, la.supérieure est la plus large: elle est située un peu au-dessous de l'angle spiral; l'inférieure occupe la partie rétrécie du canal: elle est la plus étroite et peu marquée. La spire est aussi marquée de taches rougeâtres.

\section{Long. 42 millim.}

Habite les côtes de l'île de Taïti.

Singulière espèce, remarquable par sa forme, qui lui donne l'apparence d'un fuseau. Les sillons dont toute sa surface est traversée et sa coloration la rendent également bien distincte.

277. CONE FASCIÉ. Conus fasciatus, NoBIs.

$$
\begin{aligned}
& \text { (Collect. de M. LoroIs:) } \\
& \text { Pl. CIX, fig. } 2 .
\end{aligned}
$$

C. testâ elongato-turbinatâ; albo-nebulosâ, transversìm bifasciatâ, fasciis luteo-aurantiis, seriebus punctulis nigris articulatis, interstitiis æqualiter puncticulatis; spirâ acutâ, acuminatâ ; columellâ infernè contortâ.

Coquille turbinée, un peu allongée, à plans latéraux assez droits et réguliers. La spire est peu élevée ; elle forme environ le cinquième de la longueur totale : elle est conique et acuminée au sommet; on y compte dix tours étroits; les inférieurs sont légèrement canaliculés en dessus et saillants près de la su- 
ture; le dernier est lisse, excepté vers sa base qui est munie d'une douzaine de sillons obliques; l'angle spiral de ce tour est bien marqué. L'ouverture est étroite. La columelle est légèrement tordue et excavée à sa base. La coloration est d'un blanc nuageux; la surface est ornée de deux fașcies transverses d'un jaune orangé assez pâle, garnies de lignes ponctuées noirâtres et de petites taches blanches subquadrangulaires; l'intervalle de ces fascies présente aussi des lignes transverses de petits points jaunâtres un peu plus distants entre eux. La spire est maculée de petites taches irrégulières brunes.

Long. 42 millim.

\section{Habite}

Cette espèce rappelle, dans une certaine limite, le Conus monile, soit par sa forme générale, soit par son système de coloration ; elle en est distincte par sa spire plus élevée, plus allongée, moins pyramidale. La coloration aussi est plus pâle; les lignes ponctuées sont beaucoup plus fines; les fascies mieux marquées et plus larges.

278. CONI IACINUEE. Conus lacinulatus, NoBrs.

(Collect. de M. Lorois.)

Pl. GVIII, fig. 2.

C. testâ pyramidali-turbinatâ, basi attenuatâ; aurantiâ, fasciis duobus albis, transversis laciniatis ornatâ ; spirâ conico-obtusâ ; anfractibus octo, ultimo subtùs planulato, basi granulis seriatis munito.

Coquille turbinée, pyramidale, épaisse, à spire large, peu élevée, conique; on y compte trois tours 
ètroits : le dernier est pourvu d'un angle spiral bien marqué. Toute la superficie de ce tour est lisse; sa base porte seulement deux ou trois séries transverses de petites granulations. L'ouverture est étroite, linéaire et à peu près égale. La coquille est d'un orangé pâle, avec deux larges fascies transverses blanches; ces fascies, dont les bords sont profondément découpés, surtout d'un côté, occupent la partie supérieure et le tiers inférieur du dernier tour; vers la base on remarque quelques lignes transverses rougeàtres. La spire est tachetée de blanc ou de jaune orangé.

Long. 38 millim.

Habite

Cette jolie espèce, dont l'aspect général rappelle un peu le Conus $l i$ thoglyphus, est distincte de celui-ci par ses deux fascies blanches; en outre, elle porte sur la base de son canal des séries de granulations qui la rendent très-remarquable.

279. CONE DEUIr. Conus ateralbus, NoBis.

\section{(Collect. de M. Lorors.)}

Pl. CVIII, fig. 4-4a.

C. testâ abbreviatâ, turbinatâ, crassâ ; fuscâ, maculis albis sparsis, fasciibus dispositis; spirâ depressâ, latâ; anfractibus supernè planulatis; ultimó valdè carinato, basi tenuiter striato.

Coquille épaisse, raccourcie, pyramidale, turbinée. La spire est presque plane; légèrement mucronée au sommet; on y compte six ou sept tours aplatis ou 
GENRE CÔNE.

même canaliculés en dessus; l'angle spiral du dernier est très-marqué ; sa base porte quelques sillons obliques peu prononcés. L'ouverture est étroite, un peu dilatée vers sa partie inférieure. La columelle est légèrement flexueuse, surtout vers sa base. La coquille est d'un brun foncé noirâtre avec des taches blanches irrégulières, le plus souvent de forme quadrangulaire, composant deux fascies transverses plus ou moins larges; quelquefois ces taches sont confluentes et allongées. La fascie la plus large est placée au-dessous du milieu du dernier tour; l'autre, plus étroite et interrompue, occupe l'angle spiral.

Long. 45 millim.

\section{Habite}

Espèce remarquable par sa forme raccourcie, sa spire presque blanche, ses taches fasciées blanches aussi et se détachant nettement sur le fond noirâtre. Elle a l'aspect général du Cónus nivosus, mais elle est un peu plus épaisse, plus raccourcie et ses taches sont disposées différeminent. La variété, fig. 4a est d'une couleur en général plus obscure.

280. CONI PAUTINS. Conus Paulina, Nobis.

(Collect. de M. Lorors.)

$$
\text { Pl. CVIII, fig. } 3 .
$$

C. testâ turhinatâ; albo-cinereâ, maculis fuscis subquadratis transversaliter seriatis ornatâ; spirầ latâ, obtusiusculâ; ultimo anfractu supernè angulato, ad basim tenuè sulcato; aperturâ dilatatâ,

Coquille turbinée, très-large vers sa partie supérieure. La spire est peu élevée, subconique, formée de cinq tours presque planes en dessus; l'angle spiral du 
dernier est bien marqué; ce tour porte, vers sa partie inférieure, vingt à vingt-cinq sillons transverses extrêmement fins et rapprochés entre eux. L'ouverture est large, surtout vers sa base. Le fond de la coquille est d'un blanc grisâtre, sur lequel sont disposées des taches brunes quadrangulaires plus ou moins grandes et irrégulières, formant, en général, des séries transverses. La spire est tachetée de la même manière : seulement les taches y sont toujours larges.

Long. 36 millim.

\section{Habite}

Cette espèce se distingue surtout de ses congénères par les sillons fins et nombreux qui occupent la partie, inférieure de son dernier tour et son canal. Elle se rapproche un peu du Conus proteus par sa forme et son mode de coloration, mais sa spire est plus surbaissée et plus obtuse.

Nous sommes heureux de la dédier à madame Lorois, reconnaissant de l'obligeance dont le mari de cette dame veut bien nous donner une preuve si continue, en nous faisant connaître tant d'espèces nouvelles.

281. CONE DE GABRIEI. Conus Gabrielii, CheNu.

$$
\begin{gathered}
\text { (Collect. de M. Delessert.) } \\
\text { PI. LXXIV, fig. } 4 \text {. }
\end{gathered}
$$

C. testâ elongato-turbinatâ, supernè obtusiusculâ ; cinereâ, maculis. fuscis irregularibusque laciniatis obscurè fasciatis ornatâ, puncticulis albis seriatim munitâ; spirâ subelatâ; apice prominulo, acuminato; ultimo anfractu basi latisulcato.

Coquille allongée, turbinée. La spire est peu élevée, convexe sur une partie de son étendue, conique et acuminée vers le sommet; on y compte environ douze 
tours dont les premiers sont très-étroits ; l'angle spiral du dernier est arrondi; la moitié supérieure de ce tour est lisse, l'inférieure est pourvue de dix sillons transiverses très-espacés entre eux. La coquille est d'un fond gris cendré, orné de taches brunes très-irrégulières, à bords laciniés, formant trois espèces de fascies transverses interrompues; en outre, toute la surface est parsemée de petits points blancs disposés par séries transverses, comme articulées. La spire est veinée de lignes brunes; l'angle spiral du dernier tour est accompagné d'une fascie étroite d'un gris cendré.

Long. 40 millim.

\section{Habite}

Cette espèce n'est peut-être qu'une variété du Conus cinereus, cependant on y distingue constamment quelques différences. M. Chenu a cru, pour celte raison, devoir la constituer comme espèce et la dédier au frère d'un homme si justement regretté par les savants et les artistes qui trouvaient en lui un protecteur éclairé; savant lui-même qui a puissamment contribué à répandre en France le goût et l'étude de I'histoire naturelle.

282. CONI ARDOISÉ. Conus ardisiaceus, NoBss.

$$
\text { ( Collect. de M. Lonors.) }
$$

$$
\text { Pl. GVIII, fig. } 1 .
$$

C. testâ oblongo-turbinatâ, subventricosâ; cinereoque nigro maculatâ, maculis irregularibus magnis, lineis transversis punctorum nigrorum articulatis; spirâ obtusâ ; ultimo anfractu, supernè obtuso.

Coquille oblongue, turbinée, renflée vers sa partie supérieure. La spire est : convexe, obtuse, mucronée au sommet; on y compte six ou sept tours étroits; 
l'angle spiral du dernier est obtus; ce tour 'est lisse, excepté vers sa base qui porte quelques sillons obliques. L'ouverture est sinueuse, un peu dilatée vers sa partie inférieure. La coquille est marbrée de grandes maculations noirâtres irrégulières, se détachant sur un fond gris cendré nuageux; en outre, elle est traversée par un grand nombre de lignes ponctuées, comme articulées. L'intérieur de l'ouverture est d'un brun violacé.

\section{Long. 35 millim.}

\section{Habite}

Cette espèce est si voisine du Conus cinereus, qu'on pourrait la prendre pour une variété de celui-ci; mais, en les examinant attentivement, on reconnait entre ces deux coquilles des caractères suffisants pour les rendre distinctes.

283. CONE OBTUS, Conus obtusus, NoBIs.

(Collect. de M. Lorors.)

Pl. CIX, fig. 3.

C. testâ ovato-turbinatá, supernè inflatâ, obtusâ, infernè attenuatâ ; cinereâ, maculis fuscis irregularibus longitudinaliter strigatâ; anfractibus quinque angustis; ultimo supernè rotundato, lævi, basi sulcato.

Coquille ovale, turbinée, renflée et obtuse à sa partie supérieure, atténuée vers sa base. La spire est très-courte, arrondie, formée de cinq tours légèrement convexes; l'angle spiral du dernier est arrondi et obtus; toute sa superficie est lisse; sa base seule porte 
quelques gros sillons transverses. L'ouverture est étroite, un peu élargie vers sa partie inférieure. La coloration consiste en un fond gris cendré nuageux, couvert en grande partie par des maculations brunes très-irrégulières, plus ou moins étendues et formant des espèces de fascies transverses: l'une d'elles occupe l'angle spiral. L'intérieur de l'ouverture est d'un gris cendré ; le bord droit est liseré de brun.

Long. 24 millim.

Habite

Cette petite espèce a aussi quelques rapports avec le Conus cinereus, principalement par son système de coloration, mais elle en diffère par sa forme renflée et obtuse au sommet et fortement atténuée, au contraire, vers la base; sous ce rapport, elle aurait plus de ressemblance avec notre Conus africanus, mais la spire mucronée de celui-ci, et surtout sa coloration toute particulière, suffisent pour l'en distinguer.

284. CONE BRUNETTE. Conus aulicus, LiN.

(Collect. Lam.) Rumph. Mus. t. 33, fig. 3.

Pl. LIII, fig. 1.

C. testâ subcylindricâ, elongatâ, mediơ convexâ; fuscâ aut castaneâ ; maculis subtriangularibus inæqualibus albis ; striis transversis tenuissimis; spirâ acutâ ; suturis profundis.

Coquille allongée, cylindracée, renflée vers le milieu. La spire est conique et aiguë; on y compte huit tours, réunis par une suture profonde; l'angle spiral du dernier est effacé, à peine sensible; la superficie dè ce tour est marquée de stries transverses extrême- 
ment fines et rapprochées entre elles. L'ouverture est dilatée vers sa base; la columelle est sinueuse. La coloration consiste en un fond brun ou marron sur lequel se détachent vivement de grandes maculations blanches plus ou moins larges, de forme irrégulièrement triangulaire, souvent rapprochées et confluentes entre elles de manière à former des groupes allongés ou transverses. L'intérieur de l'ouverture est jaunâtre.

Long. 90 millim.

Habite les mers des grandes Indes.

Grande et belle espèce assez répandue dans les collections, remarquable par sa forme cylindrique, régulièrement renflée. au milieu, et par sa coloration brillante.

285. CONI EvîQU工. Conus episcopus, Brog.

(Collect. de M. Delessert.) Encyclop. pl. 345, fig. 2.

PI. XCI, fig. 1 à 1c.

C. testâ subcylindraceo-turbinatâ; furvâ, maculis albis trigonis inæqualibus majusculis subfasciatis; lineis transversis albo-punctatis articulatâ; spirâ obtusiusculâ.

Coquille turbinée, subcylindracée. La spire est peu élevée, obtuse au sommet; on y compte huit tours aplatis ; l'angle spiral du dernier est obtus et arrondi; toute sa surface est couverte de stries transverses extrêmement fines et rapprochées entre elles; celles de la base, sur le canal, sont plus fortes et forment de 
véritables sillons. La coquille, d'un fond jaunâtre ou brunâtre plus ou moins foncé, est couverte de grandés taches blanches inégales, de forme trigone, disposées par larges fascies transverses plus ou moins distinctes. Dans leurs intervalles on distingue quelquefois des lignes transverses ponctuées de blanc.

\section{Long. 74 millim.}

\section{Habite les mers des grandes Indes.}

Cette espèce a de grands rapports avec la précédente ; elle en est distincte cependant par sa forme régulièrement cylindrique; l'angle spiral de son dernier tour étant mieux indiqué, et, par là, sa spire plus obtuse. Sa coloration, quoique assez semblable, offre pourtant aussi des taches plus larges et des fascies plus évidentes. Ce Cône a des variétẻs remarquables; la variété $a$ présente ses taches extrêmement larges; celles des variétés $b$ et $c$, au contraire, sont plus petites et plus nombreuses.

286. CONE DRAP-ORANGÉ. Conus auratus, Baug.

(Collect. Lam.) Gualtien, Test. t. 25, fig. X.

Pl. LXXXVI, fig. 2-2a.

C. testâ subcylindricâ, elongatâ, transversim, tenuissimè striatâ; aurantiâ, maculis albis cordatis seriebus longitudinalibus irregularibus remotisque angulatis; lineis transversis albo -punctatis, obsoletissimis ; spirâ acutâ.

Coquille allongée, cylindracée. La spire est conique, obtuse au sommet; on y compte sept tours obliquement aplatis en dessus; l'angle spiral du dernier est faiblement indiqué; ce tour est un peu renflé : sa superficie porte un très-grand nombre de stries transverses extrêmement fines devenant plus prononcées 
vers la base et sur le canal. La coquille est d'un jaune orangé avec des taches blanches subtriangulaires ou cordiformes réunies par groupes allongés ou anguleux assez espacés entre eux; quelques points blancs occupent leurs intervalles et sont quelquefois disposés par séries transverses.

$$
\text { Long. } 68 \text { millim. }
$$

Habite les mers de la Chine et des Moluques.

Cette jolie espèce est très-voisine du Conus aulicus et du Conus episcopus, mais elle en est distincte par sa forme plus allongée, sa couleur orangée, ses taches plus petites et plus nettement groupées.

287. CONE DRAP-RÉTICULÉ. Conus clavus, Lrs:

(Collect. Lay.) Lister, Conch.t. 744, fig. 34.

Pl. LXXXVII, fig. 2.

C. testâ elongato-subcylindraceâ, basi attenuatâ, transversim tenuissimè striatâ: fulvo-cinnamomeâ, maculis albis trigonis fasciatim reticulatâ ; spirâ acutâ, striatâ.

Coquille étroite, allongée, subcylindrique, atténuée et rétrécie vers le canal. La spire est conique; on y compte dix tours; les premiers sont très-étroits, les autres sont légèrement couvexes et striés transversalement; l'angle spiral du dernier est à peine indiqué ; toute la surface de ce tour est cöuverte de stries transverses extrêmement fines, celles de la base sont plus fortes et produisent de véritables sillons. Il existe, vers la naissance du canal, un rétrécissement. La co- 
GENRE CONNE.

loration consiste en un fond d'un brun jaunâtre orangé avec des taches blanches irrégulièrement triangulaires, réunies par fascies transverses et comme réticulées; ces fascies sont au nombre de trois ou quatre; leurs intervalles sont parsemés d'autres taches plus grandes de même forme et de même couleur.

Long. 56 millim.

Habite les mers des grandes Indes.

Cette espèce est très-voisine de la précédente; elle en a la forme générale, cependant elle est un peu plus allongée et surtout plus atténuée à sa partie inférieure, où il existe, à la naissance du canal, un rétrécissement qu'on ne remarque pas dans l'espèce citée; ses fascies sont aussi mieux marquées; les taches qui les constituent, plus petites et plus rapprochées entre elles, forment une espèce de réseau irrégulier.

288. CONE DRAP-FIAMBÉ. Conus aureus, BRug.

(Collect. Lam.) Knorr. Vergn. 5, t. 11, fig. 5.

Pl. LXXXII, fig. 2.

C. testâ subcylindricâ, elongatâ, medio convexâ, transversim striatâ ; luteoaurantiâ; flammis fulvis aut fulvo-purpureis linearibus longitudinalibus; maculis albis trigonis fascialim confertis; spirâ ẹxsertâ, subacutâ.

Coquille subcylindrique, allongée, légèrement renflée au milieu, atténuée à sa base. La spire est conique, subaiguë; on y compte neuf ou dix tours subaplatis, taillés en biseau et réunis par une suture bien marquée; l'angle spiral du dernier est obtus et arrondi ; ce tour est couvert de stries transverses devenant, vers la base, de véritables sillons peu espacés 
entre eux. La coquille, d'un fond orangé ou brun foncé, est couverte de zones longitudinales ou transverses, formées par un réseau de taches blanches plus ou moins larges, et de forme trigone. Dans l'intervalle de ces zones réticulées on voit de grandes lignes longitudinales ondulées d'un roux brun presque pourpré.

$$
\text { Long. } 58 \text { millim. }
$$

Habite les côtes de la Chine et celles des îles Philippines.

Cette espèce est d'une coloration extrêmement agréable; elle a iveau coup d'analogie avec le Conus auratus, mais sa forme est moins allongée, sa spire plus conique, et ses taches sont disposées d'une manière différente, outre les grandes lignes longitudinales qui remplissent l'intervalle des réseaux.

Lamarck avait donné à cette espèce le nom de $C$. auricomus.

289. CONE IÉGAr. Conus legatus, LAM.

(Collect. de M. Delessert.) Sowerby, Conch. illust. fig. 12.

Pl. LXXXIX, fig. 3.

C. testâ cylindricâ, turbinatâ, angustâ, basi attenuatâ; albo-aurantio roseoque variegatâ, fusco-undatâ ; maculis albis, cordatis, inæqualibus, seriebus longitudinalibus ornatâ; spirâ acutâ.

Coquille turbinée, étroite, cylindrique, légèrement renflée vers sa partie supérieure, atténuée à sa base. La spire est régulièrement conique et mucronée au sommet : elle est formée de sept tours aplatis obliquement en dessus; l'angle spiral du dernier est lisse jusqu'à sa base, qui est garnie de quinze sillons transverses assez fins. L'ouverture est étroite et li- 
néaire. Le fond de la coquille est rose sur certaines parties, d'un jaune assez vif sur d'autres; ces nuances alternent avec de grosses lignes longitudinales ondulées, sur lesquelles sont disposées en séries de petites taches blanches de forme trigone; sur les parties rosées domine un réseau à mailles cordiformes très-larges. La spire est veinée de lignes brunes. L'intérieur de l'ouverture est d'une teinte rosée assez vive.

Long. 42 millim.

Habite la mer de la Chine et celle des Moluques.

Cette jolie espèce se distingue facilement de ses congénères par la disposition élégante de sa coloration. Le Conus musivum de Broderip n'est qu'une variété du $C$. legatus.

290. CONE POUDING. Conus rubiginosus, Brug.

(Collect. Lam.) Favane, Conch., pl. 18, fig. C, 4.

Pl. LXXXII, fig. 1-1

Li. testâ ovato-turbinatâ, supernè ventricosiusculâ, basi angustâ; castaneâ aut fuscâ; maculis albis cordatis irregularibus, interdùm in flammulis confluentibus ; spirâ convexo-acutâ.

Coquille ovale, turbinée, large et renflée vers sa partie supérieure, atténuée et resserrée vers le canal. La spire est peu élevée, conique, formée de huit tours légèrement convexes; le dernier est aplati en dessus, son angle spiral est bien marqué et arrondi; ce tour est renflé vers sa partie moyenne, son canal porte une quinzaine de sillons transverses. La coloration con- 
siste en un fond d'un brun marron plus ou moins foncé, quelquefois de couleur fauve sur lequel sont éparses un grand nombre de taches blanches plus ou moins larges, irrégulièrement trigones ou cordiformes, se réunissant quelquefois pour former des maculations allongées et flammulées, disposées en séries transverses et comme fasciées.

\section{Long. 58 millim.}

\section{Habite l'océan Asiatique.}

Cette espèce est de forme plus raccourcie et plus large que les précédentes; elle est remarquable par ses taches cordiformes se détachant vivement sur le fond d'un brun Inarron; cependant, dans certaines valićtés, ce fond est d'une teinte beaucoup plus claire ; c'est surtout dans ces variétés que les taches, devenant confluentes, forment des espèces de flammules longitudinales obscurénent fasciées. Telle est la fig. $1^{2} \mathrm{de}$ notre pl. 82.

291. CONE SOLIDE. Conus solidus, Sow.

(Collect. du Mus.) Sowerby, Conch. illust. fig. 76.

$$
\text { Pl. LIV, fig. } 1 .
$$

C. testâ conico-turbinatâ, abbreviatâ, supernè inflatâ, transversim striatâ ; maculis subtrigonis albo-carneolis trisfasciatâ, fundo aureo lineis longitudinalibus uigricantibus strigato; spirâ convexo-acutâ, ınucronatâ.

Coquille turbinée, raccourcie, renflée vers sa partie supérieure et très-atténuée à sa base. La spire est peu élevée, conique, mucronée au sommet: on y compte sept tours aplatis en dessus et marqués de 
stries décurrentes; l'angle spiral du dernier est obtus, lisse et arrondi : un peu au-dessous de cet angle naissent des stries transverses très-fines, devenant plus prononcées vers la partie inférieure. La coloration consiste en un fond d'un jaune doré, marqué de distance en distance de grandes lignes longitudinales irrégulières et brunâtres, et de taches subtrigones d'un blanc rosé, comme imbriquées, formant trois fascies transverses dont l'un occupe l'angle spiral du dernier tour, l'autre la base du canal et la troisième à peu près le milieu de la surface. Les taches, limitées par des lignes brunes extrêmement déliées, produisent une sorte de réseau irrégulier.

$$
\text { Long. } 38 \text { millim. }
$$

Habite les côtes des îles Philippines.

Cette jolie espèce est très.facile à distinguer de ses congénères par sa forme raccourcie, très atténuée à sa partie inférieure, et par sa coloration fort élégante.

292. CONE GIOIRE DE IA MER. Conus gloria maris, CheMr.

(Collect. de M. Delessert.) Chemv. Conch. 10, t. 143.

$$
\text { fig. 1324-25. }
$$

Pl. LXXVI, tig. 1, et pl. LXXVII, fig. 1.

C. testâ elongatâ, cylindrico-turbinatâ; albâ, aurantio-fasciatâ, maculis albis trigonis subtilissimis fusco-cinctis ad apicem usquè reticulatâ; spiræ concaroacuminatæ; anfractibus superioribus nodulosis.

Coquille allongée, cylindrique, turbinée, à spire élevée, conique, acuminée, formée de dix tours étroits; 
les premiers sont garnis d'une série transverse de petits tubercules ou crénelures; les autres ont leur superficie légèrement concave, bombée sur le bord inférieur, et finement treillissée; le bord spiral du dernier de ces tours est obtus et arrondi, la base est. traversée de rayons obliques assez apparents. L'ouverture est profondément échancrée à son extrémité supérieure, elle est blanche à l'intérieur, mince et tranchante. Le coquille, d'un fond blanc rosé, veiné de jaunâtre, est couverte d'un réseau à mailles fines, inégales, triangulaires ou rhomboïdales, qui occupe toute sa superficie; en outre, on y remarque des fascies transverses, étroites, irrégulières, distantes entre elles, composées de taches interrompues d'un jaune orangé sur lesquelles ondulent quelques lignes longitudinales d'un marron rouge.

\section{Long. 90 millim.}

Habite les mers des Indes orientales.

Cette espèce est encore aujourd'hui la plus rare et la plus précieuse du genre Cône; par son système de coloration, elle rentre évidemment dans la division des Draps-d'or, mais sa forme pyramidale et très-allongée la distingue éminemment de toutes les espèces de ce groupe. 
293. CONE DRAP-D'OR, Conus textile, Lix.

(Collect. Lam.) Bonann, Recreat. 3, fig. 155.

Pl. XC, fig. 1a à 1c, et pl. CII, fig. 4 .

C. testâ cyllindraceo-ovatâ; luteâ vel aurantiâ, lineis fuscis longitudinalibus undulatis maculisque albỉs trigonis fulvo-circumligatis ; spirâ conico-acuminatâ.

Coquille cylindracée, allongée, renflée vers le milieu, à spire élevée, conique, acuminée; on y comptè dix ou douze tours légèrement concaves en dessus, arrondis sur leur bord inférieur; l'angle spiral du dernier est bien marqué, mais obtus; ces tours sont garnis de quelques stries inégales, fines et obliques. La coloration de la coquille consiste en un fond d'un jaune orangé, marqué de lignes longitudinales onduleuses d'un brun rougeâtre et parsemé de taches blanches triangulaires ou cordiformes qui sont circonscrites par des traits filiformes de couleur fauve ou brune; ces taches, produisant des fascies transverses plus ou moins interrompues, sont rares là où le fond est bien apparent, et, au contraire, très-rapprochées entre elles, disposées en écailles de grandeur inégale, plus ou'moins serrées, vers les parties où l'on distingue le moins la coloration.

\section{Long. 80 millim.}

Habite la mer des Indes.

Cette espèce, l'une des plus communes du genre, est en même temps l'une des plus élégantes sous le rapport de la coloration; elle varie 
d'ailleurs extrêmement, soit par sa forme plus ou moins cylindracée, soit par un réseau plus ou moins serré sur la surface du dernier tour. La variété 1 a de notre $\mathrm{pl.} 90$ est plus ventrue vers la partie supérieure de ce même tour, et les taches qui forment le réseau y sont plus grandes. La variété $1^{\mathrm{b}}$ est d'une coloration plus pâle, la maille du réseau y est beaucoup plus fine que dans notre espèce type. La variété 1c est remarquable par un système de coloration qui la distingue particulièrement, le réseau de sa surface étant fort diffus. La variété de notre pl. 102 est beaucoup plus petite; le fond, d'un rose violacé, est traversé de deux fascies jaunâtres, ou seulement de nombreuses lignes longitudinales onduleuses ou en zigzags, peu régulières et ne produisant aucun réseau.

294. CONE PYRAMIDAR. Conus pyramidalis, LAM.

\author{
(Collect. Lan.) Favane, Conch. pl. 18, fig. C. 1. \\ Pl. LXXXV, fig. 1-1a; et pl. XGVI, fig. 2-2a.
}

C. testâ elongato-turbinatâ, sæpiùs fusoideâ; albidâ vel aurantiâ ; lineis longitudinalibus fuscis numerosissimisque flexuoso-angulatis, quandoquè maculis subtrigonis areolatis ornatâ ; spirâ elevatâ, acuminatâ ; anfractibus superioribus nodulosis.

Coquille allongée, turbinée, plus ou moins fusoïde, à spire élevée, pyramilale et acuminée. Les tours sont au nombre de dix environ; les premiers sont chargés d'une rangée de petits tubercules; l'angle spiral du dernier est peu marqué; ses plans latéraux sont un peu convexes et sa base est fortement atténuée vers le canal, dont la partie supérieure est pourvue d'une vinģtaine de stries obliques extrêmement fines. La coloration consiste en un grand nombre de linéoles longitudinales brunes, irrégulièrement onduleuses ou en zigzzagss et comme veruniculées; ces linéoles circonscrivent quelquefois des taches irrégulièrement trigones, 
d'un blanc violacé, et forment un réseau plus ou moins apparent; le fond lui-même ne paraît çà et là que sous la forme de grandes maculations orangées portant des lignes longitudinales brunes.

\section{Long. 54 millim.}

Habite la mer des Indes.

Cette espèce est très-remarquable par sa forme allongée en fuseau. ainsi que par les lignes ondulées et vermiculées qui ornent sa surface. Dans certaines variétés (voir notre pl. 96, fig. 2, $2^{\text {a }}$ ), ces lignes forment une forme de réseau à mailles subtrigones; ces variétés sont aussi d'une forme plus élargie. L'espèce type de notre pl. 85, fig. 1, est copiée de l'Eucyclopédie; la fig. 1a, même planche, est l'individu de la collection Lamarck, lequel fait maintenant partie de celle de M. Delessert.

295. CONI IRAmAII. Conus verriculum, ReEve.

(Collect. de M. Lorors.) Reev. Conch. icon. pl. 38, fig. 208.

Pl. XGV, fig. 2.

C. testâ ovato-turbinatâ, abbreviatâ, ventricosâ, lævi , basim versùs striatâ ; maculis albis subtrigonis irregularibus latissimè reticulatis, obscurè-fasciatâ, interstitiis aurantiis longitudinaliter fusco-strigatis; spirâ elatâ, concavo-acuminatâ..

Coquille ovale, turbinée, raccourcie, un peu ventrue au milieu, rétrécie vers la base. La spire, médiocrement élevée, est concave et acuminée; ses tours sont aplatis en-dessus; l'angle spiral du dernier est bien marqué, mais obtus. La partie supérieure du canal est pourvue de quelques stries obliques assez fines. La coloration consiste en un grand nombre de taches 
blanches généralement assez larges, irrégulièrement trigones, limitées par un réseau de lignes brunes, disposées en fascies transverses très-irrégulières, reliées quelquefois par des groupes longitudinaux de taches semblables aux premières. Le fond lui-même, visible dans les interstices, est coloré d'un jaune orangé avec des lignes longitudinales plus obscures. L'ouverture est d'un blanc violacé dans l'intérieur.

\section{Long. 55 millim.}

Habite la mer des Indes, les cótes de Ceylan.

Cette espèce présente encore le même système de coloration que le Conus textile; seulement, les mailles du réseau sont généralement plus larges. plus irrégulières, et le fond lui-même n'apparaît qu'à de rares intervalles; sous le rapport de la forme, au contraire, elle diffère sensiblement de l'espèce citée, elle est plus large, plus ventrue et plus raccourcie. Enfin la spire est également plus concave et plus acuminée.

296. CONE COULEUVRÉ. Conus colubrinus, LAM.

\section{(Collect. du Mus.)}

Pl. LXXXIr, fig. 3.

C. testâ elongato-cylindraceâ; luteo-aurantiâ; maculis albis cordato-trigonis squamiformibus : strïs tranșversìm subtilissimis ; spirâ conico-subacutâ ; albomaculatâ et fusco-venulatâ.

Coquille cylindrique, allongée, légèrement renflée vers le milieu, rétrécie à sa base. La spire est assez élevée, conique et acuminée; les tours sont aplatis en dessus; on en compte environ une douzaine; l'angle 
spiral du dernier est fuyant et peu marqué ; les plans latéraux sont légèrement convexes. Toute la surface est couverte de stries transverses très-fines : celles de la partie supérieure du canal sont plus fortes et obliques. La coquille, d'un fond jaune orangé très-vif, est ornée de lignes longitudinales onduleuses, plus ou moins fines et rapprochées entre elles; en outre, elle est couverte d'un réseau extrêmement fin de linéoles brunes qui entourent un grand nombre de taches blanches irrégulièrement trigones; ce réseau forme ordinairement de grandes zones longitudinales irrégulières, et çà et là des fascies transverses; l'une de ces fascies occupe constamment l'angle spiral : elle est accompagnée en dessus par une autre fascie d'un brun uni que l'on retrouve sur la spire.

\section{Long. 56 millim.}

Habite la mer des Indes.

Jolie espèce aussi élégante par sa forme allongée et cylindrique que par sa coloration. Elle a beaucoup de rapports avec certaines variétés du Conus textile; elle en diffère cependant par l'absence de lignes longitudinales. Les deux figures du $C$. colubrinus que donne M. Reeve dans son Conch. icon., pl. 22, fig. $123 a-b$, appartiennent au Conus rubiginosus de Lamarck. 
297. CONE TEXTILIN. Conus textilinus, NoBts.

(Collect. de $\mathrm{M}^{\mathrm{me}}$ Dupont.)

Pl. CIII, fig. 5.

C. testâ pyramidatâ, basi attenuatâ ; albâ, maculis trigonis passìm minutissimis imbricalis ornatâ; lineis longitudinalibus fuscis in fundo aurantio subfasciatâ; spirâ breviore, conico-mucronatâ.

Coquille turbinée, pyramidale, élargie à sa partie supérieure, vers l'angle spiral, atténuée à sa base. La spire est peu élevée, conique, un peu convexe et mucronée au sommet. Les tours sont au nombre de huit; ils sont légèrement convexes en dessus et pourvus de stries décurrentes; le dernier est un peu concave; son angle spiral est bien marqué; ses plans latéraux sont à peu près rectilignes; la base du canal offre quelques stries obliques extrêmement fines. La coquille est couverte en grande partie d'un réseau très-fin de linéoles brunes entourant de petites taches trigones d'un blanc rosé : le fond apparaît çà et là de couleur orangée, avec des lignes longitudinales brunes assez larges et espacées entre elles.

$$
\text { Long. } 40 \text { millim. }
$$

\section{Habite}

Cette espèce se rapproche beaucoup du Conus textile, au moins par la coloration; cependant son réseau est généralement plus fin et plus étendu, sa forme est aussi assez différente; elle est toujours plus petite, plus pyramidale, plus élargie vers la spire, et ses plans latéraux sont presque rectilignes, tandis que dans l'espèce citée ils sont toujours convexes. 
298. CONE victoria. Conus Victoric, Reeve.

(Collect. de M. Bolvin.) líeeve. Conch. icon. pl. 37, fig. 202.

PI. LXXVIII, fig. 1.

C. testâ ovate-turbinatâ, tenui, subinflatâ, transversìm striatâ; albidâ, cœesio longitudinaliter inquinatâ, maculis grandibus, subsolitariis, aurantiis, fusco-undulato-virgatis trifasciatìm ornatâ, interstitiis aurantio-fusco, subtilissimè reticulatis; spirâ elevato-exsertâ, apice acutissimo.

Coquille ovale, turbinée, un peu renflée vers le milieu. La spire est élevée et fortement acuminée; les tours sont concaves en dessus et un peu étagés; l'angle spiral du dernier est caréné; ses plans latéraux sont convexes. Toute la surface est couverte de stries transverses très-fines, plus apparentes sur le canal. L'ouverture est large, dilatée à sa partie inférieure. La coquille, d'un fond jaune doré, est ornée d'un réseau qui enveloppe des taches trigones blanches plus ou moins grandes et disposées en séries transverses; ce réseau, très-étendu, laisse à peine voir le fond, qui est marqué aussi de lignes longitudinales brunes prenant quelquefois une apparence réticulée. L'ouverture est d'un violet pâle dans l'intérieur.

$$
\text { Long. } 40 \text { millim. }
$$

Habite les côtes de la Nouvelle-Hollande, à l'embouchure de la rivière Victoria.

Cette jolie espèce, voisine du Conus textile, en est distincte par l'es. pèce de désordre qu'offre son système d'ornementation. Elle a également beaucoup d'affinité avec notre Cône textilin; mais sa spire est beaucoup plus acuminée. 
299. CONE ChANOINE. Conus canonicus, Breg.

(Collect. du Mus ) KNonr. Verg. 3, t. 18, fig. 2.

PI. XGV, fig. 1.

C. 1cslâ cylindrico-turbinatâ; fuscâ, lineis transversis nigris, macủlis retibusque albis inæqualibus conlertis; spirâ acuminatâ, subgra ra nosâ; fauce rosâ.

Coquille cylindracée, un peu renflée, à spire élevée, concave et acuminée. Les tours sont aplatis ou concaves en dessus, striés circulairement; les premiers sont légèrement granuleux; l'angle spiral du dernier est bien marqué et subcaréné : toute la moitié inférieure de ce tour est traversée par des stries extrêmement fines, plus apparentes sur le canal. La coquille est presque entièrement couverte par un réseau de linéoles brunes qui circonscrivent des taches blanches écailleuses, inégales et irrégulières; les unes sont subtrigones ou cordiformes, les autres subquadrangulaires, et forment des groupes divers où on les voit tantôt plus petites, tantôt plus grandes, mêlées avec d'autres de moyenne dimension. Ce réseau de taches se divise, sur certaines parties de la surface, en fascies transverses obscurément marquées; sur d'autres, elles sont disposées en séries; le fond lui-même, d'un brun rougeâtre et orangé, n'apparaît qu'en très-peu d'endroits ; il offre également des traces de flammules ondulées brunes et de lig̣nes circulaires noirâtres. L'ouverture est d'un rose vif à l'intérieur.

Long. 65 millim.

Habite la mer des Indes. 
Cette espèce, bien distincte par sa forme cylindracée, l'est aussi par l'abondance des taches irrégulièrement trigones dont sa surface est couverte. Elle est voisine du Conus textile; mais, outre les différences que nous venons d'y signaler, on remarque encore que sa spire est plus acuminée et plus concave.

\section{CONE ARCHEV ÊQUE. Conus archiepiscopus, Brug.}

(Collect. Lam.) Encyclop. pl. 346, fig. 7.

Pl. XCVI, fig. 1 et $1 \mathrm{a}$.

C. testâ ovato-turbinatâ, ventricosâ, luteo-fulvâ, lıneis longitudinalibus fuscis flexuosis ; fasciis quatuor albo cœruleo violaceoque articulatis ; spirâ elatiore acuminatâ.

Coquille ovale, turbinée, un peu ventrue, à spire élevée, concave et acuminée. On y compte douze ou quatorze tours aplatis en dessus, convexes près de la suture; le dernier est concave en dessus, son angle spiral est obtus; ses plans latéraux sont convexes ; sa partie inférieure est pourvue de stries transverses trèsfines. Le fond de coloration est d'un jaune orangé avec des lignes longitudinales brunes assez. espacées entre elles et flexueuses; en outre, la surface est ornée de quatre fascies transverses irrégulières plus ou moins distinctes, formées par un réseau de taches trigones d'un blanc bleuâtre ou violacé; ces fascies sont fréquemment reliées entre elles par des groupes longitudinaux de taches également réticulées et irrégulières. La spire offre aussi quelques taches blanches, et surtout des taches longitudinales brunes.

Long. 74 millim.

Habite la mer des Indes. 
C'est encore avec le Conus textile que cette espèce a le plus d'analogie; elle en est cependant distincte par sa forme plus atténuée vers la base, sa spire plus acuminée, et enfin ses réticulations disposées en fascies transverses. La variété $\boldsymbol{t a}^{\text {a }}$ est moins grande, sa forme est un peu plus cylindrique, ses fascies moins distinctes et la teinte violette domine sur le fond de coloration.

301. CONE PETIT-DRAP. Conus panniculus, LAM.

(Collect. Lam.) Favanse. Conch. pl. 18, fig. B. 6. Pl. LXXXVII, fig. 1-1a.

C. testâ ovato -turbinatâ, albidâ, vel pallidè fulvâ: lineis fusco-rubiginosis lon gitudinalibus undulatis creberrimis confertis; fasciis obscuris reticulatis; spirâ acuminatâ.

Coquille ovale, turbinée, très-ventrue au milieu, atténuée et rétrécie à sa base. La spire est médiocrement élevée, conique et acuminée. Les tours sont larges et aplatis en dessus; on en compte une dizaine; l'angle spiral du dernier est bien marqué, mais obtus. La coloration, généralement assez foncée, est formée d'un réseau de petites taches irrégulières plus ou moins anguleuses, groupées de manière à produire des espèces de fascies transverses très-obscures, d'un blanc cendré ou bleuâtre; ces fascies se détachent sur le fond qui est d'un blanc jaunâtre ou orangé avec des lignes longitudinales brunes et onduleuses.

Long. 72 millim.

Habite la mer des Indes. 
Cette espèce se reconnaît bien à sa forme' un pen ventrue et à son réseau extrêmement fin et irrégulier, affectant cependant une disposition fasciée transversale. Dans certaines variétés, le réseau èst à peine distinct, ce sont les lignes longitudinales brunes qui dominent. (Voir la fig. 1a de notre pl. 27.)

302. CONE ABBÉ. Conus abbas, Brog.

(Collect. Lam.) Chesn. Conch. 10. t. 143, fig. 1326, B, C.

Pl. LXXXVI, fig. 1.

C. testâ subcylindraceo-turbinatâ; aurantiâ, fusco-undatâ, zonis subroseis reticulatis maculisque albis raris passim sparsis; spirâ acutâ.

Coquille subcylindrique, turbinée, légèrement renflée à sa partie supérieure. La spire est peu élevée, conique, pointue. Les tours sont aplatis ou légèrement concav̀es en dessus et couverts de stries décurrentes très-fines; l'angle du dernier est bien marqué et subcaréné. Le fond de la coquille est d'un jaune orangé avec des flammules longitudinales brunes et flexueuses; il est couvert en grande partie par trois fascies transverses généralement très-larges, finement réticulées et rosées; ces fascies et leurs intervalles sont parsemés de grandes taches trigones le plus souvent isolées, mais quelquefois groupées ensemble. La spire est aussi ornée de quelques-unes de ces taches mêlées de bleuâtre, mais elle est surtout garnie de lignes onduleuses d'un rouge brun.

\section{Long. 65 millim.}

Habite la mer des Indes. 
Ce Cône diffère un peu dans sa forme de l'espèce précédente; il est moins bombé vers son extrémité supérieure; il présente, dans l'élégance et la finesse du réseau qui forme ses fascies transverses ainsi que dans leur coloration rosée, des caractères qui servent à le distinguer des espèces voisines; il est également remarquable par ses grandes taches trigones blanchâtres qui ,se trouvent éparses et isolées, soit sur le fond lui-même, soit sur les fascies réticulées.

303. CONE PLUMEUX. Conus pennaceus, Born.

(Collect. Lam.) Rumpr. Mus. t. 33, fig. 4.

PI. LXXXIX, fig. 2.

C. testâ cylindraceo-turbinatâ, subovatâ, aurantio-fuscâ ; maculis albis cordiformibus longitudinaliter transversimque congestis lineis transversis fuscis albo punctatis; spirâ obtusâ.

Coquille ovale, turbinée, large et anguleuse à sa partie supérieure. La spire est peu élevée et obtuse; on y compte sept ou huit tours : 'les premiers sont légèrement convexes, le dernier est aplati, un peu canaliculé en dessus; son angle spiral est bien marqué, mais obtus. Le reste de la superficie est garni de stries circulaires, très-sensibles sur la moitié inférieure, à peine visibles sur l'autre moitié. La coquille est d'un fond brun orangé, orné de lignes brunes transverses, étroites et serrées; ces lignes sont finement ponctuées de blanc et interrompues par des taches blanches inégales, cordiformes ou ovales, groupées en écailles et formant souvent de grandes zones longitudinales.

\section{Long. 56 millim.}

Habite l'Océan Asiatique, 
C'est avec le Conus omaria que cette espèce a le plus d'analogie; le système de coloration de ces deux coquilles est à peu près semblable; seulement, dans l'espèce ici décrite, les grandes zones sont plutôt longitudinales que transverses, et le réseau qui les constitue n'est pas aussi nettement limité. La forme d'ailleurs est également différente; elle est toujours plus raccourcie et plus ventrue.

304. CONE PRÉt AT. Conus prelatus, Brog.

(Collect. Lam.) Favanne. Conch. pl. 18. fig. B 7.

Pl. LXXXIX, fig. 1-1a.

C. testâ ovalo-turbinatâ, luteo-aurantiâ vel fulvâ ; maculis trigonis vel irreguariter oblongis imbricatis, albo cæsio et incarnato variegatis, seriebus irregularibus confertis; lineis transversis albo castaneoque punctatis; spirâ acutâ.

Coquille ovale, turbinée, à plans latéraux légèrement convexes vers leur partie médiane et supérieure. La spire est un peu élevée et conique; on y compte huit ou dix tours aplatis en dessus : le dernier est légèrement concave vers cette partie; son angle spiral est arrondi et obtus. La coloration consiste en un fond jaunâtre ou orangé sur lequel sont dispersés des groupes de taches oblongues ou subtrigones, comme imbriquées et d'un blanc incarnat nuancé de violet ; ces groupes réticulés forment des fascies transverses ou des zones longitudinales irrégulières; en outre, le fond est encore couvert de lignes transverses très-fines, articulées de points alternativement blanchâtres et marrons. La spire est veinée de lignes bru- 
nes; on y distingue aussi des groupes de petites taches blanches réticulées.

Long. 48 millim.

Habite les mers des grandes Indes.

Cette espèce rappelle assez par sa coloration le Conus pennaceus; cependant ses taches sont généralement plus ovales et d'une teinte plus violacée; elle en est surtout distincte par sa forme plus allongée et par son angle spiral qui est moins prononcé. La variété $1^{a}$ offre des taches beaucoup plus nombreuses; disposées en écailles avec des interstices d'un blanc nuancé de bleuâtre ou de rose.

305. CONE DיíxISA. Conus Elisce, Nobis.

(Collect. de M. Borvin.)

PI. LXIV, fig. 1-1a.

C. testâ cylindraceo-turbinatâ, crassâ, infernè subrectè attenuatâ; fusco-castaneâ, transversim tenuissimè reticulatâ ; interstitiis punctis albis moniliformibus articulatis ; spirâ conico-obtusâ.

Coquille cylindrique, turbinée, épaisse, presque régulièrement atténuée vers la base. La spire est un peu élevée, conique, obtuse; on y compte six tours convexes à suture profonde et bien marquée ; le dernier, légèrement concave en dessus, a son angle spiral obtus et arrondi, mais saillant. La coquille est d'un brun marron plus ou moins foncé; dans le jeune âge, on distingue très-bien sur sa surface deux fascie transverses formées d'un réseau extrêmement fin, 
circonscrit par de petites taches arrondies; l'une de ces fascies occupe l'angle spiral du dernier tour et se retrouye sur la totalité de la spire; l'autre est située un peu au-dessous de la partie moyenne de la coquille. Leurs intervalles sont marqués de lignes transverses moniliformes extrêmement fines et comme articulées; sur les individus adultes, ces lignes dominent les fascies, qui sont alors à peine visibles.

\section{Long. 52 millim.}

\section{Habite}

Jolie espèce dont nous devons la connaissance à l'extrême obligeance de M. Boivin. Elle est remarquable à la fois par sa forme, qui rappelle un peu le Conus terebra, et par le réseau très - fin qui compose sa coloration. M. Reeve, dans son supplément de Conchologia Iconica, pl. 9. $f g .280^{\mathrm{b}}$, a fait représenter pour cette espèce une variété du C. monachus, et sur la même planche, fig. 280 , il a donné, comme jeune du même Cône, une coquille qui n'est autre que mon Conus stellatus, espèce cependant bien distincte.

306. CONE PERIE. Conus omaria, BRUG.

$$
\begin{gathered}
\text { (Collect. Larr.) Seba. Mus. 3, t. 47, fig. P5. } \\
\text { Pl. LXXIX, fig. 1-12. }
\end{gathered}
$$

C. testâ cylindraceo-turbinatâ, fulvo-fuscâ vel aurantiâ ; maculis albis cordato trigonis, lineisque fuscis, numerosis albo punctatis; spirâ obtusầ; apice roseo.

Coquille turbinée, subcylindrique, légèrement renflée presque dans toute sa longueur. La spire est peu 
élevée, obtuse. Les tours sont légèrement canaliculés en dessus, le dernier porte un angle spiral arrondi et obtus; toute sa surface est couverte de stries transverses extrêmement fines se confondant avec les sillons de la base. Le fond de la coquille est d'un brun plus ou moins foncé, quelquefois orangé avec un grand nombre de petits points blancs formant des lignes transverses. Sur ce fond, se détachent de grandes taches blanches, irrégulièrement trigones ou cordiformes, entourées de simples linéaments blancs, ce qui produit une espèce de grand réseau disposé par fascies transverses ou relié de distance en distance par des zones longitudinales; ces fascies et ces zones circonscrivent ainsi de grands espaces quadrangulaires. Dans certaines variétés, cette disposition est moins régulière et moins apparente.

\section{Long. 60 millim.}

\section{Habite l'océan Asiatique.}

Cette espèce n'est pas sans analogie, soit par sa forme, soit par sa coloration, avec certaines variétés du Conus episcopus, mais elle en est distincte par ses taches plus petites qui produisent un réseau mieux prononcé : elle est aussi plus obtuse. La coquille de la variété $1^{2}$ est d'un marron plus rembruni, quelquefois d'un brun cannelle, orné de taches blanches irrégulières plus petites et plus nombreuses. 
GENRE CONNE.

307. CONE CERT. Conus cervus, LAY.

(Collect. Lasr.)

Pl. LXXIV et LXXV, fig. 1.

C. testâ majusculâ, cylindraceo-ovatâ, tenui, pallidè luteâ, tæniis transversis inæqualibus fulvo et albo articulatis; spirâ brevi, subacutâ; anfractibus supernè planulatis, striatis; fauce albâ.

Coquille ovale, grande, mince, cylindracée, un peu renflée. La spire est courte, subdéprimée, mucronée au sommet; on y compte une douzaine de tours aplatis en dessus et pourvus de stries décurrentes; l'angle spiral du dernier est bien marqué, saillant, subcaréné : il est lisse dans toute son étendue. La coloration consiste en un fond d'un jaune pâle sur lequel se détachent des lignes transverses d'une teinte plus foncée; ces lignes articulées à points blancs moniliformes sont plus ou moins larges, formant quelquefois de véritables fascies sur lesquelles se détachent des taches plus grandes et irrégulières.

\section{Long. 94 millim.}

\section{Habite}

Cette belle et grande espèce, remarquable par sa coloration,"est voisine du Conus bullatus, mais elle s'en distingue aisément, soit par sa taille, soit par sa coloration. Elle est encore rare dans les collections. 
GENRE CONNE.

308. CONE BROCARD. Conus geographus, LiN.

(Collect. Lam.) Lister. Conch. t. 747, fig. 41.

Pl. XII, fig. 1.

C. testâ oblongâ, subrentricosâ, tenui, albo fulvo castaneoque variegatâ, maculis albis obscurè reticulatis nebulosâ; spirâ concavo-obtusâ, mucronatâ, tuberculis coronatâ; aperturâ dehiscente, basi excavatâ; fauce violaceâ.

Coquille oblongue, subcylindrique, mince, un peu ventrue. La spire est très-courte, concave, mucronée au sommet; on y compte sept ou huit tours aplatis en dessus, ornés près de leur suture d'une rangée de gros tubercules un peu comprimés et subtranchants, au moins sur le dernier; l'angle spiral de ce tour est. très-marqué et saillant; toute sa surface est lisse. L'ouverture est grande, dilatée à la partie inférieure où la columelle offre une sinuosité profonde. La coquille est presque entièrement couverte d'un réseau irrégulier qui circonscrit des taches rosées ou carnéolees; dans les intervalles de ce réseau paraît le fond qui forme de grandes taches irrégulières prenant souvent la forme de larges flammules longitudinales très-déchiquetées, d'un brun marron nuancé de bleuâtre ou de violacé. L'ouverture est violette dans l'intérieur.

Long. 92 millim.

Habite les mers des Indes. 
Grande et belle espèce très-commune dans les collections, facile a distinguer par sa taille, son test mince, l'ampleur de son ouverture, et enfin par sa coloration très-agréable à l'œil.

309. CONE TULIPE. Conus tulipa, LiN.

(Collect. Lam.) Lister. Conch. t. 764, fig. 13.

PI. XII, fig. 2-2a.

C. testâ tenui, oblongâ, obsoletè coronatâ, rufescente vel roseâ albo et cæruleo-undatâ ; lineis transversis fuscis albo-punctatis; spirâ brevi, obtusiusculâ ; aperturâ patente, violacescente.

Coquille ovale, oblongue, mince, lisse, un peu ventrue. La spire est surbaissee et obtuse. Les tours sont aplatis en dessus et pourvus vers leur suture d'une rangée de tubercules obsolètes tendant à disparaitre presque complétement sur le dernier; l'angle spiral de ce tour est saillant, mais obtus. La coloration consiste en un fond rose ou roussâtre sur lequel on distingue de grandes maculations irrégulières, brunes ou violacées, formant quelquefois des fascies transverses. Toute la surface est, en outre, traversée par un grand nombre de lignes articulées de points alternativement bruns et blancs.

Long. 52 millim.

Habite les mers d'Afrique et des Indes.

Cette espèce présente quelque analogie avec le.Conus geographus, au moins par son aspect général, mais elle est un peu plus épaisse; 
les tubercules de la spire sont moins marqués et finissent même par disparaître. Dans la variété $2^{2}$ la coloration diffẹrre surtout en ce qu'au lieu d'un réseau elle ne porte plus que des lignes articulées circu. laires.

Nous pensons que l'on doit rapporter à cette espèce, à titre de variétés seulement, le Conus violaceus et le Conus intermedius de Reeve.

310. CONE OBSCUR. Conus obscurus, REEv.

(Collect. de M. Borvin.) Reev. Conch. icon. pl. 16, fig. 82.

Pl. LXVIII, fig. 2.

C. testâ oblongâ, tenui, læviter inflatâ, maculis castaneo fuscis aut violaceis, variè nebulatâ, punctis violaceis sparsis ornatâ ; spirâ subelatâ, spiraliter striatâ , a pice roseo, mucronato; aperturâ dehiscente, fauce violaceo.

Coquille oblongue, mince, légèrement ventrue. La spire est conique, un peu élevée, acuminée et mucronée au sommet. Les tours sont étroits, concaves en dessus, pourvus de stries décurrentes; l'angle spiral du dernier est saillant et subcaréné. La partie supérieure du canal est pourvue de sillons obliques trèsfins. La coquille est marquée de grandes taches violettes et de points de même conleur se détachant sur un fond d'un brun marron, formé lui-même de grandes maculations nuagées. L'ouverture est violacée dans l'intérieur.

Long. 30 millim.

Habite la mer de Chine. 
GENRE CÓNE.

Cette espèce a la plus grande affinité avec le Conus tulipa, et pourrait bien n'en être qu'une variété; cependant sa forme paraît un peu plus allongée, sa spire est plus élevée et acuminée. Dans le doute où nous sommes sur l'importance de ses rapports, nous avons du la conserver comme distincte.

311. CONE DE DESHAYrs. Conus Deshayesii. Regve.

(Collect. de $\mathrm{M}^{\text {me }}$ Dupont.) Reeve. Conch. Icon, pl. 5, fig. 28.

Pl. LVIII, fig. 1.

C. testâ cylindraceo-ovatâ, tenuiculâ, inflatâ, pallidè olivaceo-fulvâ, profusè rubido-puncticulatâ, maculis albis grandibus perpaucis, sparsìm et irregulariter nebulosâ ; spirâ depresso-planâ, apice mucronato; aperturâ dehiscente, fauce quasi politâ nitente.

Coquille ovale, subcylindrique, mince, un peu ventrue. La spire est très-surbaissée, presque plane, mucronée au sommet; elle est formée de tours concaves et même canaliculés en dessus ; l'angle spiral du dernier est saillant et comme caréné : il porte vers sa base sept ou huit gros sillons obliques. L'ouverture est ample, dilatée à sa partie inférieure où la columelle est fort excavée. La coquille est d'un jaune olivâtre, avec de grandes maculations blanches, nuagées de violet, peu nombreuses, isolées, disposées transversalement de manière à produire deux sortes de larges fascies interrompues. Toute la surface est en outre traversée par un grand nombre de lignes ponctuées de brun. L'ouverture est d'un jaune verdâtre dans 
GENRE CO̊NE.

l'intérieur. Le bord droit est fauve, orné d'une série de petits points bruns.

\section{Long. 48 millim.}

Habite les mers de la Nouvelle-Hollande.

Cette espèce appartient par sa forme à la division des Cônes bullés; son test est mince, son ouverture ample; par son système de coloration elle rappelle, au contraire, jusqu'à un certain point, les C. magus et Raphanus. Cette réunion de caractères la rend facile à distinguer.

312. CONE BסILÉ. Conus bullatus, LIN.

(Collect. Lam.) Gualt, Test. t. 26, fig. C.

PI. LVIII, fig. 2.

C. testâ cylindraceo-ovatâ, ventricosâ, miniatâ, paniceo et albo variegatâ, obscurè fasciatâ ; spirå brevi, canaliculatâ, mucronatâ; aperturâ hiante; fauce aurantiâ.

Coquille ovale, cylindrique, mince, ventrue, bulloïde. La spire est surbaissée, canaliculée, mucronée au sommet; les tours sont concaves en dessus et pourvus, près de leur suture, d'une série de petites granulations; l'angle spiral du dernier est légèrement caréné; ce tour est étroit vers cette partie; on distingue à sa base une douzaine de sillons obliques et ponctués. L'ouverture est grande, dilatée vers sa base ; la columelle est légèrement tordue et comme plissée à sa partie inférieure. La coquille a une teinte générale de rouge orangé très-vif, avec un grand nombre de taches 
GENRE CÔNE.

d'une teinte plus claire; ces taches sont isolées, en forme de gouttelettes ou réunies en zones transverses et en lignes ponctuées. L'ouverture est d'un jaune orangé qui s'étend dans toute la cavité.

Long. 68 millim.

Habite la mer des Indes et celle des Moluques.

Belle espèce bien distincte de ses congénères, soit par sa forme bulloïde, soit par sa coloration.

\section{SUPPLÉMENT ET ADDITIONS.}

$-0818-$

313. CONE DE VAUTIER. Conus Vautieri, NoBls.

(Collect. de M. Bernardi.)

Pl. C, fig. 3.

G. testâ turbinatâ, subinflatâ, solidâ, lævigatâ, basi sulcatâ ; albâ, rosoque fusconebulosâ, punctis fuscis vel nigris sparsìm ornatâ ; spirâ plano-depressâ, tuberculis crassis coronatâ.

Coquille turbinée, épaisse, legèrement renflée, à spire plane, déprimée, dont les tours assez nombreux sont couronnés par une série de gros tubercules coniques. L'angle spiral du dernier est bien prononcé; presque toute l'étendue de ce tour est lisse, sa base 
seulement est garnie de quelques sillons obliques assez distants entre eux. La coloration consiste en un fond blanchâtre nuagé de rose et de brun, sur lequel se détachent un grand nombre de points bruns ou noirâtres, irrégulièrement épars, quelquefois agglomérés, principalement sur les parties nuagées de brun.

Long. 32 millim.

Habite

Cette espèce est voisine du Conus pulicarius, mais en est distincte par plusieurs caractères importants, surtout par l'aplatissement plus considérable de la spire et par le plus grand développement des tubercules, enfin par ses points bruns plus nombreux et accompagnés de nébulosités. Nous avons dédié cette espèce à M. Vautier, aniateur zélé qui habite le Calvados.

314. CON2 RABOTEUX. Conus scaber, Nobis.

(Collect. de M. Bernardi.)

Pl. C, fig. 1.

C. testâ inflato-turbinatâ, crassâ, basi angustâ; spirâ exsertâ, conico-mucronatâ, tuberculis crassis coronatâ, circuliter striatâ ; ultimo anfractu tuberculis moniliformibus albis per seriibus transversis dispositis ornatâ ; aurantiâ, lineolisque punctibus reticulatis obscurè fasciatâ.

Coquille turbinée, épaisse, renflée au milieu, atténuée et rétrécie à sa partie inférieure. La spire, médiocrement élevée, est couronnée par une rangée de gros tubercules obtus. L'angle spiral du dernier tour est bien prononcé ; presque toute la surface de ce tour est ornée de séries transversales de petits tubercules moniliformes très-réguliers et d'un blanc lacté : ces 
tubercules trancbent ainsi sur le fond de la coquille, formée d'un grand nombre de linéoles orangées, constituant une sorte de réseau irrégulier qui circonscrit de petits espaces blanchâtres.

Long. 28 millim.

Habite les mers de l'Océanie.

M. Reeve, qui a mentionné cette espèce d'après nos figures, la rapporte cependant à titre de variété au Conus miliaris. Malgré l'analogie de forme qui existe entre ces deux espèces, il est évident qu'elles présentent des différences assez importantes pour être classées distinctement. Ainsi, dans notre $C$. scaber, les tubercules de la spire sont plus prononcés, la forme est moins élargie, la surface couverte de granulations moniliformes; enfin, le système de coloration est tout à fait différent en ce sens qu'il est constitué par un réseau de linéoles orangées, tandis que dans le $C$. miliaris, il est formé de lignes ponctuées.

315. CONב DE mIGRrss. Conus Mighelsi, NoвIs.

\section{(Collect. de M. Largilliert.)}

PI. CIII, fig. 1.

C. testâ turbinatâ, albâ, punctis nigris per seriebus, transversim articulatis ornatâ, cum fasciâ ferrugineâ in medio cinctâ ; spirâ coronatâ, nigro-maculatâ ; aperturâ intùs violaceâ; ultimo anfractu supernè lævi, infernè transversim granulato.

Coquille assez régulièrement turbinée, très-étroite vers sa partie inférieure. La spire est peu élevée, conique et mucronée au sommet; elle est couronnée par une rangée de tubercules médiocrement prononcés. L'angle spiral du dernier tour est bien marqué; la moitié supérieure de ce tour est lisse, l'autre moitié 
porte des séries transverses de petits tubercules. La coloration consiste en un fond blanchâtre sur lequel se détachent des séries de points noirs subquadrangulaires allongés et comme articulés; vers le milieu de la coquille, il existe une fascie transverse roussâtre plus ou moins interrompue. Le canal et l'intérieur de l'ouverture sont colorés de brun violacé.

\section{Long. 56 millim:}

Habite la mer des Indes.

Cette jolie petite espèce offre quelque analogie de forme avec le $\mathrm{Co}$ nus musicus, mais elle en est nettement distincte par ses séries transverses de points noirs qui sont plus gros et par la fascie médiane. Nous sommes donc étonné que M. Reeve, qui a mentionné ce Cône d'après nos figures, l'ait rapporté au $C$. musicus lui-même à titre de variété ; il suffit de comparer les figures des deux espèces pour se convaincre de leurs différences. M. Largilliert, à qui nous devons la communication de cette intéressante espèce qui fait partie de sa belle collection, lui a vait déjà donné le nom de M. Mighels, docteur à Portland.

316. CONE PATRICIEN. Conus patricius, Hinds.

(Collect. de M. Belcher.) Reeve. Conch. icon. pl. 13. fig. 63.

Pl. LXXXVIII, fig. 4.

C. testâ pyriformi, tumidâ, carneâ, epidermide luteâ indutâ ; spirå concavoelatâ, minutè tuberculato-coronatâ; apice valdè acuminato; undulatis, superni plicato, infernè valdè attenuato; labro tenui, acuto.

Coquille allongée, pyriforme, renflée et commt tronquée à sa partie supérieure, très-atténuée ver: 
GENRE CÔNE.

sa base. Sa spire est assez élevée et acuminée; on y compte neuli ou dix tours légèrement excavés en dessus et dont l'angle externe est couronné d'une rangée de petits tubercules moniliformes. Sur le dernier tour, ces tubercules se prolongent en forme de plis longitudinaux et un peu obliques; toute la surface du tour est traversée par un grand nombre de stries extrêmement fines et un peu onduleuses. La coquille est d'un blanc rosé, comme carnéolé, et revêtued'un épiderme jaunâtre.

$$
\text { Long. } 30 \text { millim. }
$$

Habite les côtes du Mexique.

Cette jolie espèce offre quelque analogie par sa forme générale av ec le Conus Orbignyi, mais elle en diffère éminemment par tous les détails de sa structure et de sa coloration.

327. CONI IA BOURÉ. Conus liratus, REEvE.

(Collect. de M. Largilliert:) Reeve, Conch. icon. pl. 47. fig. 268.

Pl. GIII, fig. 2.

G. testâ subabbreviato-turbinatâ, liris subprominulis undiquè circumdatâ ; albidâ, maculis paucis aurantio-fuscis longitudinaliter confluentibus biseriatim cinctâ : spirâ exsertâ, noduliferâ, apice pallidè-rosaceo ; basi et aperturæ fauce vividè violaceo-roseâ.

Coquille turbinée, biconique, régulièrement atténuée à sa partie inférieure. La spire est assez élevée et 
GENRE GÔNE.

un peu étagée ; elle est formée de tours anguleux couronnés d'une rangée de tubercules saillants. Toute la superficie du dernier tour est traversée par des stries très-saillantes et subtranchantes. Le fond de la coquille est blanc avec des flammules longitudinales orangées, brunes, un peu flexueuses, quelquefois confluentes et formant deux fascies transverses dont l'une occupe les deux tiers supérieurs du dernier tour et l'autre la base du canal. L'intérieur de l'ouverture est assez vivement coloré d'un violet rose.

$$
\text { Long. } 20 \text { millim. }
$$

\section{Habite}

Petite espèce extrêmement remarquable par l'élévation de sa spire el par les stries subtranchantes de son dernier tour. Sa coloration sert aussi à la distinguer très-nettement de ses congénères.

318. CONE CRÍNUIÉ. Conus crenulatus, NoBss.

(Collect. de M. Lorors.)

Pl. CIX, fig. 1. .

C. testâ fusiformi turritâ, medio inflatâ, extremitatibus valdalattenuatis; albolutesccnte; spirâ clatâ, acuminatâ, tuberculis subcompressis coronatâ, ultimo anfractu transversim costatoque tuberculifero, interstitiis longitudinaliter striatis; labro acuto flcxuoso.

Coquille allongée, fusiforme, turriculée, renflée au milieu, fortement atténuée vers ses extrémités. La spire est acuminée, très-élevée et forme près de la moitié 
de la longueur totale; elle se compose de douze ou treize tours étroits, tectiformes, garnis de stries décurrentes, et dont la suture est ornée d'une rangée de tubercules un peu comprimés qui sont portés sur une espèce de cordon décurrent. Toute la surface du dernier tour est traversée par des côtes saillantes chargées de petits tubercules moniliformes. L'intervalle de ces côtes est pourvu de stries verticales extrêmement fines. L'ouverture est fort étroite: le bord droit est mince, tranchant, flexueux :la coquille est d'un blanc jaunâtre très-pâle.

Long. 32 millim.

\section{Habite}

Cette charmante espèce, dont nous devons la communicationà M. Lorois, a une forme très-distincte, quoique offrant quelque rapport avec le Conus Orbignyi; mais sa spire est beaucoup plus élevée, son dernier tour plus atténué vers la partie inférieure, de plus, ses côtes transverses sont surmontées de tubercules moniliformes.

319. CON2 SANGUIN. Conus sanguineus, NoBIs.

$$
\text { (Collect. de M. Verreaux.) }
$$

Pl. CXI, fig. 2.

C. testâ pyramidali turbinatâ, incrassatâ ; rubro-sanguinolentâ, maculis pallidis irregularibus elongatisque angulatis, in tribus fasciatis dispositis ornatâ ; lineis transversis punctorum nigrorum articulatis omninè instructâ; spirâ breviore subcontabulatâ, granulis obsoletis coronatâ.

Coquille turbinée, pyramidale. La spire est conique, un peu élevée; on y compte trois tours étroits : les 
premiers sont légèrement anguleux et munis d'une rangée de tubercules peu prononcés; le dernier est aplati, excavé en dessus; son angle spiral est obtus. Toute la surface est lisse, à l'exception du canal de la base qui présente quelques sillons obliques. La coloration consiste en un fond d'un rouge sanguinolent trèsvif sur lequel on distingue un grand nombre de lignes transverses articulées de très-petits points noirâtres. Trois fascies occupent le dernier tour : l'une est placée vers l'angle spiral, l'autre vers la partie supérieure du canal et enfin la troisième qui est la plus importante, est située un peu au-dessous du milieu du tour. Ces fascies sont formées de la réunion de grandes maculations blanchâtres, très-irrégulières, allongées, anguleuses et quelquefois trigones.

Long. 44 millim.

\section{Habite}

Cette belle espèce est, extrêmement voisine du Conus archon; elle a à peu près l'ensemble des caractères de ce dernier Cône, mais elle en diffère par quelques nuances; sa forme est moins pyramidale, sa spire un peu étagée; ses premiers tours sont obscurément couronnés; enfin sa coloration présente des taches moins nombreuses et moins disséminées. 
320. CONE DE BIAINVIrIE. Conus Blainvillei, Nobls.

\author{
(Collect. de M. Verreaux.)
}

Pl. CXI, fig. 1 .

C. testâ abbreviato-turbinatầ, subincrassatâ ; luteo-viridescenté, bifasciatâ lineis transversalibus punctorum nigrorum articulatis ornatâ; spirâ brevi, acutâ, anfractibus supernè pauciter angulatis; fauce violaceâ, albo bifusciatâ.

Coquille turbinée, raccourcie, assez épaisse. La spire conique est un peu élevée; elle est formée de sept tours étroits, lisses, subanguleux en dessus; l'angle spiral du dernier est bien marqué, mais obtus; toute sa surface est lisse, seulement la partie supérieure du canal offre quelques légères stries obliques. La coquille a une teinte générale d'un jaune verdâtre; presque toute son étendue est traversée de lignes ponctuées et comme articulées qui sont séparées en deux faisceaux par une espèce de fascie d'un jaune plus clair ; cette fascie est située un peu au-dessous du milieu du dernier tour; une autre fascie, de même teinte, occupe la partie supérieure de la coquille près de l'angle spiral. L'ouverture est violacée dans l'intérieur. On distingue sur le bord droit deux traces blanches qui correspondent aux fascies externes.

Long. 38 millim.

Habite

Cette espèce a une certaine analogie avec le Conus Reevii, mais elle en est éminemment distincte par sa forme et sa coloration. 
32x. CONE OXIVACE. Conus olivaceus, NoBrs.

(Collect. de M.Verreaux.)

Pl. CXI, fig. 3.

C. testâ turbinatâ, pyriformi, subinflatâ ; luteâ, obscurè trifasciatâ ; spirâ breviore acutâ, mucronatâ; fauce violaceâ, albo bifasciatâ.

Coquille turbinée, pyriforme, un peu renflée vers la partie supérieure, atténuée à la base. La spire est surbaissée, excavée, mucronée au sommet. L’angle spiral du dernier tour est arrondi et obtus; ce tour est lisse excepté vers sa base qui est munie d'environ quinze sillons obliques bien marqués. La coloration consiste en un fond jaunâtre sur lequel se détachent à peine deux ou trois fascies transverses, étroites, mal limitées et à peu près de la même couleur que le fond ou un peu plus foncées. L'ouverture est vivement colorée à l'intérieur d'un violet foncé; le bord droit est marqué de deux fascies blanches qui correspondent à celles de l'extérieur.

$$
\text { Long. } 55 \text { millim. }
$$

Habite

Cette espèce se rapproche un peu par sa forme générale du Conus venulatus, elle est pourtant plus pyriforme; sa coloration, au contraire, lui donne de l'analogie avec notre Conus Blainvillei; mais elle est d'une teinte générale plus claire et n'a point de lignes transverses articulées. 
322. CONE DE TASTÉ. Conus Taslei, NoBis.

(Collect. de la Société de Vaxies.)

Pl. CX, fig. 5.

C. testâ turbinato pyriformi, supernè inflatâ, infernè valdè attenuatâ; lutescente, fasciis lividisque albis cinctâ; spirâ conicâ, mucronatâ ; fauce violacescente, albo-bifasciatâ.

Coquille turbinée, pyriforme, renflée vers sa partie supérieure, fortement atténuée à sa base. La spire est un peu élevée, conique, mucronée au sommet; on y compte sept ou huit tours étroits, lisses en dessus; l'angle spiral du dernier est arrondi et renflé ; ce tour porte à sa base une douzaine de petits sillons obliques. La coquille a une teinte générale d'un jaune verdâtre ou livide; elle est traversée par deux fascies blanchâtres dont l'une est située un peu au-dessous du milieu du dernier tour et l'autre près de l'angle spiral. La spire est généralement brunâtre. L'ouverture est d'un violet foncé dans l'intérieur avec deux traces de fascies blanches sur le bord droit qui correspondent à celles de l'extérieur.

$$
\text { Long. } 32 \text { millim. }
$$

Habite

C'est avec notre Conus olivaceus que cette espèce a le plus d'analogie; son mode de coloration, surtout, est bien semblable, mais sa forme plus renflée vers la partie supérieure ét en même temps plus atténuée à sa base, l'en distingue aisément. 
323. CONE UNTBANDE. Conus unifusciatus. Nobrs.

(Collect. de la Société de Vannes.)

Pl.CX, lig. 4.

C. testâ oblongo-turbinatâ, ovoideâ; fusco-castaneâ, infernè obscurè, transversim lineolatâ, supernè albo zonatâ; spirâ elatâ, conicâ, apice mucronato albescente; fauce violaceâ, albo unifasciatâ.

Coquille turbinée, oblongue, ovoïde, un peu renflée. La spire est conique, assez élevée et mucronée au sommet. Les tours, au nombre de huit, sont étroits et lisses en-dessus; le dernier est arrondi vers son angle spiral, il porte à sa base et sur le canal quelques stries obliques très-fines. La coquille est d'un brun foncé ou marron, avec une fascie blanchâtre qui occupe la partie supérieure du dernier tour. La coloration brune est en partie composée de lignes transverses; mais, prenant une teinte plus foncée en quelques endroits, elle semble produire de véritables fascies. Le sommet de la spire est blanchâtre. L'ouverture est d'un brun violacé avec la trace de la fascie externe sur le bord droit.

$$
\text { Long. } 24 \text { millim. }
$$

\section{Habite}

Cette jolie petite espèce par sa forme a la plus grande analogie avec certaines variétés du Conus mercator; cependant sa spire est plus allongée et sa coloration brune, presque uniforme, sans trace de réseaux la rendent aussi facilement distincte de ce dernier Cône. 
324. CONE MAImEÉ. Conus concatenatus, NoBls.

\author{
(Collect. de M. Lorors.)
}

Pl. CX, fig. 1.

G. testâ turbinatâ, ovato-oblongâ, tenui ; albâ, lineolis aurantiis angulatis laxè textilosis ornatâ ; spirâ conicà, subelatâ ; aperturâ dilatatâ intùs albâ.

Coquille turbinée, mince, ovale, oblongue. Spire médiocrement élevée, conique, un peu acuminée, formée de sept tours étroits et lisses en-dessus; l'angle spiral du dernier peu marqué et obtus, il porte à sa base quelques stries obliques extrêmement fines. L'ouverture est large vers sa partie inférieure ; le bord droit mince et tranchant. La coloration de la coquille consiste en un fond blanchâtre sur lequel se détache une sorte de grand réseau très-irrégulier, formé par des linéoles orangées plus ou moins fines et anguleuses.

\title{
Long. 55 millim.
}

\section{Habite}

Par son système de coloration cette espèce appartient à la division des Draps-d'or ; seulement le réseau dont elle est ornée est remarquable par la largeur et l'irrégularité de ses mailles. Son test est aussi plus mince. 


\section{TABLE ALPHABÉTIQUE}

\section{DU GENRE CONE.}

\begin{tabular}{|c|c|c|c|c|c|c|c|}
\hline onus & Abbas. & Brug. & 338 & Conus & Ateralbus. & Nobis. & 315 \\
\hline - & Achatinus. & Brug. & 188 & - & Augur. & Brug. & 116 \\
\hline - & Aculeiformis. & Reeve. & 195 & - & Aulicus. & Lin. & $\mathbf{3 1 8}$ \\
\hline - & Acuminatus. & Brug. & 137 & - & Aurantius. & Brug. & 19 \\
\hline - & A cutangulus. & Chemn. & 155 & - & Auratus. & Brug. & 320 \\
\hline - & Adamsonii. & Brod. & 288 & - & Aureus. & Brug. & 322 \\
\hline - & Adansonii. & Lam. & 245 & 一 & Auricomus. & Lam. & 323 \\
\hline - & AEmulus. & Brod. & 251 & - & Aurisiacus. & Lin. & 176 \\
\hline - & Africanus. & Nobis. & 260 & - & Aurora. & Lam. & 244 \\
\hline- & Albo-maculatus. & Sow. & 56 & 一 & Australis. & Chemn & 295 \\
\hline - & Algoensis. & Sow. & 198 & & & & \\
\hline - & Alveolus. & Sow. & 166 & Conus & Badius. & Nobis. & 89 \\
\hline - & Amabilis. & Lam. & 85 & - & Bæticulus. & Reeve. & 169 \\
\hline- & Amadis. & Chemn. & 120 & - & Balteatus. & Sow. & 27 \\
\hline - & Ambiguus. & Reeve. & 150 & - & Bandanus. & Brug. & 6 \\
\hline - & Amiralis. & Lin. & 134 & - & Barbadensis. & Brug. & 43 \\
\hline - & Anemone. & Lam. & 235 & - & Bernardii. & Nobis. & 220 \\
\hline - & Aplustre. & Reeve. & 205 & - & Bœtulinus. & Lin. & 74 \\
\hline - & Araneosus. & Brug. & 10 & - & Blainvillei. & Nobis. & 320 \\
\hline - & Archiepiscopus. & Brug. & 336 & - & Boivinii. & Nobis. & 282 \\
\hline- & Archon. & Brod. & 146 & - & Broderipii. & Reeve. & 252 \\
\hline - & Arcuatus. & Brod. & 157 & - & Bruguierei. & Nobis. & 221 \\
\hline- & Ardisiaceus. & Nobis. & 316 & - & Brunneus. & Wood. & 24 \\
\hline - & Arenatus. & Lam. & 38 & - & Bulbus. & Reeve. & 258 \\
\hline - & Artoptus. & Sow. & 305 & - & Bullatus. & Lin. & 349 \\
\hline
\end{tabular}




\begin{tabular}{|c|c|c|c|c|c|c|c|}
\hline nus & Cœlebs. & nds. & 232 & Conus & Dactylosus. & Nobis. & 506 \\
\hline - & Cœrulescens. & $\mathrm{m}$. & 233 & - & Daucus. & Brug. & 98 \\
\hline - & Caillaudi. & ohis. & 285 & 一 & Decrepitus. & Nobis. & 263 \\
\hline- & Caledonicus. & Brug. & 34 & - & Delessertii. & Récluz. & 156 \\
\hline- & Cancellatus. & Brug. & 151 & 一 & Deshayesii. & Reeve. & 348 \\
\hline- & Candidus. & Nobis. & 214 & 一 & Dispar. & Sow. & 211 \\
\hline- & Canonicus. & ug. & 355 & 一 & Distans. & Brug. & 28 \\
\hline- & Capita & & 85 & - & Dupontii. & Nobis. & 273 \\
\hline- & Cardinalis. & Brug. & 37 & - & Dux. & Brug. & 292 \\
\hline- & Carir & Swains. & 111 & & & & \\
\hline- & Castaneus. & Nobis. & 209 & Conus & Eburneus. & Brug. & 67 \\
\hline - & Catus. & B & 185 & - & ulatus. & bis. & 270 \\
\hline- & Cecilei. & bis. & 286 & 一 & Elis & obis. & 341 \\
\hline- & Cedonulli. & ug. & 18 & 一 & Elon & eve. & 30 \\
\hline- & Cent & Born. & 148 & - & Ema & ve. & 131 \\
\hline - & Cerv & Lam. & 344 & 一 & Enc: & ois. & 54 \\
\hline - & Cey & g. & 59 & - & Episcopus. & ag. & 319 \\
\hline - & eristicus. & Chemn. & $20 \mathfrak{3}$ & 一 & Eques. & ig. & 274 \\
\hline - & $\mathrm{Cib}$ & s. & 242 & - & Erythræensis. & ck. & 154 \\
\hline - & Cid & s. & 57 & 一 & Exaratus. & eeve. & 239 \\
\hline - & Cine & Brug. & 233 & - & Exiguus. & Lam. & 62 \\
\hline 一 & Cing & $\mathrm{L}$ & 142 & & & & \\
\hline- & $\begin{array}{l}\text { Citr } \\
\text { Cla }\end{array}$ & Nobis. & 248 & - & Fas & Tobis. & $\begin{array}{l}201 \\
311\end{array}$ \\
\hline- & $\begin{array}{l}\text { Clas } \\
\text { Clav }\end{array}$ & Brug. & $\begin{array}{r}87 \\
321\end{array}$ & 一 & Figulinus. & Lin. & 76 \\
\hline- & Cler & Reeve. & 168 & - & Flammeus. & Lam. & 138 \\
\hline- & Cocc & Reeve. & 241 & 一 & Flavescens. & Gray. & 58 \\
\hline- & Cocs & Gmel. & 36 & - & Fla & Lam. & 96 \\
\hline - & Colu & Lam. & 331 & - & Floceatus. & Sow. & 287 \\
\hline - & Colu & Brug. & 269 & 一 & Franciscanus. & Brug. & 192 \\
\hline- & natus. & Nobis. & 362 & 一 & Fulgurans. & Brug. & 159 \\
\hline- & Concolor. & Sorv. & 97 & 一 & Fulmen. & Reeve. & 178 \\
\hline - & Consors. & Sow. & 101 & - & Fumigatus. & Brug. & 103 \\
\hline- & Conspersus. & Reeve. & 200 & 一 & Furvus. & Reeve. & 307 \\
\hline - & Corallinus. & Nobis. & 246 & 一 & Fuscatus. & Reeve. & 13 \\
\hline - & Costatus. & Chemn. & 31 & - & Fusiformis. & Lam. & 194 \\
\hline - & Crenulatus. & Nobis. & 355 & - & Fustigatus. & Brug. & 40 \\
\hline - & Cretaceus. & Nobis. & 264 & & & & \\
\hline - & Crocatus. & Lam. & 162 & onus & Gabricle & Chenu. & 315 \\
\hline - & Cuneo & Reeve. & 224 & 一 & Generalis. & Lin. & 122 \\
\hline - & Cylindraceus. & Brod. & 302 & - & $\begin{array}{l}\text { Genuanus. } \\
\text { Geographus. }\end{array}$ & $\begin{array}{l}\text { Lin. } \\
\text { Lin. }\end{array}$ & $\begin{array}{l}163 \\
545\end{array}$ \\
\hline
\end{tabular}




\begin{tabular}{|c|c|c|c|c|c|c|c|}
\hline onus & Gladiator. & Brod. & 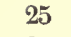 & Conus & Lineatus. & Chemn. & 107 \\
\hline - & Glans. & Brug. & 300 & - & Liratus. & Reeve. & 354 \\
\hline - & Glaucus. & Lin. & 78 & - & Lithoglyphus. & Brug. & 127 \\
\hline - & Gloria-Maris. & Brug. & 326 & - & Litteratus. & Lin. & 65 \\
\hline- & Gradatus. & Gray. & 140 & - & Lividus. & Brug. & 29 \\
\hline- & Granarius. & Nobis. & 215 & - & Longurionis. & Nobis. & 308 \\
\hline - & Granulatus. & Lin. & 29.4 & - & Lorenzianus. & Chemn. & 159 \\
\hline- & Griseus. & Nobis. & 114 & - & Loroisi. & Nobis. & 91 \\
\hline- & Gubba. & Nobis. & 289 & - & Luteus. & Brod. & 297 \\
\hline- & Gubernator. & Brug. & 281 & $\rightarrow$ & Luzonicus. & Brug. & 180 \\
\hline- & Guinaicus. & Brug. & $18 \tilde{z}$ & & & & \\
\hline - & Guttatus. & Nobis. & 259 & $\begin{array}{c}\text { Conus } \\
-\end{array}$ & & $\begin{array}{l}\text { Brug. } \\
\text { Chenu. }\end{array}$ & $\begin{array}{l}194 \\
293\end{array}$ \\
\hline ionus & Ilebræus. & Lin. & 45 & - & Nagellanicus. & Brug. & 99 \\
\hline- & Hep & Nobis. & 227 & - & Magus. & Lin. & 285 \\
\hline - & Hieroglyphicus. & Duclós. & 181 & - & Mal & eeve. & 170 \\
\hline - & Hybridus. & Nobis. & 256 & - & Nal & rug. & 119 \\
\hline - & Iyena. & Brug. & 83 & - & $\begin{array}{l}\text { Nal } \\
\text { Mar }\end{array}$ & ug. & 123 \\
\hline Conus & Imp & Lin. & 11 & - & Marmoreus. & Lin. & 4 \\
\hline- & Incarn & Reeve. & 104 & - & Mart & Reeve. & 280 \\
\hline - & Inflatus. & Sow. & 253 & - & Mauri & Brug. & 173 \\
\hline - & Informis. & Brug. & 230 & - & raneus. & Brug. & 195 \\
\hline- & Insculptus. & Nobis. & 309 & - & Nelancholicus. & Lanı. & 279 \\
\hline - & Inscriptus. & Reeve. & 255 & - & Me & 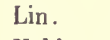 & 222 \\
\hline- & Interr & Brod. & 152 & - & Nig & Nobis. & 552 \\
\hline- & Iodostomus. & Reeve. & 247 & - & Mile & Trug. & 94 \\
\hline & & & & - & & Brug. & 42 \\
\hline Conus & Jamaicensis. & Brug. & 194 & - & nctatus. & Lam. & 64 \\
\hline - & Janus. & rug. & 128 & - & Minda & Brug. & 191 \\
\hline - & Japonicus. & rug. & 125 & - & Minir & Lin. & 44 \\
\hline- & Jaspideus. & Nobis. & 218 & - & Mitratus. & Brug. & 303 \\
\hline & & & & - & Noluccensis & Chemn. & 49 \\
\hline Conus & Lacinulatus. & Nobis. & 312 & - & Monachus. & Lin. & 236 \\
\hline- & Lacteus. & Lam. & 268 & - & Monile. & Brug. & 123 \\
\hline- & Lamarckii. & Nobis. & 240 & - & Monilifer. & Brod. & 141 \\
\hline- & Largillierti. & Nobis. & 212 & - & Mozambicus. & Brug. & 231 \\
\hline- & Lautus. & Reeve. & 250 & - & Sucronatus. & Reeve. & 216 \\
\hline- & Legatus. & Lam. & 523 & - & Muriculatus. & Sow. & 52 \\
\hline- & Lentiginosus. & Reeve. & 149 & - & Mus. & Brug. & 23 \\
\hline- & Leoninus. & Brug. & 72 & - & Muscosus. & Lan. & 204 \\
\hline - & Lignarius. & Reeve. & 112 & - & Musicus. & B̀rug. & 61 \\
\hline
\end{tabular}




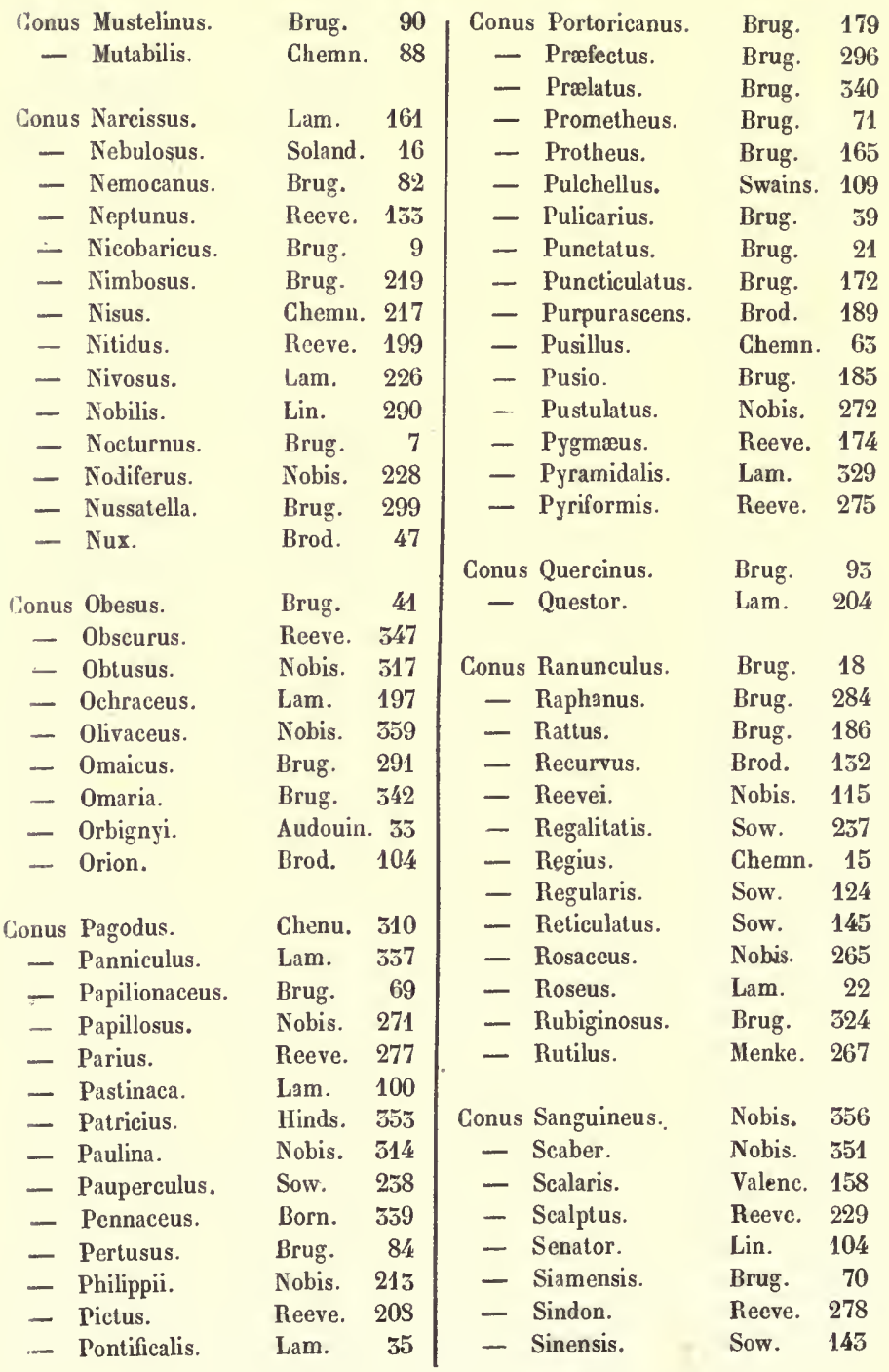




\begin{tabular}{|c|c|c|c|c|c|c|c|}
\hline Conus & Solanderi. & Sow. & 36 & Conus & Tinianus. & Brug. & 202 \\
\hline- & Solidus. & Sow. & 325 & 一 & Tornatus. & Brod. & 155 \\
\hline- & Spectrum. & Lin. & 262 & - & Tulipa. & Lin. & 346 \\
\hline- & Splendidulus. & Sow. & 147 & & & & \\
\hline - & Sponsalis. & Brug. & 48 & Conus & Undatus. & Nobis. & 210 \\
\hline - & Stellatus. & Nobis. & 225 & - & Unicolor. & Sow. & 46 \\
\hline - & Stcreus-Muscarur & mLin. & 206 & 一 & Unifasciatus. & Nobis. & 61 \\
\hline- & Stramineus. & Lam. & 254 & & & & \\
\hline - & Striatus. & Lin. & 280 & Conus & Variegatus. & Nobis. & 61 \\
\hline 一 & Strigatus. & Brug. & 234 & 一 & Varius. & Lin. & 20 \\
\hline- & Striolatus. & Nobis. & 266 & - & Vautieri. & Nobis. & 50 \\
\hline- & Subulatus. & Nobis. & 243 & - & Venulatus. & Brug. & 82 \\
\hline - & Sugillatus. & Reeve. & 102 & - & Vermiculatus. & Lam. & 46 \\
\hline- & Sulcatus. & Brug. & 32 & - & Verreauxii. & Nobis. & 249 \\
\hline- & Sulphuratus. & Nobis. & 150 & - & Verriculum. & Reeve. & 530 \\
\hline- & Sumatrensis. & Brug. & 80 & 一 & Verrucosus. & Brug. & 55 \\
\hline- & Suratensis. & Brug. & 75 & - & Verulosus. & Brug. & 501 \\
\hline- & Suturatus. & Reeve. & 115 & - & Vexillum. & Brug. & 79 \\
\hline & & & & 一 & Vicarius. & Lam. & 136 \\
\hline Conus & Tabidus. & Reeve. & 55 & - & Victor. & Brod. & 91 \\
\hline - & Tæniatus. & Brug. & 164 & 一 & Victoriæ. & Recve. & 334 \\
\hline - & Tritensis. & Brug. & 187 & 一 & Violaccus. & Reeve. & 347 \\
\hline - & Taslei. & Nobis. & 560 & - & Virgo. & Lin. & 95 \\
\hline - & Tendineus. & Brug. & 504 & - & Viridulus. & Lam. & 12 \\
\hline - & Terebra. & Brug. & 298 & - & Vittatus. & Brug. & 110 \\
\hline - & Terminus. & Lam. & 282 & - & Vitulinus. & Brug. & 106 \\
\hline 一 & Tessellatus. & Brug. & 68 & 一 & Voluminalis. & Hinds. & 167 \\
\hline 一 & Testudinarius. & Brug. & 177 & 一 & Vulpinus. & Brug. & 105 \\
\hline - & Textile. & Lin. & 328 & & & & \\
\hline - & Textilinus. & Nobis. & 333 & Conus & Zebra. & Lam. & 171 \\
\hline - & Thalassiarchus. & Gray. & 118 & 一 & Zebroides. & Nobis. & 257 \\
\hline 一 & Tiaratus. & Brod. & 50 & - & Zonatus. & Brug. & 14 \\
\hline - & Timorensis. & Brug. & 207 & & & & \\
\hline
\end{tabular}




\section{ERRATA.}

Pag. 35, no 19, C. Gladiator. Voyez pl. 109, fig. 4-4

- $39, \mathrm{n}^{\circ} 31$, C. Pulicarius. Voyez pl. 111, fig. 4.

- 47, no 38, C. Nux. Voyez pl. 102, fig. 3.

- 61, no 53, C. Millepunctatus. Voyez pl.1.

- 70, n5 58. C. Siamensis, pl. 91, fig. 1, lisez : pl. 93, fig. 5.

- 71, no 59. C. Prometheus, pl. 92, lisez: pl. 85.

- 245, $\mathrm{n}^{0}$ 113. C. d'Adamson, lisez : C. d'Adanson, Lam.

- 245, no 113. Pl. 44, fig. 1, lisez: pl. 61, fig. 1.

P1. 41, fig. 2, C. strigatus, lisez: C. australis.

- 43, fig. 2, C. pusillus, lisez: C. catus junior.

- 61, fig. 4, C. unicolor, lisez: C. Adansoni.

- 78, fig. 4, C. citrinus, lisez: C. sulphuratus.

- 92, fig. 5, C. Neptunus, lisez: C. acuminatus, $\mathrm{V}_{\mathrm{AR}}$

- 92, fig. 6, C. subulatus, lisez: C. longurionis.

- 107, tig. 4, C. roseus, lisez: $C$. rosaceus. 


\section{Table}

\section{DES ESPECES DE CONES}

DIVISÉES EN SIX GROUPES.

\section{Premier Groupe.}

\section{LES COURONNEES.}

Cône Damier.

- de Banda.

- Nocturne.

- Marquis.

- Impérial.

- Verdâtre.

- Maure.

- de Nicobar.

- Esplandian.

- Zonal.

- Royal.

- Memnonite.

- Livide.

- Allongé.

- Gladiateur.

- Spleen.

- Cibiel.
Conus Marnıoreus.

- Bandanus.

- Nocturnus.

- Marchionatus.

-- Imperialis.

- V Viridulus.

- Fuscatus.

- Nicobaricus.

- Araneosus.

- Zonatus.

- Regius.

- Distans.

- Lividus.

..- Elongatus.

- Gladiator.

- Tabidus.

- Cibieli.

$\begin{array}{lrrr}\text { Auteurs. } & \text { Pag. } & \text { Pl. } & \text { Fig. } \\ \text { Lin. } & 4 & 2 & 1 \\ \text { Brug. } & 6 & 4 & 1 \\ \text { Brug. } & 7 & 2 & 2-2 \\ \text { Hinds. } & 5 & 57 & 1 \\ \text { Lin. } & 11 & 5 & 1 \text { à } 1 \text { b } \\ \text { Lam. } & 12 & 7 & 1 \\ \text { Brug. } & 13 & 7 & 2 \\ \text { Brug. } & 9 & 8 & 1-2 \\ \text { Brug. } & 10 & 6 & 1 \\ \text { Brug. } & 14 & 3 & z \\ \text { Chemn. } & 15 & 3 & 2 \\ \text { Brug. } & 28 & 3 & 1 \\ \text { Bruy. } & 29 & 9 & 2-2 \\ \text { Reeve. } & 30 & 33 & 1 \\ \text { Brod. } & 25 & 109 & 4-4 a \\ \text { Reeve. } & 53 & 66 & 2 \\ \text { Nobis } & 242 & 107 & 2 \\ & & \mathbf{4 7} & 4\end{array}$


Tône Piqûre-de-mouches. Conus Arenatus.

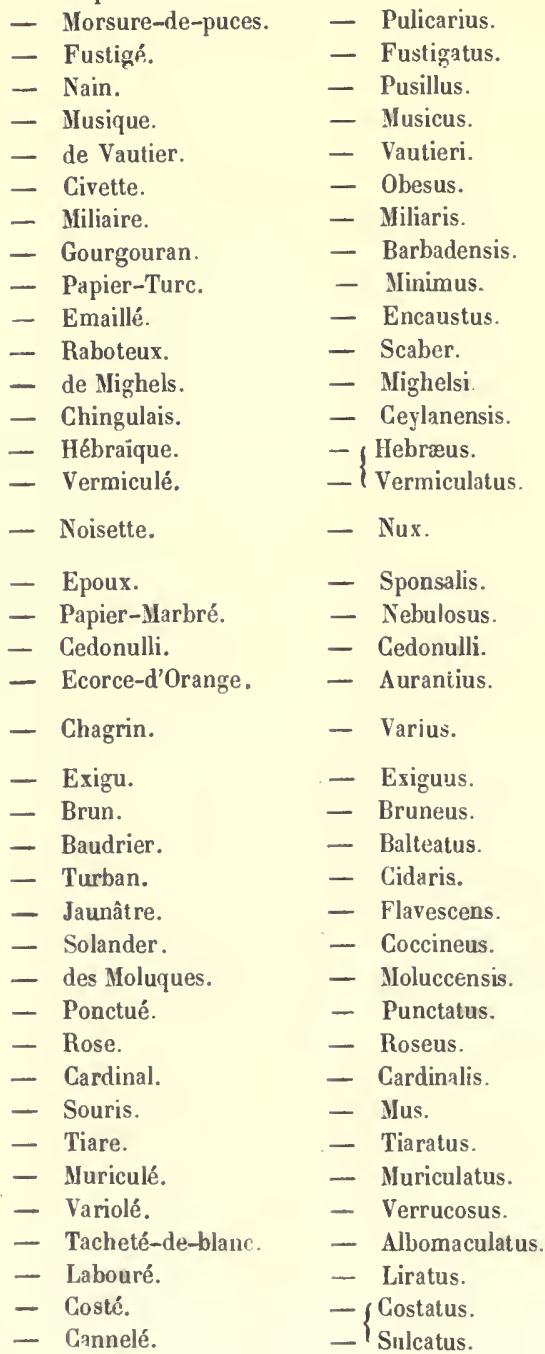

Auteurs. Pag. Pl. Fig.

$\begin{array}{lllll}\text { Brug. } & 38 & 10 & 1 \text { à } \mathbf{1}^{\mathrm{b}}\end{array}$

$\begin{array}{llll}\text { Brug. } & 59 & 10 & 2\end{array}$

Brug. $\quad 40 \quad 11 \quad 5$

Chemil. $63 \quad 55 \quad 7-7^{\text {a }}$

Brug. $\quad 61 \quad 13 \quad 6-6$ a

Nobis. $\quad 550 \quad 100 \quad 5$

$\begin{array}{llll}\text { Brug. } & 41 & 10 & 5\end{array}$

$\begin{array}{llll}\text { Brug. } & 42 & 13 & 1\end{array}$

Brug. $\quad 43 \quad 13 \quad 2$

Lam. $44 \quad 14 \quad 1$ à $1^{\mathrm{e}}$

Nobis. $\quad 54 \quad 14 \quad 2$

Nobis. $\quad 551 \quad 100 \quad 1$

Nobis. $\quad 352 \quad 10 \tilde{3} \quad 1$

$\begin{array}{llll}\text { Brug. } & 59 & 14 & 5\end{array}$

Lam. $\quad 45$; 42

Lam. $\quad \begin{cases}3-3^{a} \\ \end{cases}$

Brod. $47 \quad\left\{\begin{array}{rr}102 & 2 \\ 11 & 3\end{array}\right.$

Brug. $\quad 48 \quad 14 \quad 4$

Soland. $\quad 16 \quad 24 \quad 2-2$ a

Brug. $\quad 18 \quad 16 \quad 1$ à $1^{\mathrm{e}}$

Brug. $\quad 19 \quad 15 \quad 2-2^{\text {a }}$

Lin. $20 \mid 73-5$ a

Lam. $\quad 62 \quad 11 \quad 1$

Wood. $24 \quad 15 \quad 1-1$ a

Sow. $\quad \begin{array}{lll}27 & 15 & 3\end{array}$

Nobis. $\quad 57 \quad 63 \quad 1-1$ a

Gray. $\quad 58 \quad 68 \quad 1$

Gmel. $\quad 36 \quad 77 \quad 3-3^{\mathrm{a}}$

Chemn. $\quad 49 \quad 75 \quad 2$

$\begin{array}{llll}\text { Brug. } & 21 & 9 & 1\end{array}$

Lam. $\quad 22 \quad 9 \quad 3$

$\begin{array}{llll}\text { Brug. } & 37 & 14 & 3\end{array}$

Brug. $\quad 23 \quad 24 \quad 5$

$\begin{array}{llll}\text { Brod. } & 50 & 11 & 2\end{array}$

Sow. $\quad 52 \quad 72 \quad 2$

Brug. $55 \quad 66$ 6-fa

$\begin{array}{llll}\text { Reeve. } & 56 & 83 & 2\end{array}$

Reeve. $354 \quad 103 \quad 2$

Chemn. $31 \quad 6$

Brug. 32 
TABLE.

Cône Calédonien.

- Patricien.

- d'Orbigny.

- Pontifical.

- Crénulé.

Conus Caledonicus.
- Patricius.
- Orbignyi.
- Pontificalis.
- Crenulatus.

Auteurs. Pag.

PI.

Fig. $\begin{array}{llll}\text { Brug. } & 34 & 79 & 3\end{array}$ Hinds. $\quad 555 \quad 88 \quad 4$ Audouin. $\quad 33 \quad 13 \quad 3$ Lam. $\quad 35 \quad 13 \quad 5$ Crenulatus.

Nobis. $\quad 355$

$109 \quad 1$

\section{Deuxième Groupe.}

\section{LES TURBINEES.}

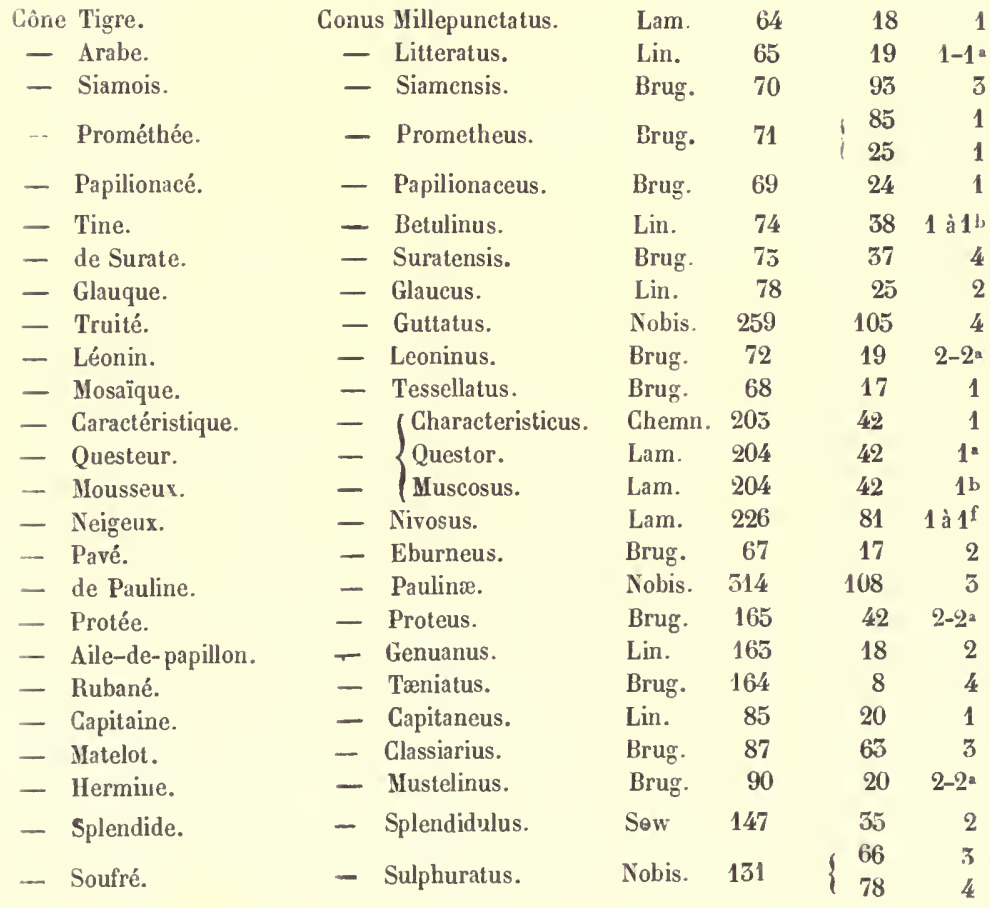


Cône Rouge.

- Aumusse.

- Piqueté.

- Aimable.

- Pyriforme.

- Centurion.

- Loup.

- Bois-de-frêne.

- Hyène.

- Zébroïde.

- de Lorois.

- Minime.

- Olivacé.

- de Taslé.

- Changeant.

- Linée.

- Acajou.

- Concolor.

- Aurore.

- Navet.

- Consort.

- Striolé.

- Cierge.

- Blondin.

- Carotte.

- Magellanique.

- Flétri.

- Panais.

- Grisâtre.

- Suturé.

- Hépatique.

- Crétacé.

- Ambigu.

- Ligné.

- Etourneau.

- Ocracé.

- Lacinulé.

- Janus.

- Spectre.

- Maillot.
Conus Rutilus.

- Vexillum.

- Pertusus.

- Amabilis.

- Pyriformis.

- Centurio.

- Sumatrensis.

- Nemocanus.

- Myæna.

- Zebroïdes.

- Loroisii.

- Figulinus.

- Olivaceus.

- Taslei.

- Mutabilis.

- Quercinus.

- Badius.

- Concolor.

- Aurora.

- Miles.

- Consors.

- Striolatus.

- Virgo.

- Flavidus.

- Daucus.

- Magellanicus.

- Sugillatus.

- Pastinaca.

- Griseus.

- Suturatus.

- Hepaticus.

- Cretaccus.

- Ambiguus.

- Lignarius.

- Lythoglyphus.

- Ochraceus.

- Lacinulatus.

- Janus.

- Spectrum.

- Voluminalis.
Auteurs. Pag.

Pl. Fig.

Menke. 267

Brug. $\quad 79$

Brug. $\quad 84$

Lam. 85

Reeve. $\quad 275$

Born. 148

Brug. $\quad 80$

Brug. $\quad 82$

Brug. 83

Nobis. 257

Nobis. 91

Lin. $\quad 76$

Nobis. $\quad 359$

Nobis. $\quad 360$

Chemn. 88

Brug. $\quad 93$

Nobis. $\quad 89$

Sow. $\quad 97$

Lam. 244

Lin. $\quad 94$

Sow. 101

Nobis. 266

Lin. $\quad 95$

Lam. 96

Brug. $\quad 98$

Brug. $\quad 99$

Reeve. 102

Lam. 100

Nobis. 114

Reeve. 113

Nobis. 227

Nobis. 264

Reeve. 150

Reeve. 112

Brug. $\quad 127$

Lam. 197

Nobis. $\quad 312$

Brug. $\quad 128$

Lin. $\quad 262$

Hinds. 167
$73 \quad 4$

$34 \quad 3$

351

$35 \quad 1$ a

$44 \quad 4$

$36 \quad 2-2$ a

$36 \quad 3$

$35 \quad 3$

$35 \quad 4$

1055

$65 \quad 1$

$28 \quad 1$ à 1 b

1113

1103

$70 \quad 1$

$32 \quad 1$

$33 \quad 2$

$33 \quad 3$

$45 \quad 2$

$45 \quad 1$

$58 \quad 2$

$73 \quad 5$

1051

$36 \quad 1$

$26 \quad 4$

$26 \quad 1$ à 1

$29 \quad 3$

$26 \quad 3$

$26 \quad 2$

$63 \quad 2$

$88 \quad 1$

$97 \quad 5$

$99 \quad 1$

703

273

$29 \quad 1-1$ a

$37 \quad 2-2^{2}$

$108 \quad 2$

292 à $2^{\mathrm{b}}$

44 5-5

715 


\begin{tabular}{|c|c|c|c|c|c|c|}
\hline Còne & Préfet. & Conus Præfectus. & Brug. & 296 & 41 & 3 \\
\hline - & Sénateur. & - Senator. & Lin. & 104 & 27 & $1-12$ \\
\hline - & Renard. & - i Vulpinus. & Brug. & 105 & D & D \\
\hline - & de Reeve. & - Reevii. & Nobis. & 115 & 44 & 2 \\
\hline - & Cierclé. & - Vittatus. & Brug. & 110 & 63 & 5 \\
\hline - & Safrané. & - Crocatus. & Lam. & 162 & 52 & 3 \\
\hline - & Narcisse. & - Narcissus. & Lam. & 161 & 52 & 4 \\
\hline - & Rat. & - Rattus. & Brug. & 186 & 44 & 3 \\
\hline - & Violet. & - Taitensis. & Brug. & 187 & 66 & 4 \\
\hline- & Cordelier. & - Fumigatus. & Brug. & 105 & $\left\{\begin{array}{l}50 \\
79\end{array}\right.$ & $\begin{array}{r}-2 a \\
2\end{array}$ \\
\hline & Deuil. & - Ateralbus. & Nobis. & 515 & 108 & $4-4^{2}$ \\
\hline - & de Blainville. & - Blainvillei. & Nobis. & 558 & 111 & 1 \\
\hline- & Suaire. & - Sindon. & Reeve. & 278 & 94 & 4 \\
\hline- & Lacté. & - Lacteus. & Lam. & 268 & 60 & 4 \\
\hline- & Albâtre. & - Parius. & Reeve. & 277 & $\left\{\begin{array}{r}60 \\
103\end{array}\right.$ & 4 \\
\hline - & de Martini. & - Martinianus. & Recve. & 276 & 60 & 2 \\
\hline - & de Gubba. & -- Gubba. & Nobis. & 289 & 104 & 1 \\
\hline- & d'Oma. & - Omaïcus. & Brug. & 291 & 32 & 2 \\
\hline- & Amadis. & - Amadis. & Ghemn. & 120 & $\left\{\begin{array}{l}41 \\
84\end{array}\right.$ & $\begin{array}{r}-12 \\
2\end{array}$ \\
\hline - & de Malaca. & - Malacanus. & Brug. & 119 & $\left\{\begin{array}{r}22 \\
101\end{array}\right.$ & $\begin{array}{l}2 \\
5\end{array}$ \\
\hline- & de Neptune. & - Neptunus. & Reeve. & 153 & 99 & 5 \\
\hline- & Réticulé. & - Reticulatus. & Sow. & 145 & 66 & $\mathbf{5}$ \\
\hline - & Peint. & - Pictus. & Reeve. & 208 & 68 & 4 \\
\hline- & Grand-Amiral. & - Thalassiarchus. & Gray. & 118 & 22 & 5 à $3^{h}$ \\
\hline - & Vitulin. & - Vitulinus. & Brug. & 106 & 22 & 1 \\
\hline- & Picoté. & - Augur. & Brug. & 116 & 18 & $\mathbf{5}$ \\
\hline- & Fileur. & - Lineatus. & Chemm. & 107 & $\left\{\begin{array}{r}18 \\
102\end{array}\right.$ & 3 \\
\hline - & Agréable. & - Pulchellus. & Swains. & 109 & 59 & $1-1=$ \\
\hline - & Alvéole. & - Alveolus. & Sow. & 166 & 59 & 8 \\
\hline- & Noble. & - Nobili & Lin. & 290 & 49 & 1 à $1^{\mathrm{c}}$ \\
\hline - & Etagé. & - Gradatus. & Gray. & 140 & 94 & 6 \\
\hline- & Flamboyant. & _ Generalis. & Lin. & 122 & 31 & 2 à $2^{\text {a }}$ \\
\hline - & Faisan. & - Monile. & Brug. & 123 & 31 & $1 \mathrm{a} 1^{b}$ \\
\hline- & de Gléry. & - Cleryi. & Reeve. & 168 & 94 & 2 \\
\hline - & Emarginé. & - Emarginatus. & Reeve. & 151 & 23 & 4 \\
\hline - & Régulier. & - Regularis. & Sow. & 124 & 23 & 5a \\
\hline - & Eclair. & - Flammeus. & Lam. & 138 & 25 & \\
\hline
\end{tabular}


Cône de Lorenz.

- Amiral.

- de Rumphius.

- Magistrat.

- Sanguin.

- Lieutenant.

- Pluie-d'or.

- A taches-rousses.

- Chagriné.

- de Largilliert.

- Foudroyant

- Chiné.

- Pointillé.

- de la mer Rouge.

- Aplustre.

- Pygmée.

- Colombe.

- Papilleux.

- Pustulé.

- Echinulé.

- Nodifer.

- Jaunâtre.

- Epervier.

- Rosacé.

- Mucroné.

- Corallin.

- Aculéifornie.

- Disparate.

- Sillonné.

- Brillant.

- Chétif.

- Iodostome.

- Fascié.

- Candide.

- de Philippi.

- Recourbé.

- à collier.

- Brûlé.

- de Gécile.

- Sanglé.
Conus Lorenzianus.

- Amiralis.

- Acuminatus.

- Archon.

- Sanguineus.

- Vicarius.

- Japonicus.

- Lentiginosus.

- Granarius.

- Largillierti.

- Fulgurans.

- Mauritianus.

- Puncticulatus.

- Erythrœensis.

- Aplustre.

- Pygmœus.

- Columba.

- Papillosus.

- Pustulatus.

- Echinulatus.

- Nodiferus.

- Flavescens.

- Nisus.

- Rosaceus.

- Mucronatus.

- Corallinus.

- Aculeiformis.

- Dispar.

- Exaratus.

- Nitidus.

- Fauperculus.

- Iodostomus.

- Fasciatus.

- Gandidus.

- Philippii.

- Recurvus.

- Monilifer.

- Furvus.

- Gecilei.

- Gingulatus.
Auteurs. Pag.

Chemm. 159

Lin. 134

Brug. 137

Brod. 146

Nobis. $\quad 356$

Lam. 136

Brug. 125

Reeve. 149

Nobis. 215

Nobis. 212

Brug. 159

Brug. 173

Brug. 172

Beck. 154

Reeve. 205

Reeve. 174

Brug. $\quad 269$

Nobis. 271

Nobis. 272

Nobis. 270

Nobis. 288

Gray. 196

Chemn. 217

Nobis. 265

Reeve. 216

Nobis. 246

Reeve. 195

Sow. 211

Reeve. 259

Reeve. 199

Sow. 238

Reeve. 247

Nobis. 311

Nobis. 214

Nobis. 213

Brod. 132

Brod. 141

heeve. 307

Nobis. 286

Lam. 142
Pl. Fig.

551

211 à $1^{d}$

391 à $1^{\mathrm{b}}$

; $75 \quad 3$

$104 \quad 4$

1112

$37 \quad 3$

$79 \quad 4$

$88 \quad 3$

$98 \quad 1$

(98 3

1011 à 1"

1014

$\begin{array}{ll}69 & 2\end{array}$

601 à 1

$71 \quad 4$

$74 \quad 2^{1}$

102 1 à 1 b

$77 \quad 2$

724

1012

1052

$100 \quad 4$

$92 \quad 2$

$59 \quad 4$

$107 \quad 4$

$92 \quad 1$

73

$92 \quad 4$

1015

726

63 4-4

725

727

1095

$97 \quad 1$

$98 \quad 2$

$97 \quad 4-4$ a

$93 \quad 1$

$80 \quad 3$

( 98 4

3

$93 \quad 2$ 
TABLE.

$\begin{array}{lc}\text { Cône Acutangle. } & \text { Conus Acutangulus. } \\ \text { - Chinois. } & - \text { Sinensis. } \\ \text { - à spirale. } & - \text { Scalaris. } \\ \text { - Subulé. } & - \text { Subulatus. } \\ \text { - Ondé. } & - \text { Undatus. } \\ \text { - Delessert. } & - \text { Delesserti. } \\ \text { - Arqué. } & - \text { Arcuatus. } \\ \text { - Pagode. } & - \text { Pagodus. } \\ \text { - en Fuseau. } & - \text { Fusiformis. } \\ \text { - Treillissé. } & - \text { Cancellatus. } \\ \text { - Ciselé. } & - \text { Insculptus. } \\ \text { - Effilé. } & - \text { Longurionis. }\end{array}$

Auteurs. Pag.

Pl. Fig.

Chemm. 155

Sow. 145

Valenc. $\mathbf{1 5 8}$

Nobis. 243

Nobis. 210

Recluz. 156

Sow. 157

Chenu. 510

Lam. 194

Brug. 151

Nobis. $\quad 509$

Nobis. 308

$\begin{array}{ll}72 & 1 \\ 71 & 1 \\ 88 & 5 \\ 70 & 2 \\ 94 & 1 \\ 23 & 2 \\ 72 & 5 \\ 70 & 4 \\ 76 & 5 \\ 76 & 4 \\ 99 & 2 \\ 92 & 6\end{array}$

\section{Troisième Groupe.}

\section{LES TURGIDEES.}

Còne Peau-de-serpent.

Conus Testudinarius.

- Achatinus.

- Ranunculus.

- Magdalenæ.

- Purpurascens.

- Castaneus.

- Catus.

- Pusio.

- Tornatus.

- Interruptus.

- Nahogani.

- Mediterraneus.

- Jamaïcensis.

- Madurensis.

- Franciscanus.

- Bruguierei.

- Mindanus.

- Adansoni.

- Hybridus.

- Inscriptus.
Mlartini. $\quad 177$

Brug. $\quad 188$

Brug. $\quad 189$

Chenu. 293

Brod. $\quad 189$

Nobis. 209

Brug. 185

Lam. 185

Brod. $15 \overline{3}$

Brod. 152

Reeve. 170

Brug. 195

Brug. 194

Brug. 194

Brug. 192

Nobis. 221

Brug. 191

Lam. 245

Nobis. $\quad 256$

Reeve. 255
571 à $1 \mathrm{e}$

401 a 1 is

$40 \quad 1^{\mathrm{c}}$

$69 \quad 4$

$\begin{cases}59 & 2 \\ 61 & 5\end{cases}$

$104 \quad 5$

431 à $1^{d}$

$45 \quad 2$

วิบ 5

542

$74 \quad 5$

561 à $1^{\mathrm{f}}$

$56 \quad 1$ a

$56 \quad 1^{\text {t }}$

$52 \quad 2$

56 2

595

614

831

$105 \div 3$ 


\section{Cinquième Groupe.}

\section{LES TEXTILEEES.}

\section{Cône Gloire-de-la-mer. Conus Gloria-maris.}

$$
\text { - Drap-d'or. }
$$

- Pyramidal.

- Textilin.

- Victoria.

- Couleuvré.

- Maillé.

- Tramail

- Chanoine.

- Archevêque.

- Petit-drap.

- Abbé.

- Pouding.

- d'Elisa.

- Plumeux.

- Prélat.

- Drap-flambé.

- Légat.

- Solide.

- Brunette.

- Evêque.

- Perlé.

- Drap-orangé.

- Drap-réticulé.
- Textile.

- Pyramidalis.

- Textilinus.

- Victoriæ.

- Colubrinus.

- Concatenatus.

- Vcrriculum.

- Canonicus.

- Archiepiscopus.

- Pauniculus.

- Abbas.

- Rubiginosus.

- Elisæ.

- Pennaceus.

- Prælatus.

- Aureus.

- Legatus.

- Solidus.

- Aulicus.

- Episcopus.

- Omaria.

- Auratus.

- Clavus.
Auteurs. Pag. Brug. 236

Lin. $\quad 328$

Lam. $\quad 329$

Nobis. $\quad 353$

Reeve. 334

Lam. 331

Nobis. $\quad \mathbf{3 6 2}$

Reeve. 330

Brug. 335

Brug. $\quad 336$

Lam. $\quad 337$

Brug. $\quad 338$

Brug. 324

Nobis. 341

Brug. $\quad 539$

Brug. $\quad 340$

Brug. $\quad 322$

Lam. 325

Sow. $\quad 325$

Lin. 318

Brug. $\quad 319$

Brug. 342

Brug. $\quad 520$

Lin. $\quad 321$
Pl. Fig.

$\begin{cases}76 & 1 \\ 77 & 1\end{cases}$

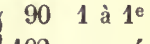

$852-2=$

$\{96$ 2-2n

$105 \quad 5$

$78 \quad 1$

$82 \quad 3$

$110 \quad 1$

$95 \quad 2$

951

96 1-1

87 1-1

$86 \quad 1$

$82 \quad 1-1$ a

64 1-1*

$89 \quad 2$

89 1-1

$82 \quad 2$

$89 \quad 3$

$54 \quad 1$

$53 \quad 1$

911 à $1^{\mathrm{c}}$

79 1-1

86 2-2.

87 2 
TABLE.

\section{Sixième Groupe,}

\section{LES BULLEES.}

Gơne Cert.

- Brocard.

- Tulipe.

- Obscur.

- de Deshayes.

- Bullé.
Conus Cervus.

- Geographus.

- Tulipa.

- Obscurus.

- Deshayesii.

- Bullatus.

\begin{tabular}{|c|c|c|c|}
\hline Auteurs. & Pag. & PI. & Fig. \\
\hline Lam. & 344 & 74 & 1 \\
\hline & & $75^{\circ}$ & \\
\hline Lin. & 345 & 12 & 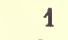 \\
\hline Lin. & 346 & 12 & $2-2^{a}$ \\
\hline Reeve. & 347 & 68 & \\
\hline Reeve. & 348 & 58 & 1 \\
\hline Lin. & 349 & 58 & 2 \\
\hline
\end{tabular}

Paris - Imp. Simon Rageon a cie, no d'Eforth, 1. 
is

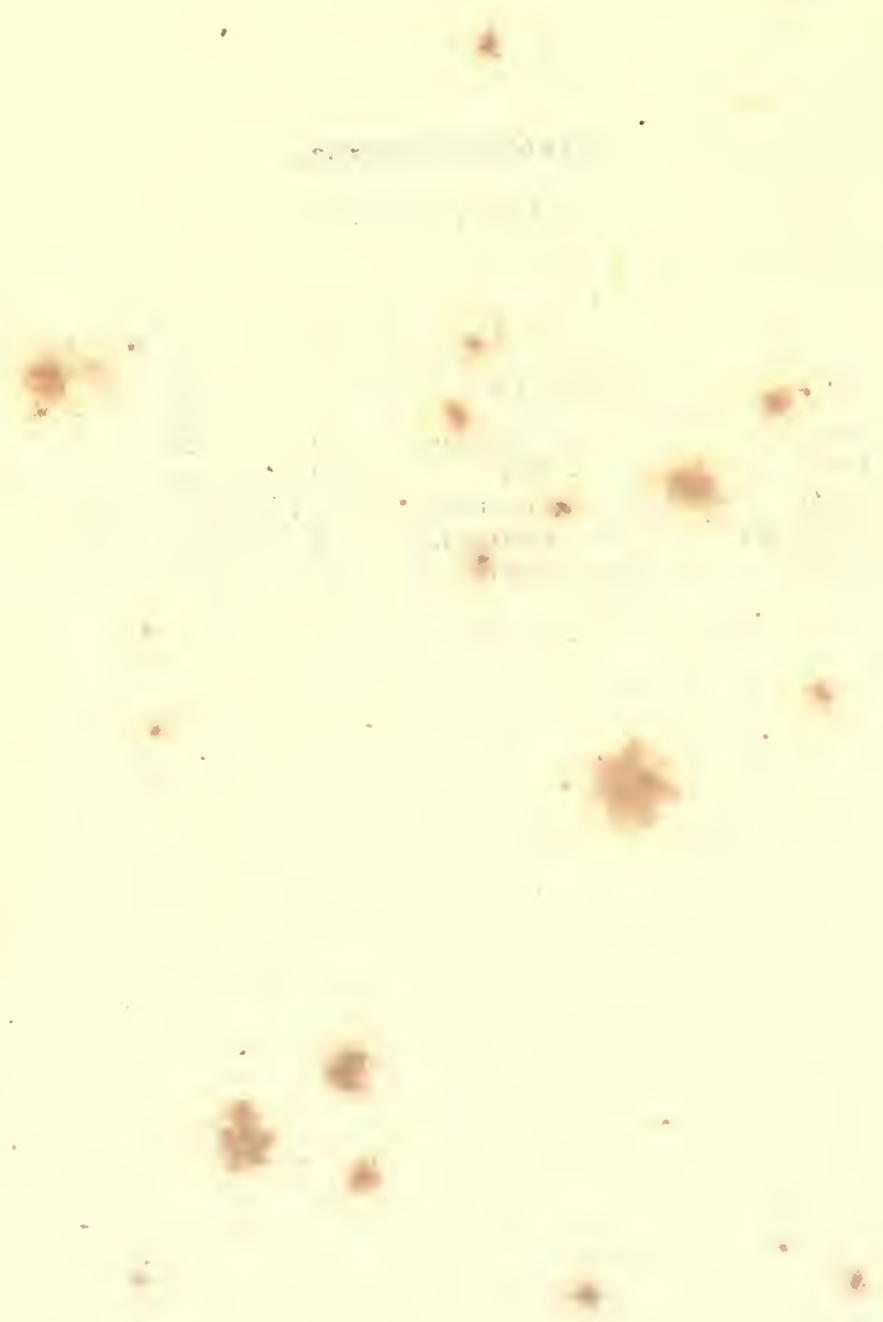




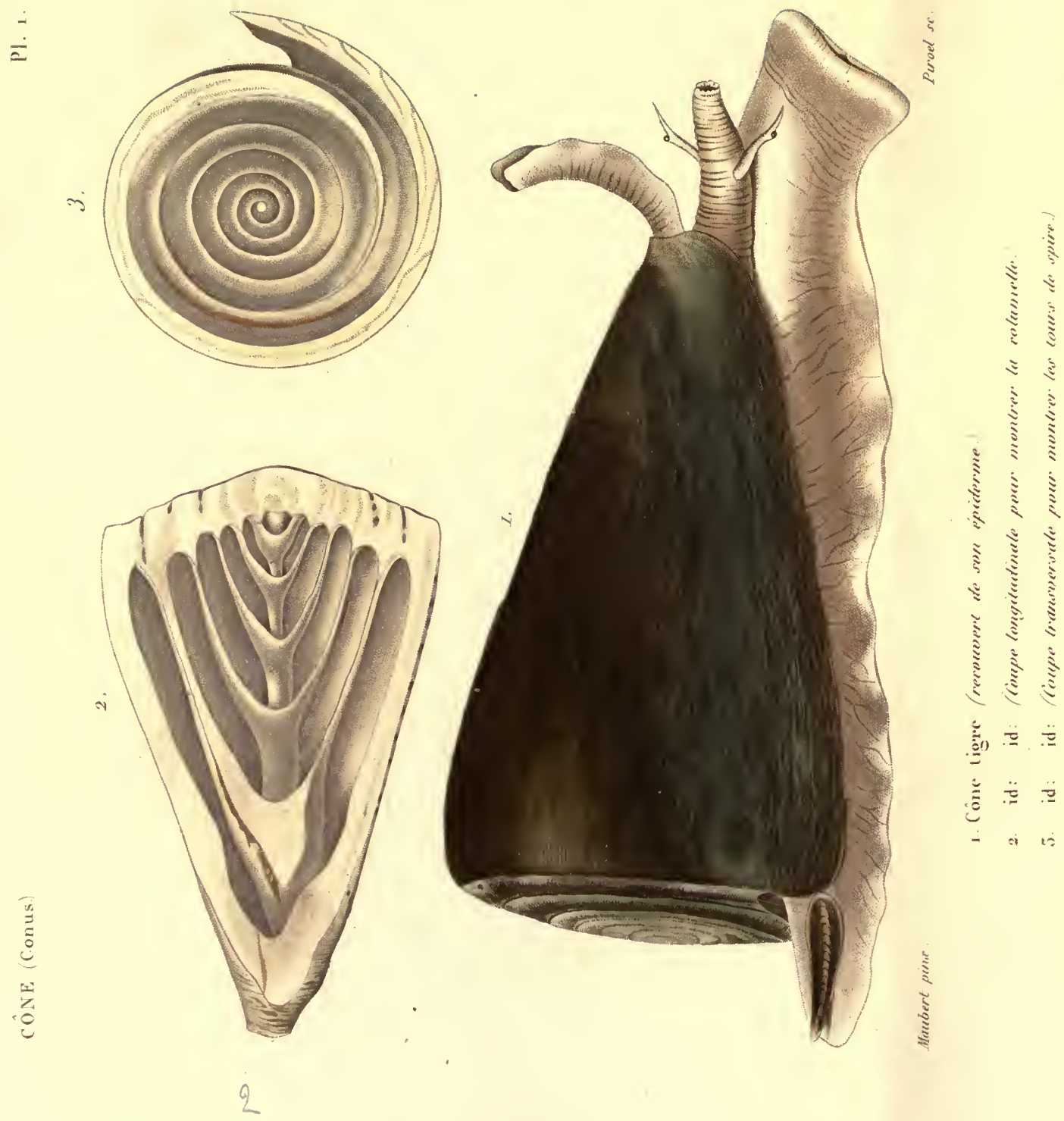




\section{THE LIBRARY \\ OF THE \\ HWIYEESITY OF ILLLMOIS}




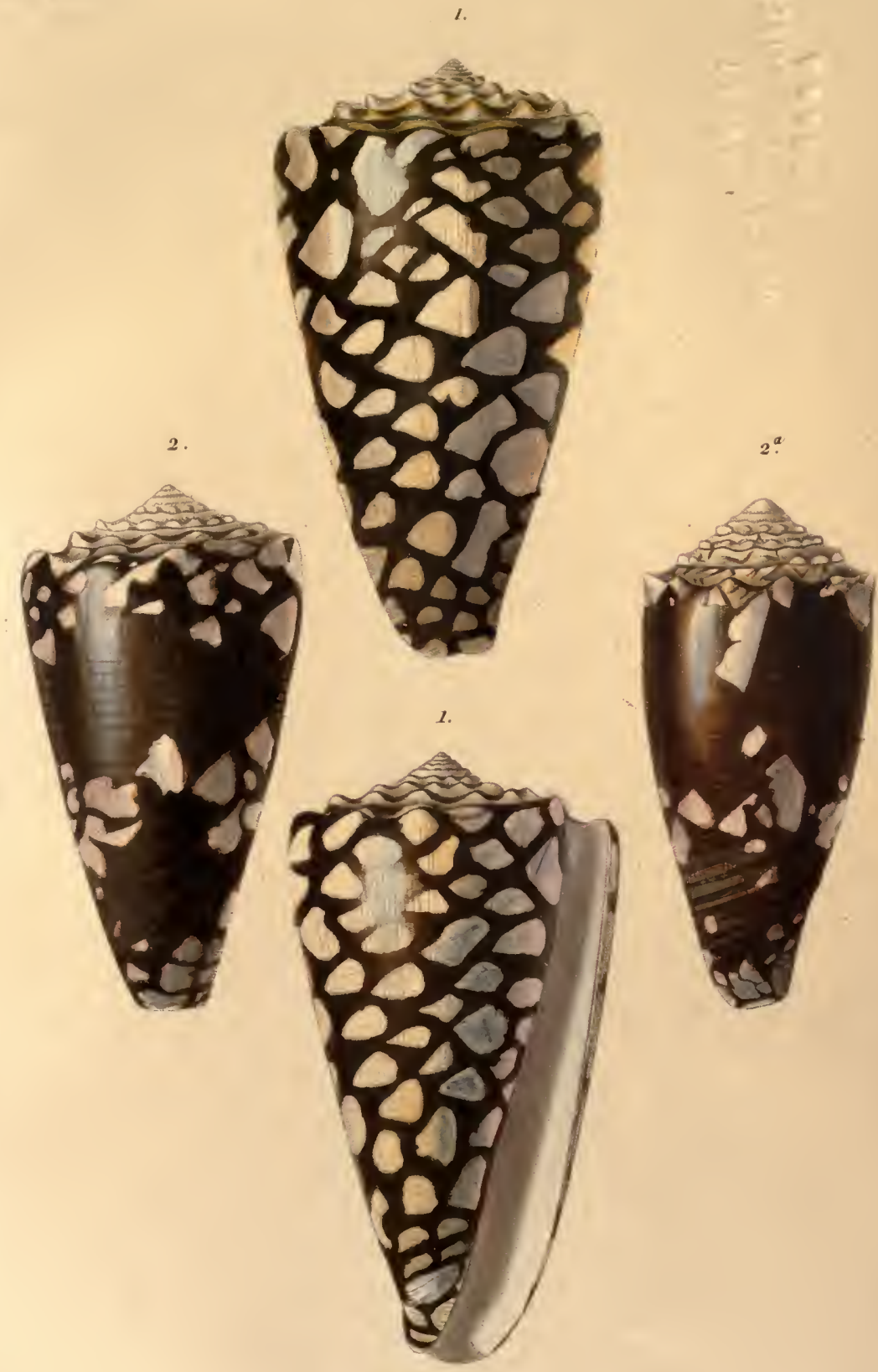

1. Cóne damier.

2. Cône nocturne.

$2^{a}$ id: id: var.

I. 


\section{THE LBRTARY \\ OF ThE \\ UWIYGRSITY OF ILUHOS}


CONF (Conus)

PI. 3.

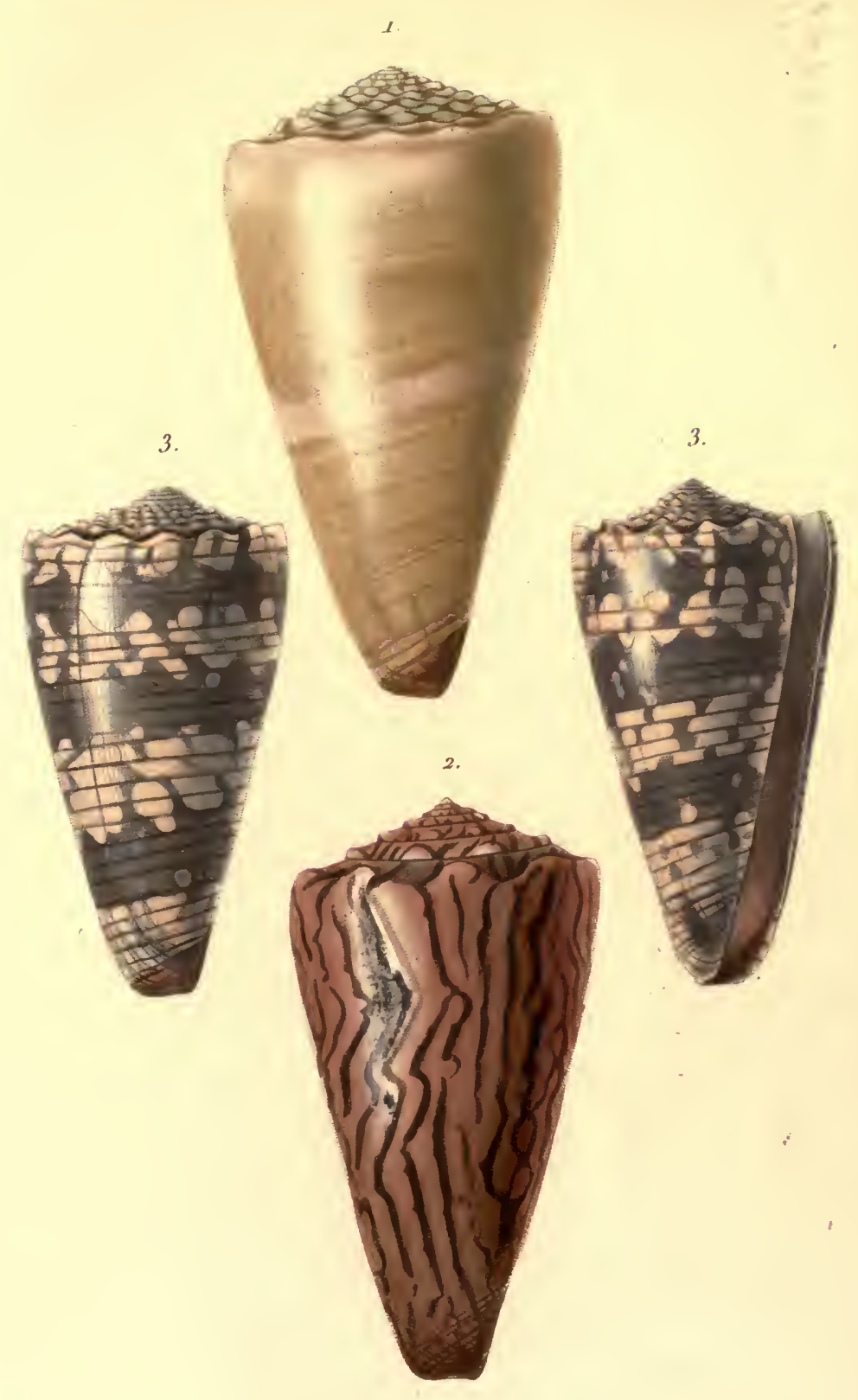
1. Cone memnonite
(Conus destans Brug)
2. Cone roval.
(Conus reyius. Chemn.
5. Còne zonal.
(Conews zonalews. Brug.) 
THE LIBRARY

OF THE

UNIYERSITY OF ILEMOIS 


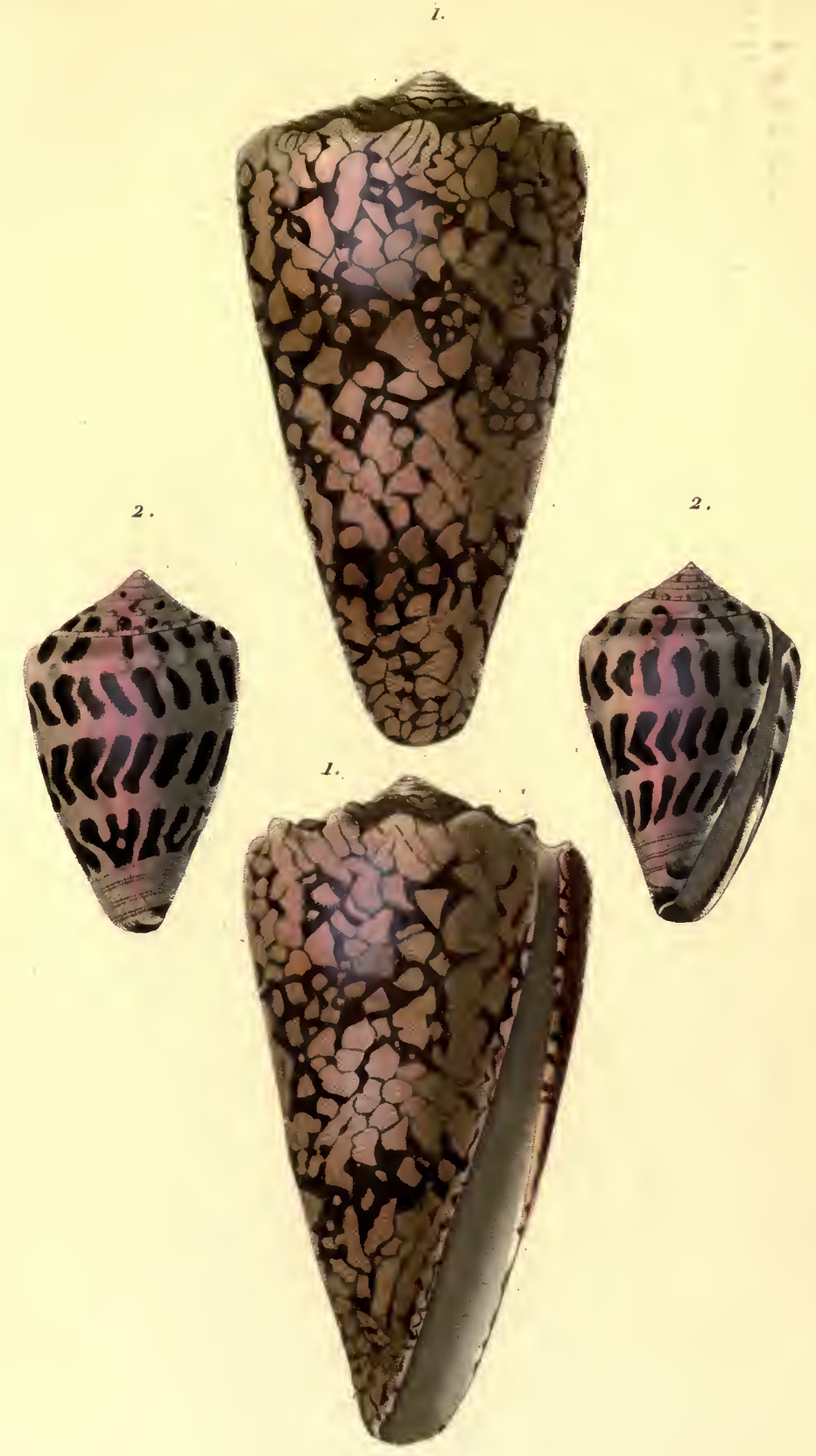

1. Cóne de Banda.

2. Cône hébraiqque.
(Conus Bandanis. Brug.)

(lomes hebraes. Lam) 
THE LIBRARY

OF THE

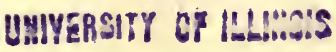




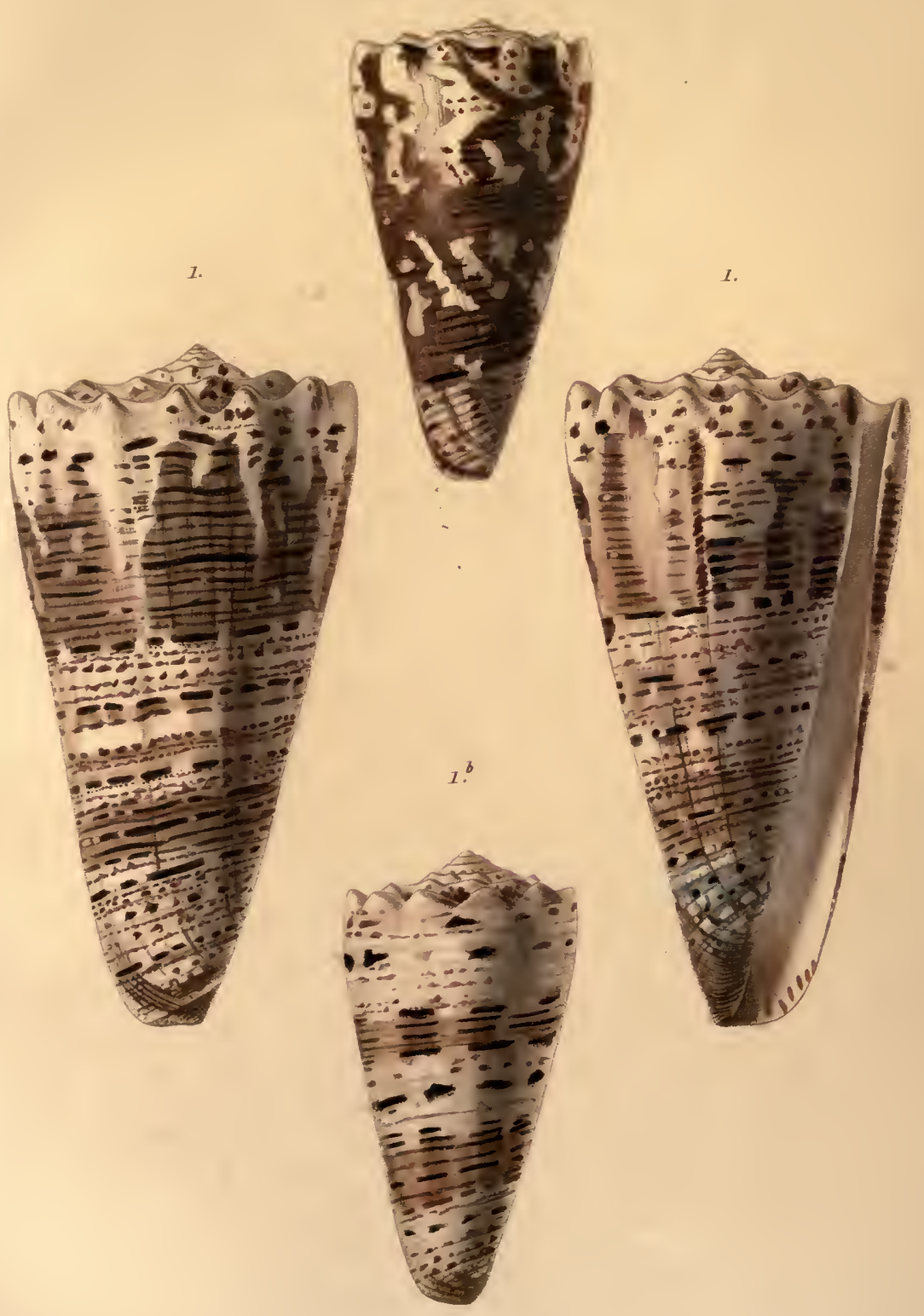

1. Cône impérial.

$1 \stackrel{a, b}{b}$ id: id: vartés
1.

/Conus imperialis Linf

( id : id : vartes ) 


\title{
THE LIBRABY
}

\author{
OF THE
}

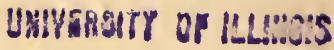




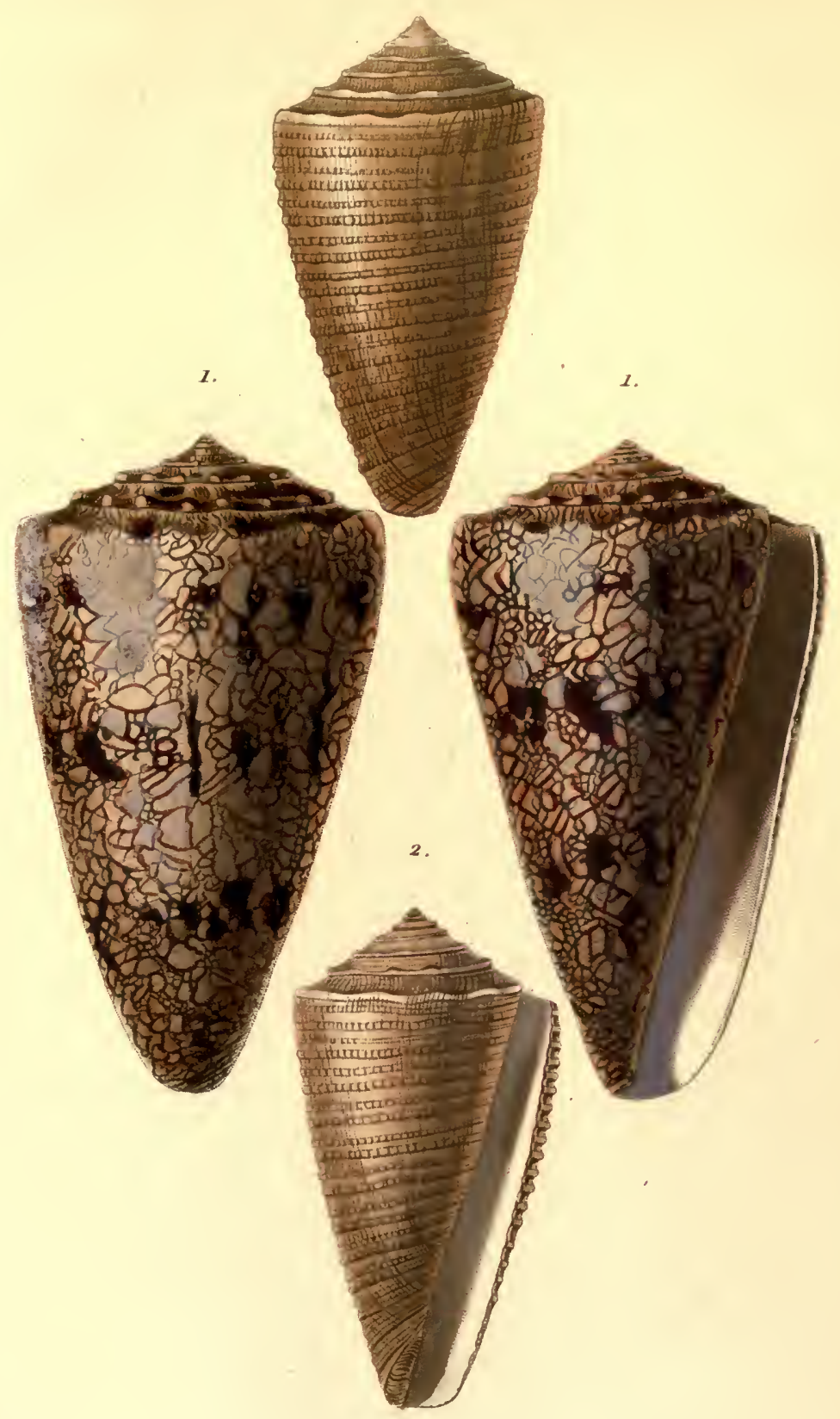
1. Cone esplandian.
(Conus ardneosus Bruy.)
2. Cône costé .
- (Conus costrutus. Chemn) 


\section{THE UB?aAY \\ OF THE

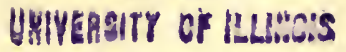



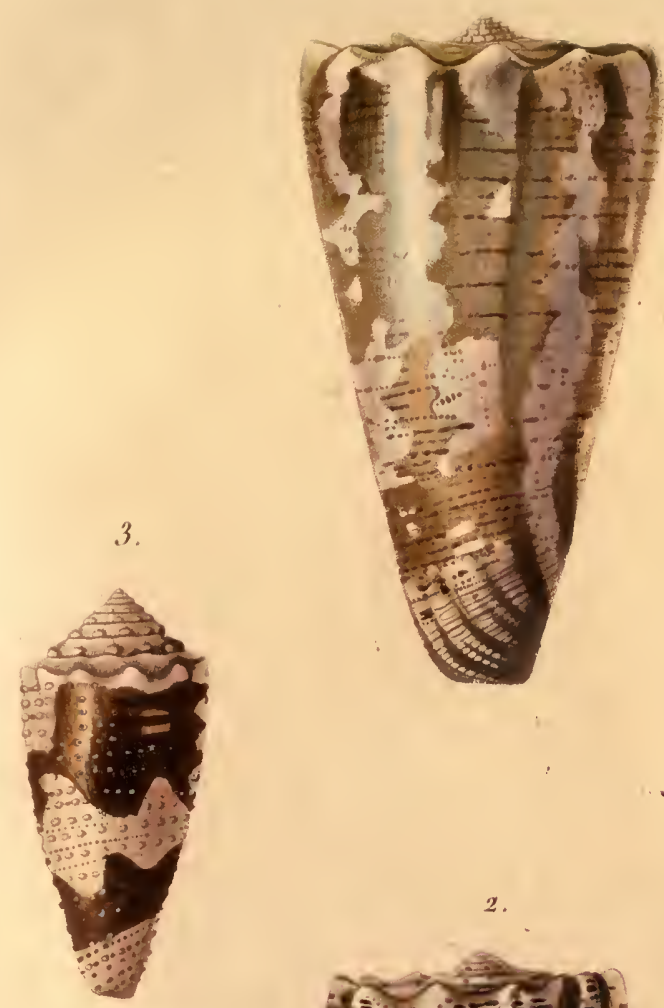

2 .
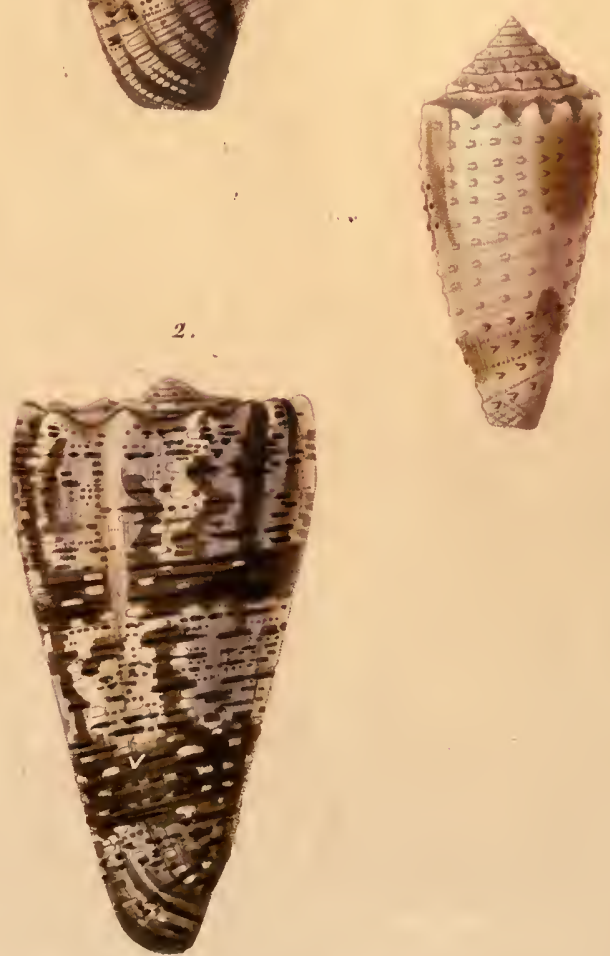
1. Cone impérial.
var. $\left\{\begin{array}{c}\text { Conus imperialis var. } \\ \text { id : viridulus. }\end{array}\right.$
2. Cône maure Conus fuscales. Brugt)
3. Cône chagrin.
(Conus barius. Lims)
3. id. id. var.
(id: id: bar: I 
THE LIBRARY

OF THE

UMIVERSITY OF ILLI:C'S 
3

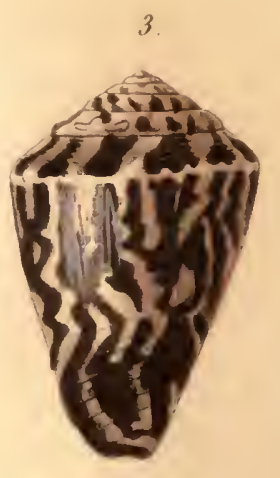

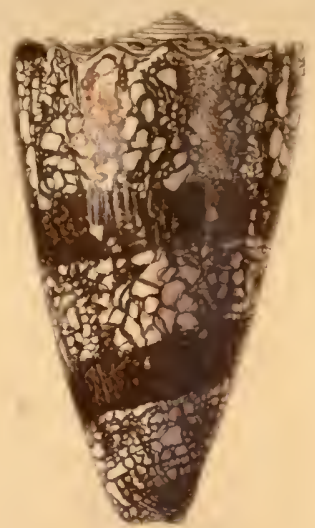
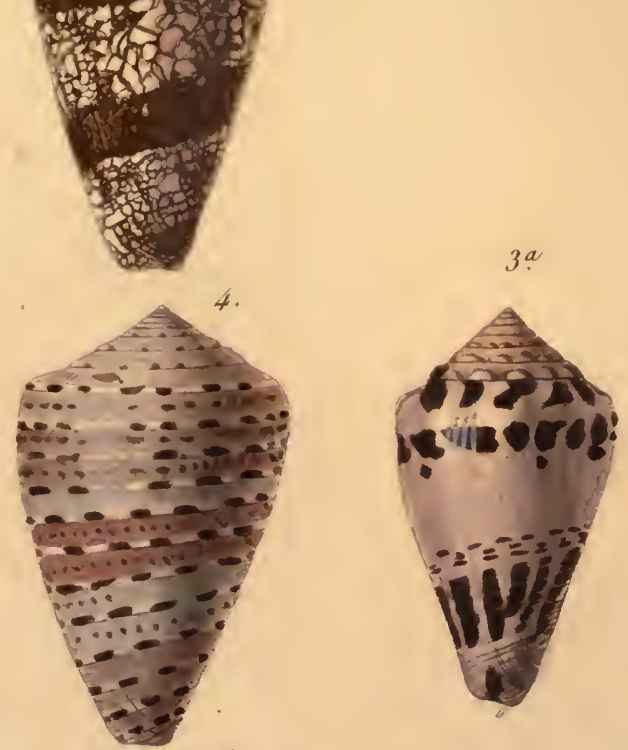

1. Cone de nicobar

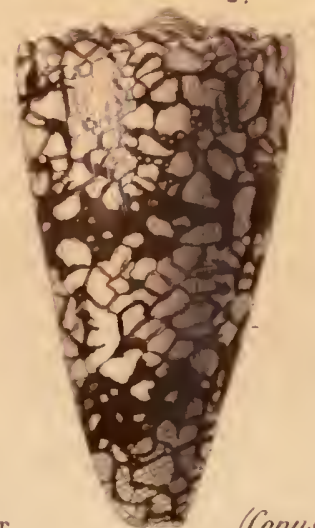

2. Cône id. var.

3. Cone hébraique var.

(Comus hisbropus zar. )

$3^{\mathrm{a}}$ id. id

t. Còne rubanć

I id. id.

liones carniatus.

Brug ) 


\section{THE LIBRARY}

\section{OF THE}

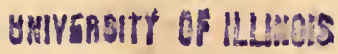




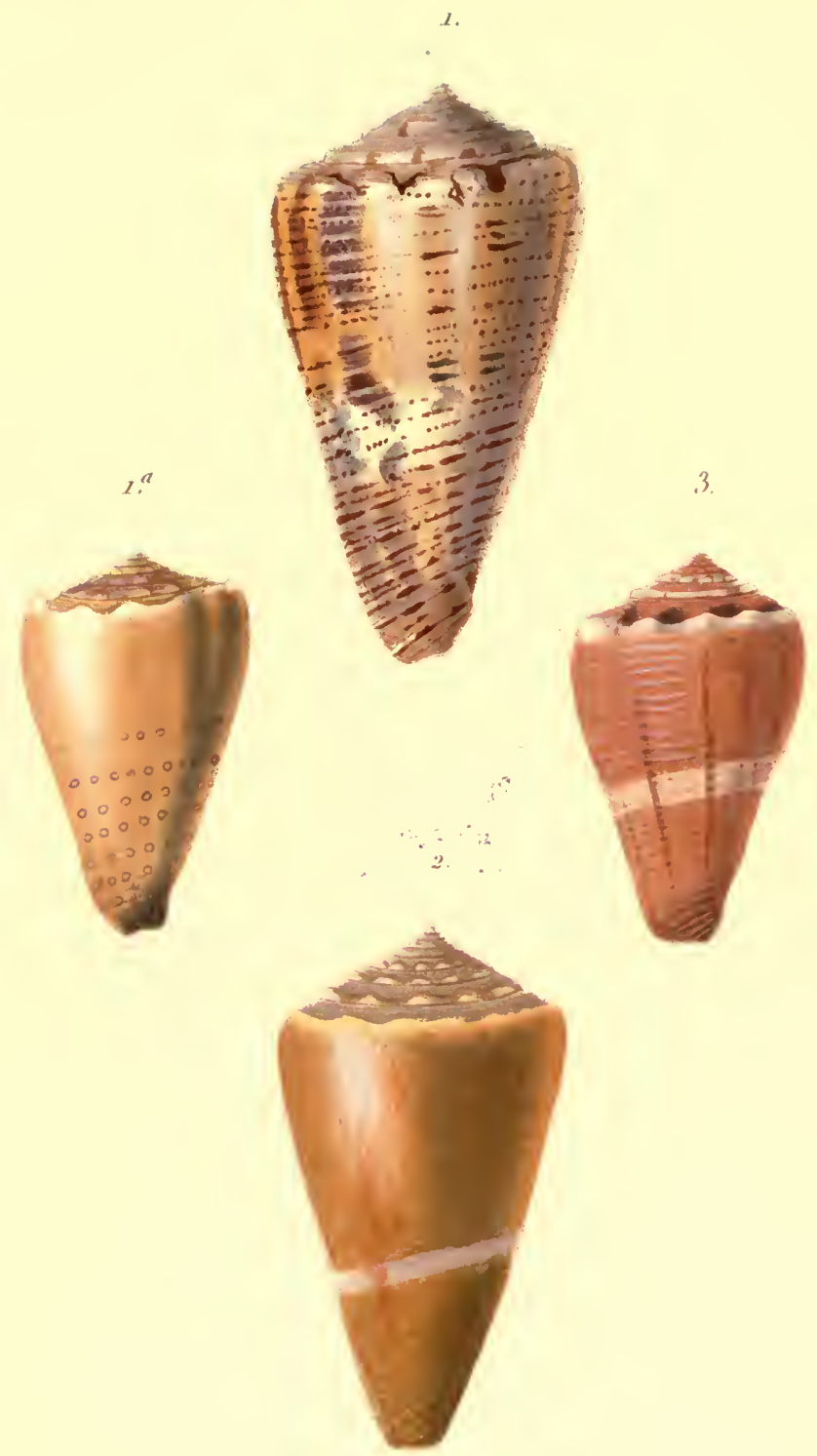

1. Cône ponctué.

2. Cône livide.

2 , id: id: var:

5. Cỏne rosé .
(Conus punctatus: Brug.)

(Conus lividus. Brug.)

( id: id: var: )

(Conus roseus. Lam.) 
THE LIERARY

OF THE

UMHERSITY OF ILLW:DS 

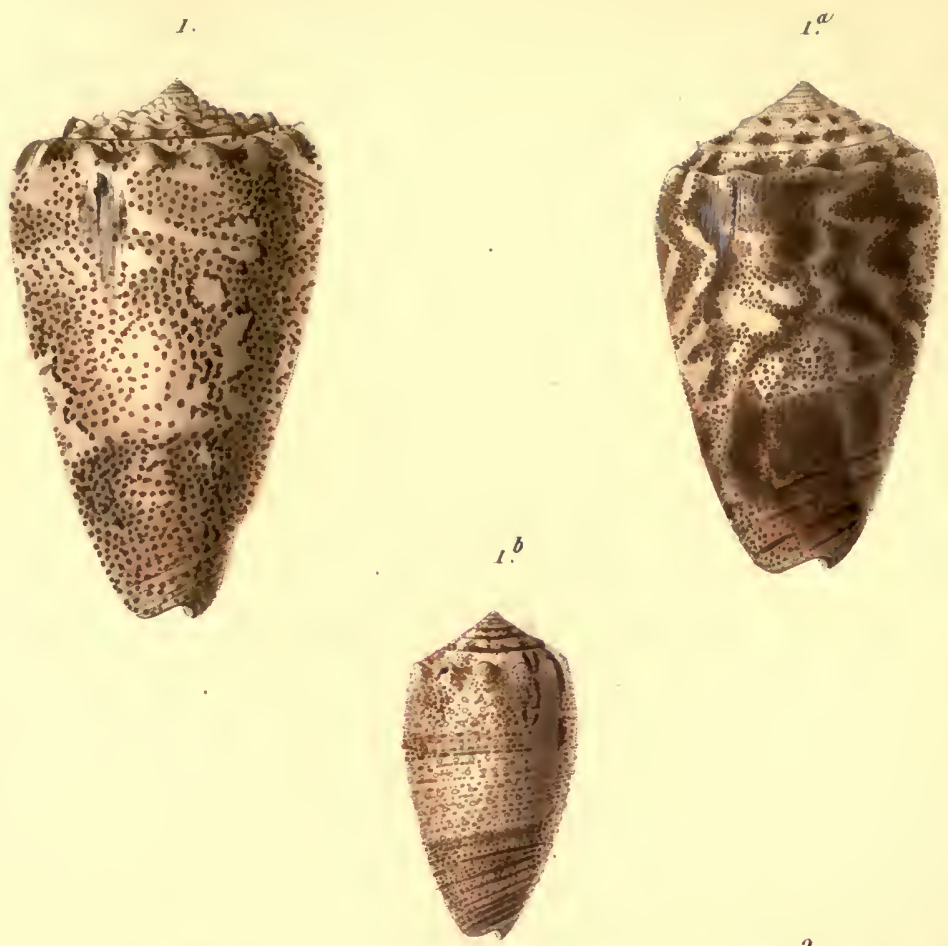

2.

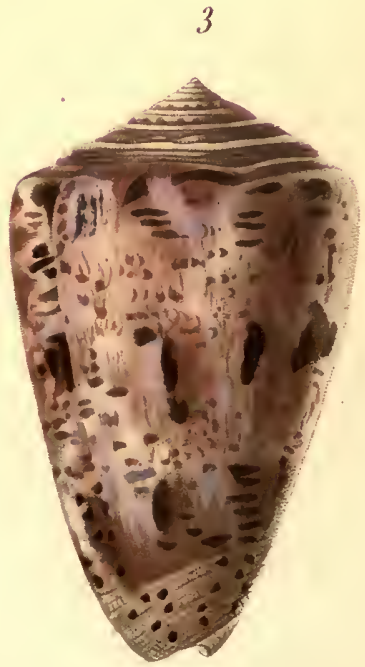

1. Cône piqúre-de-mouche .

(Conus arenalus Brug.)

1. 1 id: id: var.

' id: id: var. '

2. Cône morsuredepuce.

(Conus pulicarius Brug.)

3. Cone civette.

(Conus obesur. Brug.) 
fHe U⿴囗十⺝⿱

of THE

Giveneitr of rusuions 

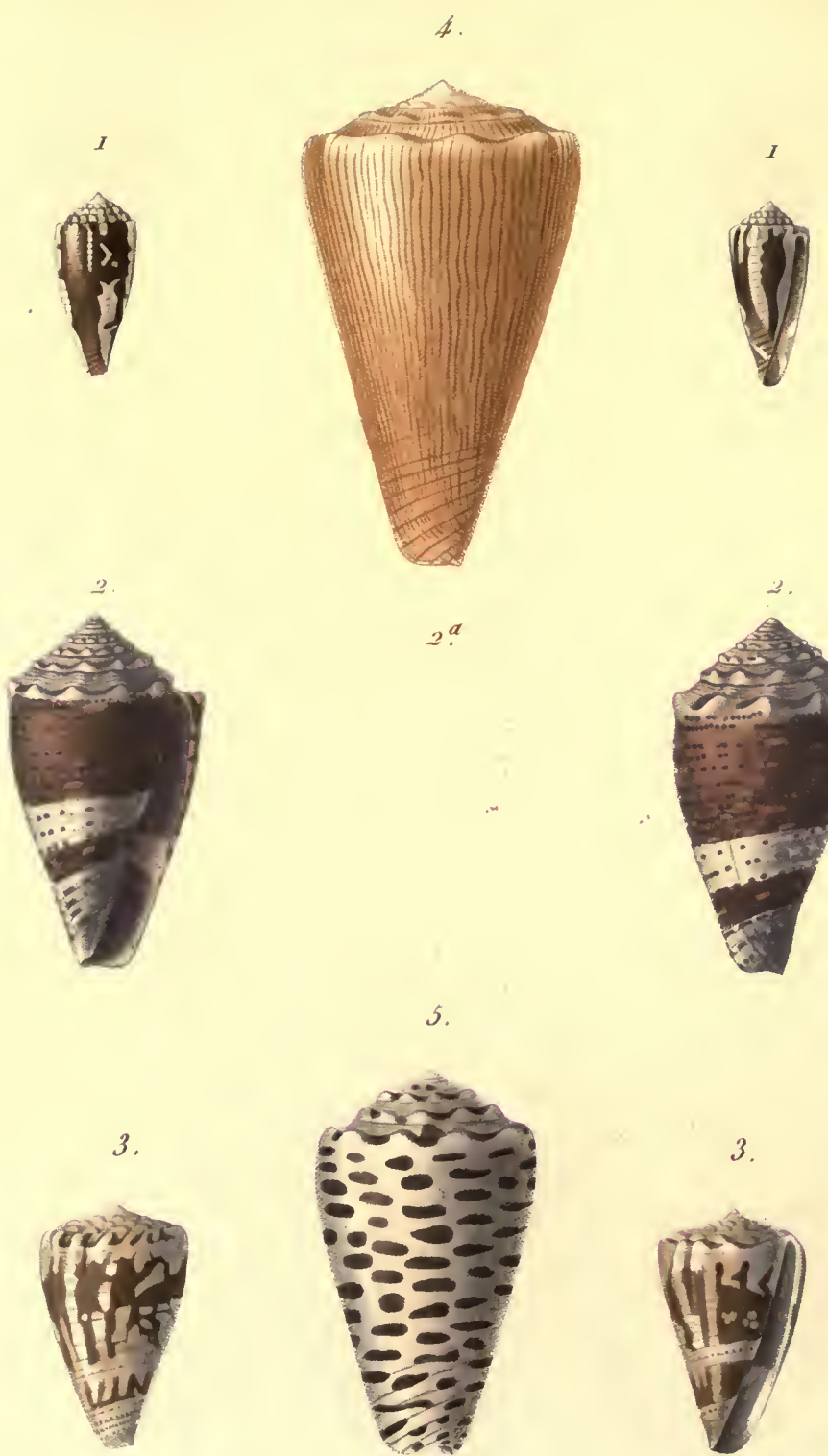

Maubert pinax.
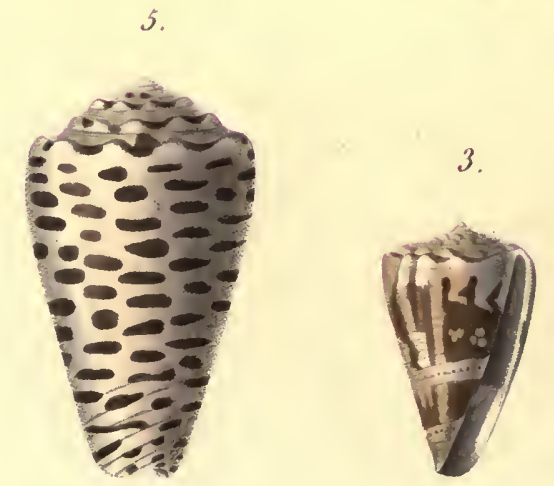

Pirod sc.
1. Cône éxigu.
3. Cone liare
$2^{\mathrm{a}}$ id: id: jeune
3 Cône noiselte.
f. Cons royal var:
5 Conc fustigé.

$2^{a}$

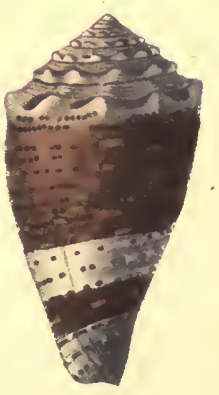

(Conus exiguus. Lam)

(Coness liaralus Brod)

( id: id : junior:)

(Comes newo. Brod)

(Conus reguius var: )

(Conus fustigatus. Brugt 
IME LIBRARY

OF THE

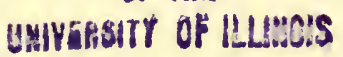




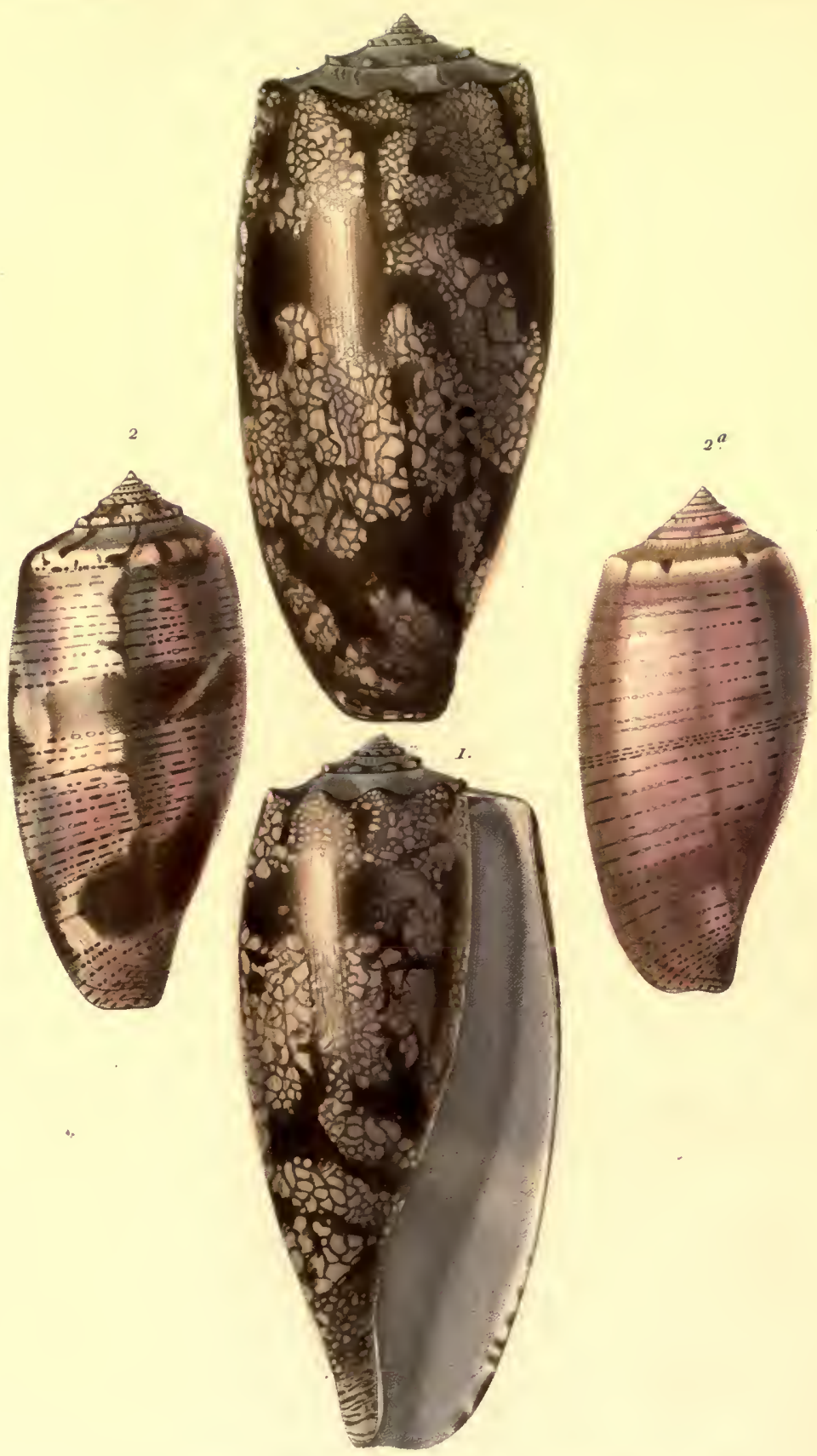

1. Cône brocart.

2 Cône tulipe.

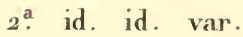

(Conus geographus. Tin.)

(Conus lulipa. Lin.)

( id. id. var. 


\section{THE LIBPARY}

OF THE

UHVERSITY of ILLUM!S 

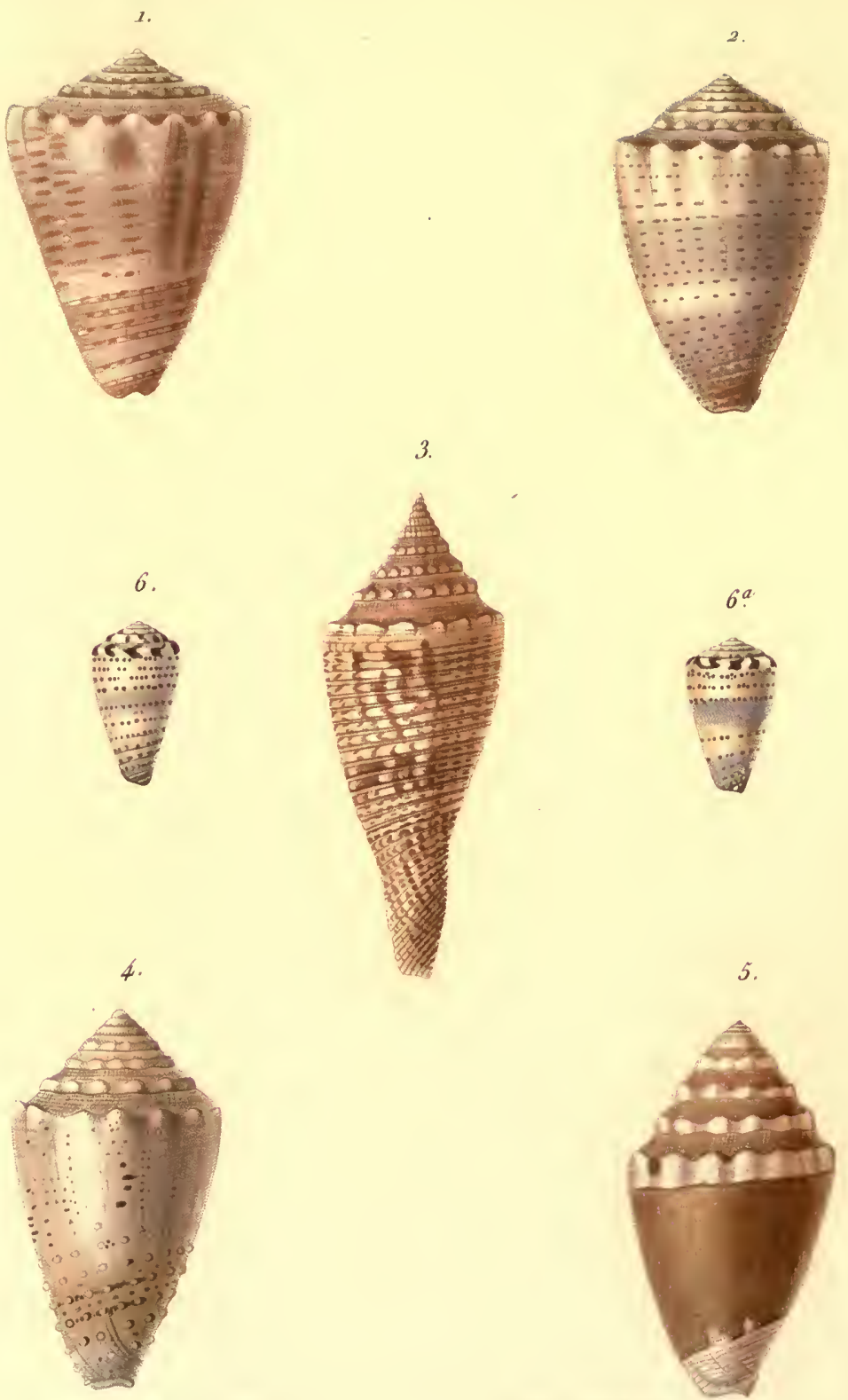
1. Cône miliaire.
2. Cône gourgouran.
3. Còne de d'Orbigny.
4. Cône chagrin
5. Cone pontifical.
6. Cone musique.
6 a id
id :
var:

(Conus miliaris. Brug.)

Conus barbadensis. Brug.)

lConus Orbigmyi. Audouind

Conus varius var.

(Conus pontificalis. Lam.

lConus messicus Brug.

I id:

id: var.: 


\section{THE LIBPARY}

$$
\text { OF THE }
$$

UWYERSITY OF ILLMOIS 

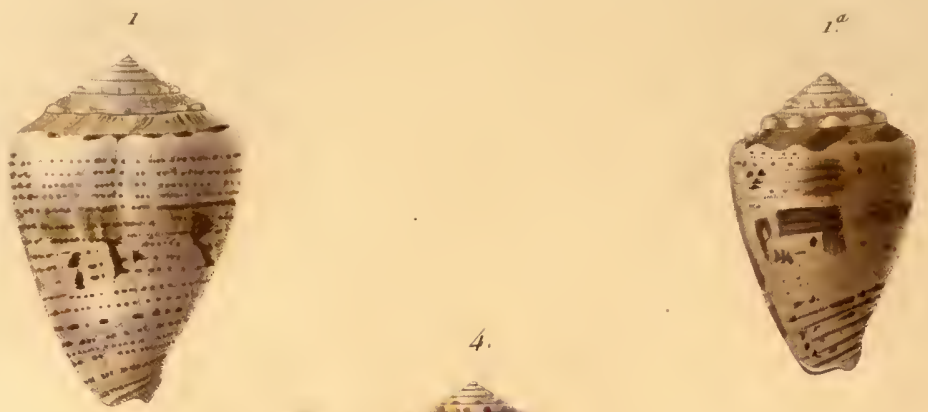

2.

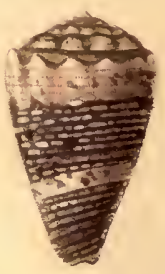

3.

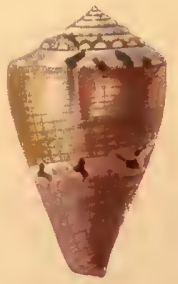

5.
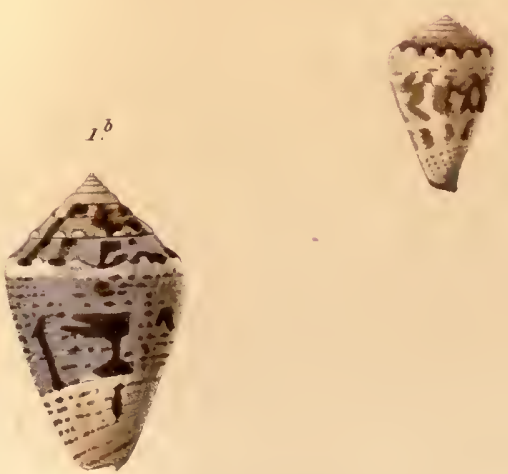

1. Conc papier-lure la is id: rall:

lones minimus. loint)

3. Come ćmaillé.

Iit: it: val: ।

5. Cone cardinal.

Gonus encruesters. noticis)

4. Cône époux.

(Coneas cardinatis. Bruy)

5. Còne chingulais.

(Comes sponsalis. Breag)

(Comes ceylanenetir. Bruy) 
THE LIBRABY

OF THE

UMIVERSITY OF ILLMOLS 
CONE (Conus.)

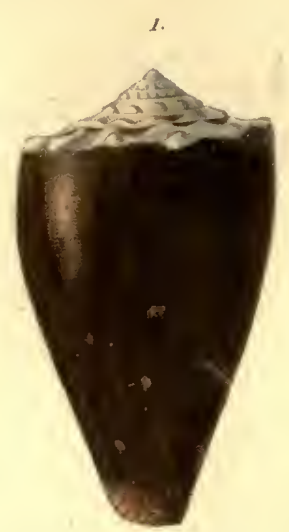

2.

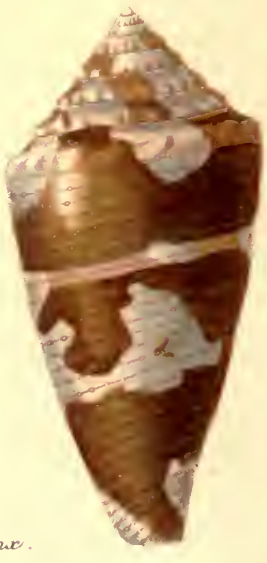

Maubart pinat

\section{Cône brun}

1. id: id: var:

2 Cône écorce d'orange.

2 ? id: jd: var:

3. Cône baudrier.

+ Comr ogadialcur.
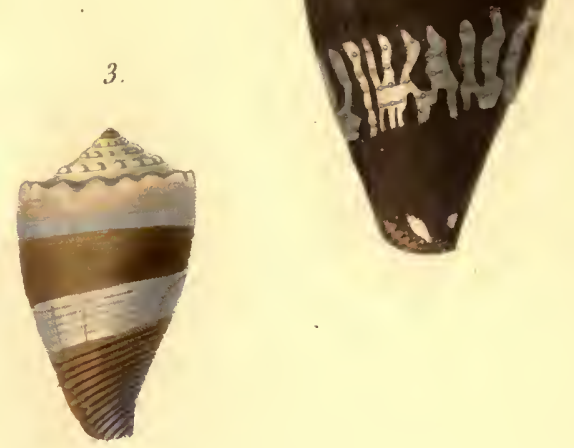

4.
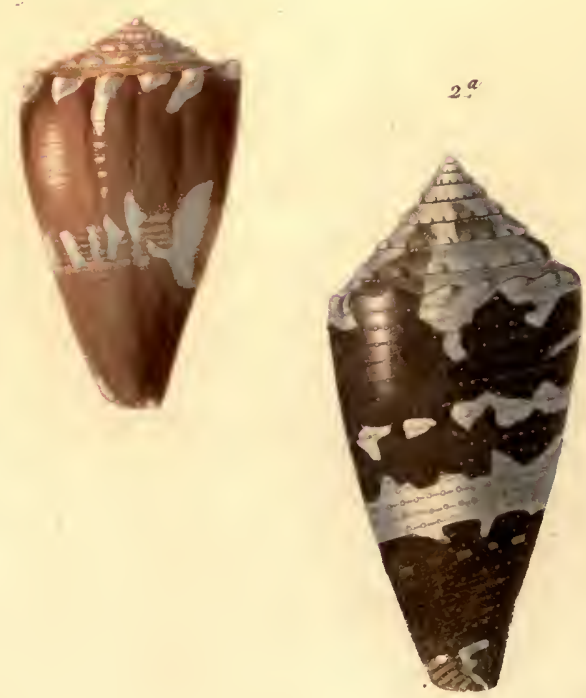

Piroel $x$.

(Conus brunneus Wood) ( id: id: var: , (Conus aurankius.Brug.) ( id: id: var: ) (Conus ballealus. Sow.) (limes gladiator: Brod.) 
PHE LIBRARY

OF THE

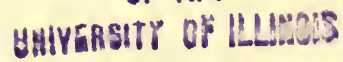



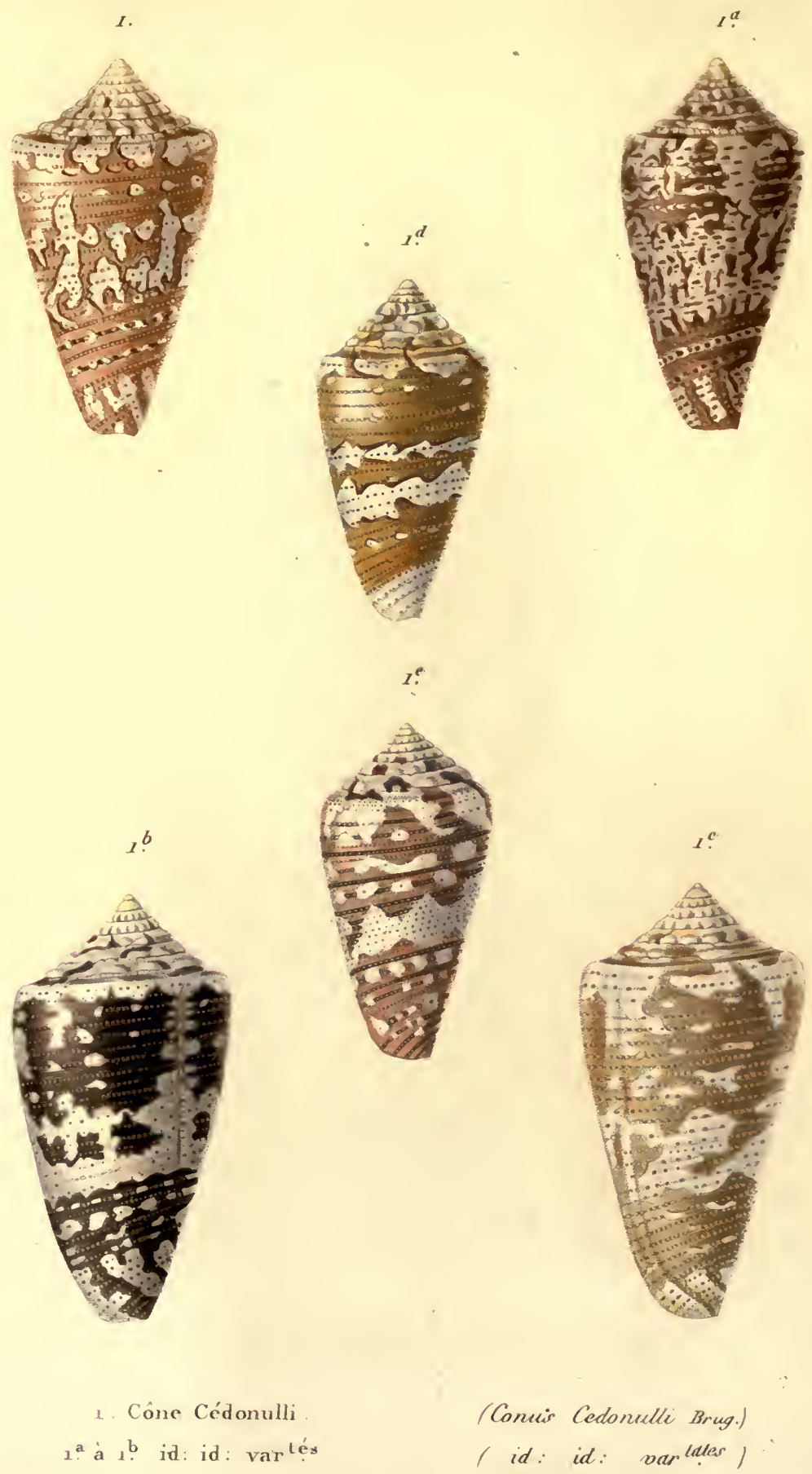

1. a a 1 b id: id: vartés

( id: id: varlales ) 


\section{THE LBBTARY}

OF THE

HeIVEROTY OP ILLEOS 


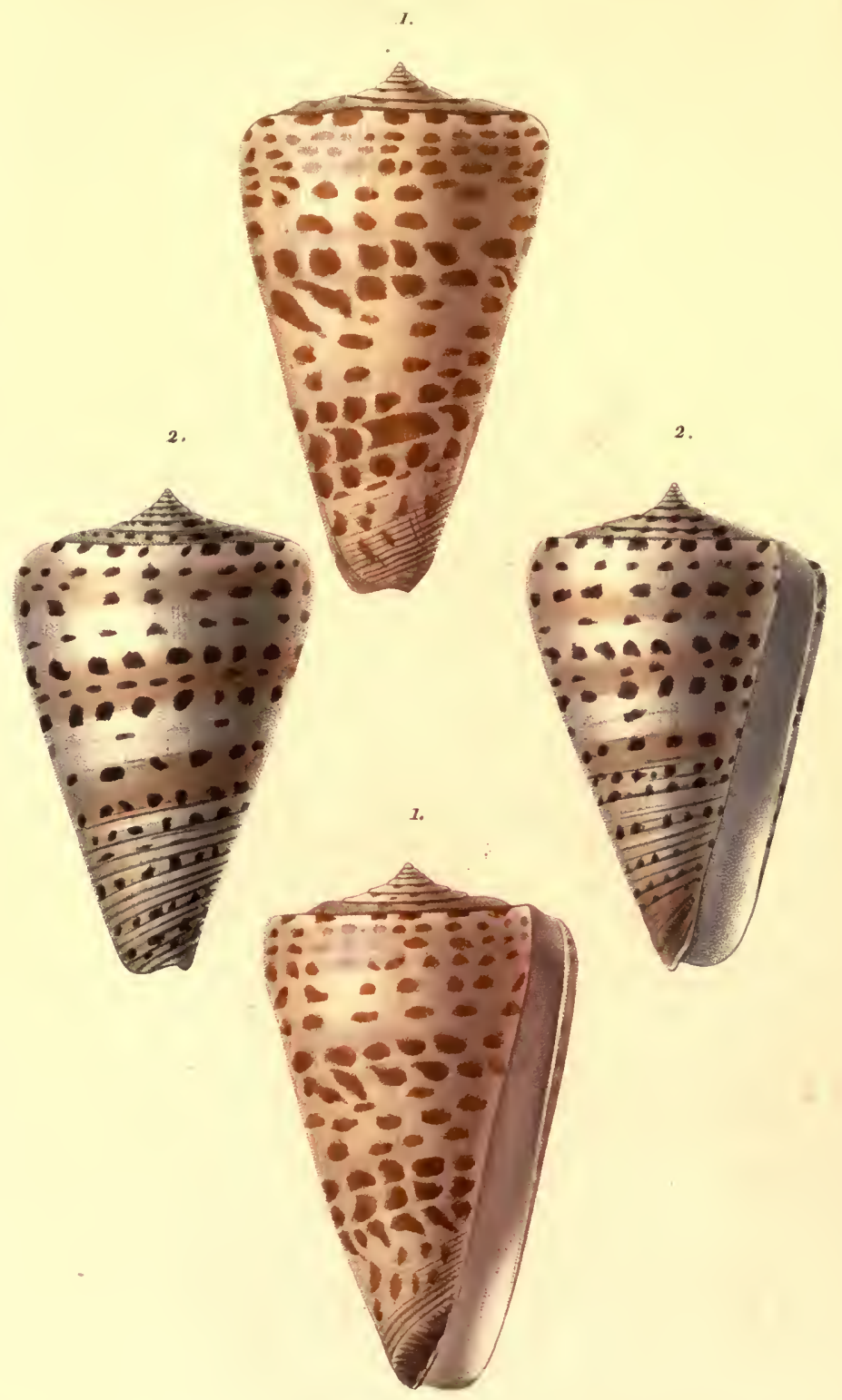
1. Cóne mosaïque.
(Conus tessellatus. Brug.)
2. Cone pavé.
(Conus eburneus. Brug) 


\section{THE LIBRARY}

of the

HUIYERSTT OF ILLU: 


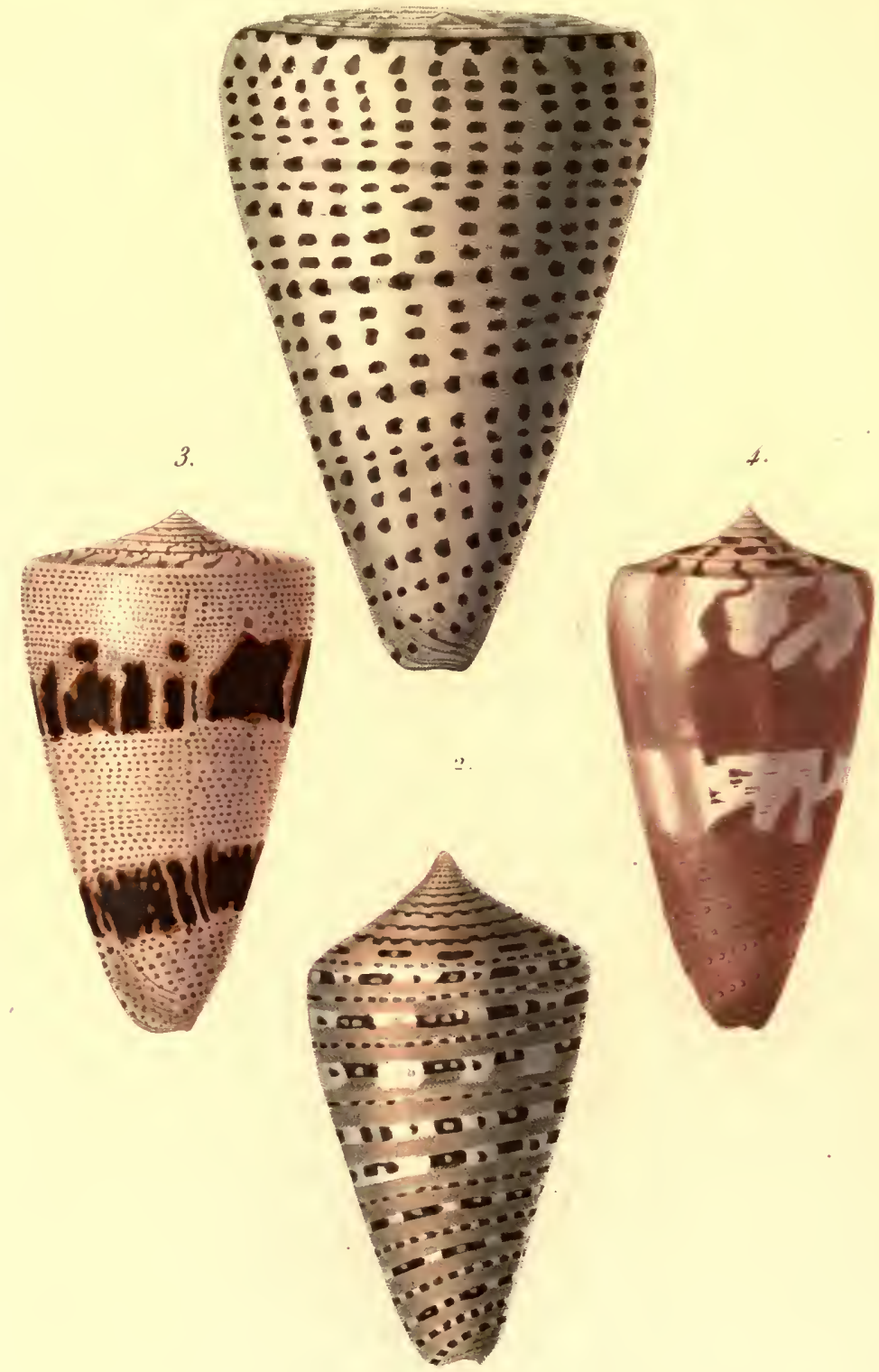

(Conus millepunctatis. Lam.)

(Conus genuanus. Lin.)

(Conus augur., Brug.)

Conus lincalus. Chemd 


\section{PHE LIRPARY}

OF THE

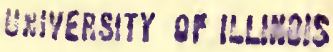




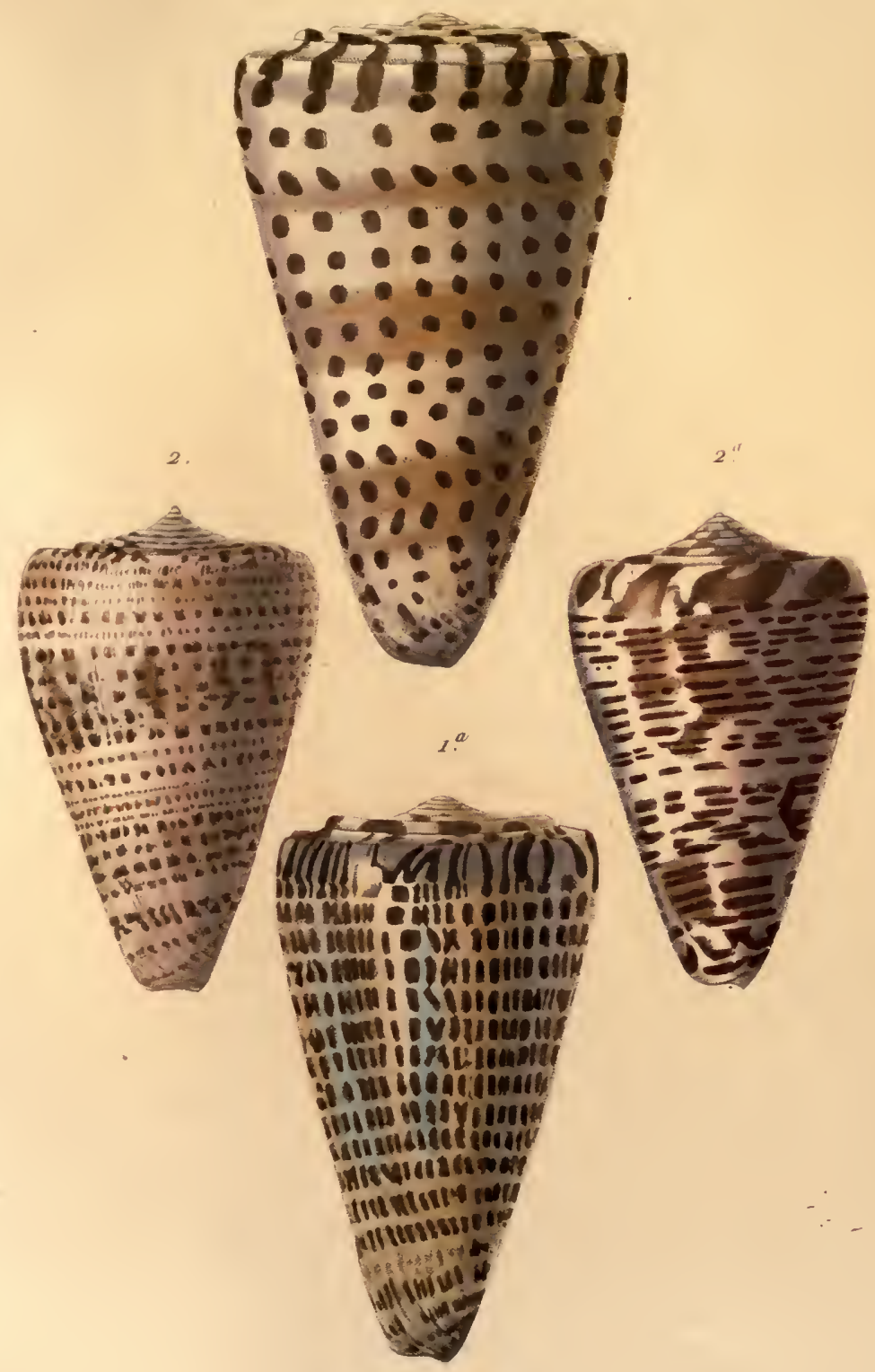

1 Cône arabe

1. id: id: var

2. Cône léonin.

$2^{\text {? }}$ id: id: var
(Conews lieleralus. Lin.)

I id: id: var: ।

(Conus leoninues. Brugt)

( id: id: var: , 


\section{THE LIRRARY}

OF THE

UWYEREITY OF ILUMOLS 


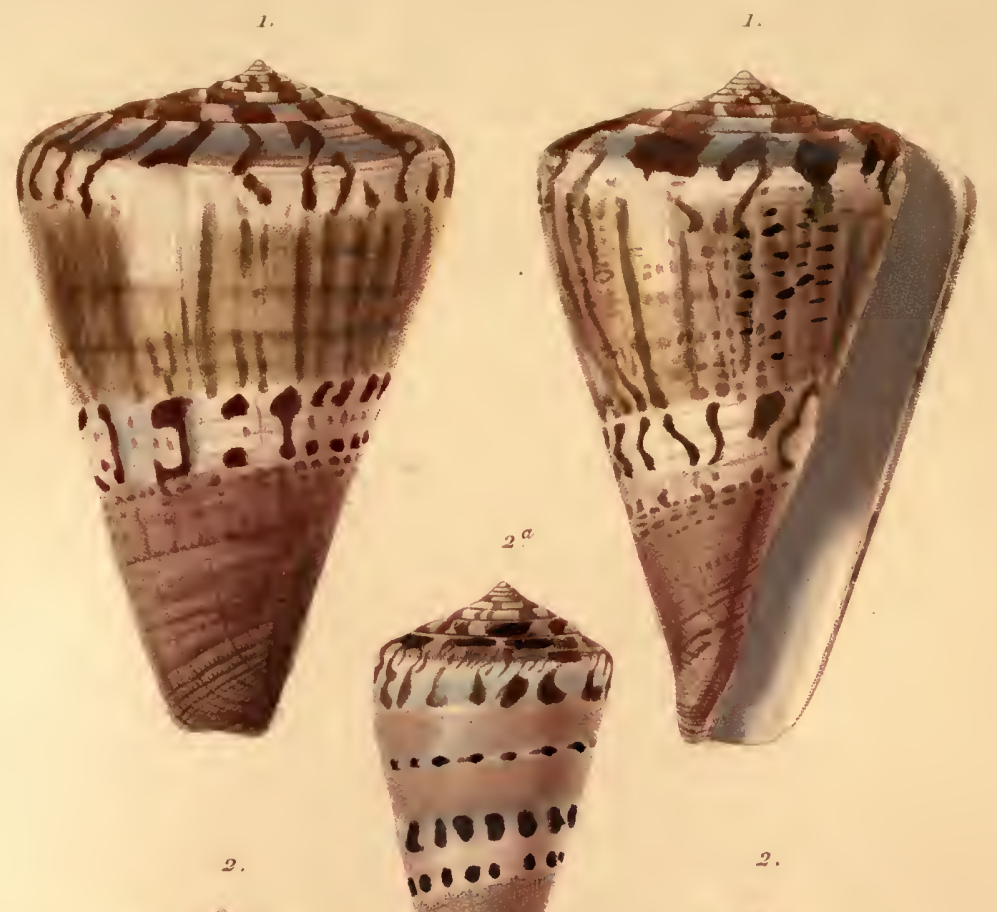

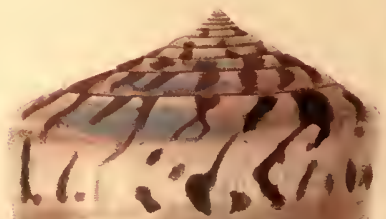

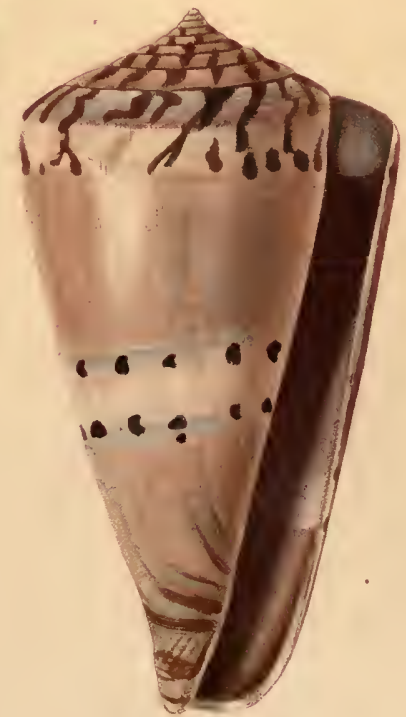

1. Cône capitains

2. Cone hernine

3 id id.
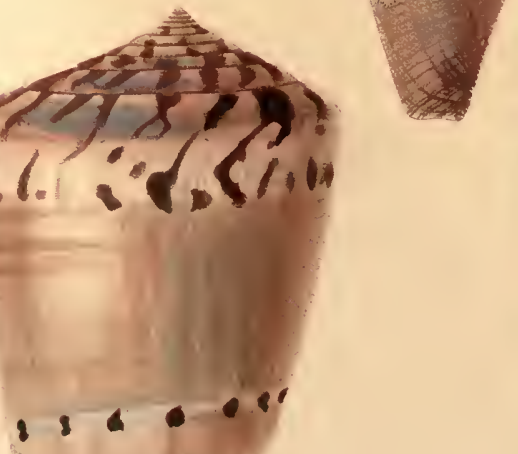

$1 .-28 \div$

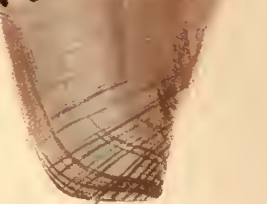

\footnotetext{
IConus capilancus: Lin
}

('muns mustelinus.

Brug

1 ith id var. 
THE LIBRABY

OF THE

GWIVEREITY of ILLNOLS 

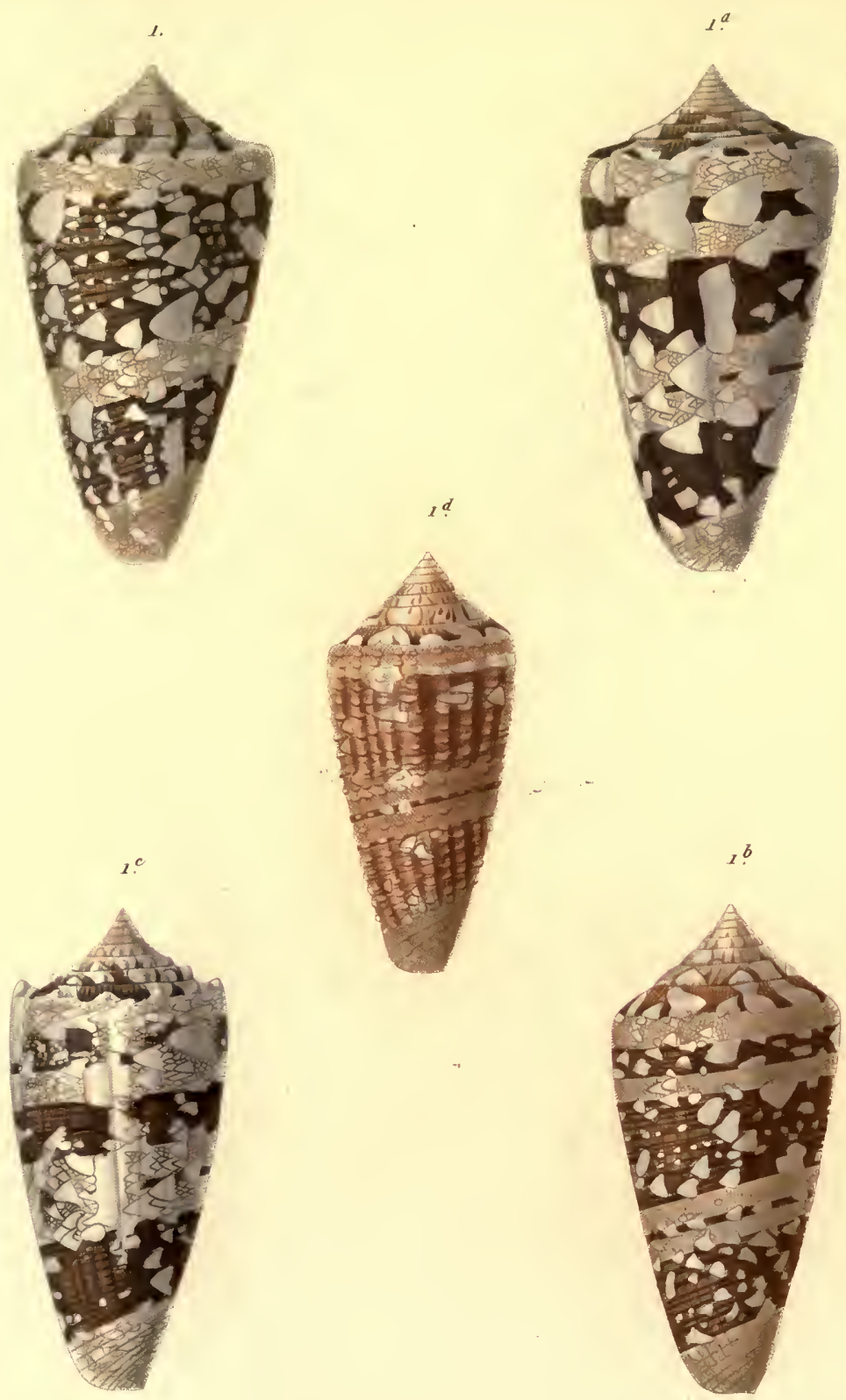

1. Cône amiral

(Conew amiratis. Linf)

1. à 1 id: id: vartés

( id: id: nastates, 
IHE LIBRARY

OF THE

HNIVERBIIT of ILLIMOIS 

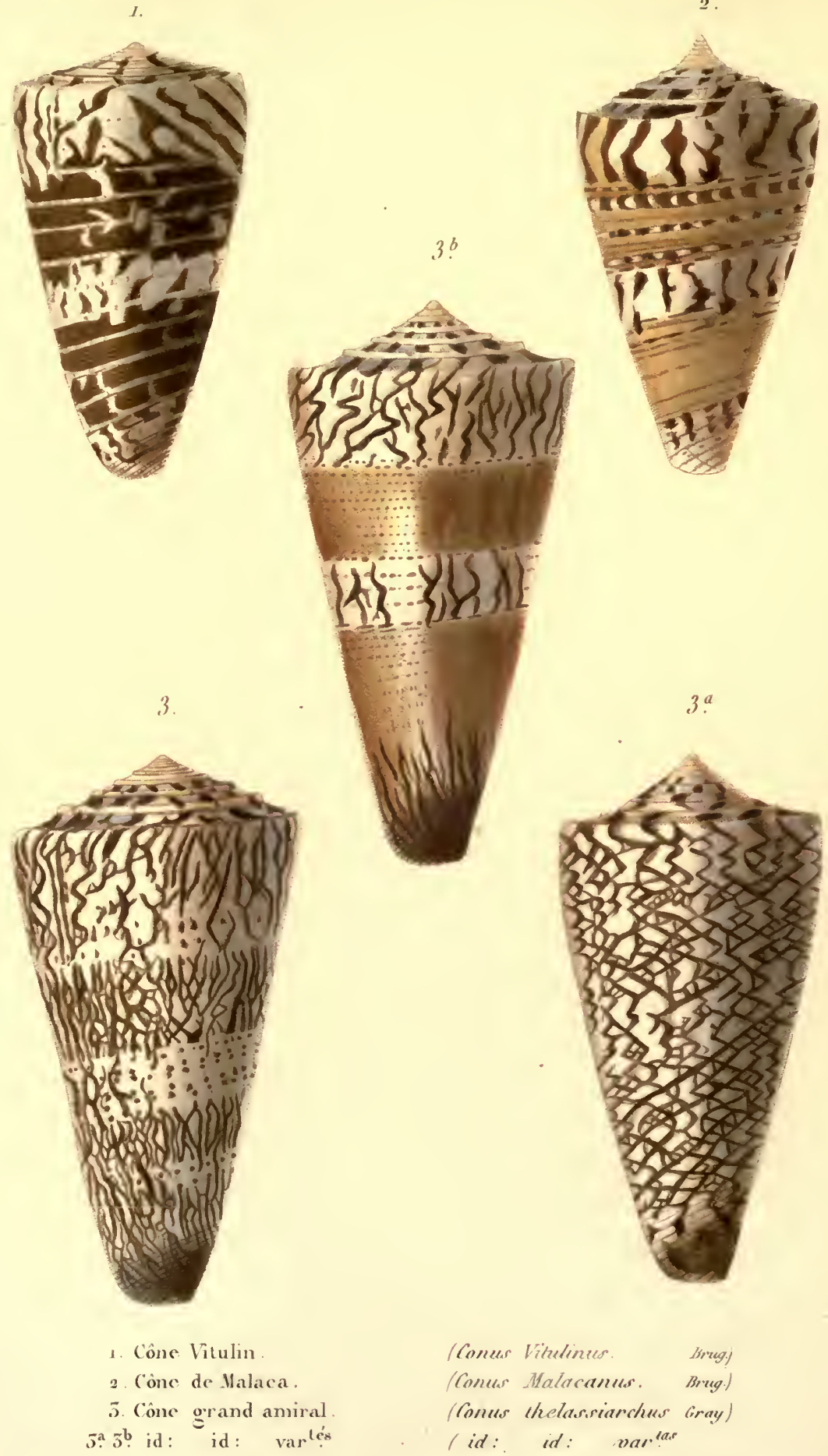
THE LIBRARY

OF IHE

GNIVERSITY Of ILLMDIS 

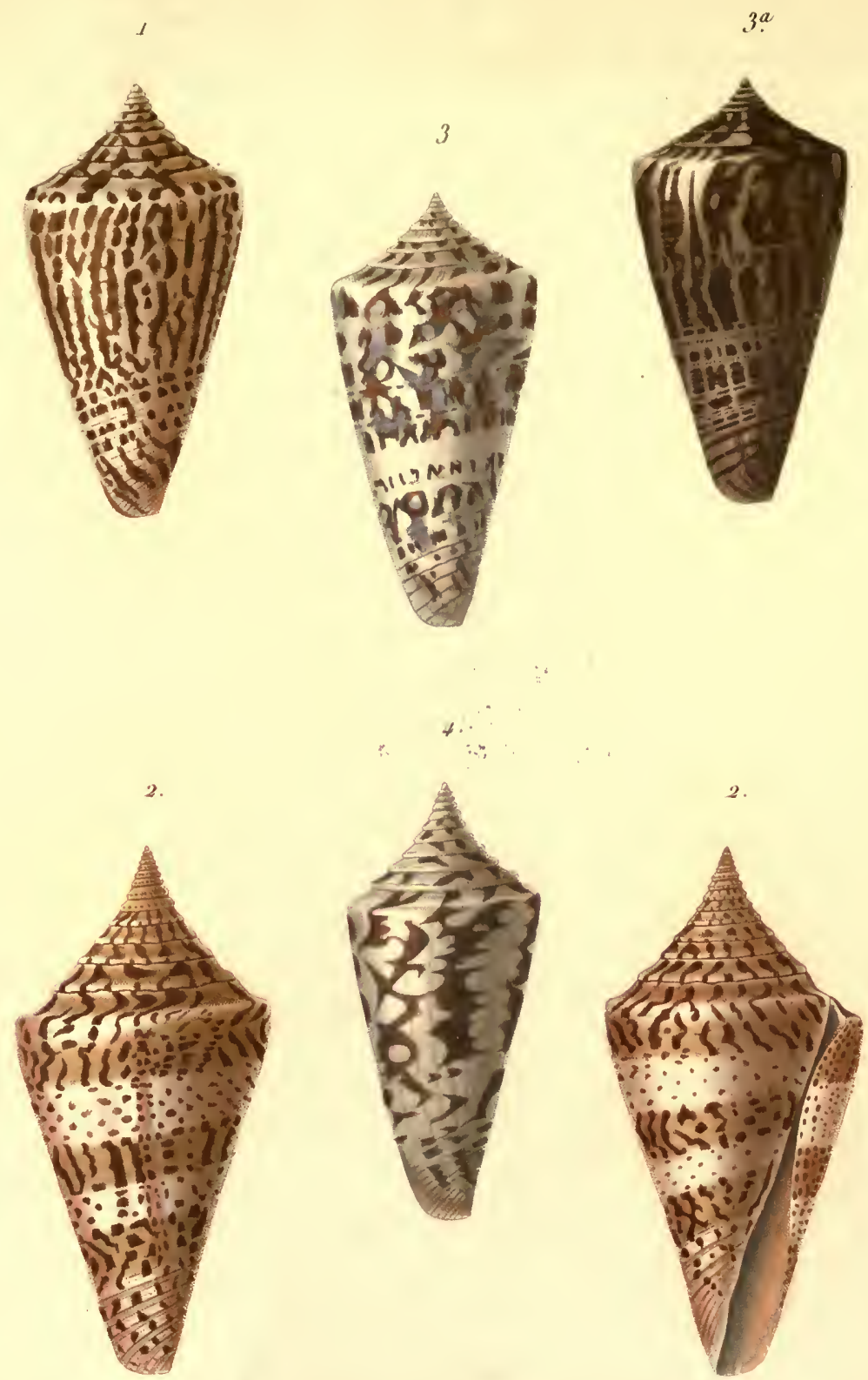

1. Cone éclair.

2. Cône de Delessert

(Conus Pammers. Jam )

5. Cone régulier.

(Conus Delessertiu. Rédux)

3. id: id: var:

(Comus regularis. Sovv.)

f. Cone ćmarginé.

( id: it: var: )

(romes' emaryinathas. Reeve) 


\section{THE LIBRARY \\ OF THE GWVERSIT of LLUWOSS}




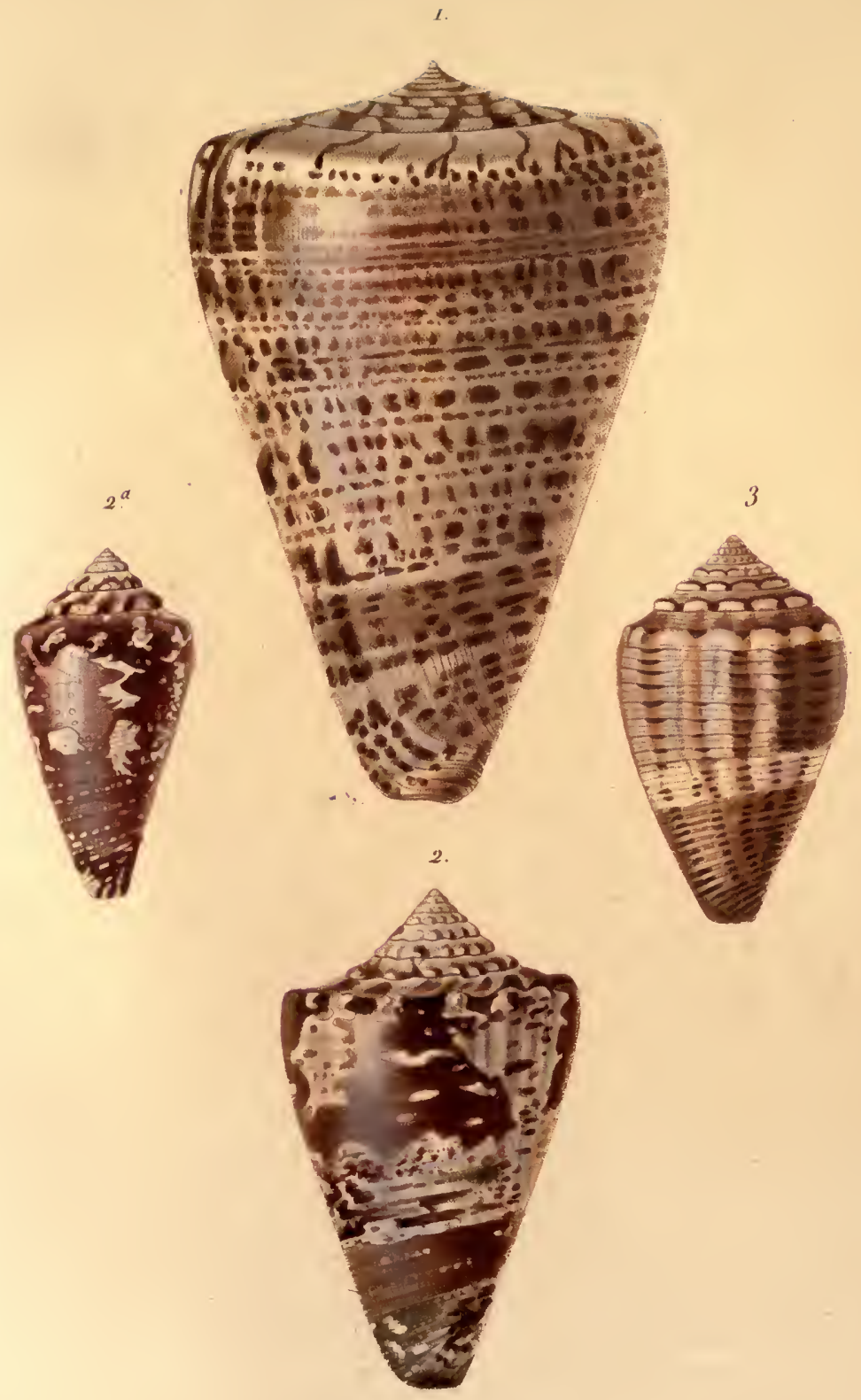

1. Cône papilionaeé .

2. Cone papier-narbré.

2? id: id: var:

J) Cone somis.
(Conus papilionaceus.Bruy)

(Conus nebulosus soland)

/ id. id: nas: I

(Conus mus. Brug.) 
IHE LIBRARY

OF THE

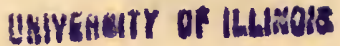




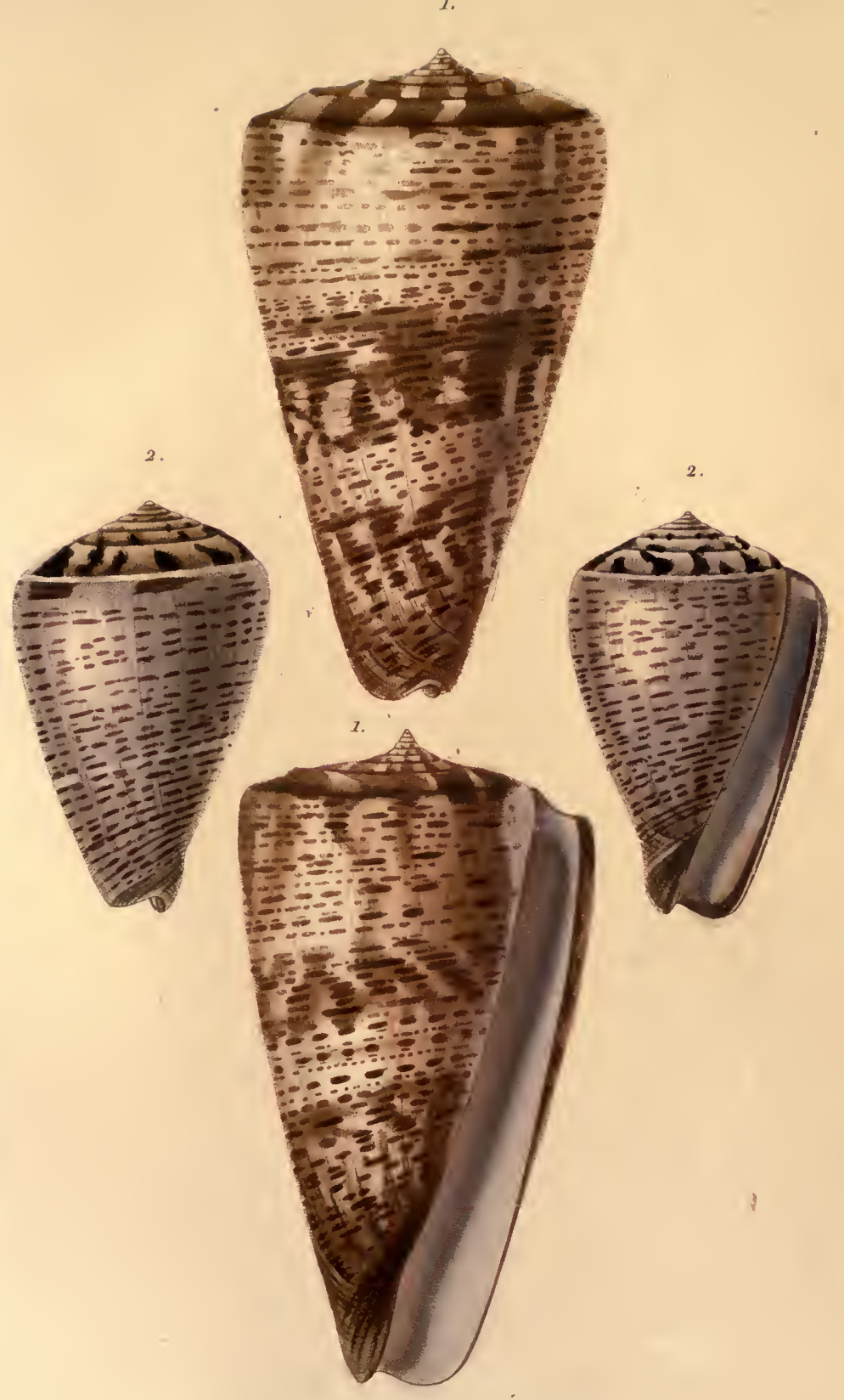
1. Cône prométhée
(Conus prometheus: Brug.)
2. Cône glauque.
lionus glaucees. Lins) 


\section{THE LIBRARY \\ OF THE

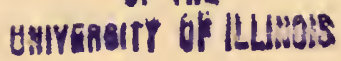


côNe (Conus)
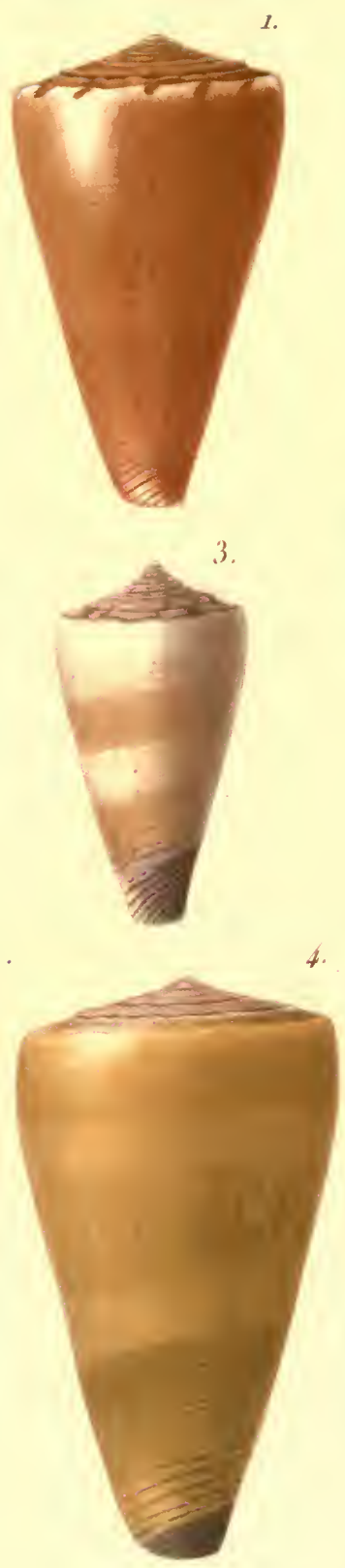

1. Cone carotte.

$a^{a}, b$ id id: var:

2. Conc panas

3 (ond flitri.

+ Cone blondin.
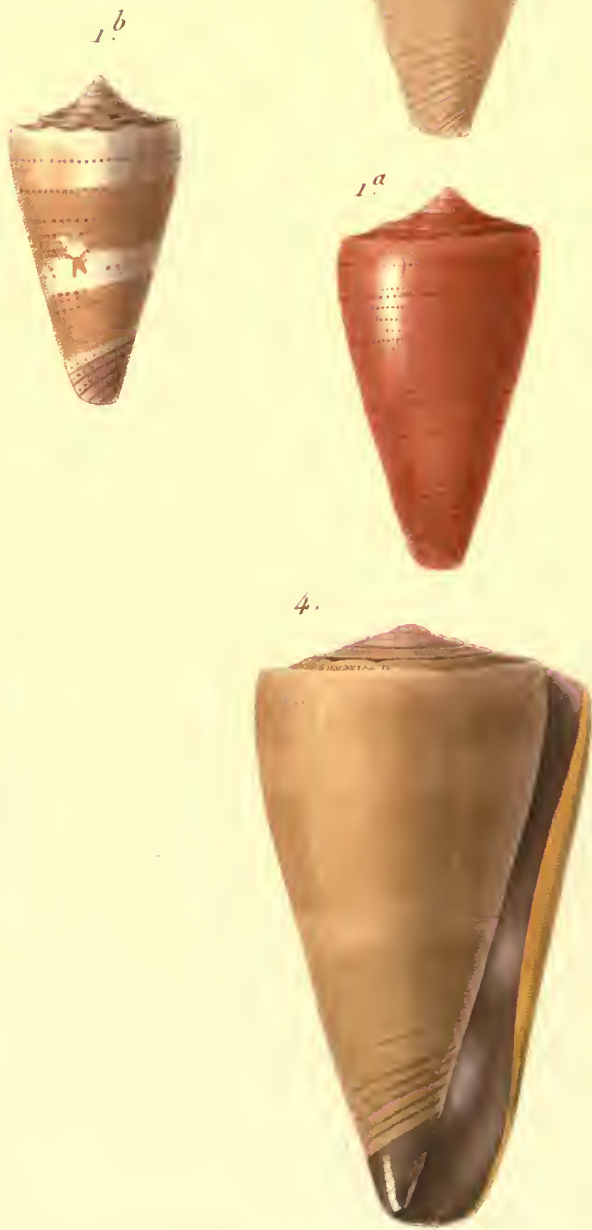

(Comes daucus. Brug.)

( id: id: varles )

(Comes paslinaca lam.)

(bonus sugillatur. Rceves)

(Comener flaveitus. Lame.) 
THE LIBRARY

OF THE

USYYEREITY OF ILLWHOS 
1.

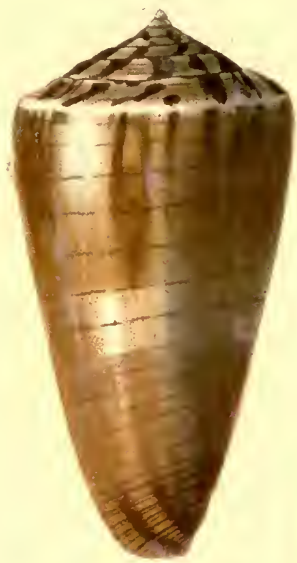

2.

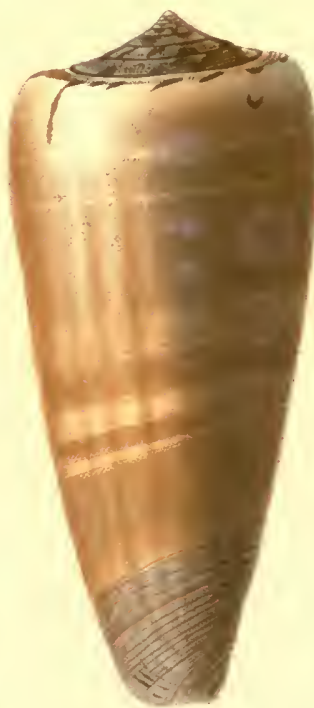

$2^{a}$

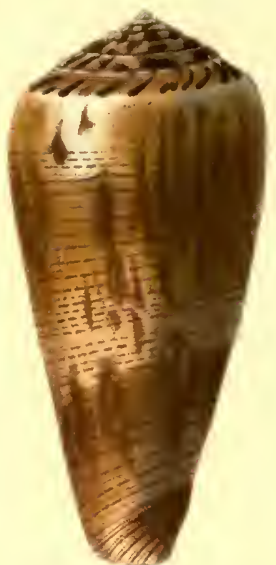

3.

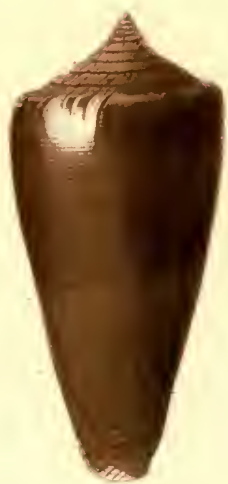

1. Cone sénateur.

1. id: id: var.

2. Cône caréné.

$2^{a}$ id: id: var:

3. Cone ligné
(Cones senator. Lin. )

(id: id: nar: )

(Conus carinalas. Smains.)

( id: id: var: )

(Conus lignarius. Reeve) 
THE LIBRARY OF THE

IYIYEPSITY of IHLingus 


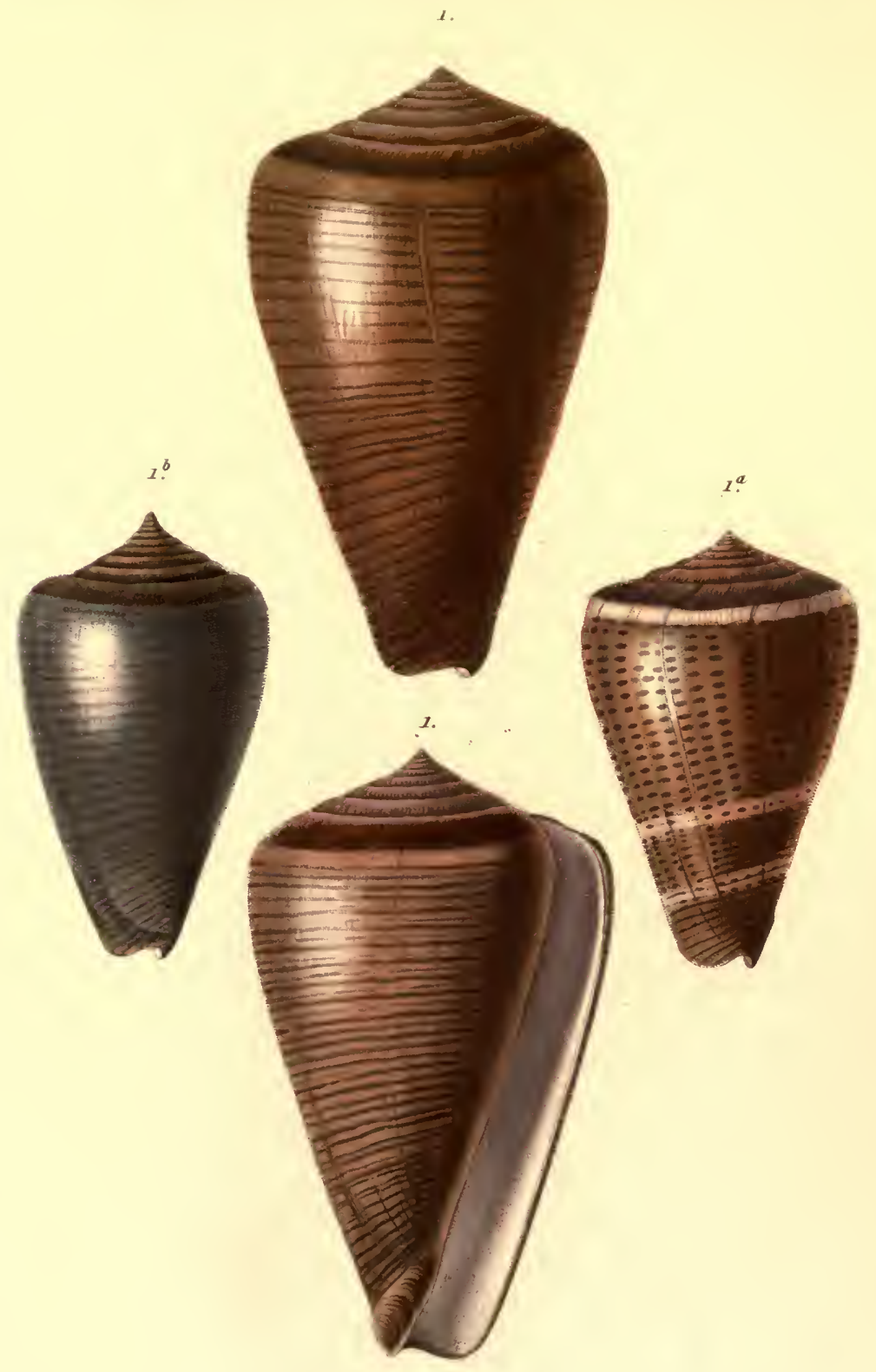

1. Cóne minime.

1. $1^{b}$ id id vartés
(Conus figutinus. Lin.)

I id id vartes I 
THE LIBRARY

OF THE

HมแY 

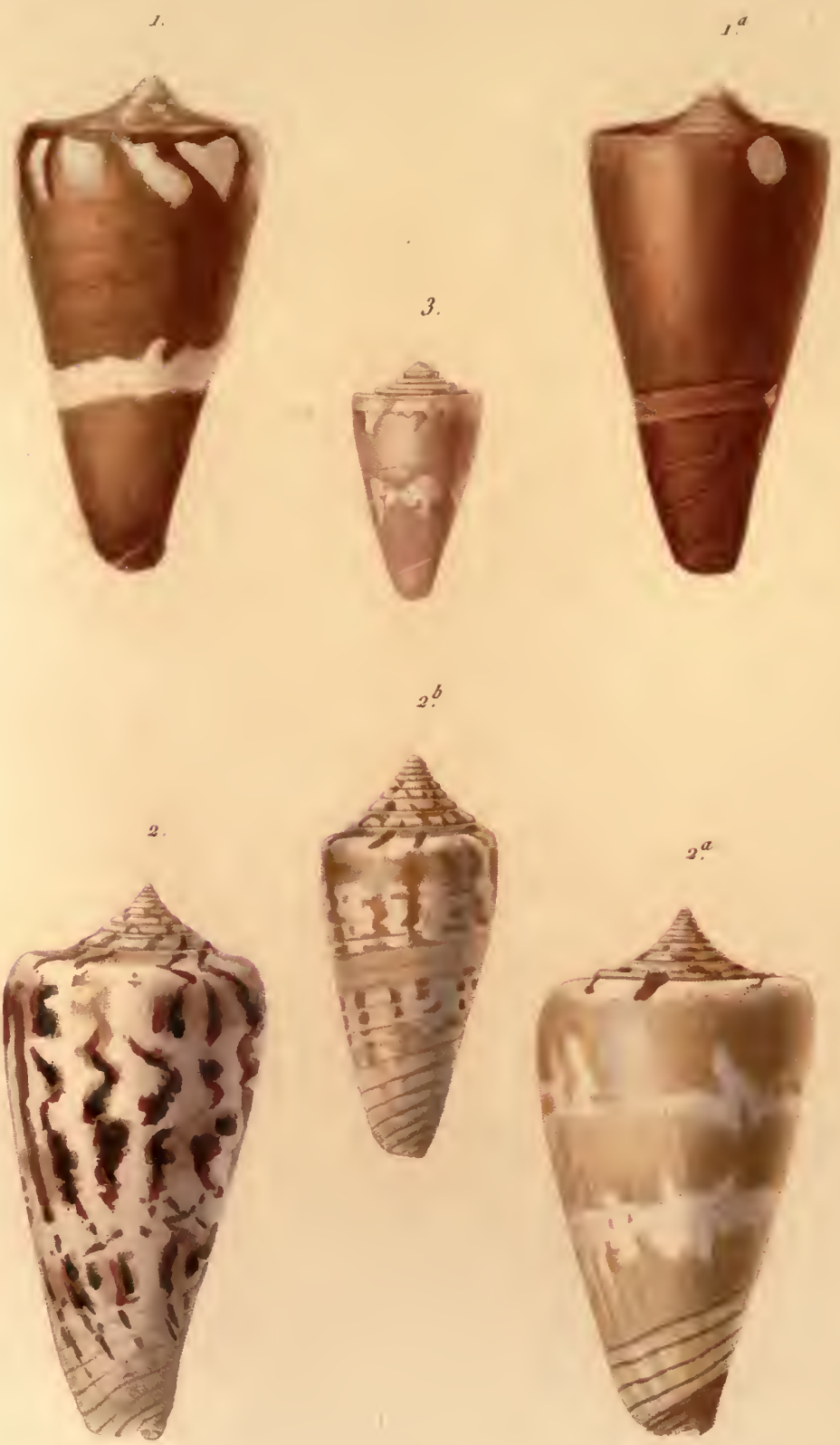

1. Cône ritourneau.

$i^{\text {a }}$ dd: id var

2. Cone janus

$2^{\mathrm{a}} 2^{\mathrm{b}}$ id: id: var.

5. Cone magellanique.
(Conus lithoglyphus. Brug:)

id: id: our: ,

(Comus junus. Brug:)

Id: il nar: )

(Comes magellanimus Brugy.) 


\section{THE LIBTARY}

Of THE

suiverser or losimas 


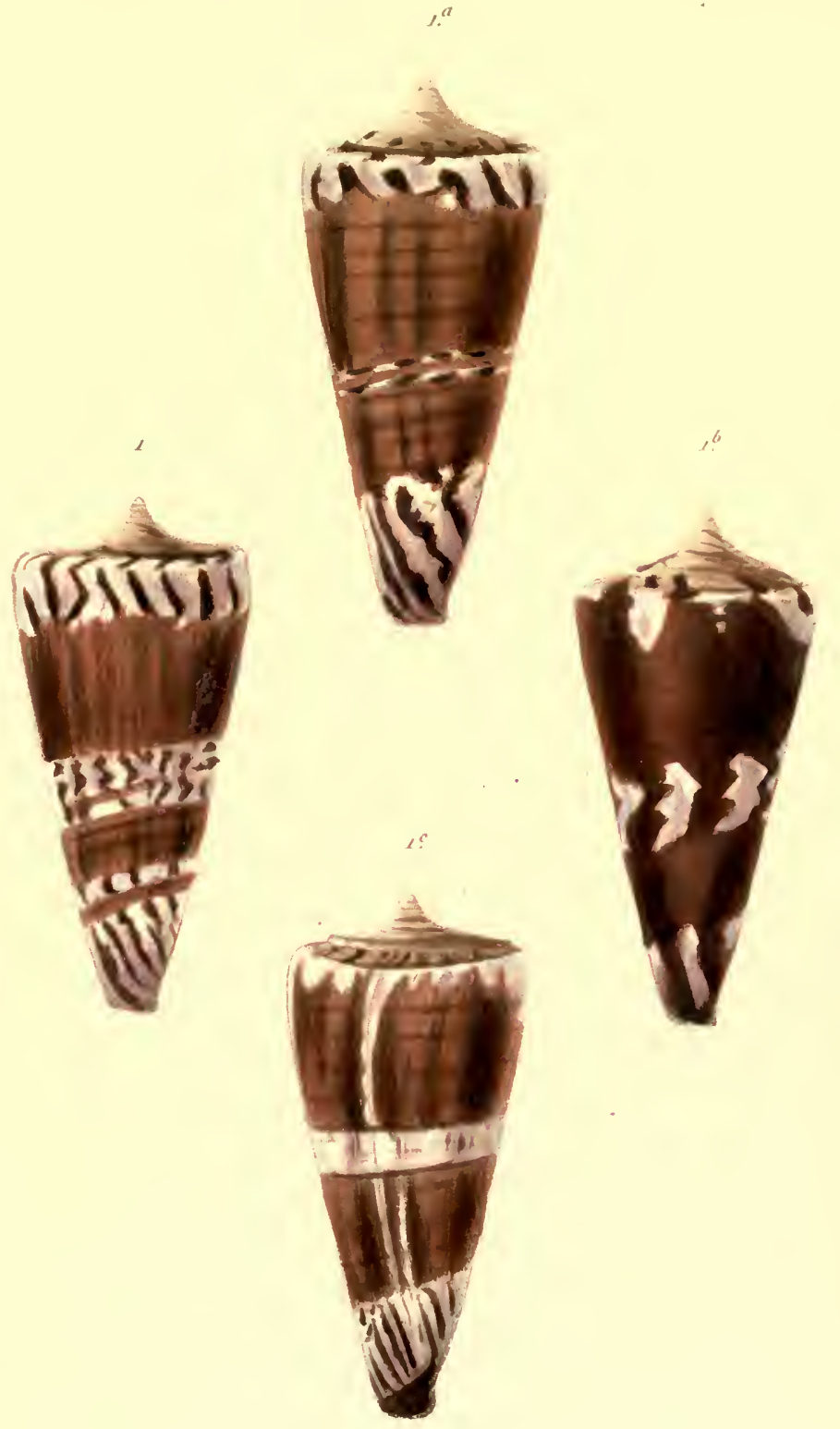

\footnotetext{
1. Cone flambovant

(Conus generalis hin.)

a a s cone id: var

I id: id: ent: ,
} 


\section{THE LIBPARY}

OF THE

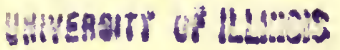



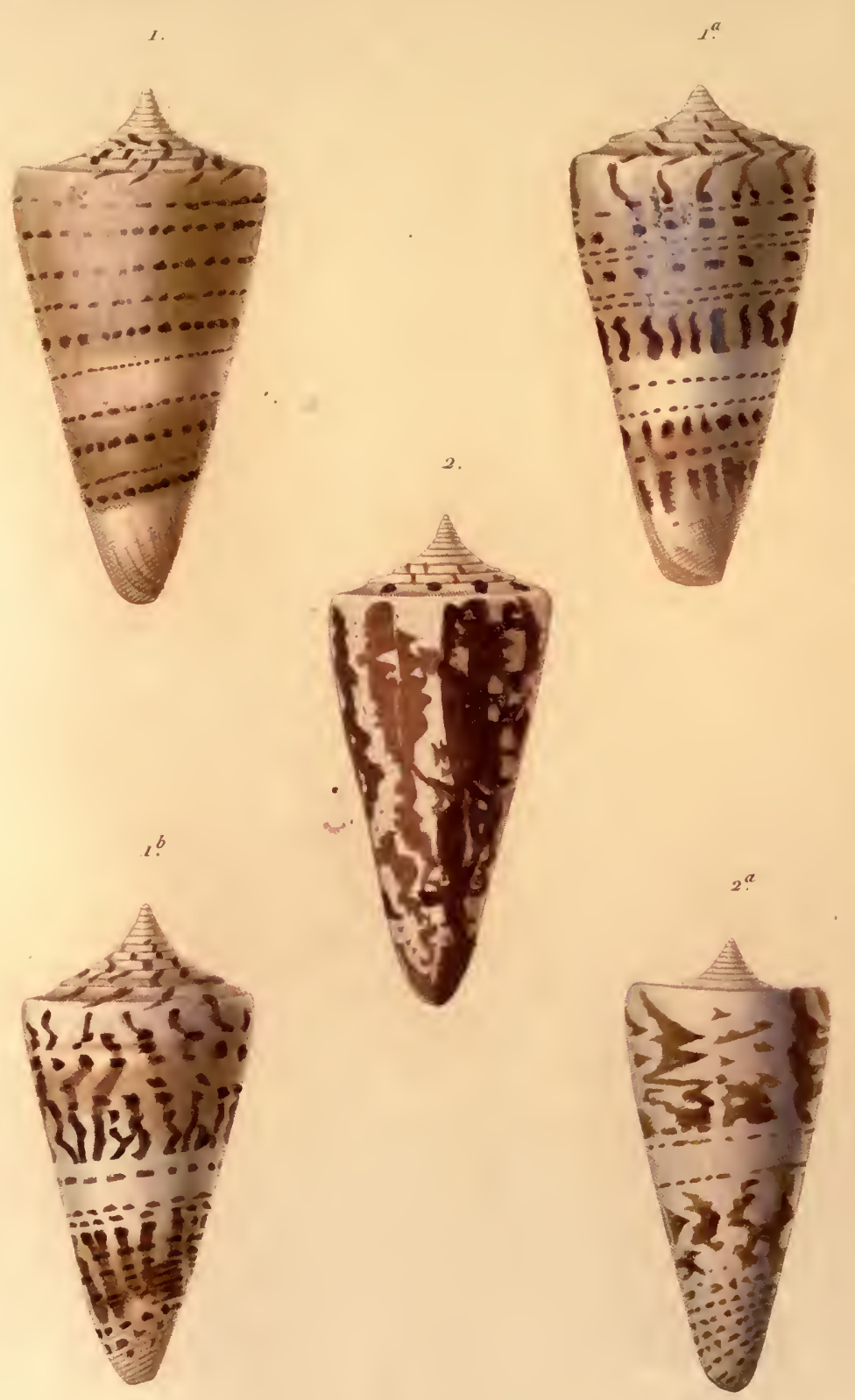

1 Conc faisan.

(Comus monile Brug)

1. $1^{b}$ id: id: var:

( id: id: var: ,

2.2. Cone flamboyant var:

(Conus generalis var:) 
THE LIBRARY

OF THE

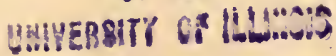




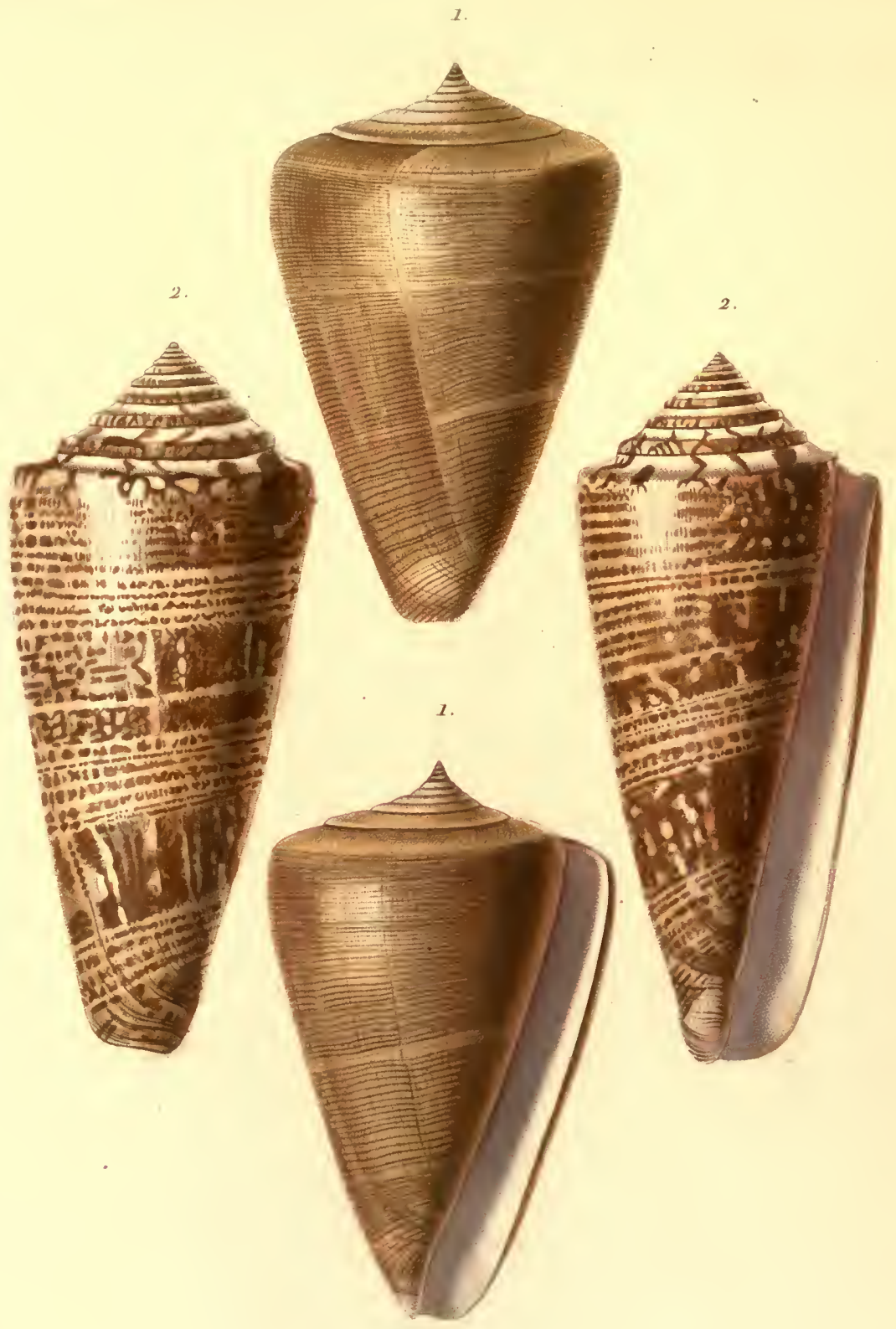
1. Cône linéé .
( Conus quercinus. Brug.)
2. Cone d'Oma
(Conus Omaicus. Brug.) 
IHE LIBGABY

OF IHE

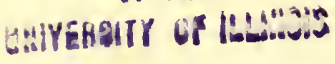


Cồr (Conus.)

Pl. 33.

2.
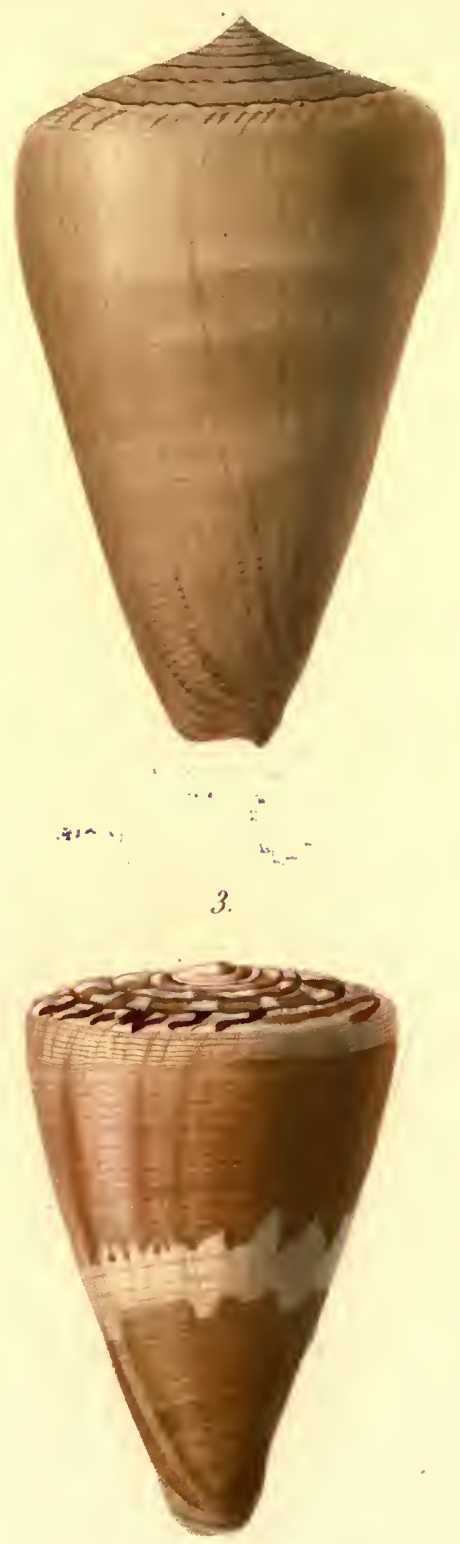

1.
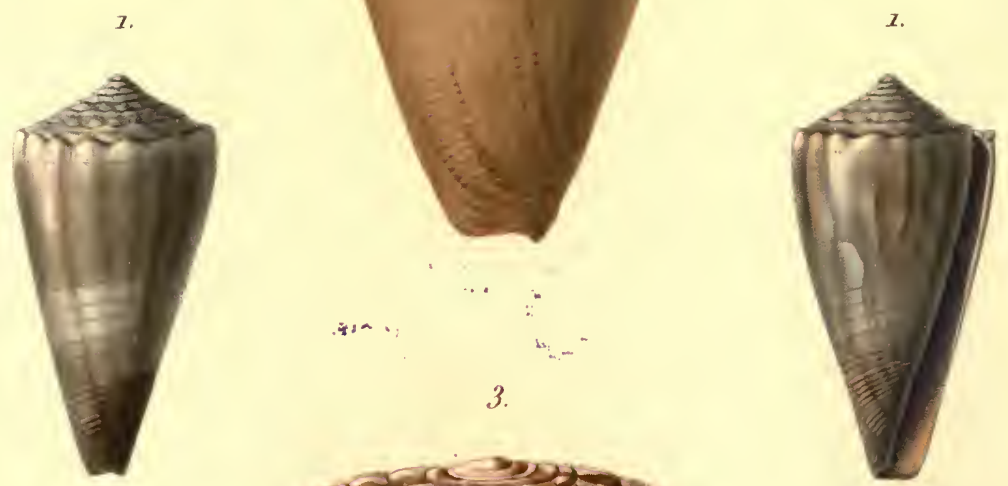

1. Cône allongé.

2 Cône linée var:

3. Cône acajou.
(Conus clongatus Reeve)

(Conus quercinus vary)

(Conus badius. nobis.) 
THE LIBRARY

OF THE

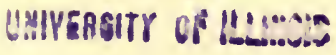


CONF. (Conus)

P1.34.

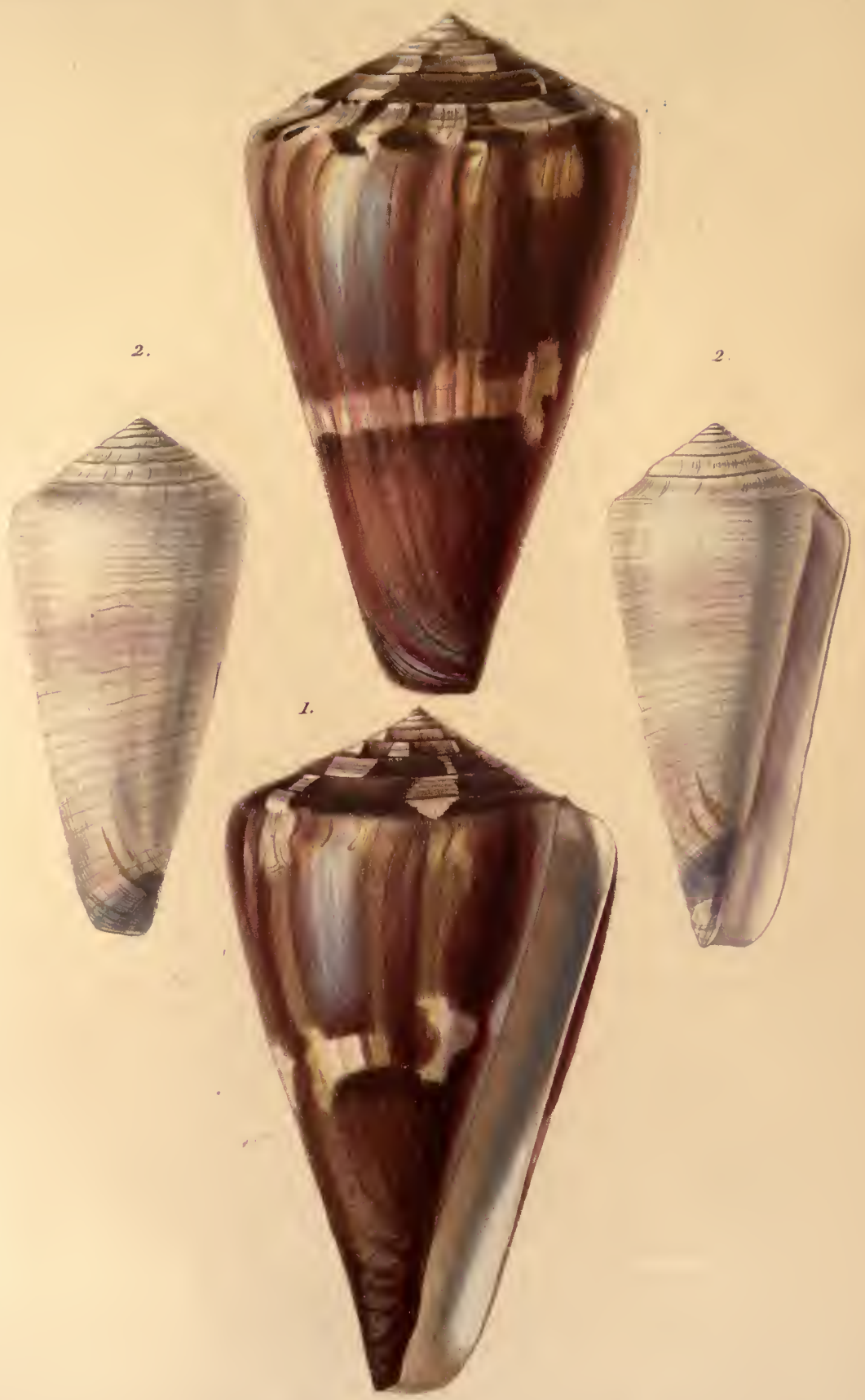

1. Cone aumusse

2. Cône tarrière.
(Conus vaxillum. Brug.)

(Conus lercbra. Brug.) 
mand 

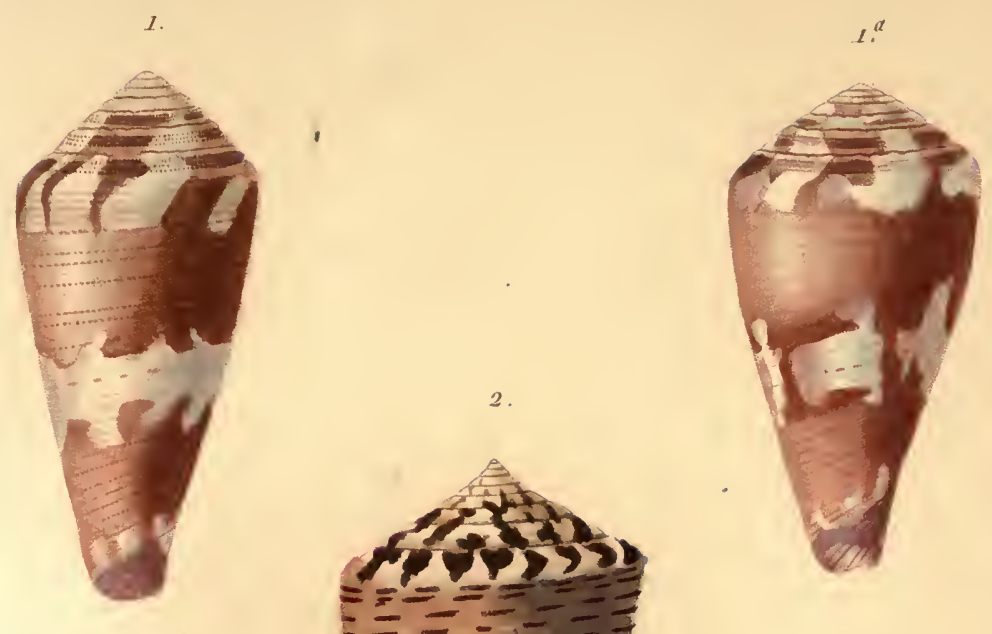

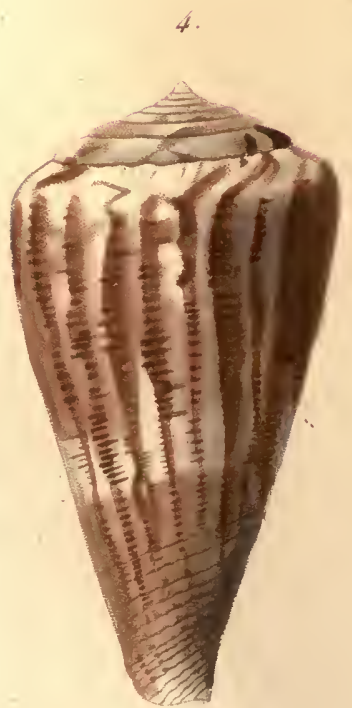

1. Cône piqueté

$1^{\text {a }}$ id : id : val:

2. Cone splendide

3. Cone bois-de-freme

t. Cone Hyene.
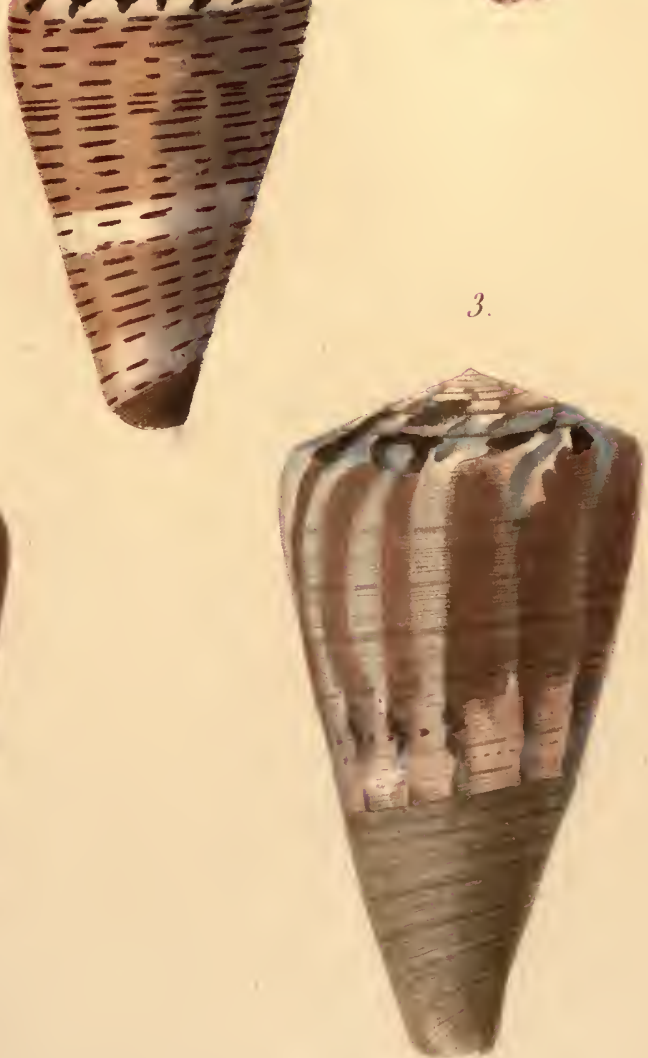

fConue perlusus. Breg.

|comus amabilis. Lam.|

Conus splendidulus. Sow.)

(onnus nemocatnus. Brug.)

(onus Hyarna. Brug.) 
THE LIBRARY

OF THE

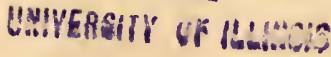


1.

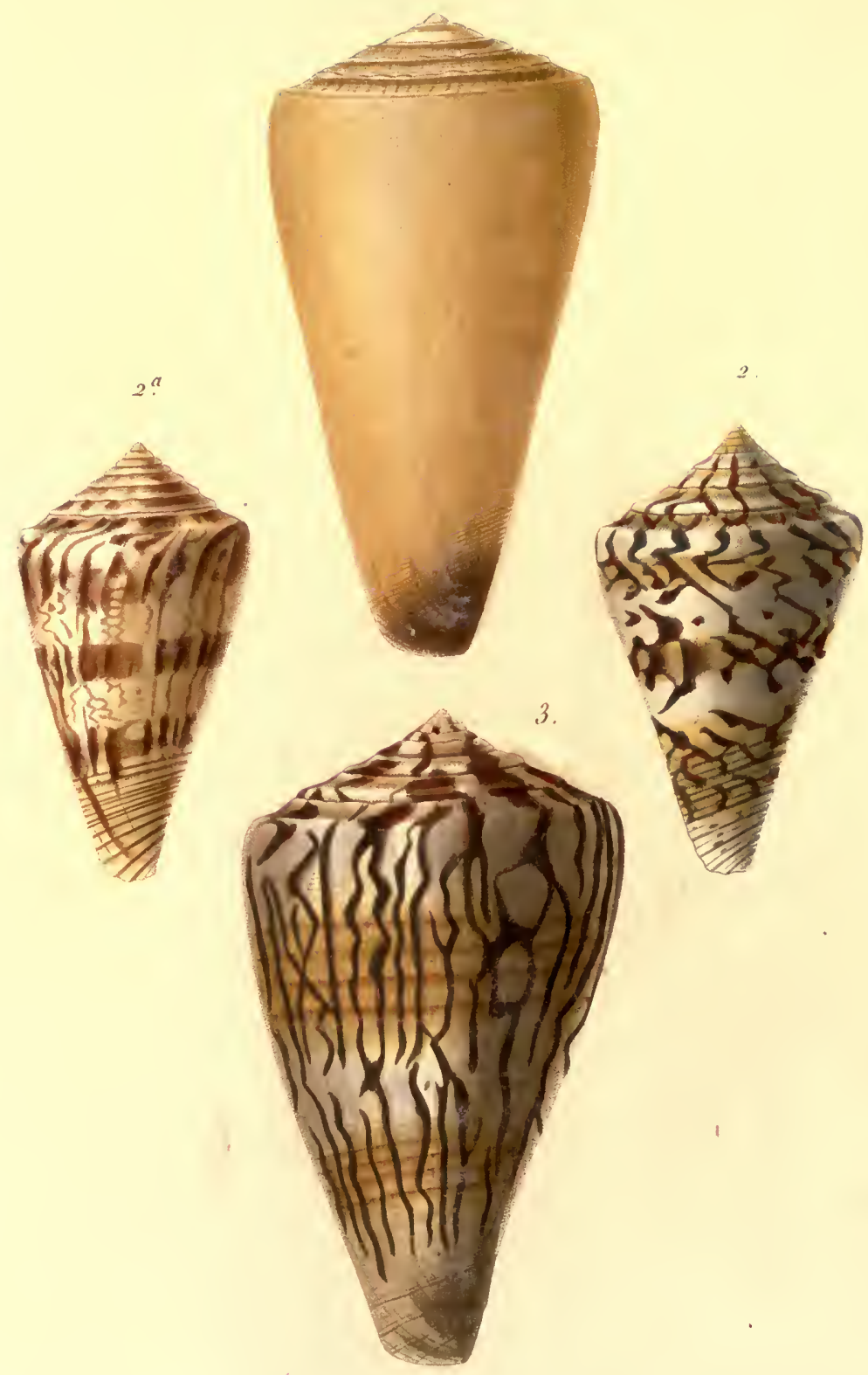
1. Cône cierge
(Conus virgo. Lin.)
2 Cone centurion.
(Conus centurio. Born.)
$2^{\text {a }}$ id: id: var:
(id: id: var: )
3. Cône loup. (Conus sumalrensis Brug.) 
THE LIBSARY

OF THE

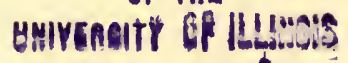



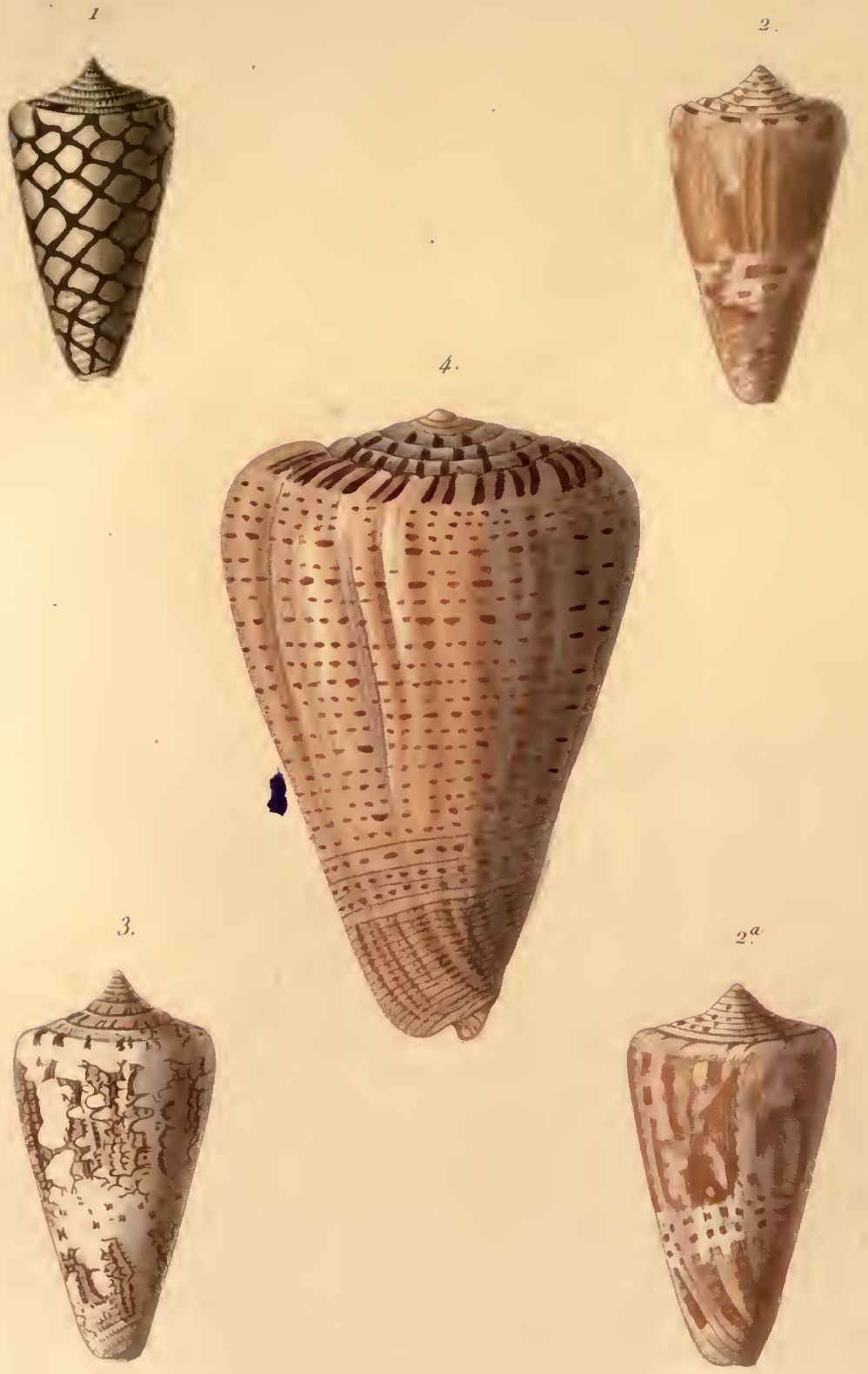

1. Cônc maseruis

2. Cone ocracé

2. id: id: vas:

5. Cone licutenant.

4. Cone de Surate.
Goness mardionntles. Hinds.

Cimses ocheresess. Tam,

it: it var: ,

lemes micarius. Tiam )

/ Conus suracelustas. Brug । 
THE LIGRARY

OF THE

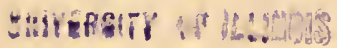



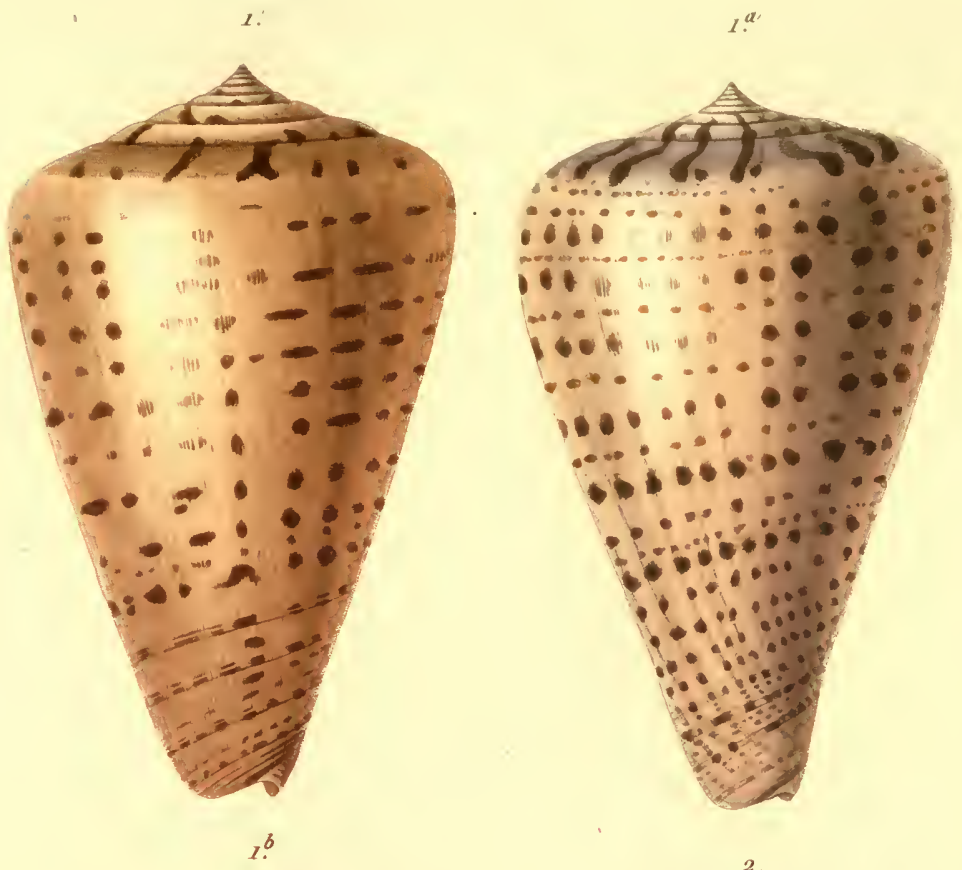

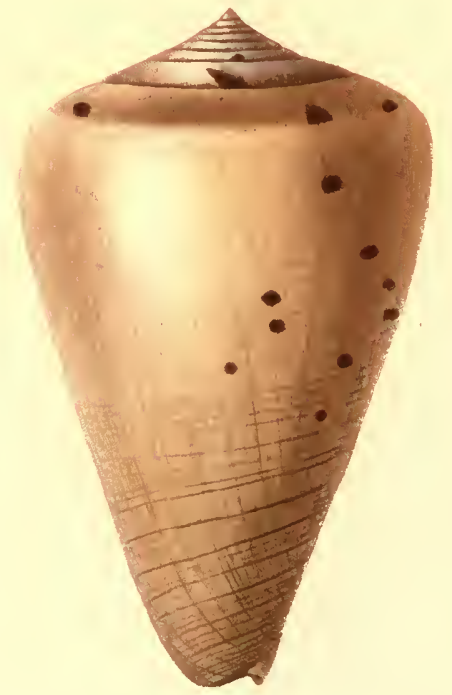

1. Cône tine.

1. , id. id. var.

2. Cône navet.

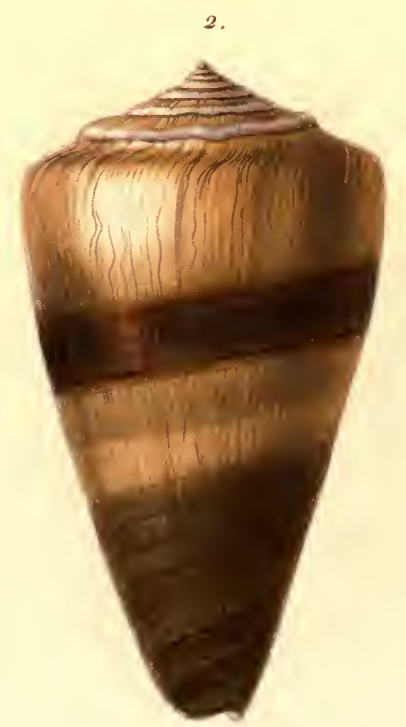

(Conus betulinus. Lins)

I id. id. var. I

tonus miles. Lint 


\section{THE LIBTARY}

OF THE

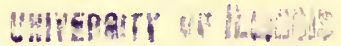



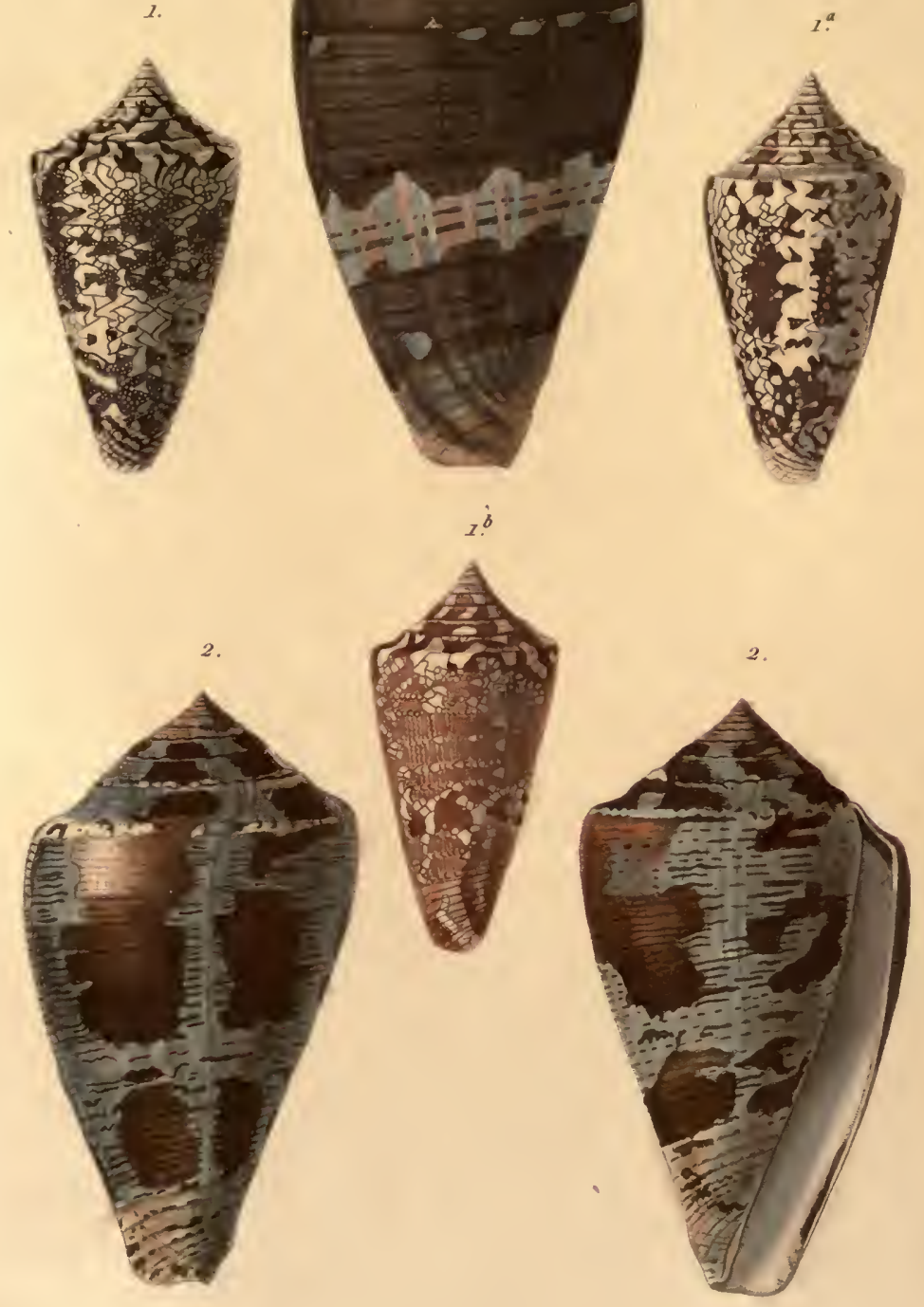

1. Cone de Rumphius.

a. 1 id: id: vartés

2. Cone pourpré.

J. Cone rovaute.
(Cones acuminalus Brug.)

(id: id: varktes )

(Conus purpurascens Brod)

(Conus resalitulis. Sum.) 


\section{THE LISRARY}

\section{OF THE}

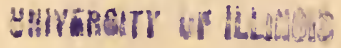




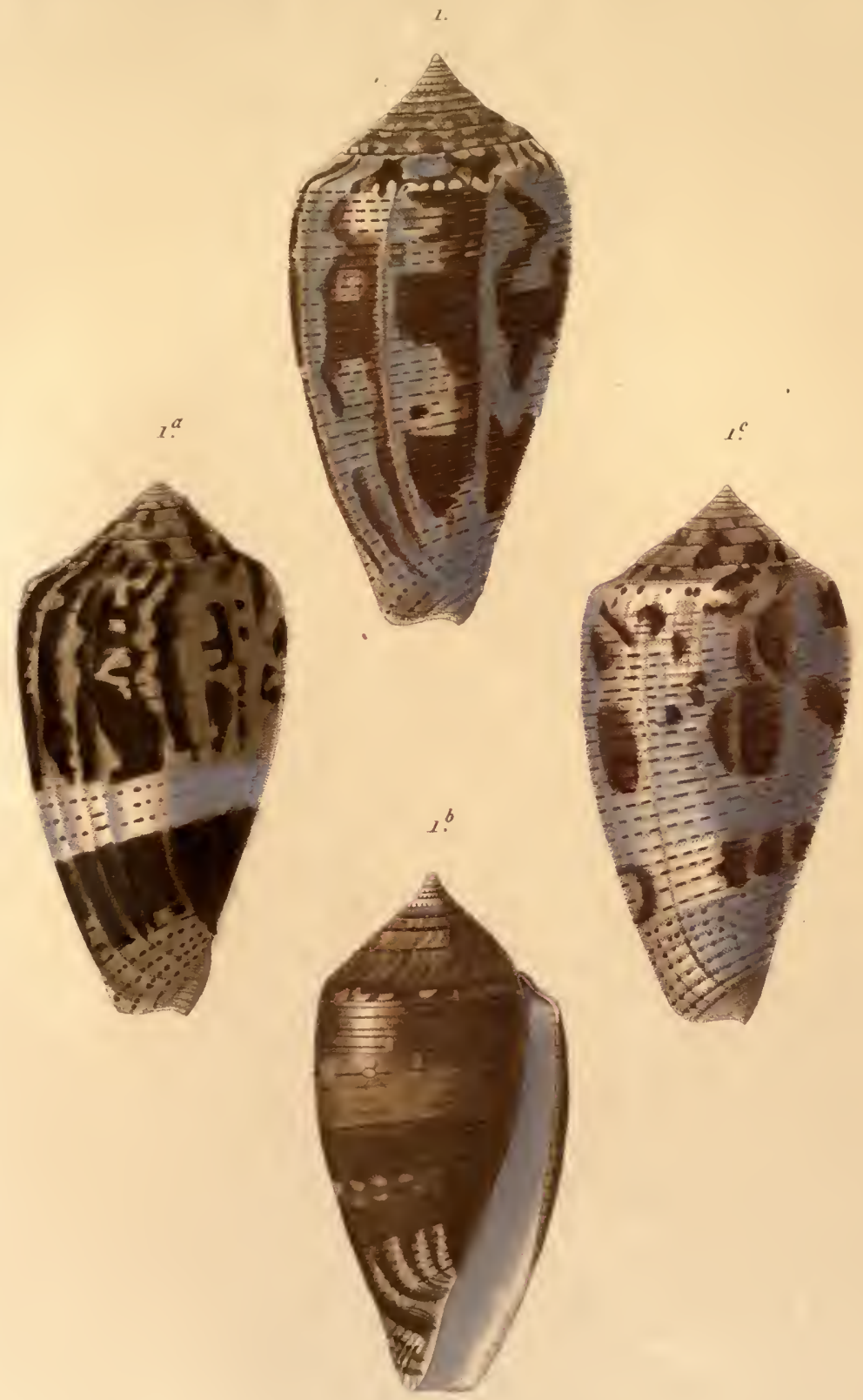
1. Cone agathe
1. $1^{b}$ id: id: vale és
(Coness achaliness. Bregg.)
1. id: id: vartés
( id: idt: matles )
(idt: id: var. )
Cones ranuencules. Brueg.

Publié par J B Baillière et fils, Paris 


\section{PHE LIBRARY}

$$
\text { OF THE }
$$

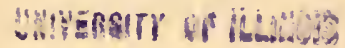




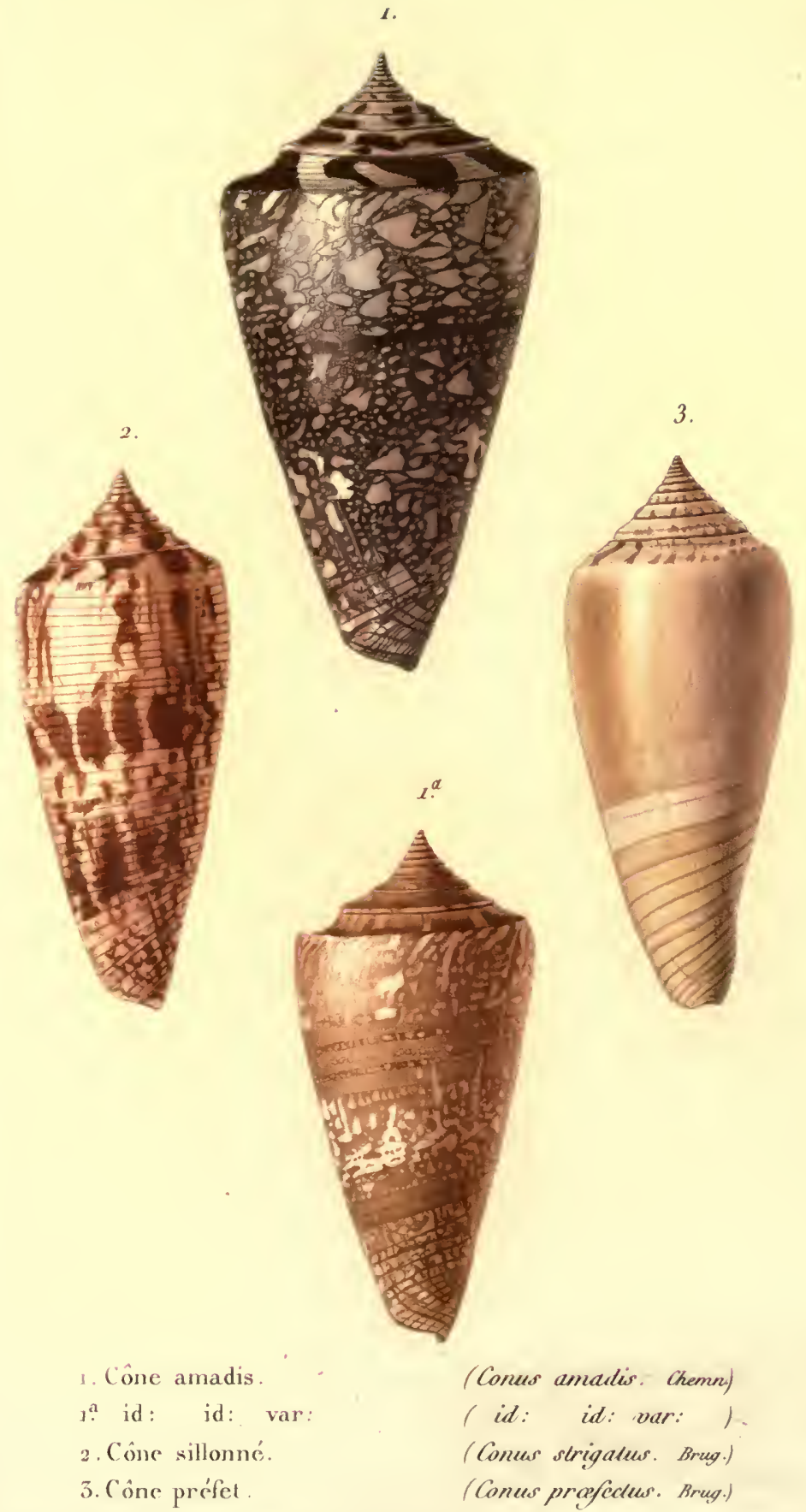


THE LIBRARY

of the

sumbert of 

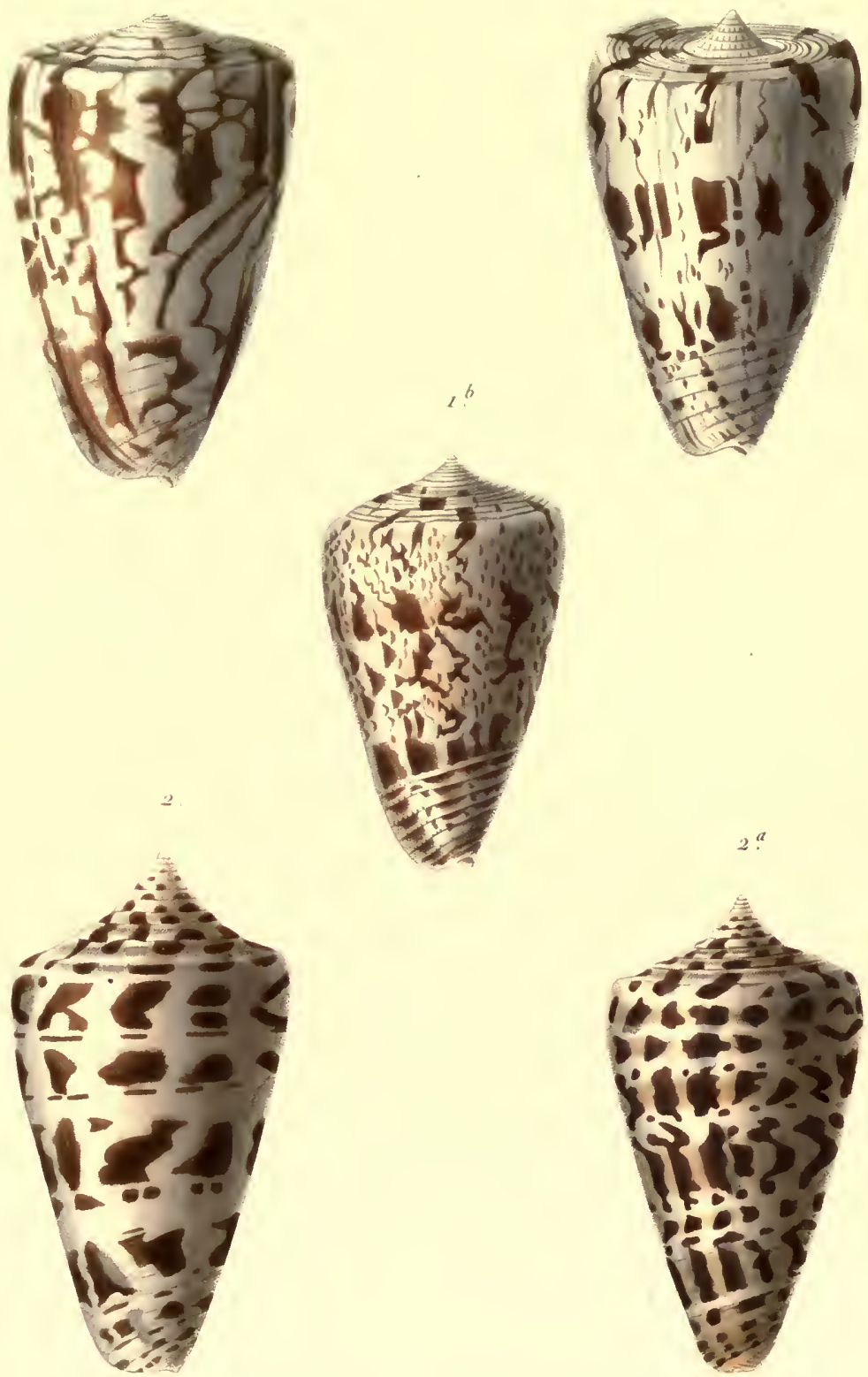

: Cone caractéristique
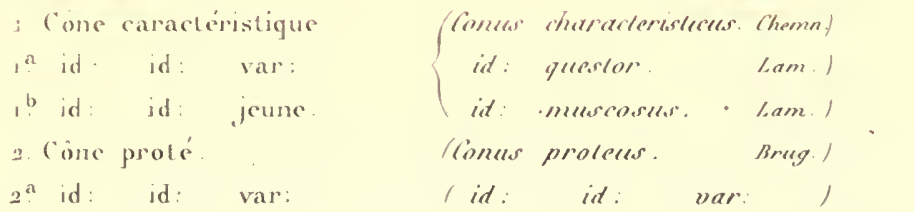


\section{IHE LIBRARY}

of THE

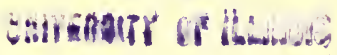



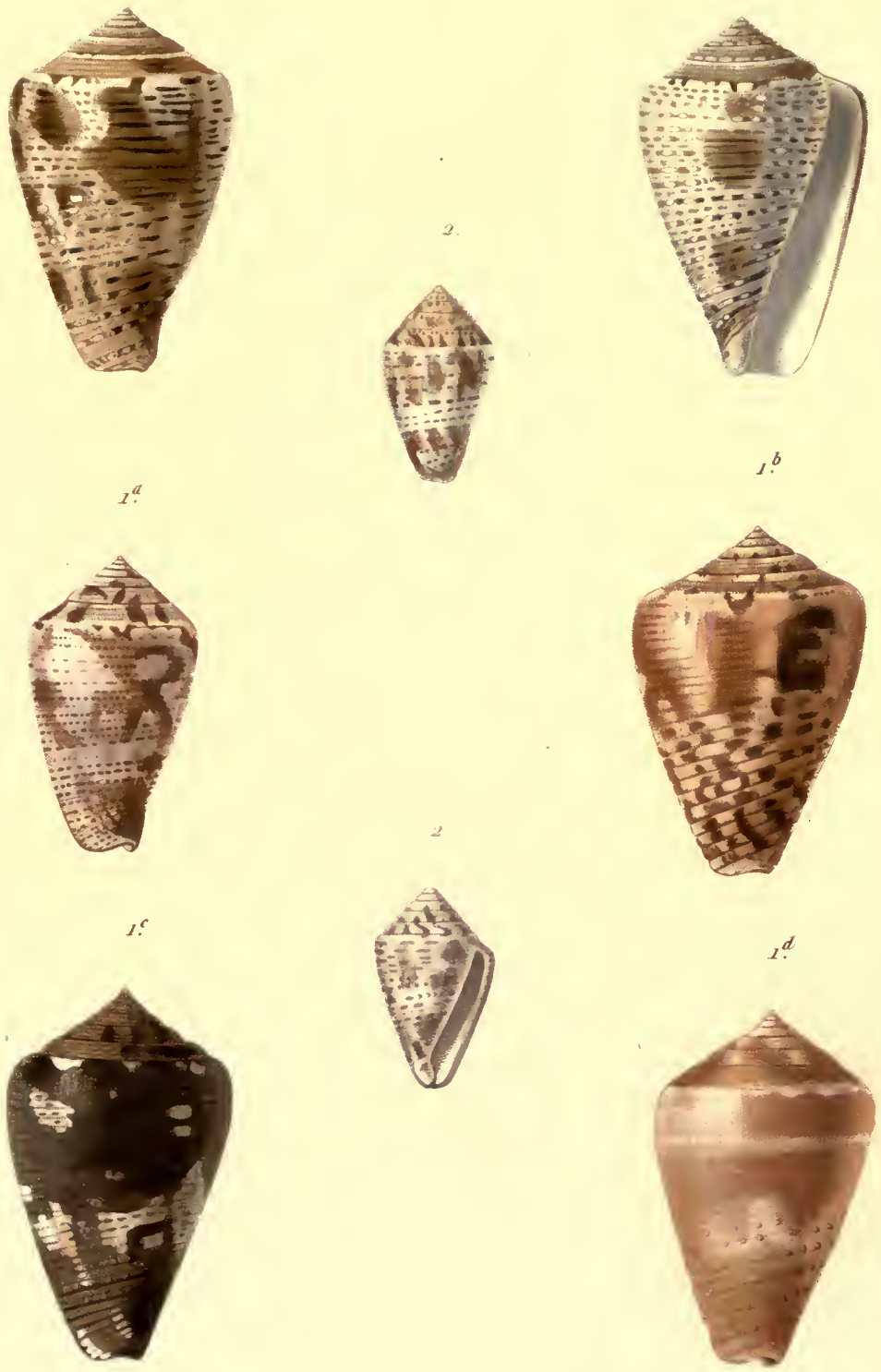

1 Conse chat.

(Conus cales. Brug.)

in a id: id: var: ( id: id: var:)

2 Cone main. (Conus pusillus chemn) 
THE LIBRARY

OF THE

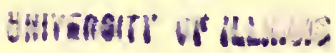


I.
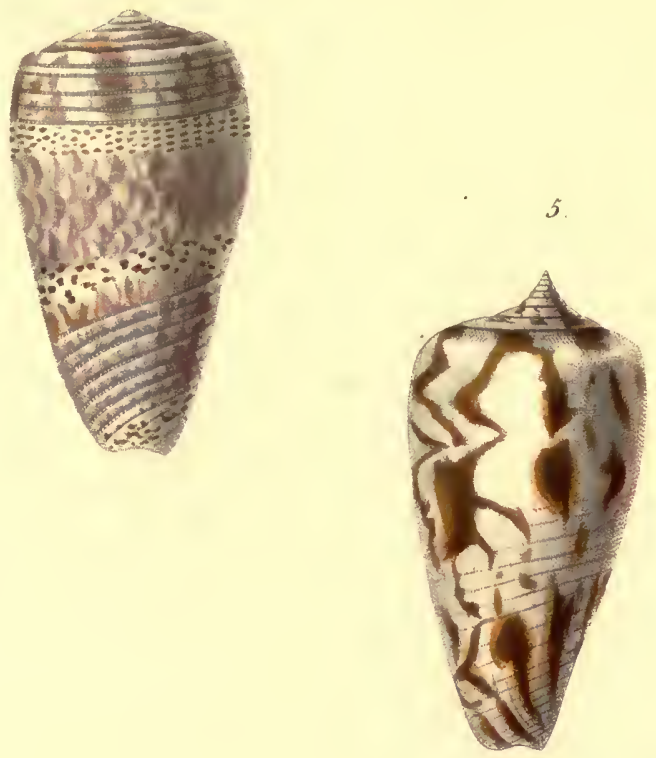

$5^{a}$

3.

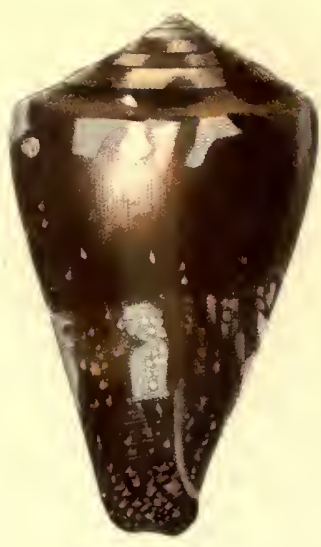

1. Cônc d'Adamson.

2. Cône de Reeve.

3. Cône rat.

4. Cône pyriforme.

5. Cône spectre

5. id: id: jeune.
2.

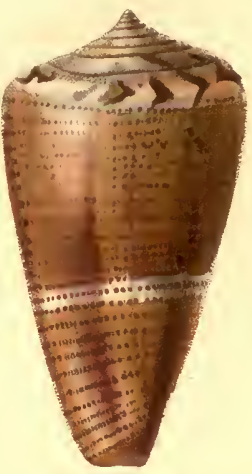

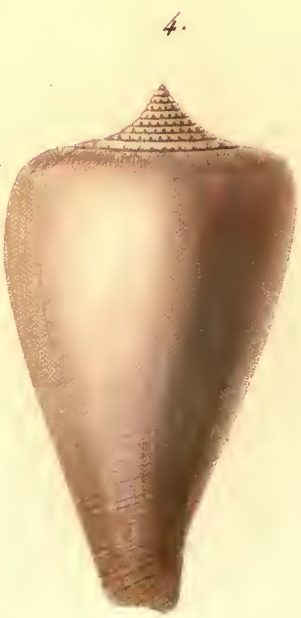

(Conus Adamsoni Brod.)

(Conus Reevei. nobis.)

(Conus ralkes. Brug.)

(Conus pyriformis. Reve)

(Conus spectrum. Tin.)

(id: id: junior.) 


\section{THE LIBRARY}

OF THE

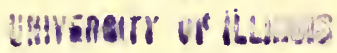




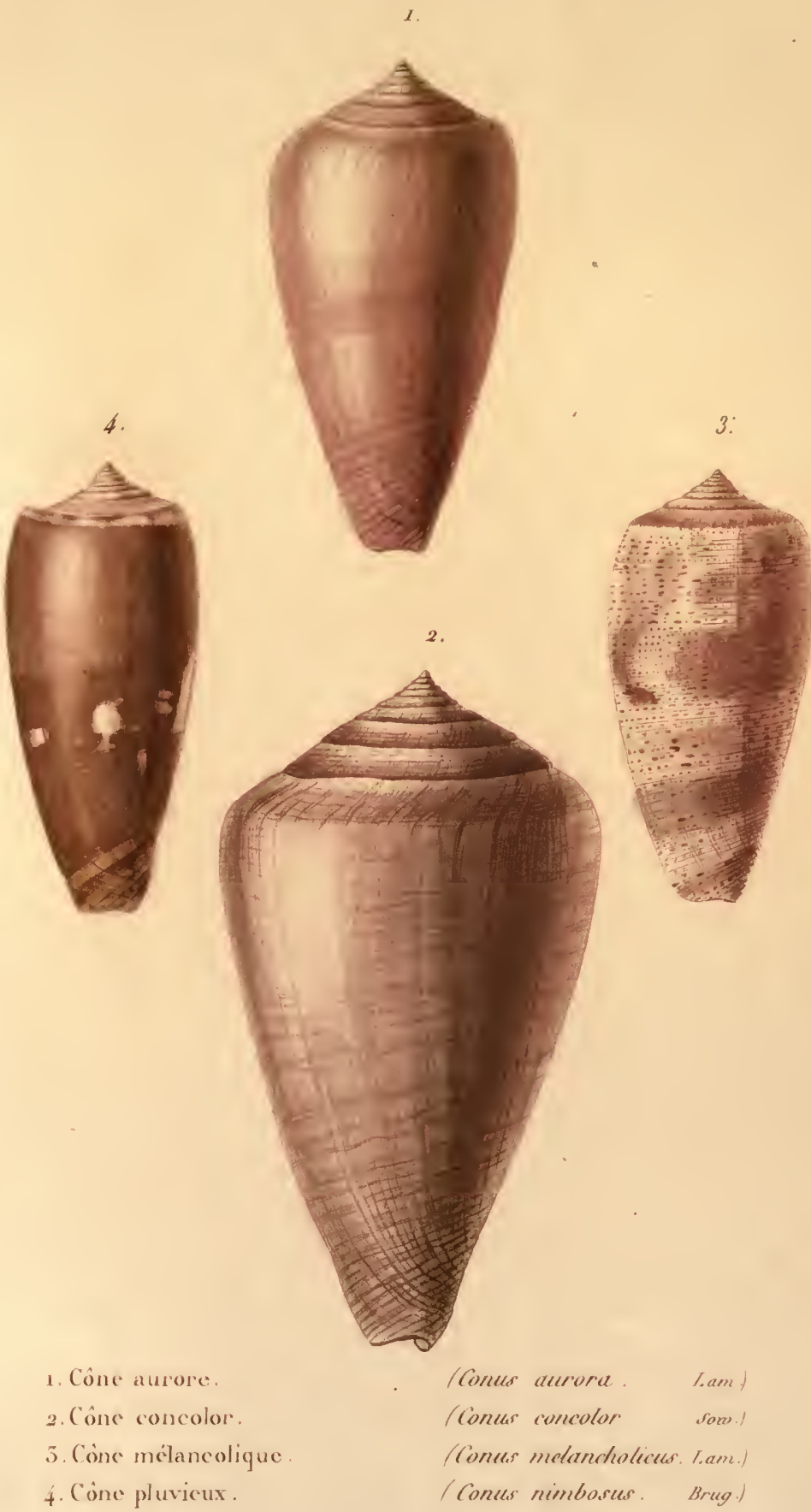




\section{THE LIBRARY}

of THE

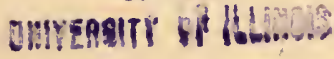



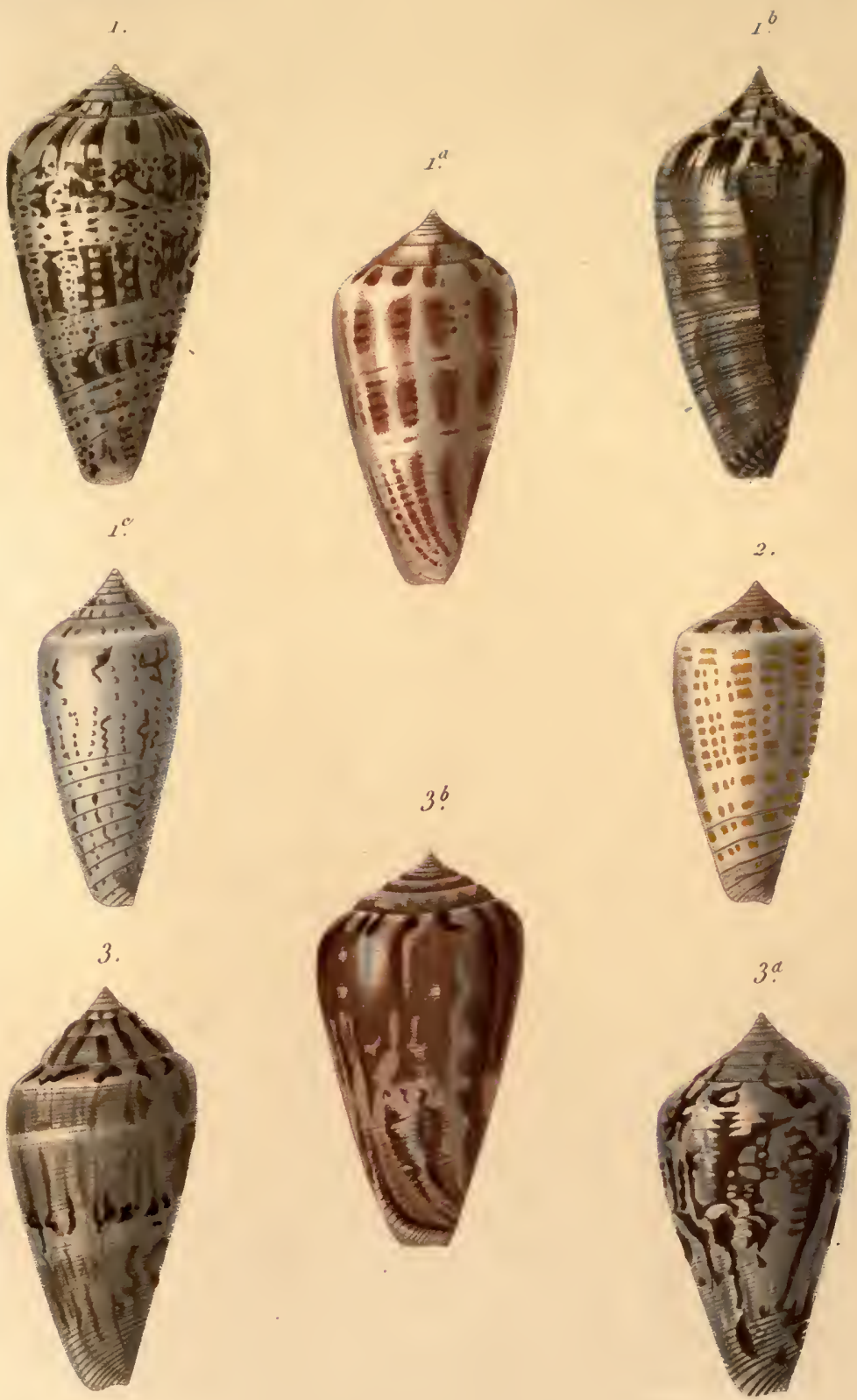

1. Cone taupin.

a. a 1 c id: id vartés

2. Cone paillet.

3. Cone anémone.

3a. $3^{\mathrm{b}}$ id: id: $\operatorname{var}^{\mathrm{t}} \mathrm{e}^{\mathrm{c}}$
(Conus cinercus Brug.)

(id : id: varles )

lioness stramineus Lam-

(Comus anemone. Lam.)

( id: id: varres , 


\section{THE LIBRARY \\ OF THE \\ onweratr or HL.....}


1.

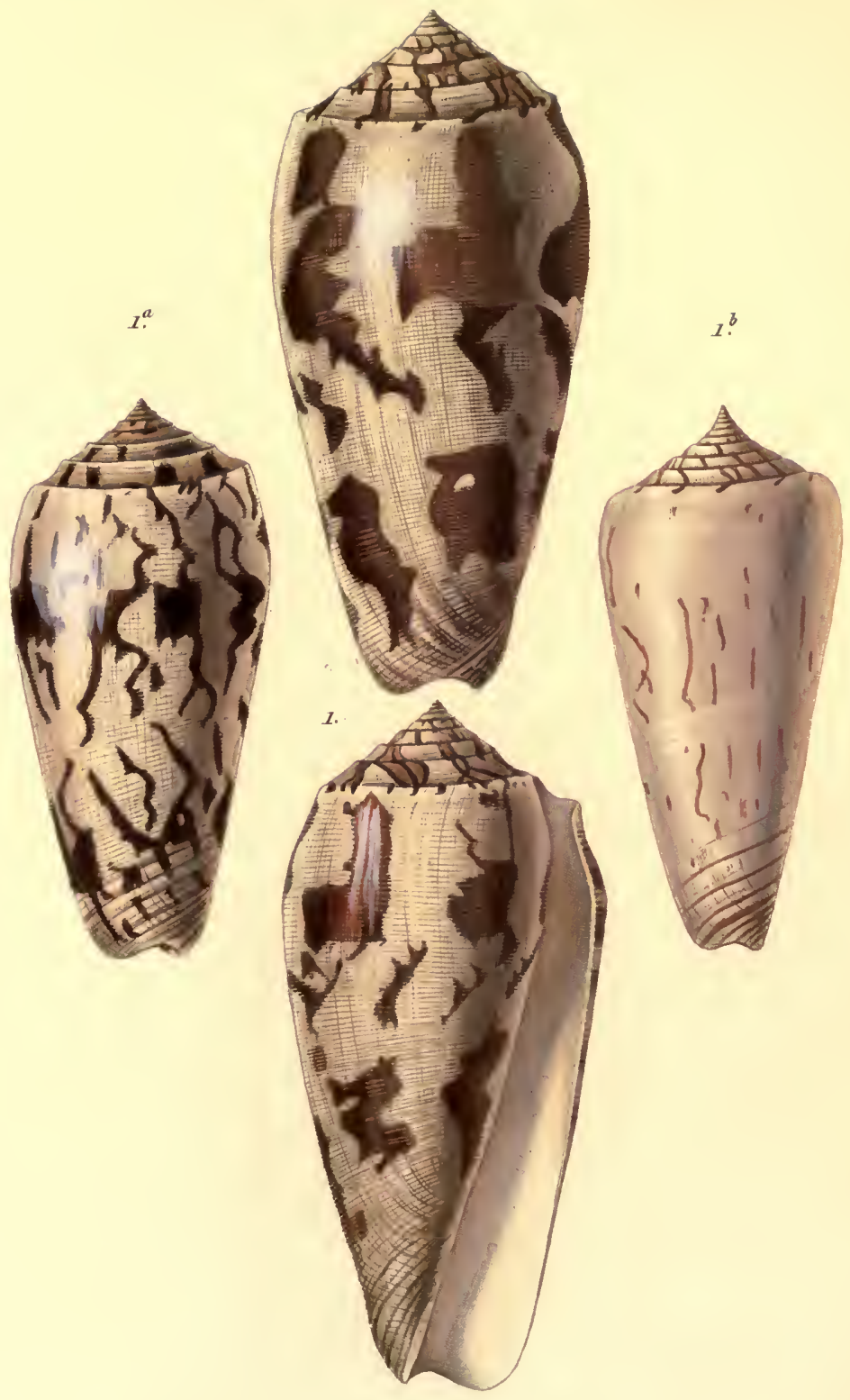

1. Cone strić.

1. 1 b id. id vartés
(Contes striatus. Lin.)

( id: id: vartes ) 
k

\section{THE LIBRABY}

OF THE

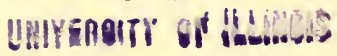



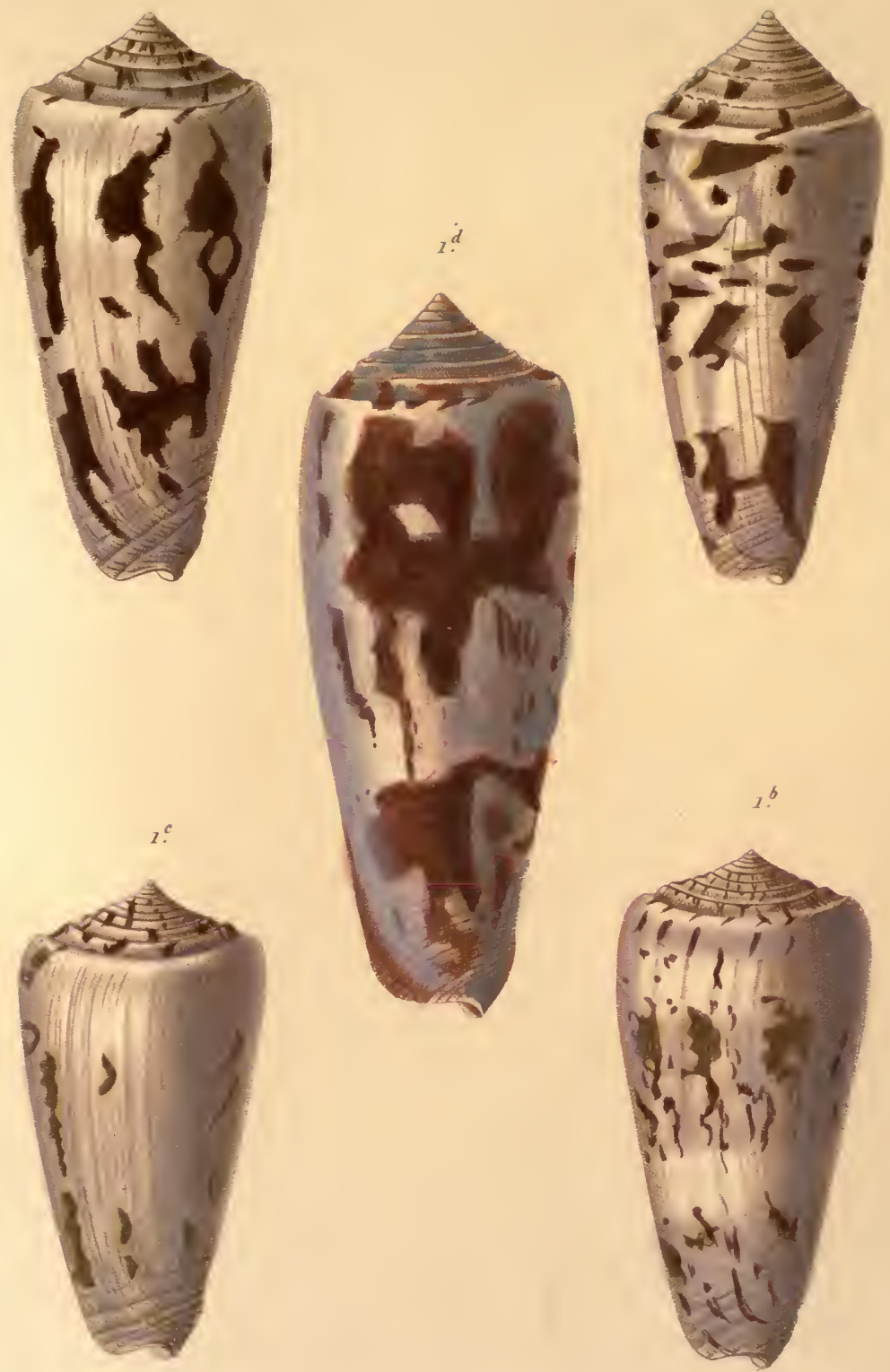

1. Cone gouverneur.

1. à 1 id: id: varlés

Comes qubernalor: Brug.

1. a 1. id: id: Tart

1. id: id: ras:

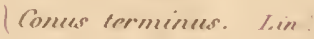


THE LIBRARY

OF THE

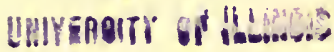



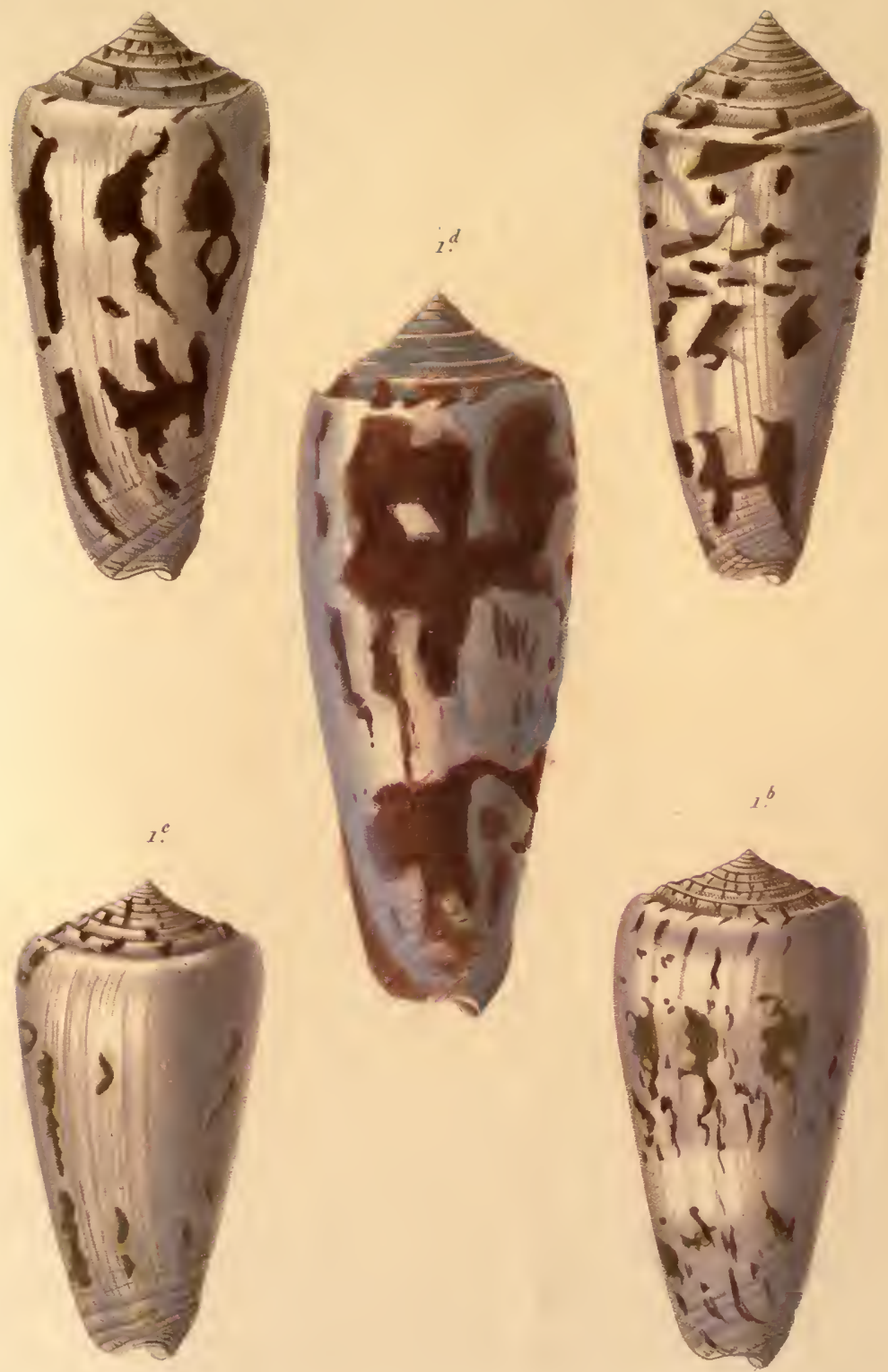

1. Cone gouverneur.

Comus gubernalor: Brug.

1. à 1 c id: id: vartés

(id: id: varles )

1. id: id: var:

id: id: var:

( Conear eermineser. Lin 


\section{IHE LIBRARY}

OF THE

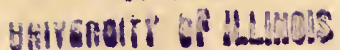



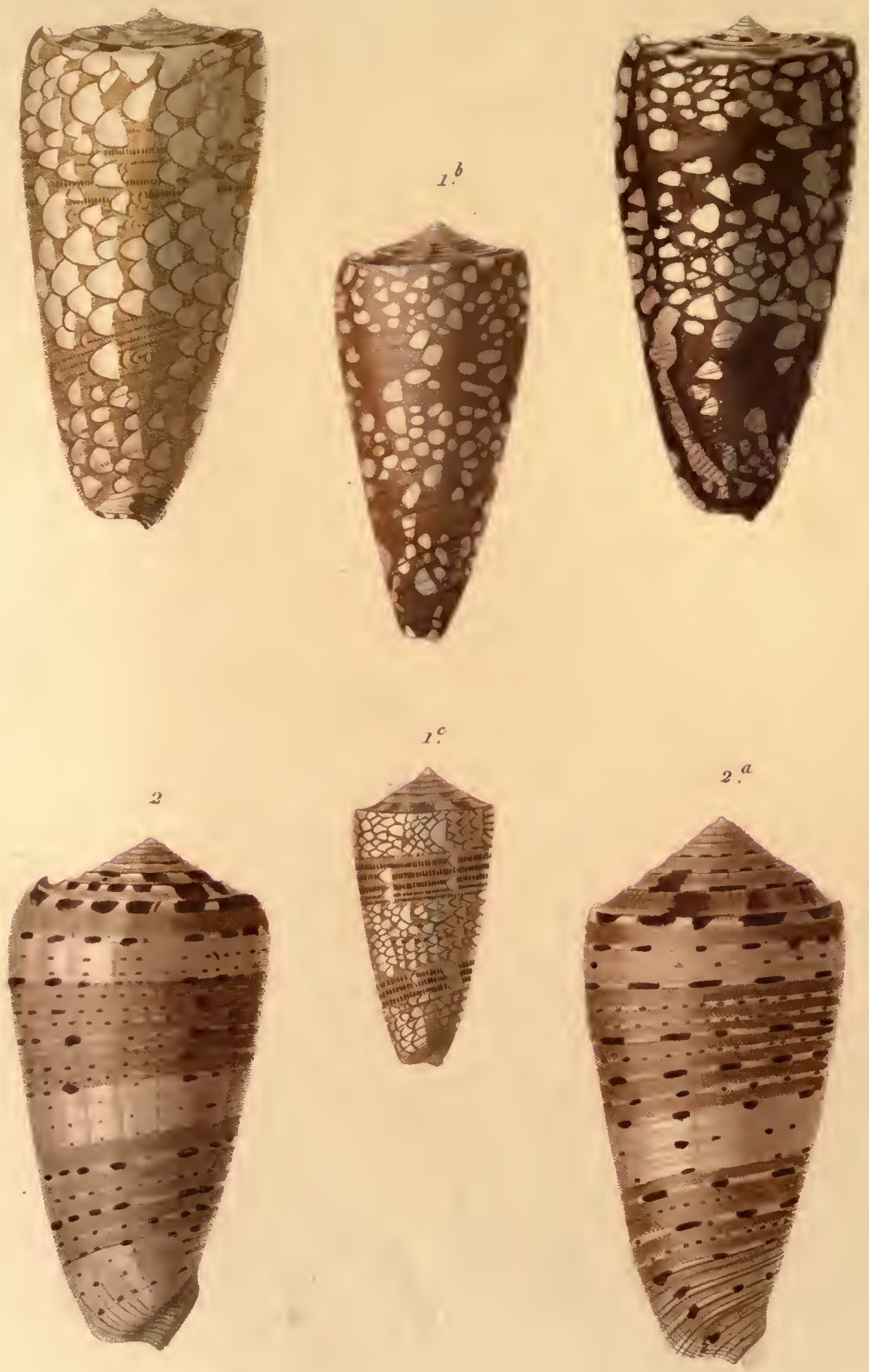

1. Còne noble.

a. à 1f id: id: vartés

2. Cone d'orange.

3. id: id: var:

(Comes nobilis. Lin.)

I id: idt: vartes I

(Counes aterisiacus. I.in.)

I id: idt: var: 
IHE LIBYARY

OF THE

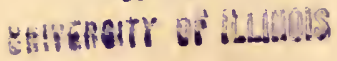



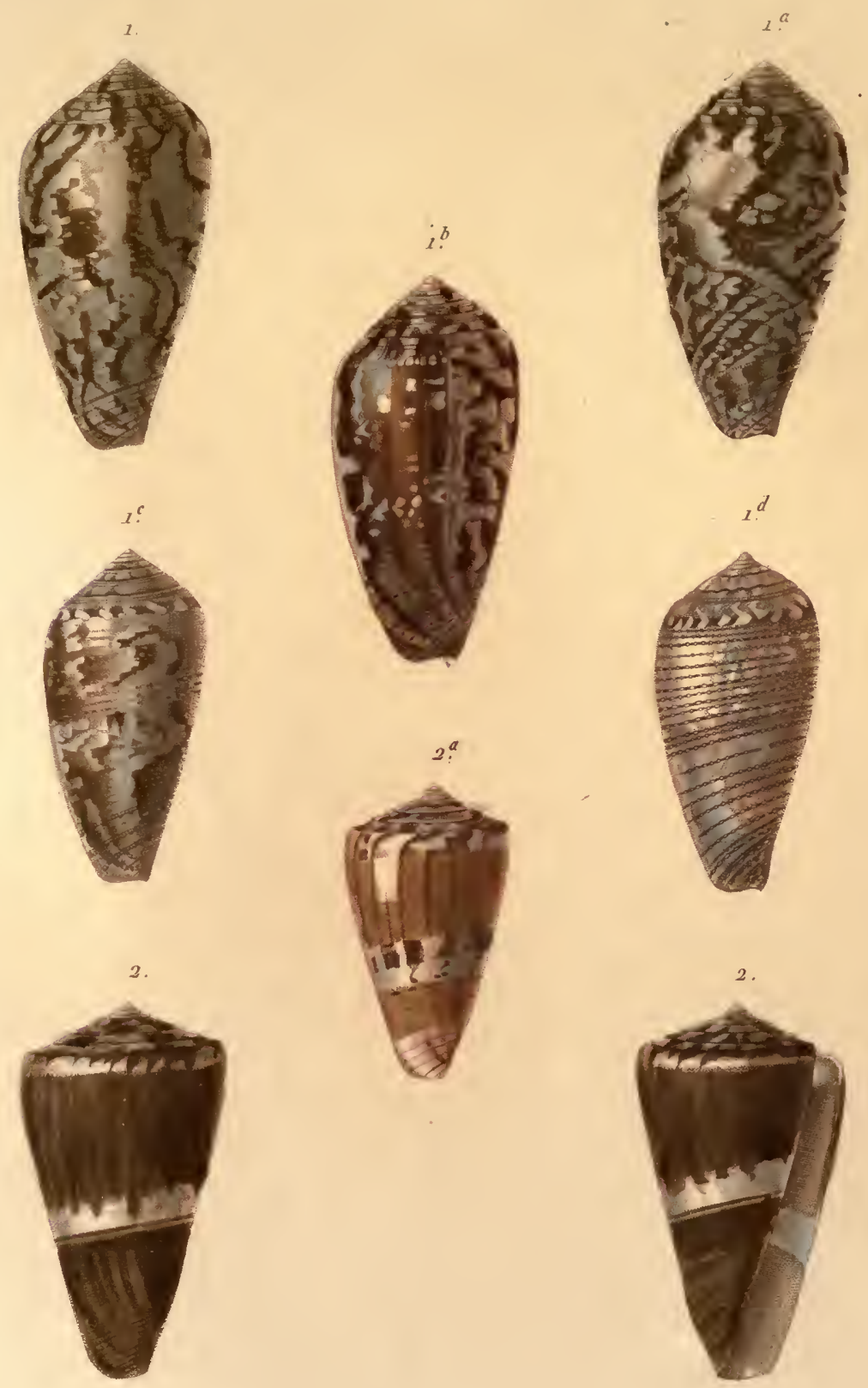

1. Cône moine.

(Conus monachees. Lin.)

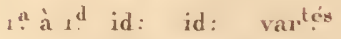

( idt: id: vartes ,

3. Cone cordelier:

/Conter fiunnigatus: Brught

2a id: id: var: , id: id: var:, ,

Naubeser puist . Publie par J.B.Bailhère et fils Parie

Piroel on. 


\section{IHE LIBRAAY \\ OF THE

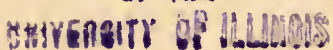



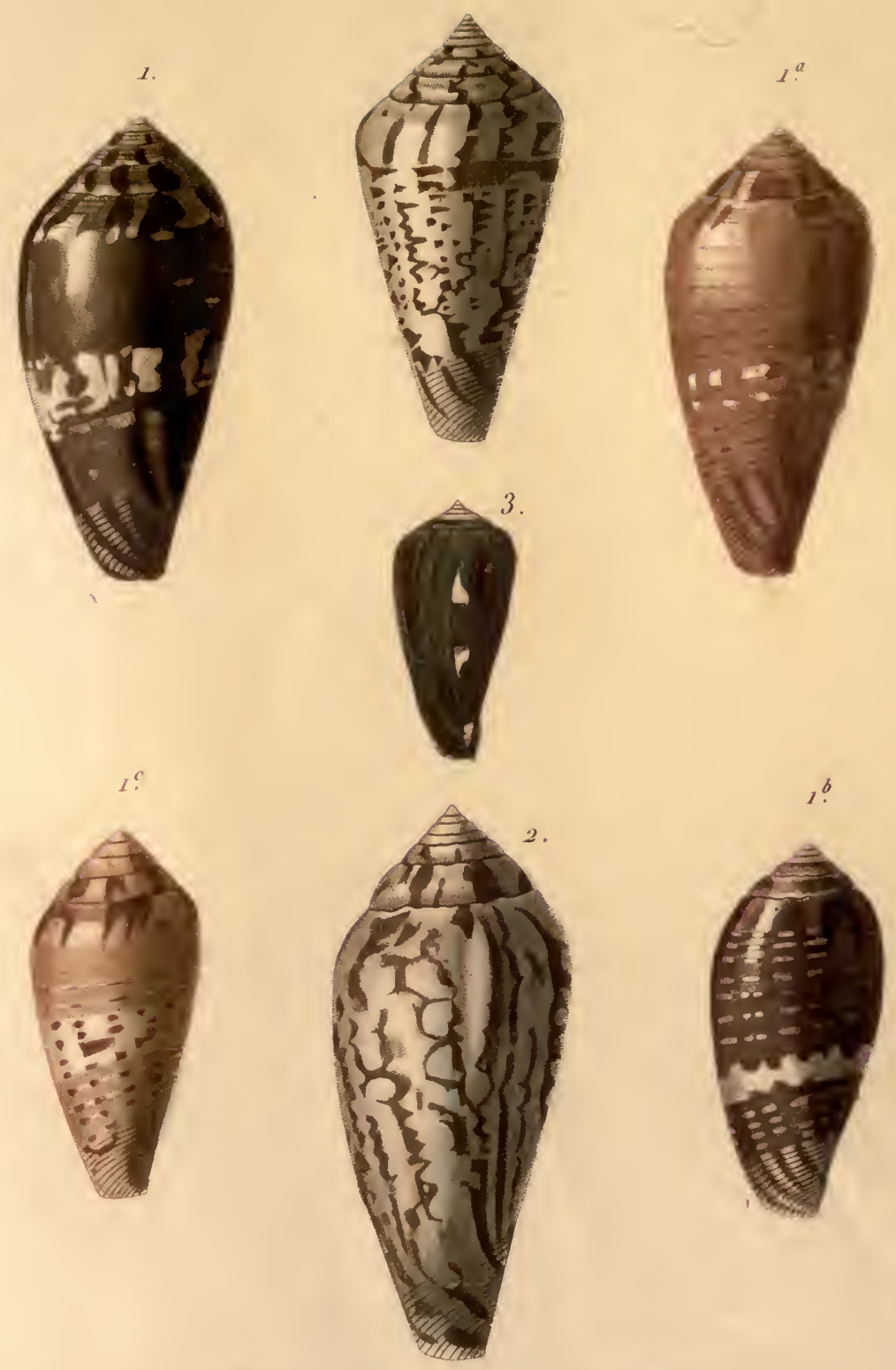

1. Cone de Mosambique.

(Conew Moxambicus. Brug)

a. à te id: id: vartés

2. Cône informe.

2. id: id: var:

3. Cône Bachelier.

( id: id: vartutes )

(Cones informiss Bruy)

(id: id: var: ,

(Conus Caclebs: Hinds) 
IME LIBRARY

OF THE

Hurengir of llumots 

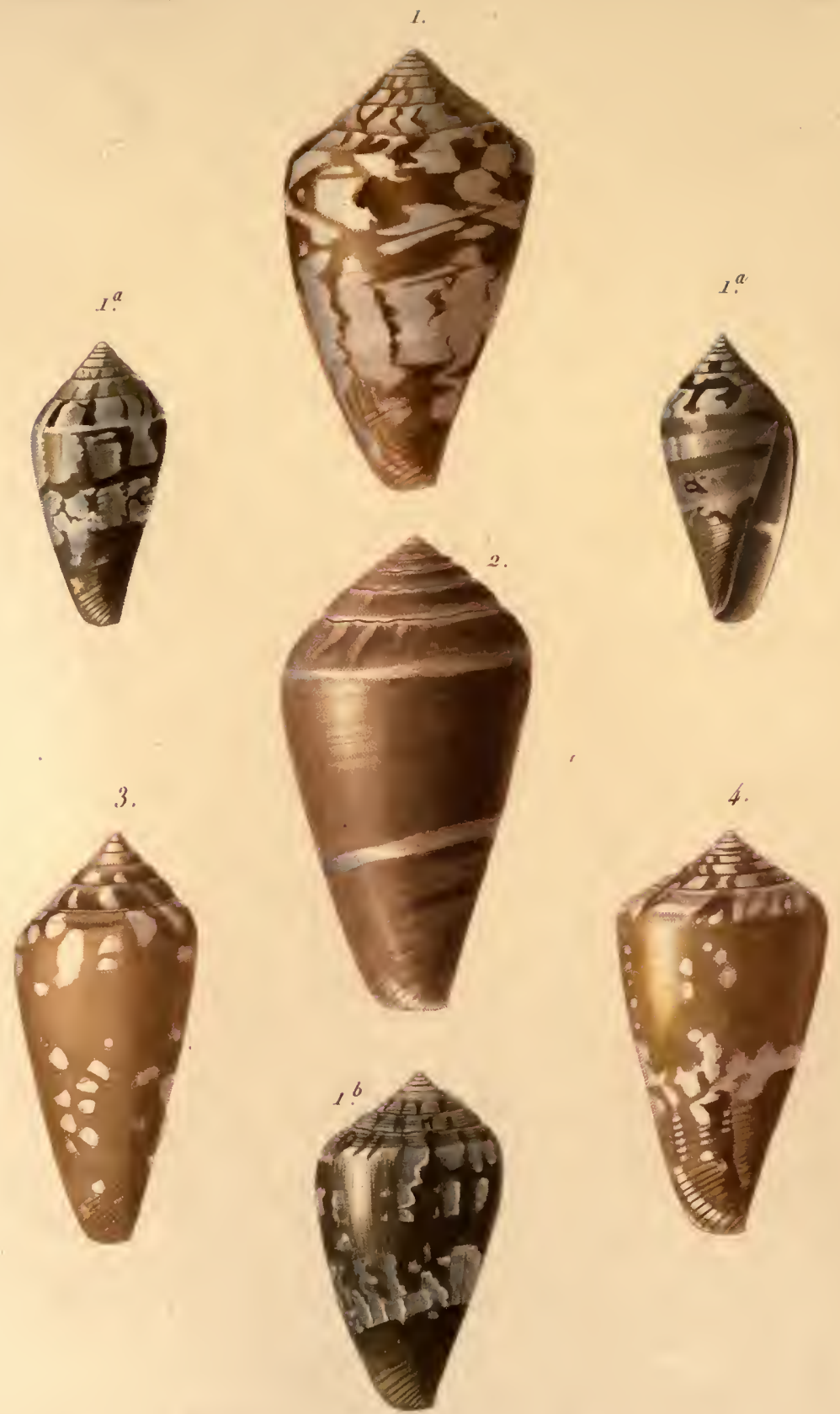
1. Cône de Guinće.
$1^{a} 1^{b}$ id: id: vartés
/Conus Guinaicus. Brug.)
2. Cône franciscain.
1 i id:
id: vartates ।
5. Coms salinué.
+. Conce nareisse.
(Conus frameiscarmus. Bruy.)
(Conus cracatus. Lam.)
(Conses narcirsens. Lam.) 
FHE LIBRARY

OF THE

Ehivergiry of llumoss 


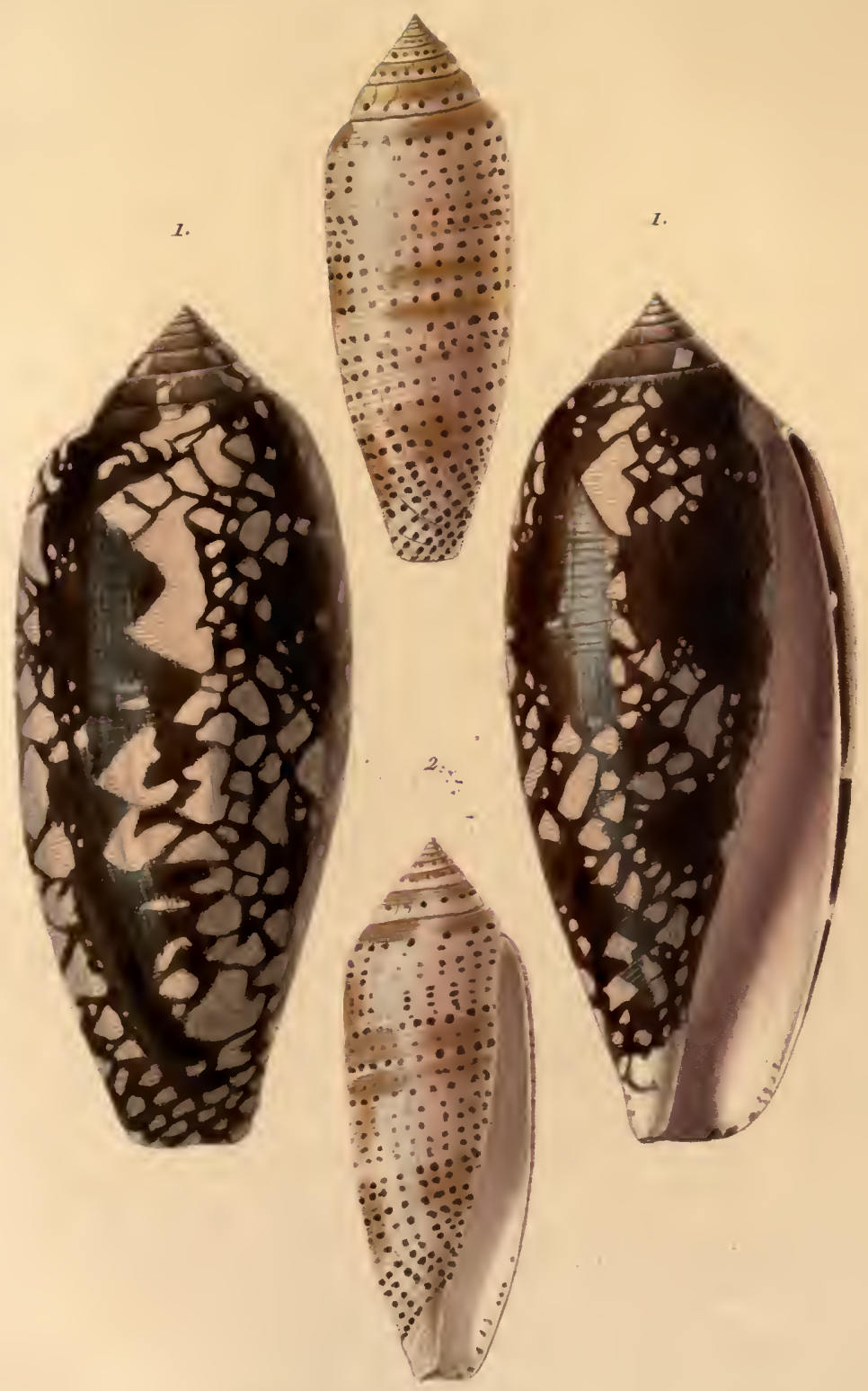

1. Cône brunette.

2. Cóne nussatelle.
(Conur aulicus. Jinn. I

(Consus nussatella. Brug) 


\section{THE LIGRARY}

$$
\text { OF THE }
$$

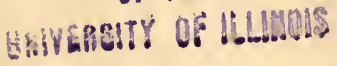



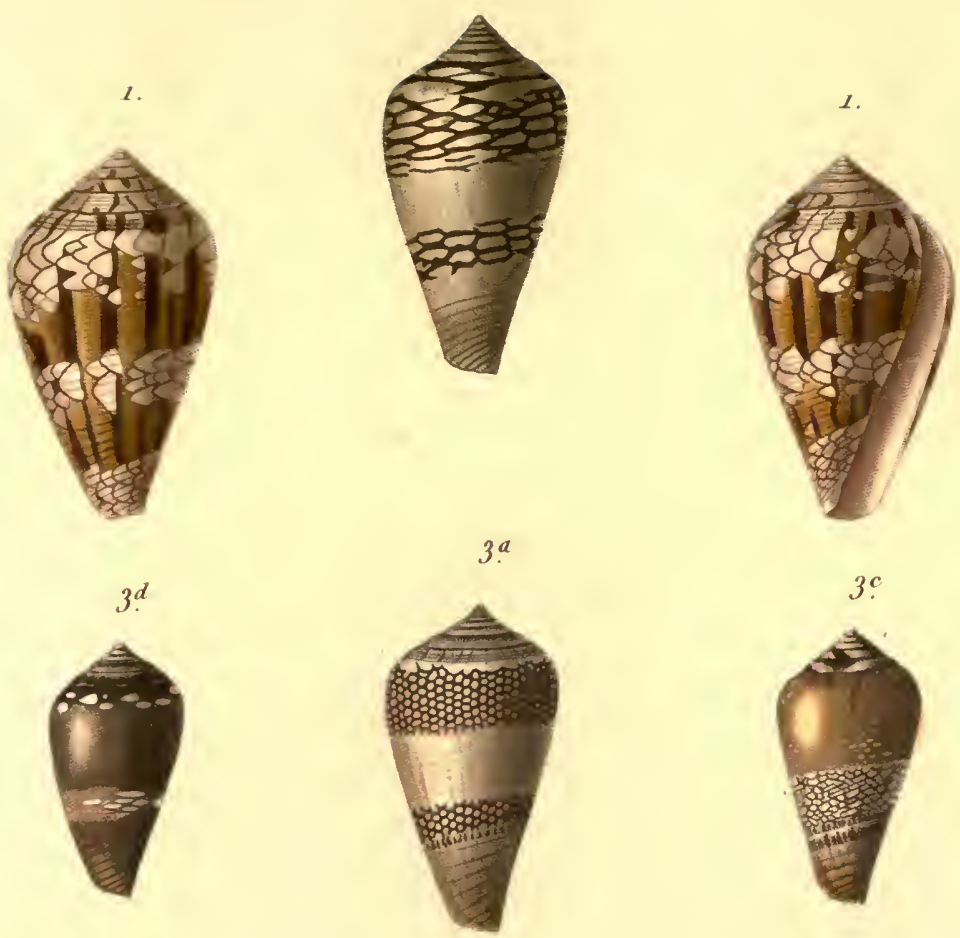

2
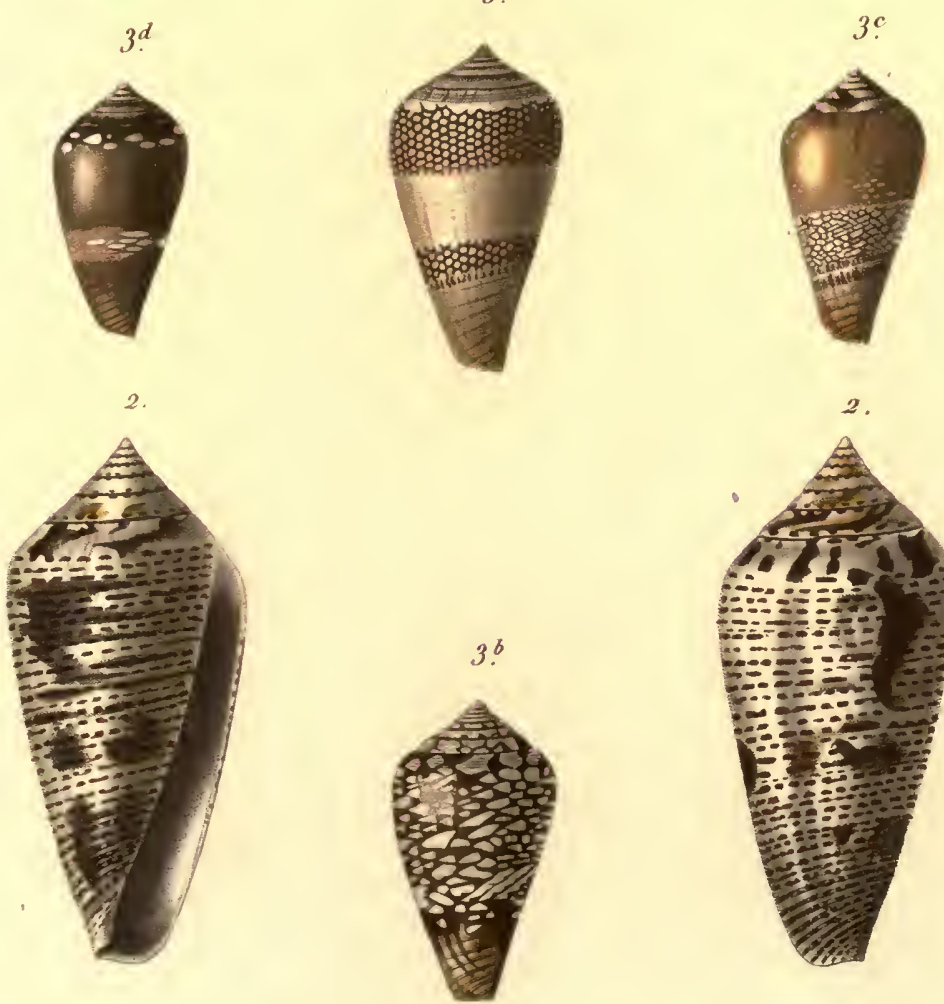

2.

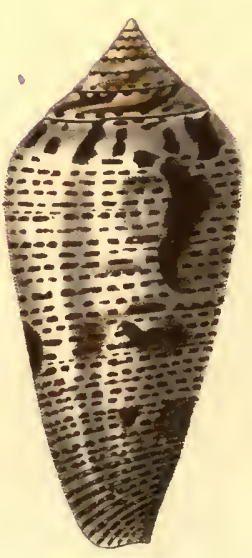

1. Cône solide.

(Conus solidus. sov.)

2. Cône interjompu.

(Conus incermplus. Bred.)

3. Conc riscau.

3a a $3^{\text {d }}$ id: id: vartés

('omus mprocalor. Lin.)

/ id: id : var!es ) 


\section{THE LIBRABY}

OF THE

UWIYEABITY OF ILLUMOIS 

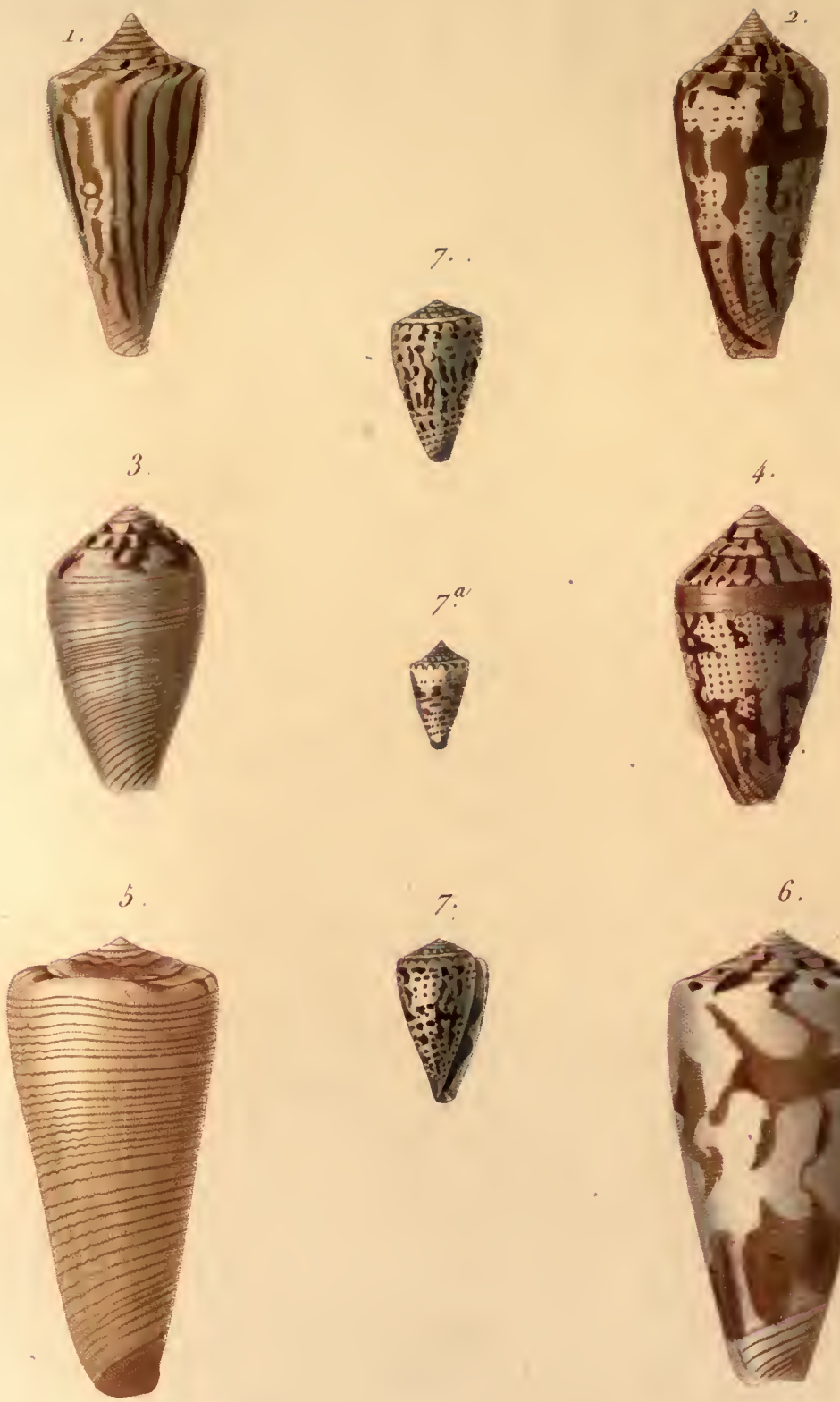
1. Cone Lorenz
2. Cône Andalous
3. Cone rayé
4. Cone jaspé.
5. Cône de Caillaud
6. Cone cheville.
7. Cône nain.

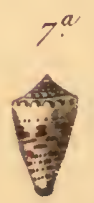

6.

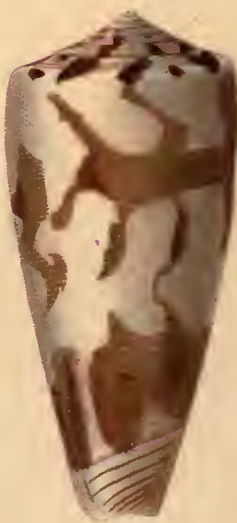

Conus Lorentianus. Chemn)

(Conus Brelicus. Reene)

(Conus scriplus. Reeve.)

(Conus , jerspideus. mabir.)

(Conus cuillnudi, nobis.)

(Conus epuistomium Reene.)

(Conks puritlus. Chemin) 
YHE LISPARY

OF THE

unvarisity of llumals 

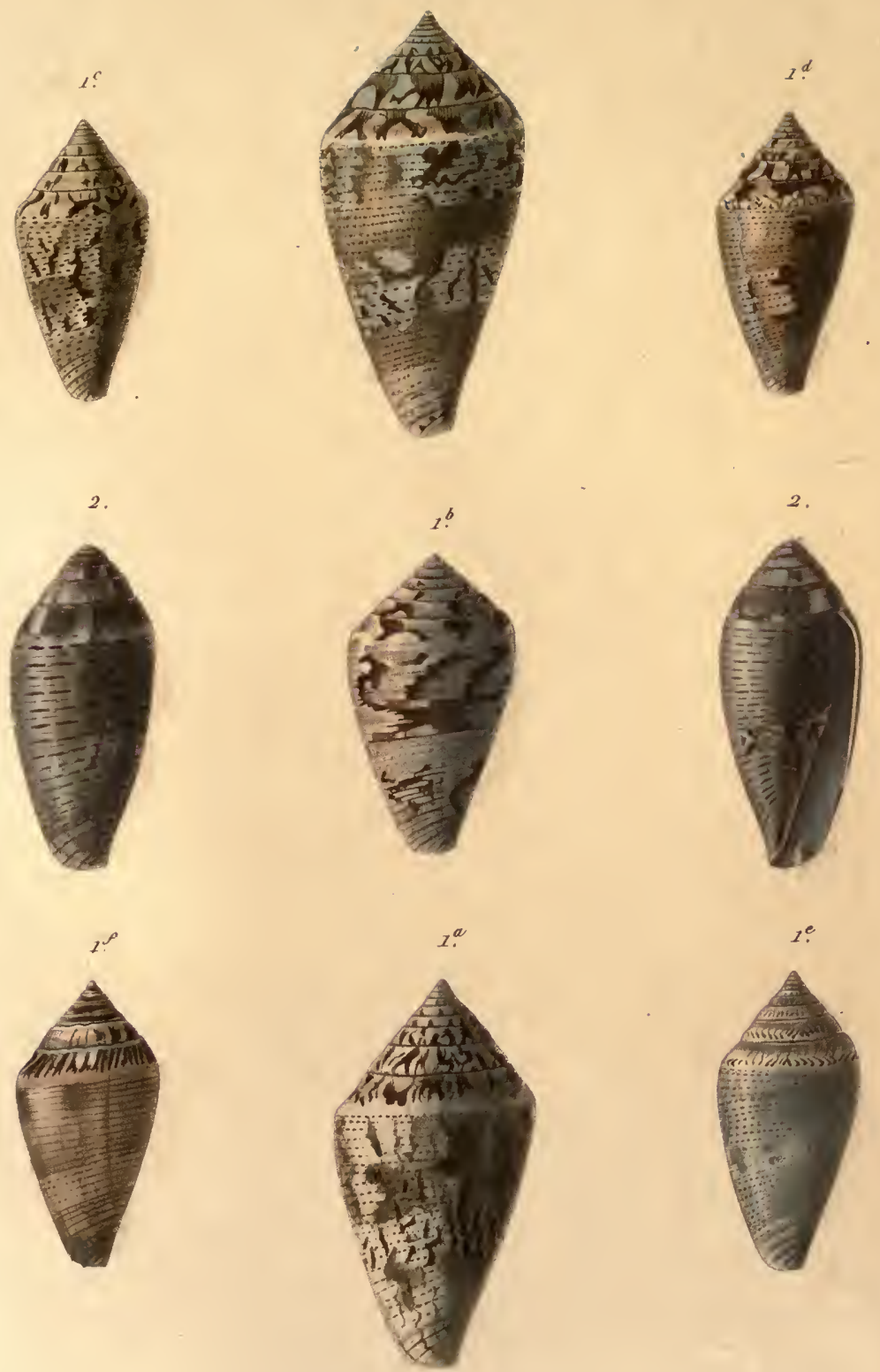

1. Cône méditerranéen.

r. à 1 f id: id: var:

(Conus medilerraneus. Brug.)

2. Cône de Bruguieres.

( id: id: var: )

(Conus Bruguieresi. nobis) 


\section{THE LIBAARY}

OF THE
unIVEgITY of ILUMOIS 

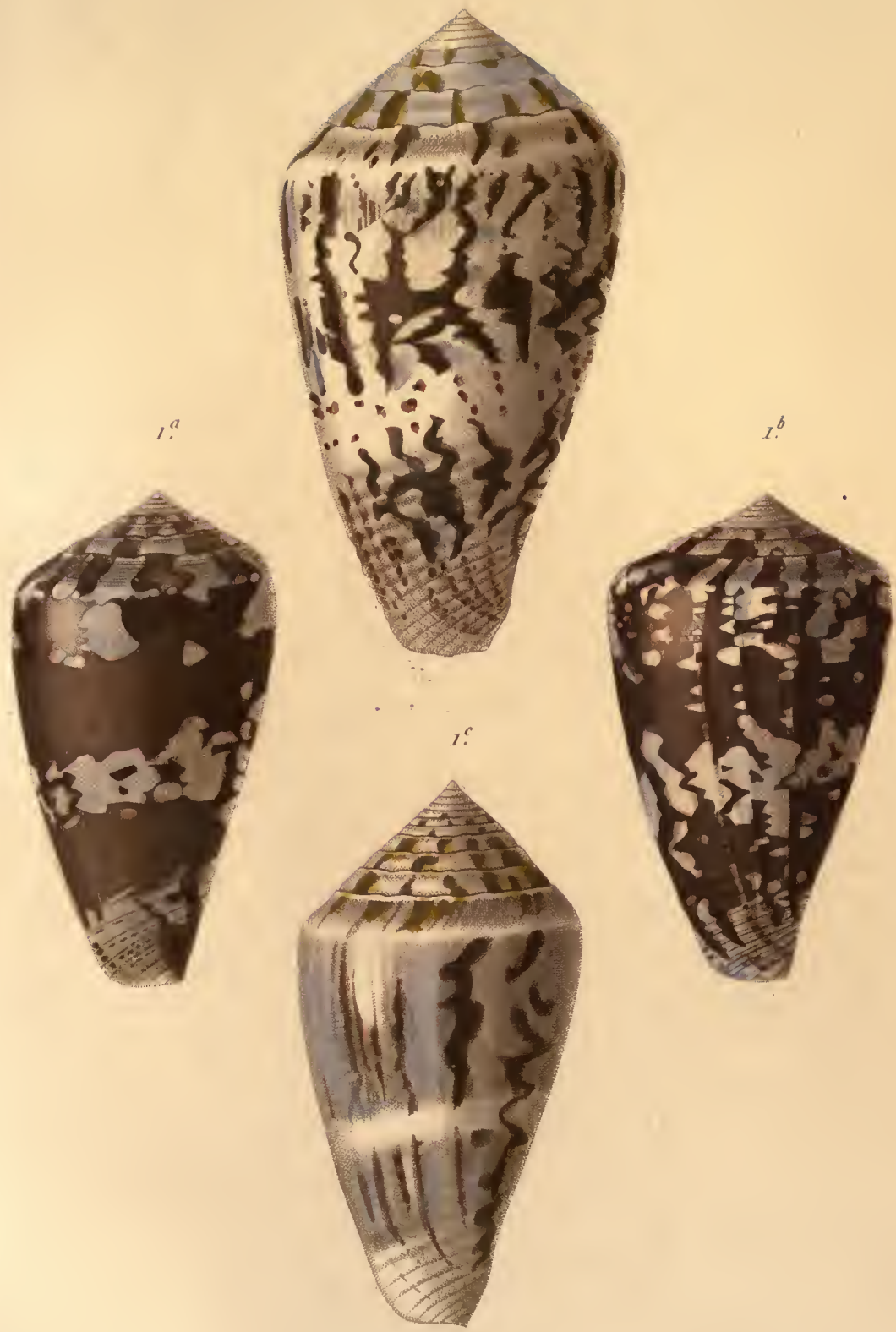

1. Cone peau-de-serpent.

(Cones lesludinarues. Varlini)

1. à ic id: id: vartés / id: id: marlales. ) 
IAE LIBRARY

OF THE

URirunisity of ILLMOIS 

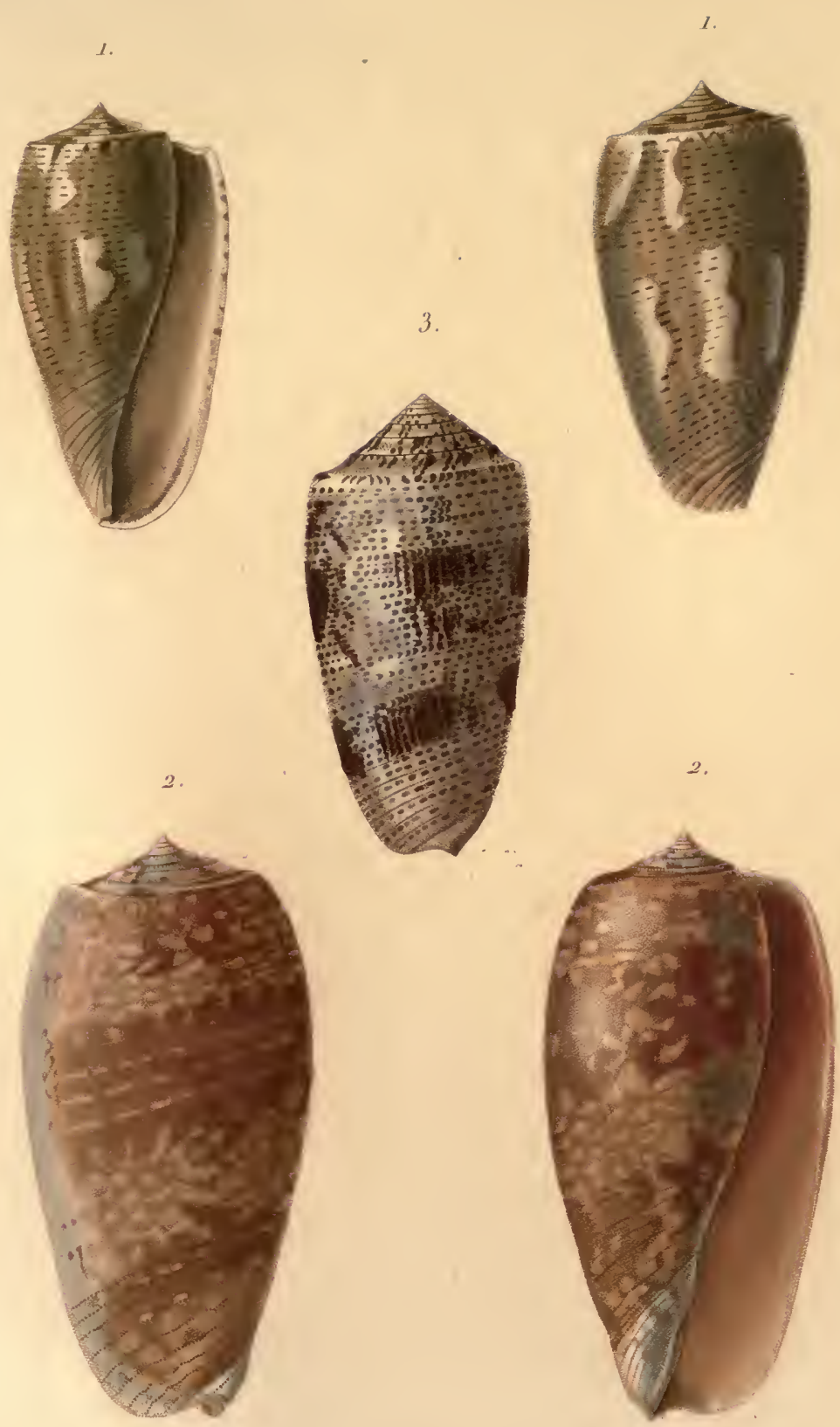

1. Cone de Deshaves.
Conus Deshayesï.
Reere.)
lCones bullatus.
Lin. I
(Cones wercas-muscarum: Jin .)

2. Cône bullé

3. Cône drap-d'arogent. 
THE LIRRABY

of TuE

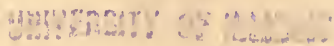




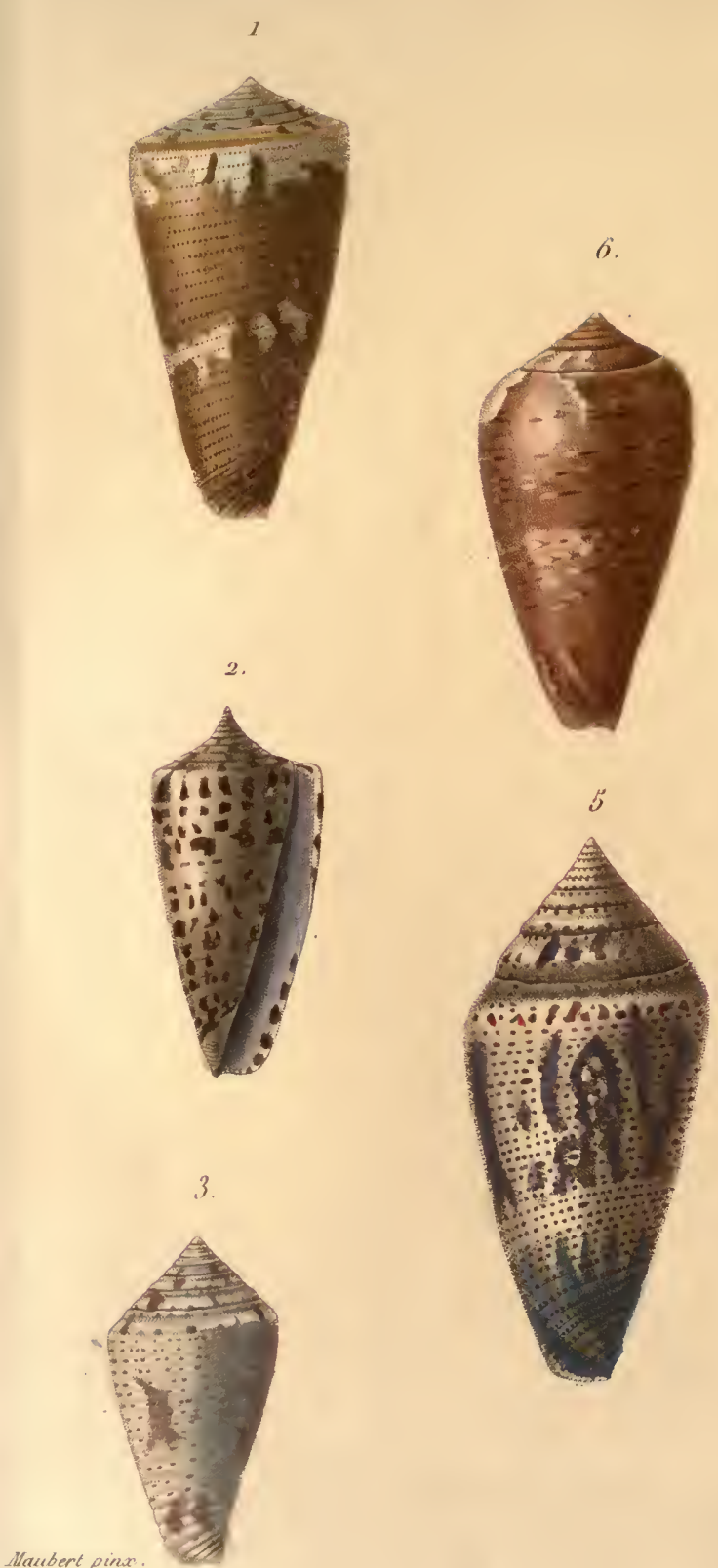

1. Cone agréable.

I. id: id: var:

2. Cône alvéole.

3. Cône pluic d'argent

4. Cône épervier.

5. Cône loupic.

6. Cone Citrin.

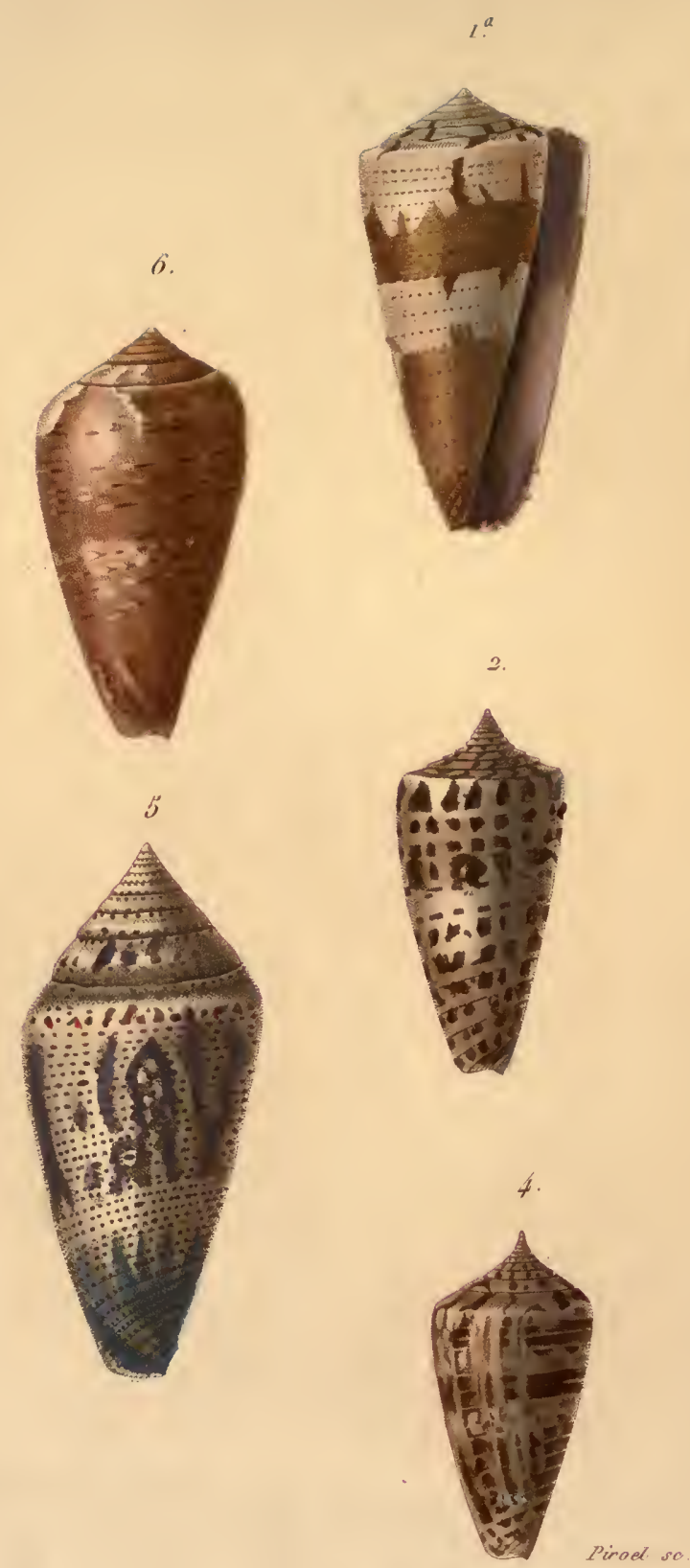

(Comus pulchellus Sivains.)

I id: id: var: , )

(Conerer alneolus. souv. )

(Cones mindarnus. Brug.)

(Conus misus. Chemn)

(Conces lopnalus. Brod.)

( Coneses Citrinues. nobsir.) 


\section{THE LIBRARY}

OF TIE

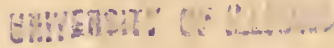



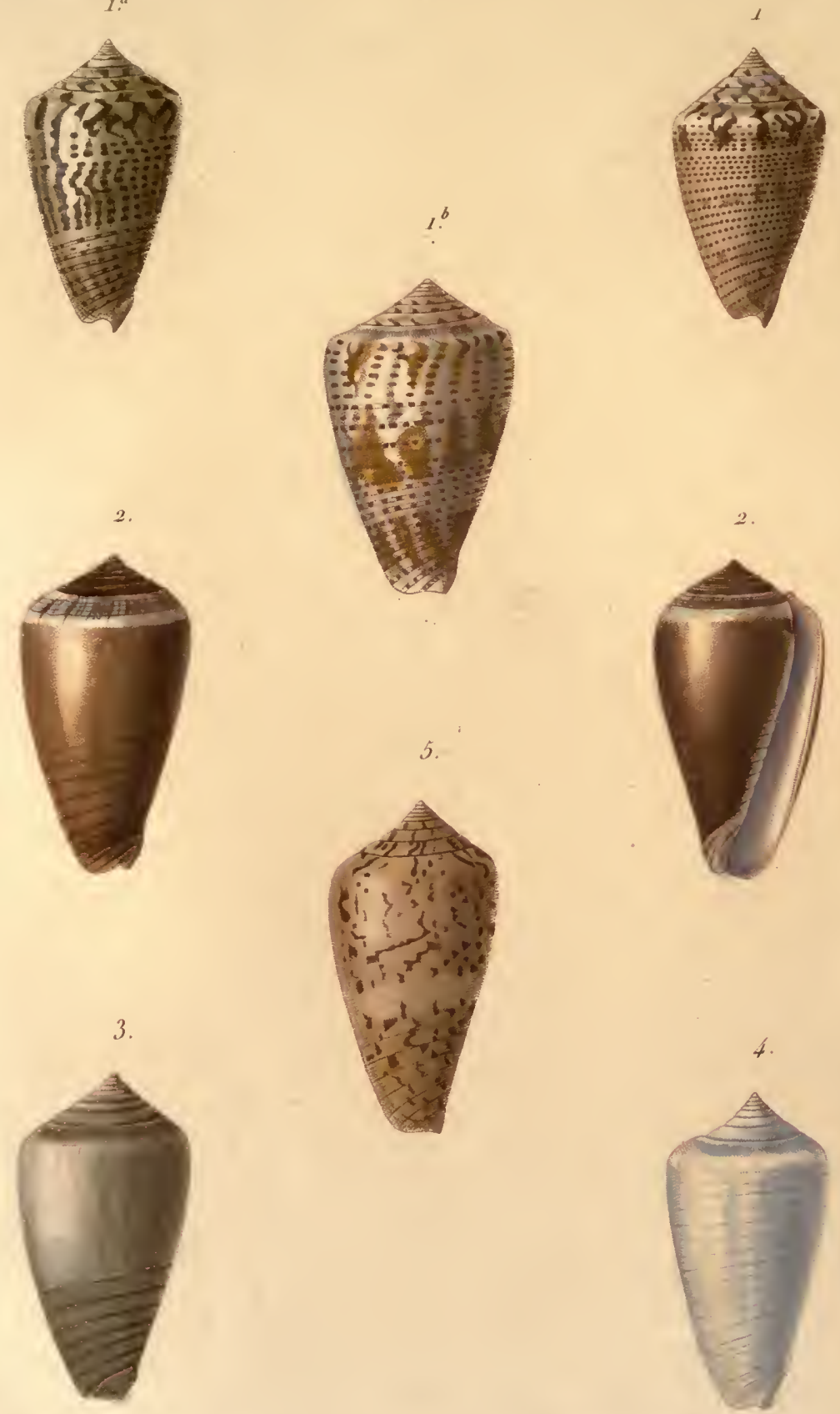

1 Cone pointillé. 1. 1 b id: id: var: 2. Cone de Marlini. 3. Cone albâtre.

4. Cone lacté.

5. Cône de lerteaux

Coness pundiculeders.

1 id: id: var:

/ Conus Marlincunus: Reevef

I Comus Pariust. Reene.)

(Conus liscleus. liam.

(Conus lerrecuaris. nobus.) 
THE LIBRARY

of ruE

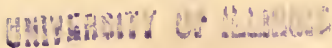



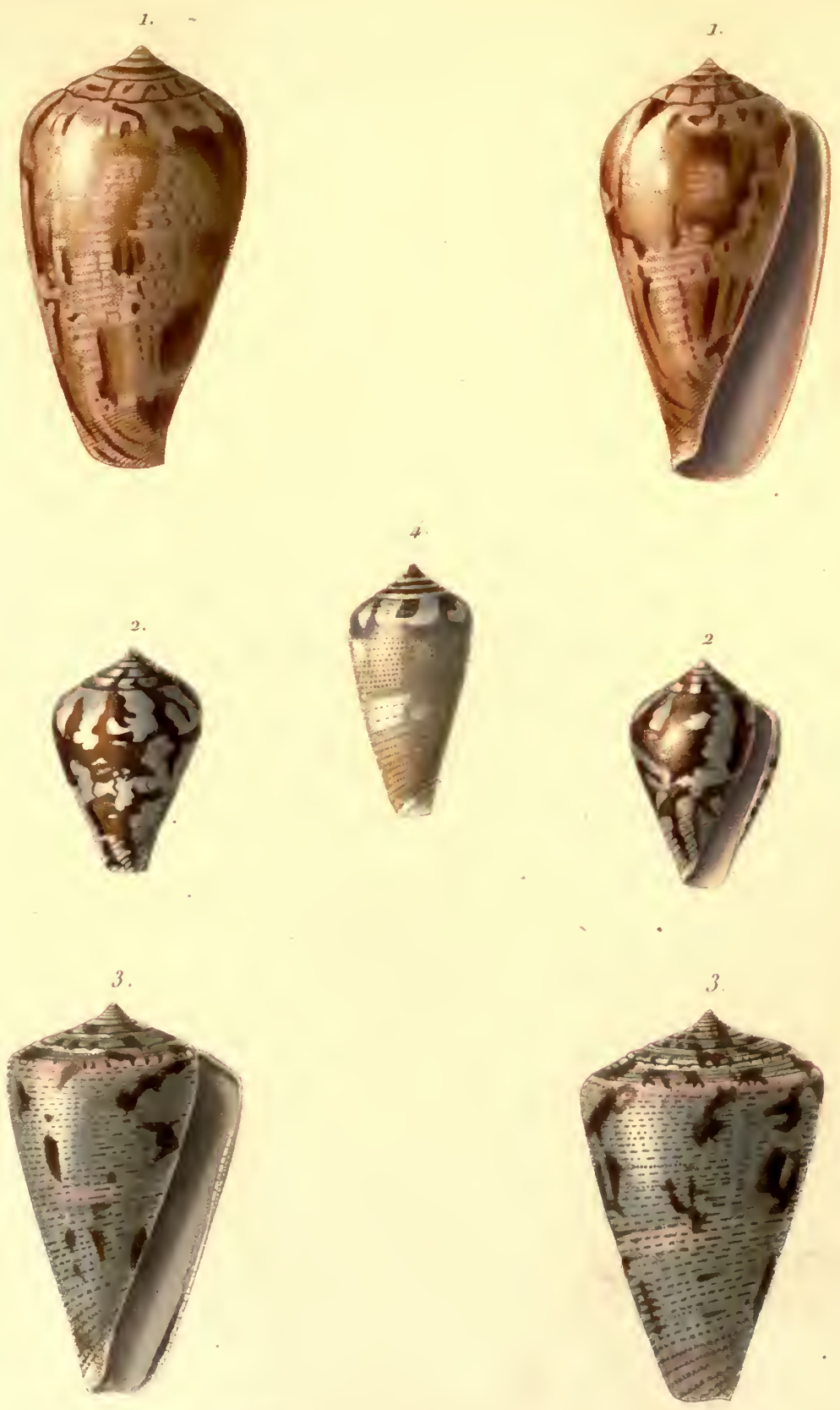

1. C'ome ambassadeur.

2. ('one de Bupont.

5. Cone pouspré var:

f. Cône unicolor. .

(Coness limiarues. Brug.)

(Conus Duponlii. nobis)

(Conus purpurascens. var)

(Conus unicolor. Sou.) 
THE LIBGARY

DF THE

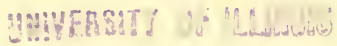



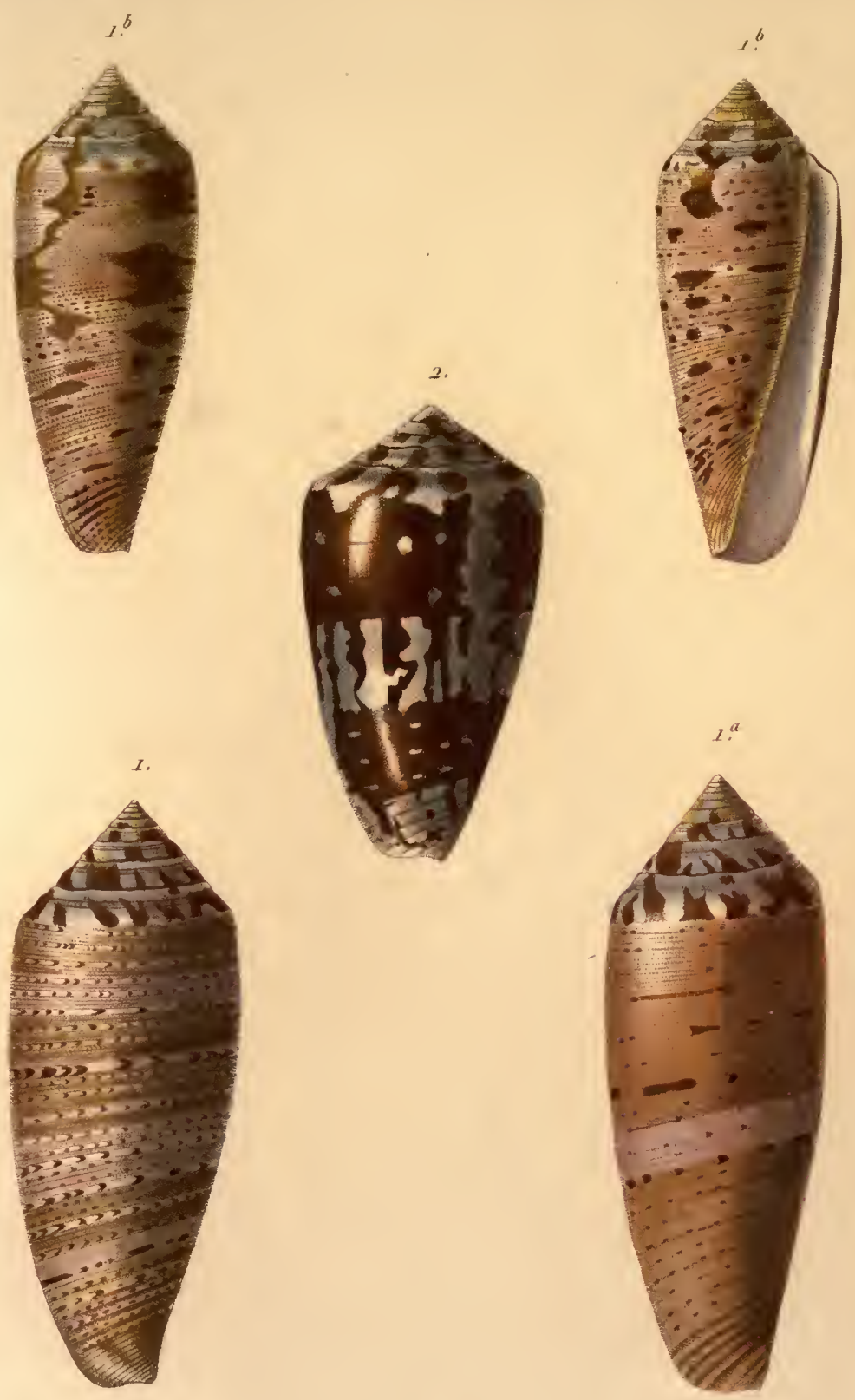
1. Cone commandant.
1. 1 b id: id: varlés
2. Cone floconncux.

(Goness deas. Bresy.)

I idt: id: vestluter fo

(Conuer Mocrutues soun) 


\section{THE LIBRARY}

OF THE

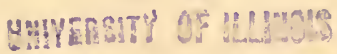



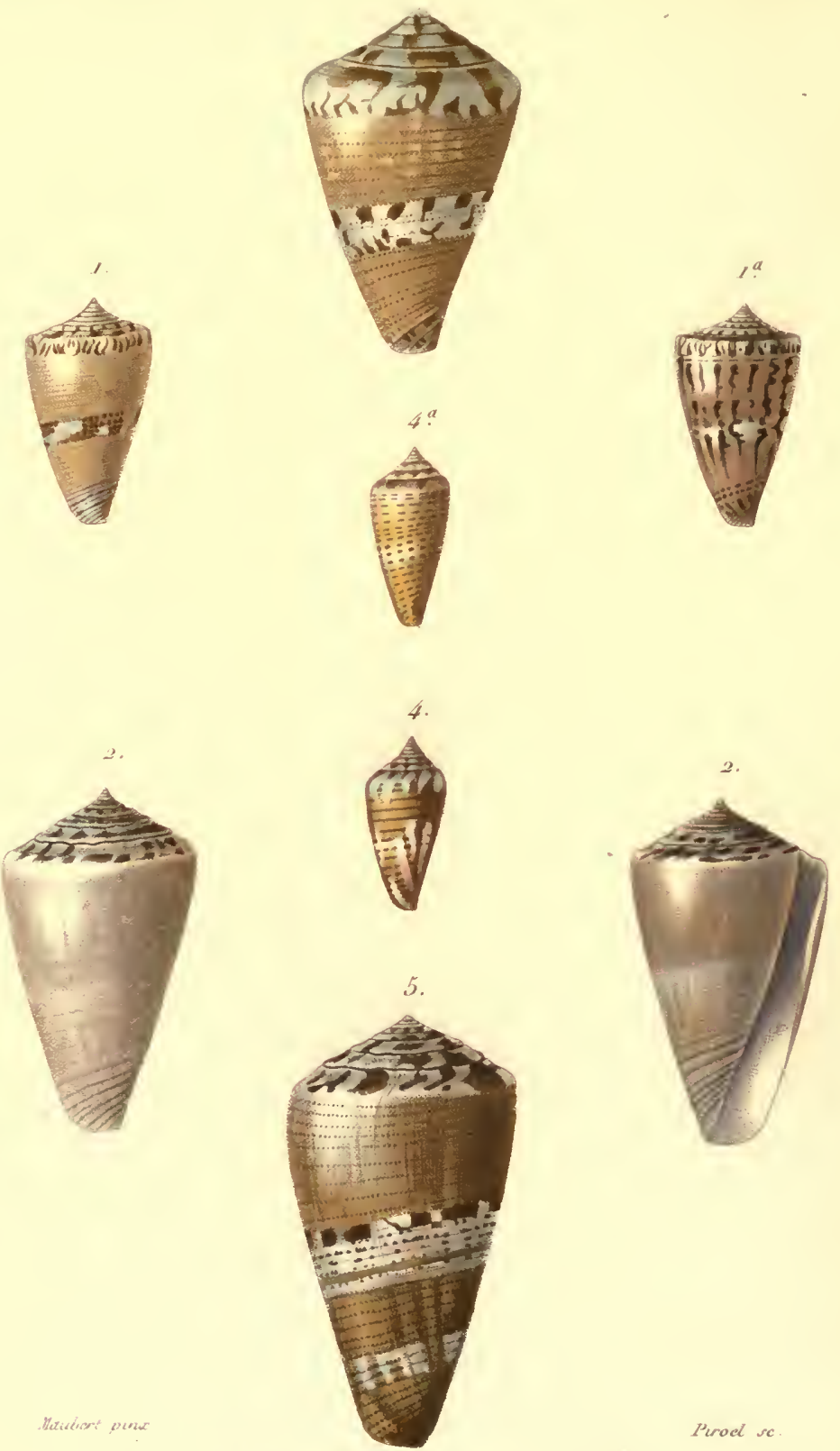

1. Cont turban. $1^{a}$ id: id: var:

lomus citaris.

Piroel sc

3 Cone grisitre.

3. Cone matelot.

4. Cone brillant

4. id: id: vas:

, id: id: var: ।

(Conus griscuss. nobis)

(Conus classarius. Brug.)

5. Cone cerelí

(Conur nitidus. Recve)

( id: id: vor: ,

Conees vittatus. Brug 
THE LIBRARY

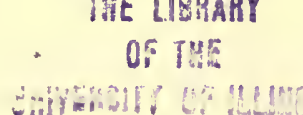



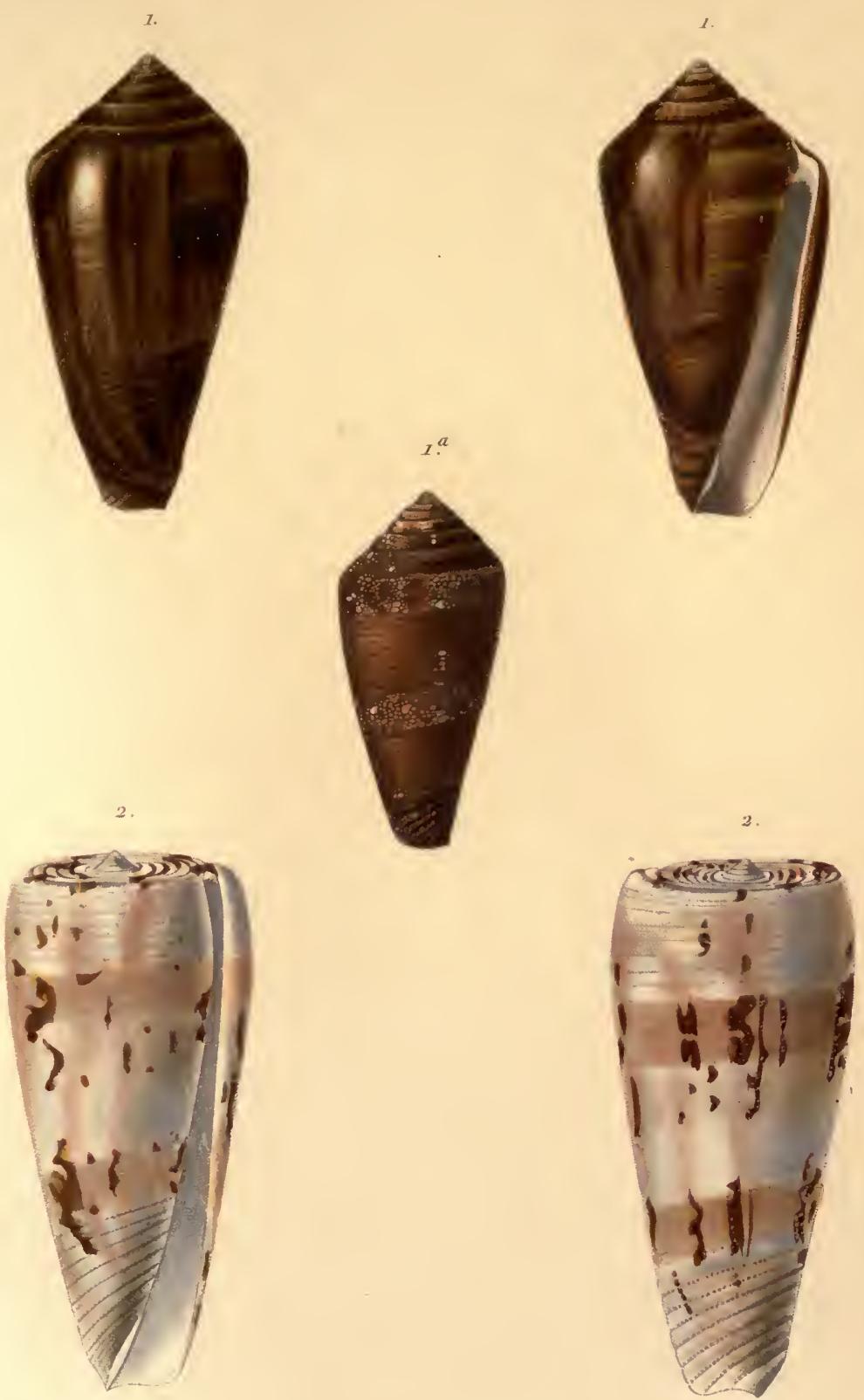

1. Cone lilixa

1. id: id: jeume

2. Cone de Borvin.

(Conus Elisor nobus.)

(id: id junior. )

(Comer Bocinine nobis) 
THE LIBRARY

of rlis

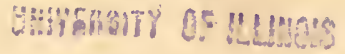


(O)E (Conus)
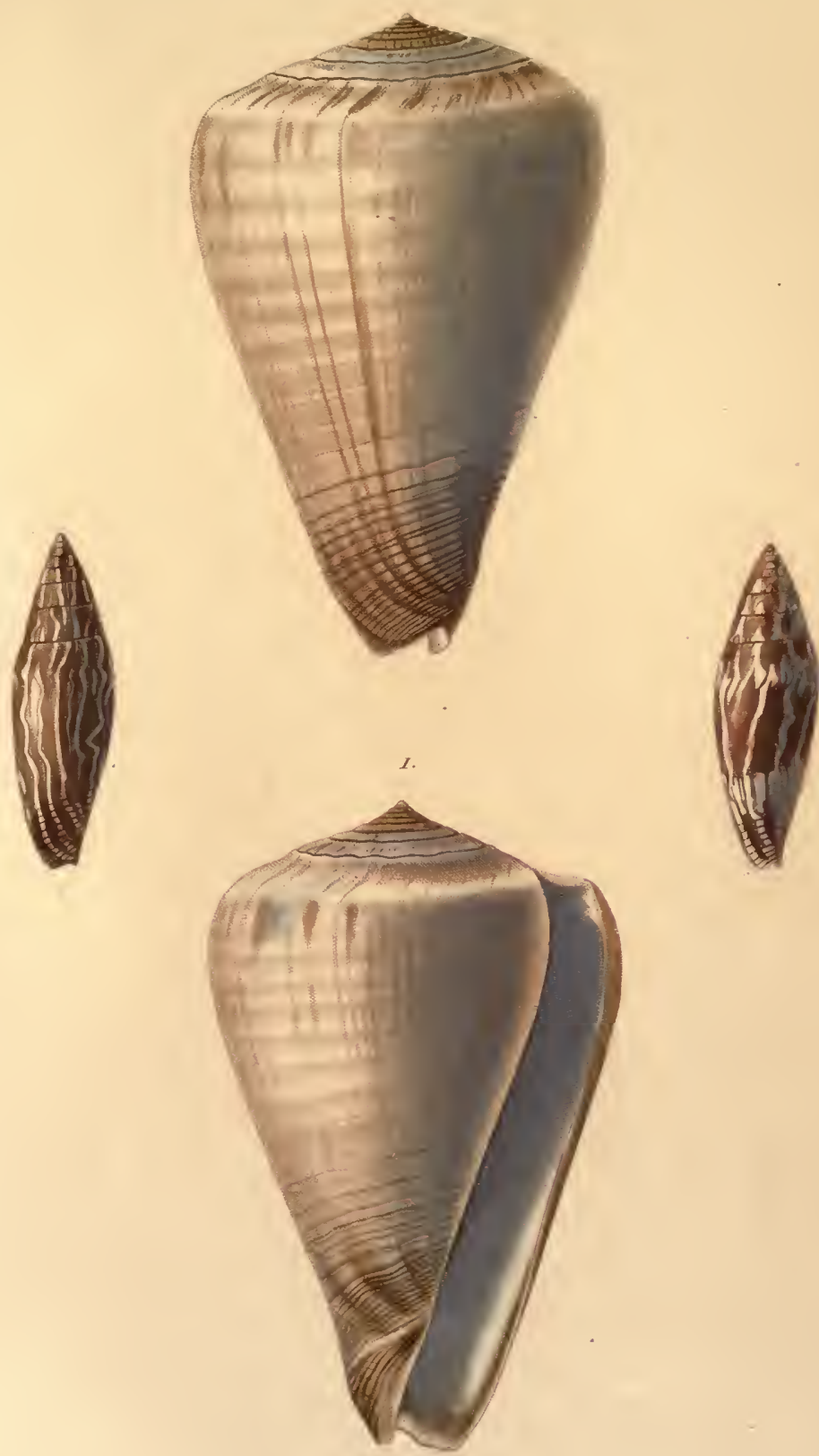

1. Cone de l.orois.

2. Cône Cvlindracé.
(Comes Loroisü nobur)

Clonus Cylindraceus. Brod. 
THE LIRPARY

of ris

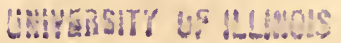



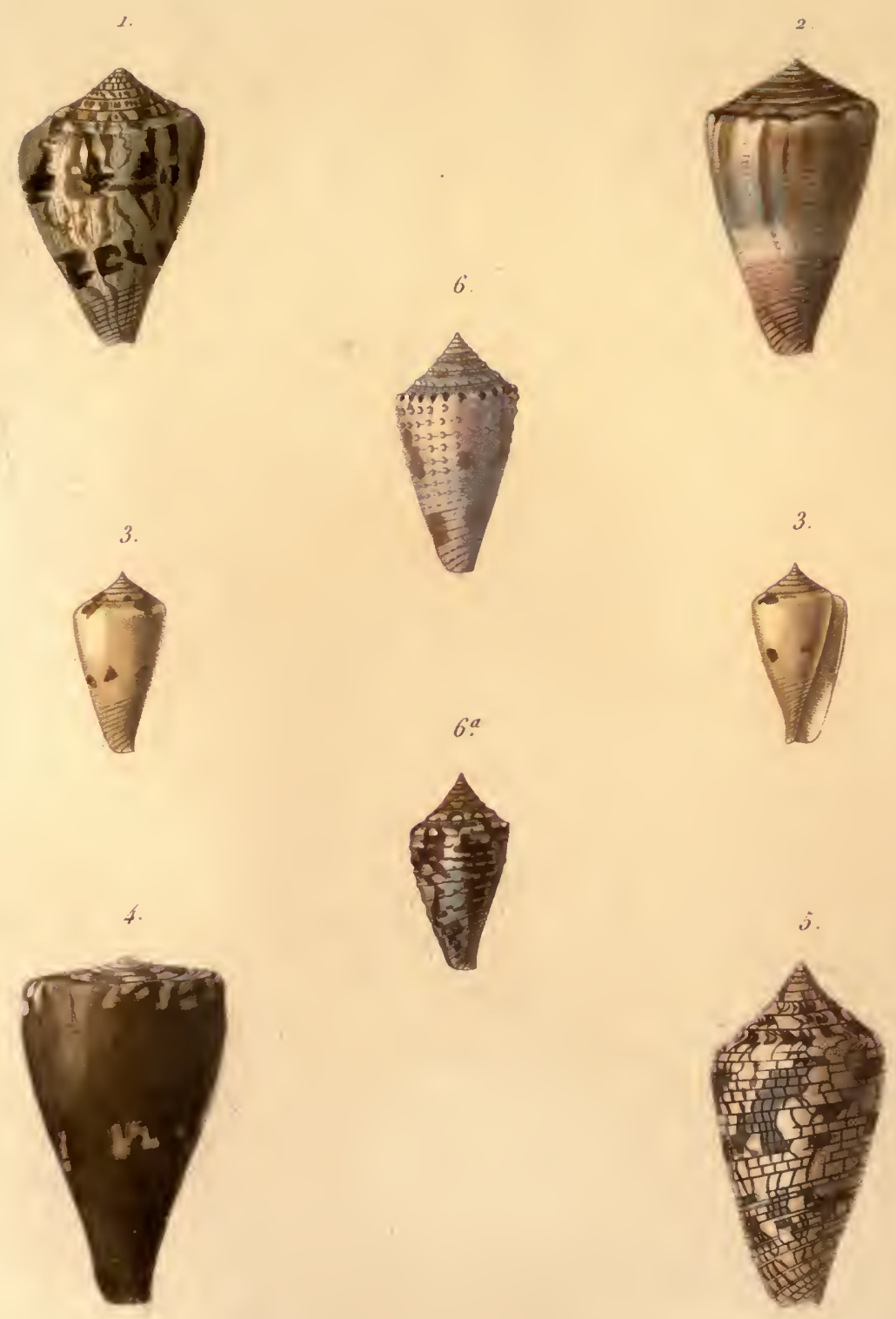

3.
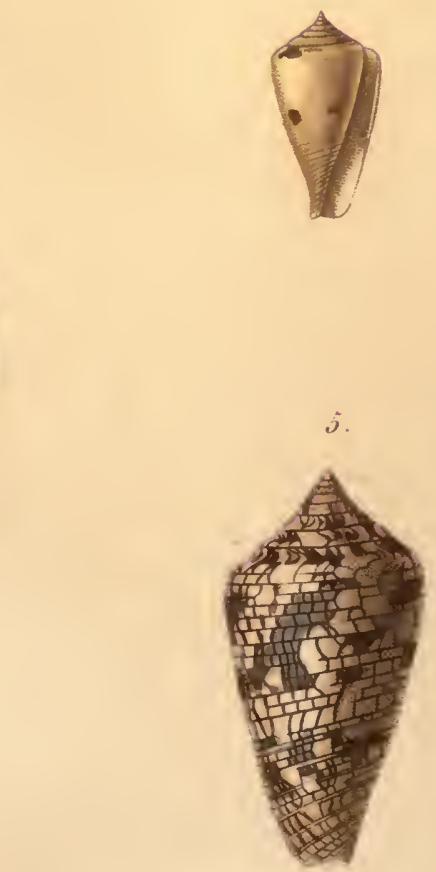

3. Cone chevalier.

Conus eques.

Brug.|

(Conus tabidus. Rereve)

2. Cóne spleen.

(Conews sulphueratus. nobis.)

3. Cone soufre.

(Conus laitensis. Brugy)

4. ('one violet.

(Conus reticulutus. Som.)

i. Cone réliculé.

(Coness merrencureur. Brug.)

6. Cone variole.

( idt: id: var:l 


\section{THE LIBPARY}

OF THE

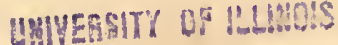



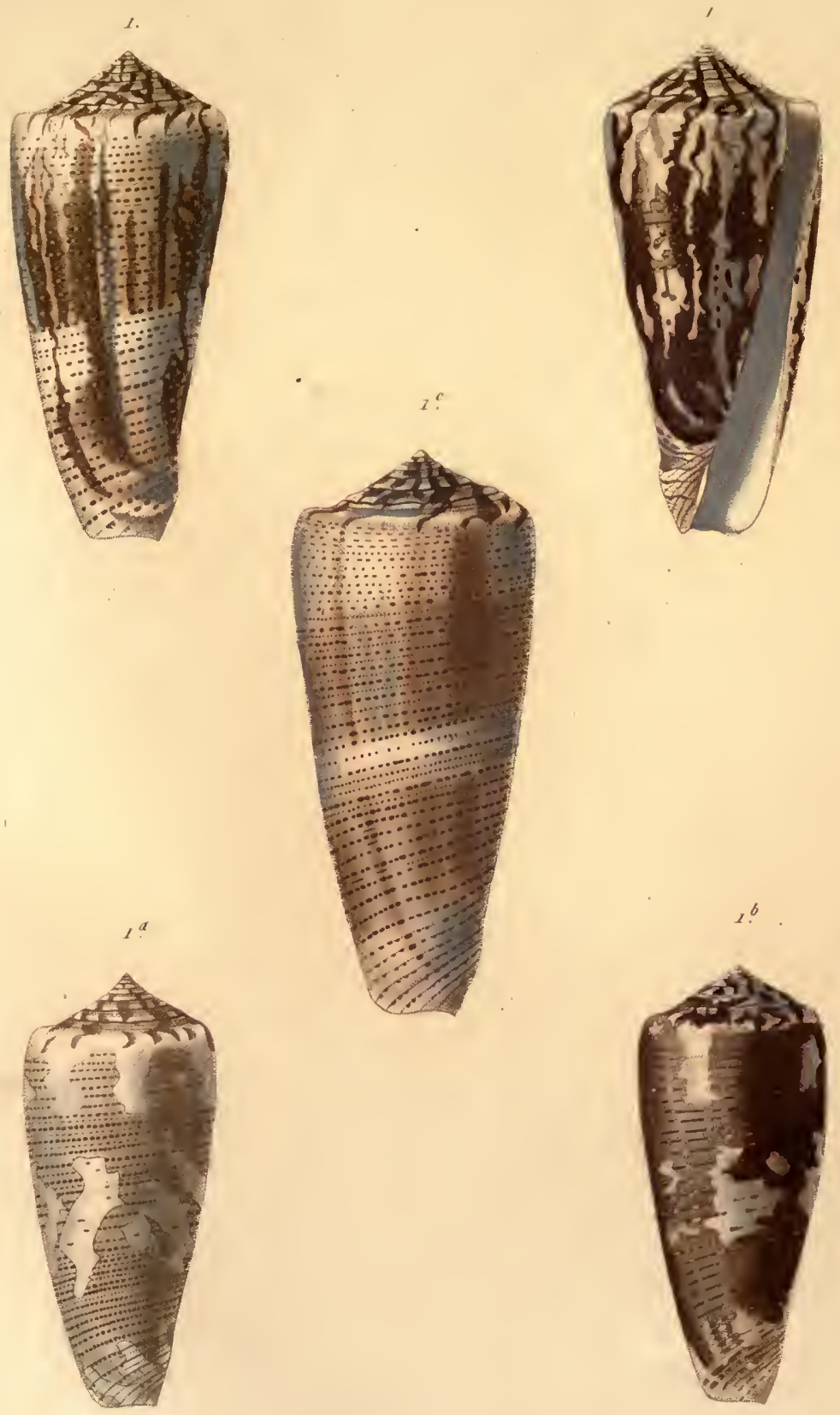
1. Cone nébuleux
(Conus magyes. Lin.)
a. l. $^{\text {id }}$ id: var tem
( idt: id: maritetes.)
1) id: id: viu:
(it: it: var: )
(Gonus raythunus. Brugg.) 
THE LIBRARY

OF THE

UHIVEASITY OF ILLIMO!S 

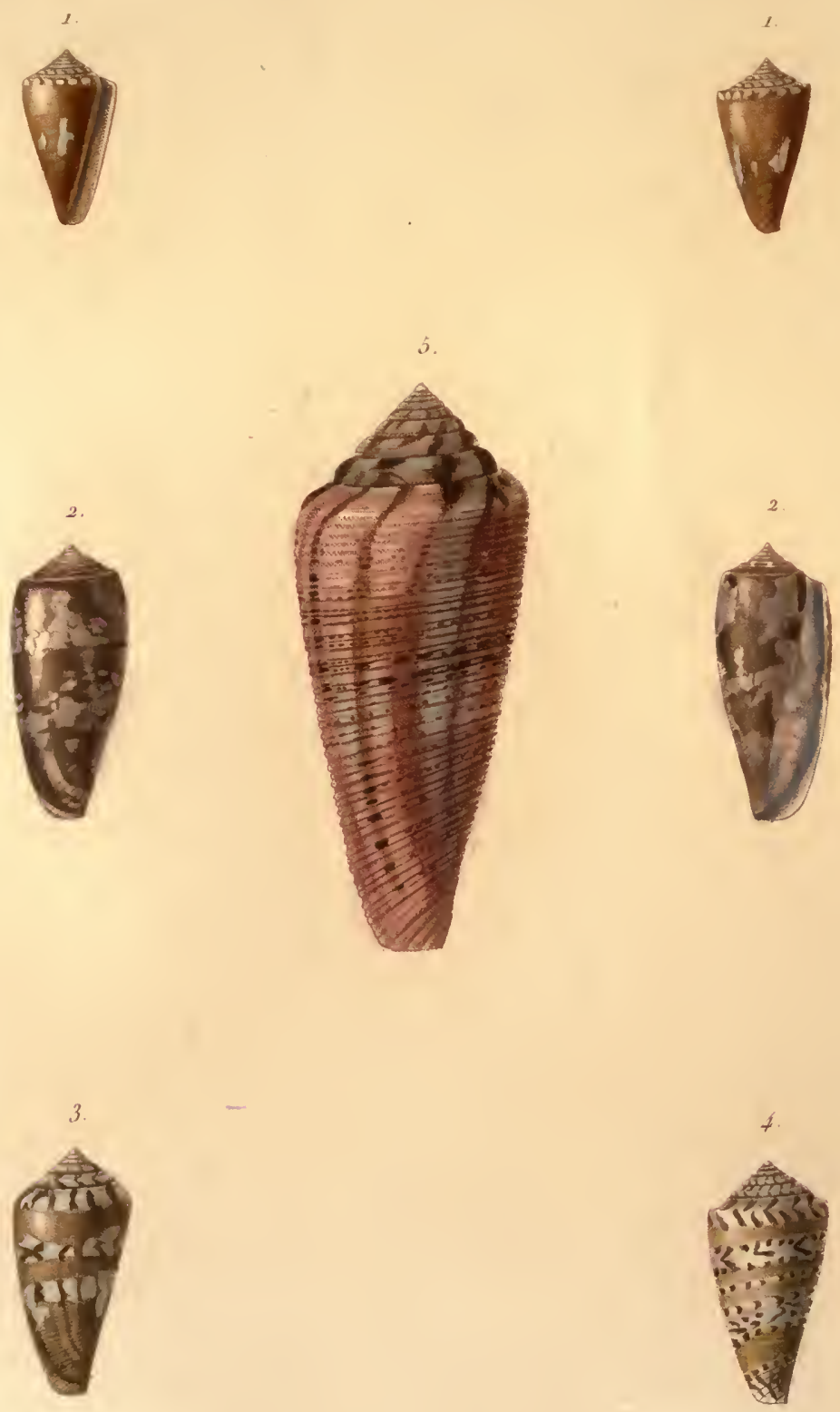

1. Còne jausc.

(Conus fleweacrens: Gray.)

2. Cone abseur

(ionus obscuerus. Itump)

7. Coner d' llogara

(imus atgoensis. ion.)

+ Come peint

ciones pirtess. Remel

$\therefore$ Cone gimunlem

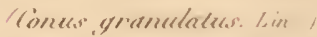




\section{THE LIBRGAY}

OF THE

UHIVEASITY OF ILLUMOIS 
CôNE: (Conus.)
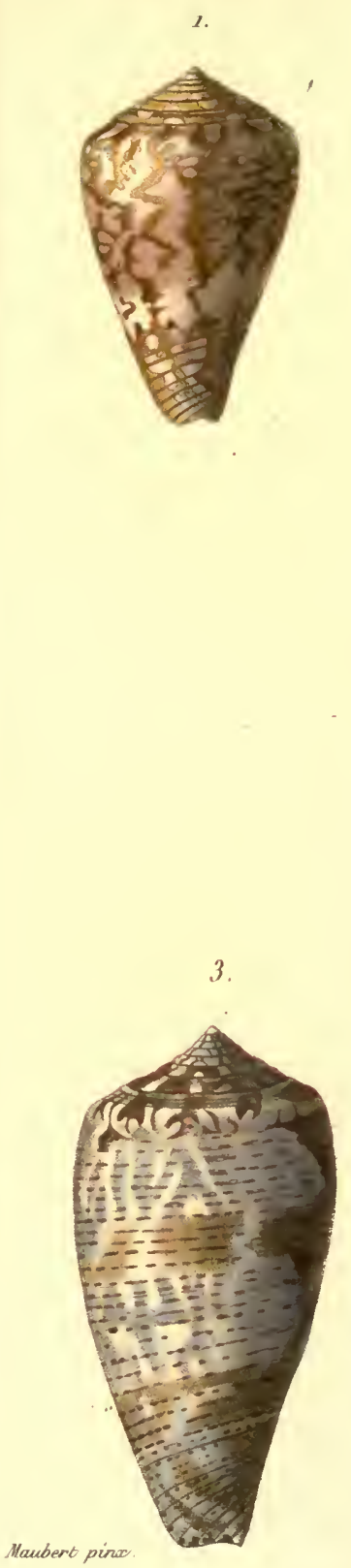
1. Còne veiné.
2. Cône chiné var.
3. Cône agathe var.
4. Cône de madclaine.
5. Cone véruleux.

PI. 69.

2.

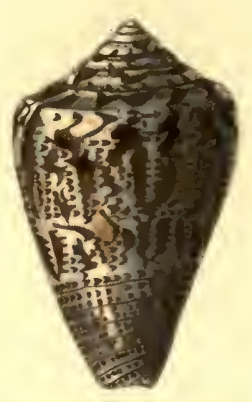

5.
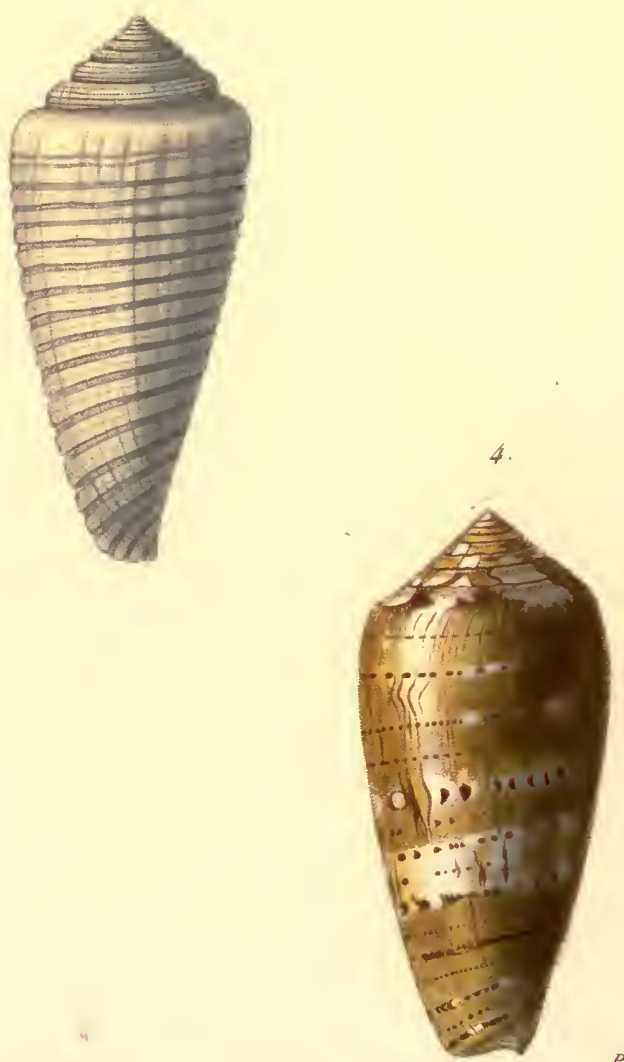

Piroed no.

(Coness benulates. Brug)

(Cones mauritianus bar: Lum.)

(Cones achalinus var: )

(Comus magdelenas. Chenu)

(Conus verulosess. Brug) 
THE LIBRARY

OF THE

UHIFASITY OF ISHUOIS 


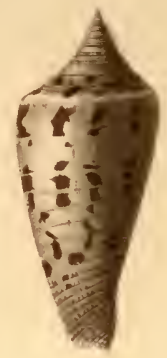

1.

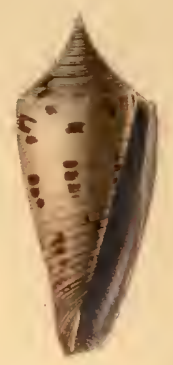

3.
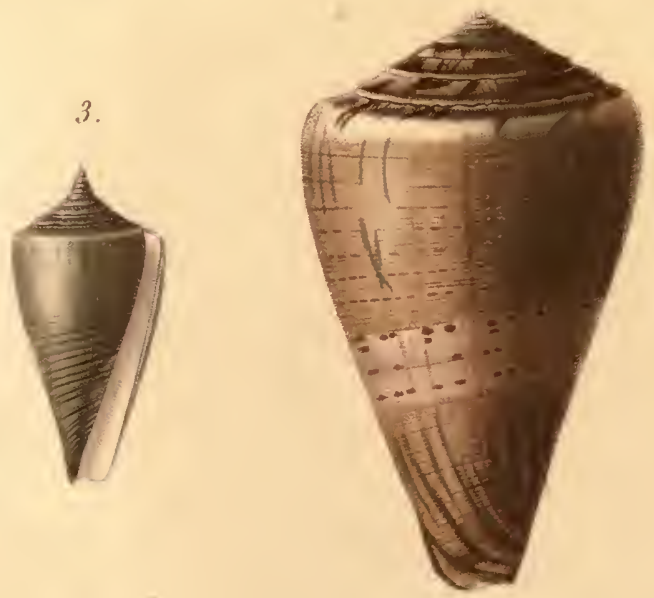

3.

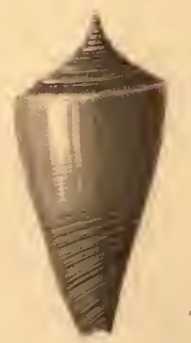

4.
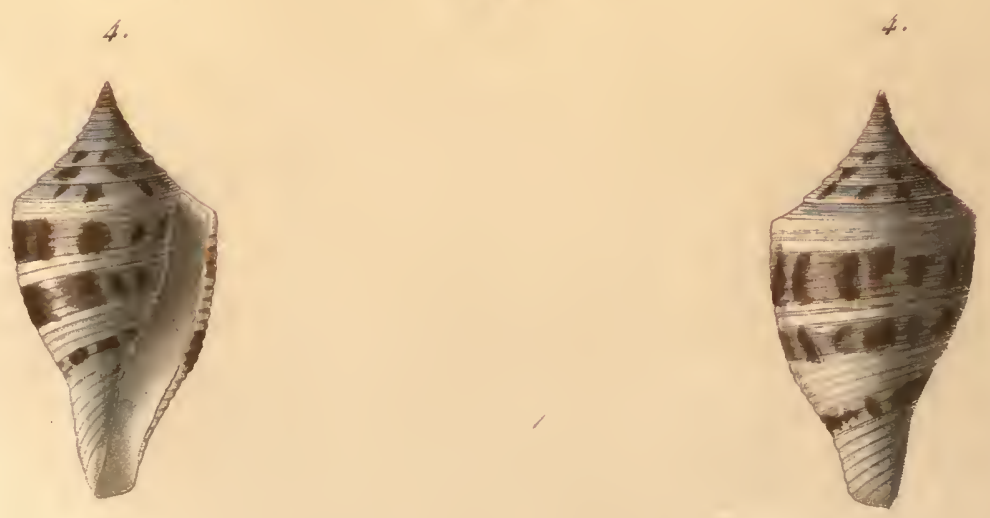
1. Cône changeant
2. Cône subulé
3. Cône ambiogu.
4. Cone pagode.

(Conus mukabilis. Chemn

(ronzes subulatus. nobirs.)

(Conus ambigutus. Reeve)

(Coness pagodus. Chenu) 
THE LIBRARY

OF THE

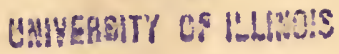



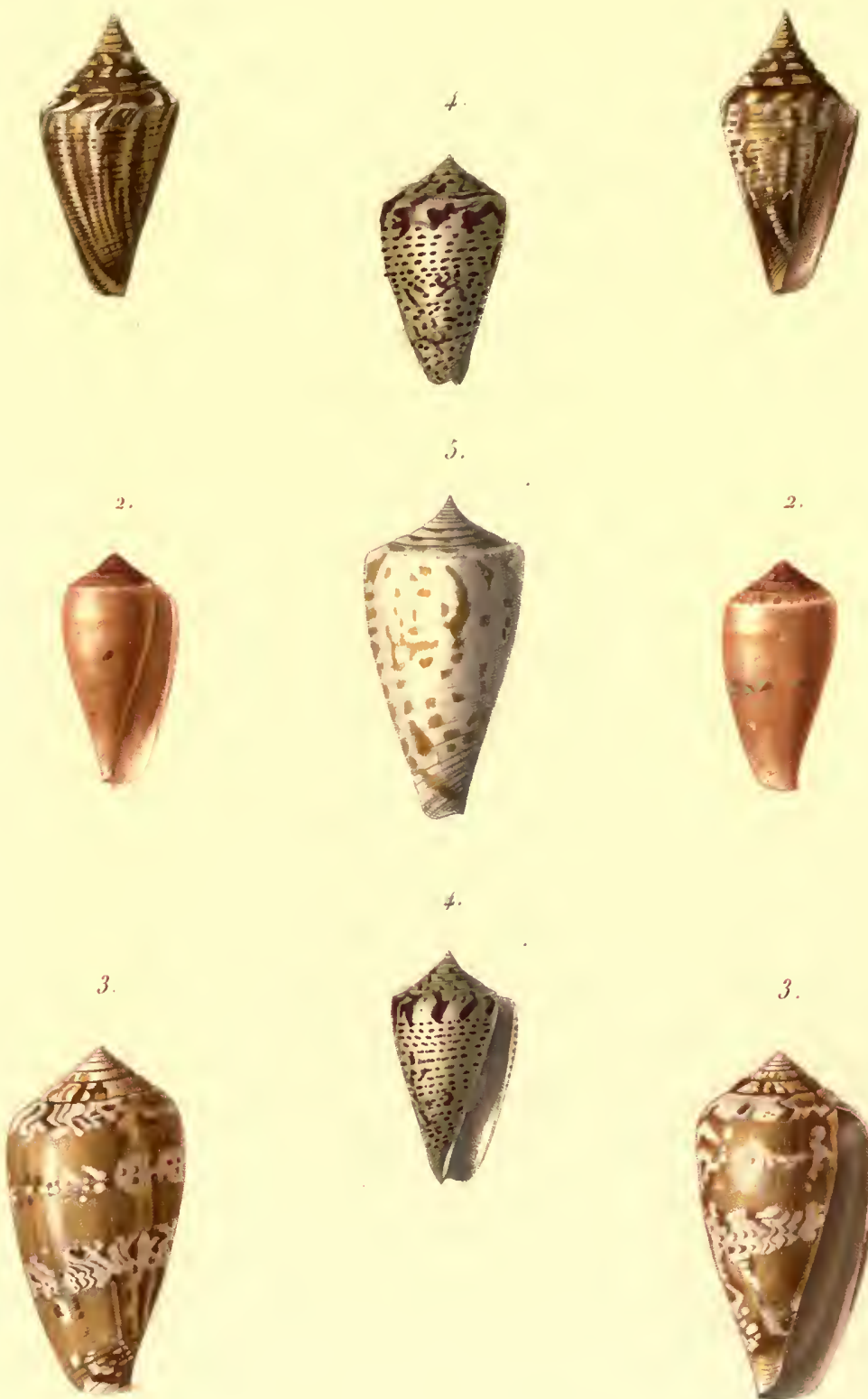

3.

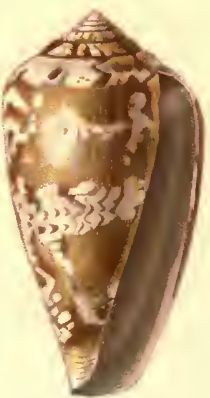

1. Cône chinois.

(Conus sinensis. Sow.) 2. Cone de Broderip.

3. Cône enfé.

4. Cône de la mer rouge.

(Conur Broderipuie. Reeve)

(Comes inflatur. Sow.)

(Conus erythrarensis. Bent.)

5. Cône maillot.

(Corns voluminatis. Hinds) 
THE LIBRARY

OF TMS

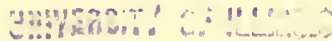


1.
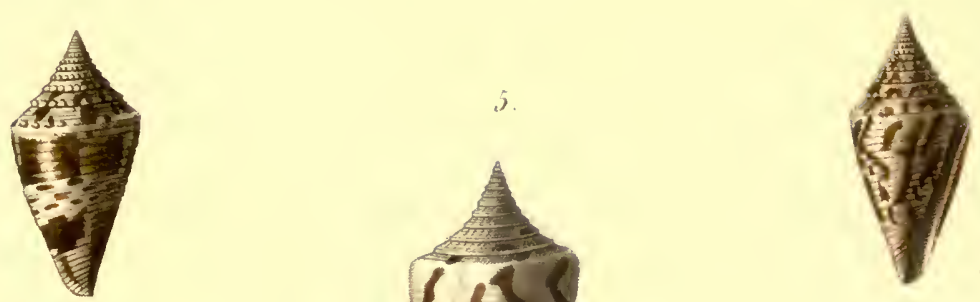

2.

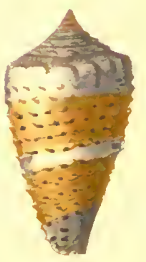

7

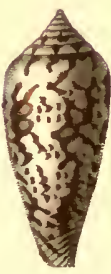

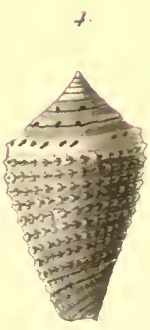

1. Cone acutangle 2. Cone muriculé.

3. Cone chétif.

4. Cône papilleux.

5 Cône arqué.

6. Còne sillonné.

7. Cone iodostome.
3.

6.

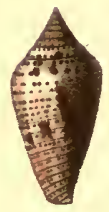

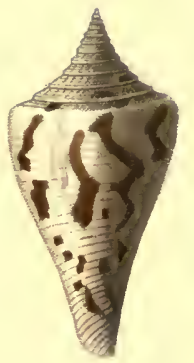

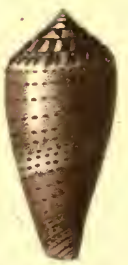

1.

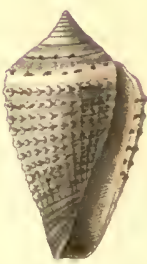

(Conus acutangulus. Chemn)

(Conus muriculalus. Sono.)

(Conus pauperculus. Soro.)

(Conus papillosus. nobis)

(Conus. arcuales. Brod.)

(Conus exaralus. Reeve)

(Conus iodostomes. Reeve) 
THE LIBPARY

OF THE

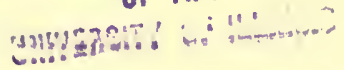



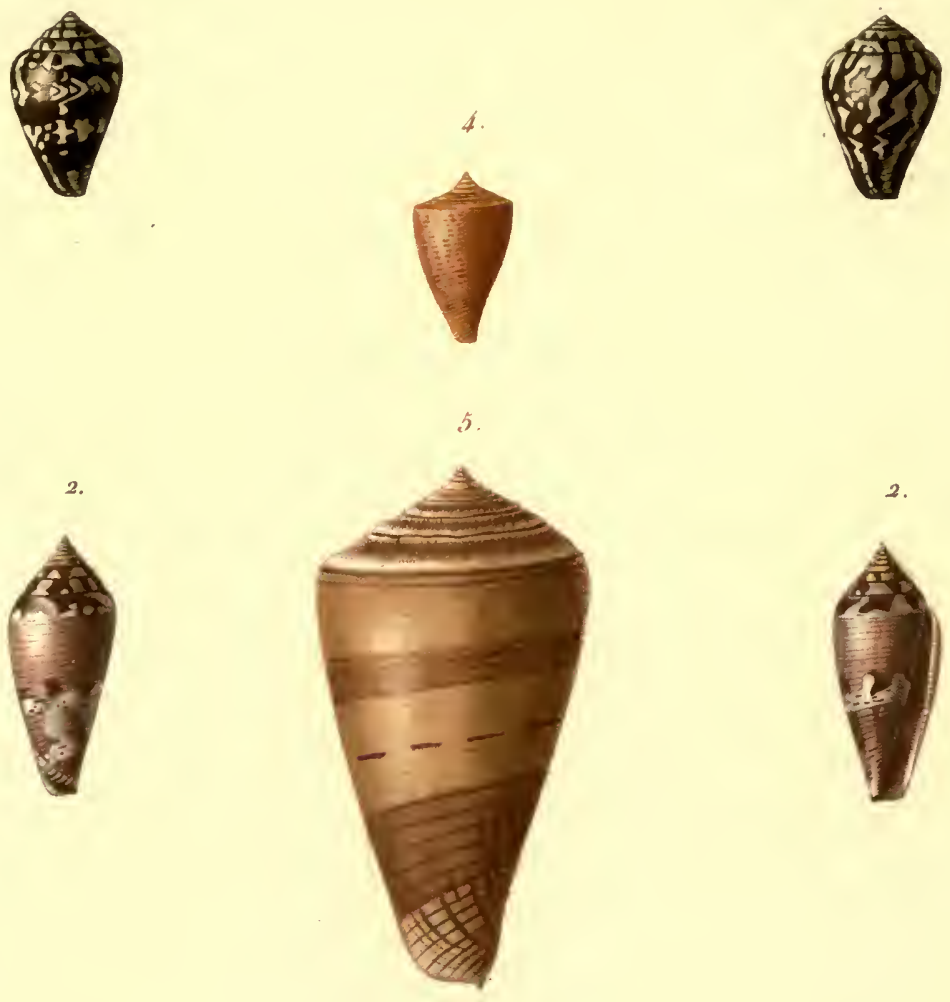

2.

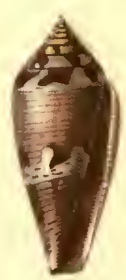

$3^{a}$

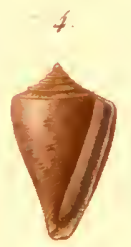

3.

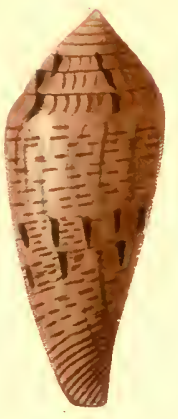

1. Cone hiéroglyphique.

1. id: id: var

2. Conc corallin.

var:

3. Cone jaune

3. id: id: var:

4. Cône rougec.

j. Cone consort.

Iruberl pinats

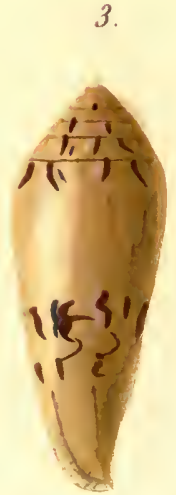

(Comes hieroglyphicus Dudos.)

\begin{tabular}{|c|c|c|}
\hline id: & id: & var: \\
\hline (Cones & corallinus. & nobis ) \\
\hline ( Conus & luteres. & Brod:) \\
\hline id. & id: & var: \\
\hline Conus & rutilus. & Menke) \\
\hline on & conte & Sow. \\
\hline
\end{tabular}


THE LIBRARY

OF TME.

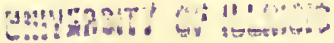


2.

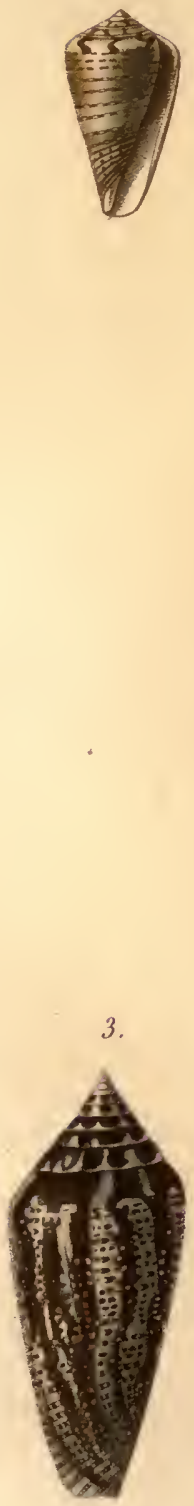

1.

2

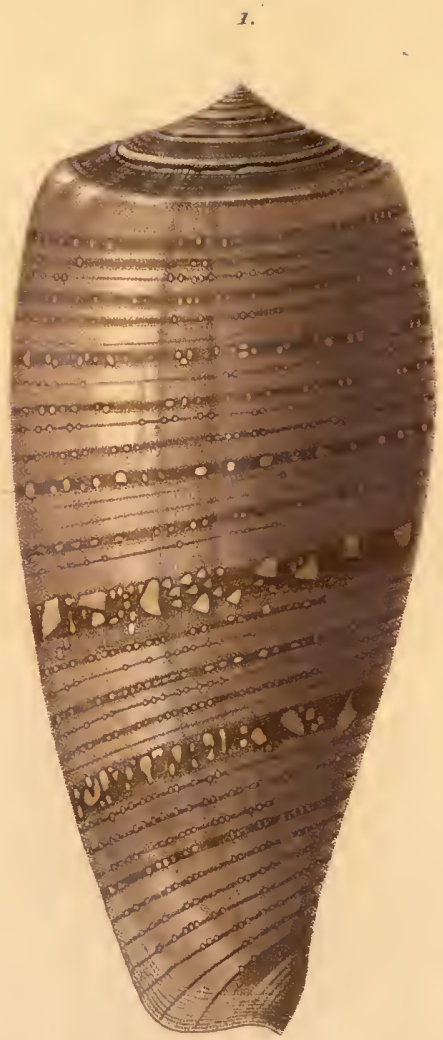

1. Cône Cerf.

(Conus Cermus. Tham.)

2. Cône Aplustre.

(Conus Aplustere. Reere)

3. Cône Mahogani

(Cimas Mahogani. Reone)

4. Cône de Gabricl.

Yconas Gabrielii

(henue) 
THE LIBRARY

OF THE

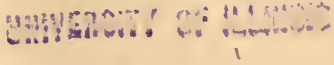




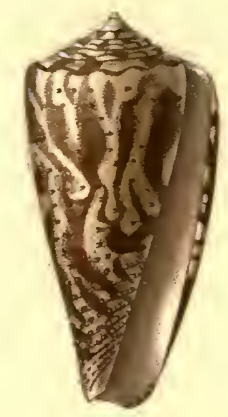

3.
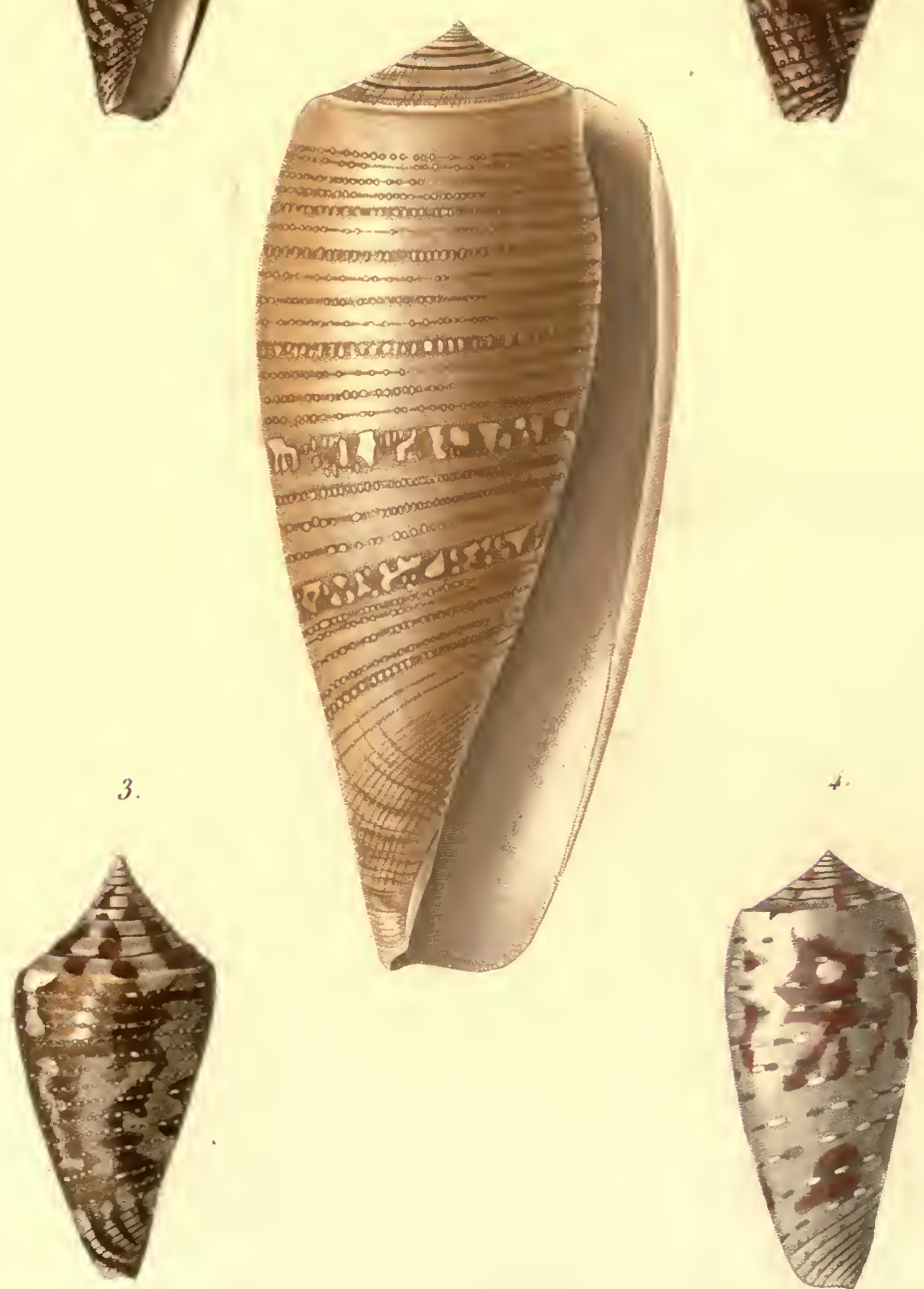

1. Cone Cerf

Conus Cervus.

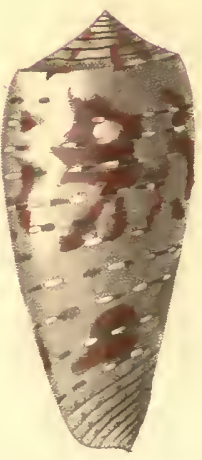

2. Cône des moluques.

(Conus molucceusis. Chemnt

3. Cône magistrat

Conus archon.

Brod. I

4. Cône satiné.

(Conus kimorensis. Brug.) 


\section{THE LIBRARY}

OF THE

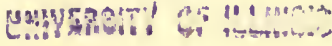



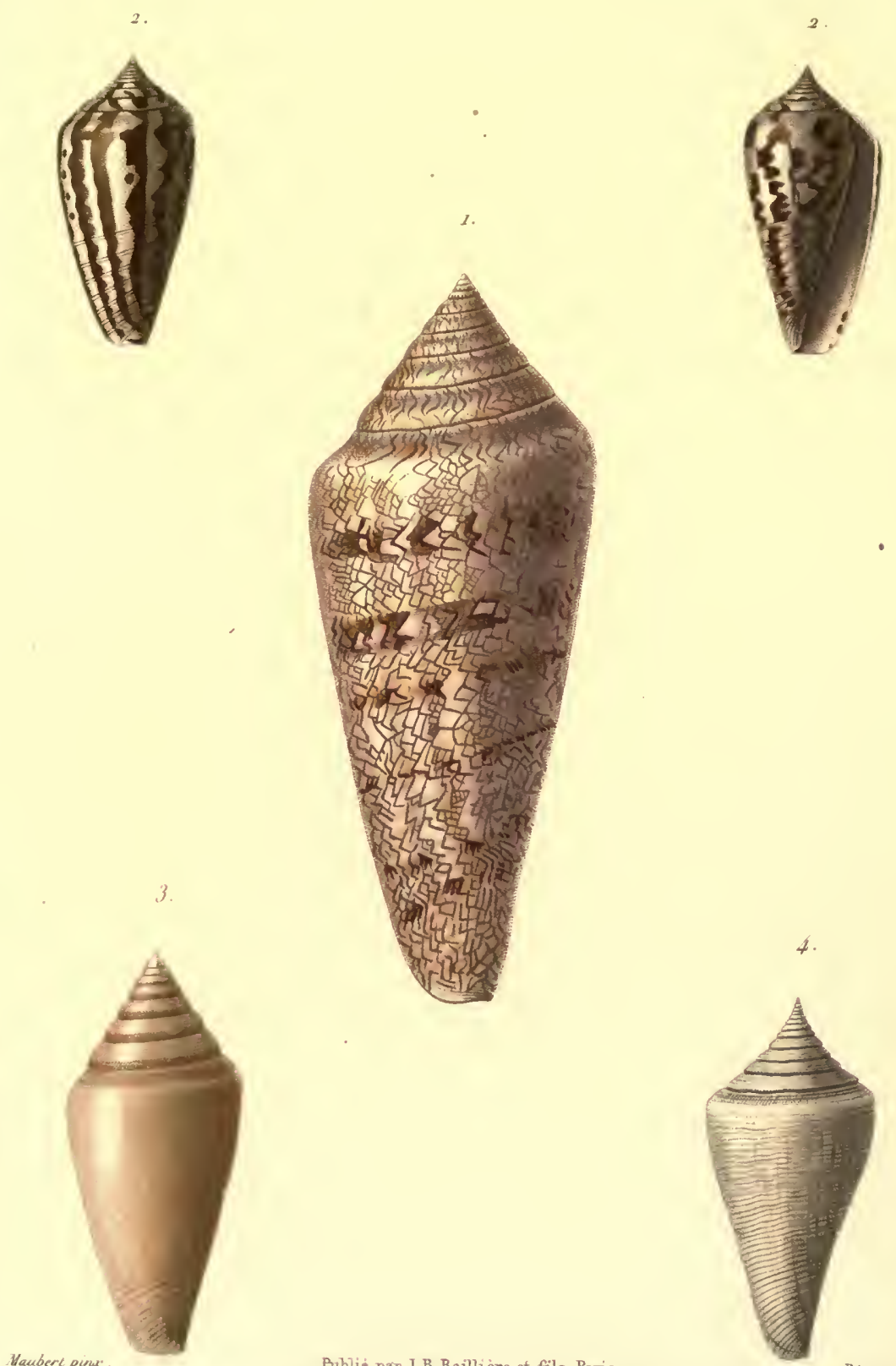

1 Cône gloire de - la-mes".

2. Cone zébre.

3 Cone en fuscau.

4. Cône trenthssé.
(Conew gloria/maris. Chemen)

(Conus sebra. tam.)

(Conus fusiformes. Lam.)

(Conus cancellatur. Brug:) 


\section{THE LIBRABY}

OF rec

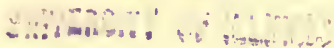


2.

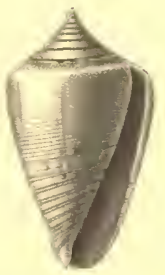

3.

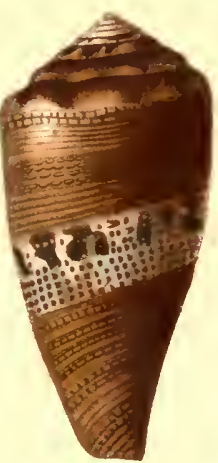

1. Cone gloire-dc-la-mer.

2. Cone colombe

3. Cone de Solander

4. id:

id :

var:

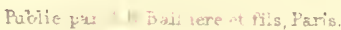

2.

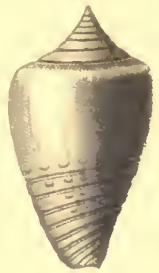

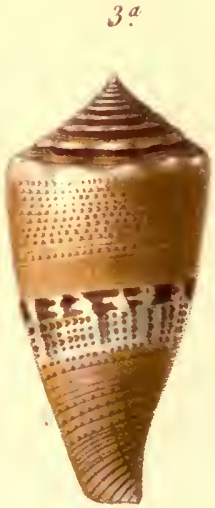

(Conus glorsa-maris. Chemn:

(Conuer columba. Brug.)

(Conus coccineus. Gmel.)

( id: id: var: .) 


\section{THE 'LIBRARY}

$$
0 \% \text { : }
$$


1.

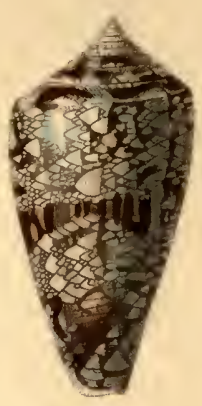

2.
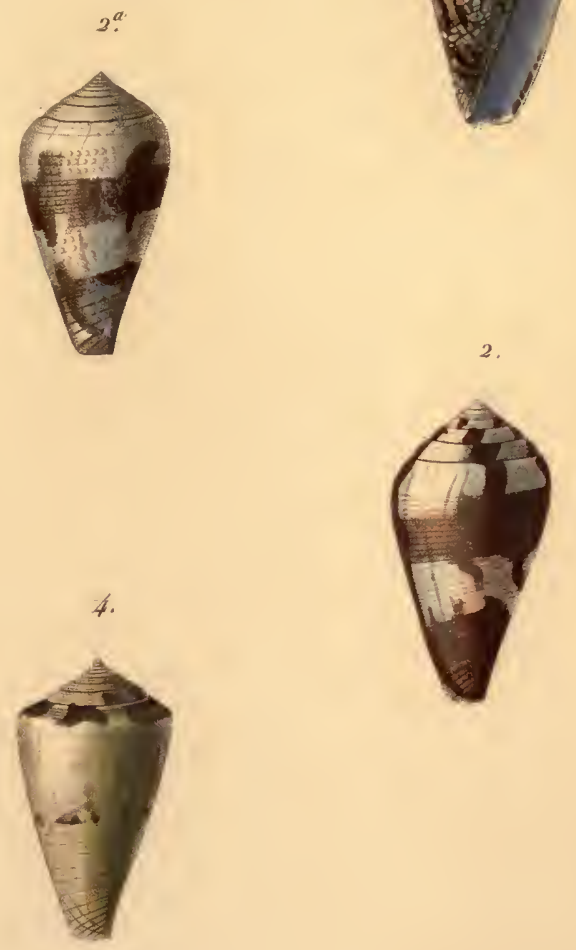

3.
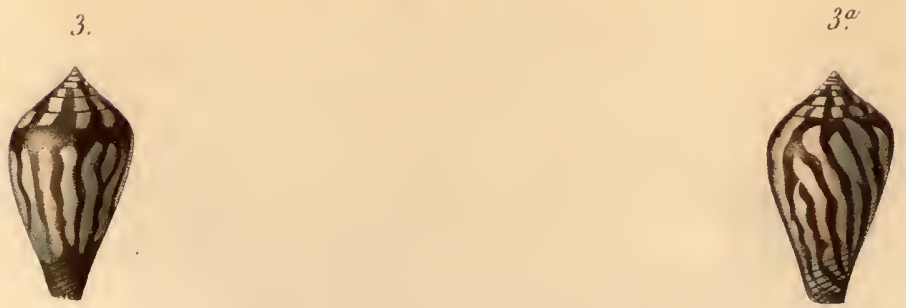

1. Cone de Vietoria

(Conus Victorian Reve.)

2. Cone fóverole.

(Conus fabulat Sow.)

2. id: id: var:

( id: id: var: ,

5. Cone bulbe.

(Conus bulbus. Reene)

$5^{\mathrm{a}}$ id: id: var:

4. Cone citrin.

( id: idt var: )

(Coness cilrimes. nobis) 
THE LIBRARY

Q. $: \because$

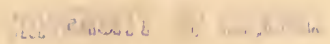



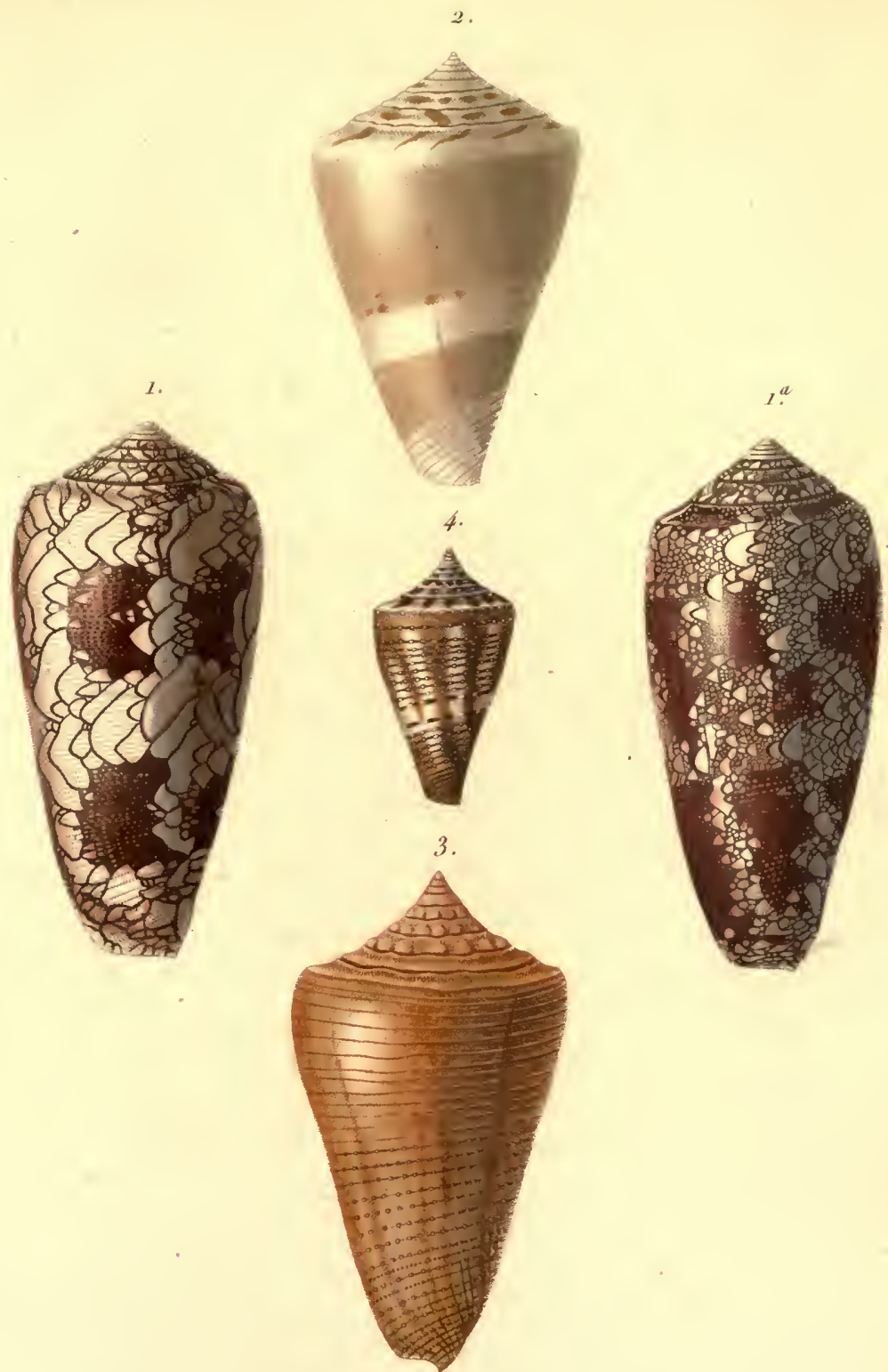

1. Cône perlé

1. id: id: var:

Conus omaria. Brug.)

(id: id: oar: )

2. Cône cordelier var:

(Conus, fumigalus var: !

3. Cône calédonien.

(Coneas caledonicus Brug.)

4. Còne pluie-d'or.

Naubert pinx.

Publie par J.B.Baillière et fils, Perris

(Conus japonicus. Brug.)

Pirod ses 
THE LIBRARY 


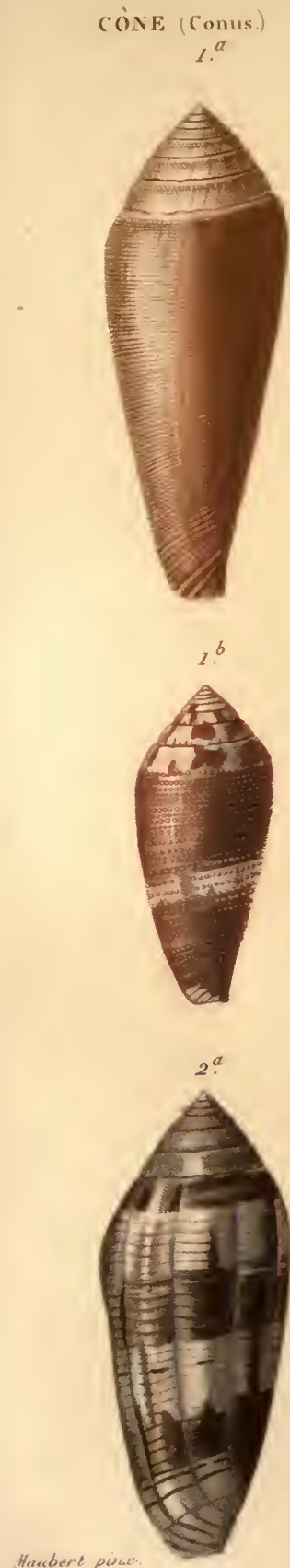

1. Cone gland

$1^{a}$ a 1 c id: id: vartes

3. Cone batonnet.

$2^{\text {a }}$ id: id: var

3. Cône brûlé.
P'. 8o.

I.
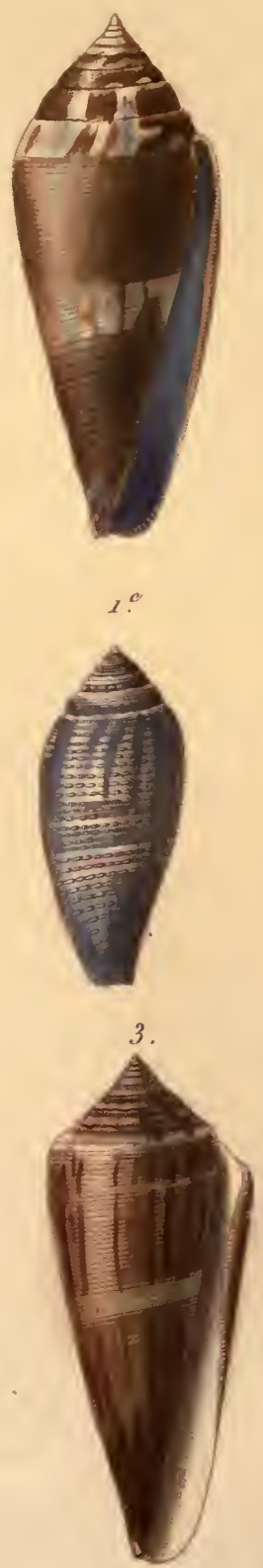

Puroed se

(Conses glans. Brug)

(id: itt: vartites )

(Foness tendisueus. Bnug)

(id: id: var: )

(fonuar, furbus. Reeve) 


\section{THE LIBRARY}

OS TuE

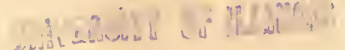



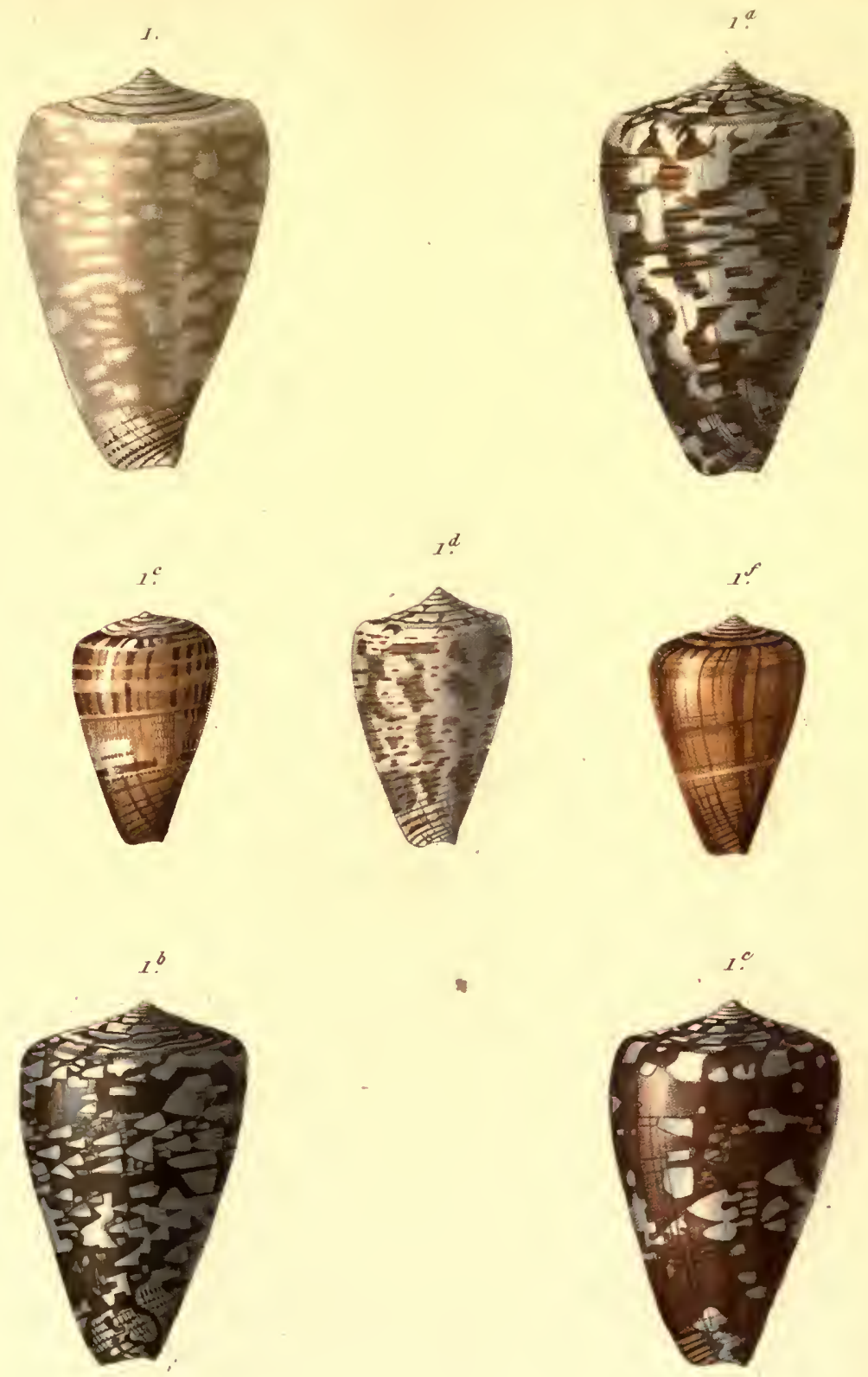

-

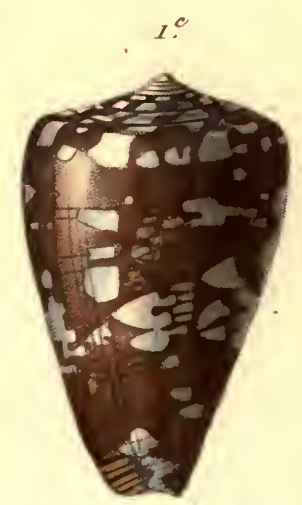

1. Còne neigeux.

$1^{n}$ a $1^{f}$ id : id: vartés

/Comes mivosers. Lam.

(id: idt: vareletes 
THE LIBRARY

of ?is 

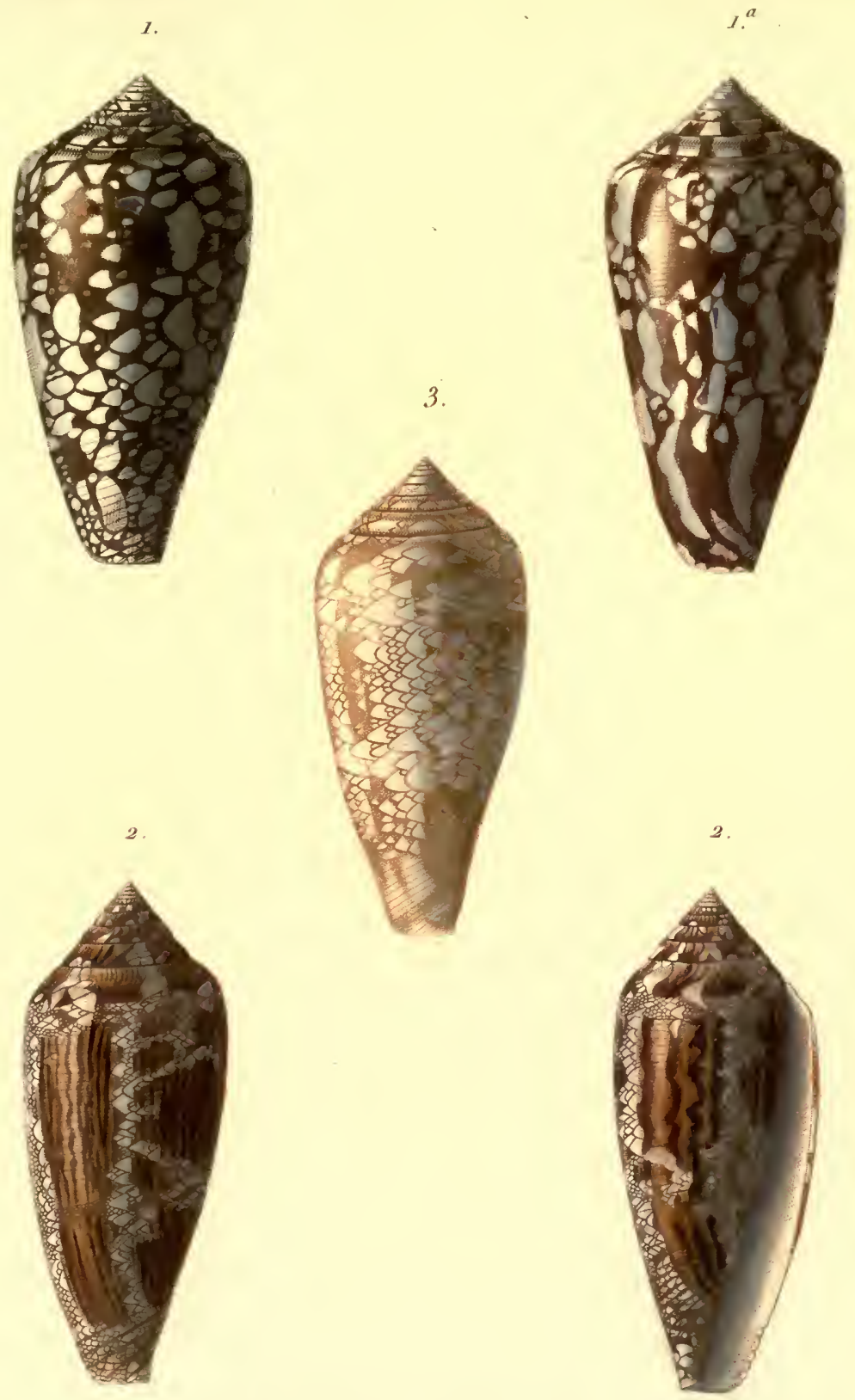

1. Cône pouding:

(Conus rubiginosus. Brug.)

a id: - id: var:

id:

id: var: ।

2. Cône drap.llambé.

(Conus aurews. Brug.)

3. Cône couleuvré.

(Conus colubrinus. Lam.) 
THE LIBRARY

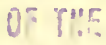

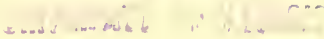


côse (Conus)

PI. 83.
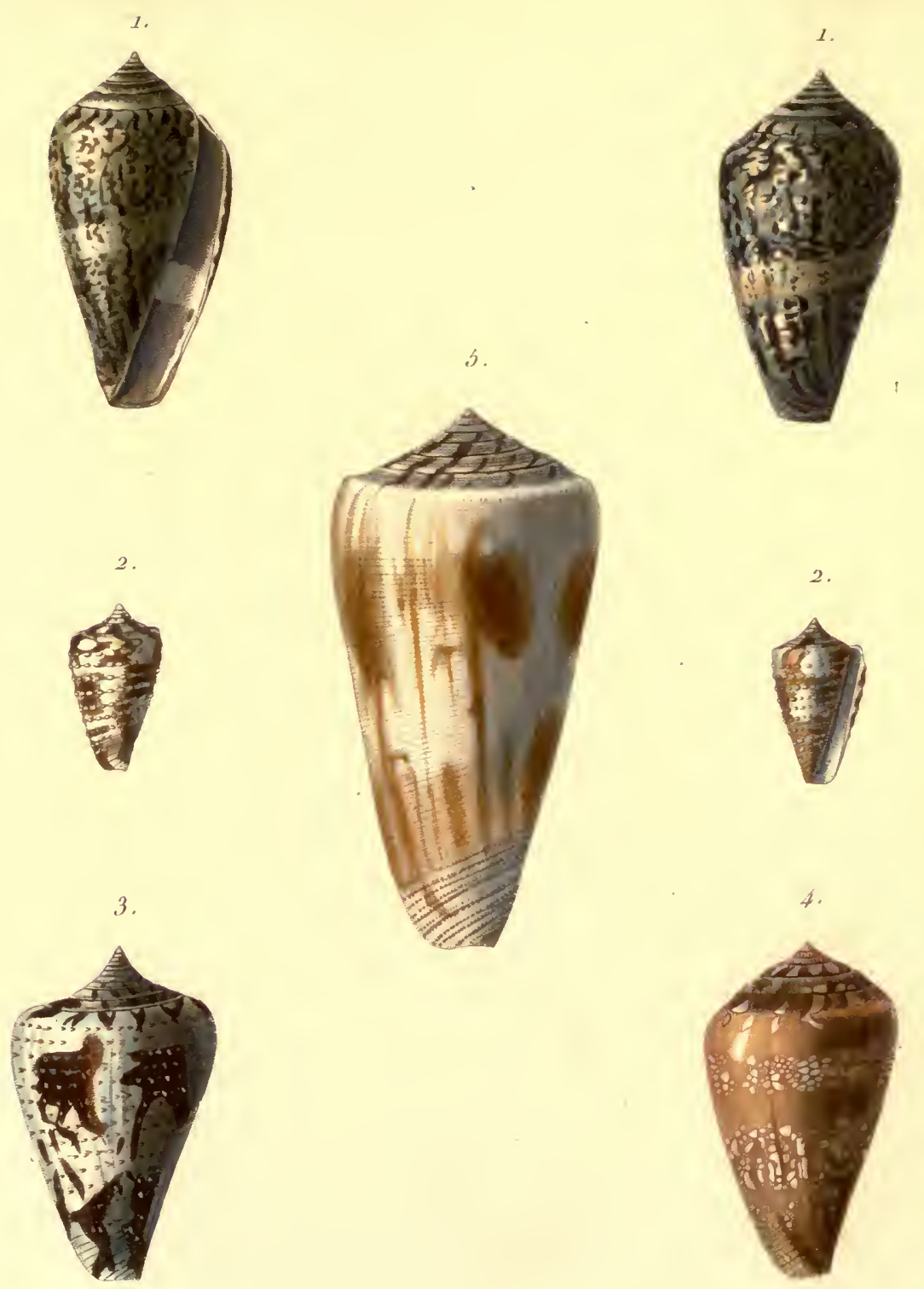

3. Cone hybride.

(Conus hybridus. nobis.)

2. Cone tacheté de blanc.

(Conus albimaculatus. Sons.)

5 Cone velours.

(Conew lusonicus. Brug)

4 . Cone de Lamarek.

(Conuer Lamarckie. nobis)

5. Cone radis var.

(Cones raphanus. var: ) 
THE 'LIBRARY

OF Ting

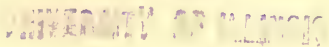




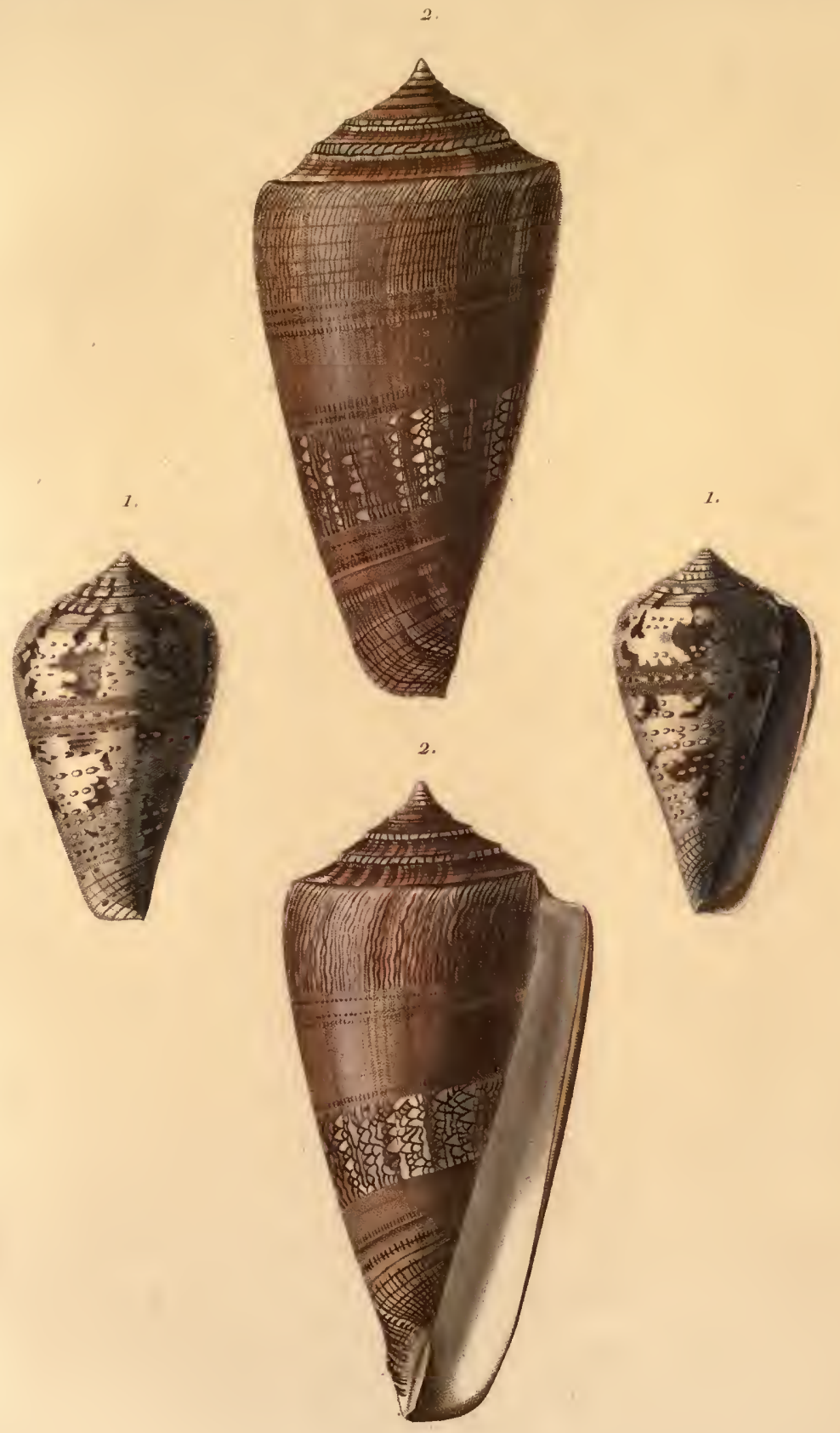
1. Cône de Porto-Ricco.
(Conus Portoricanues Brug.)
2. Côné amadis var:
fonews amadis var. 


\section{THE LIBPARY}

of THE Ganizest? 


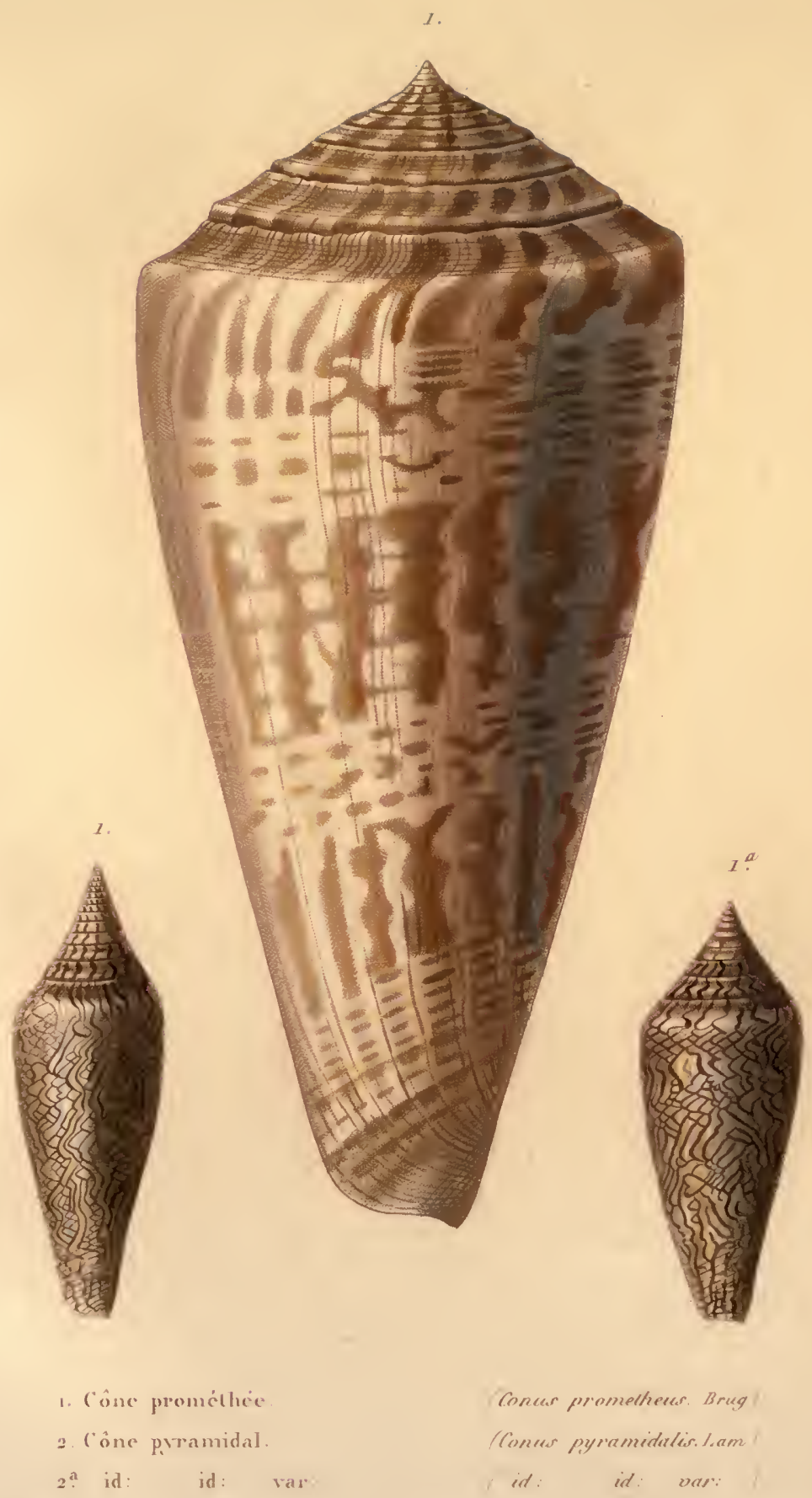




\section{THE LIBRARY}

of pens

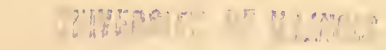




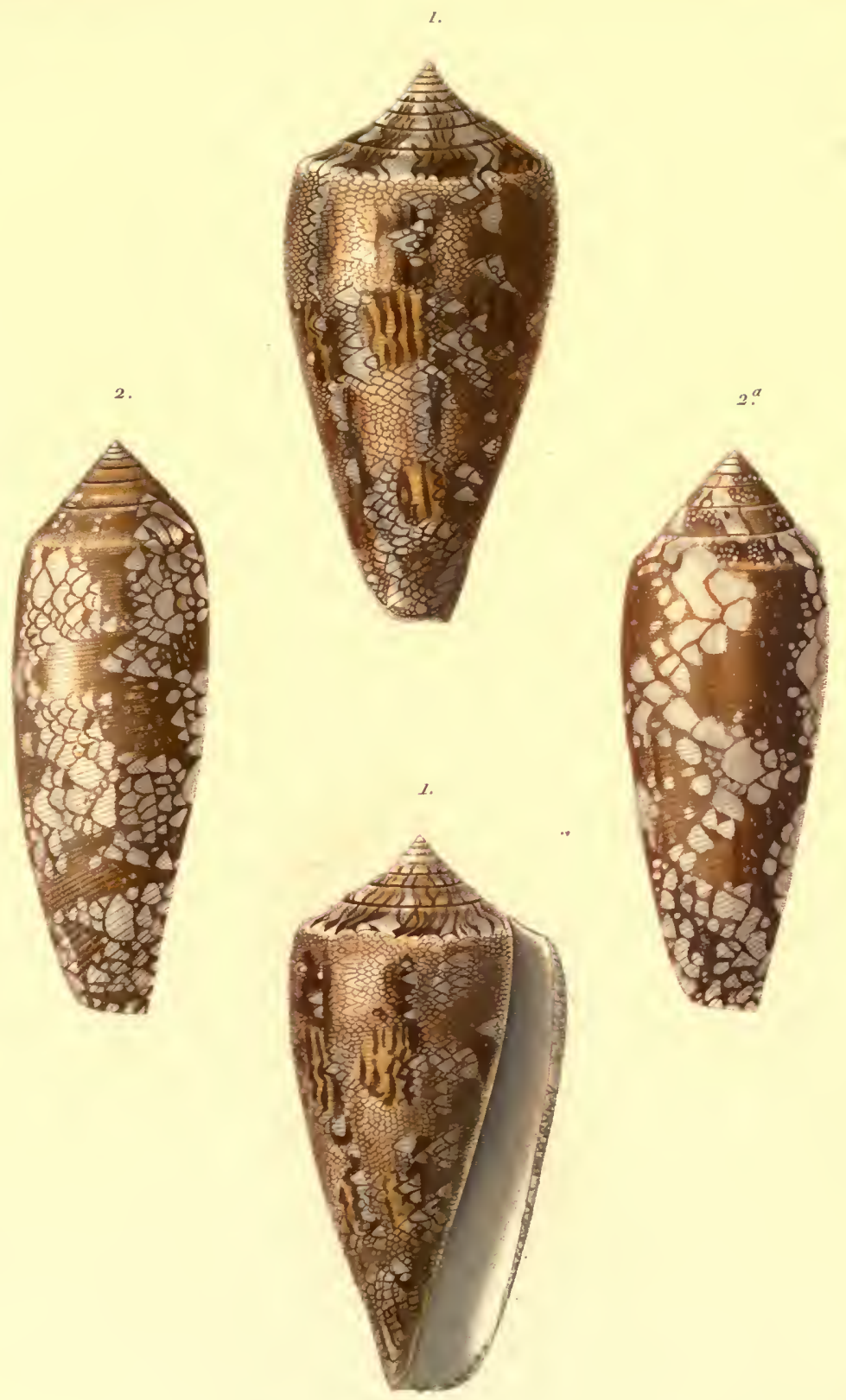
1. Cone abbé
(Conus abbas. Brug.)
2. Cone drap-orangé
(Comess auralus. Brug)
$2^{\text {a }}$ id: id: var:
( id: id: var.

Haubere pens.

Publiè par J. B. Bailliène ef fils, Paris. 


\section{THE LIBRARY}

$$
\text { o. ?IS }
$$

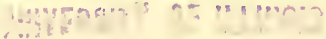



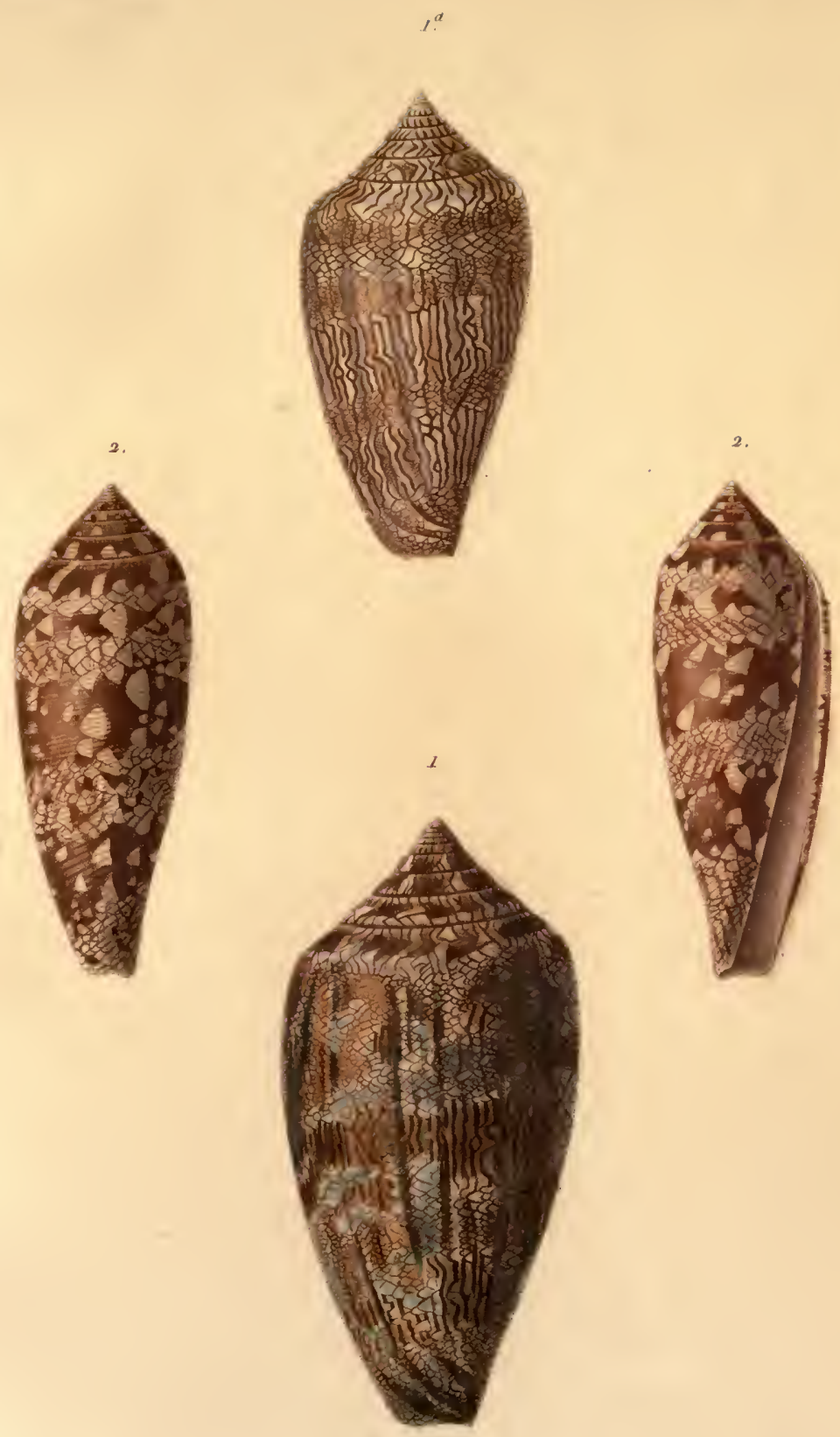

1. Cone petit-drap.

$1^{\text {a }}$ id: id: var

2. (ône drap-réticule".
Comes panniculess. Lames

(id: id: varr)

(Conus slauss. Tin.) 


\section{THE LISRARY}

c. TIE

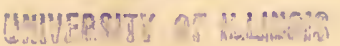




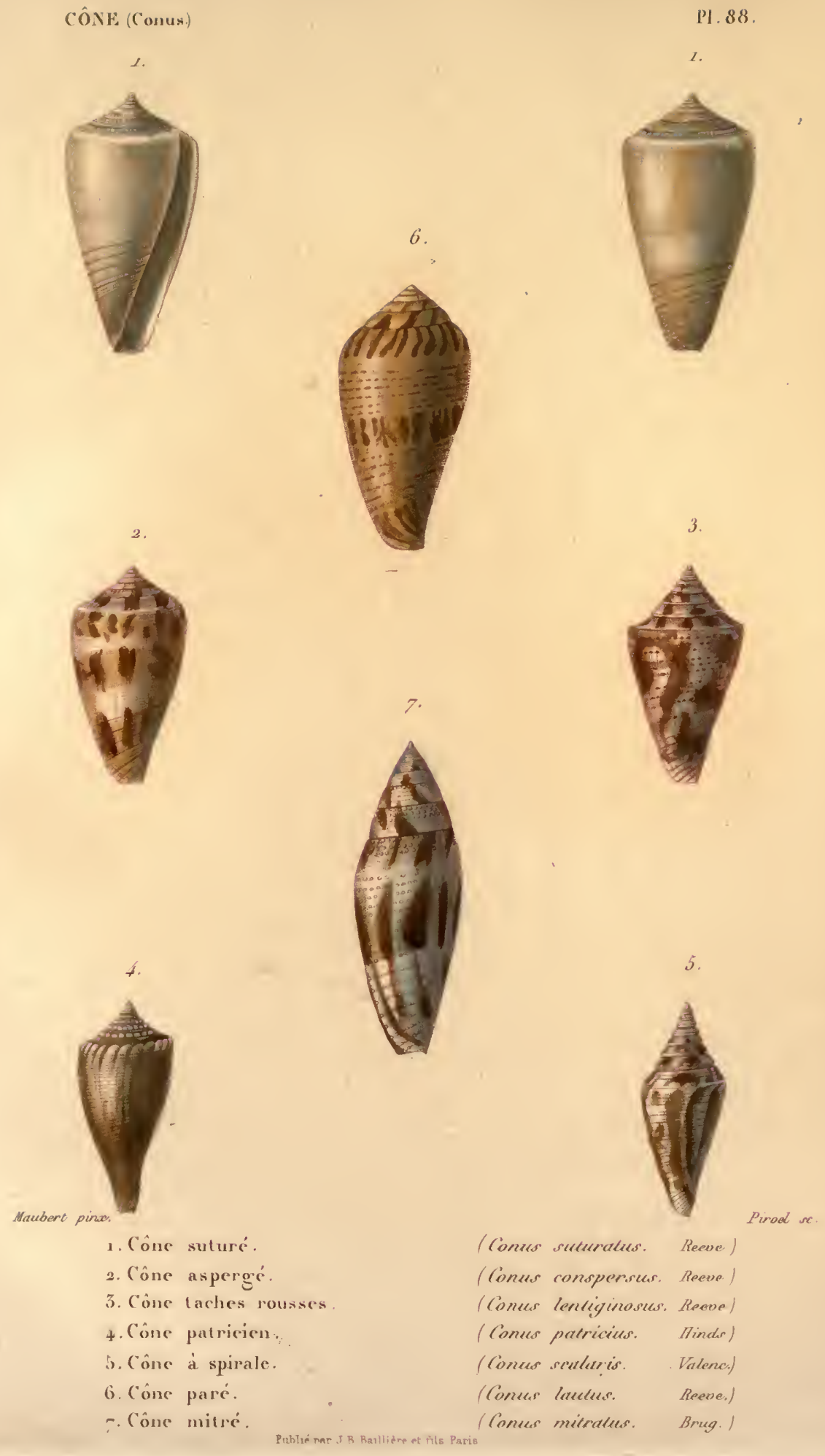


THE LISRARY

OP TUE

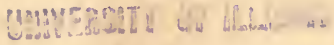



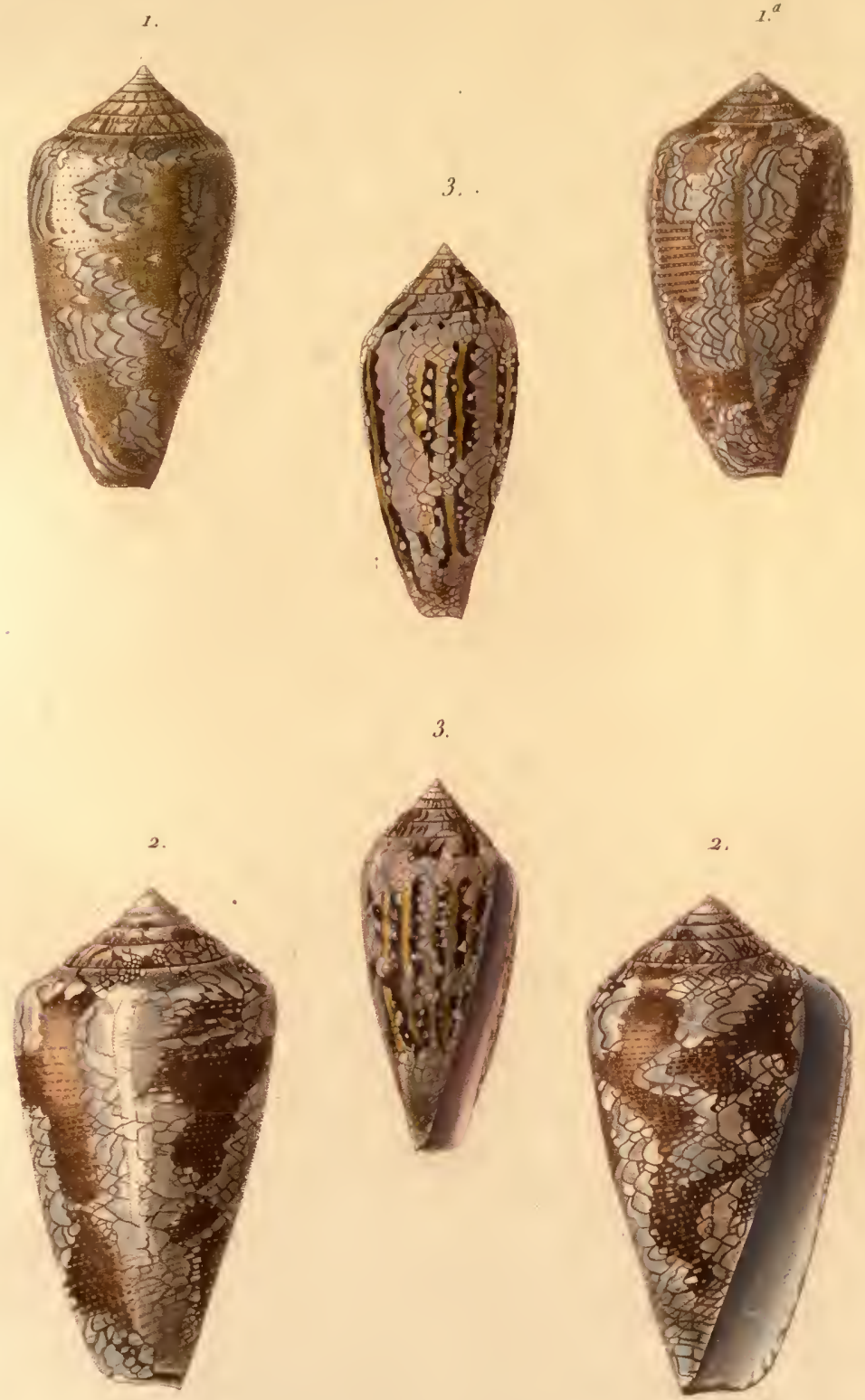

1. Cone prélat

(Conus pialalus. Brug.)

$r^{a}$ id: id: var.

(id: id: var. .

2. Cone plumeux.

(Comus pennaceus. Born)

5. Cone ligat

(Conear legalus.' Tram) 
THE LIBสมกY

(I) TIME

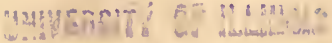




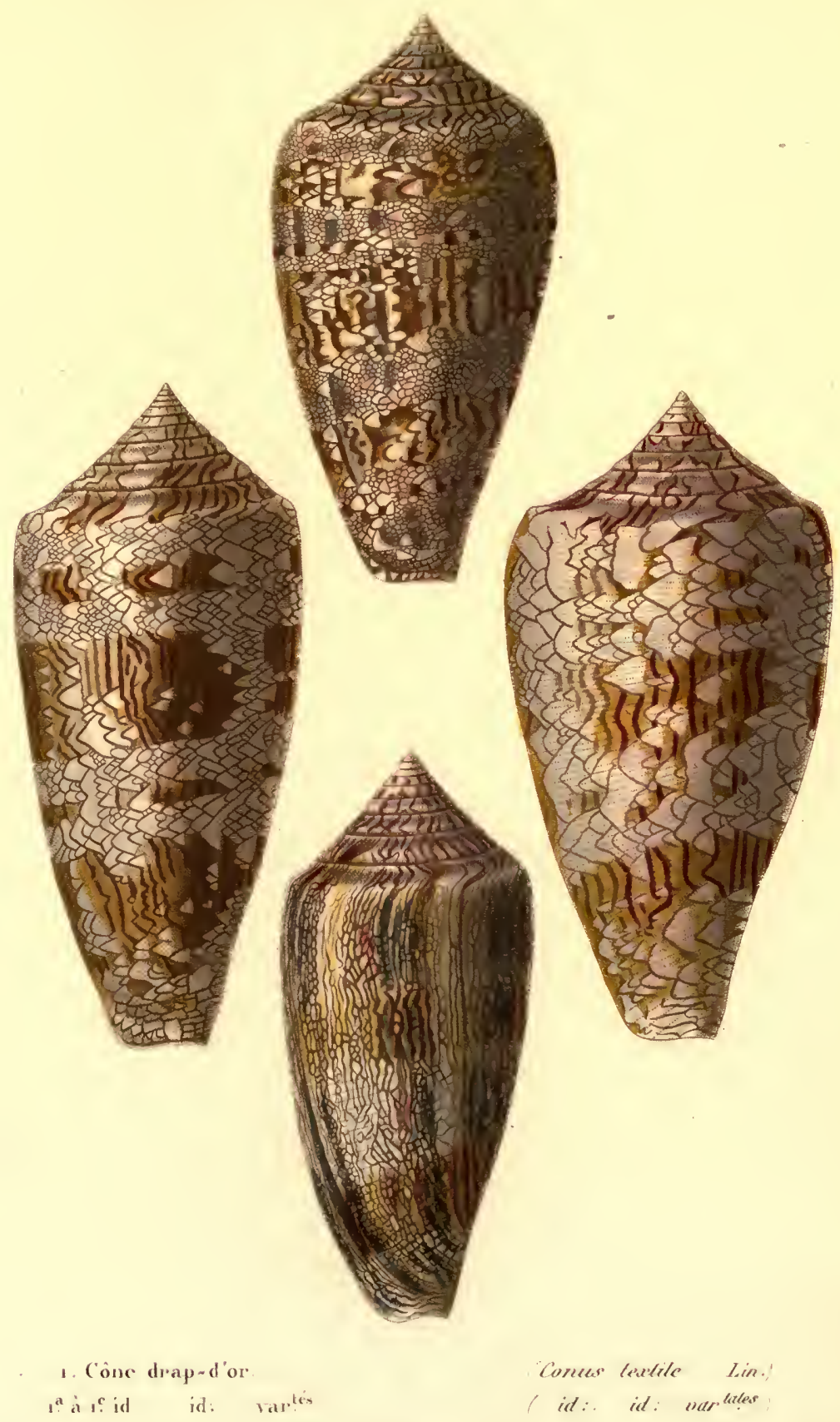




\section{VHE LIBRARY}

OF INE

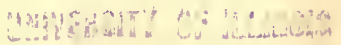



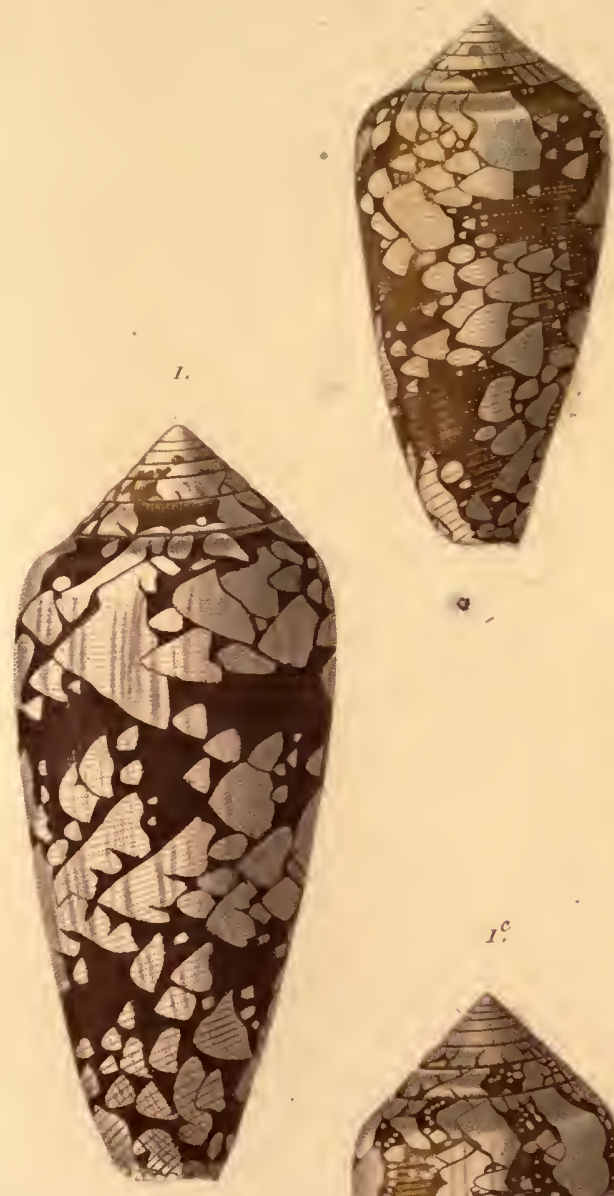

$\checkmark$
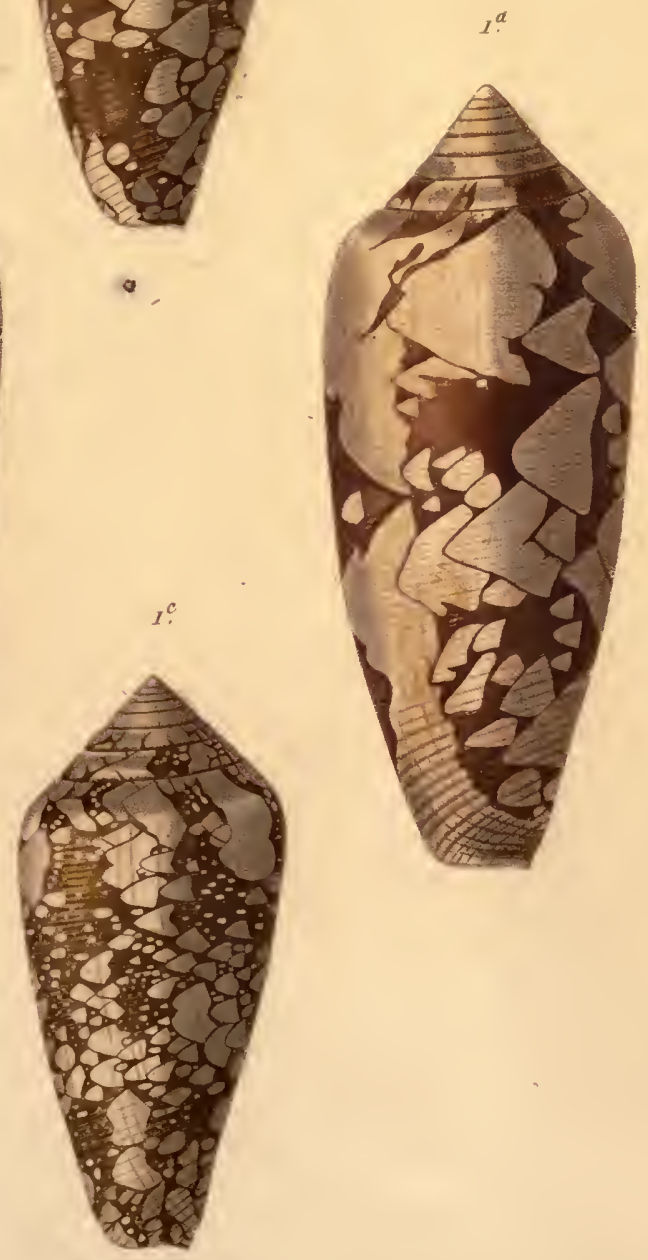

1. Cône évéque.

(Conus episcopus: Brug.)

1. a is id: id: vartés

(id: id: vartalas) 


\section{THE LIBRARY \\ OF THE

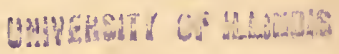




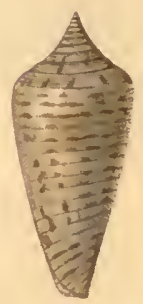

1.
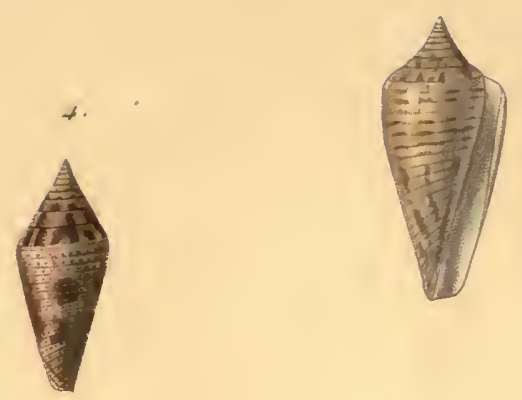

5.
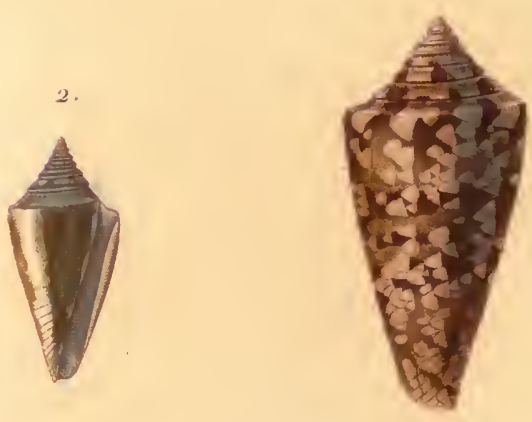

2.

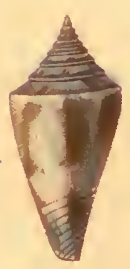

6.
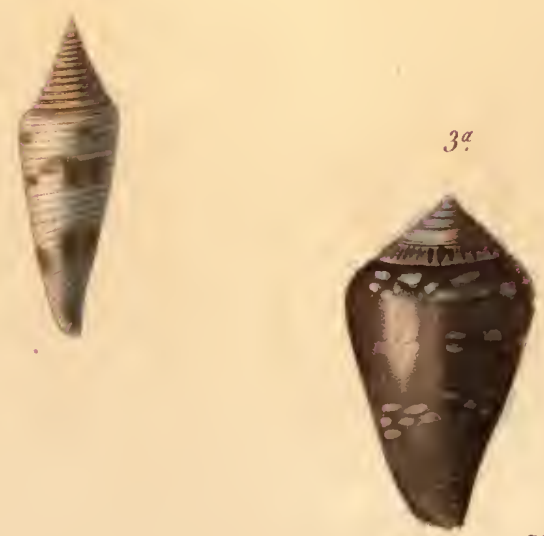

Moubert del.

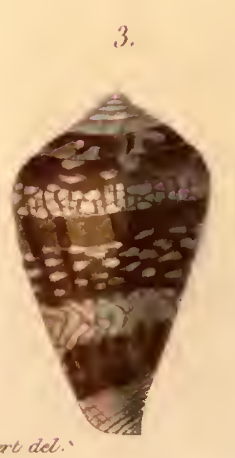
1. Cone mucroné
2. Cone jaunatre.
3. Cone petit-coin.
3a id: id: var:
4. ('one aculeiforme.
5. Cone Neptune.
6. Cone subulé.

(Conus mucronalus. Reeve.)

(Conus, Aavescens. Gray.)

(Conus cuncolus. Reeve)

( id: id: var: )

(Conus aculeiformis. Reever.)

(Conus Noptunus. Reeve.)

(Conus subulatus. nobis.) 
THE LIBRARY

OF THE

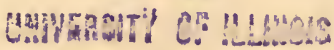



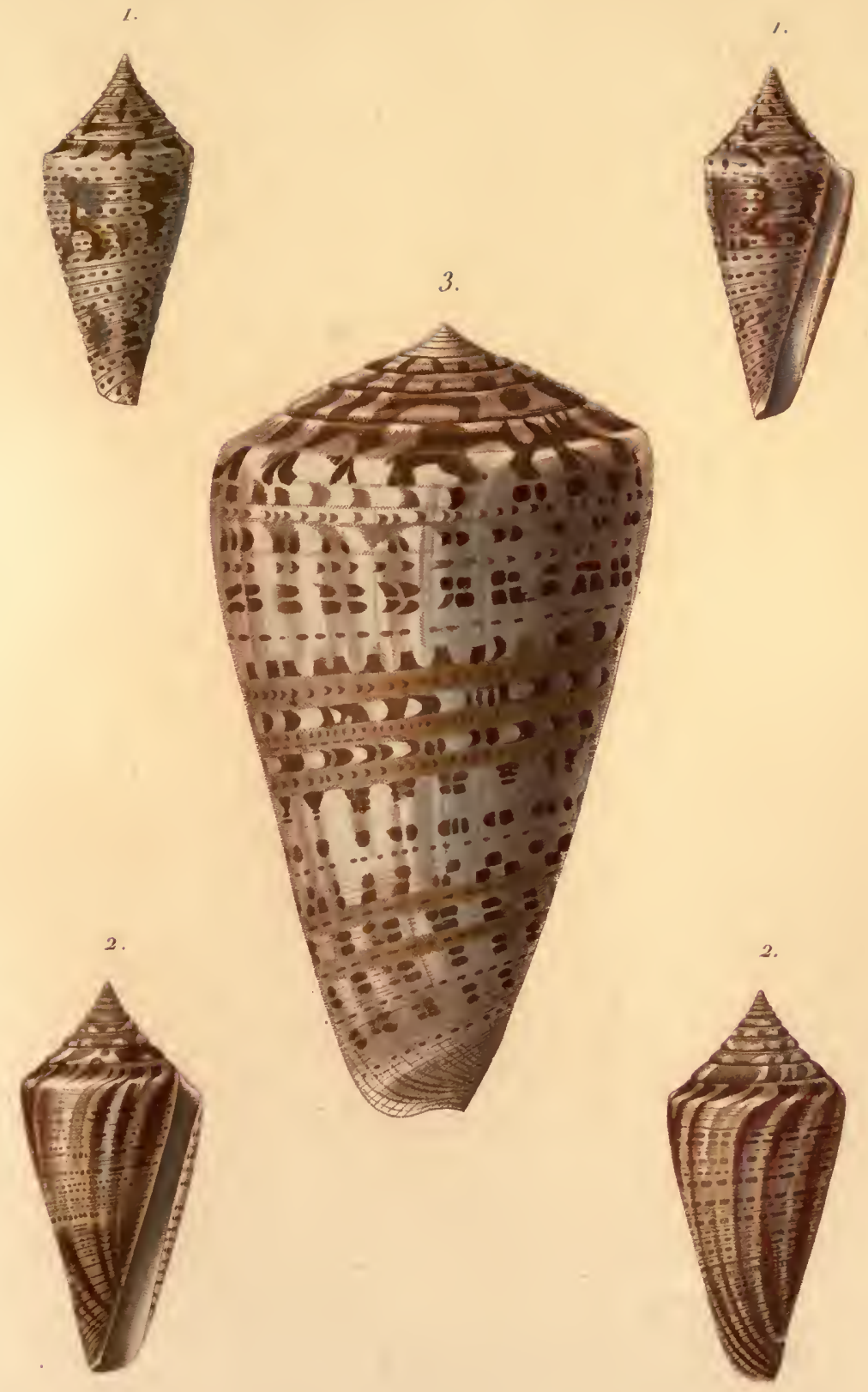
1. Cone $\dot{a}$ collier.
2. Cone sanglé
3. Cone siansois.

\author{
(Conear monilifer: Brod.) \\ (Cones cingulutes'. Lam:) \\ (Cones sciesuresess Brus.)
}


THE LIBRARY

OF IME

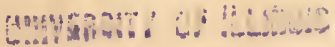



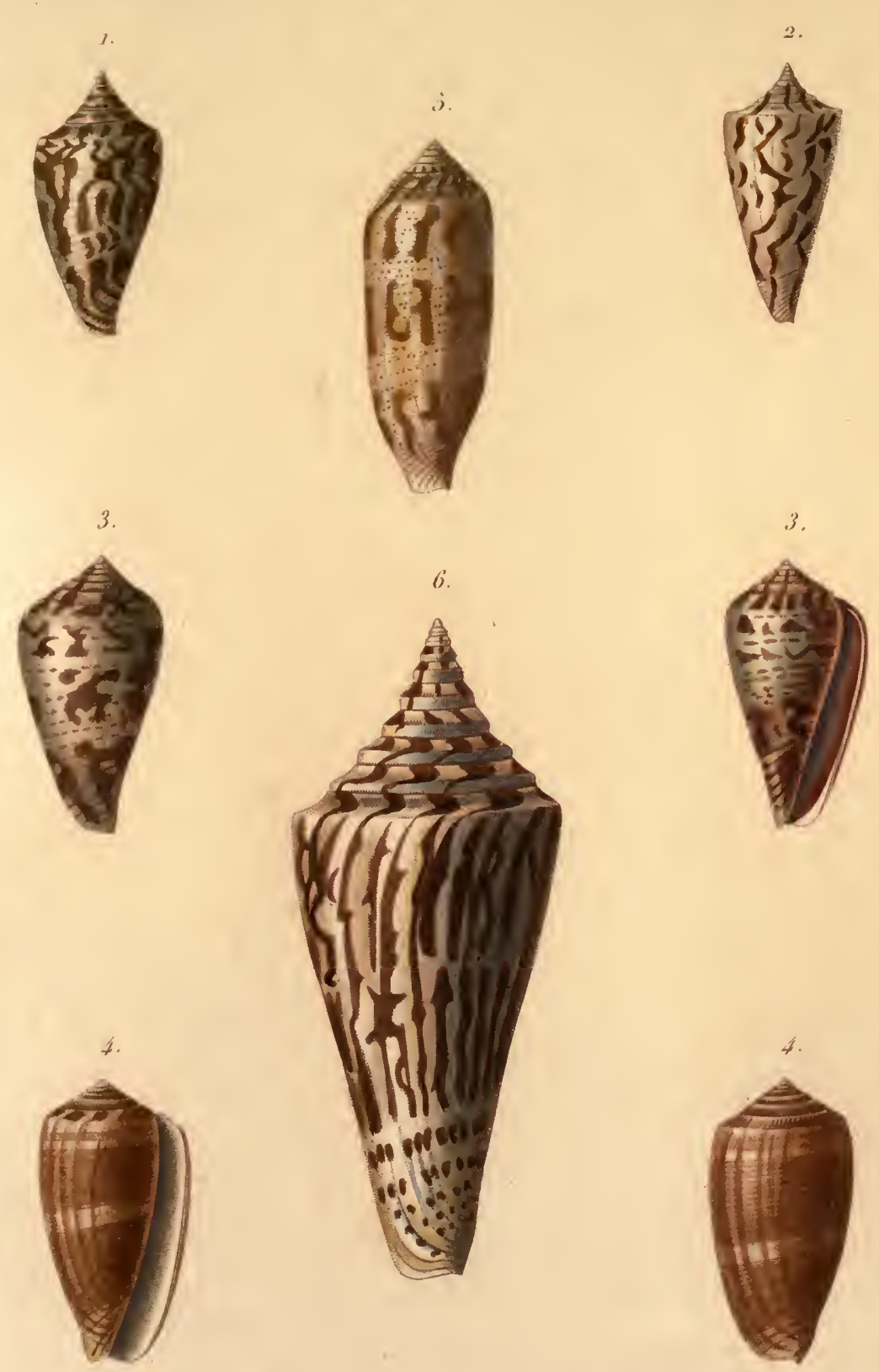
1. Cone ondé
2. Cone de (leme
3 cone imule.
4. Cone suaire.
5. Cone artople
6. C'ine chagé
(Coness undertes nobis:)
(comes (lorii. Reeve)

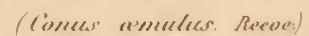
(ioness simelore. Reave)
(imeles arlopples. Jiow.)

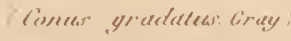


THE LIBRARY

OF TUE

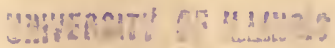



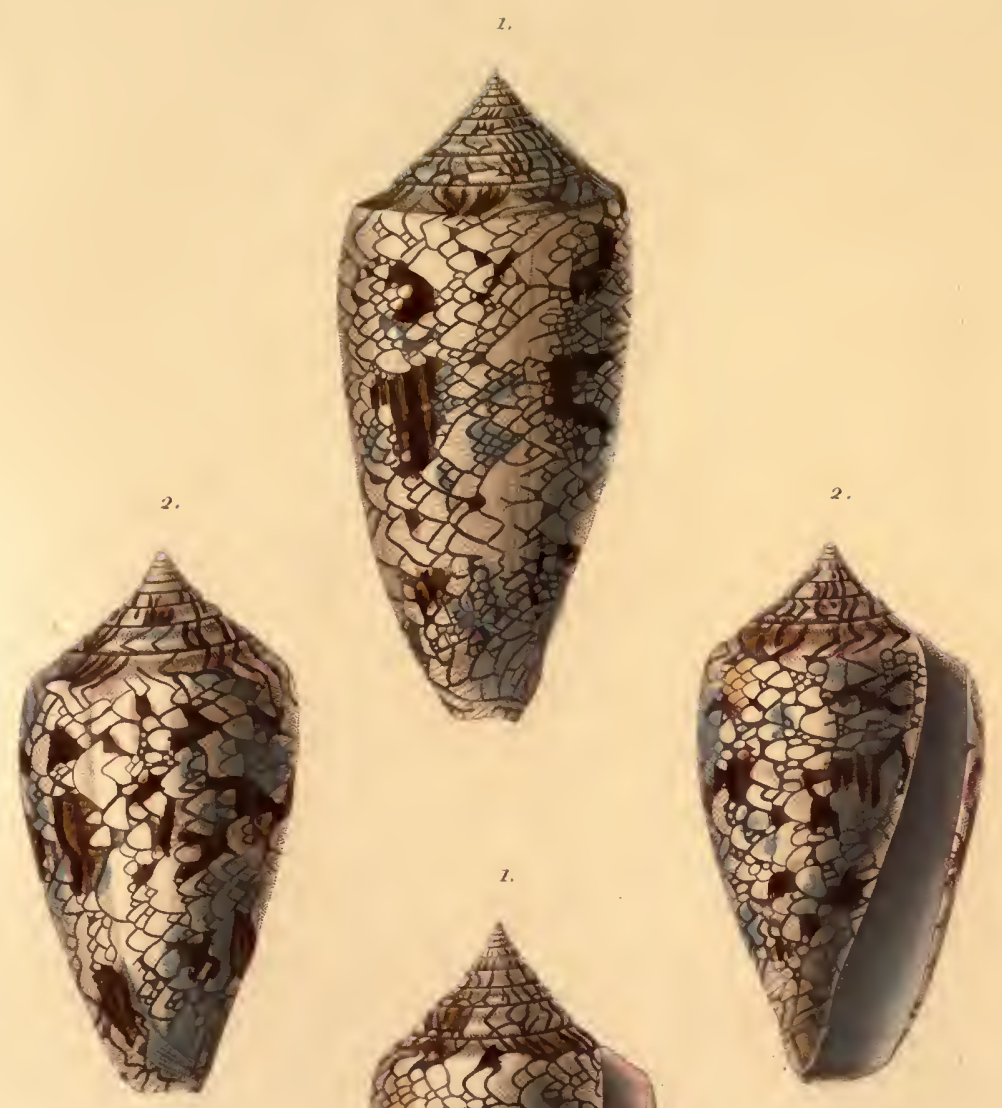
1. Cone chanoine
(Conus cunonicus. Brug.)
2. Cône tramail.
(Conus verriculum: Reeve) 


\section{THE LIBARRY}

QIF IME

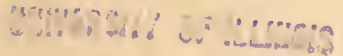



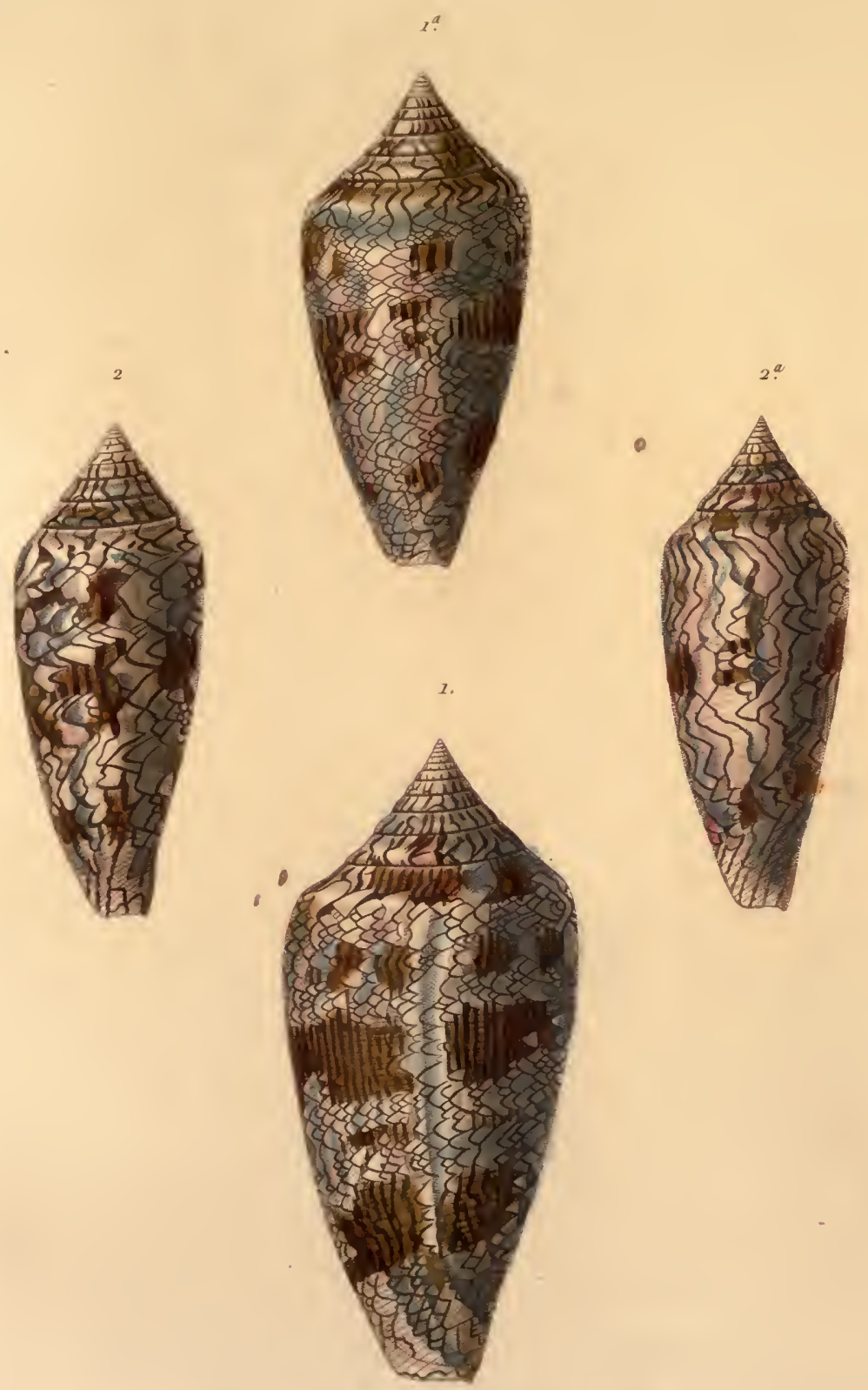

1. Còne arehevêque.

(Conus archiepiscopus. Brug.)

$\mathrm{J}^{\mathrm{a}}$ id: id: var:

(it: id: var: ।

2. Come prramidal var:

2 a id: id: var:

(Conus pyramidalis var: )

Publie par. 3. B. Baillière et fils, Pans

ist: var: ) 
THE LIBraRY

OF TUE

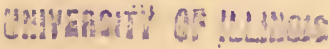




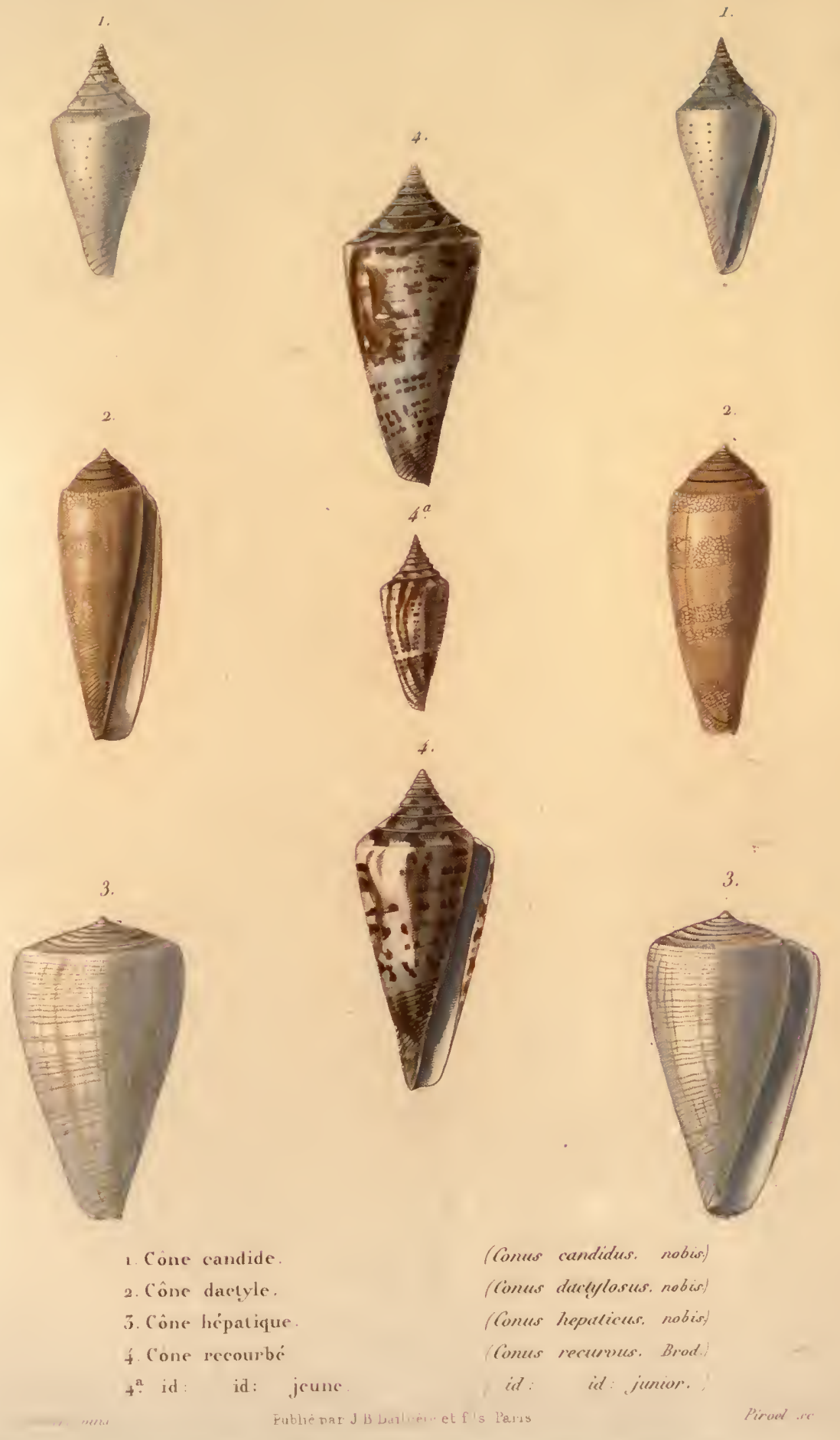


THE LIBRARY

OF SNE

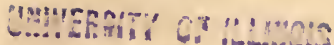



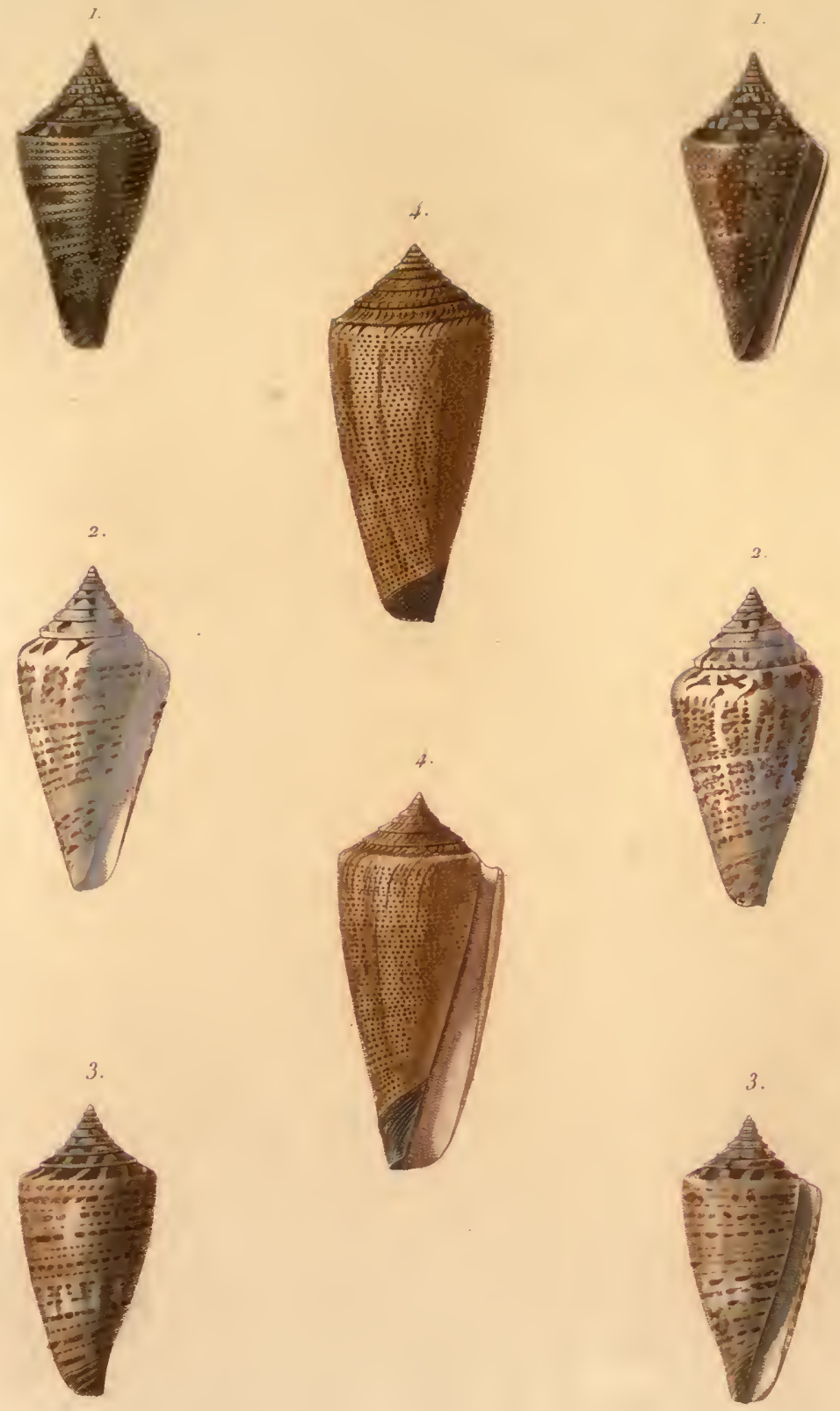

1. Cône chagriné

Conus grunarius. nobis.

2. Cone de Mhilippi.

(Conus Philippie. nobis:)

i. Cone de Largilliert

lonus Lurgilliertii. nebis?

*. Cone de Cécile.

Conus resitei.

nabios 
fhe l19Rsar

of ruE

4...t. 

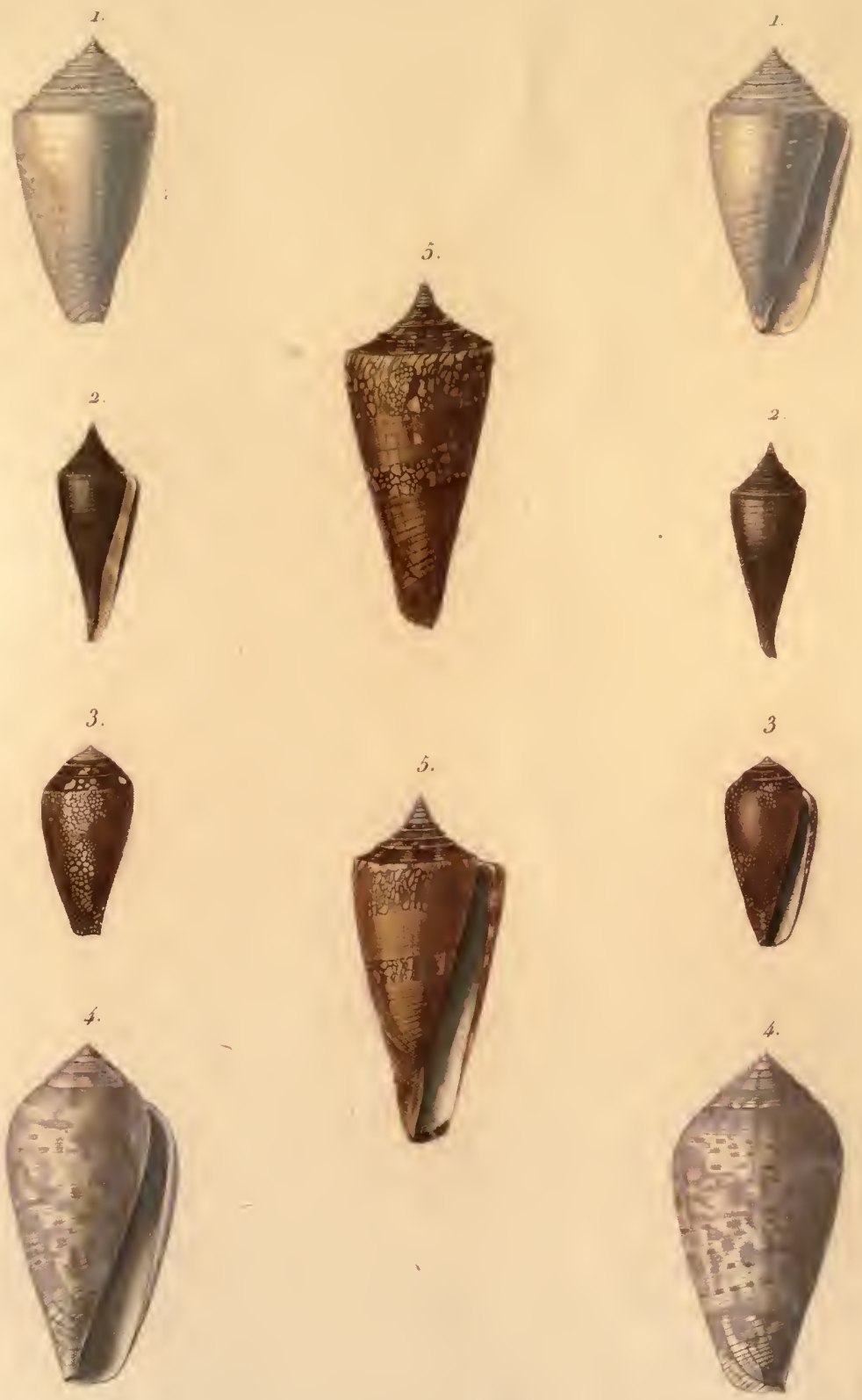

1. Cône crélacé

2. Cône eisclé.

3. Cône étoilé

+. Cône décrépit

5) Cone de Neptune

(Conus cretaceus nobisy)

(Conus insculptus. nobis)

(Conus stellatus. nobio')

(Conus desrepitus. nobis.)

(Conus Heplunus. Reene) 


\section{THE LIBRaRY}

of rins

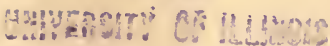


)
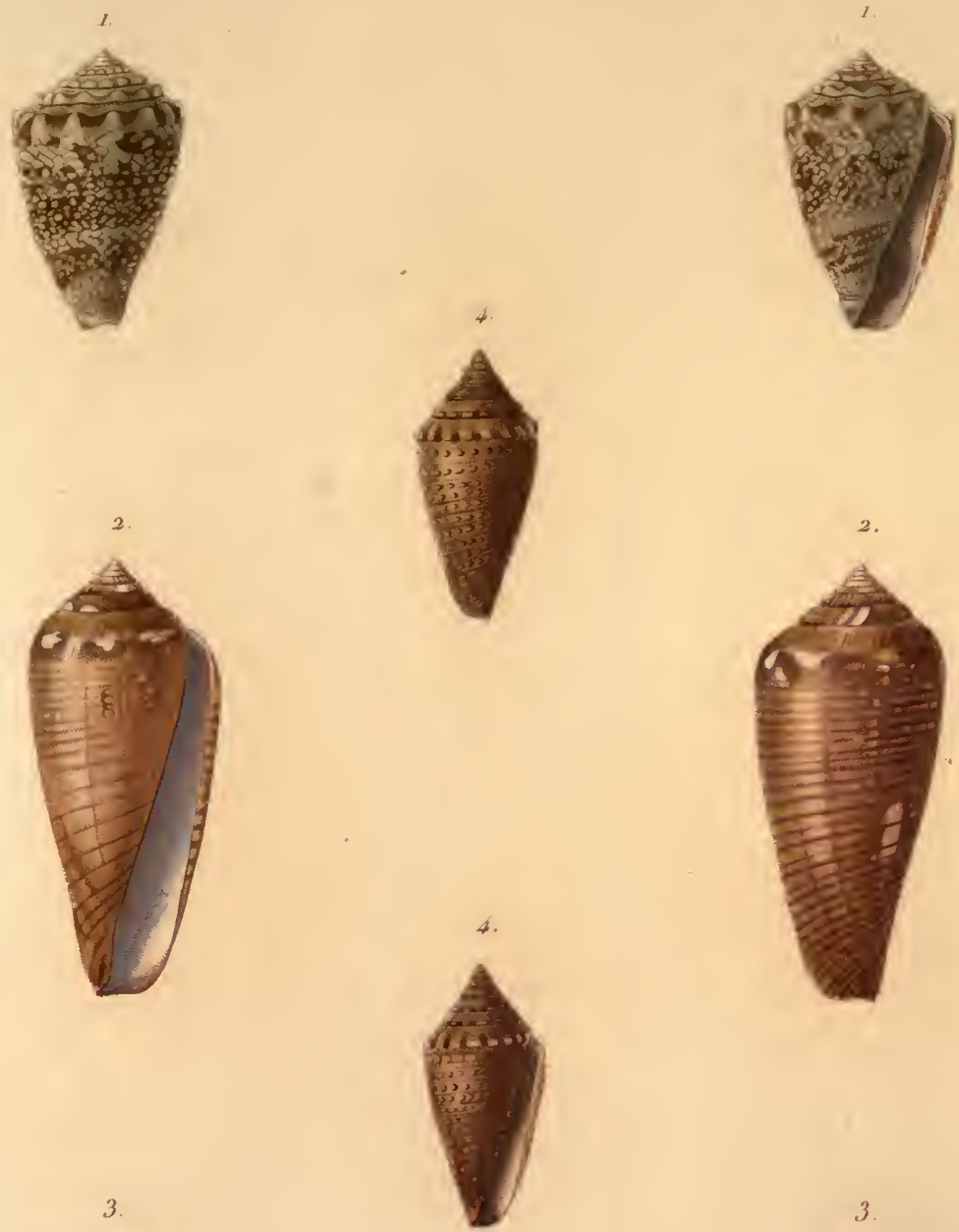

3.
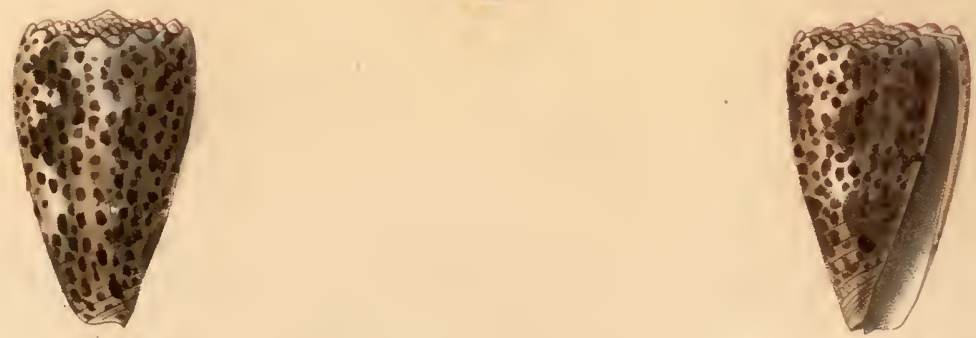

1. Conc raboleux

Conus scaber.

nobio.

2. Come de bernardi

Comeas Bernardii. nobes:

3. Cone de Vaulier

ínes laulieri. nobis.

4. Cone nodifer

Comus nodiferts. nobis. 
IHE LISPARY

of ruE

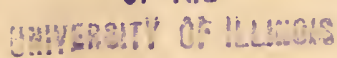



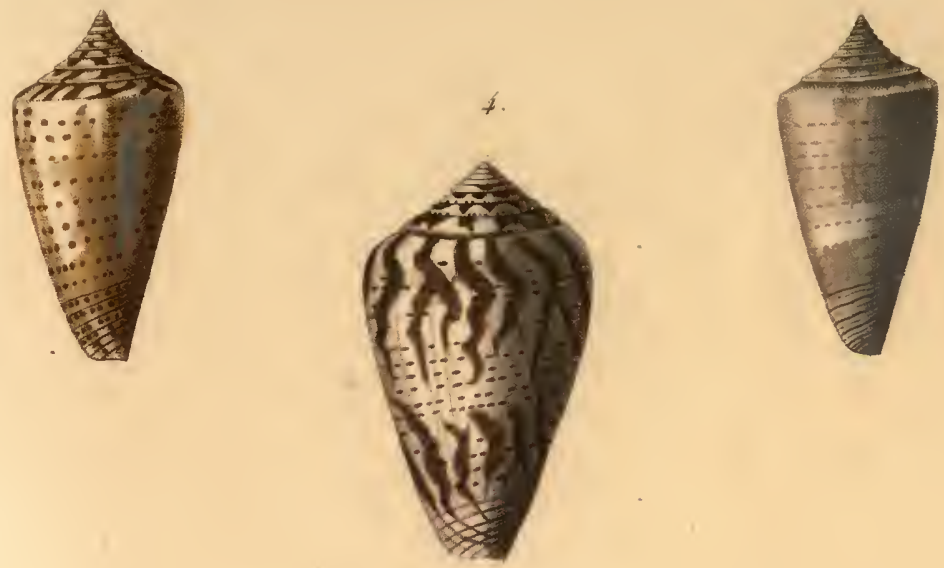

2.
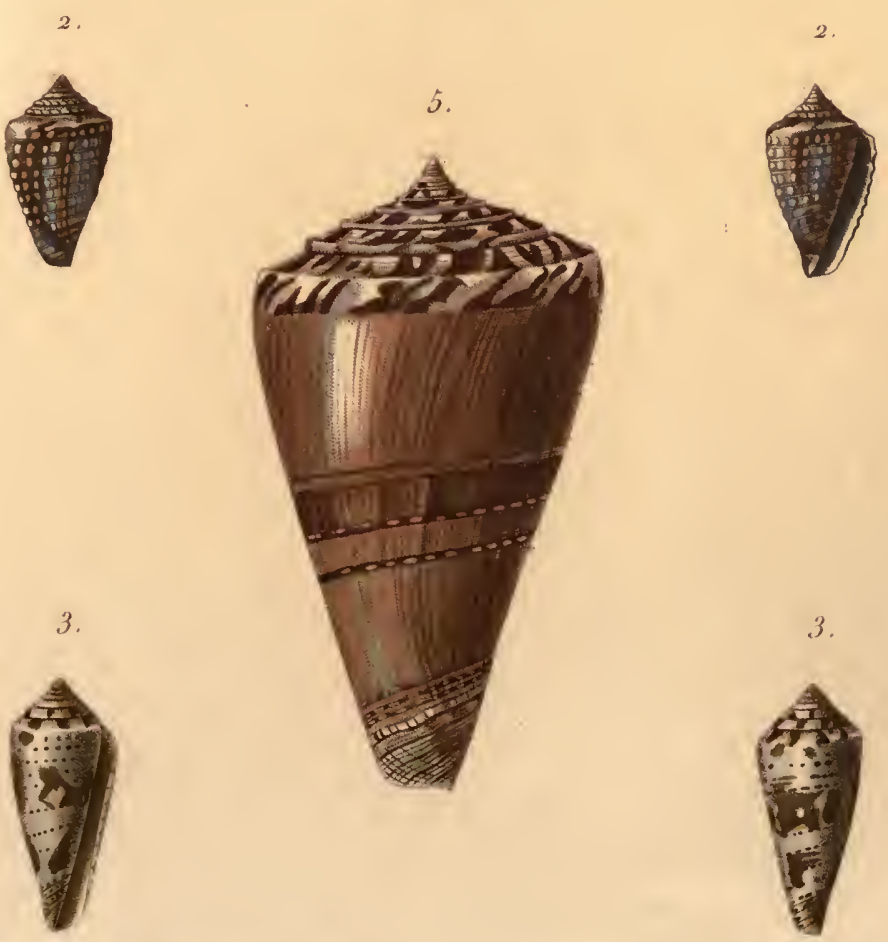

1. $x^{\text {b }}$ Cone de Largilliert var:

2. Cône pustulé.

3. Cône disparate.

4. Cone foudrovant.

j. Cone de Halaca.
Conus Largillierti var

cones puslulants. nobis

(Conus dispar. Sow.)

Conus fulgurans. Brug.)

Cones Malucanus var: 
THE IORARY

of r I

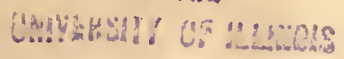



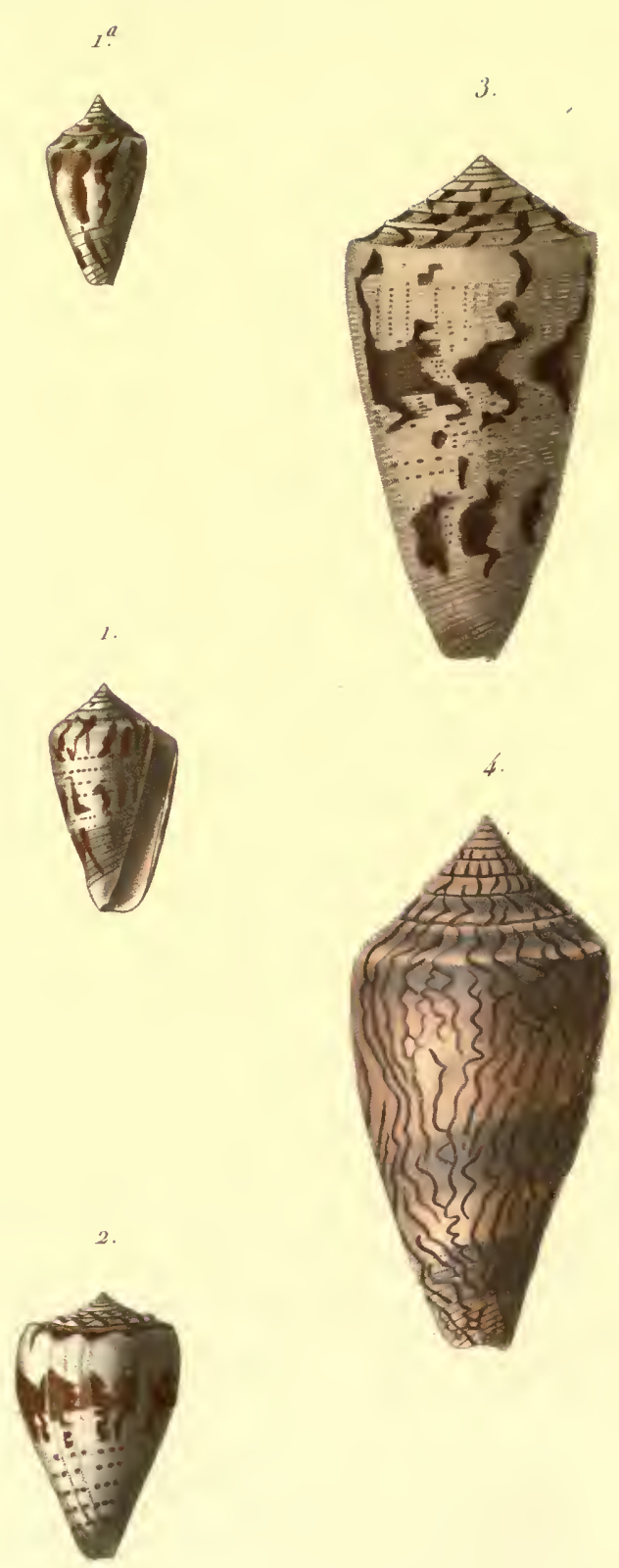

$1 ?$

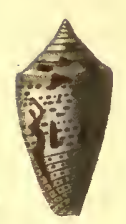

1.

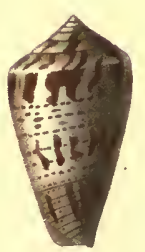

2.
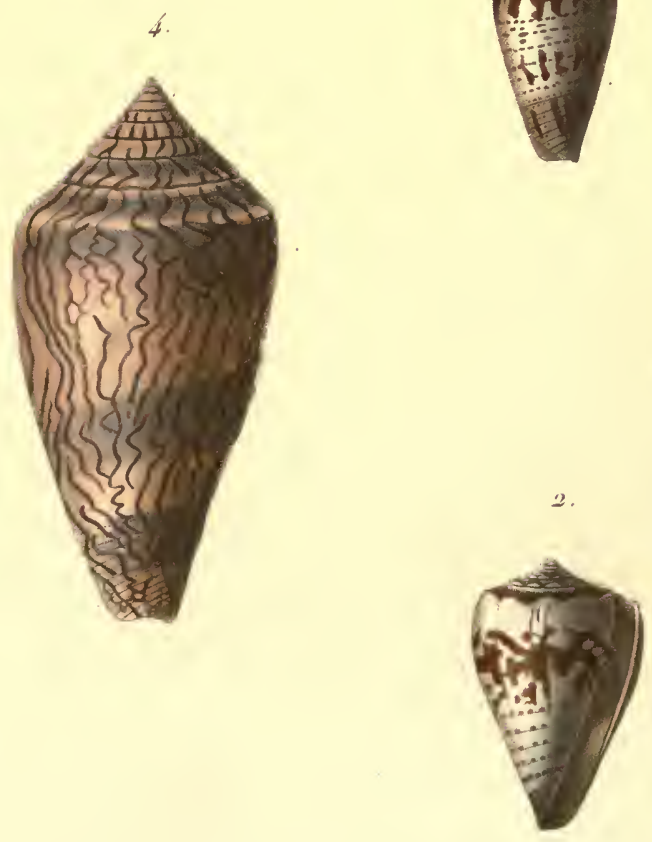

1. Cône ryg'mé.

1.1 1 id: id: vartés

2. Cône noiselle var:

3. Cône fileur var:

4. Cone drap-d'or var:

(Conus Pygmarus Reeac)

(id: id vartatas)

(Conus nux sar: )

(Conus lineatus war:)

(Conus tervile var: ) 
THE LIBRARY

OF THE

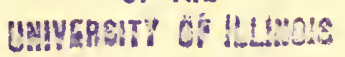



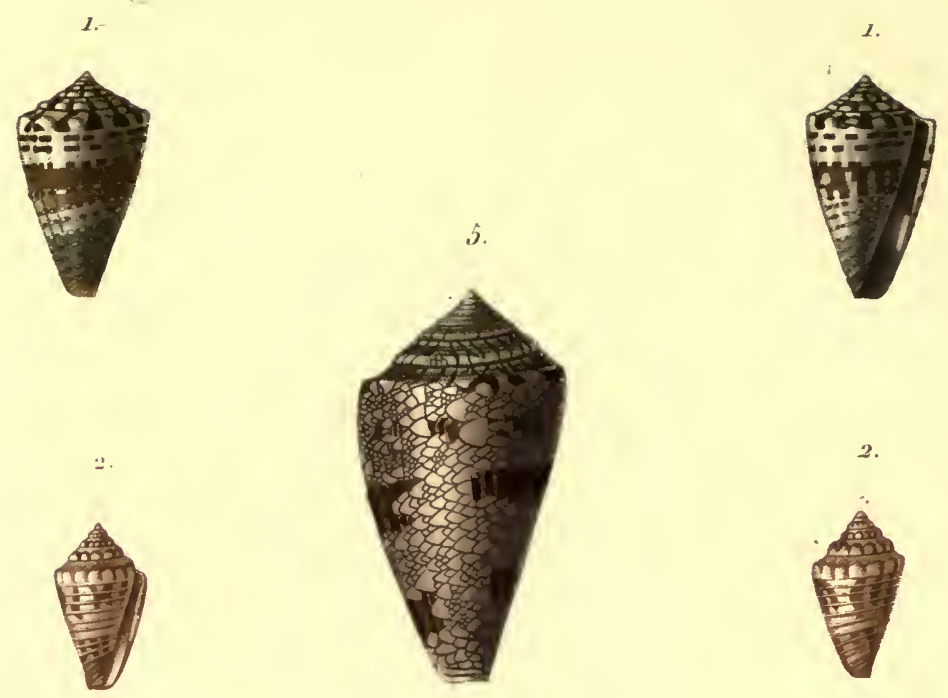

3.
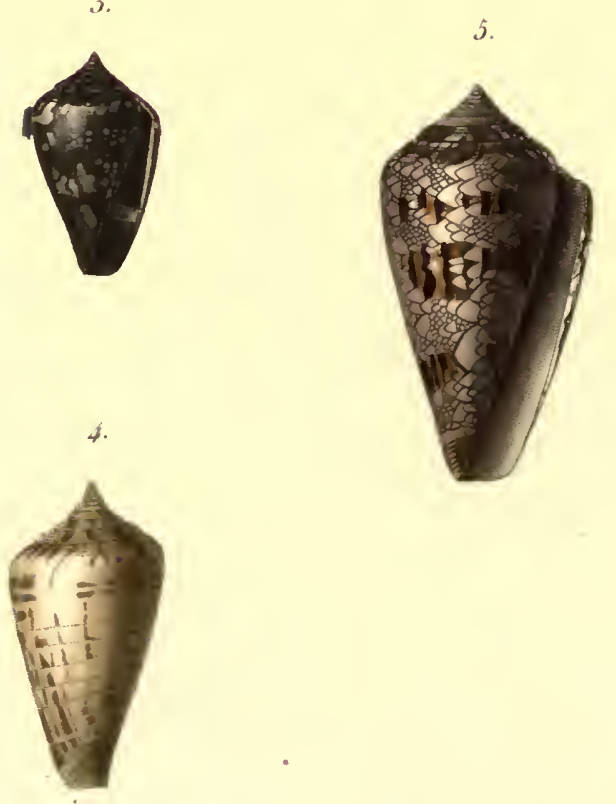

3.

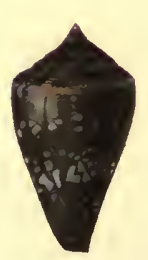

4.

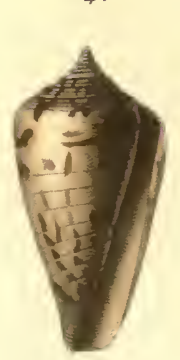

3. Cône de Mighels.

2. Cone labouré.

(Conus Mighelsi. nobis)

(Conses liralus. Reese)

3. Cône hieroglyphique var:

(Conus hieroglyphicus oary

4. Cône de Paros var:

(Conus Parius var: )

5. Cône textilin.

Conus textitinuer

nobis) 
THE LIBRARY

OF THE

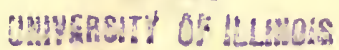



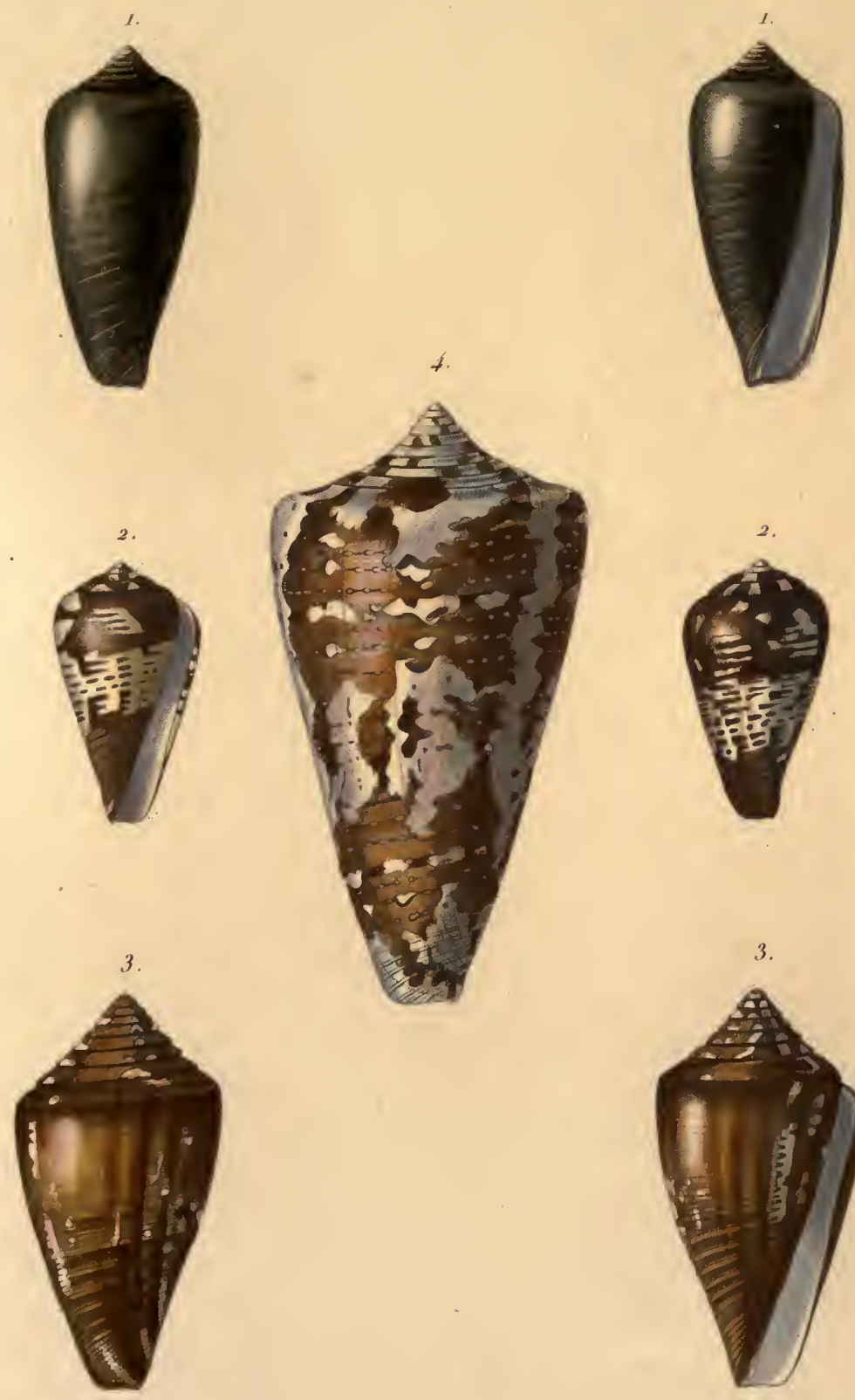
1. Cone Gubba.
(Conus Gubba. nobis.)
2. Cone africain
(Conus africumus, nabis.)
3. Cône marron.
(Conus crstaneus. nobis.)
4. Cone magistrat
Conus archon. Brod.' 


\section{TME LIRRARY}

of rise

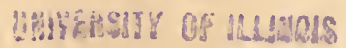




\section{coxe (Conus)}

P1. $10 \%$.
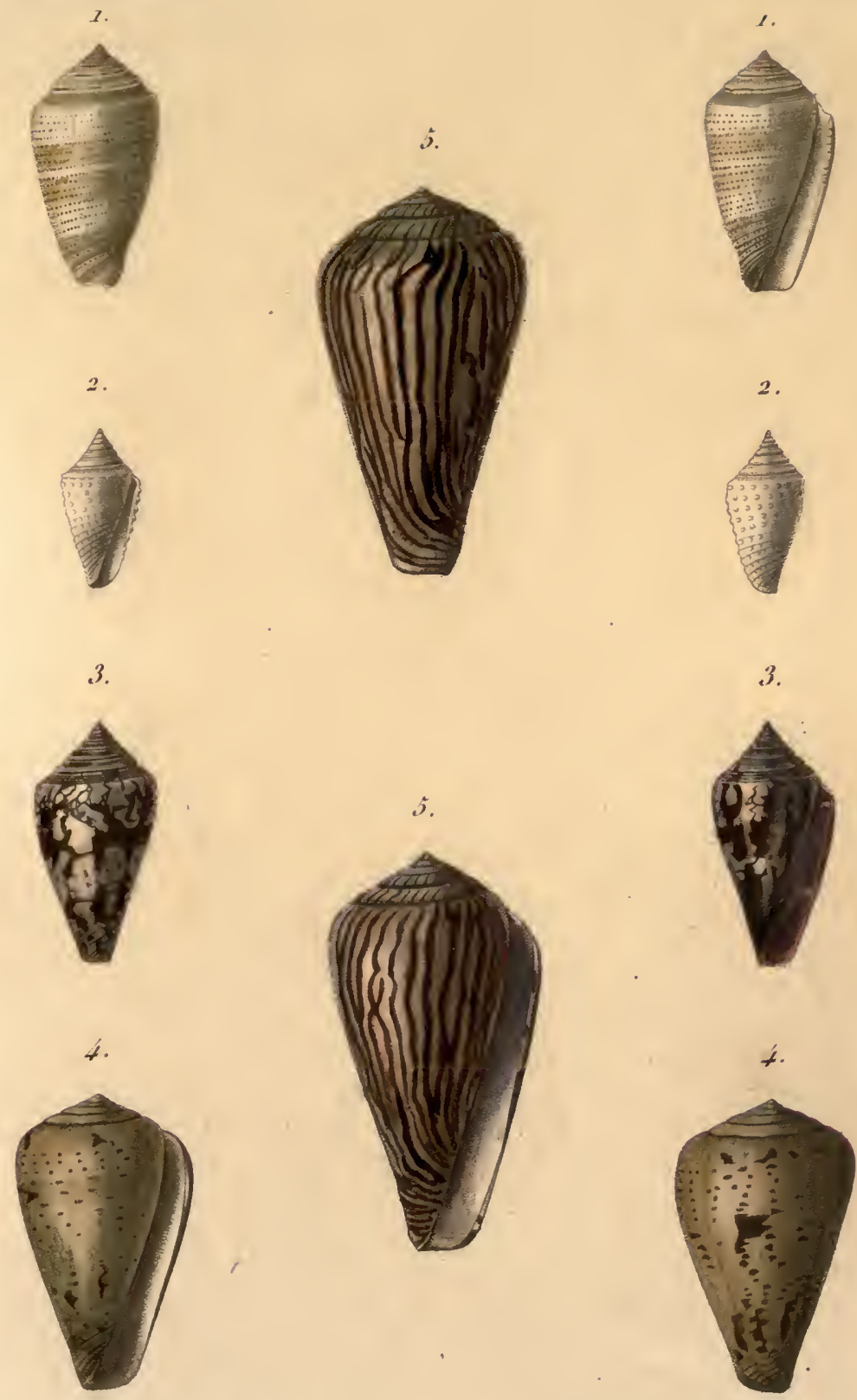

1. Cône striolé.

(Conus striolutus nobis.)

2. Cône échinulé.

(Conus echinulatus notis.)

3. Cône érit.

/Conus insoriptus Resene't

4. Cône truité.

(Comus gutturtuss nobris.)

5. Cône zébroìde.

/Conses sebrvïtes nobis.) 


\section{THE LIBRARY}

OF THE

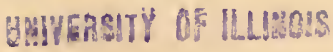


coNe (conus.)
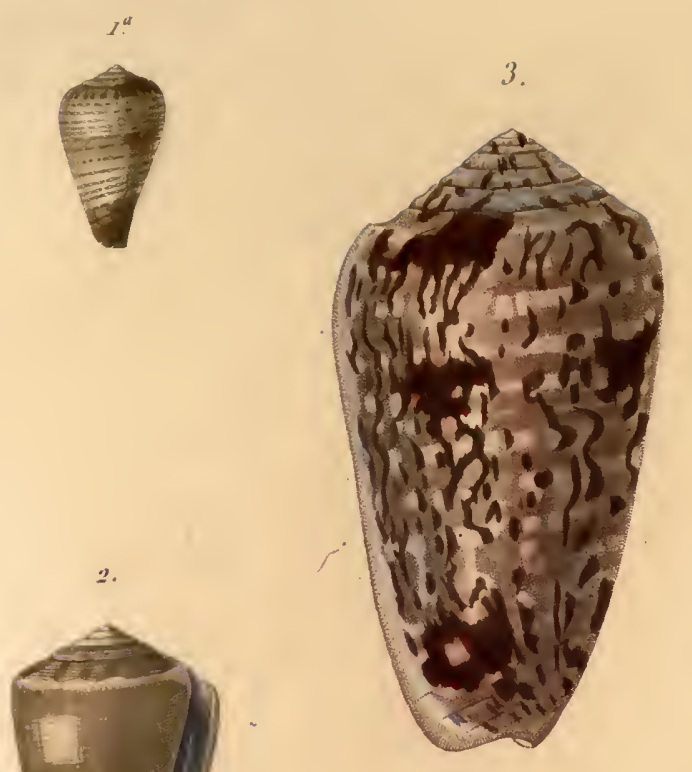

3.
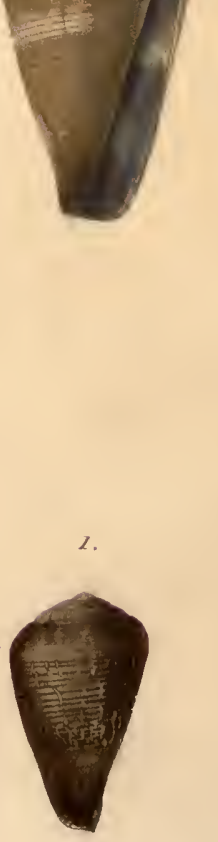

1. Conse mouchets.

$I^{n}$ id. id. var

a. cône blondin val"

3. Coune floconneus.
PI. 106

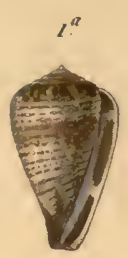

2.

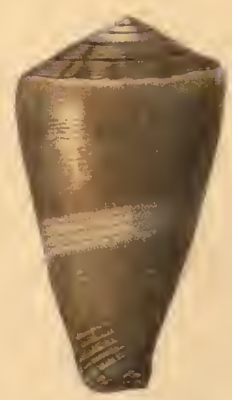

1.

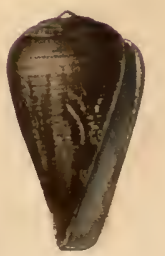

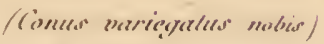

(id. id. war. )

(coness" Alarsidus mars. )

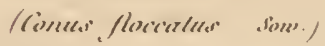


TME IIGRARY

of rus

UsVLnstr os lLumors 

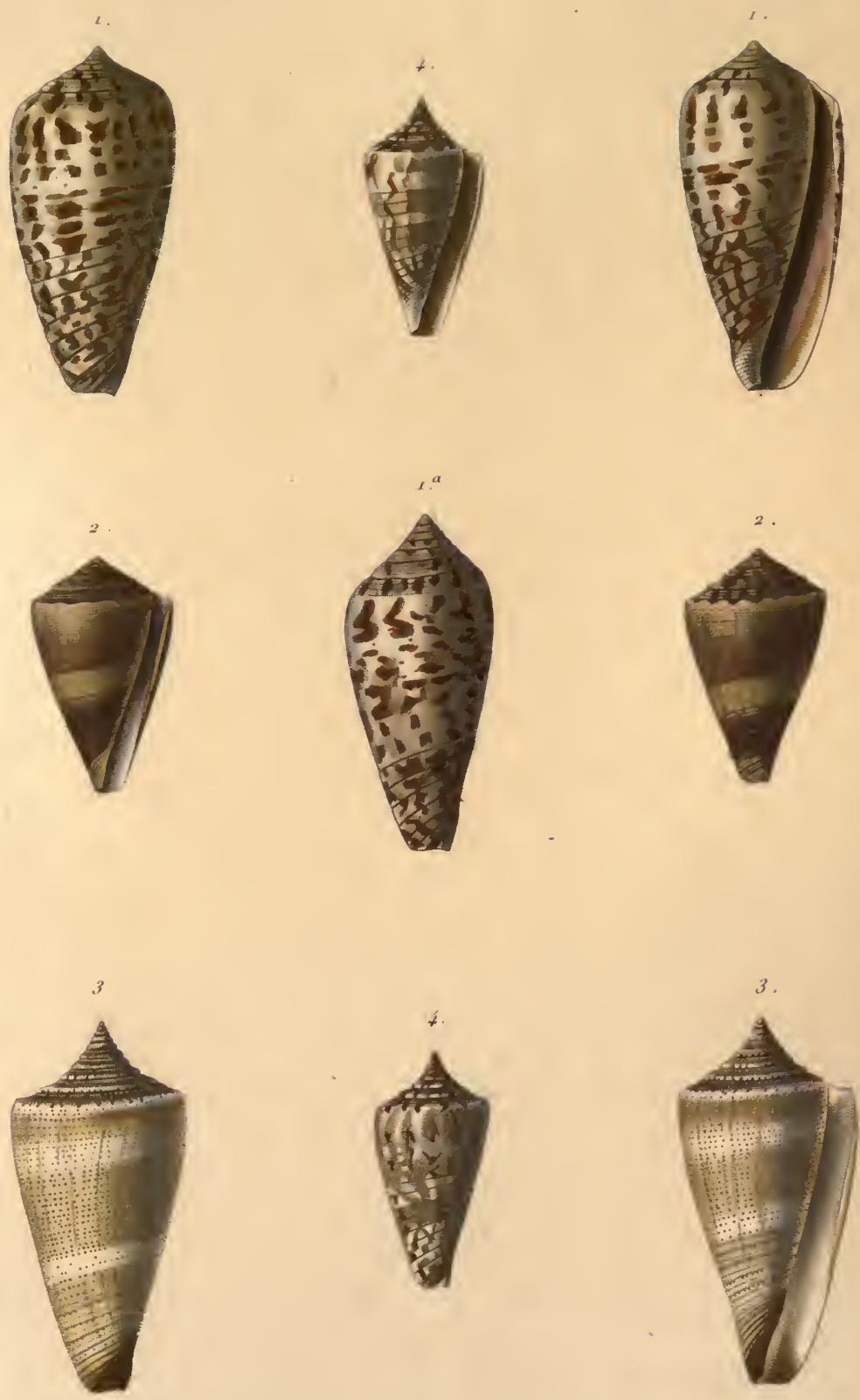

1. Cóne tacheté d'écarlate

( Comus Cocceur Reeve)

a id. id. var.

( iut. iut. var. )

3. Cone de Cibiel.

( Conur cibicli nobir )

3. Cone de Cecile var.

( Comuer cécilei var. )

4. Cione rose.

( conus rosellos nobior) 
THE LIBRARY

OF THE

UHWEASTY OF ILLMOSS 

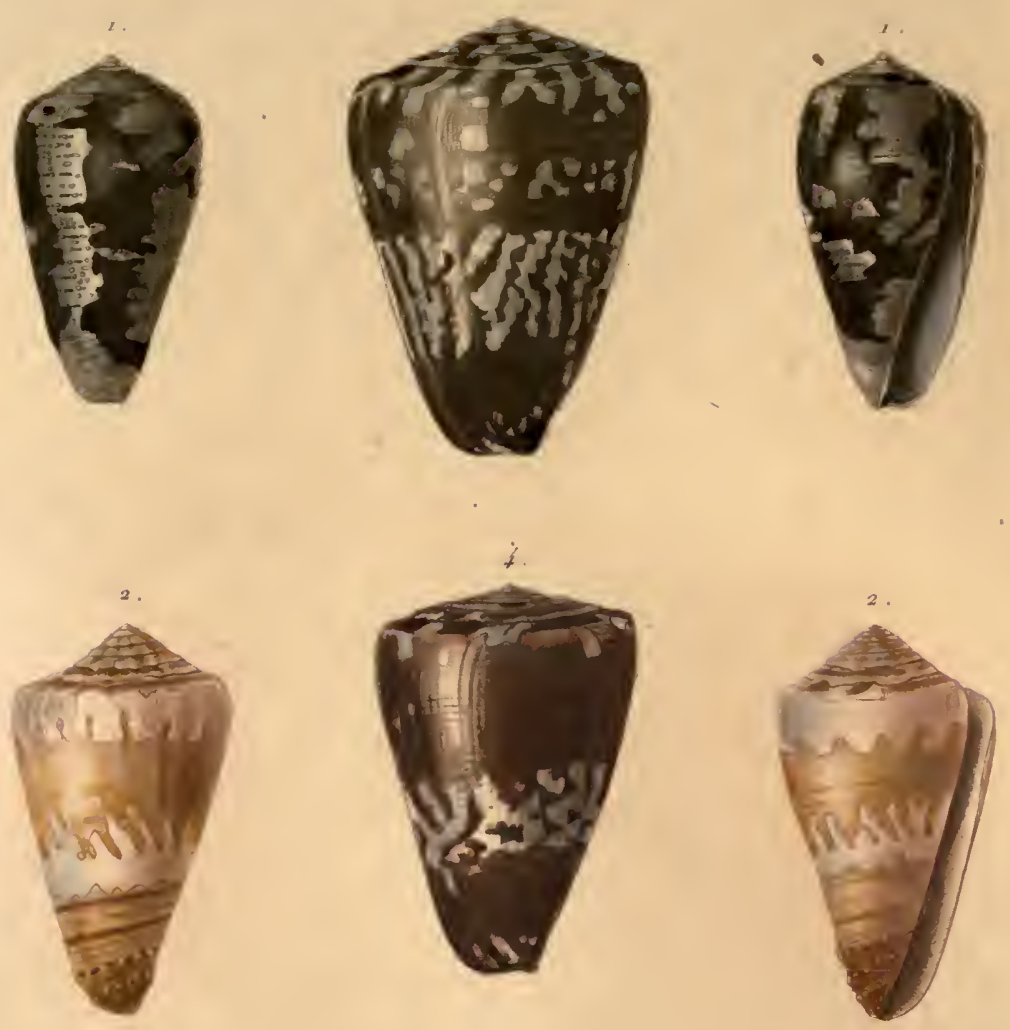

3.
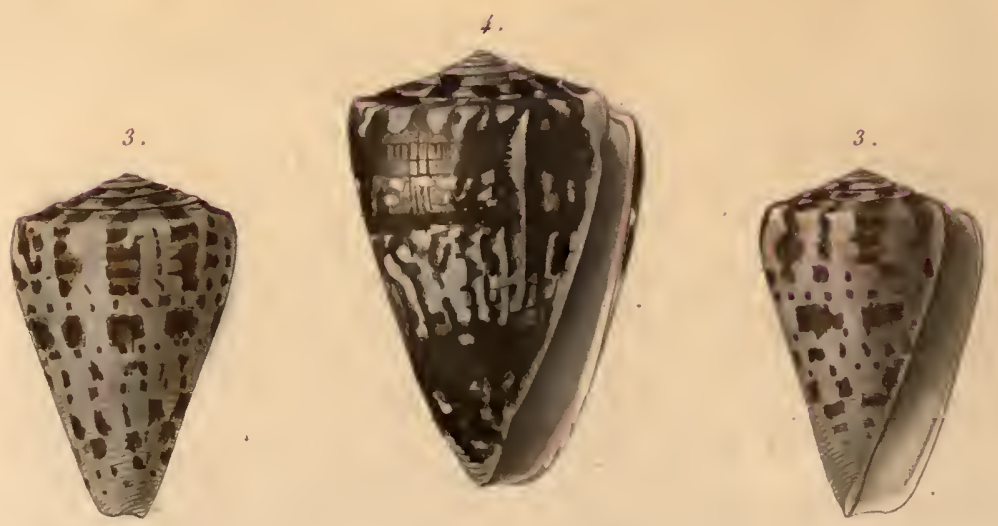

1. Cone ardoise

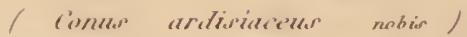

2. Cone lacinulé

(Conmes lecinuluatur nobirs )

5. Conc Pauline

1 Conme' Poulimu

nobis /

+. Cone deuil

1 commen ulerealbus

nobies /

.$+^{a}$ id. id. vil. 
THE LBBRARY

OF THE

UMIYEREITY OF ILLIMOIS 

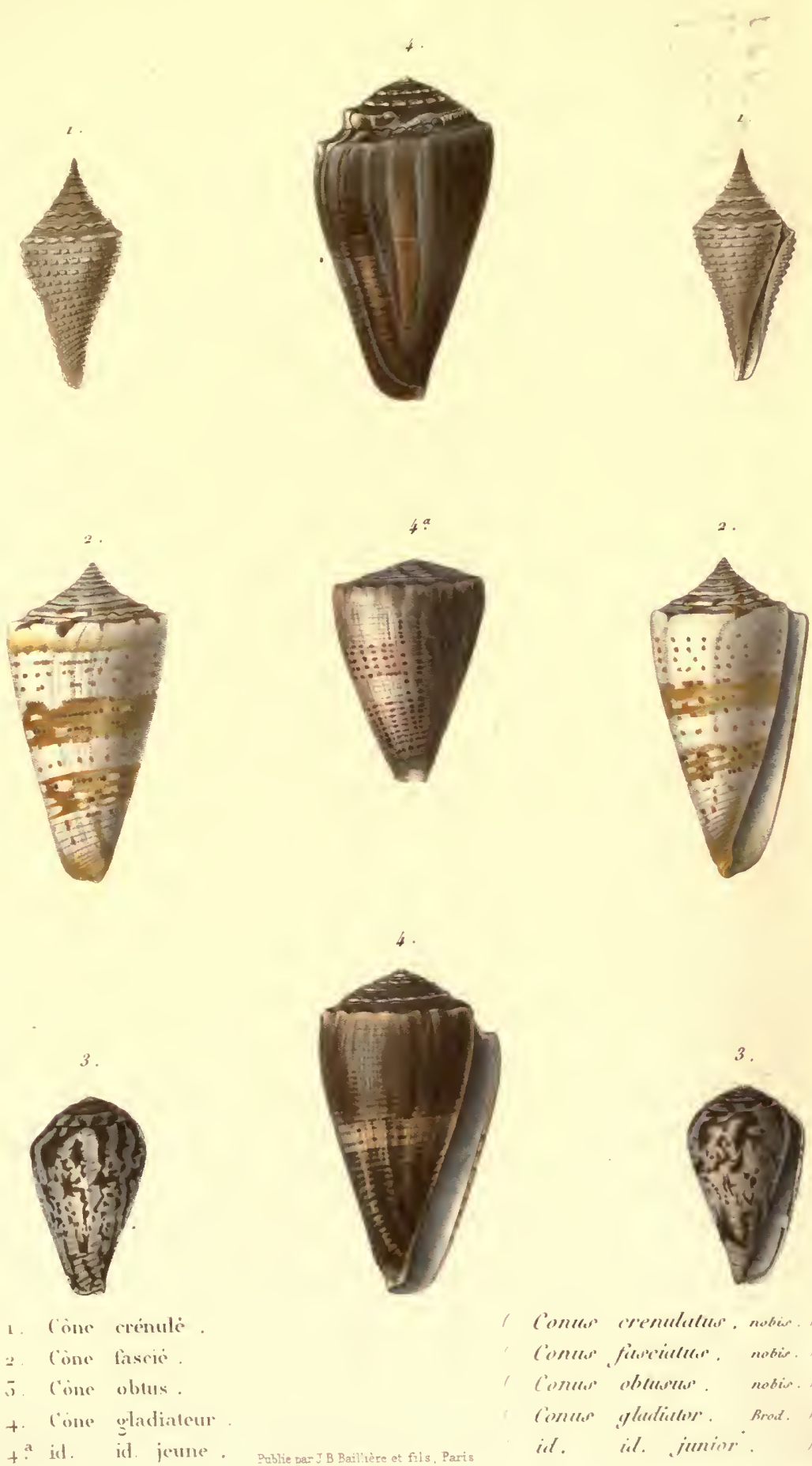

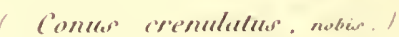

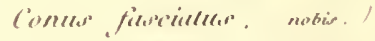

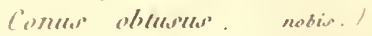
(imnes glestiules. Brot. I id. ill junier. । 


\section{THE LIBPARY}

OF THE

UHYERSTYY OF ILLHOIS 

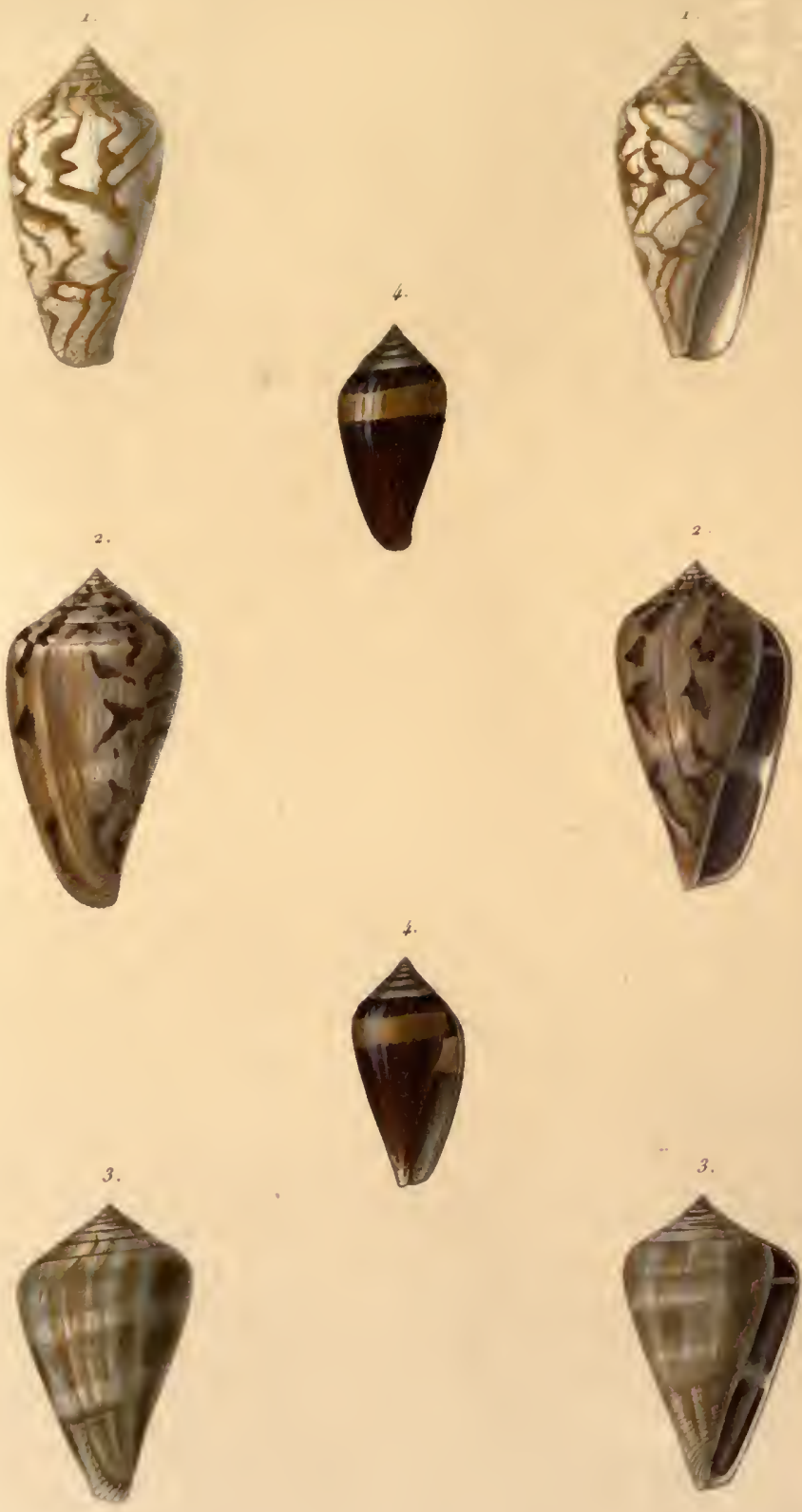

1. Cone maillé

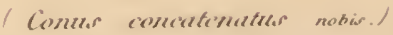

2 Cone de Guiné raste

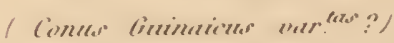

3. Cine de Taslé

I Comsor Tisolei

notine.)

t. Conce unibande

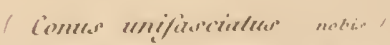

lullunt pim. Public par J. B. Baillière et fils, Paris 
THE LIBRARY

OF THE

UMYรคMTY OF ILLI:DLS 

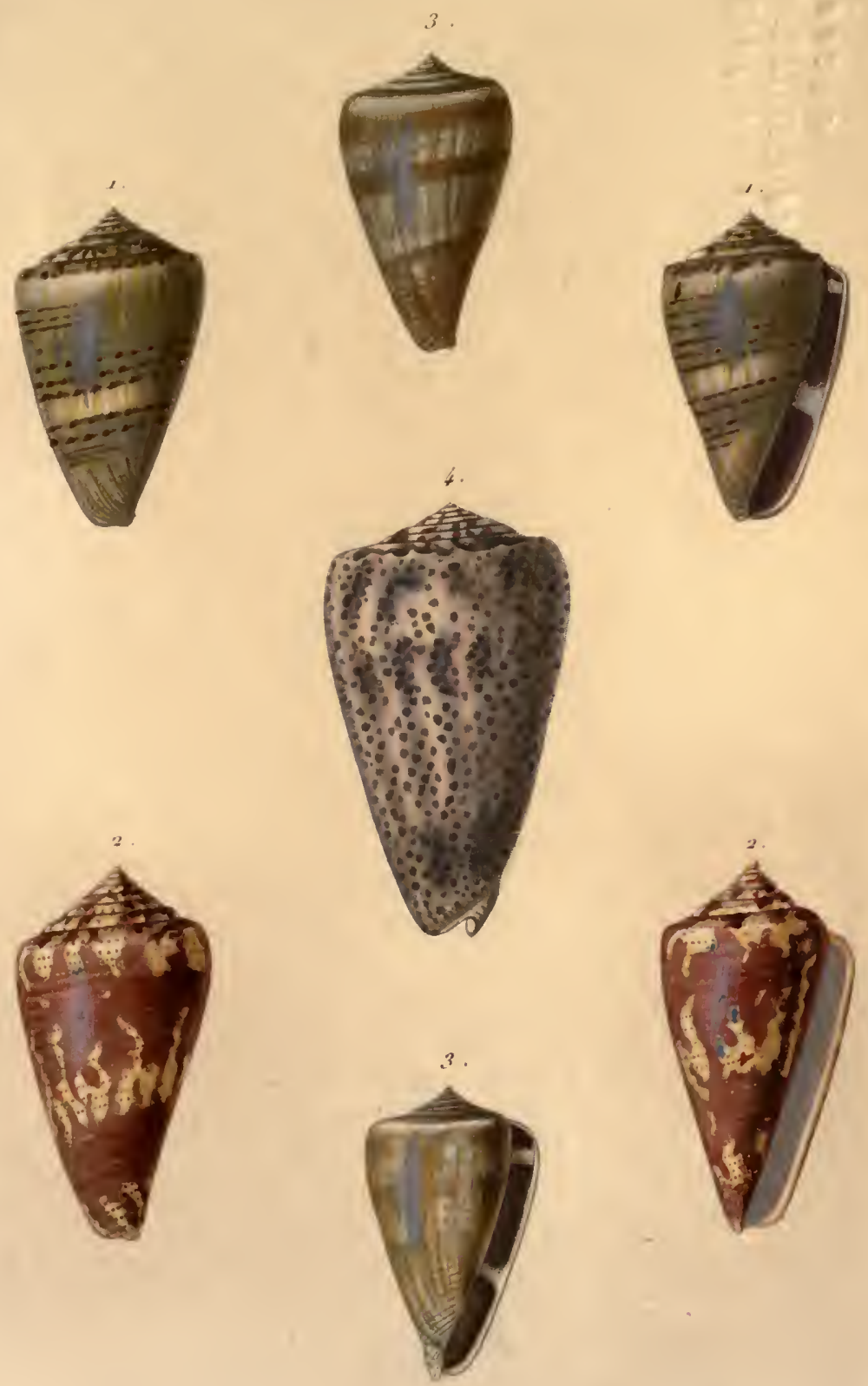

1. Cone de Blanville

2. Cone sanguin

3. "Cone olivace

+ Cone morsure-de-Puce

\begin{abstract}
I Comus Bluinuallei nobio.

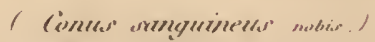

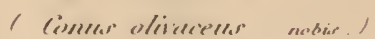

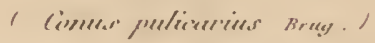




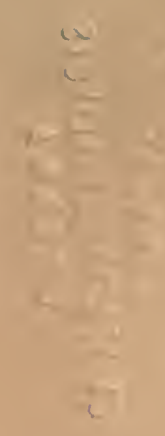

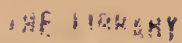

$$
\begin{aligned}
& \text { if } \mathrm{ric}
\end{aligned}
$$



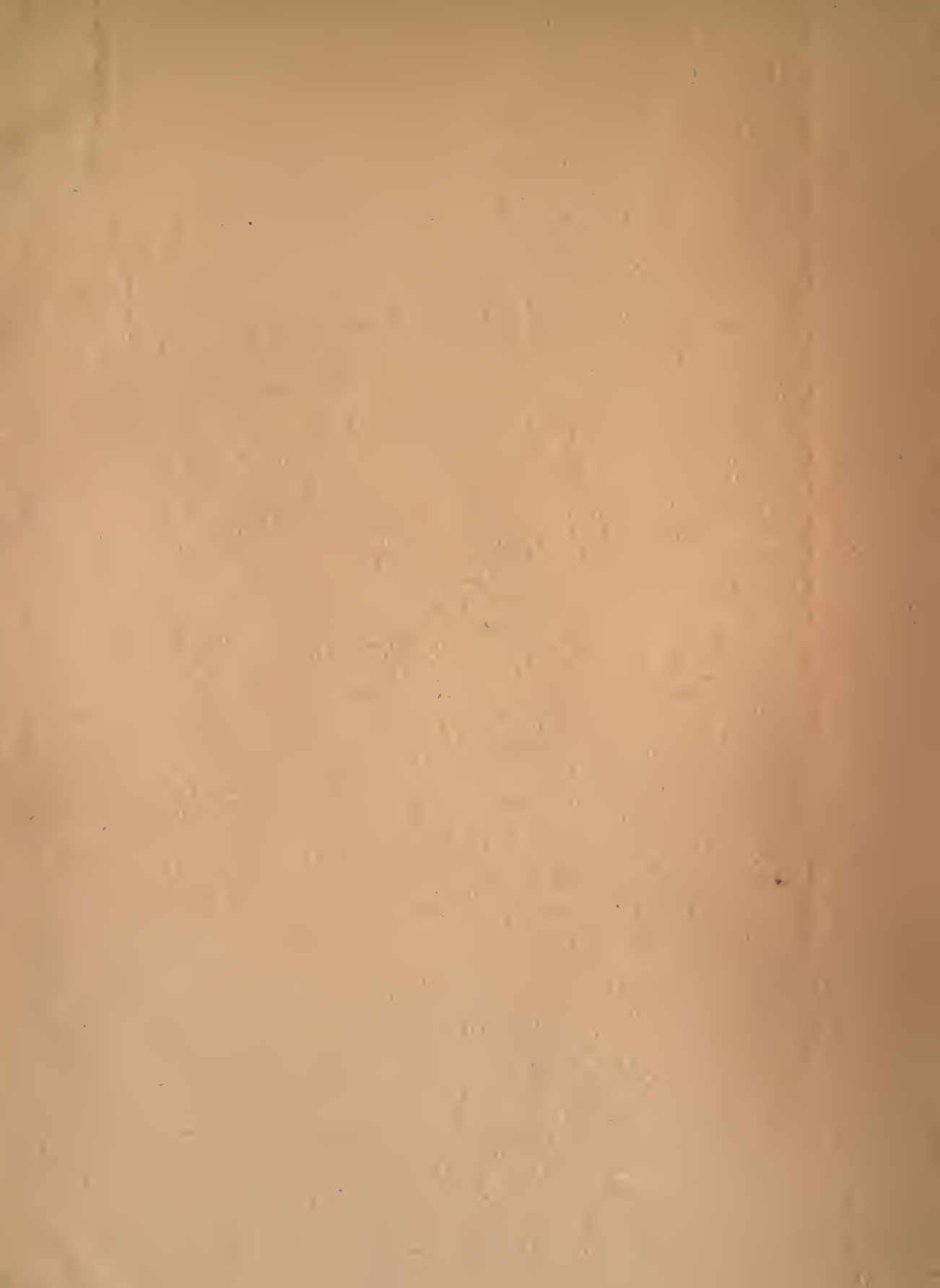



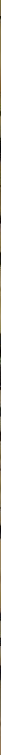




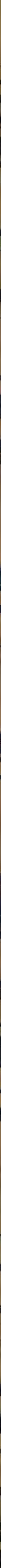


UNIVERSTTY OF MLINOIS-URBANA 